\title{
Reinforced Concrete Element Resistance to Contact Explosion Effects and Mitigation Strategies
}

by

Alok Dua

A thesis submitted to the Faculty of Graduate and Postdoctoral Affairs in partial fulfillment of the requirements for the degree of

Doctor of Philosophy

in

Civil Engineering

Carleton University

Ottawa, Ontario

(C) 2019

Alok Dua 


\section{Abstract}

Protection of critical infrastructure and iconic buildings against terrorist attacks has become an integrated part of building design due to the ever-larger looming threats in today's environment. Consequently, the response analysis of structures for blast loading has gained importance in the recent past. Blast loading is categorized as far-field, near-field and contact explosions in terms of the scaled distance to a building or structural element. Far-field and near-field loading are associated with explosions that occur at scaled distances of more than and less than $1.18 \mathrm{~m} / \mathrm{kg}^{1 / 3}$, respectively, while contact explosion loading occurs in contact with the target. For near-field blasts and contact explosions, the interaction between blast waves and structures is more complex. Near-field and contact explosion events are characterized by a high-temperature fireball and extremely high magnitude, nonuniform overpressure. The existing empirical charts are inaccurate for scaled distances less than $0.4 \mathrm{~m} / \mathrm{kg}^{1 / 3}$ and underpredict the blast parameters. Moreover, there are limited experimental tests on the response of reinforced concrete members subjected to contact explosion effects reported in the literature. Experimental tests on full-scale RC members subjected to live explosion are cost prohibitive and require expertise in explosive handling. This makes live explosive testing outside the capability of many researchers.

This thesis presents experimental and numerical studies on RC slabs, columns, and walls subjected to contact explosion effects and parametric studies to 
understand the response mechanism in order to recommend cost-effective mitigation strategies. An empirical equation to predict the breach diameter of RC slabs including the effects of reinforcement ratio and the contact area of explosive mass is presented in the thesis. The experimental tests on RC columns demonstrate that a significantly small amount of explosive mass can initiate failure in a column as compared to RC slab or wall with the same depth. Also, the damage phenomenon is predominantly local and global response is negligible in case of contact explosion events. Furthermore, it is shown that the gap offered by a column cladding can effectively mitigate contact explosion effects. Lastly, an increase in the width of an RC column transforms the failure mechanism from two-dimensional (2D) failure as in the case of square RC columns to one-dimensional (1D) failure as in the case of RC slabs. It is concluded that RC walls retain more than $25 \%$ residual axial capacity when subjected to breach threshold explosive mass for an RC slab of same depth. 


\section{Acknowledgments}

I would like to express my sincere gratitude towards my supervisor and mentor Dr. Abass Braimah for his patient support, guidance, and encouragement throughout my journey of this Ph.D. study. I am truly grateful for the opportunity he provided and for the inspiration all along. His experience in the field of blast analysis of structures is above and beyond which helped me achieve a feat while conducting my experimental and numerical work.

I would also like to extend my heartfelt gratitude toward my wife, kids and parents to have supported me emotionally and financially all along. They were the true reason for my perseverance.

I thank Shastri Indo-Canadian Institute for funding the experimental work and providing me the opportunity to improve the study. Dr. Manish Kumar who collaborated the joint funding provided generous advice during the experimental work at Indian Institute of Technology Bombay (IITB) for which I am sincerely thankful.

Lastly, I would like to thank Carleton University and Dr. Abass Braimah again for their generous financial support at various stages that made my study possible. 


\section{Table of Contents}

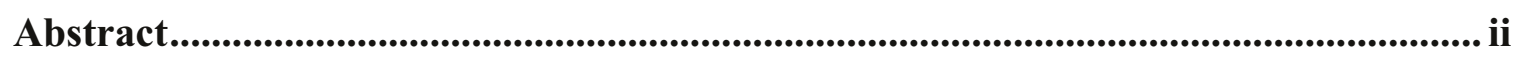

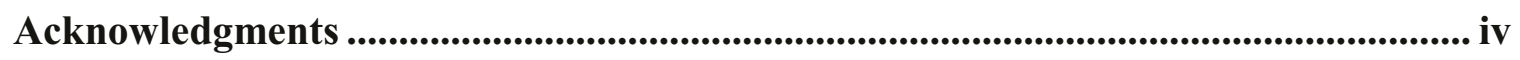

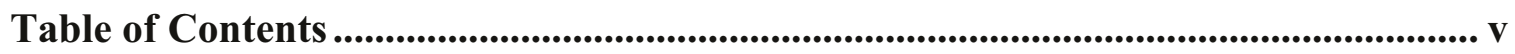

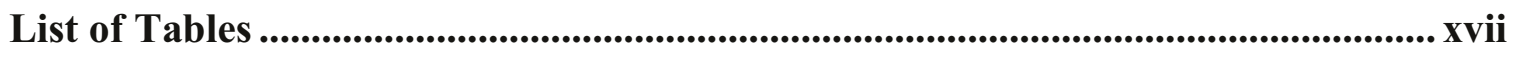

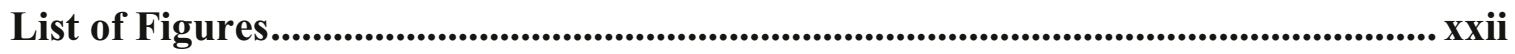

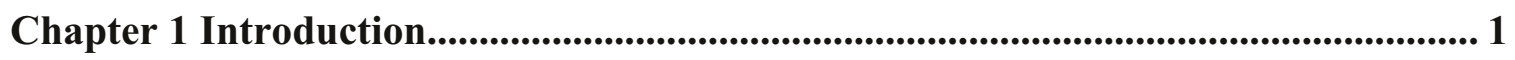

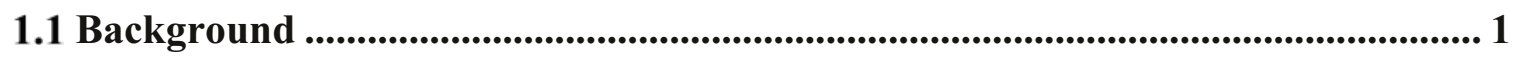

1.2 Problem Statement....................................................................................... 2

1.3 Research Objectives........................................................................................ 3

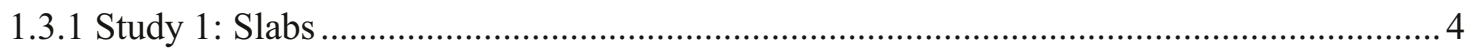

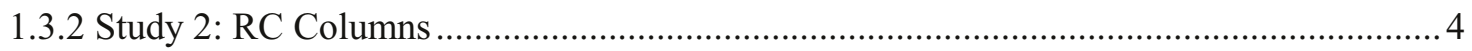

1.3.3 Study 3: Mitigation of Contact Explosion Effects by Plywood Cladding ........................ 5

1.3.4 Study 4: Mitigation of Contact Explosion Effects by Aspect-ratio of RC Walls ..............5

1.4 Research Approach......................................................................................................... 6

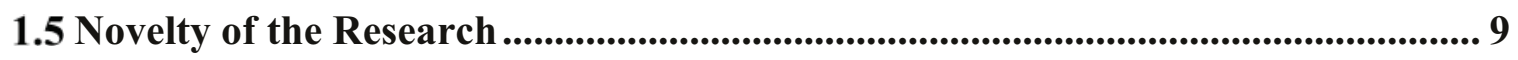




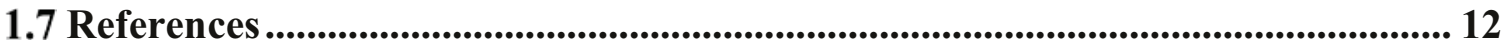

Chapter 2 Theoretical and Technical Background..................................................... 14

2.1 Introduction ........................................................................................................................ 14

2.2 Current State-of-the-Art for Far-Field Explosion Analysis.................................... 16

2.3 Near-field and Contact Explosion Event Versus Far Field Event......................... 18

2.4 References................................................................................................................................. 20

Chapter 3 Assessment of Reinforced Concrete Slab Response to Contact Explosion

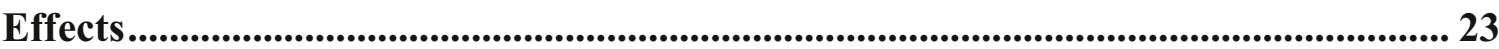

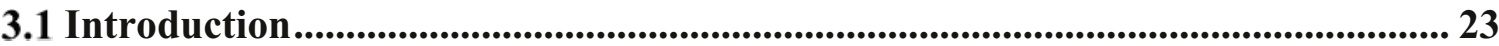

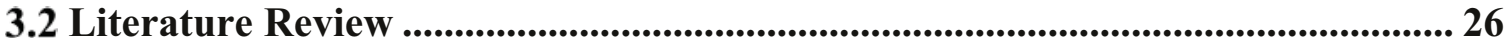

3.2.1 Studies on RC Members Subjected to Contact Explosion..............................................26

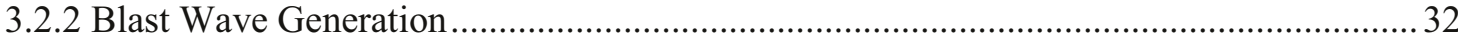

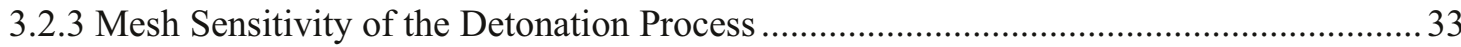

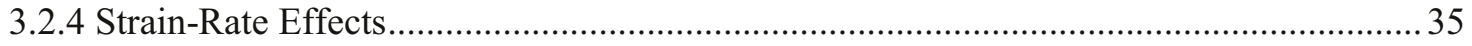

3.3 Research Objective ........................................................................................................... 35

3.4 Experimental Investigation ................................................................................ 37 
3.5.1 PC Slab 39

3.5.2 RC Slab. 40

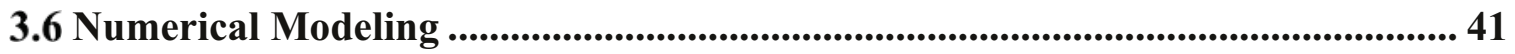

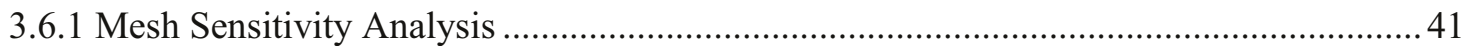

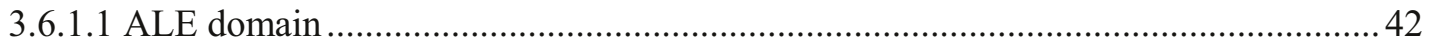

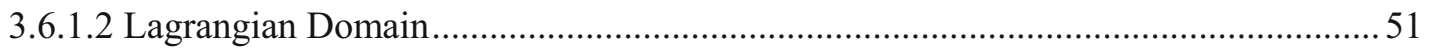

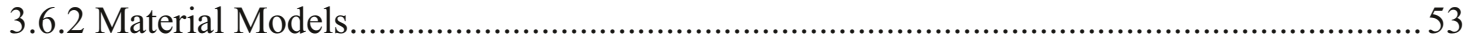

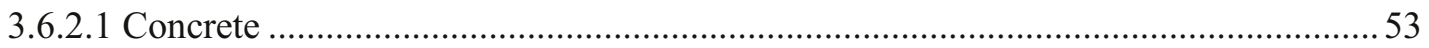

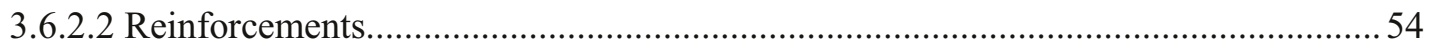

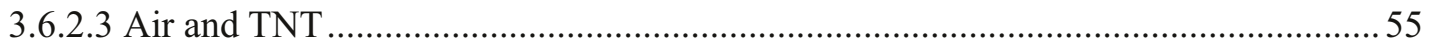

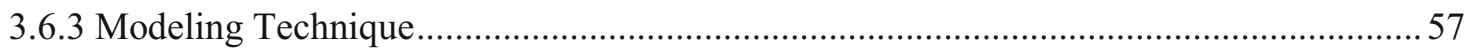

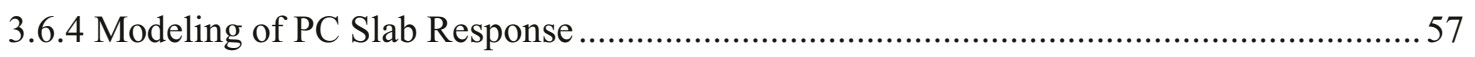

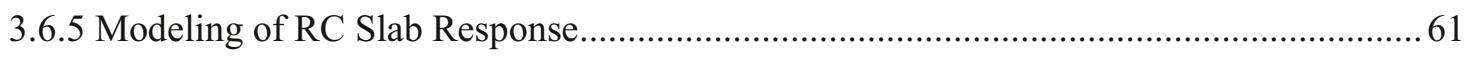

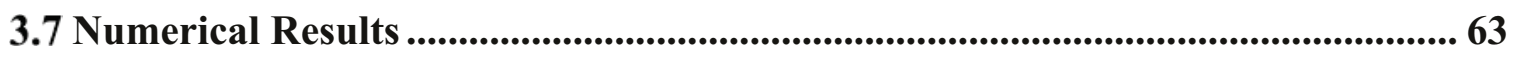


3.9 Parametric Analysis...................................................................................................... 66

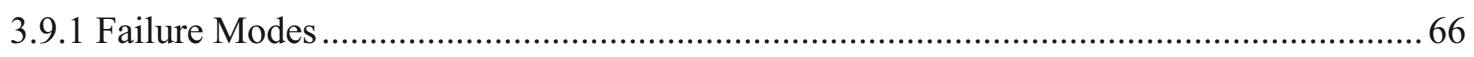

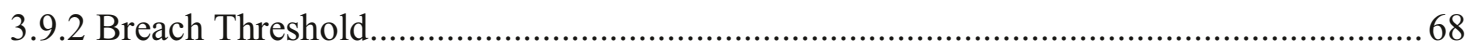

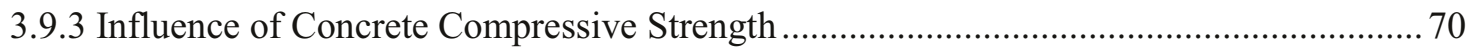

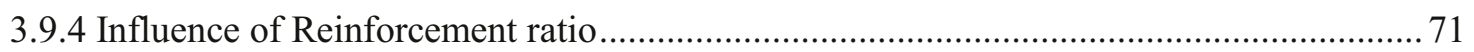

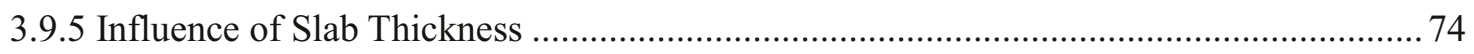

3.9.6 Influence of Contact Area between the Explosive and the Target .................................. 74

3.10 Dimensional Analysis: Breach Diameter ........................................................ 77

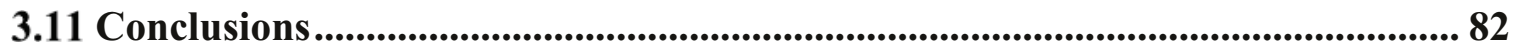

3.12 References ....................................................................................................................... 83

Chapter 4 Contact Explosion Response of Reinforced Concrete Columns: Experimental and Numerical Investigation..................................................................... 91

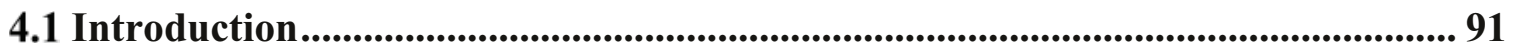


4.2.1 Past Studies on Contact Explosion Events 94

4.2.2 Numerical Modeling 100

4.3 Research Significance ........................................................................................... 101

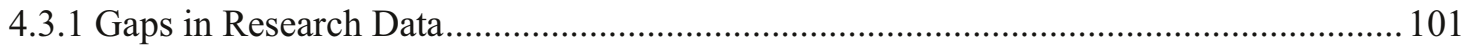

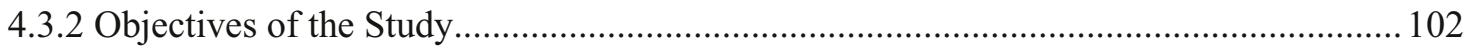

4.4 Experimental Investigation ...................................................................... 103

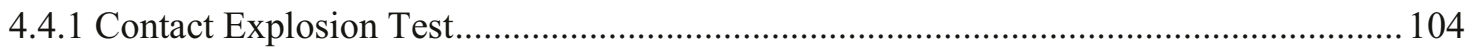

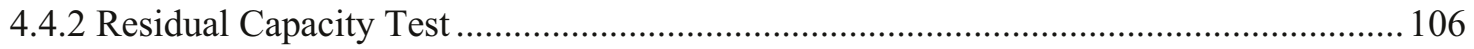

4.5 Experimental Results.............................................................................................. 109

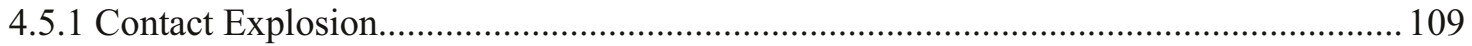

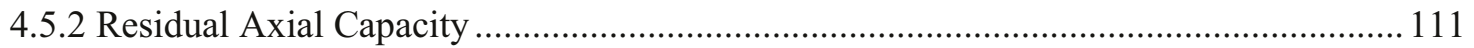

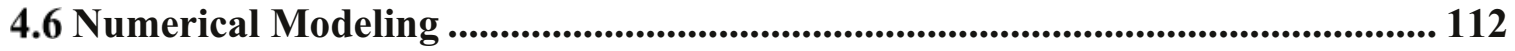

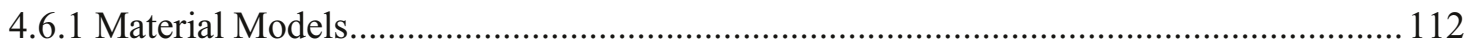

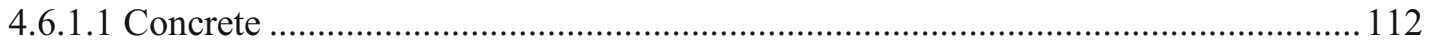




\subsection{Presentation of Results and Discussion}


4.10 Conclusions

4.11 References

Chapter 5 Mitigation of Contact Explosion Effects by Claddings on RC Columns152

5.1 Introduction. 
5.5.1 Contact Explosion.

5.5.2 Residual Axial Load Capacity....

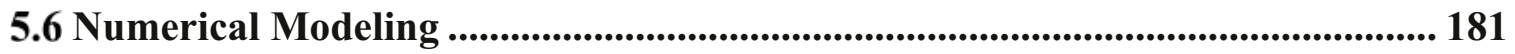

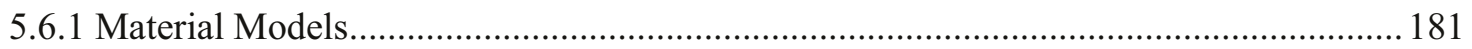

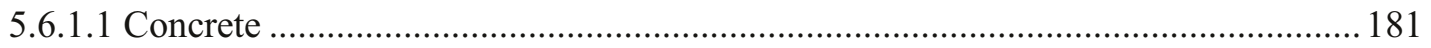

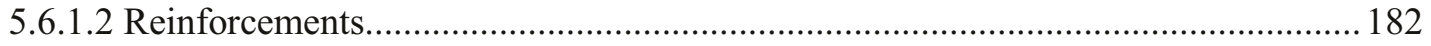

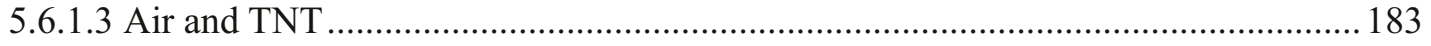

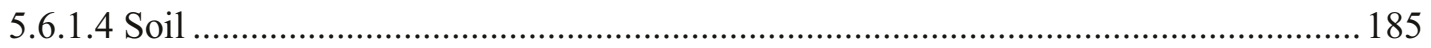

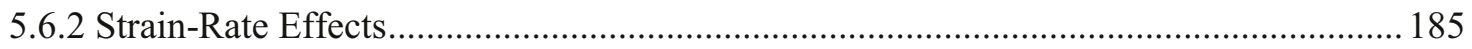

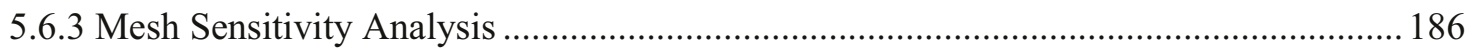

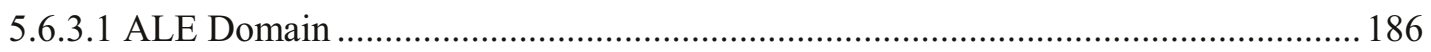

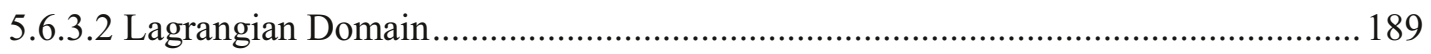

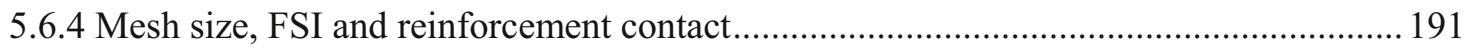

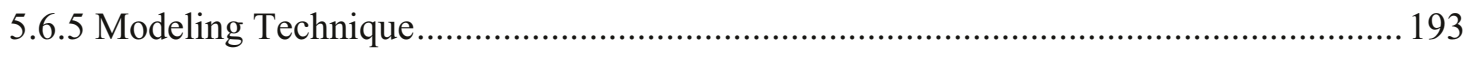


5.7.1 Clad Column $(50 \mathrm{~mm})$ Subjected to $115 \mathrm{~g}$ TNT Contact Explosion

5.7.2 Clad Column (100 mm) Subjected to 500 g TNT Contact Explosion

5.7.3 Clad Column $(50 \mathrm{~mm})$ Subjected to $500 \mathrm{~g}$ TNT Contact Explosion .202

5.8 Summary and Discussion 204

5.8.1 Summary .204

5.8.2 Shock Wave Propagation in RC columns .205

5.8.3 Failure Mechanism of Blast Damaged RC Columns. 207

5.8.4 Mitigation Potential of the Cladding Induced Gap..... .208

5.9 Influence of Energy Absorbing Material in Cladding Gap 210

5.10 Conclusions 213

5.11 References 215

Chapter 6 Experimental and Numerical Investigation of Reinforced Concrete Walls Under Contact Explosion Effects ..................................................................... 224

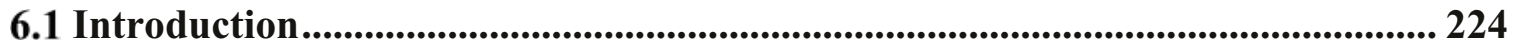

6.2 Literature Review ............................................................................................. 226 
6.2.1 Contact Explosion

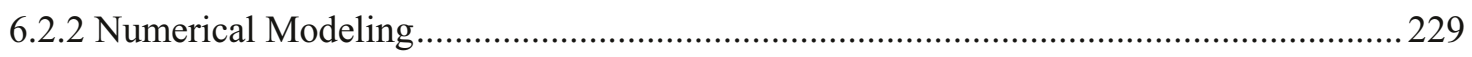

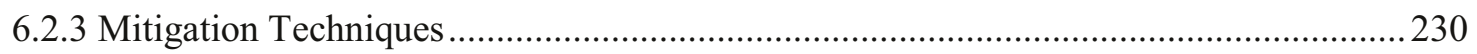

6.3 Research Significance .................................................................................................... 231

6.4 Experimental Investigation .......................................................................................... 232

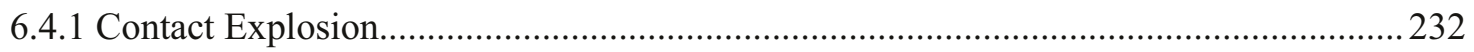

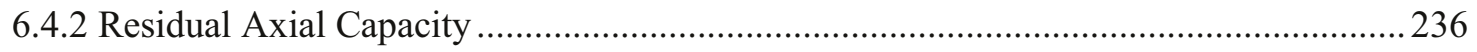

6.5 Experimental Results................................................................................ 237

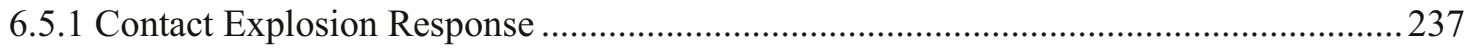

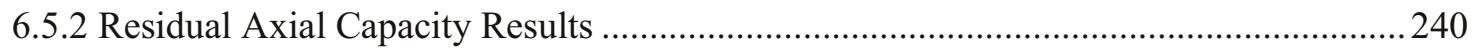

6.6 Numerical Modeling …................................................................................................. 242

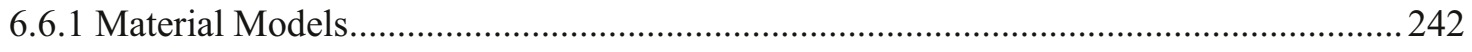

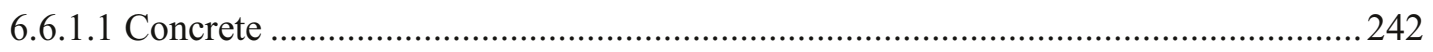

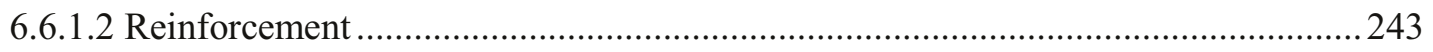

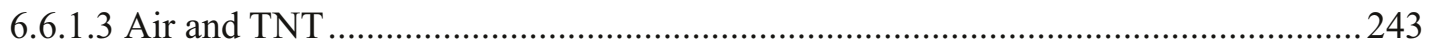


6.6.1.5 Strain-Rate Effects .246

6.6.2 Mesh Sensitivity Analysis ..... 246

6.6.2.1 ALE Domain: Detonation and Blast Wave Propagation. 246

6.6.2.2 Lagrangian Domain. 249

6.6.3 Mesh size, FSI and Reinforcement contact 251

6.6.4 Modeling Technique..... .253

6.6.5 Numerical Model Details 255

6.6.5.1 Axial Capacity of Undamaged RC Wall 256

6.6.5.2 Contact Explosion Loading. 256

6.6.5.3 Residual Axial Capacity of Blast-damaged RC Wall. 259

6.7 Numerical Results 260

6.7.1 Axial Capacity of Undamaged RC Wall .260

6.7.2 Contact Explosion Response .... .260

6.7.3 Residual Axial Capacity .262 
6.8 Summary and Discussion of Experimental and Numerical Results.

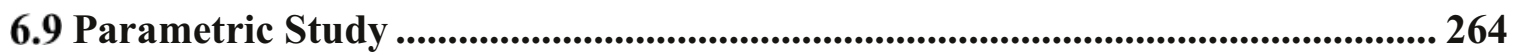

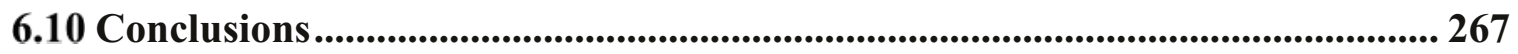

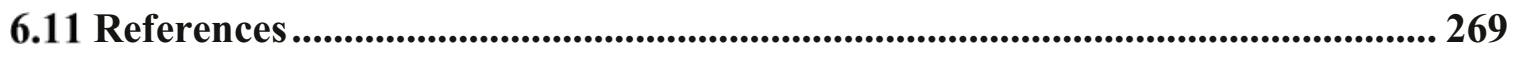

Chapter 7 Summary and Contributions ............................................................... 276

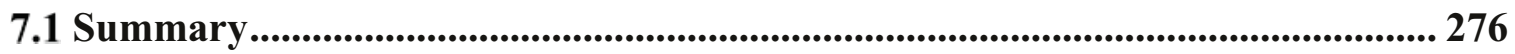

7.2 Recommendation for Further Research ................................................................... 280

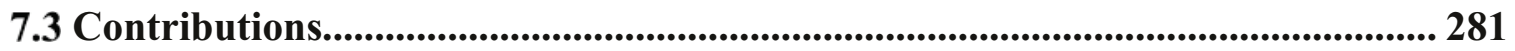

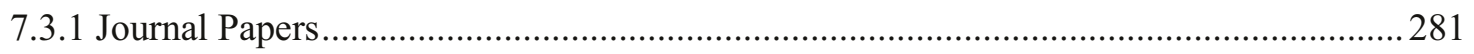

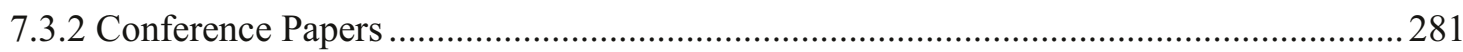

Appendix A: Keyword Files for RC Slabs ................................................................ 283

Appendix D: Keyword Files for RC Bare Columns/Cladded Columns/Walls........ 298 


\section{List of Tables}

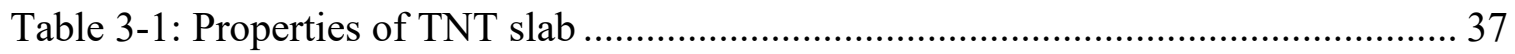

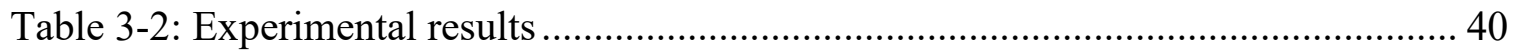

Table 3-3: MAT_HIGH_EXPLOSIVE_BURN properties for C4 (Dobratz \& Crawford,

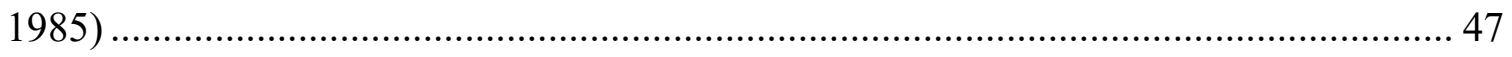

Table 3-4: JWL EOS parameters (Dobratz \& Crawford, 1985) .................................... 47

Table 3-5: EOS parameters for modelling air as ideal gas (Dobratz \& Crawford, 1985;

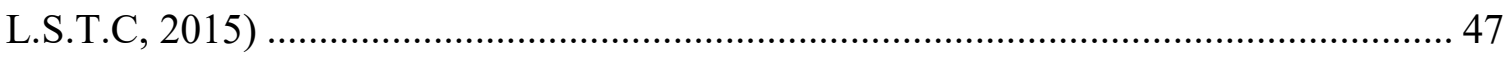

Table 3-6: Input parameters for CONTROL_ALE keyword...................................... 48

Table 3-7: Mesh Sensitivity Analysis for Reflected Pressure and Impulse.................... 51

Table 3-8: Input Parameters for Mat_159 Concrete Constitutive Model ........................ 54

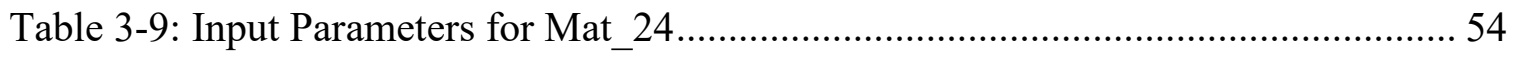

Table 3-10: Input parameters for CBIS keyword ................................................. 55

Table 3-11: Input Parameters for Air Domain ....................................................... 56

Table 3-12: Input Parameters for MAT_HIGH_EXPLOSIVE_BURN and EOS_JWL .. 57

xvii 
Table 3-13: Comparison of numerical and experimental observations

Table 3-14: Numerically predicted damage profiles for varied explosive mass loading . 68

Table 3-15: Influence of concrete compressive strength 70

Table 3-16: Influence of reinforcement ratio on breach threshold explosive mass ..... 72

Table 3-17: Influence of reinforcement spacing on breach threshold explosive mass ..... 73

Table 3-18: Influence of slab thickness on breach threshold explosive mass 74

Table 3-19: Parameters considered for dimensional analysis. 77

Table 3-20: Response data for dimensional analysis 80

Table 4-1: Summary of Experimental Tests 111

Table 4-2: Input Parameters for Mat_159 113

Table 4-3: Input Parameters for Mat_24 114

Table 4-4: Input parameters for CBIS keyword 114

Table 4-5: Input Parameters for Air Domain 115

Table 4-6: Input Parameters for MAT_HIGH_EXPLOSIVE_BURN and EOS_JWL .. 116 
Table 4-7: Input Parameters for MAT_MOHR_COULOMB 116

Table 4-8: CLIS parameters for Concrete and Soil 118

Table 4-9: Mesh Sensitivity Analysis for Reflected Pressure and Impulse. 122

Table 4-10: Influence of element mesh size on the axial capacity of the pristine column 124

Table 4-11: Quantitative error between Numerical and Experimental results 133

Table 4-12: Influence of explosive mass on the damage index of RC column 139

Table 4-13: Influence of concrete compressive strength on the damage index of RC column subjected to $115-\mathrm{G}$ TNT explosion in contact 141

Table 4-14: Influence of transverse Reinforcement spacing on the damage index of RC column subjected to $300-\mathrm{g}$ TNT explosion in contact 143

Table 5-1: Recommended values for material factors (DoA, 2007) 157

Table 5-2: Test Matrix 170

Table 5-3: Input Parameters for Mat_159 Concrete Constitutive Model 182

Table 5-4: Input Parameters for Mat_24. 182 
Table 5-5: Input parameters for CBIS keyword 183

Table 5-6: Input Parameters for Air Domain 184

Table 5-7: Input Parameters for MAT_HIGH_EXPLOSIVE_BURN and EOS_JWL .. 185

Table 5-8: Input Parameters for MAT_MOHR_COULOMB 185

Table 5-9: Mesh Sensitivity Analysis for Reflected Pressure and Impulse. 189

Table 5-10: Influence of element mesh size on the axial capacity of the pristine column 191

Table 5-11: Validated CLIS parameters for Concrete and Soil 192

Table 5-12: Keyword parameters for implementing contacts 193

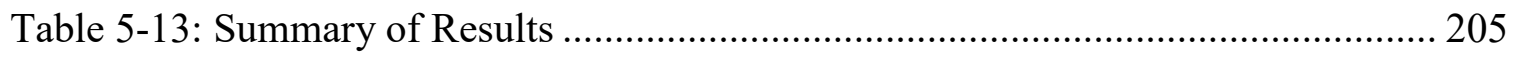

Table 5-14: Constitutive properties of the Aluminum Foam.......................................... 210

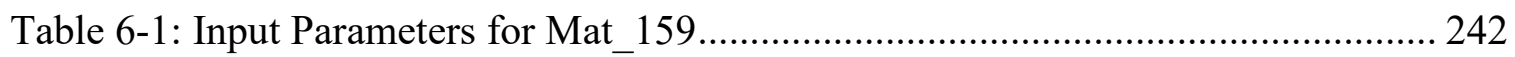

Table 6-2: Input Parameters for Mat_24 .................................................................. 243

Table 6-3: Input parameters for CBIS keyword ……………................................. 243

Table 6-4: Input Parameters for Air Domain ........................................................... 244 
Table 6-5: Input Parameters for MAT_HIGH_EXPLOSIVE_BURN and EOS_JWL .. 245

Table 6-6: Input Parameters for MAT_MOHR_COULOMB ….................................. 246

Table 6-7: Mesh Sensitivity Analysis for Reflected Pressure and Impulse................... 249

Table 6-8: Influence of element mesh size on the axial capacity of the undamaged column

251

Table 6-9: Validated CLIS parameters for Concrete and Soil .................................... 252

Table 6-10: Damage indices for members subjected to contact explosion effects of $500 \mathrm{~g}$

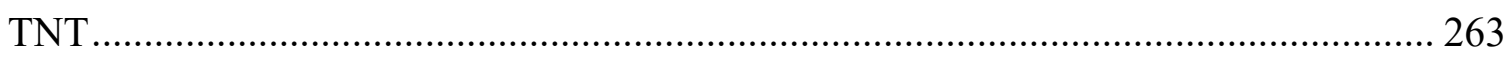




\section{List of Figures}

Figure 1-1: 1995 Alfred P. Murray building bombing (FEMA, 1996)............................ 1

Figure 1-2 (a) RC slab and (b) RC column subjected to 500g TNT explosion in contact.. 3

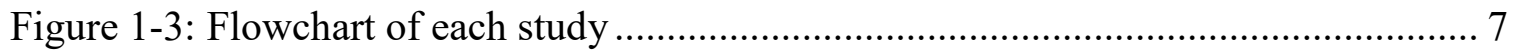

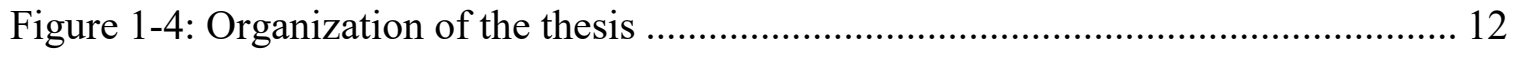

Figure 2-1: Pressure time history of a blast wave (DoD, 2008) ….............................. 17

Figure 3-1: Threshold scaled distance definition of a near-field event ........................ 24

Figure 3-2: (a) Far-field explosion (global response) (b) Near-filed explosion (local

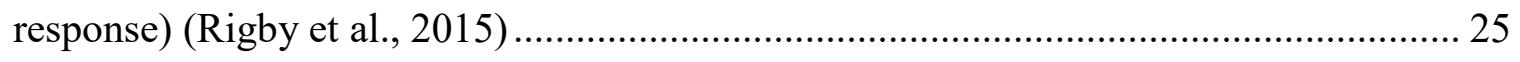

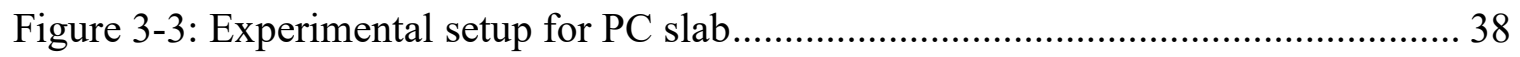

Figure 3-4: (a) Reinforcement layout (b) Slab cross-section (c) Experimental setup (d)

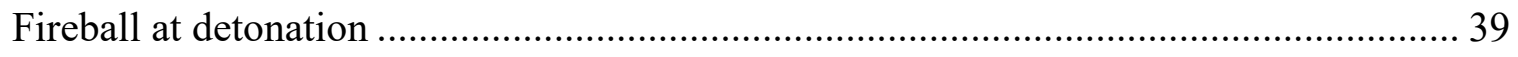

Figure 3-5: Response of PC slab to effects of $500 \mathrm{~g}$ TNT detonation .............................. 40

Figure 3-6: (a) Typical crater on the incident face (b) Typical scab at the distal face ..... 41 
Figure 3-7: Test arrangement for reflected blast pressure time history (a) Schematic (b)

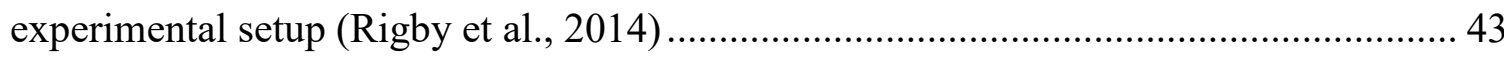

Figure 3-8: Experimentally acquired blast parameters (a) Reflected pressure (b) Reflected

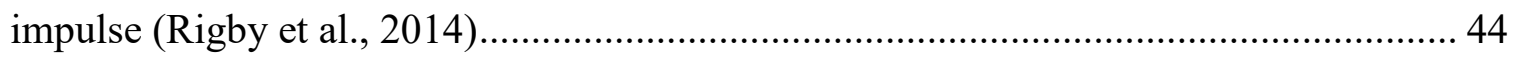

Figure 3-9: Numerical model for mesh sensitivity analysis 45

Figure 3-10: (a) Pressure fringe plot (1-mm); Time-histories for reflected (b) pressure (c) impulse (d) impulse after smoothening (e) pressure after smoothening...... 50

Figure 3-11: Mesh sensitivity for the Lagrangian domain (a) 2-mm mesh (b) 10-mm mesh 52

Figure 3-12: Simulation of detonation with 1-mm size element mesh (a) Quarter model (b) Pressure plot at $0.02 \mathrm{~ms}(\mathrm{c})$ Extent of detonation products 59

Figure 3-13: Pressure fringe plots for third run (a) 0.02-ms (b) 0.15-ms (c) Extent of

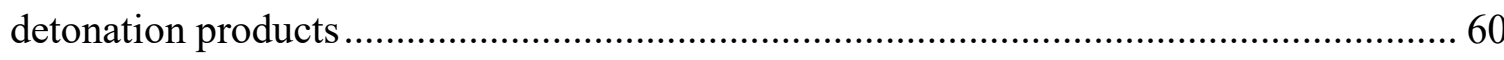

Figure 3-14: Velocity time-history plot of the PC slab during the third simulation......... 61

Figure 3-15: (a) Quarter symmetric model setup (b) Pressure fringe plot at $0.015 \mathrm{~ms}$ (c) Extent of detonated material at $0.015 \mathrm{~ms}$ 62 
Figure 3-16: (a) Pressure fringe plot at $0.12 \mathrm{~ms}$ (b) Extent of detonated material at $0.12 \mathrm{~ms}$

Figure 3-17: Damage profiles on the PC slab (a) Experimental test (b) Numerical

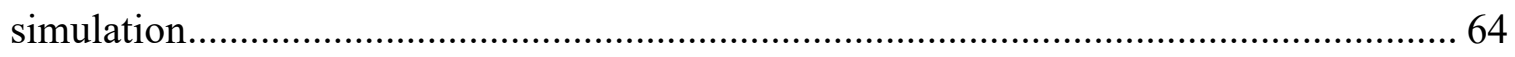

Figure 3-18: (a) Numerically predicted damage profiles and (b) Experimental damage

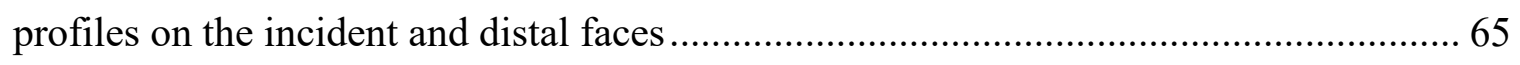

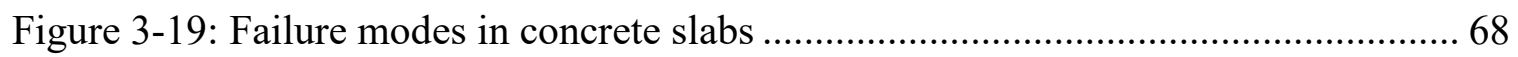

Figure 3-20: Influence of contact area between explosive and target (a) $4 \mathrm{~kg}$ as $180 \times 160 \times 90$ $\mathrm{mm}$ (b) $4.5 \mathrm{~kg}$ as $200 \mathrm{x} 200 \times 70 \mathrm{~mm}$ (c) $4.5 \mathrm{~kg}$ as $180 \times 180 \times 90 \mathrm{~mm} \ldots \ldots \ldots \ldots \ldots \ldots \ldots \ldots \ldots . . .75$

Figure 3-21: Response of $200 \mathrm{~mm}$ thick RC slab to $1500 \mathrm{~g}$ TNT explosion in contact (a) $120 \mathrm{~mm}$ thick TNT slab with $\mathrm{l} / \mathrm{h} \sim 0.75$ (b) Damage profile of the cross-section............ 76

Figure 3-22: Breach damage parameter as a function of scaled explosive mass .............. 79

Figure 3-23: Fitted function for calculating breach diameter ......................................... 82

Figure 4-1: (a) Material factor for breaching charges (b) Placement factor for ground placed

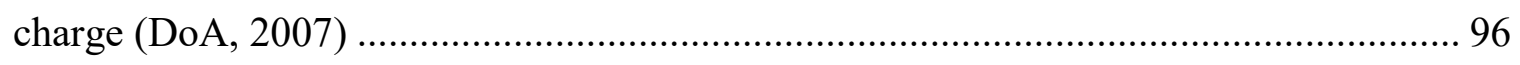

Figure 4-2: (a) Test column details (b) Test designations ................................................ 104

Figure 4-3: Experimental test setup for (a) 1000-g TNT (b) 115-g TNT equivalent ..... 106 xxiv 
Figure 4-4: Column interaction diagram 107

Figure 4-5: Reaction frame for axial loading of damaged columns 108

Figure 4-6: Post blast damage profiles for (a) 1000-g TNT (b) 500-g TNT and 115-g TNT (c) Incident face (d) Distal face 110

Figure 4-7: Load-Displacement curve for residual axial load carrying capacity test ..... 111

Figure 4-8: Damage profile of blast-damaged RC column subjected to 115-g TNT explosion in contact due to non-eccentric axial loading..... 112

Figure 4-9: Geometrical model for multistage simulations 119

Figure 4-10: (a) Quarter symmetric model (b) Pressure fringe plot (1-mm); Time-histories for reflected (c) pressure (d) impulse (e) impulse after smoothening (f) pressure after smoothening. 121

Figure 4-11: Mesh sensitivity analysis for blast response with (a) 2-mm mesh and (b) 10mm mesh; (c) Experimental response 123

Figure 4-12: Load-displacement time-histories for axially loaded pristine columns with varying mesh sizes. 124

Figure 4-13: Sequence of chained simulations 127

Figure 4-14: Numerical vs analytical strength of the pristine column......................... 128 
Figure 4-15: Multistage pressure fringe plots (a) initial pressure for 1-mm element size (b) last cycle for 1-mm element size

Figure 4-16: Blast wave propagation of 115-g TNT detonation (a) Initial pressure for 5$\mathrm{mm}$ element size (b) last cycle for 5-mm element size. 130

Figure 4-17: Cross-section across the point of contact with the explosive representing the damage profile of RC column subjected to (a) 115-g TNT (b) 500-g TNT

Figure 4-18: (a) Numerical model for residual axial load carrying capacity of the blastdamaged column (b) Load-displacement curve for the residual axial load capacity of the blast-damaged RC column 132

Figure 4-19: Cross-section at the point of contact presenting the damage in concrete core of the blast-damaged RC column subjected to the detonation of explosive mass (a) 115-g TNT (b) 200-g TNT (c) 300-g TNT (d) 500-g TNT 138

Figure 4-20: Influence of explosive mass on the damage index of the blast-damaged column (dashed arrows show damage indices). 138

Figure 4-21: Influence of concrete compressive strength on the damage index of the blastdamaged column (dashed arrows show damage indices) 140

Figure 4-22: Influence of reinforcement tie bar on the damage index of the blast-damaged column (dashed arrows show damage indices). 142 
Figure 5-1 (a) 1995 Alfred P. Murray building bombing (FEMA, 1996) (b) 1993 World

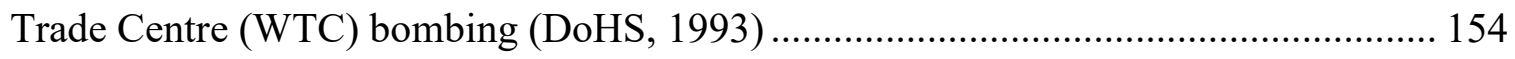

Figure 5-2: Placement factor for a charge mass placed on the ground (DoA, 2007) ..... 158

Figure 5-3: RC column details for (a) Bare columns (b) Clad columns; Test layout for (c)

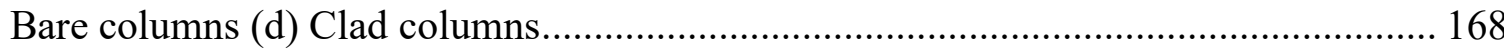

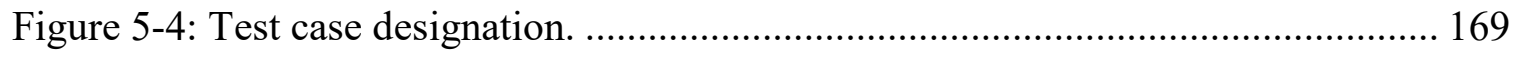

Figure 5-5: Column interaction diagram for (a) Bare columns (b) Clad columns; Loaddisplacement curve for (c) Bare columns (d) Clad columns.................................... 170

Figure 5-6: Experimental layout for residual axial capacity tests (a) Illustration (b) Actual

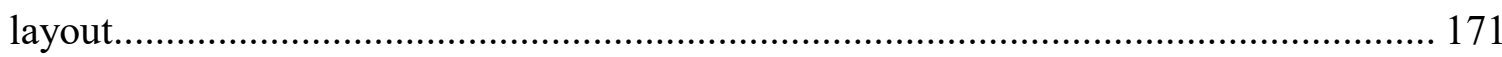

Figure 5-7: Preparation of columns for residual axial load carrying capacity tests (a) Wire saw concrete cutting (b) CFRP wrapping at top and bottom for strain compatibility .... 172

Figure 5-8: Response of RC columns to the detonation of (a) $1000 \mathrm{~g}$ TNT (b) $500 \mathrm{~g}$ TNT (c) $115 \mathrm{~g}$ TNT 174

Figure 5-9: Comparison of bare and clad columns (a) E-115-0 (b) E-115-50.............. 175

Figure 5-10: Damage profile of blast-damaged (a) E-500-50 (b) E-500-0 ................... 176

Figure 5-11: (a) Test setup (b) Post-explosion damage profile .................................. 177 
Figure 5-12: Residual axial load carrying capacity for test E-115-0 178

Figure 5-13: Residual axial load carrying capacity for E-115-50 (a) Blast-damaged column prior to axial loading (b) Post residual axial load capacity test damage profile 179

Figure 5-14: Residual axial load carrying capacity of test E-500-50 180

Figure 5-15: Residual axial load carrying capacity for test E-500-100 181

Figure 5-16: (a) Quarter symmetric model (b) Pressure fringe plot (1-mm); Time-histories for reflected (c) pressure (d) impulse (e) impulse after smoothening (f) pressure after smoothening. 187

Figure 5-17: Mesh sensitivity analysis for blast response with (a) 2-mm mesh and (b) 10mm mesh; (c) Experimental response 190

Figure 5-18: Load-displacement time-histories for axially loaded pristine columns with varying mesh sizes. 190

Figure 5-19: Geometrical model for multistage simulations 192

Figure 5-20: Sequence of multi-stage simulations for response prediction of RC columns with cladding. 194

Figure 5-21: Blast wave propagation in 5-mm element size mesh (a) first time step (b) last time step 196 
Figure 5-22: Half-symmetric cross-section of the RC column across the point of detonation at the last step of the third simulation 197

Figure 5-23: Damage profile of RC column subjected to 115-g TNT 197

Figure 5-24: (a) Numerical model setup (b) Numerical vs experimental results (dashed arrows show damage indices)

Figure 5-25: Pressure fringe plots at (a) first time-step \& (b) last time-step in 1-mm air domain; (c) first time-step \& (d) last time-step in 5-mm air domain for E-500-100 test. 200

Figure 5-26: (a) Numerically predicted damage profile vs (b) experimentally observed damage profile 201

Figure 5-27: Numerical vs experimental load-displacement time-histories for 500-g TNT on 100-mm gap cladding 202

Figure 5-28: (a) Numerically predicted damage profile vs (b) experimentally observed damage profile 203

Figure 5-29: Load-displacement curve for residual axial capacity tests 204

Figure 5-30: Shock wave propagation in RC slabs and RC columns 205 
Figure 5-31: Damage profile of RC column with 50-mm spaced cladding on the (a) Front face (b) Left face (c) Right face (d) Back face 207

Figure 5-32: Load-Displacement curves bare and cladded blast-damaged columns subjected to (a) $115 \mathrm{~g}$ TNT (b) $500 \mathrm{~g}$ TNT explosion effects (arrows show damage indices)

Figure 5-33: Numerical models with (a) $50 \mathrm{~mm}$ and (b) $100 \mathrm{~mm}$ thick Aluminum foam panels 211

Figure 5-34: Damage profiles of RC columns with (a) $50 \mathrm{~mm}$ and (b) $100 \mathrm{~mm}$ thick Aluminum foam panels due to contact explosion effects of $500 \mathrm{~g}$ TNT 211

Figure 5-35: Influence of Aluminum foam in mitigating contact explosion effects ...... 212

Figure 6-1: (a) RC column details for benchmark tests (b) Test setup for $1 \mathrm{~kg}$ explosive (c)

Test designations 233

Figure 6-2: RC wall details for $500 \times 300 \mathrm{~mm}, 700 \times 300 \mathrm{~mm}$ and $900 \times 300 \mathrm{~mm}$ aspect-ratios 234

Figure 6-3: Test case designation 235

Figure 6-4: Experimental test setup for E-500-900 test 236 
Figure 6-5: Test setup for residual axial load capacity (a) Schematic layout (b) Actual layout. 237

Figure 6-6: Damage profile for (a) E-1000-300 (b) E-500-300 (c) E-115-300 238

Figure 6-7: Damage profiles (front and back) for (a) E-500-900 (b) E-500-700 (c) E-500500. 240

Figure 6-8: Damage profile of blast-damaged RC wall with $300 \times 500-\mathrm{mm}$ cross-section after the residual axial capacity test (a) Side (b) Front 241

Figure 6-9: (a) Quarter symmetric model (b) Pressure fringe plot (1-mm); Time-histories for reflected (c) pressure (d) impulse (e) impulse after smoothening (f) pressure after smoothening..... 248

Figure 6-10: Mesh sensitivity analysis for blast response with (a) 2-mm mesh and (b) 10mm mesh; (c) Experimental response 250

Figure 6-11: Load-displacement time-histories for axially loaded pristine columns with varying mesh sizes. 251

Figure 6-12: Sequence of chained simulations 255

Figure 6-13: Geometric model for the nominal axial capacity of undamaged RC wall . 256 
Figure 6-14: Geometric model for E-500-500 illustrating the (a) Explosive mass (b) Extent of the detonation products \& (c) the pressure fringe plot at the last time-step 257

Figure 6-15: (a) Extent of detonation products \& (b) Pressure fringe at $0.06 \mathrm{~ms}$. 258

Figure 6-16: (a) Geometrical setup for the last simulation without ALE domain (b) Damage accumulation in the RC wall. 259

Figure 6-17: Numerically predicted and analytical axial capacity of 500×300 mm wall260

Figure 6-18: Comparison of damage profiles for N-500-500 and E-500-500 (a) Experimental profile (front face) (b) Numerical profile (front face) (c) Cross-section across incident face (d) Experimental profile (back face) (e) Numerical profile (back face) ... 261

Figure 6-19: Load-time curve under axial loading of E-500-500 and N-500-500 test cases 262

Figure 6-20: Damage profiles on the front and back faces) for (a) N-2500-500 (b) N-2500900 (c) N-2500-1200. 266

Figure 6-21: Comparison of damage indices of walls subjected to contact explosion effects of $2.5 \mathrm{~kg}$ TNT (arrows show damage indices). 267 


\section{Chapter 1 Introduction}

\subsection{Background}

Military structures and civilian buildings of iconic importance are the most likely targets for terrorist attacks due to the high exposure and a high number of casualties it can cause. Most of the bombings of such magnitude over the past two decades had one common modus operandi: destroying the most critical structural members; for example, the columns. The 1995 attack on Alfred P. Murrah building targeted a critical load-bearing column and caused a progressive collapse of a large part of the building Figure 1-1.

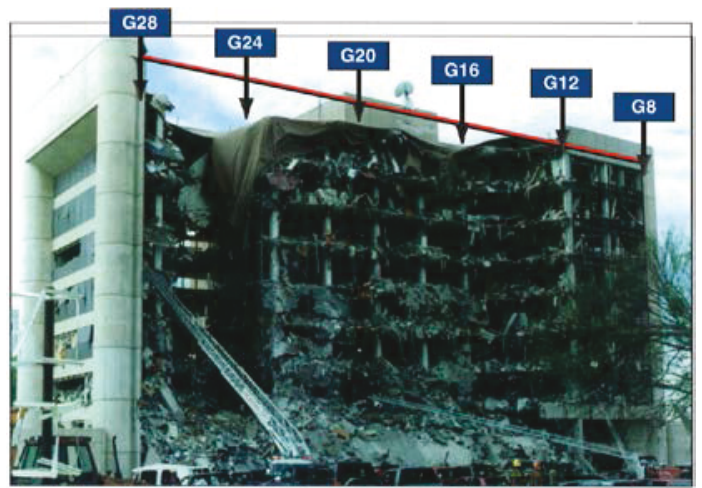

Figure 1-1: 1995 Alfred P. Murray building bombing (FEMA, 1996)

An 1814 kg (4000 lbs) Trinitrotoluene (TNT) equivalent vehicle-borne improvised explosive device was detonated in front of the building leading to shear failure of two load-bearing exterior columns. An insufficient redundancy further caused failure of a transfer beam and then the progressive collapse of a large part of the building. The unfortunate event resulted in the fatality of 268 people and severe 
damage to nearby buildings which were later demolished (Mlakar et al., 1998; Tagel-Din \& Rahman, 2006).

Terrorist attacks such as the Oklahoma City Bombing highlight that buildings are the primary target for terrorists as they can lead to high fatality rate. Now more than ever, governments are willing to understand the vulnerabilities of their structures to blast loading. A systematic design approach for resilient structures is presented in design standards like FEMA (2005); DoD (2007a, 2007b, 2008); ASCE (2011). However, the design approach is applicable to far-field events. In today's heightened security environment, there is less possibility of a conventional terrorist attack involving a high amount of explosive mass. A detonation of $1-25 \mathrm{~kg}$ TNT-equivalent explosive mass in contact with reinforced concrete (RC) member can cause considerable local damage leading to failure of the member. Such attacks pose a credible threat to the security of the structure.

\subsection{Problem Statement}

Unlike far-field blast events, contact explosion causes a highly nonlinear response, both temporally and spatially. The extreme impulsive load on the RC member due to contact explosion leads to local damage and brisance in the member (Figure 1-2). Severe local damage can result in failure of the member to resist the applied loads, leading to a redistribution of the loads in the structural frame. Furthermore, failure of the critical load carrying members can cause a cascading failure of the structure. To prevent such failure modes, it is of paramount importance to 
understand the failure mechanism during contact explosion events and how the effects can be mitigated.

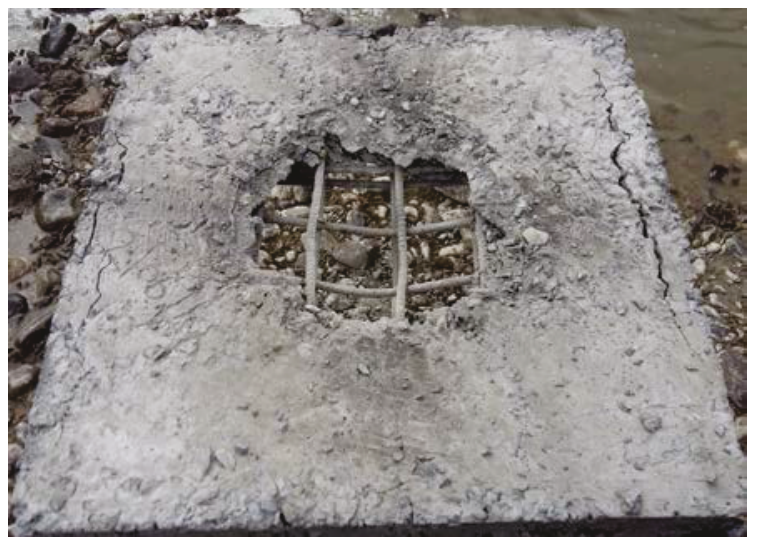

(a)

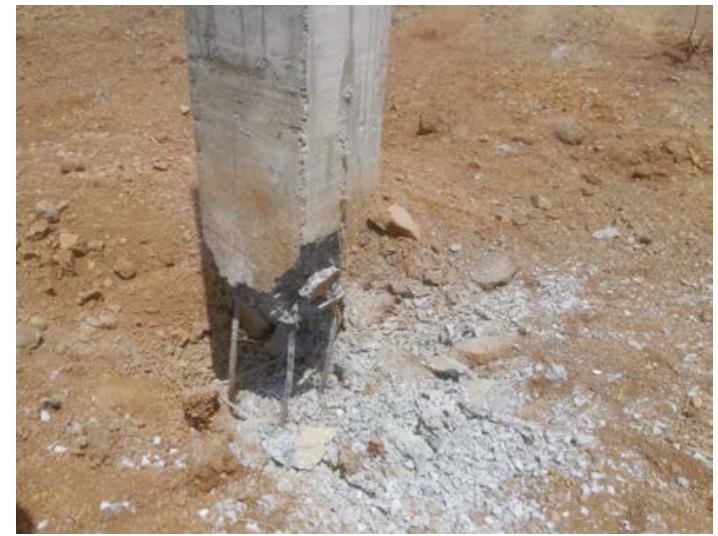

(b)

Figure 1-2 (a) RC slab and (b) RC column subjected to 500g TNT explosion in contact

The damage mechanism during a contact explosion event is not well understood and there are no empirical or analytical methods available to assess the damage response to contact explosion effects on RC columns. Limited research is available in the literature on the response of RC members to contact explosion effects. Albeit, a few researchers have studied the response of RC beams, columns and slabs, there is much to be done in the field of contact explosion response of RC slabs and columns.

\subsection{Research Objectives}

In view of the abovementioned lack of information and understanding of the response of RC slabs and columns to contact explosion effects, the objectives of this Ph.D. thesis are: 


\subsubsection{Study 1: Slabs}

- Experimentally investigate the response of slabs subjected to contact explosion effects and record the damage profile/failure modes.

- Develop and validate LS-DYNA numerical models using the experimental results to predict the response of $\mathrm{RC}$ slabs subjected to contact explosion effects.

- Using the validated numerical models, perform parametric analysis to investigate the effect of explosive charge mass, concrete strength and reinforcement ratio on the response of RC slabs subjected to contact explosion effects.

- Develop an empirical relation for calculating the breach diameter incorporating the effects of reinforcement ratio.

\subsubsection{Study 2: RC Columns}

- Characterize the damage profile on RC columns subjected to the detonation of different TNT explosive charge masses in contact with the column face and placed on the ground.

- Determine the residual axial load carrying capacities of the blast-damaged columns and quantify the range of explosive charge mass that can render an RC column to zero residual axial capacity. 
- Establish experimentally, validated numerical models to perform parametric analyses to evaluate the effect of different design parameters on the response of RC columns under contact explosion effects.

- Numerically investigate the influence of explosive charge mass, concrete compressive strength and transverse bar spacing on the residual axial load carrying capacity of the blast-damaged RC columns.

\subsubsection{Study 3: Mitigation of Contact Explosion Effects by Plywood Cladding}

- Experimentally acquire the damage profile of plywood cladded RC columns subjected to contact explosion effects from varying explosive mass and gap between plywood cladding and column.

- Determine the residual axial load carrying capacity of the blast-damaged columns and compare the results against the benchmark to establish the mitigation capability of plywood cladded RC columns

- Develop validated numerical model in LS-DYNA to establish response of cladded RC columns. Investigate the influence of energy absorbing material filled in the gap between cladding and column face.

\subsubsection{Study 4: Mitigation of Contact Explosion Effects by Aspect-ratio of RC} Walls

- Experimentally determine the range of aspect ratio of the RC column crosssection that precludes side face spalling due to contact explosion effects 
produced by $500 \mathrm{~g}$ TNT and establish the mitigation capability of aspectratio of the column cross-section.

- Develop an experimentally validated LS-DYNA numerical model to predict the residual capacity of the RC wall subjected to contact explosion effects of $500 \mathrm{~g} \mathrm{TNT}$.

- Numerically determine the width of the RC wall that can retain $30 \%$ residual axial load carrying capacity when subjected to contact explosion effects produced by the breach threshold explosive mass for an RC slab of same depth.

\subsection{Research Approach}

The response mechanism of concrete members subjected to contact explosion effects is a complex phenomenon and differs considerably for slabs and columns. Each study presented in the thesis evolved from the previous one. The concrete slabs were investigated first, which involved a simpler experimental setup. The findings from the first study on concrete slabs formed the basis for the study on $\mathrm{RC}$ columns. It provided the benchmark for comparing the damage mechanism in slabs and columns. The findings also indicated appropriate explosive mass to be used for testing the columns. Live explosive testing of RC columns is cost prohibitive and subjecting the column to very high explosive mass do not provide meaningful observations. The findings from slabs and columns evolved into mitigation strategies that were investigated in the third and fourth studies. The influence of an induced standoff gap between the explosive mass and column by 
means of plywood cladding was investigated in the third study. The effect of varying the aspect ratio to induce 1D failure mode (punching or breach) as in case of slabs was investigated in the fourth study in order to mitigate the contact explosion effects on columns. All the studies were carried out in the same sequence of six steps as illustrated in Figure 1-3. The numerical simulations were implemented with the following unit system; (a) Mass in metric-ton (mT) (b) Time in second (s) (c) Distance in millimeter ( $\mathrm{mm}$ ) and (d) Pressure in Megapascal (MPa). The concrete slabs were modeled using quarter-symmetric models and the concrete columns were modeled using half-symmetric models. The numerical residual axial capacities of columns were accordingly multiplied by two for comparison with experimental results.

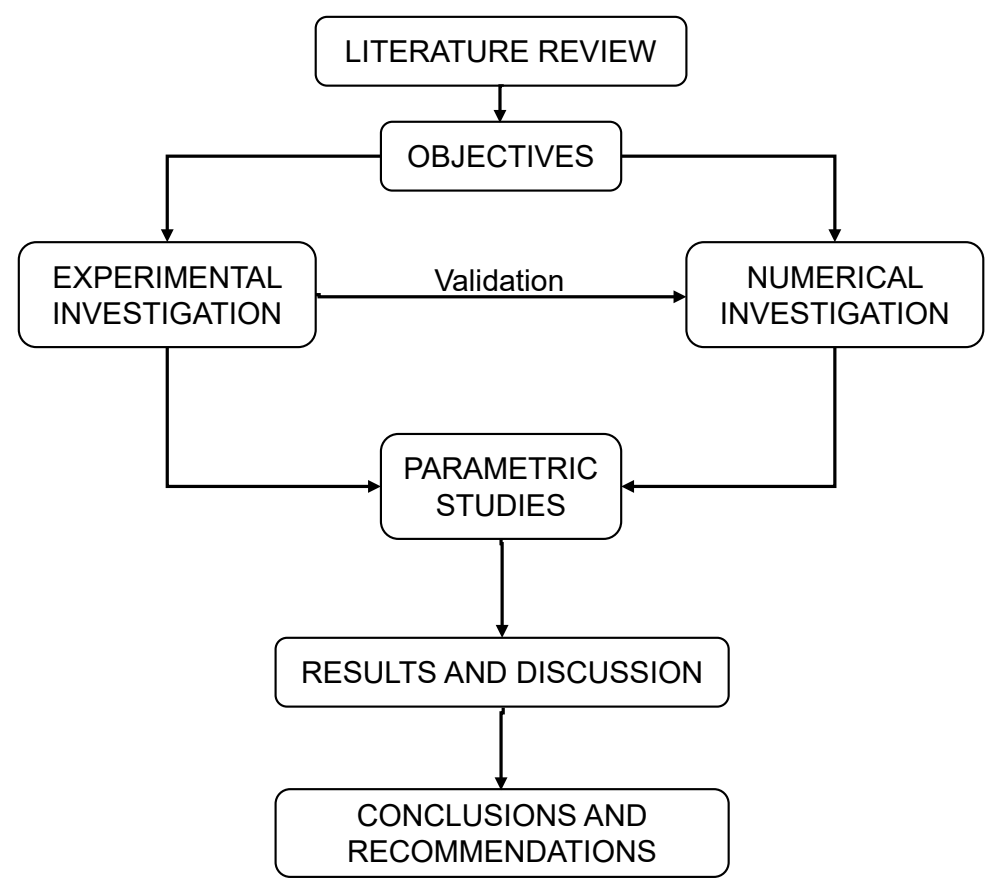

Figure 1-3: Flowchart of each study

In the first study on slabs, the response of plain concrete (PC) \& RC slabs under contact explosion effects were investigated experimentally and numerically. PC 
and RC slabs were subjected to contact explosion effects produced by a known explosive mass and the qualitative damage profiles recorded. An experimentally validated LS-DYNA numerical model was developed. The failure modes observed in an RC slab subjected to contact explosion effects were characterized experimentally and numerically and used to develop an understanding of the phenomenon. Furthermore, parametric studies were conducted to investigate the influence of explosive mass, explosive contact area, slab depth, and reinforcement ratio on the response of $\mathrm{RC}$ slabs. Dimensional analysis was carried out to formulate an empirical equation to predict the breach diameter of an $\mathrm{RC}$ slab based on the experimental and numerical results.

The second study on RC columns was conducted to investigate the response of $\mathrm{RC}$ columns under contact explosion effects and how it differs from that on RC slabs. Three RC columns with square cross-sections were subjected to contact explosion effects of varying explosive charge mass. The residual axial capacity of the blast-damaged columns was determined experimentally for quantitative validation of the numerical models. A parametric study was conducted to understand the damage mechanism and factors influencing the residual axial capacity of blast-damaged columns. The results were used as benchmark for investigating the mitigation strategies in the last two studies.

The third study on plywood cladded RC columns was conducted to investigate the mitigation capability of the gap induced by the cladding when subjected to contact explosion effects. RC columns with square cross-sections, same as the 
benchmark RC columns, were cladded with plywood with varying gaps between the cladding and the column face. The cladded columns were subjected to contact explosion effects due to varying explosive mass and the residual axial load carrying capacity of the blast-damaged columns were determined experimentally. The residual capacities of the blast-damaged cladded columns were compared to the benchmark results to highlight the mitigation capability.

In the last study, the improvement in residual axial capacity of the RC columns by varying the aspect-ratio of the cross-section i.e increasing the width of the column was investigated. The columns were termed as walls in this study. Three walls of same depth as the benchmark columns and of varying widths were subjected to a known explosive charge mass. A range of width was identified at which the $2 \mathrm{D}$ damage mechanism as observed in columns, transformed into 1D damage mechanism as in the case of slabs. The residual axial load carrying capacities of the walls were determined for comparison with the benchmark results. Experimentally validated numerical models were developed to predict the residual capacity of the blast-damaged columns and parametric studies performed.

\subsection{Novelty of the Research}

The empirical equations available in the literature for predicting the breach diameter of RC slabs do not consider the reinforcement ratio and hence are conservative in nature. Chapter 3 contributes to the state-of-the-art by presenting an empirical equation that includes the reinforcement ratio and contact area of 
explosive mass for predicting the breach diameter of RC slabs due to contact explosion effects.

Chapter 4 presents the quantitative analysis of the response of RC members subjected to contact explosion effects which is a novel contribution to the research field. So far only qualitative experimental results have been presented in the literature by comparing the damage profiles of the RC columns subjected to contact explosion effects. Hence, the numerical models are not validated conspicuously. Moreover, the element mesh size implemented in past studies for detonation and fluid-structure-interaction (FSI) has been very coarse. The mesh sensitivity analysis presented in the thesis indicates that the results vary significantly due to a coarse element mesh size. The quantified response of RC columns under contact explosion effects by testing the residual axial load carrying capacity of the blast-damaged columns has been presented in this chapter. The study also provides a benchmark for future studies related to contact explosion analysis.

The mitigation capability of cladded columns has not been investigated before. Chapter 5 demonstrates the mitigation capability of the induced gap of plywood cladded RC columns by comparing the residual axial capacity of blast-damaged columns to the benchmark.

The concept of equivalent $R C$ walls in place of square $R C$ columns to mitigate the contact explosion effects have not been studied earlier. Chapter 6 presents the 
mitigation capability of RC walls subjected to contact explosion effects for the first time.

\subsection{Thesis Organization}

The organization of the thesis is illustrated in Figure 1-4.

Chapter 1 provides the background and introduction of the studies carried out as part of the thesis. The problem statement, objectives, adopted approach and novelty are discussed in this chapter.

Chapter 2 presents the theoretical and technical background for analysis of blast response for far-field events. A separate literature review chapter has not been provided in the thesis as it has been covered in the chapters represented by the papers. The contents of the papers presented as Chapter 3 to Chapter 6 have not been omitted in any way and hence portions of these chapters are repetitive.

Chapter 7 summarizes the conclusions and contributions of the thesis and recommends future research. 


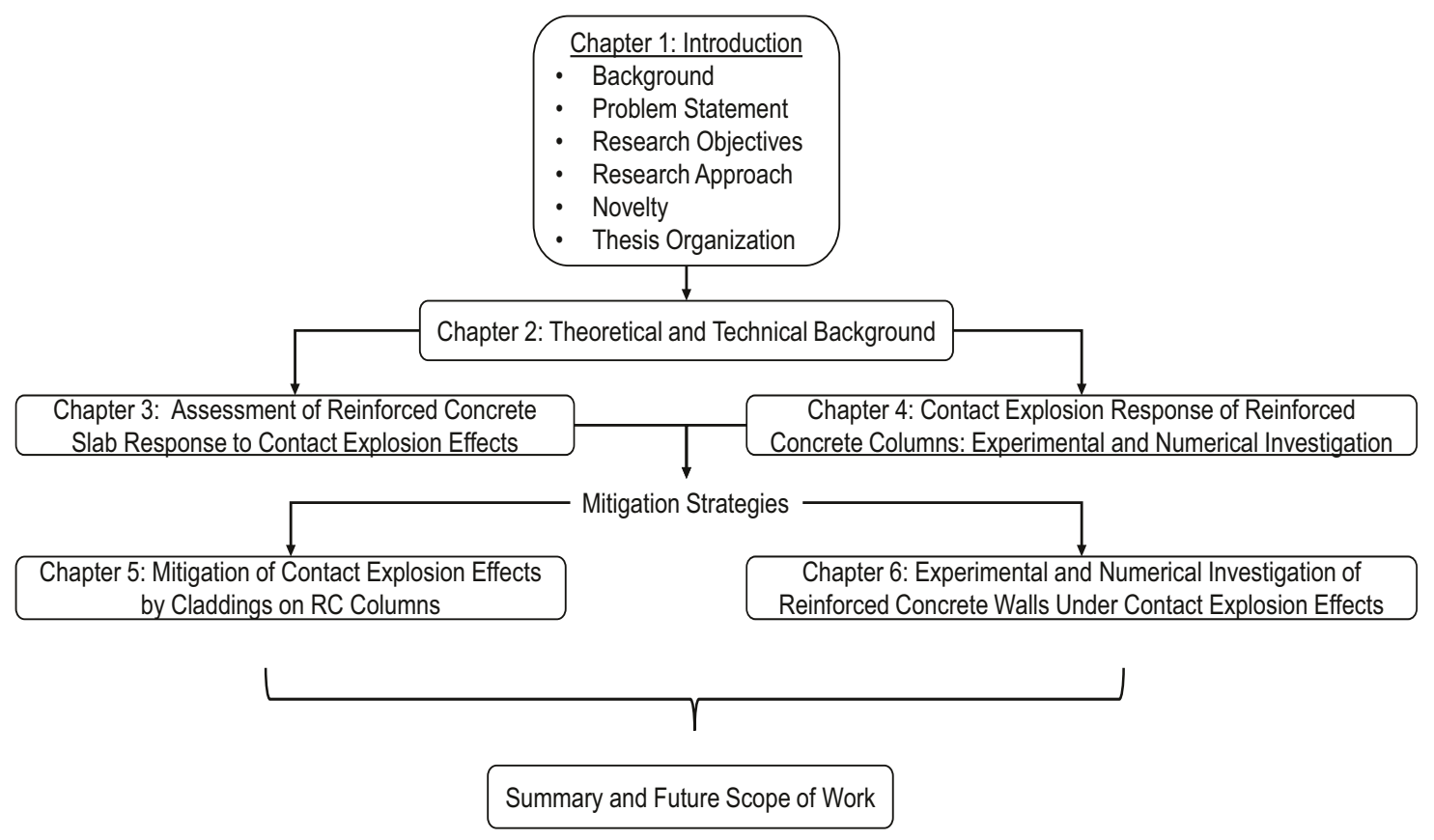

Figure 1-4: Organization of the thesis

\subsection{References}

ASCE. 2011. Blast Protection of Buildings: Standard ASCE/SEI 59-11: American Society of Civil Engineers (ASCE). USA.

US Department of Defense (DoD). 2007a. Minimum Antiterrorism Standards for Buildings, UFC-4-010-01. Department of Defense (UFC-4-010-01), USA.

US Department of Defense (DoD). 2007b. DoD Minimum Antiterrorism Standoff Distances for Buildings, UFC-4-010-02. Department of Defense (UFC-4010-02), USA.

US Department of Defense (DoD). 2008. Design of structures to resist the effects of accidental explosions, UFC-3-340-02. Department of Defense Washington, D.C. 
Federal Emergency Management Agency (FEMA). 1996. The Oklahoma City Bombing: Improving Building Performance through Multi-hazard Mitigation, FEMA-277. Federal Emergency Management Agency Washington, DC, USA.

Federal Emergency Management Agency (FEMA). 2005. Reference Manual to Mitigate Potential Terrorist Attacks Against Buildings, FEMA-426. Federal Emergency Management Agency (FEMA) USA.

Mlakar, P. F., Corley, W. G., Sozen, M. A., \& Thornton, C. H. 1998. The Oklahoma City Bombing: Analysis of Blast Damage to the Murrah Building. Journal of Performance of Constructed Facilities, 12(3): 113-119.

Tagel-Din, H., \& Rahman, N. A. 2006. Simulation of the Alfred P. Murrah Federal Building Collapse Due to Blasts Loads. Architectural Engineering Conference: ASCE Nebraska, USA. pp. 32-47. 


\section{Chapter 2 Theoretical and Technical Background}

This chapter discusses the background and state-of-the-art for response analysis in far-field events and elucidates the differences with near-field and contact explosion events. The literature review pertaining to the four studies has been presented in the respective chapters and is not reproduced in this chapter.

\subsection{Introduction}

An explosion is defined as a sudden release of energy and hot gases, within a very short period. Explosions can be accidental or intentional and can cause a catastrophic effect on structures and the proximate environment. The increased number of accidental and terrorist events around the world has led to more focused research in the field of resilient structures. However, there is limited experimental data available when compared to other forms of extreme loads such as wind, earthquake, and impact. The dearth of experimental data is due to a lack of access to experimental facilities and the cost involved in carrying out field testing when compared to other load categories. Until recently, blast resilient design procedures were limited to the military only. As the threat of attack has migrated from against military installations to against the public and civilian infrastructures, many researchers are now investigating the effects of explosions on conventional structures. Access to test sites is however still restricted to select government agencies and their contractors. 
At present blast-resistant design procedures are based on simplified methods elucidated in design manuals like FEMA (2005); DoD (2008); ASCE (2011). The empirical polynomial equations developed by Kingery and Bulmash (1984) form the basis of blast load parameters for spherical air burst and hemispherical surface burst. These equations are based on four Trinitrotoluene (TNT) explosions of 5 to 500 tons conducted between 1959-1964 (Kingery \& Pannill, 1964). The semiempirical high-order polynomials are also incorporated into Conventional Weapons Effects (ConWep), a computer program for calculating blast load parameters for a range of $0.053-252 \mathrm{~m} / \mathrm{kg}^{1 / 3}$ scaled distances (Hyde, 1988). However, the charts provide inaccurate parameters for a scaled distance of 0.053 $\mathrm{m} / \mathrm{kg}^{1 / 3}$ that represents the surface of spherical TNT explosive. The blast overpressure of $0.053 \mathrm{~m} / \mathrm{kg}^{1 / 3}$ scaled distance is expected to be close to the detonation pressure of the explosive. However, the pressure calculated with the Kingery-Bulmash polynomials is significantly less. For TNT, the detonation pressure is $21 \mathrm{GPa}$ (Dobratz \& Crawford, 1985) whereas the blast overpressure at $0.053 \mathrm{~m} / \mathrm{kg}^{1 / 3}\left(0.134 \mathrm{ft} / \mathrm{b}^{1 / 3}\right)$ scaled distance is $50 \mathrm{MPa}$ as predicted by the charts. Furthermore, the data represented in the near-field range has been reported to be inaccurate when compared to numerical and experimental results (Luccioni et al. (2006); Sherkar et al. (2010); Wang et al. (2008); Cormie et al. (2014a)). The definition of near-field range varies in the literature. ASCE (2011) DoD (2008) and CSA (2017) defines near-field as explosions occurring at scaled distances less than $1.18 \mathrm{~m} / \mathrm{kg}^{1 / 3}$ whereas Cormie et al. (2014b) define the nearfield range as explosions at scaled distances less than $0.4 \mathrm{~m} / \mathrm{kg}^{1 / 3}$. Regardless of 
the definition, the Kingery-Bulmash charts are not accurate for small scale distances and contact explosions. In case of near-field explosions, the empirical expressions cannot be applied with confidence because of the complexity of the flow processes involved in the propagation of detonation products close to the point of detonation. No clear and simple guidance exists on how to define the magnitude and spatial variation of near-field blast loading or contact explosions. Numerical analysis of detonation process, shock propagation and shock-structure interaction are available in commercially available finite element software packages. However, experimental data to validate such models remain scanty (Rigby et al., 2014).

\subsection{Current State-of-the-Art for Far-Field Explosion Analysis}

The detonation of an explosive generates high-temperature and high-pressure gases. The hot gases propagate radially outwards at high velocities from the point of detonation, forming a shock wave which is preceded by a thin high-pressure layer known as the shock front. When the shock front reaches a point in space (originally at the ambient pressure) an instantaneous increase in pressure (peak incident pressure $\mathrm{P}_{\text {so}}$ ) is observed. Figure $2-1$ shows a typical blast pressure time history as described in DoD (2008). The shock front velocity diminishes with time as it propagates and so also does the peak incident pressure, $\mathrm{P}_{\text {so. }}$ As the shock wave impacts a surface, it is reflected/reinforced and is termed as reflected pressure, $\operatorname{Pr}$ which is higher than the incident pressure. 


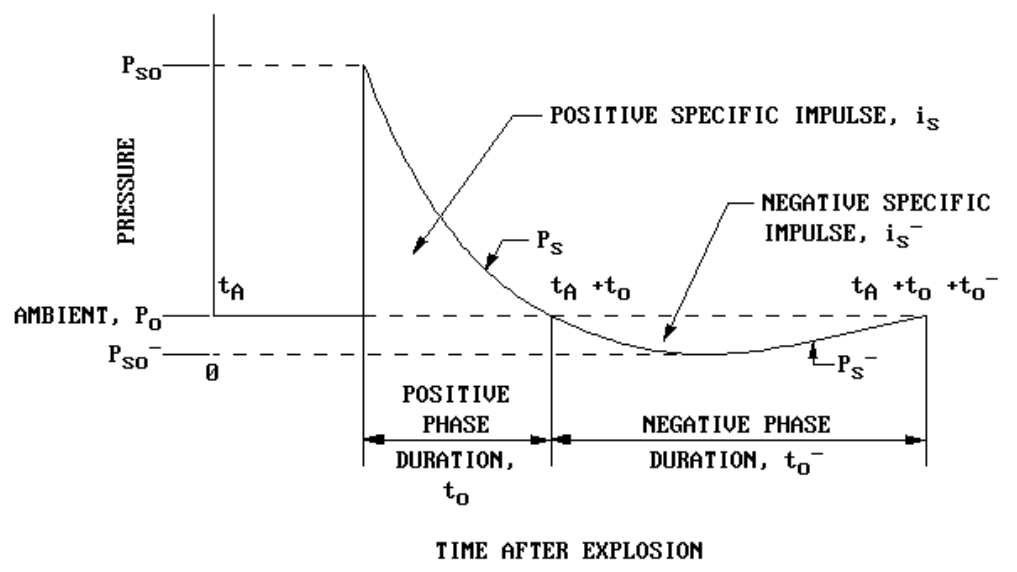

Figure 2-1: Pressure time history of a blast wave (DoD, 2008)

The method of analysis for structures subjected to far-field blast loads involve the determination of blast load parameters and performing dynamic analysis to ascertain the behavior of the structure. The blast parameters form the basis for blast loading on structures. Blast load parameters for conventional high explosives have been researched in detail and are well established. Peak overpressures due to spherical (free air burst/air burst) and hemispherical (surface burst) charges based on the Hopkinson-Cranz scaling law have been presented by various researchers and defense manuals (Brode (1955); Newmark and Hansen (1961); Mills (1987); DoD (2008); Mays and Smith (1995)). The blast load parameters can be calculated from the empirical equations or read from the charts corresponding to a scaled distance. The dynamic response of structural members to blast loading is usually determined by means of single-degree-of-freedom (SDOF) analysis. The basic advantage of using these empirical charts and SDOF analysis is speed and simplicity. The actual structural member is represented as a simple oscillator (SDOF system) with a concentrated mass attached to a massless spring (stiffness element) and a dash-pot (damping element). The blast loads (forcing function) 
represented by Figure 2-1 can be idealized as a triangular load. The equation of motion for the SDOF system can be solved to arrive at the time history of displacement response for the system. DoD (2008) provides a family of response curves that can accurately predict the ductility requirement for an elasto-plastic SDOF system under the considered loads. This simplicity, however, is based on major assumptions which precludes the application of results obtained to cases where: (a) the blast load is spatially non-uniform over the structure, (b) the structure cross section is not constant across the structure, (c) blast loading results in significant local damage due to material failure.

\subsection{Near-field and Contact Explosion Event Versus Far Field Event}

A structural system may be designed using SDOF approach however effects like P-Delta, localized deformations, concrete panel zone deformations and other localized response characteristics associated with near-field explosions are not captured (Smilowitz \& Tennant, 2010). Near-field explosions produce highintensity blast loads that are extremely non-uniform across a structural member. The loading of the structural member takes place within the detonation by-products and explosion fireball. In addition, high-velocity primary fragments from the explosive casing, if any, are likely to impact the structure. Under such situations the analytical tools developed for far-field analysis are less reliable especially for scaled distances less than $1.18 \mathrm{~m} / \mathrm{kg}^{1 / 3}$ (Smilowitz and Tennant (2010), Cormie et al. (2014a), Sherkar et al. (2010), Wang et al. (2008), Luccioni et al. (2006)). The charts further loose accuracy for charges other than spherical and hemispherical 
shape (Smilowitz \& Tennant, 2010). It is vital to determine the accurate blast pressure/impulse load in order to accurately predict the response of the structure subjected to the near-field blast.

The near-field blast loading is spatially non-uniform and hence the structural members (beams/columns) are likely to fail in shear (Rigby et al., 2014). In case of far-field explosions, the pressure and impulse take-up of the members is uniform thereby resulting in bending action. Whilst the tools and techniques for measuring the blast parameters for far-field explosion are well developed, measuring the blast parameters in near field explosion (in fireball and detonation products) is difficult.

In addition to the temporal and spatial non-uniformity, there are variations between non-spherical and spherical charges in the near-field. The blast wave from a cylindrical charge is predominantly directed in either radial or axial direction depending on the length-to-diameter ratio unlike a spherical charge wherein the blast wave is omni-directional. Also, the point of initiation of an explosive charge influences the blast parameters significantly in the near-field in case of cylindrical charges (Anderson et al., 2002).

During a contact explosion, the duration of blast loading may be shorter than the time to maximum response of the member. In such cases, the structural members are analyzed for impulse loading and not the blast overpressure loading. A contact explosion initiates a compressive wave on the incident face of the target. The compressive wave propagates through the material radially outwards from the 
point(s) of contact. Upon reaching the boundary of the target, the change in media results in an impedance mismatch and reflection of the compressive wave into a tensile wave. The reflected tensile wave becomes subtractive on interacting with the in-bound compressive wave and can cause tensile stress on the target near the boundary. Hence, a contact explosion initiates a compressive failure at the incident face and a tensile failure at the distal boundaries, in case the loading exceeds the respective compressive and tensile strengths of the target material. A low tensile strength, in the case of concrete targets, result in spalling at distal faces creating a scab. The incident face may also be crushed if the compressive stress is higher than the compressive strength causing cratering. The failure of both front and back faces culminating at a common point will lead to a breach; leaving a hole in the member.

\subsection{References}

Anderson, J. G., Katselis, G., \& Caputo, C. 2002. Analysis of a Generic Warhead Part-I : Experimental and Computational Assessment of Free Field Overpressure.

ASCE. 2011. Blast Protection of Buildings: Standard ASCE/SEI 59-11: American Society of Civil Engineers (ASCE). USA.

Brode, H. L. 1955. Numerical solution of spherical blast waves. Journal of Applied Physics, American Institute of Physics, New York.

Cormie, D., Shin, J., Whittaker, A. S., \& Aref, A. J. 2014a. Air Blast effects on civil structures, MCEER-14-0006. State University of New York. 
Cormie, D., Shin, J., Whittaker, A. S., \& Wilkinson, W. 2014b. Numerical modelling of close-in detonations of high explosives. Engineering Structures, 81: 8897.

Canadian Standards Association (CSA). 2017. Design and Assessment of Buildings Subjected to Blast Loads, S850-12 (R2017). Canada.

Dobratz, B., \& Crawford, P. 1985. LLNL explosives handbook.

US Department of Defense (DoD). 2008. Design of structures to resist the effects of accidental explosions, UFC-3-340-02. Department of Defense Washington, D.C.

Federal Emergency Management Agency (FEMA). 2005. Reference Manual to Mitigate Potential Terrorist Attacks Against Buildings, FEMA-426. Federal Emergency Management Agency (FEMA) USA.

Hyde, D. 1988. User's guide for microcomputer programs CONWEP and FUNPRO - Applications of TM 5-855-1.

Kingery, C. N., \& Pannill, B. F. 1964. Peak overpressure vs scaled distance for TNT surface bursts (hemispherical charges).

Kingery, C. N., \& Bulmash, G. 1984. Air blast parameters from TNT spherical air burst and hemispherical surface burst. Ballistic Research Lab (BRL), Technical Report, ARBRL-TR-02555.

Luccioni, B., Ambrosini, D., \& Danesi, R. 2006. Blast load assessment using hydrocodes. Engineering Structures, 28(12): 1736-1744.

Mays, G. C., \& Smith, P. D. 1995. Blast effects on buildings: Thomas Tedford publications. 
Mills, C. A. 1987. The design of concrete structure to resist explosions and weapon effects. Proceedings of the 1st international conference on concrete for hazard protections: Edinburgh, UK

Naito, C., Olmati, P., Trasborg, P., Davidson, J., \& Newberry, C. 2014. Assessment of insulated concrete walls to close-in blast demands. American society of civil engineers, 10.

Newmark, N. M., \& Hansen, R. J. 1961. Design of blast resistant structures: Eds Harris and Crede McGraw-hill, New York,(Vol. Shock and vibration handbook, Volume 3).

Rigby, Tyas, A., Clarke, S., Fay, S., Warren, J., Elgy, I., \& Gant, M. 2014. Testing apparatus for the spatial and temporal pressure measurements from nearfield free air explosions. 6th International Conference on Protection of structures against hazards: Tianjin, China.

Sherkar, P., Whittaker, A. S., \& Aref, A. J. 2010. Modelling the effects of detonations of high explosives to inform blast resistant design. MCEER: Earthquake engineering to extreme events.

Smilowitz, R., \& Tennant, D. 2010. Structural Systems Design, Handbook for BlastResistant Design of Buildings: Wiley \& Sons. USA.

Wang, F., Wan, Y. K. M., Chong, O. Y. K., Lim, C. H., \& Lim, E. T. M. 2008. Reinforced concrete slab subjected to close-in explosion. LS-DYNA Conference: Bamberg. 


\title{
Chapter 3 Assessment of Reinforced Concrete Slab Response to Contact Explosion Effects
}

\begin{abstract}
Precise response prediction of critical structural members under extreme loads is essential for the survivability of infrastructure and its occupants. In a threat scenario of reinforced concrete (RC) members subjected to contact explosion effects, the member may undergo abrupt failure, initiating the progressive collapse of the structure. Research on the response of $\mathrm{RC}$ components to explosion effects is limited to far-field events. Response mechanism of a contact explosion event is not well understood and is a continuing field of research. Specifically, a breach in an RC slab presents a serious threat to the occupants and structural integrity of the infrastructure. Limited experimental data is available for determining the breach charge mass for contact explosion on an RC slab. The numerical and analytical studies found in the literature focus on plain concrete (PC) slabs and the influence of reinforcement ratio is not well researched. This paper presents the results of an experimental investigation on the response of PC and RC slabs subjected to contact explosion of 500-g of TNT. A finite element model was developed and used to predict the experimental results within a $24 \%$ error. The validated finite element model was used to conduct parametric studies on the influence of various design parameters. Concrete compressive strength was found to have little influence on the threshold breach charge mass when compared to the reinforcement ratio. An empirical equation is proposed based on the numerical results for predicting the threshold breach charge mass that incorporates the effect of reinforcement ratio.
\end{abstract}

Keywords: LS-DYNA, FSI, contact explosion, near-field blast, mesh sensitivity analysis, SHPB, impact, breach threshold.

\subsection{Introduction}

Blast-resistant structures are often designed according to guidelines and design manuals issued by government agencies such as Federal Emergency Management Agency (FEMA, 2005) and Unified Facilities Criteria (DoD, 2002, 2007a, 2007b, 2008). These guidelines and manuals were initially developed for

Submitted to the Journal of Performance of Constructed Facilities, ASCE in a revised form.

Authors - Dua, Alok and Braimah, Abass 
hardened military infrastructure; however, they are now being adapted for civilian structures as well. The empirical charts presented in these manuals and the Conventional Weapons Effects (ConWep) program for calculating the blast load parameters are based on data collected between 1959 to 1964 from experimental tests performed with 5 to 500 -ton Trinitrotoluene (TNT) explosive masses at various scaled distances (Kingery \& Pannill, 1964). The design procedure involves generation of blast load parameters from the charts based on scaled distance. DoD (2008), CSA (2017) and ASCE (2011) defines the range of the near-field explosion as scaled distances less than $1.18 \mathrm{~m} / \mathrm{kg}^{1 / 3}$ (Figure 3-1). The blast parameters calculated with the empirical charts and ConWep are accurate in the far-field range but lose accuracy at scaled distances below $0.4 \mathrm{~m} / \mathrm{kg}^{1 / 3}$ (Cormie et al., 2014; Braimah et al., 2015) (Figure 3-1).

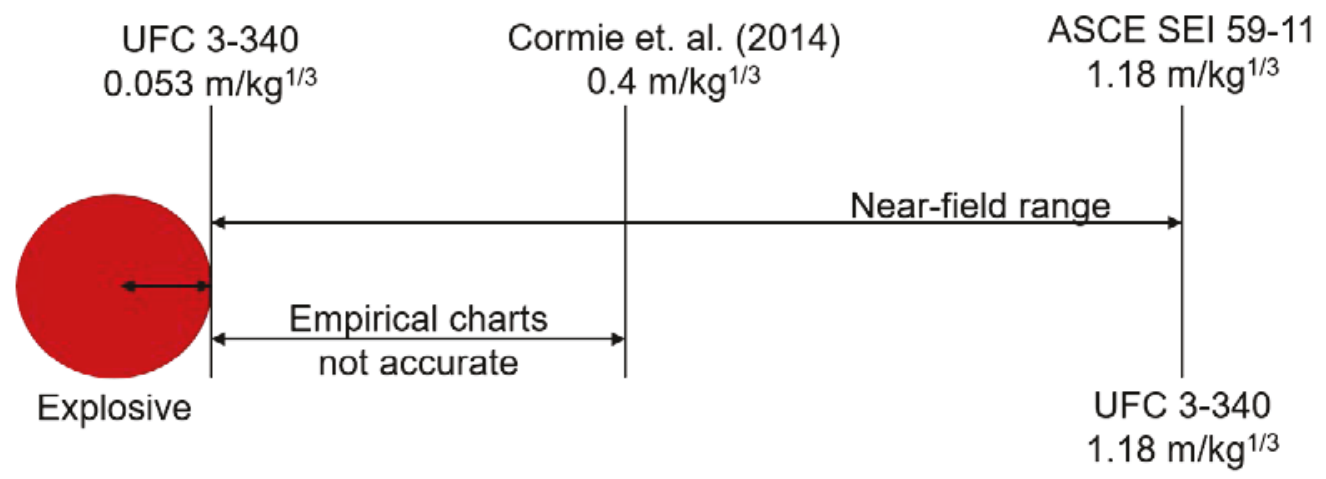

Figure 3-1: Threshold scaled distance definition of a near-field event

Most of the buildings in congested cities cannot be provided with the required standoff distances by means of barriers in order to limit the structural damage due to blast effects. For such buildings, the far-field explosion threat may not be applicable and a near-field or contact explosion poses a viable threat. A review of 
terrorist events in the last few decades reveals that most of the vehicle-borne or person-borne attacks were in close range of their intended targets (Ducibella \& Cunningham, 2010). In far-field blast events, the shock front is planar producing uniform and simultaneous loading on the target structural element (Figure 3-2(a)). In near-field range, however, the blast pressures are spatially and temporally nonuniform (Figure 3-2 (b)) resulting in localized damage. Additionally, local response modes and material damage complicate the response analysis of structural elements. Hence, post-blast response prediction may not be analytically possible due to the high non-linearity involved in near-field and contact explosion events.
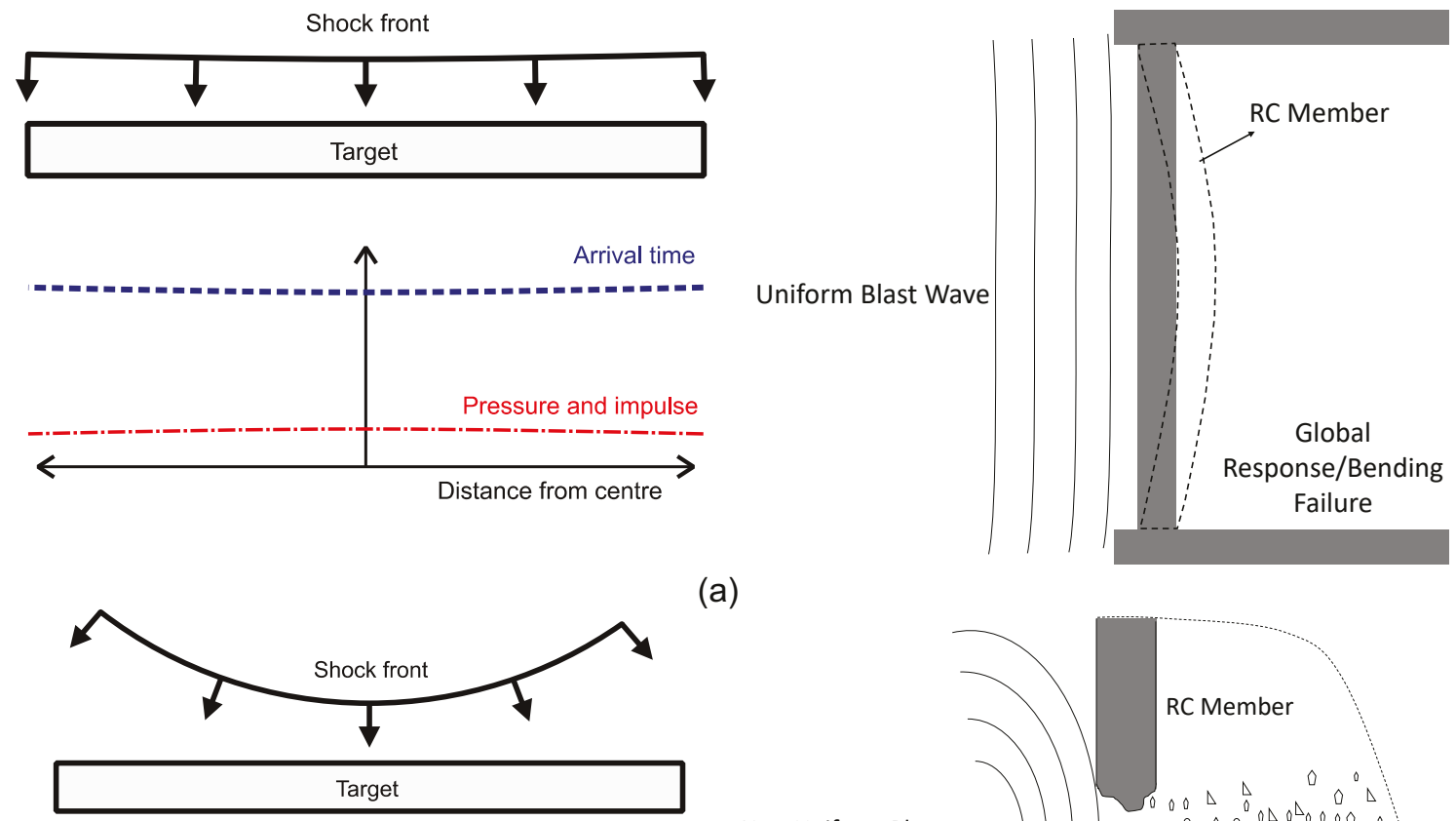

(a)

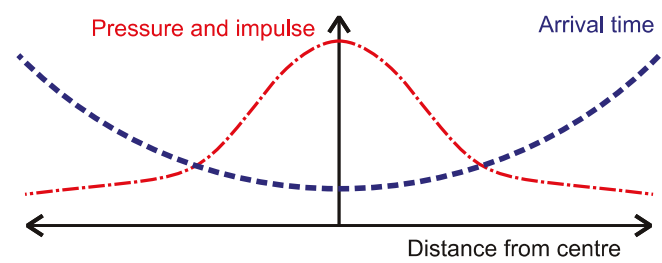

Non-Uniform Blast Wave

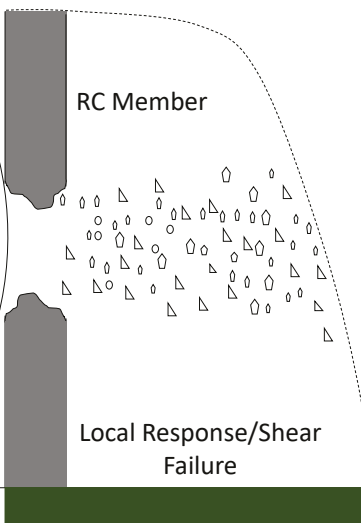

(b)

Figure 3-2: (a) Far-field explosion (global response) (b) Near-filed explosion (local response) (Rigby et al., 2015) 
Studies on the response of reinforced concrete $(R C)$ slabs subjected to contact explosion effects are limited. Most of the studies are numerical and analytical. Additionally, the influence of reinforcement ratio and reinforcement layout on the response is lacking from these studies.

Experimental investigation on RC slabs subjected to contact explosion effects is presented in this study. Experimentally validated LS-DYNA numerical models were implemented for parametric studies on the influence of slab design parameters.

\subsection{Literature Review}

\subsubsection{Studies on RC Members Subjected to Contact Explosion}

One of the earliest experimental studies on the response of RC members subject to contact explosion effects was performed by Weerheijm et al. (1984). The magnitude of the peak blast pressure and duration from a contact explosion were

reported as 10-15 GPa and $10^{-4} \mathrm{~s}$, respectively. An empirical relationship, given by Equation 3-1, was proposed to calculate the critical slab thickness that precludes a complete breach of the concrete slab.

$$
\mathrm{d}_{\mathrm{c}}=0.134 \mathrm{~W}^{1 / 3}
$$

where critical thickness $\left(d_{c}\right)$ is in $\mathrm{m}$ and explosive weight $(W)$ is in $\mathrm{kg}$. For contact explosion events, the concrete compressive strength and end boundary conditions were reported to have no effect on the critical slab thickness, $d_{c}$. 
Morishita et al. (2000) conducted contact explosion tests on RC slabs and reported that the concrete compressive strength and reinforcement spacing did not correlate with the intensity of the local damage of concrete slabs and fragmentation. Equation 3-2 was proposed for calculating the critical slab thickness to preclude breach of plain concrete $(\mathrm{PC})$ slab:

$$
\frac{T}{W^{1 / 3}}=2
$$

where $\mathrm{T}$ is the critical thickness of the $\mathrm{PC}$ slab in $\mathrm{cm}$ to preclude breach and $\mathrm{W}$ is the equivalent TNT charge mass in $\mathrm{kg}$. The influence of reinforcement was not investigated in this study.

Gebbeken et al. (2004) presented a computational tool XPLOSIM for response calculation of RC slabs subjected to close-in (near-field) and contact detonation effects. Damage functions of concrete were developed from numerical and experimental results that formed the core of the computational tool. The damage assessment parameters of RC slabs were predicted within $4.3 \%$ of the experimental results except for the back face spall depth which was predicted with a higher error of $22.2 \%$ (Gebbeken et al., 2004).

Akers et al. (2005) reported experimental results of full-scale explosive tests on $\mathrm{RC}$ slabs. Two RC slabs were subjected to contact explosion effects of $8.5 \mathrm{~kg}$ and $780 \mathrm{~g}$ TNT. The authors also reported numerical results from simulations using a computer program called Zapotek (Bessette et al., 2003). The Microplane and 
Karagozian and Case $(\mathrm{K} \& \mathrm{C})$ concrete material models were implemented for modeling concrete on Zapotek program. Akers et al. (2005) concluded that the K \& C concrete constitutive model predicted excessive damage and did not correlate well with the experimental results. The Microplane concrete constitutive model in Zapotek predicted the experimental results with reasonable accuracy.

The reference manual by the US Army Corps of Engineers (DoA, 2007) presented explosive and demolition procedures for combat operations. An empirical relationship was proposed to predict the breaching charge mass required for demolition of RC members like bridge pier, bridge abutments, and field fortifications. The weight of TNT required to breach RC piers was represented by Equation 3-3:

$$
P=R^{3} K C
$$

where $P$ is the TNT charge weight in pounds, $R$ is the required breach radius in feet, $K$ is the material factor and $C$ in the placement factor. Equation 3-3 is based on field trials, details of which are not documented in the manual. Effects of concrete compressive strength, transverse reinforcement spacing and, longitudinal reinforcement ratio are not included in the empirical relation.

Lin et al. (2008) subjected RC slabs to contact explosion of varying charge mass. Four failure mechanisms were reported by the authors; namely; cratering, spalling, perforation, and punching. Numerical simulations of the contact explosion were performed with Multi-material Arbitrary Lagrangian Eulerian (MMALE) formulation 
using an average element size of $8 \mathrm{~mm}$. The concrete material was modeled using Mat_16 (Geological Model) of LS-DYNA which is the erstwhile version of Mat_159 (Continuous Surface Cap Model (CSCM)). The reinforcement was modeled with Mat_24 (piecewise linear plasticity model). Experimental validation for these results was not reported.

Beppu et al. (2010) evaluated the effectiveness of fibre sheet reinforcement on explosive resistance of concrete slabs when subjected to contact explosion. Carbon fibre and Aramid fibre sheets were used for reinforcements. The typical local failure modes in fibre reinforced concrete slabs subjected to contact explosion effects were identified as; crater-spall, breach, diagonal crack and interface damage (interface of sheet and concrete). The carbon fibre reinforced polymer (CFRP) sheets did not prevent the crater-spall formation, however, reduced the crater-spall diameters. On the other hand, the aramid sheet reinforcement prevented crater-spall formation and improved the explosion resistance of the concrete slab (Beppu et al., 2010).

Williams and Williamson (2011) presented the response of bridge columns subjected to blast loads at various scaled distances and to contact explosion. The experimental results presented by Williams and Williamson (2011) illustrated that a bridge column can survive a contact explosion if a small standoff is provided between the edge of the charge and the column. A mesh density of 1.15 to 1.76 elements per cubic inch was reported to produce results that best correspond to the experimentally measured displacements. 
B. Li et al. (2012) experimentally evaluated the residual axial capacity of RC columns subjected to simulated blast loads. RC column specimens were deflected laterally to emulate numerically predicted lateral response to far-field blast loading. These specimens were then loaded axially to acquire the axial capacity of simulated blast-damaged columns. The study concluded that a higher transverse reinforcement ratio provided additional shear strength, thereby improving the blast resistance of the RC column when subjected to far-field blast loads. It was also reported that axial load on the $\mathrm{RC}$ column resulted in smaller lateral deflection in the column on being subjected to far-field blast loads.

Arlery et al. (2013) presented numerical simulations for predicting damage and loss of axial capacity in RC columns subjected to contact explosions. Experimental results presented by Wu et al. (2011) were used to validate the ABAQUS model results and were reported to be a good match. The RC columns, air domain, and explosive domain were meshed with $15-\mathrm{mm}$ sized elements. The damage index representing the residual axial capacity of RC columns subjected to contact explosion under different scenarios were presented. The authors validated the numerical models qualitatively from the damage profiles and accelerometer readings.

Remennikov et al. (2015) presented analytical models for explosive breaching of concrete and masonry walls. The models included prediction of breach charge mass and damage profile of various failure modes in RC and masonry slabs subjected to contact explosion effects. The predictions were compared to 
experimental results reported by Beppu et al. (2010) and were reported to have errors less than $5 \%$ for the breach charge mass and damage profile. The analytical models were based on Krivtsun and Mentus (2009) and Salamakhin (1974). Equation 3-4 and 3-5 were derived from principles of blast physics and conservation laws for predicting the breach charge mass and the crater dimensions:

$$
\begin{aligned}
& \mathrm{C}=\mathrm{K}_{0} \frac{\mathrm{n}^{2}}{\mu} \mathrm{h}^{3} \\
& \mathrm{C}=18 \mathrm{Kr}_{\mathrm{c}}{ }^{3}
\end{aligned}
$$

where $\mathrm{C}$ is the breach explosive charge mass, $\mathrm{K}_{0}$ and $\mathrm{K}$ are target and explosive material coefficients, $\mathrm{n}$ is spall size coefficient, $\mu$ is the charge shape coefficient, $h$ is the target thickness and $r_{c}$ is the radius of ejection crater. The coefficients $K_{0}$ and $\mathrm{K}$ were derived for $\mathrm{RC}$ slabs and the influence of reinforcement ratio was not presented explicitly.

Yuan et al. (2017) reported the experimental and numerical response of 1/3-scale bridge columns with square and circular cross-sections, subjected to contact explosion. The column length of 1-m from the point of detonation was meshed with 8-mm Lagrangian elements and outside of this was meshed with 20-mm element size. The ground surface was modeled as rigid elements with a very coarse mesh. The air and explosive domains were meshed with $20-\mathrm{mm}$ sized elements. The 
nodal accelerations obtained from the simulations were compared to the histories acquired by the accelerometers and were reported to be a reasonable match.

\subsubsection{Blast Wave Generation}

Far-field blast load parameters are evaluated from empirical equations based on experimental data reported by (Kingery \& Bulmash, 1984). For numerical modeling of the blast wave, commercial software like LS-DYNA offers two options; Load_Blast_Enhanced (LBE) based on the empirical equations and Initial_detonation that models the physical detonation process and blast wave propagation in the Eulerian domain. The LBE data or the Kingery and Bulmash (1984) curves provide an incident pressure of $50 \mathrm{MPa}$ at a scaled distance of 0.053 $\mathrm{m} / \mathrm{kg}^{1 / 3}$, which corresponds to the charge radius or the surface of the explosive charge (Figure 3-1). However, the detonation pressure of a TNT explosive is reported to be $21 \mathrm{GPa}$ (Dobratz \& Crawford, 1985). This shows the discrepancy between the reported values from the empirical Kingery and Bulmash (1984) curves and the chemical properties of TNT which is accepted to be accurate (Cormie et al., 2013).

Hanssen et al. (2004), Kakogiannis et al. (2010), Zakrisson et al. (2011), Cormie et al. (2013); Cormie et al. (2014) recommend modeling the explosive detonation explicitly for near-field and contact explosions, with MMALE element formulation. MMALE formulation provides a complete description of blast wave parameters (Børvik et al., 2009). The technique involves modeling the chemical reaction during detonation and subsequent blast wave propagation. The main disadvantage of 
modeling detonation and propagation is the fine mesh requirements for accuracy (Kakogiannis et al., 2010) and hence an associated high computational cost. Souli et al. (2013); Kalra et al. (2014) presented a 2D to 3D MMALE mapping technique in LS-DYNA for reducing the computational cost. The explosive detonation and blast wave propagation was simulated in a finely meshed $2 \mathrm{D}$ domain and then mapped to a coarse meshed $3 \mathrm{D}$ domain to implement the Fluid-StructureInteraction (FSI) between the blast wave and the Lagrangian structural elements. This technique, however, cannot be implemented for modeling contact explosions as the explosive detonation and FSI occur simultaneously. Hence, a 3D domain with a fine mesh is required from the time of explosive detonation through the interaction.

Rigby et al. (2015) experimentally validated the overpressure and impulse predicted numerically by modeling the detonation of $100-\mathrm{g}$ TNT explosive at a scaled distance of $0.15 \mathrm{~m} / \mathrm{kg}^{1 / 3}$. The reflected overpressure and impulse timehistories due to the explosion were acquired by Hopkinson pressure bars (HPB) and reported in the paper.

\subsubsection{Mesh Sensitivity of the Detonation Process}

The MMALE formulation has been reported to be appropriate for modeling explosive detonation and blast wave propagation. The main disadvantage is, however, its mesh dependency (Hanssen et al., 2004; Børvik et al., 2009; Kakogiannis et al., 2010). The accuracy of numerical results is highly sensitive to the mesh properties and can lead to significant differences in the blast wave 
properties. Zukas and Scheffler (2000) reported that the numerical results from the same problem provided by four experienced LS-DYNA users varied by $80 \%$ due to different mesh properties. In particular, the mesh dependency is directly related to the computational requirement for simulating near-field or contact explosion. Hence, mesh sensitivity analysis is important for such studies in order to predict accurate results from a computationally cost-effective model. Moreover, the mesh sensitivity analysis must be compared and validated with experimental data to establish the adequacy of the mesh for detonation and blast wave propagation modeling.

Trajkovski et al. (2014) presented a mesh sensitivity study for generating incident and reflected blast parameters. The incident and reflected blast parameters were generated with MMALE formulation for different mesh sizes and compared to parameters from DoD (2008). Trajkovski et al. (2014) reported that reasonably accurate blast parameters can be generated using 10 elements per charge radius if the minimum distance between the charge and the Lagrangian part is four times the charge radius (Trajkovski et al., 2014).

Lapoujade et al. (2010), Souli et al. (2013) and Kalra et al. (2014) presented a method for mapping blast waves from $2 \mathrm{D}$ to the $3 \mathrm{D}$ domain to maintain the accuracy and lower computational costs. The 2D domain allows simulation of explosive detonation and blast wave propagation with a fine mesh and hence higher accuracy. The blast wave properties from the last timestep of the 2D model are mapped to a $3 \mathrm{D}$ domain; usually just before it interacts with the Lagrangian 
elements. Cormie et al. (2014) reported that an element size of $\bar{r} R / 500$ is enough to predict pressure time histories in the near-field where $\mathrm{R}$ is the standoff distance and $\bar{r}$ is the charge radius.

\subsubsection{Strain-Rate Effects}

Concrete exhibits strain-rate dependency and fails at higher stress values in both tensile and compressive regime. In analytical solutions, the strength increase is incorporated with a dynamic increase factor (DIF) (Telford, 1993); defined as the ratio of dynamic to static failure load. The DIFs are incorporated in simple input constitutive models like Mat_72R3 and Mat_159. Mat_72R3 adopted DIF reported by Telford (1993) while Mat_159 constitutive model adopted DIFs reported by Murray (2007) that are a good fit to strain-rate effects both in tension and compression regime (Murray, 2007). The strain-rate effects can be activated through the IRATE parameter on the Mat_159 keyword.

\subsection{Research Objective}

The literature review presented above brings out the inaccuracy of the empirical equations in predicting blast parameters for explosions at scaled distances of less than $0.4 \mathrm{~m} / \mathrm{kg}^{1 / 3}$ and for contact explosion events. Experimental investigation on the response of RC slabs subjected to contact explosion effects is limited in the literature. Consequently, numerical models are often not adequately validated. Moreover, the effect of design parameters for protective design is not well understood. 
Explicit modeling of explosive detonation and blast wave propagation is an appropriate method to represent near-field and contact explosion events. An element size of $0.5-\mathrm{mm}$ to $2-\mathrm{mm}$ for the explosive and air domains have been reported to yield accurate blast parameters (Trajkovski et al., 2014). Yet the results reported in the literature are with element size ranging from $10 \mathrm{~mm}$ to $20 \mathrm{~mm}$. This probably can be attributed to the computational requirements for fine-meshed explosive and air domains while simultaneously implementing the FSI with Lagrangian entities. Lastly, the experimental, numerical and analytical studies found in the literature do not account for the reinforcement ratio in RC slabs. The response analysis found in the literature is limited to concrete compressive strength and the thickness of the RC slabs.

This study presented in this chapter has the following objectives.

- Experimentally investigate the response of RC slabs subjected to contact explosion effects and record the damage profile/failure modes.

- Validate the numerical model with experimental results by comparing the damage profile of the RC slab.

- Perform parametric analyses to investigate the effect of explosive mass, concrete strength, and reinforcement ratio on the response of RC slabs subjected to contact explosion effects.

- Develop an empirical relationship for the breach diameter incorporating the effects of reinforcement ratio. 


\subsection{Experimental Investigation}

A contact explosion event results in a local response of crater-spall or perforation/punching failure modes. Experimental tests were performed to investigate both failure modes by subjecting $75-\mathrm{mm}$ thick PC slab (punching failure mode) and 200-mm thick RC slab (crater-spall failure mode) to contact explosion of 500-g TNT.

A PC slab of $750 \times 750 \times 75 \mathrm{~mm}$ was cast with a nominal concrete mix design to achieve $25 \mathrm{MPa}$ cube compressive strength. The slab was cast in a plywood formwork and was moist cured with burlaps. The compressive strength of concrete cubes cast along with the slabs was tested to be $25 \mathrm{MPa}$ which corresponds to 20 MPa cylindrical strength. The slab was supported on a 900-mm high steel frame without edge fixity. The PC slab was subjected to contact explosion effects from 500-g TNT detonation at the center of the slab (Figure 3-3). The physical and material properties of the explosive are presented in Table 3-1. The explosive was detonated with an electric detonator placed in the center of the TNT slab.

Table 3-1: Properties of TNT slab

\begin{tabular}{|c|c|c|c|}
\hline Dimensions, $\mathrm{mm}$ & Explosive Mass, $\mathrm{g}$ & Density, $\mathrm{g} / \mathrm{cc}$ & Detonation Velocity, $\mathrm{m} / \mathrm{s}$ \\
\hline $120 \times 80 \times 40$ & $500 \mathrm{~g}$ & 1.55 & 6900 \\
\hline
\end{tabular}




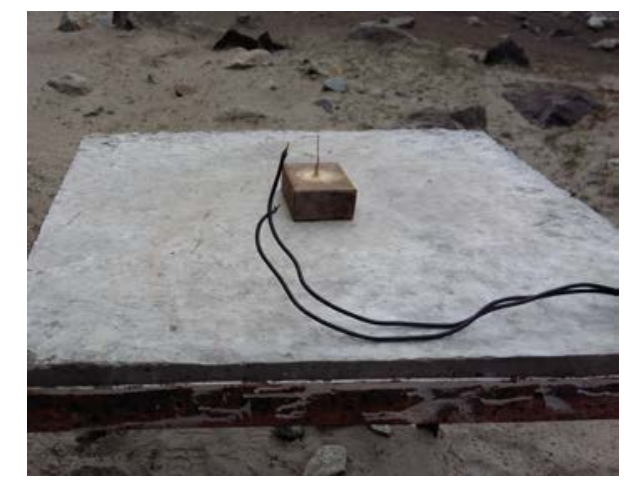

Figure 3-3: Experimental setup for PC slab

Additionally, two $900 \times 900 \mathrm{~mm} \mathrm{RC}$ slabs of $200 \mathrm{~mm}$ thickness were cast and subjected to contact explosion effects of 500-g TNT, to investigate the crater-spall failure mode. A nominal concrete mix design of $25 \mathrm{MPa}$ was used to cast the slabs in a plywood formwork. The average compressive strength of concrete cubes cast along with the slabs was tested to be $25 \mathrm{MPa}$ ( $20 \mathrm{MPa}$ cylindrical strength). The slab was provided with two-way reinforcement of 12-mm diameter rebar at $100 \mathrm{~mm}$ $\mathrm{c} / \mathrm{c}$ with a $30 \mathrm{~mm}$ cover at top and bottom. The reinforcement ratio is equivalent to 0.011. The details of the RC slab and reinforcement layout is presented in Figure 3-4 (a) \& (b). A 500-g TNT slab with electric detonator in the center of the TNT slab was detonated at the center of the concrete slab. A simply-supported support condition was provided by means of a steel frame as seen in Figure 3-4 (c). The fireball over the RC slab during detonation of the explosive can be seen in Figure 3-4 (d). The material properties for the TNT charge used for the tests are same as presented in Table 3-1. 


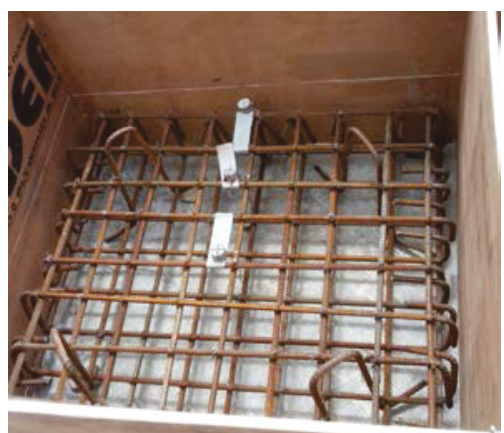

(a)

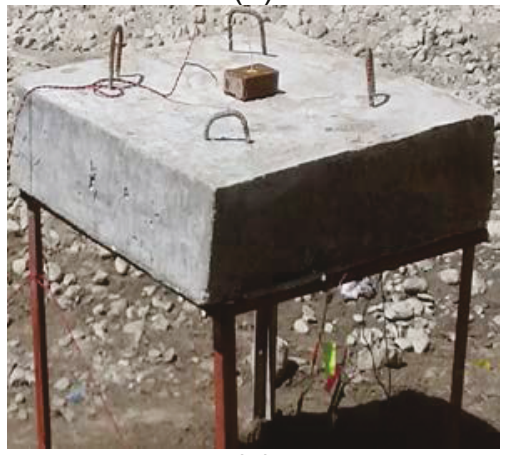

(c)

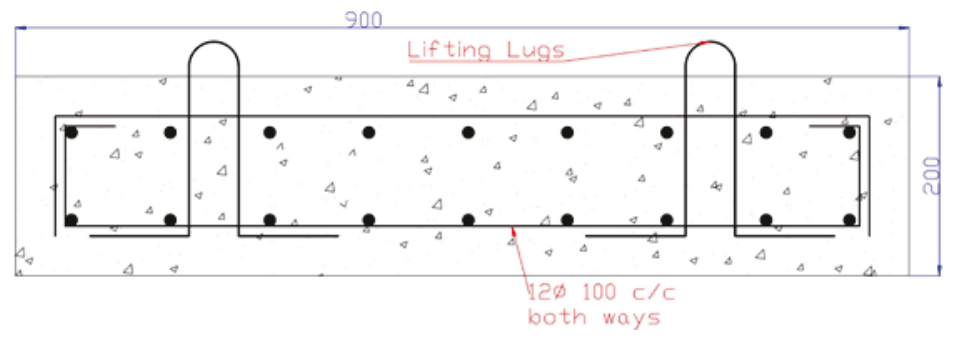

(b)

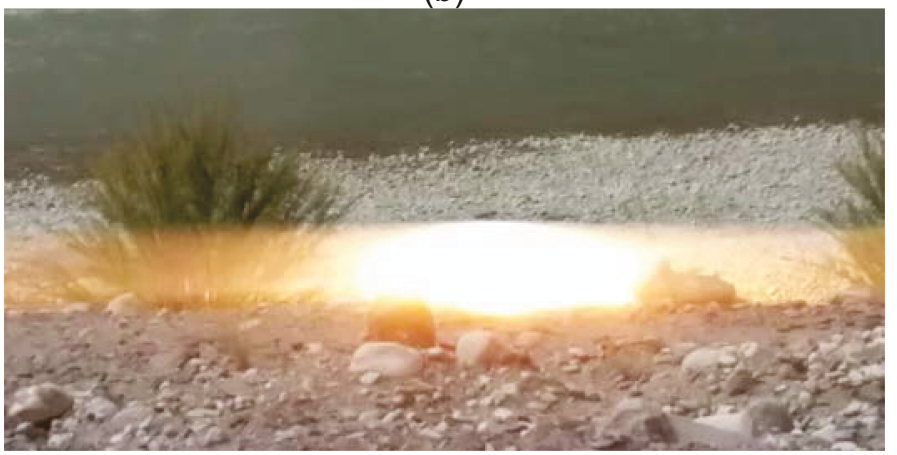

(d)

Figure 3-4: (a) Reinforcement layout (b) Slab cross-section (c) Experimental setup (d) Fireball at detonation

\subsection{Experimental Results}

\subsubsection{PC Slab}

A 350-mm diameter breach was formed in the PC slab due to the contact explosion effects of $500 \mathrm{~g}$ TNT. Full-depth diagonal cracks emanated from the circular hole towards the edges. The damage profile and dimensions of the breach are presented in Figure 3-5. 


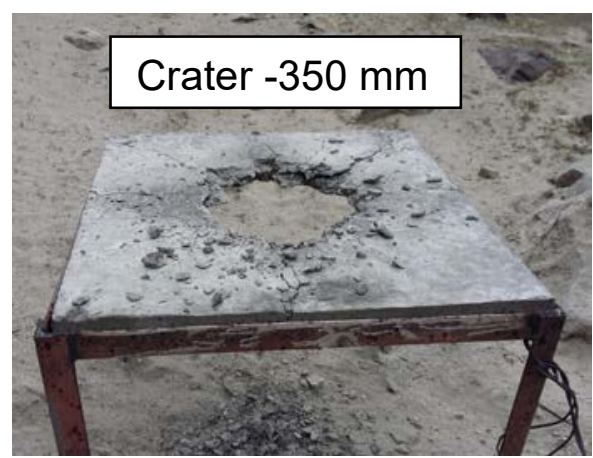

Figure 3-5: Response of PC slab to effects of $500 \mathrm{~g}$ TNT detonation

It is evident from the experimental results that contact explosion effects of $500-\mathrm{g}$ TNT on a PC slab of $75 \mathrm{~mm}$ thickness and $20 \mathrm{MPa}$ compressive strength results in a breach failure mode. The failure mode and the crack pattern correlated well with the results reported by Weerheijm et al. (1984).

\subsubsection{RC Slab}

The experimental observations from the RC slab tests are tabulated in Table 3-2 and post-event photos showing the top face spalling are presented in Figure 3-6.

Table 3-2: Experimental results

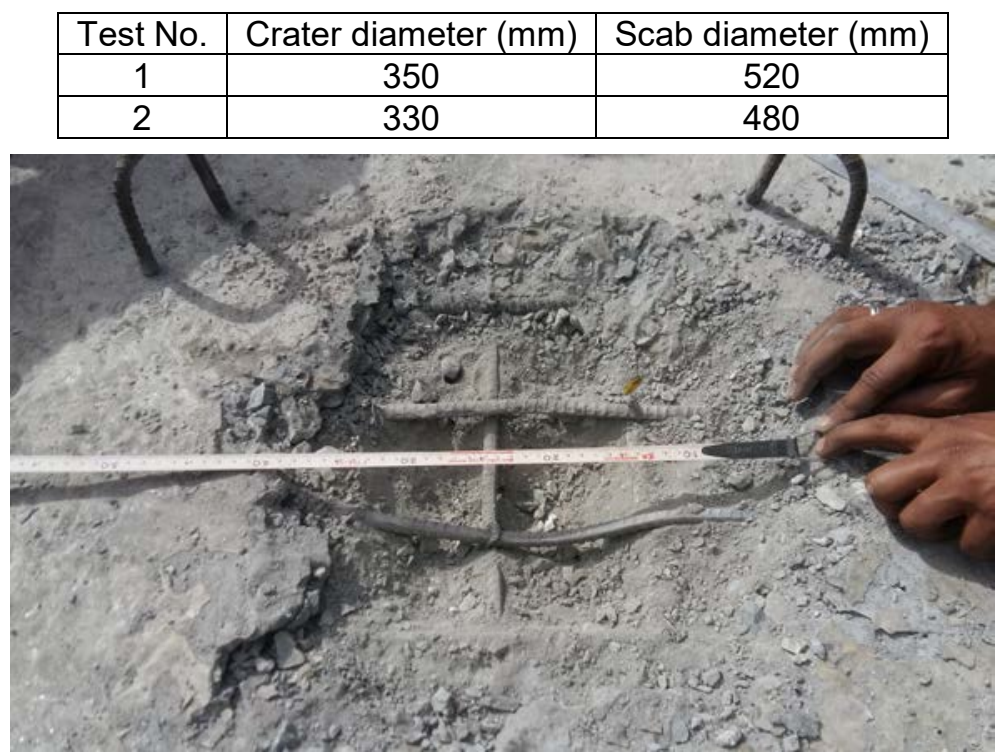

(a) 


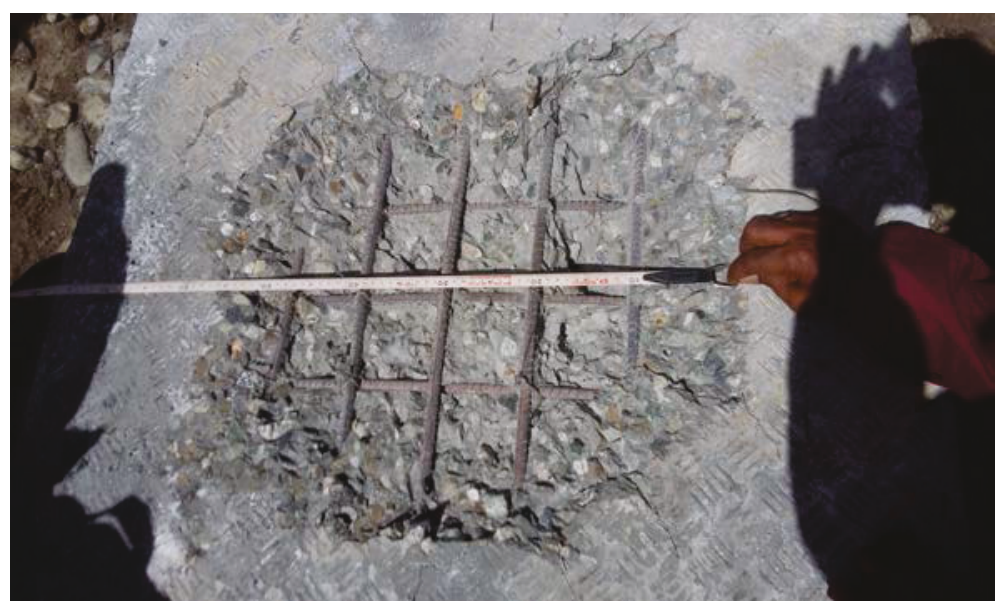

(b)

Figure 3-6: (a) Typical crater on the incident face (b) Typical scab at the distal face

The RC slab exhibited cratering of the incident surface and concrete scabbing was observed from the distal face of the slab. The top layer reinforcement directly under the explosive was bent by approximately $90 \mathrm{~mm}$ downwards while the bottom layer reinforcement suffered negligible bending. The scabbing occurred at the reinforcement-concrete interface and the diameter of the scab was larger than the diameter of the crater on the attack face. Similar results were observed for both the tests.

\subsection{Numerical Modeling}

\subsubsection{Mesh Sensitivity Analysis}

Non-linear explicit analysis involving ALE domains is sensitive to the element mesh size and it is recommended that a mesh sensitivity analysis is performed to determine the appropriate element mesh size for the loading regime being modeled (Trajkovski et al., 2014). For this study, mesh sensitivity analyses were 
carried out for the ALE domain and the Lagrangian domains for modeling the PC and RC slabs tested experimentally.

\subsubsection{ALE domain}

Rigby et al. (2014) presented experimental results of reflected blast parameters measured by Hopkinson pressure bars (HPB) at a scaled distance of $0.15 \mathrm{~m} / \mathrm{kg}^{1 / 3}$. A 100 -g plastic explosive (PE4) charge was detonated at $75 \mathrm{~mm}$ from a $100-\mathrm{mm}$ thick steel plate. The test arrangement is presented in Figure 3-7.

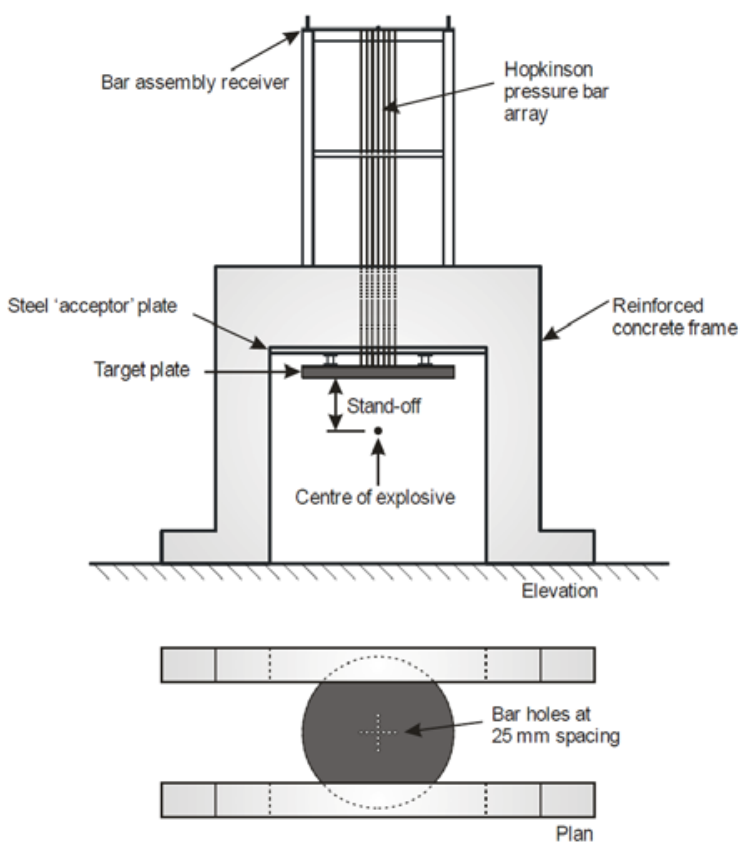

(a) 


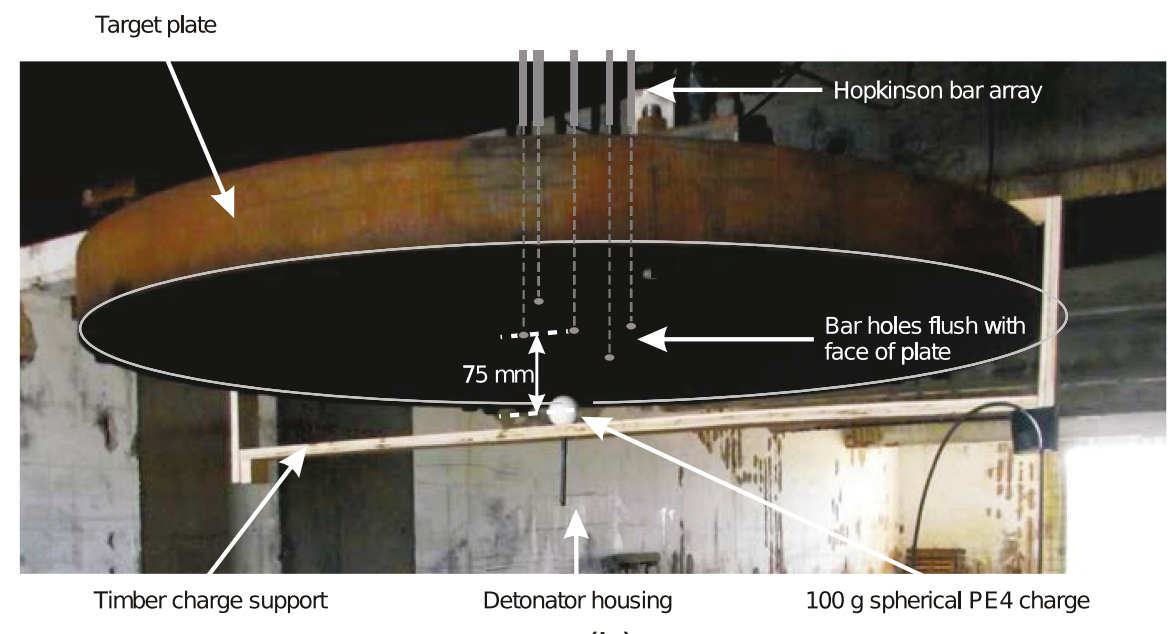

(b)

Figure 3-7: Test arrangement for reflected blast pressure time history (a) Schematic (b) experimental setup (Rigby et al., 2014)

Six sets of normal and radial reflected pressure time histories were acquired through the five bars shown in Figure 3-7. The normal reflected pressure and impulse for the six tests are presented in Figure 3-8.

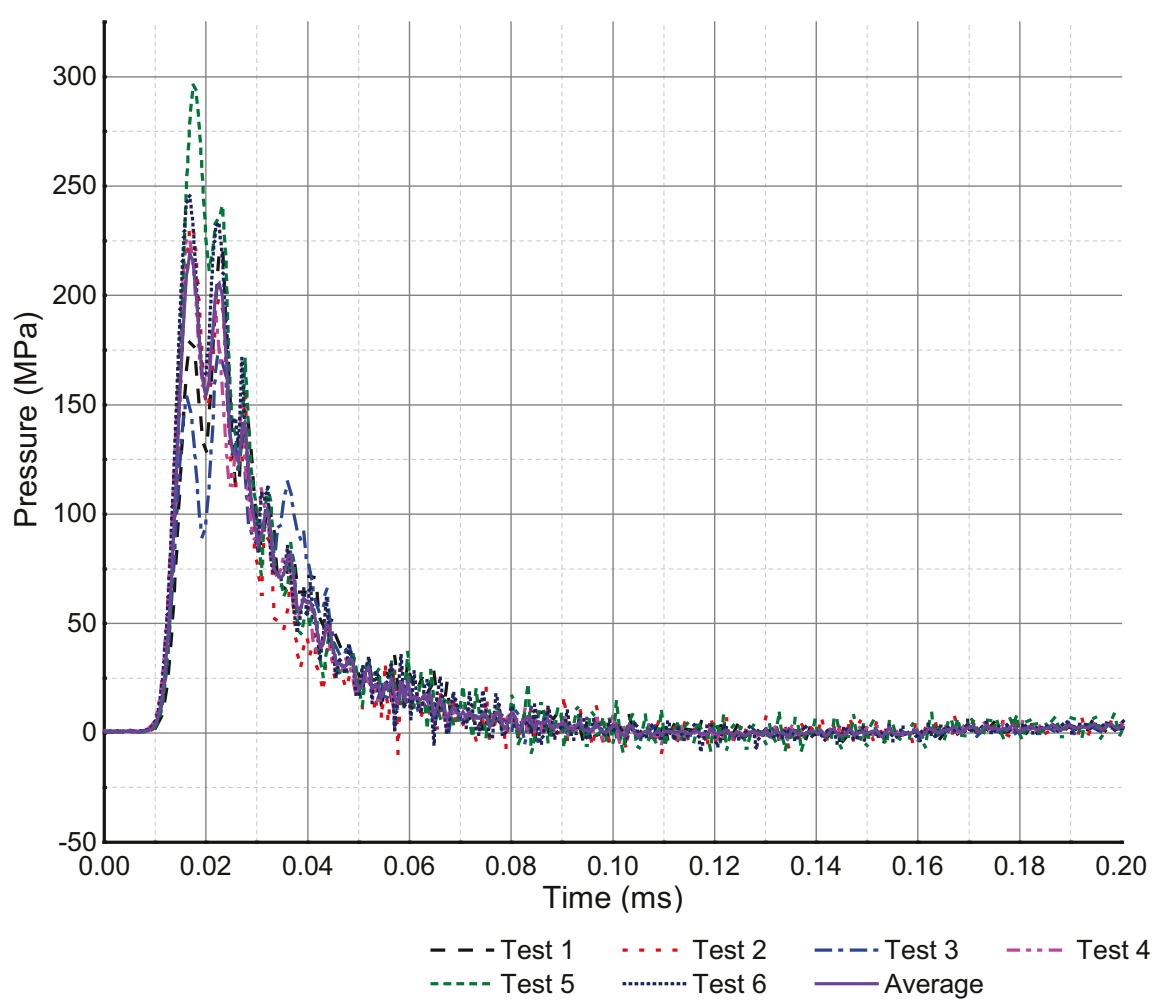

(a) 


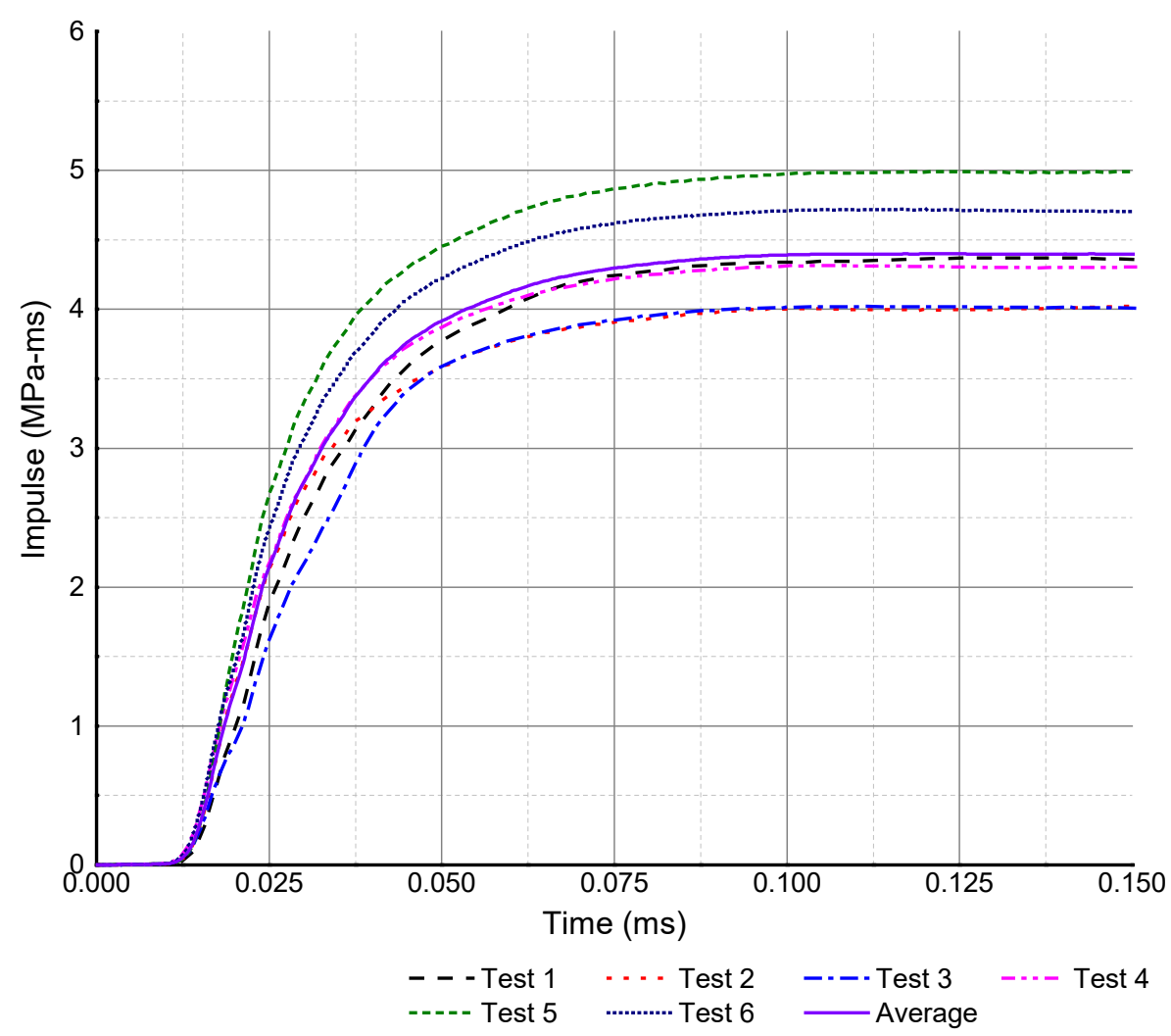

(b)

Figure 3-8: Experimentally acquired blast parameters (a) Reflected pressure (b) Reflected impulse (Rigby et al., 2014)

The average peak reflected pressure and impulse were $255 \mathrm{MPa}$ and $4.3 \mathrm{MPa} . \mathrm{ms}$ respectively. The upper bound for peak reflected pressure was $290 \mathrm{MPa}$ and lower bound was $220 \mathrm{MPa}$ whereas the bounds for impulses were 3.8-4.8 MPa.ms.

The experimental tests presented by Rigby et al. (2014) were modeled with MMALE and Lagrangian elements. The FSI between the blast wave (MMALE) and rigid plate (Lagrangian) was implemented with CONSTRAINED_LAGRANGE_IN_SOLID (CLIS). Quarter symmetric models were generated with varying element size for the air domain (Figure 3-9). The plate was modeled as a rigid part at $75 \mathrm{~mm}$ from the explosive center. Accordingly, tracers were placed on the rigid plate at $75 \mathrm{~mm}$ from the center of the charge and 
at $100 \mathrm{~mm}$ radially that corresponded to the locations of SHPB in the experimental tests. A 49.2-mm diameter C4 explosive was modeled that correlates to $100 \mathrm{~g}$.

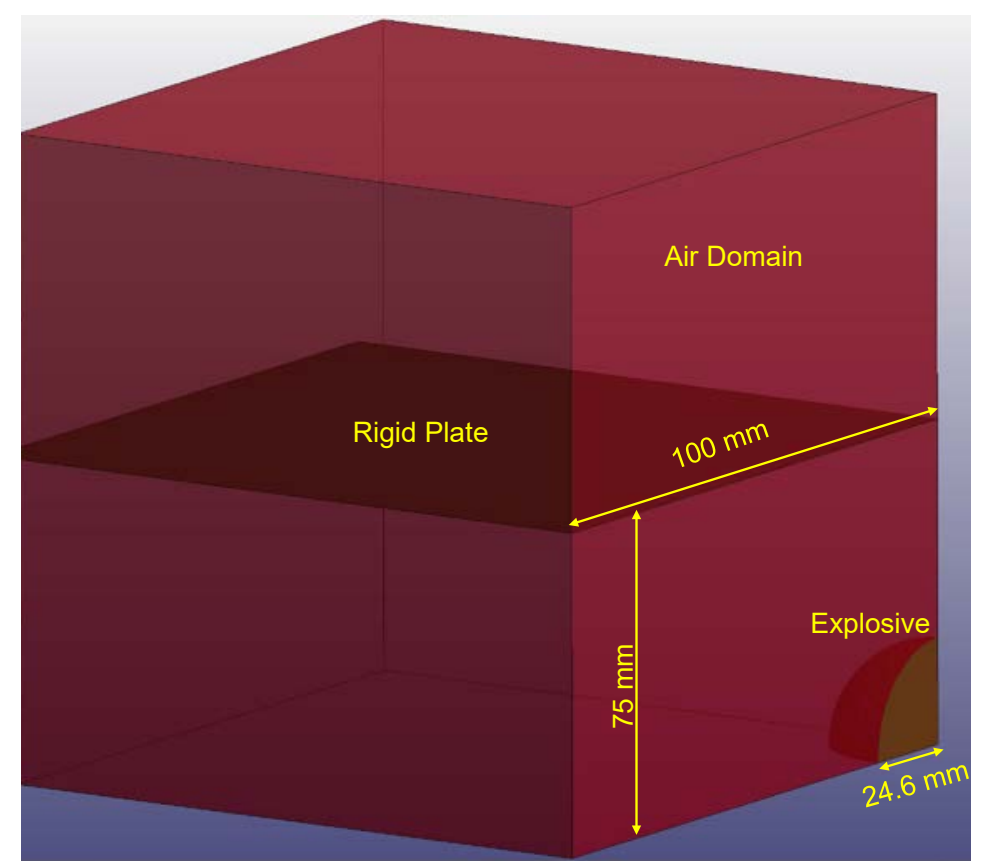

Figure 3-9: Numerical model for mesh sensitivity analysis

The air domain was meshed with a varying element size of $0.75-\mathrm{mm}$ to $2-\mathrm{mm}$ to investigate the mesh sensitivity. The explosive was modeled with INITIAL_VOLUME_FRACTION_GEOMETRY keyword that defines the explosive entity by filling a portion of the air domain and hence the mesh size is the same for both the air and explosive.

The MAT_HIGH_EXPLOSIVE_BURN constitutive material and Jones-Wilkins-Lee (JWL) equation of state (EOS) in LS-DYNA allows simulation of the detonation reaction of an explosive. The pressure ( $p$ ) in an element defined with this material is derived from the burn fraction $(F)$ and the pressure from the EOS (peos) (Equation $3-6)$. 


$$
\mathrm{p}=\mathrm{Fp}_{\mathrm{eos}}(\mathrm{V}, \mathrm{E})
$$

Equation 3-7 gives the burn fraction $(F)$ at time $t$ for an element and is taken as the larger of $F_{1}$ and $F_{2}$.

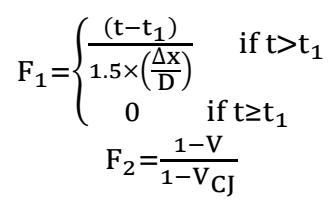

where $t_{1}$ is the detonation time of the element calculated from the detonation velocity (D) and distance from the point of detonation, $\Delta x$ represents the grid spacing, $\mathrm{V}$ is the volume and $\mathrm{V}_{\mathrm{c} J}$ is the Chapman-Jouguet relative volume (Giroux, 1973).

On completion of detonation of the explosive domain, the detonated material takes gaseous form and the generated pressure wave propagates through the air domain. The MMALE formulation implements the above equations to track the pressure-time history of each material through all the elements of the defined mesh (L.S.T.C, 2015). The coupling mechanism for modeling the FSI between the gaseous fluid generated by the detonation of explosive and the structure created with Lagrangian shell/solid entities is implemented with the CLIS keyword. L.S.T.C (2015) recommends penalty coupling (CTYPE 4 or 5) for modeling FSI of explosive detonation and Lagrangian solid elements. 
The explosive material properties and EOS parameters for JWL (C4) and linear polynomial (air as an ideal gas) implemented for the simulation are presented in Table 3-3 to Table 3-5. The unit system used for these simulations was Mass in metric ton $(\mathrm{T})$, distance in $\mathrm{mm}$, time in $\mathrm{s}$, and pressure in $\mathrm{MPa}$.

Table 3-3: MAT_HIGH_EXPLOSIVE_BURN properties for C4 (Dobratz \& Crawford, 1985)

\begin{tabular}{|c|c|c|}
\hline $\begin{array}{c}\text { Mass Density (Ro), } \\
\mathrm{T} / \mathrm{mm}^{3}\end{array}$ & $\begin{array}{c}\text { Detonation Velocity }(\mathrm{D}), \\
\mathrm{mm} / \mathrm{s}\end{array}$ & $\begin{array}{c}\text { Chapman-Jouguet pressure }\left(\mathrm{P}_{\mathrm{CJ}}\right), \\
\mathrm{MPa}\end{array}$ \\
\hline $1.6 \times 10^{-9}$ & 8193000 & 28000 \\
\hline
\end{tabular}

Table 3-4: JWL EOS parameters (Dobratz \& Crawford, 1985)

\begin{tabular}{|c|c|c|c|c|c|c|}
\hline $\begin{array}{c}\text { EOS } \\
\begin{array}{c}\text { Coefficient } \\
(\mathrm{A}), \mathrm{MPa}\end{array}\end{array}$ & $\begin{array}{c}\text { EOS } \\
\text { Coefficient } \\
(\mathrm{B}), \mathrm{MPa}\end{array}$ & $\begin{array}{c}\text { EOS } \\
\text { Coefficient } \\
\left(\mathrm{R}_{1}\right)\end{array}$ & $\begin{array}{c}\text { EOS } \\
\text { Coefficient } \\
\left(\mathrm{R}_{2}\right)\end{array}$ & $\begin{array}{c}\text { EOS } \\
\text { Coefficient } \\
(\omega)\end{array}$ & $\begin{array}{c}\text { Detonation } \\
\text { energy }\left(\mathrm{E}_{0}\right), \\
\mathrm{MPa}\end{array}$ & $\begin{array}{c}\text { Initial } \\
\text { relative } \\
\text { volume } \\
\left(\mathrm{V}_{0}\right)\end{array}$ \\
\hline 609.8 & 12.95 & 4.5 & 1.4 & 0.25 & 9000 & 1 \\
\hline
\end{tabular}

Table 3-5: EOS parameters for modelling air as ideal gas (Dobratz \& Crawford, 1985; L.S.T.C, 2015)

\begin{tabular}{|c|c|c|c|c|c|c|c|c|}
\hline $\begin{array}{c}\text { EOS } \\
\text { Coefficie } \\
\text { nt }\left(C_{0}\right)\end{array}$ & $\begin{array}{c}\text { EOS } \\
\text { Coefficie } \\
\text { nt }\left(C_{1}\right)\end{array}$ & $\begin{array}{c}\text { EOS } \\
\text { Coefficie } \\
\text { nt }\left(C_{2}\right)\end{array}$ & $\begin{array}{c}\text { EOS } \\
\text { Coefficie } \\
\text { nt }\left(C_{3}\right)\end{array}$ & $\begin{array}{c}\text { EOS } \\
\text { Coefficie } \\
\text { nt }\left(\mathrm{C}_{4}\right)\end{array}$ & $\begin{array}{c}\text { EOS } \\
\text { Coefficie } \\
\text { nt }\left(\mathrm{C}_{5}\right)\end{array}$ & $\begin{array}{c}\text { EOS } \\
\text { Coefficie } \\
\text { nt }\left(\mathrm{C}_{6}\right)\end{array}$ & $\begin{array}{c}\text { Initial } \\
\text { intern } \\
\text { al } \\
\text { energ } \\
\mathrm{y} \\
\left(\mathrm{E}_{0}\right) \\
\mathrm{MPa} \\
\end{array}$ & $\begin{array}{c}\text { Initial } \\
\text { relativ } \\
\mathrm{e} \\
\text { volum } \\
\mathrm{e},\left(\mathrm{V}_{0}\right)\end{array}$ \\
\hline$-1 \times 10^{6}$ & 0 & 0 & 0 & 0.4 & 0.4 & 0 & $\begin{array}{c}0.253 \\
4\end{array}$ & 1 \\
\hline
\end{tabular}

The advection logic for MMALE formulation and the blast wave propagation are specified in the CONTROL_ALE keyword. L.S.T.C (2015) recommends alternate advection logic for explosive simulations which can be invoked by the DCT flag in CONTROL_ALE keyword. It also recommends Van leer + Half-index-shift as the advection method for the METH flag. The parameters implemented for the simulations presented in this study are reported in Table 3-6. 
Table 3-6: Input parameters for CONTROL_ALE keyword

\begin{tabular}{|c|c|c|c|c|c|}
\hline DCT & NADV & METH & AFAC & EBC & P REF \\
\hline-1 & 1 & -2 & -1 & 2 & $101 \mathrm{kPa}$ \\
\hline
\end{tabular}

L.S.T.C (2015) recommends the Lagrangian element size to be less than the element size in the air domain. Alternatively, NQUAD in CLIS keyword should be set to a high value, however, this increases the computational cost considerably. Furthermore, the penalty factor (PFAC) for coupling the ALE elements to the Lagrangian elements is to be selected appropriately to avoid excessive blast pressure leakage into the lagrangian parts. The NQUAD and PFAC were selected on trial and error basis to ensure complete coupling of the blast wave with the Lagrangian domain. For the results presented in this section, the element size of the rigid plate was varied as per the air domain mesh size to ensure no leakage occurs.

LS-DYNA currently does not support non-reflecting (flow out) boundaries for MMALE formulation. Hence the only possibility is to define a large air domain to avoid reflected blast waves from the air domain boundaries arriving back at the tracer and corrupting the pressure-time history. The presented simulations were executed for $0.15 \mathrm{~ms}$ during which the blast pressure decayed to zero and the reflected waves did not arrive back at the tracer.

Quarter symmetric models of the experimental setup were developed with varying element size for the air domain (Figure 3-10 (a)). The generated time histories for reflected blast parameters at a scaled distance of $0.15 \mathrm{~m} / \mathrm{kg}^{1 / 3}$ for different MMALE 
element sizes were plotted together with the upper and lower bound results from the six tests reported by Rigby et al. (2015) and presented in Figure 3-10 (b) \& (c).

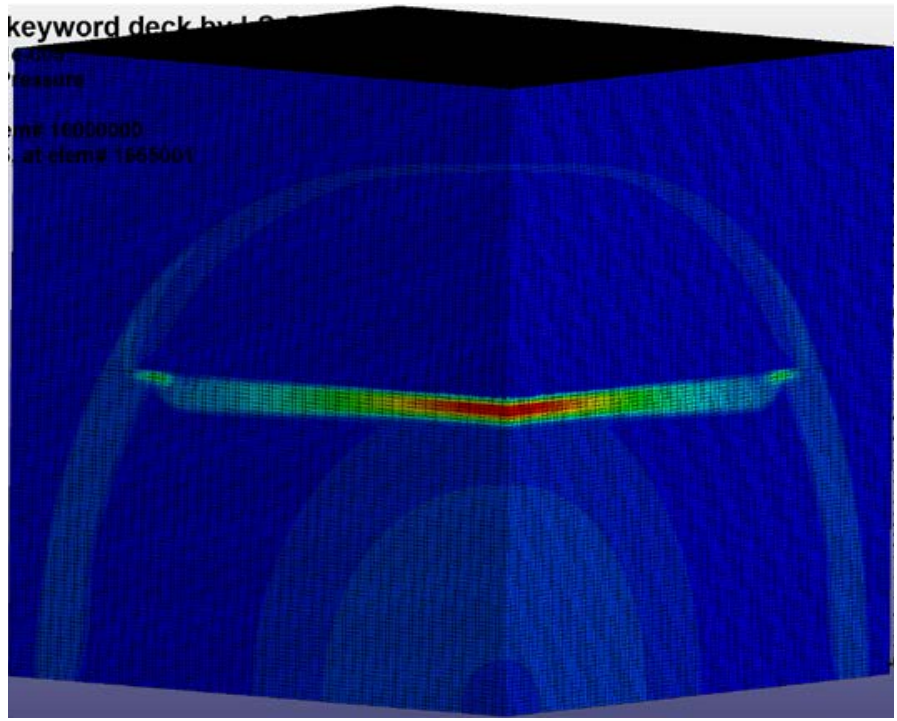

(a)

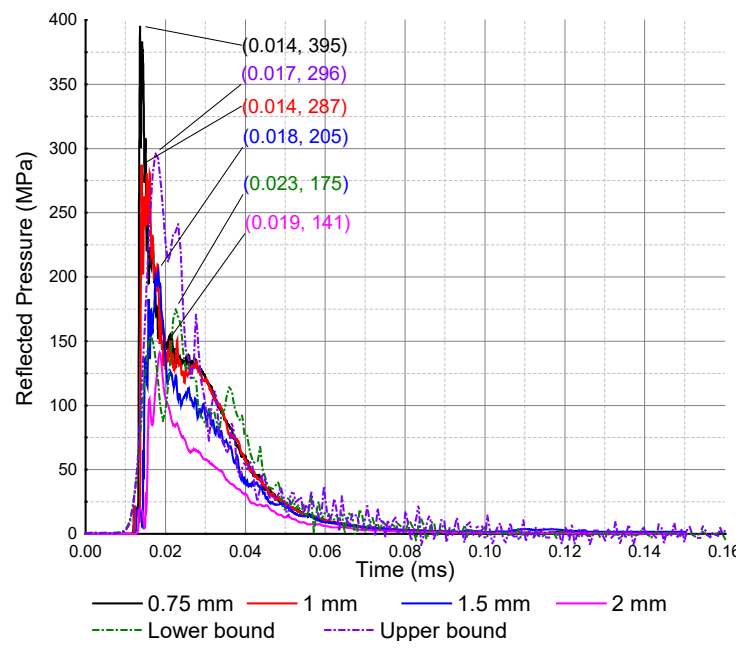

(b)

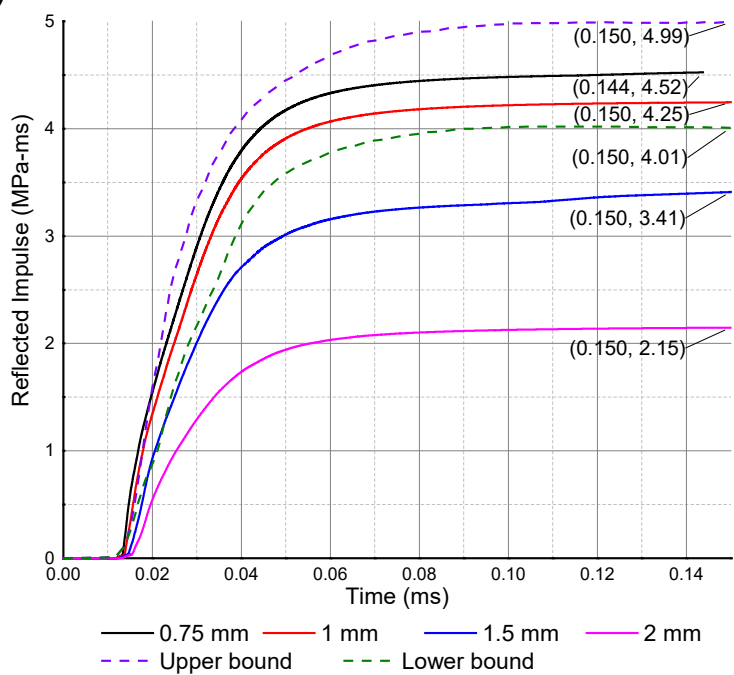

(c) 


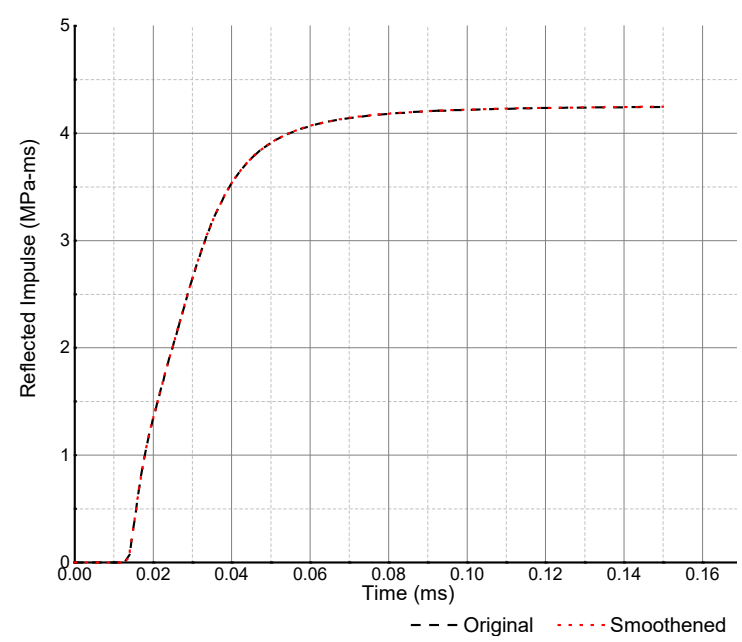

(d)

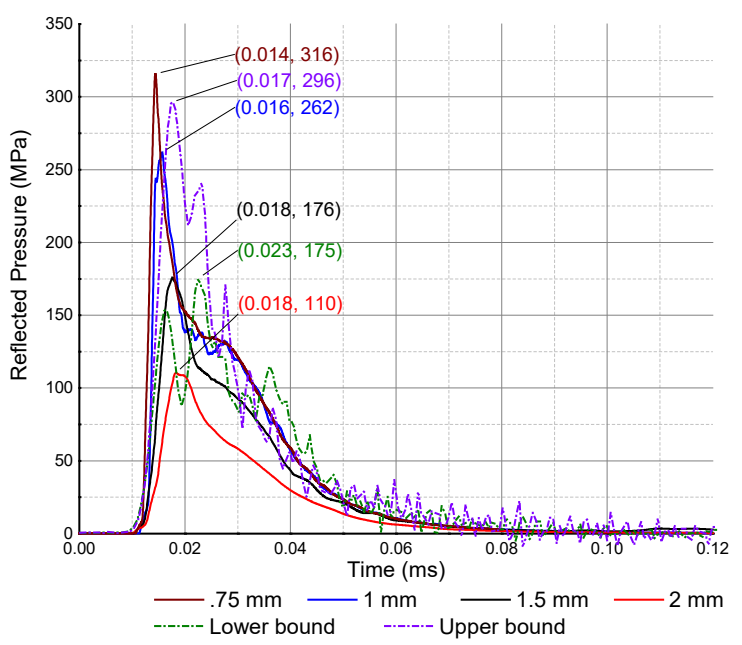

(e)

Figure 3-10: (a) Pressure fringe plot (1-mm); Time-histories for reflected (b) pressure (c) impulse (d) impulse after smoothening (e) pressure after smoothening

The numerically predicted impulse values converged at $1 \mathrm{~mm}$ size element mesh as there was negligible change in the impulse $(6.35 \%$ increase) with a $0.75 \mathrm{~mm}$ element size mesh. The reflected impulse for $0.75 \mathrm{~mm}$ and $1 \mathrm{~mm}$ size element mesh predicted numerically were within the upper and lower bound experimental results, while $1.5 \mathrm{~mm}$ and $2 \mathrm{~mm}$ size mesh predicted the impulse outside of this range. This is in agreement with the results reported by Rigby et al. (2014); Clarke et al. (2015); Rigby et al. (2015). The oscillating peaks in the pressure-time history predicted numerically are due to the shocked air trapped between the expanding detonation products and the target. These oscillatory peaks do not represent the true peak overpressure due to the explosion (Rigby et al., 2014; Clarke et al., 2015; Rigby et al., 2015). To ascertain the mesh convergence, these oscillations were smoothened by the adjacent-average method (AAM). There was no change in impulse-time history due to this smoothening (Figure 3-10 (d)). The peakoverpressure converged for a 1-mm element size mesh and was within the upper and lower bound experimental results (Figure 3-10 (e)). 
As presented in Table 3-7, the peak impulse is highly sensitive to the air domain element size. The peak reflected impulse converged with 1-mm element size air domain and was also validated from the experimental results. This is in agreement with the results reported by Trajkovski et al. (2014).

In view of the foregoing results, 1-mm element size was implemented for the air domain and explosive material in order to generate accurate peak impulse value which is critical for modeling near-field or contact explosion events. The computer system's memory (RAM) requirement for simulating the response of a Lagrangian entity with the same mesh size as the ALE domain (1-mm element size) can be significant (more than $256 \mathrm{~GB}$ ). Additionally, the time required for running the simulations is also expected to be very long. Hence the NQUAD value in CLIS keyword was set to ensure there is no blast pressure leakage.

Table 3-7: Mesh Sensitivity Analysis for Reflected Pressure and Impulse

\begin{tabular}{|c|c|c|c|c|c|}
\hline Air Mesh & Experimental Range & $0.75 \mathrm{~mm}$ & $1 \mathrm{~mm}$ & $1.5 \mathrm{~mm}$ & $2 \mathrm{~mm}$ \\
\hline Reflected peak pressure (MPa) & $296-175$ & 316 & 262 & 176 & 110 \\
\hline Reflected peak impulse (MPa.ms) & $4.01-4.99$ & 4.52 & 4.25 & 3.41 & 2.15 \\
\hline
\end{tabular}

\subsubsection{Lagrangian Domain}

Mesh sensitivity analysis was performed for the contact blast response of Mat_159 concrete constitutive model. PC and RC slabs were modeled with $10-\mathrm{mm}$ and 2$\mathrm{mm}$ element sized mesh and subjected to 500-g TNT explosive in contact. The numerical parameters were kept the same for both the models. The physical and material characteristics of the PC and RC slabs were the same as the experimental 
tests. The damage profiles predicted numerically with the two mesh sizes are compared to the experimental results in Figure 3-11.
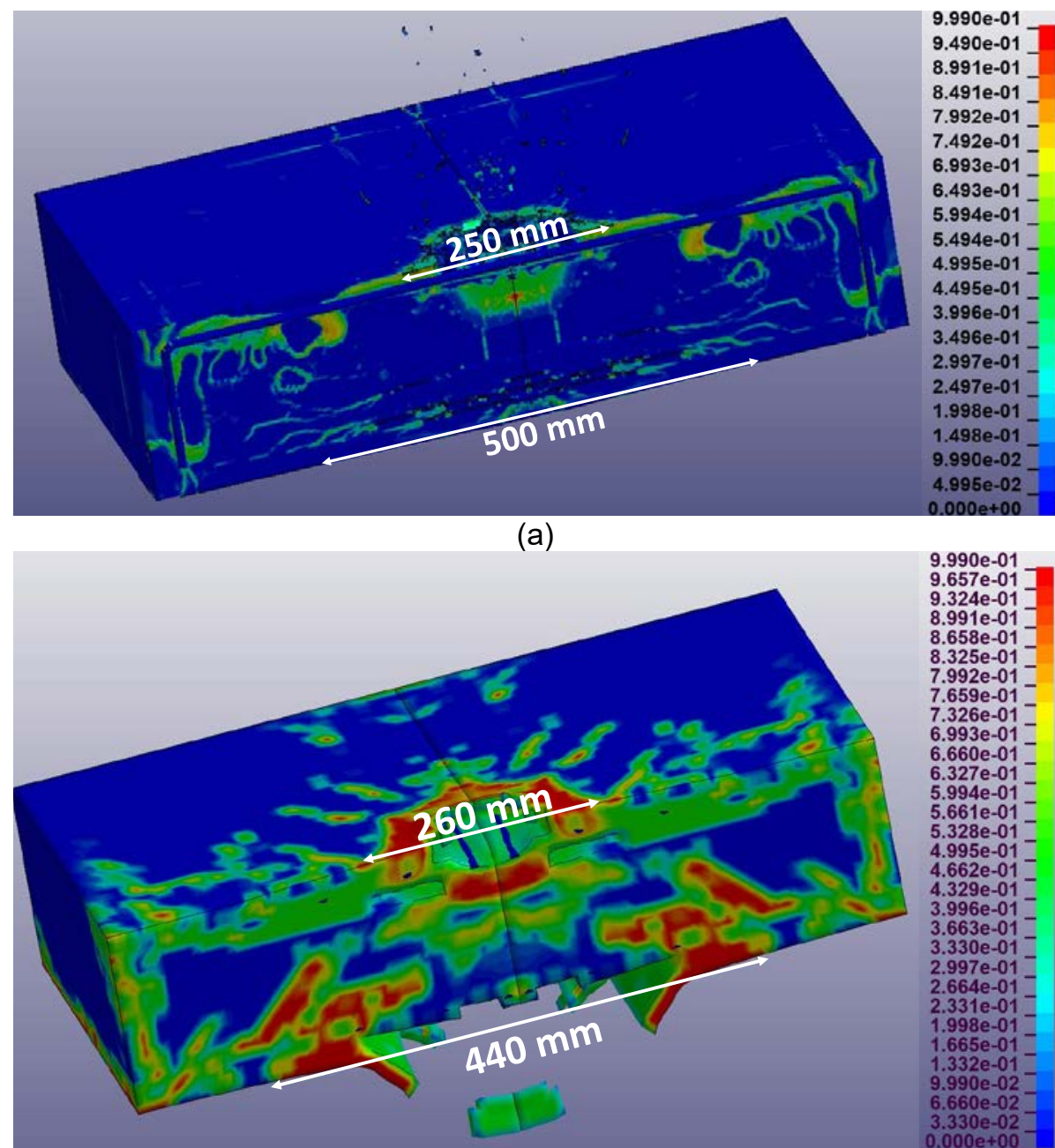

(b)

Figure 3-11: Mesh sensitivity for the Lagrangian domain (a) 2-mm mesh (b) 10-mm mesh

Mesh size dependency of concrete material is due to the fracture energy that significantly changes element size variation. One solution to promote mesh convergence is to manually adjust the damage parameters in the softening zone as a function of element size to keep the fracture energy constant (L.S.T.C, 2015). Elaborate experimental tests are required to identify the material properties and arrive at the correct fracture energy for various element sizes. This approach is not 
practical as it defeats the purpose of using automated concrete constitutive models. To regulate mesh sensitivity, Mat_159 concrete model maintains constant fracture energy regardless of the element size by adjusting the fracture energy. This is evident from the numerical results in comparison with the experimental. The crater and spall diameters on an RC slab subjected to contact explosion are well correlated for 2-mm and $10-\mathrm{mm}$ mesh size domains. The crack pattern is more pronounced in 2-mm element size domain, however, that does not provide any additional information for analysis of crater-spall or breach failure modes. The computation time for 2-mm Lagrangian mesh is more than $300 \%$ higher when compared to $10-\mathrm{mm}$ Lagrangian mesh. In this study, $10-\mathrm{mm}$ element mesh size has been implemented for the Lagrangian domain.

\subsubsection{Material Models}

\subsubsection{Concrete}

LS-DYNA offers many options for concrete constitutive material models that are implemented depending upon the loading regime. These constitutive models require an understanding of the heterogeneous material behavior and its response when subjected to high strain rate loading such as contact explosions. Mat_72R3 (Karagozian and Case Model), Mat_159 (Continuous Surface Cap Model or CSCM) and Mat_84 (Winfrith model) are a few models that allow automatic generation of material parameters from the unconfined compressive strength of concrete. The underlying material parameters in the model are based on experimental tests performed for a wide range of unconfined compressive 
strength. In this study, Mat_159 was implemented for modeling concrete based on the results presented by Sullivan et al. (2006) and Dua et al. (2017). The material input parameters in the adopted unit system are presented in Table 3-8.

Table 3-8: Input Parameters for Mat_159 Concrete Constitutive Model

\begin{tabular}{|c|c|c|c|c|}
\hline $\begin{array}{c}\text { Density, } \\
\mathrm{T}^{\prime} \mathrm{mm}^{3}\end{array}$ & $\begin{array}{c}\text { Unconfined Compressive } \\
\text { Strength, MPa }\end{array}$ & $\begin{array}{c}\text { Aggregate Size, } \\
\mathrm{mm}\end{array}$ & $\begin{array}{c}\text { Erosion } \\
\text { Criteria }\end{array}$ & $\begin{array}{c}\text { Rate } \\
\text { Effects }\end{array}$ \\
\hline $2.635 \times 10^{-9}$ & 20 & 25 & 1.7 & on \\
\hline
\end{tabular}

\subsubsection{Reinforcements}

The response of RC members is sensitive to the confinement effects of the reinforcement. The mat_159 concrete constitutive model can simulate the shear dilation phenomenon if the reinforcement is coupled with the concrete elements. A comprehensive review of various techniques available for modeling reinforcement in RC members has been presented by Schwer (2014) where the CONSTRAINED_LAGRANGE_IN_SOLID (CLIS) algorithm with constraint type (CTYPE) 2 has been recommended for modeling reinforcement. Recently an improved version of the CLIS technique, CONSTRAINED_BEAM_IN_SOLID (CBIS), was implemented to address some limitations of the CLIS technique (L.S.T.C, 2015). The MAT_PIECEWISE_LINEAR_PLASTICITY (Mat_24) constitutive model was adopted for modeling the reinforcement in this study. The input parameters for the constitutive model and CBIS keyword in the adopted unit system are presented in Table 3-9 and Table 3-10 respectively.

Table 3-9: Input Parameters for Mat_24

\begin{tabular}{|c|c|c|c|c|}
\hline $\begin{array}{c}\text { Density, } \\
\text { T/mm }\end{array}$ & $\begin{array}{c}\text { Modulus of } \\
\text { Elasticity, MPa }\end{array}$ & $\begin{array}{c}\text { Poisson's } \\
\text { Ratio, }-\end{array}$ & $\begin{array}{c}\text { Yield Strength, } \\
\mathrm{MPa}\end{array}$ & $\begin{array}{c}\text { Tangent Modulus, } \\
\mathrm{MPa}\end{array}$ \\
\hline $7.85 \times 10^{-9}$ & $2 \times 10^{5}$ & 0.3 & 500 & 1600 \\
\hline
\end{tabular}


Table 3-10: Input parameters for CBIS keyword

\begin{tabular}{|c|c|}
\hline No. of coupling points, NCOUP & Coupling Direction, CDIR \\
\hline 2 & 0 (All directions) \\
\hline
\end{tabular}

\subsubsection{Air and TNT}

The multi-material ALE (MMALE) formulation was adopted for modeling the air and explosive domains. MMALE is an extension of the Eulerian algorithm used for describing gas flow from explosive detonation. An MMALE element can have several different materials, with tracked material interfaces in one single element. This is considered to be more efficient for modeling gas flow with large pressure gradients as there can be Eulerian elements in the model with both air and detonation products (Zakrisson et al., 2011). MMALE currently remains the most widely used fluid-structure interaction algorithm for blast analysis in both far-field and near-field explosion events (Trajkovski et al., 2014).

In MMALE formulation the air domain is defined as MAT_NULL which allows the equation of state (EOS) to be considered without computing deviatoric stresses (Tagel-Din \& Rahman, 2006). The linear polynomial EOS (EOS_LINEAR_POLYNOMIAL) defines the air domain and permits it to behave like a fluid. The pressure, $\mathrm{P}$ in an air element is given by Equation 3-8 where $\mathrm{C}_{0}$ to $\mathrm{C}_{6}$ are polynomial equation coefficients and $\mu$ is given by $\frac{\rho}{\rho_{0}}-1$ ( $\rho$ is the reference density and $\rho_{0}$ is the current density).

$$
\mathrm{P}=\mathrm{C}_{0}+\mathrm{C}_{1} \mu+\mathrm{C}_{2} \mu^{2}+\mathrm{C}_{3} \mu^{3}+\left(\mathrm{C}_{4}+\mathrm{C}_{5} \mu+\mathrm{C}_{6} \mu^{2}\right) \mathrm{E}
$$


Input parameters for MAT_NULL and EOS_LINEAR_POLYNOMIAL in the adopted unit system are presented in Table 3-11.

Table 3-11: Input Parameters for Air Domain

\begin{tabular}{|c|c|c|c|c|c|c|}
\hline Density, $\mathrm{T} / \mathrm{mm}^{3}$ & $\mathrm{C}_{0}$ & $\mathrm{C}_{1}, \mathrm{C}_{2}, \mathrm{C}_{3}$ and $\mathrm{C}_{6}$ & $\mathrm{C}_{4}$ & $\mathrm{C}_{5}$ & $\mathrm{E}_{0}, \mathrm{MPa}$ & $\mathrm{V}_{0}$ \\
\hline $1.29 \times 10^{-12}$ & $-1 \times 10^{-6}$ & 0 & 0.4 & 0.4 & 0.2531 & 1 \\
\hline
\end{tabular}

The explosive domain can be defined by two techniques: creating a separate part for the explosive or with the INITIAL_VOLUME_FRACTION keyword. The first option requires that all the boundary nodes of the explosive domain be merged with the air domain nodes. On the other hand, with the second option, a defined geometrical shape within the air domain is filled with the explosive. The second option was adopted for the simulations presented in this study.

The explosive material was defined with MAT_HIGH_EXPLOSIVE_BURN which allows the modeling of detonation of a high explosive when defined with an EOS. EOS_JWL was adopted for the detonation modeling which defines the pressure, $p$ as Equation 3-9 where $A$ and $B$ are constants with units of pressure, $E_{0}$ is the detonation energy per unit volume, $V_{0}$ is the initial relative volume and $R_{1}, R_{2} \& \omega$ are unitless constants.

$$
p=A\left(1-\frac{\omega}{R_{1} V}\right) e^{-R_{1} V}+A\left(1-\frac{\omega}{R_{2} V}\right) e^{-R_{2} V}+\frac{\omega E}{V}
$$

The input parameters for the above two keywords required to define the explosive domain (TNT) are presented in Table 3-12. 
Table 3-12: Input Parameters for MAT_HIGH_EXPLOSIVE_BURN and EOS_JWL

\begin{tabular}{|c|c|c|c|c|c|c|c|c|c|}
\hline $\begin{array}{c}\text { Density, } \\
\text { T/mm3 }\end{array}$ & $\begin{array}{c}\text { Detonation } \\
\text { Velocity, } \\
\mathrm{mm} / \mathrm{s}\end{array}$ & $\begin{array}{c}\text { Chapman- } \\
\text { Jouguet } \\
\text { Pressure, } \\
\mathrm{MPa}\end{array}$ & $\mathrm{A}, \mathrm{MPa}$ & $\begin{array}{c}\mathrm{B}, \\
\mathrm{MPa}\end{array}$ & $\mathrm{R} 1,-$ & $\mathrm{R} 2,-$ & $\omega,-$ & $\begin{array}{c}\text { E0, } \\
\mathrm{MPa}\end{array}$ & $\mathrm{V} 0,-$ \\
\hline $\begin{array}{c}1.55 \times 10- \\
9\end{array}$ & $6930 \times 103$ & 21000 & 371200 & 3231 & 4.15 & 0.95 & 0.3 & 7000 & 1 \\
\hline
\end{tabular}

\subsubsection{Modeling Technique}

The Lagrangian entities (concrete and rebar) were initialized with the stresses at the last timestep of the first run and a full deck restart was implemented with a larger air domain of 5-mm sized MMALE elements. The air domain was initialized with the pressures in each element mapped from the last timestep of the previous run using the INITIAL_ALE_MAPPING keyword (L.S.T.C, 2015). A 3D-3D pressure mapping was implemented which is more appropriate for contact explosion events (Lapoujade et al., 2010; Zakrisson et al., 2011; Souli et al., 2013; Kalra et al., 2014).

A contact explosion event lasts up to $0.1 \mathrm{~ms}$ (Weerheijm et al., 1984), however, the concrete material does not develop full stress condition due to inertial effects. A third simulation was implemented without the ALE domain to allow the concrete material to develop stresses due to the event. This simulation was run until the velocity of concrete elements was almost zero. The system of units implemented for numerical modeling in the study was $\mathrm{MPa}, \mathrm{mm}, \mathrm{sec}, \mathrm{T} / \mathrm{mm}^{3}$, and $\mathrm{N}$.

\subsubsection{Modeling of PC Slab Response}

A quarter-symmetric model was implemented for simulating the response of $750 \times 750 \times 75 \mathrm{~mm}$ slab. The slab was modeled with $10-\mathrm{mm}$ sized solid elements in 
the Lagrangian domain while the air domain for the first simulation was implemented with $1-\mathrm{mm}$ element sized mesh of $150 \times 150 \times 250 \mathrm{~mm}$ extent. The simulation was terminated at $0.02 \mathrm{~ms}$ to avoid reflection of the generated blast waves from the air domain boundaries. The model parameters were the same as discussed in the preceding sections however the $\mathrm{NQUAD}=15$ and $P F A C=15$ were selected based on trial and error. Figure 3-12(a) and (b) present the quartersymmetric model and the pressure fringe plot at $0.02 \mathrm{~ms}$ respectively. The pressure plot shows that the blast wave has not arrived at the boundaries of the air domain. Also, no leakage of detonated material into the PC slab was observed. This signifies complete coupling between the ALE and Lagrangian domain (Figure 3-12 (c)). The complete response of the PC slab is not captured within $0.02 \mathrm{~ms}$ due to inertial effects. A full deck restart was implemented in the second simulation to remap the pressure in ALE domain and to initialize the stresses in the Lagrangian domain from the last timestep of the previous run.

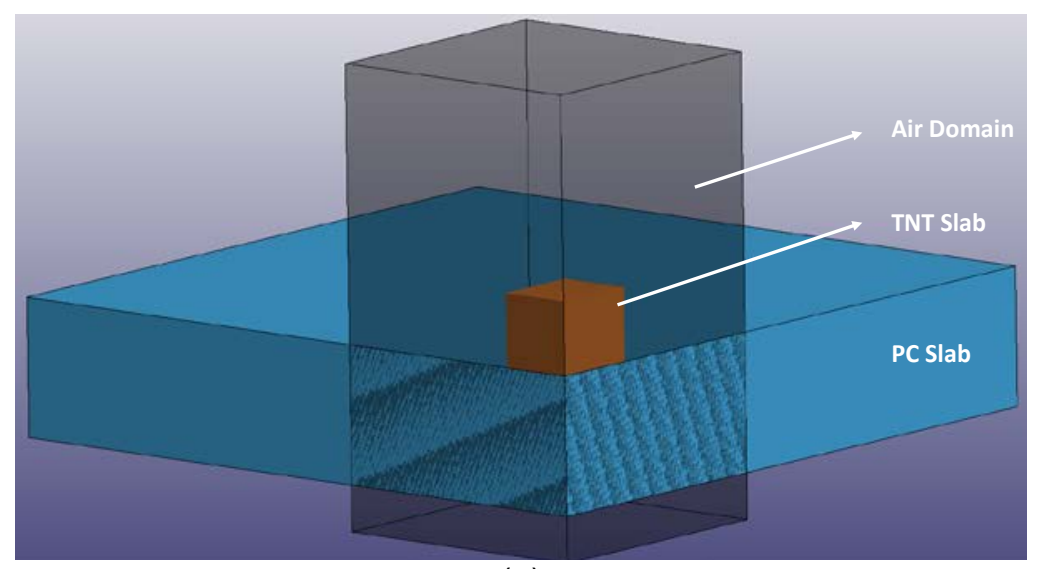

(a) 


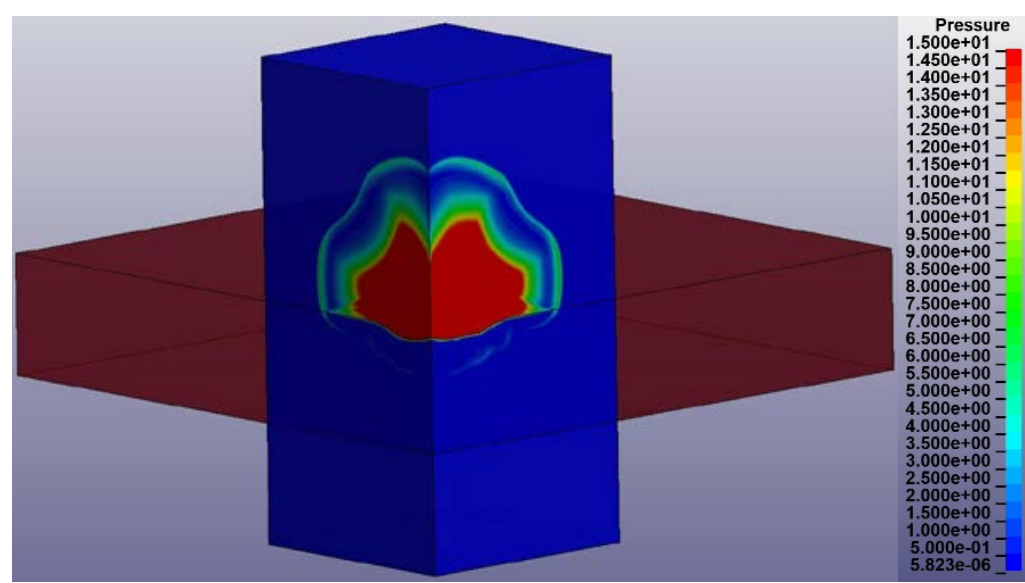

(b)

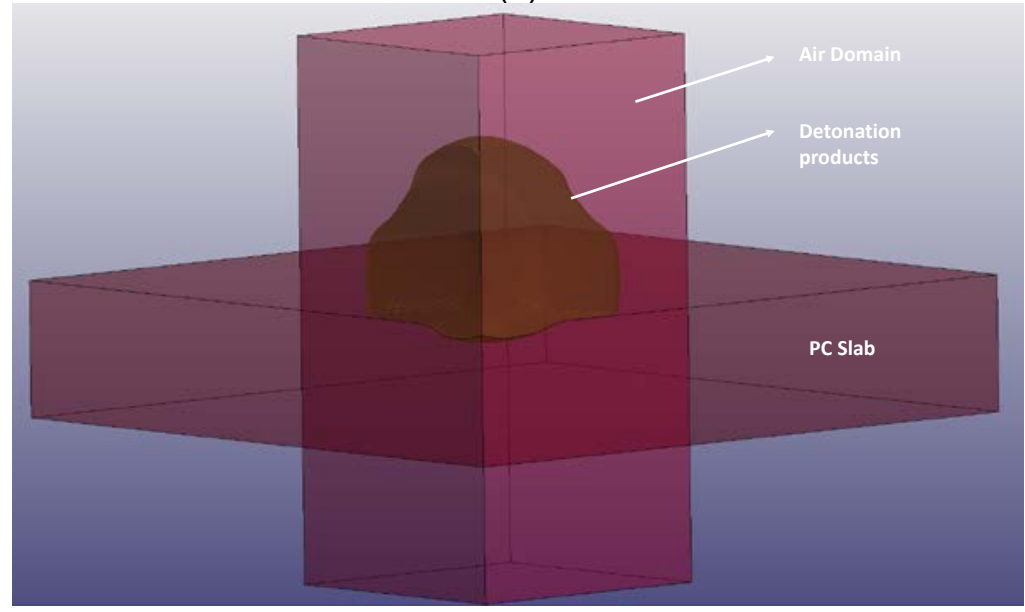

(c)

Figure 3-12: Simulation of detonation with 1-mm size element mesh (a) Quarter model (b) Pressure plot at $0.02 \mathrm{~ms}$ (c) Extent of detonation products

A 5-mm element sized air domain was modeled for the second simulation and the 1-mm sized air domain was removed. The simulation was run to $0.15 \mathrm{~ms}$ with the same parameters as before but an $\mathrm{NQUAD}=15$ and $\mathrm{PFAC}=5$ were implemented respectively. Figure 3-13 (a) and (b) presents the pressure fringe plots for the second simulation in the 5-mm element sized air domain at the first and the last timesteps. Figure 3-13 (c) presents the extent of detonation products. Figure 3-13 (b) and (c) implies that the blast wave has cleared from the PC slab. This implies that the impulse generated due to the contact explosion has been imparted to the slab. It is highlighted that the detonation products do not wrap around the target 
(PC slab) but it is the pressure wave that wraps around the target. Accordingly, in analytical solutions, the target sides are loaded with a uniformly distributed pressure over time. It is also observed that the complete response of PC slab is not captured even after the contact explosion event as the response time of concrete is higher than the loading time. Hence numerical simulations must be run until the velocity of the Lagrangian domain has reduced to almost zero to signifies complete damage has been captured by the simulation.

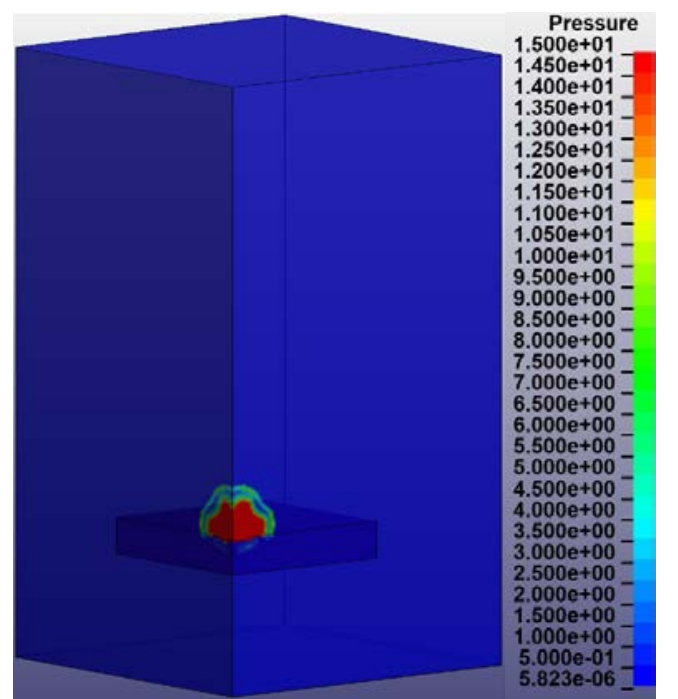

(a)

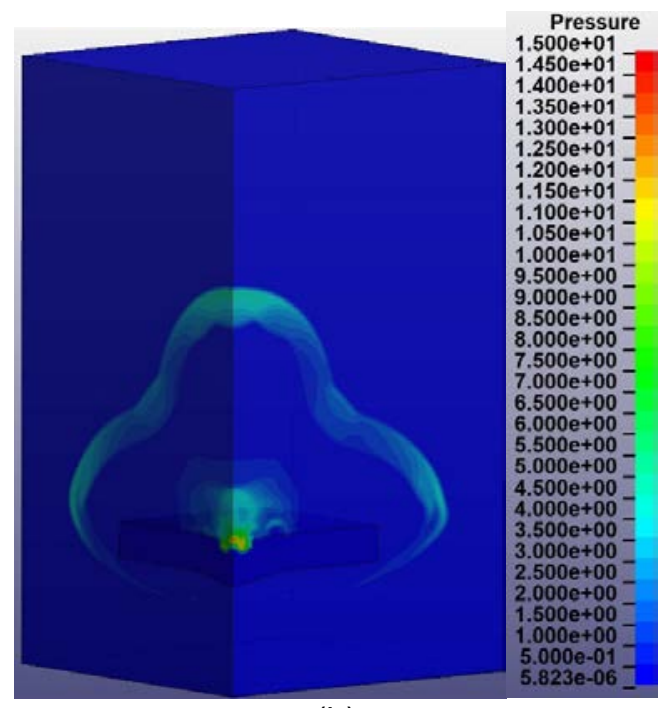

(b)

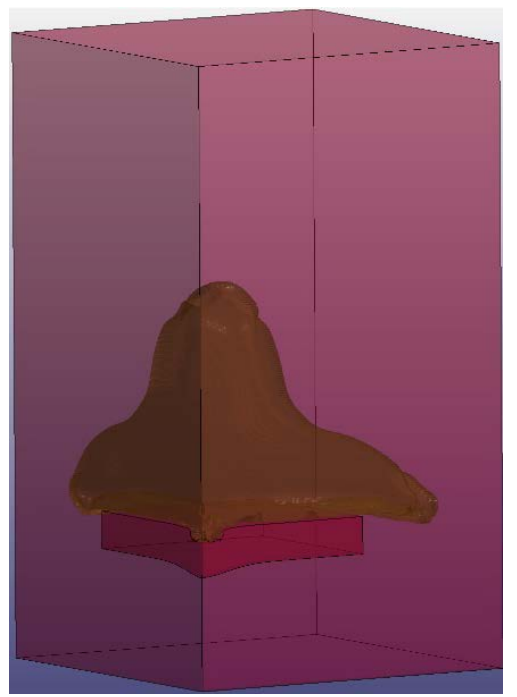

(c)

Figure 3-13: Pressure fringe plots for third run (a) 0.02-ms (b) 0.15-ms (c) Extent of detonation products 
A full-deck restart was implemented in the third simulation without the ALE domain and the concrete slab was initialized to the stress condition from the last timestep of the previous run. The velocity of slab elements reduced to zero at approximately $6 \mathrm{~ms}$ implying that the damage has been captured by the simulation (Figure 3-14).

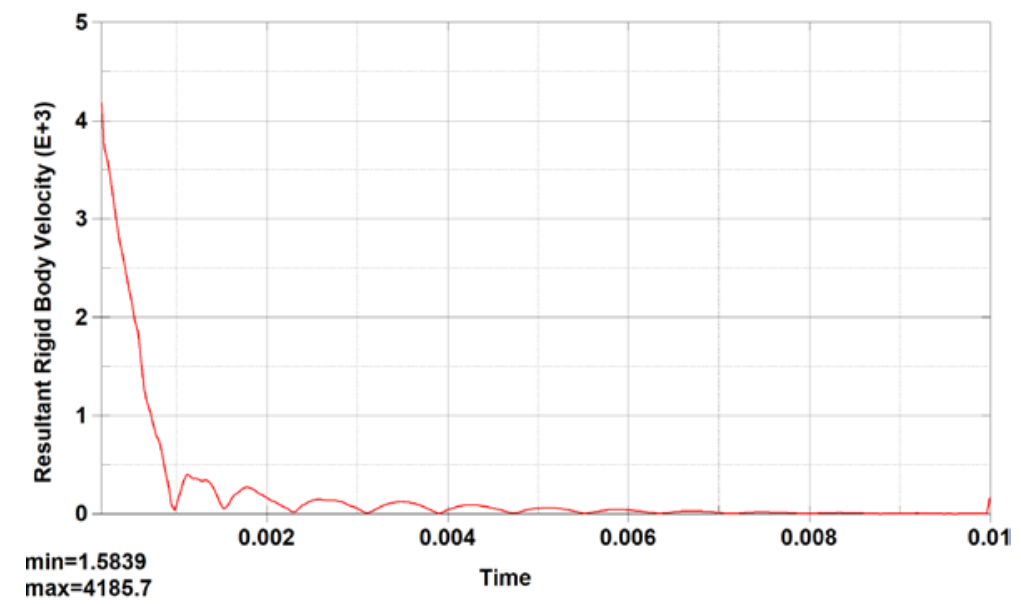

Figure 3-14: Velocity time-history plot of the PC slab during the third simulation

\subsubsection{Modeling of RC Slab Response}

A quarter model simulation was performed for predicting the response of RC slab subjected to contact explosion effects of 500-g TNT (Figure 3-15 (a)). For the first simulation, the explosive was detonated in a 1-mm element sized mesh. The extent of the air domain was $120 \times 100 \times 240 \mathrm{~mm}$ depending on the available memory resources for the simulation. The simulation was run for $0.015 \mathrm{~ms}$ to avoid reflection from the boundaries of the air domain (Figure 3-15 (b)). It can be observed from Figure 3-15 (c) that there is no leakage of ALE material into the Lagrangian domain. 


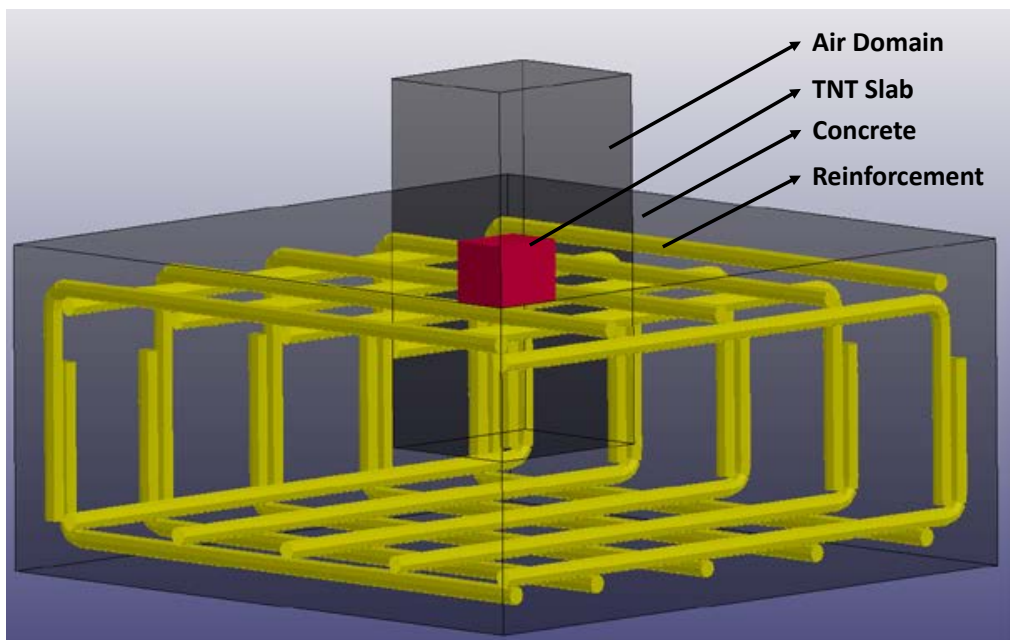

(a)

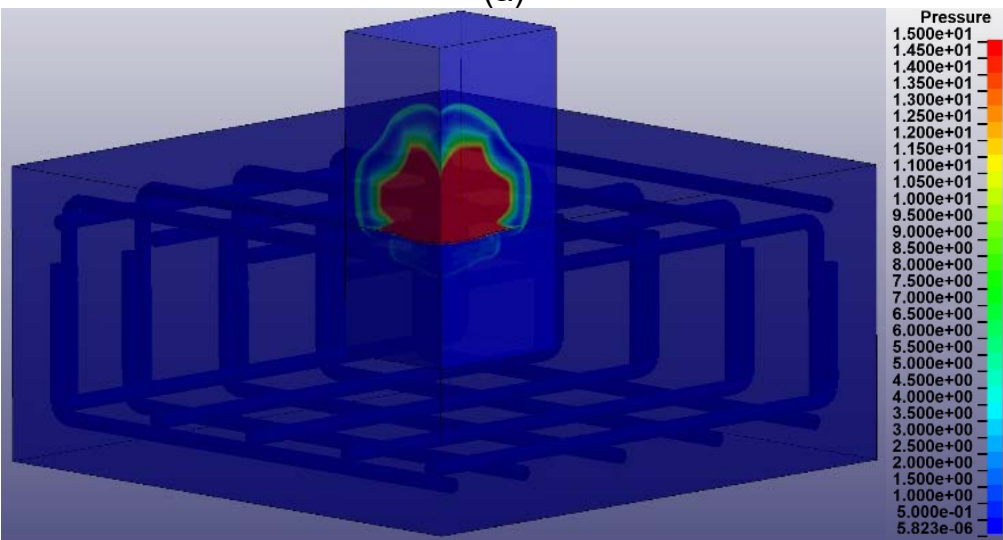

(b)

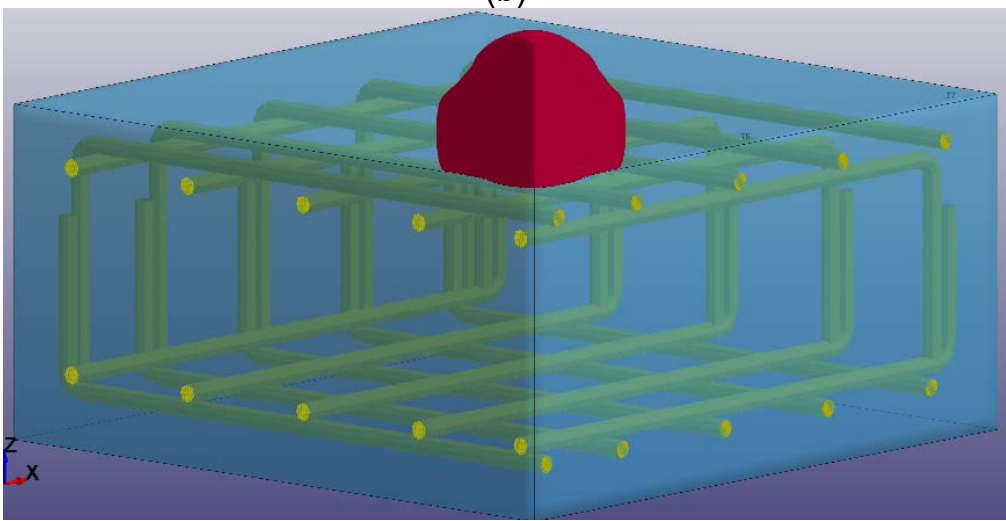

(c)

Figure 3-15: (a) Quarter symmetric model setup (b) Pressure fringe plot at $0.015 \mathrm{~ms}$ (c) Extent of detonated material at $0.015 \mathrm{~ms}$ 


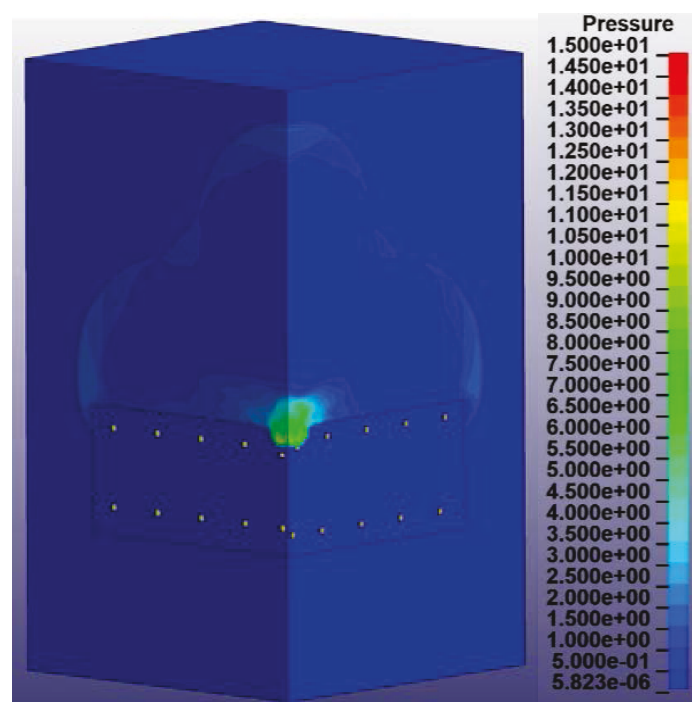

(a)

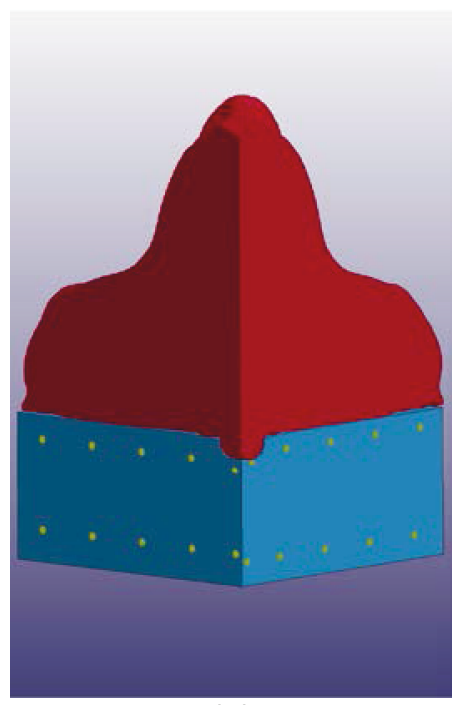

(b)

Figure 3-16: (a) Pressure fringe plot at $0.12 \mathrm{~ms}$ (b) Extent of detonated material at $0.12 \mathrm{~ms}$

For the second simulation, a full-deck restart was implemented. The stresses in the Lagrangian domain and the pressure in the ALE domain were initialized from the last timestep of the previous run. The 1-mm sized air domain was increased to a 5-mm sized air domain to allow propagation of the blast wave and FSI. The simulation was run to $0.12 \mathrm{~ms}$ and terminated to avoid reflection of the blast wave. Figure 3-16 shows the pressure fringe plot and the extent of detonated material for the last timestep of the second simulation.

To capture the complete damage in the RC slab a third simulation was run to 0.4 ms and the ALE domain was removed.

\subsection{Numerical Results}

\subsubsection{PC Slab}

The numerically predicted damage profile of the PC slab has been compared to the experimental observations in Figure 3-17. The elements shaded in red 
represent damaged elements that do not have any capacity in both tensile and compressive regime and are akin to spalled or crushed concrete. The elements deleted in the center of the slab are also damaged elements that have distorted beyond $40 \%$ strain and were deleted for numerical stability.

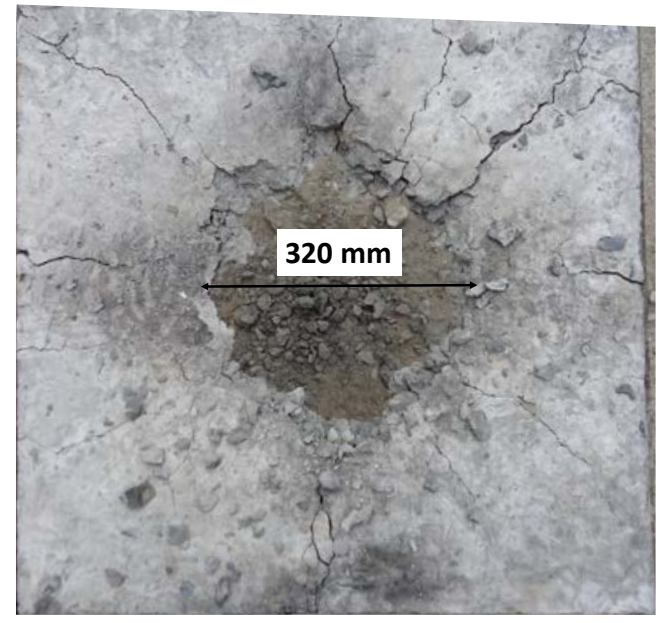

(a)

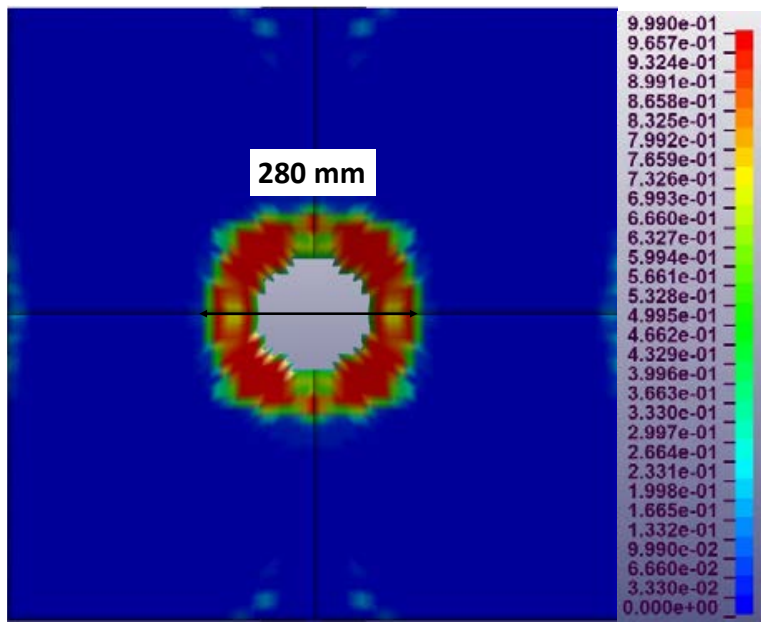

(b)

Figure 3-17: Damage profiles on the PC slab (a) Experimental test (b) Numerical simulation

\subsubsection{RC slab}

Figure 3-18 compares the damage profile at the last timestep of the third simulation with the experimental results. A crater of $260-\mathrm{mm}$ diameter was formed on the incident face due to the crushing of the concrete. A 440-mm diameter scab was formed on the bottom face and the concrete cover within this area spalled at the interface of the lower reinforcement mat (Figure 3-18). 

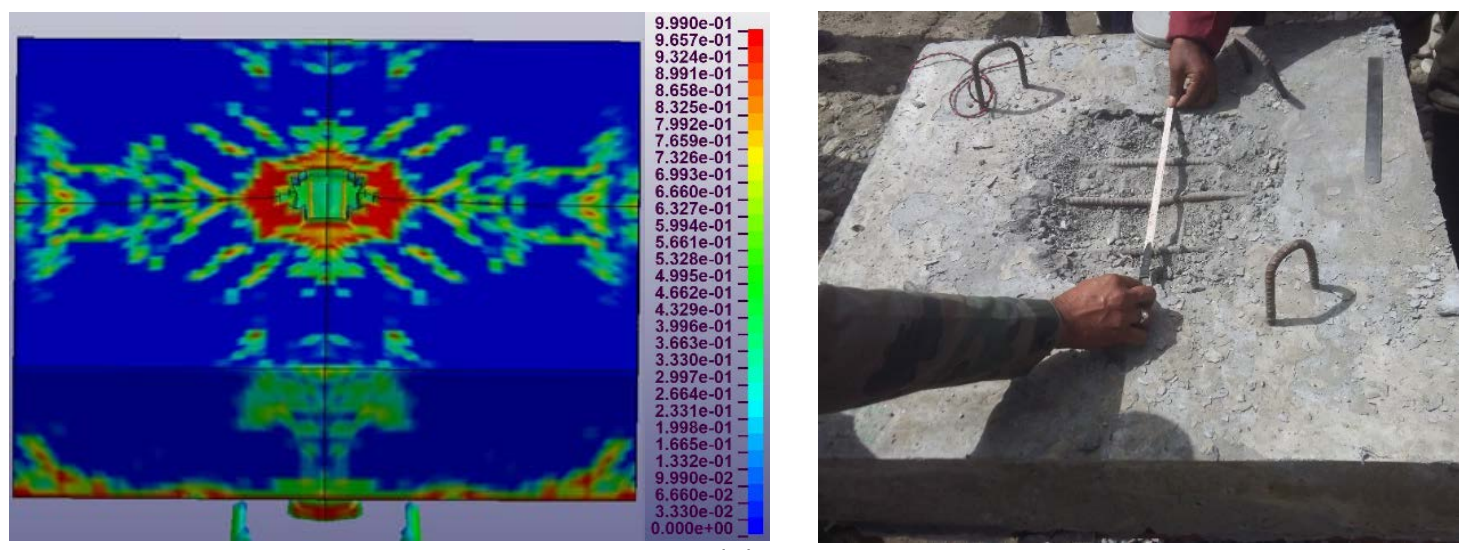

(a)
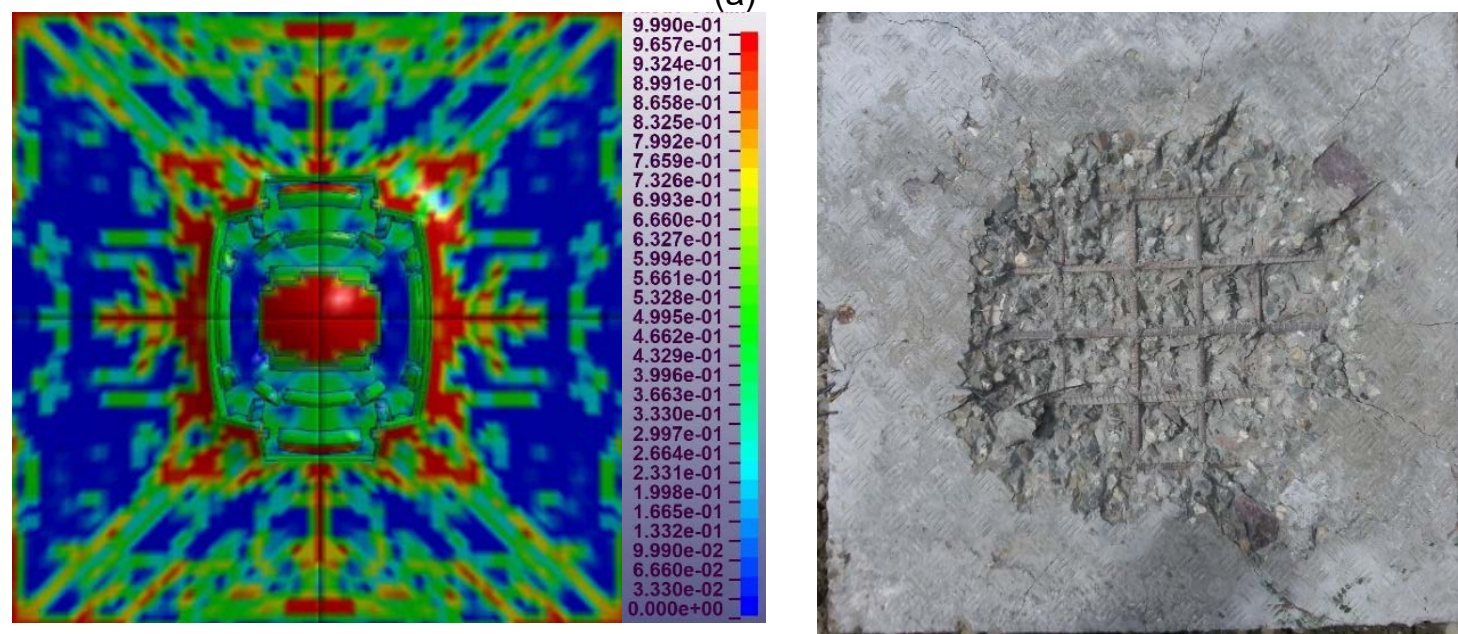

(b)

Figure 3-18: (a) Numerically predicted damage profiles and (b) Experimental damage profiles on the incident and distal faces

The crater-spall failure mode was predicted by the numerical model presented above and the crater-spall diameters correlated well with the experimental results. The error in numerically predicted spall diameter on the distal face was higher (24\%) due to the coarse mesh for the Lagrangian domain and is in agreement with the similar results reported by Gebbeken et al. (2004). The experimental and numerical results are presented in Table 3-13.

Table 3-13: Comparison of numerical and experimental observations

\begin{tabular}{|c|c|c|}
\hline Parameter & Crater diameter, $\mathrm{mm}$ & Spall diameter, $\mathrm{mm}$ \\
\hline Experimental & 340 & 500 \\
\hline Numerical & 260 & 440 \\
\hline
\end{tabular}




\subsection{Discussion of Experimental and Numerical Results}

A novel chained numerical modeling technique was implemented to predict the two failure modes in RC slabs subjected to contact explosion effects. The breach failure mode was predicted for the PC slab subjected to 500-g TNT explosion while the crater-spall failure mode was predicted for the RC slab subjected to the same explosive charge mass. The numerical models predicted comparable results with the experimental observations and can thus be used in parametric analyses to investigate the effect of various parameters on the response of $P C$ and $R C$ slabs under contact explosion effects. The concrete crushing in the crater was predicted with an error of $-80 \mathrm{~mm}$ and the spall on the back face was predicted with $-60 \mathrm{~mm}$. This error significantly reduces with a finer mesh when the crater and spall diameters are compared with experimental test results. However, the breach diameter of the PC slab was predicted with an error of $-40 \mathrm{~mm}$ only.

\subsection{Parametric Analysis}

\subsubsection{Failure Modes}

Figure 3-19 represents the failure modes in concrete slabs subjected to contact explosion effects. The breach failure mode can further be divided into punching and perforation failures.

In case of RC slabs, the reinforcement distributes the impulsive load across the slab resulting in a smaller crater diameter than the spall diameter and prevents 
punching failure unless the thickness is smaller than a critical thickness for the explosive charge mass. The critical thickness is a function of the impact load due to contact explosion and the material and geometric properties of the slab. For slab thickness greater than the critical thickness, the crater is limited to the concrete cover zone between the explosive and the deformed reinforcements and do not extend significantly below the deformed reinforcement as seen in the experimental and numerical results. In case of a slab less than its critical thickness for the explosion effects being considered, the crater will extend below and coalesce with the spall on the distal face to form a perforation failure mode. Furthermore, if the crater extends all the way to the distal face a punching failure mode will ensue.

While analyzing the numerical results for this section, the above facts were considered. The damage fringe plots for the cross-sections across the depth of the slab were examined to identify breach as per the above failure modes which may not be identifiable from the damage fringe plot on the edges. 

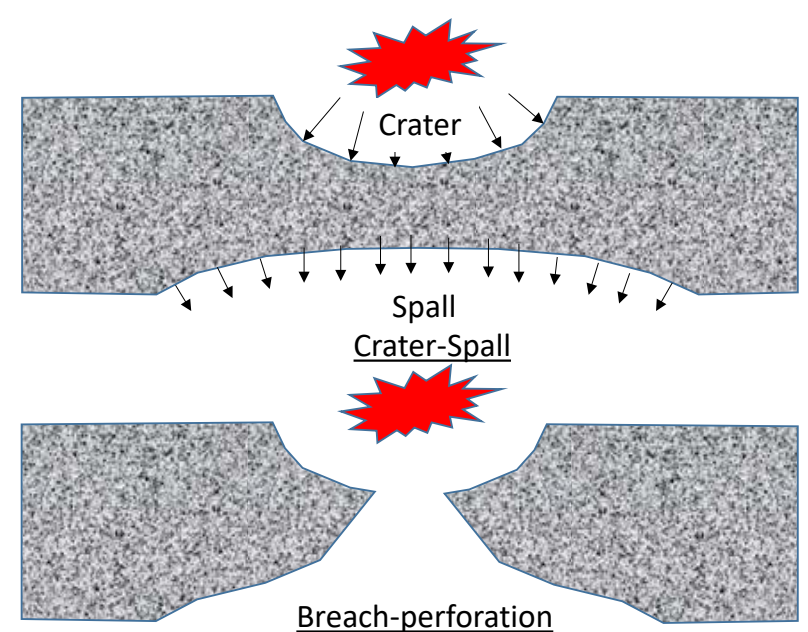

Breach-perforation

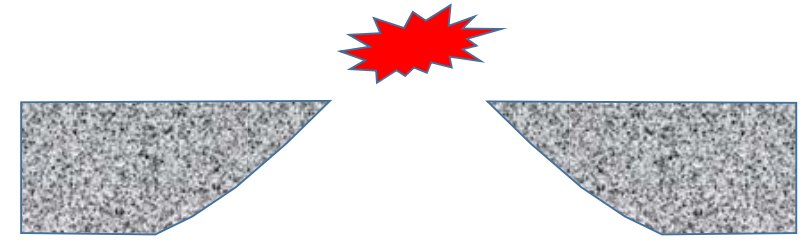

Breach-punching

Figure 3-19: Failure modes in concrete slabs

\subsubsection{Breach Threshold}

In protective design, it is usually important to determine the minimum explosive charge mass (threshold explosive mass) required to breach an $\mathrm{RC}$ slab of a given thickness. To determine the breach threshold explosive mass, the explosive mass was increased from 500-g until a breach was observed in the 200-mm thick RC slab with the same properties as the experimental tests. The damage profiles predicted by the validated numerical model due to the detonation of the various explosive masses are presented as Table 3-14.

Table 3-14: Numerically predicted damage profiles for varied explosive mass loading

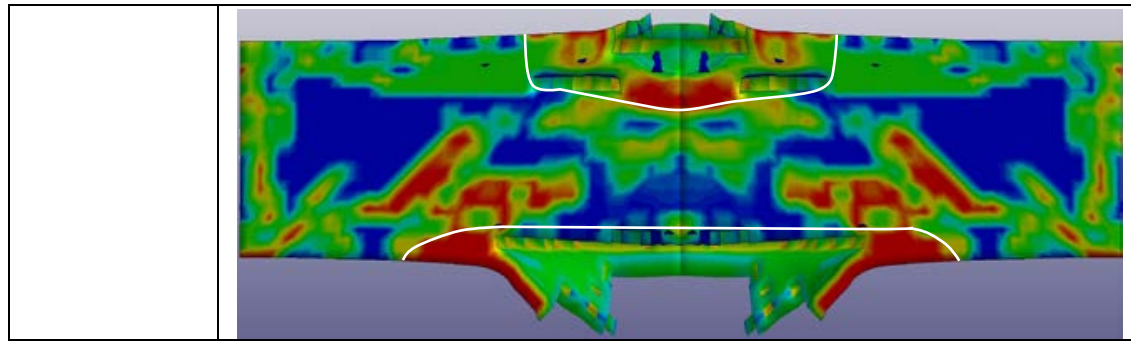

$500 \mathrm{~g}$ TNT Crater-260 mm

Crater Depth-75 mm Spall-440 mm

Spall Depth- $30 \mathrm{~mm}$ No breach 


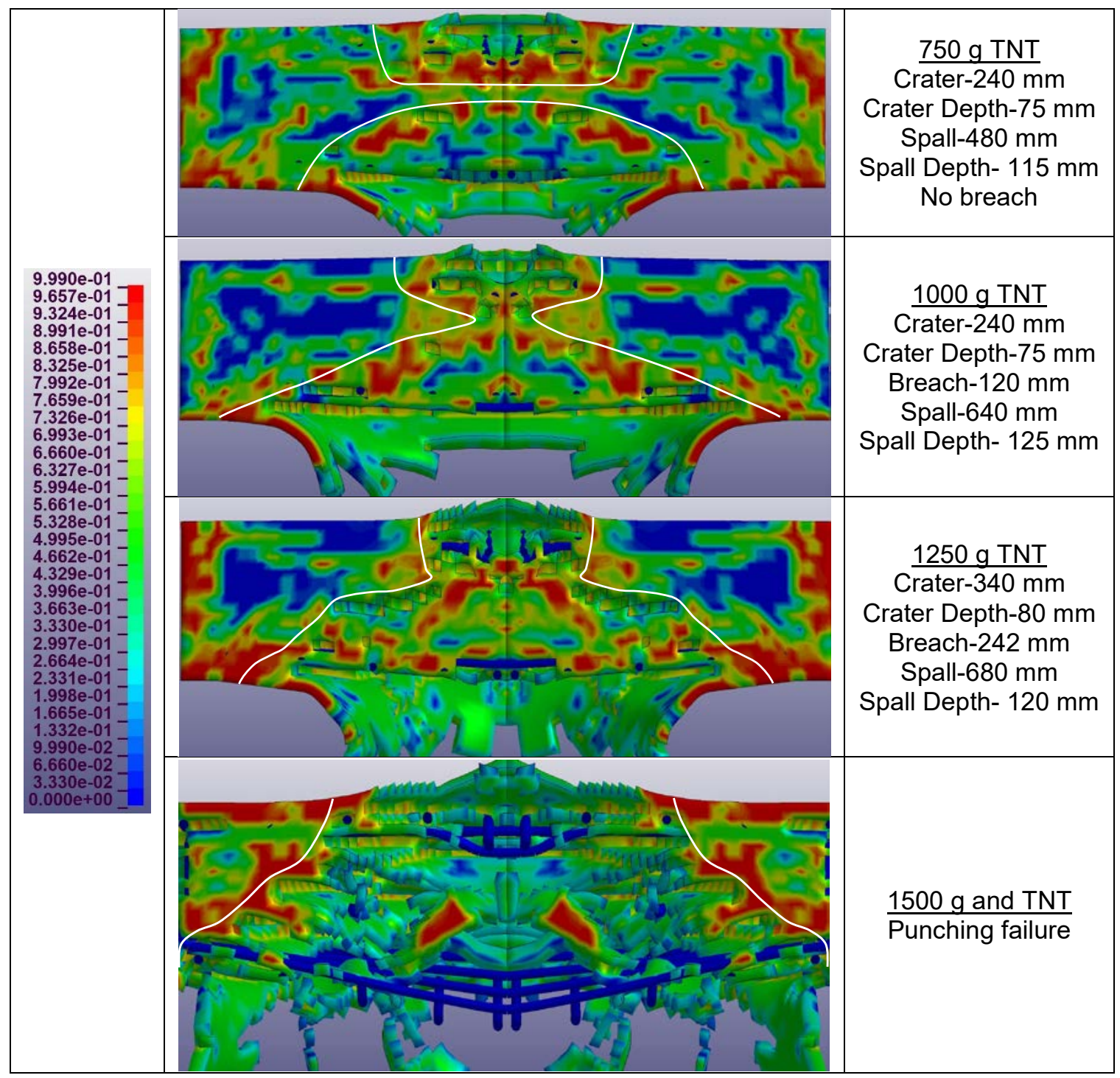

There is a trend of increasing crater and spall diameters with the increase in the explosive mass. The $200-\mathrm{mm}$ thick slab was breached by an explosive loading of 1000-g TNT detonated in contact with the slab. This indicates the breach threshold explosive mass for a $200 \mathrm{~mm}$ thick $\mathrm{RC}$ slab with 0.012 reinforcement ratio is in the range of $750-1000 \mathrm{~g} \mathrm{TNT}$. The predicted mass is close to the results predicted by Morishita et al. (2000) and DoA (2007) (Equation 3-2 and 3-3) which give breach explosive masses of $1000 \mathrm{~g}$ and $890 \mathrm{~g}$ respectively for a $200-\mathrm{mm}$ thick slab. The 
failure mode was observed to change from crater-spall to punching failure for an explosive mass of $1500 \mathrm{~g}$ TNT.

\subsubsection{Influence of Concrete Compressive Strength}

The influence of unconfined concrete compressive strength was investigated numerically by implementing the experimentally validated numerical model with different compressive strengths. The concrete compressive strength was varied in the range of $20 \mathrm{MPa}-75 \mathrm{MPa}$ for a $200-\mathrm{mm}$ thick RC slab with 0.012 reinforcement ratio. An explosive mass of $1500 \mathrm{~g}$ TNT that caused punching failure in the RC slab was detonated in contact with the slabs and the associated failure modes are presented in Table 3-15.

Table 3-15: Influence of concrete compressive strength

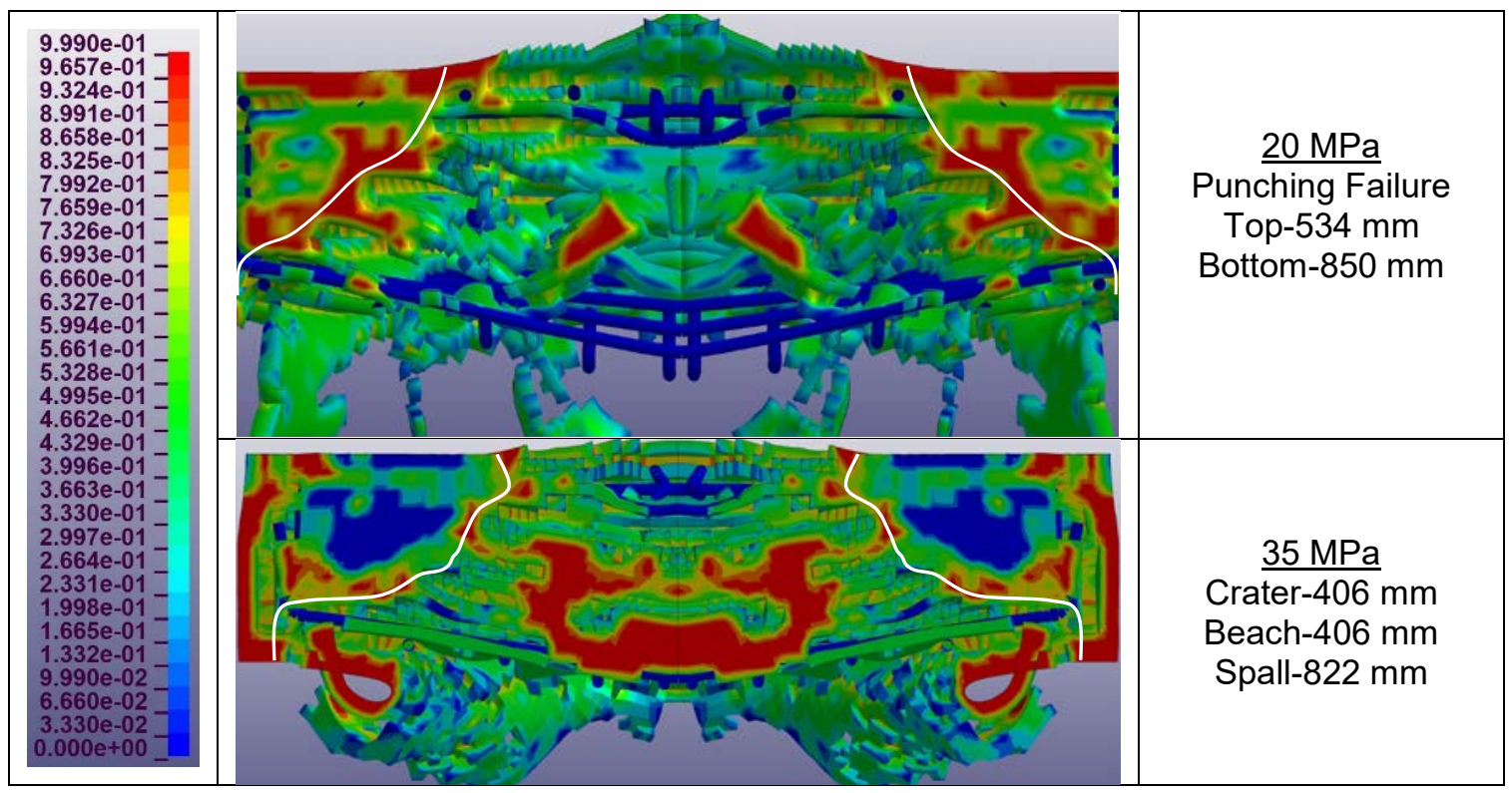




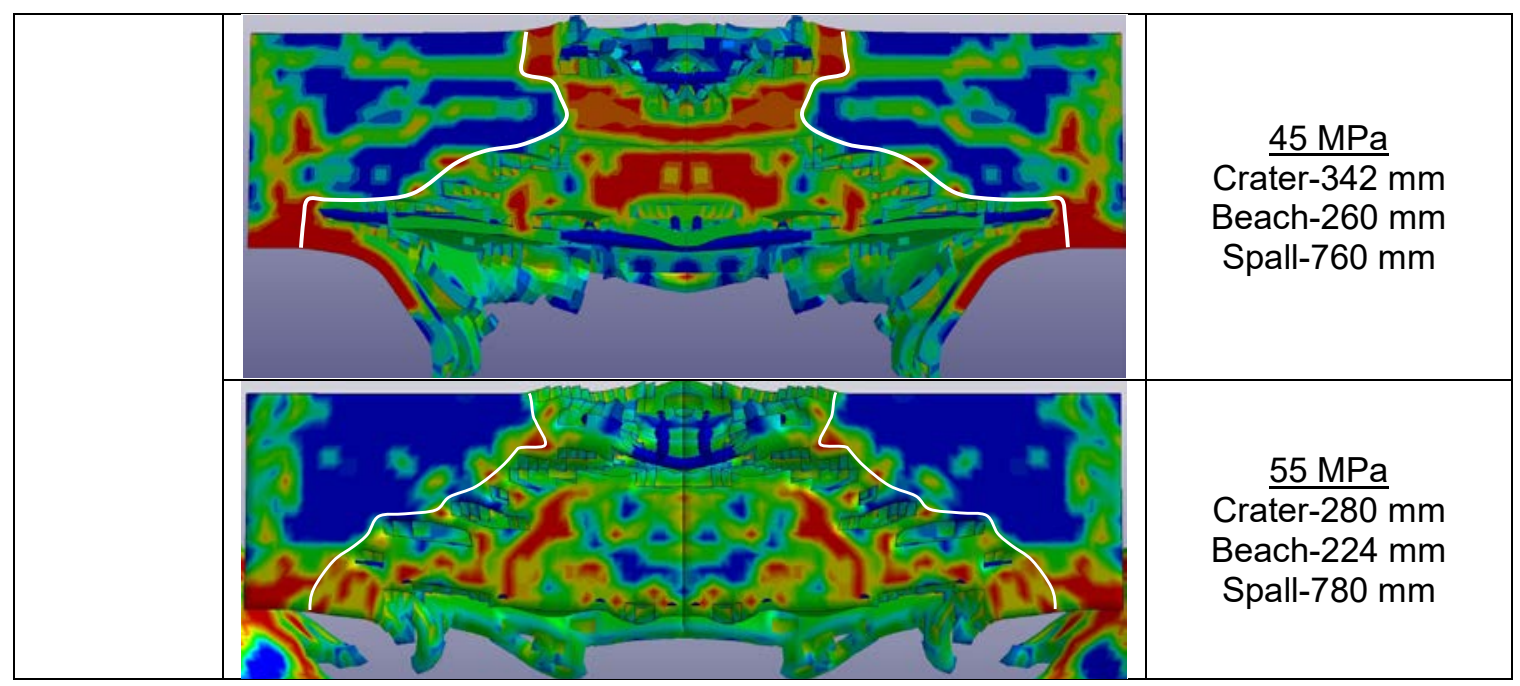

An increase in the concrete compressive strength from $20 \mathrm{MPa}$ to $45 \mathrm{MPa}$ did not prevent a breach failure of the slab subjected to contact explosion effects. However, the failure mode transitioned from punching to crater-spall. Hence, numerical results above show that concrete compressive strength can improve the resistance of the $\mathrm{RC}$ slab to contact explosion effects, but the improvement is not significant in this context.

\subsubsection{Influence of Reinforcement ratio}

To investigate the effects of reinforcement ratio on the response of $\mathrm{RC}$ slabs to contact explosions, the reinforcement diameter, and reinforcement spacing was varied. A 200-mm thick slab with 0.022 reinforcement ratio (\$16 @ 100 c/c) was numerically subjected to the breach-threshold explosive mass of $1000 \mathrm{~g}$ TNT that caused a breach in the 200-mm thick slab with 0.011 (Ф12 @ 100 c/c) reinforcement ratio. The damage profiles predicted by the validated numerical model are presented in Table 3-16. An increase in the reinforcement ratio from 0.011 to 0.022 precluded the breach in the slab. This can be attributed to higher 
confinement provided by the reinforcement that prevents a breach in the concrete core. The crater-spall failure mode was observed in both the simulations however breach occurred only in case of 0.011 reinforcement ratio.

Table 3-16: Influence of reinforcement ratio on breach threshold explosive mass

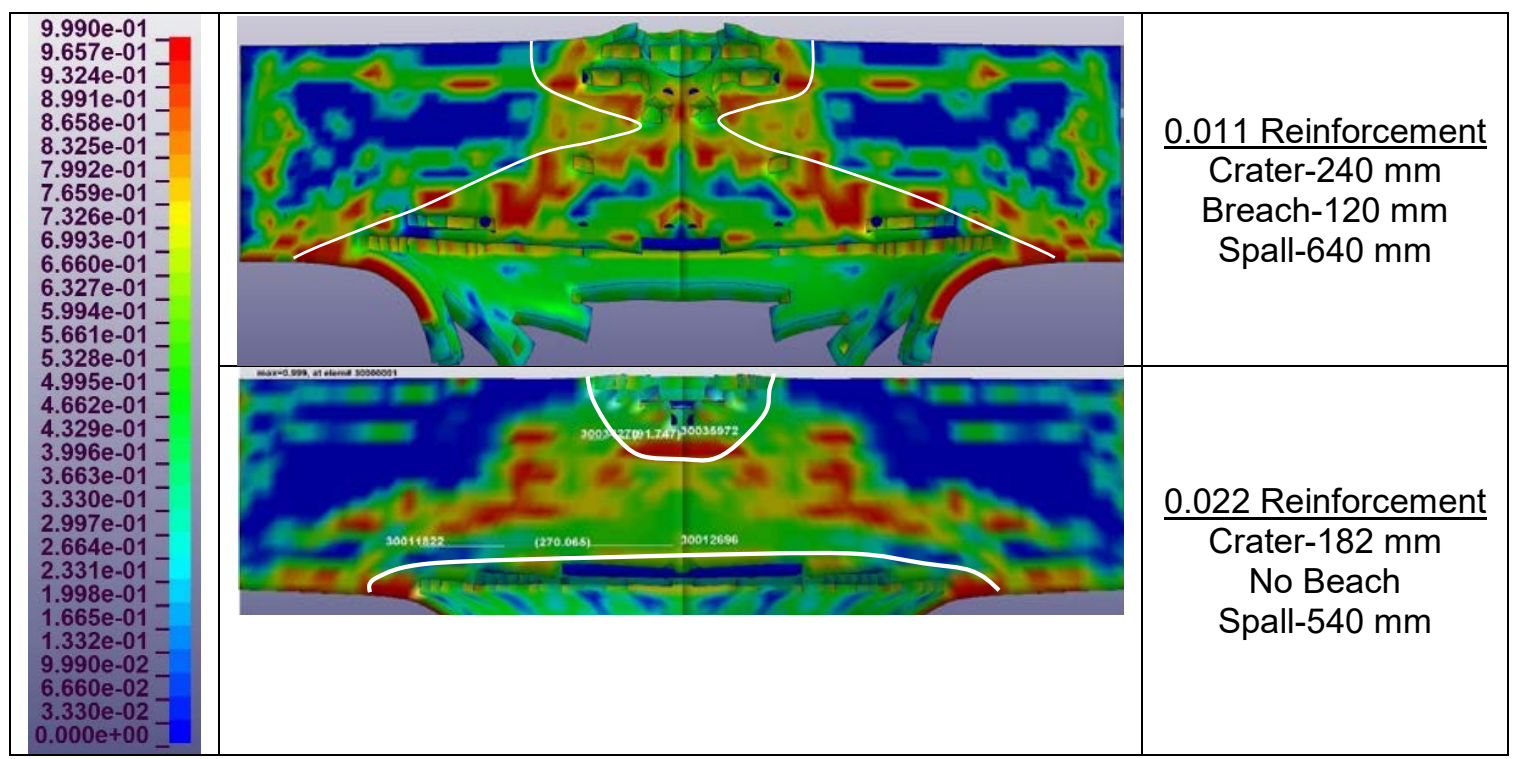

To investigate the effect of reinforcement spacing, a $200-\mathrm{mm}$ thick slabs were reinforced with a constant reinforcement ratio while the rebar spacing was varied between $50 \mathrm{~mm}$ and $100 \mathrm{~mm}$. The RC slabs were subjected to $1250 \mathrm{~g}$ TNT detonation. The damage profiles for reinforcement spacing at $100 \mathrm{~mm}, 75 \mathrm{~mm}$ and $50 \mathrm{~mm}$ are presented in Table 3-17. There was no significant change in the damage profile of the $\mathrm{RC}$ slab with the change in reinforcement spacing. 
Table 3-17: Influence of reinforcement spacing on breach threshold explosive mass

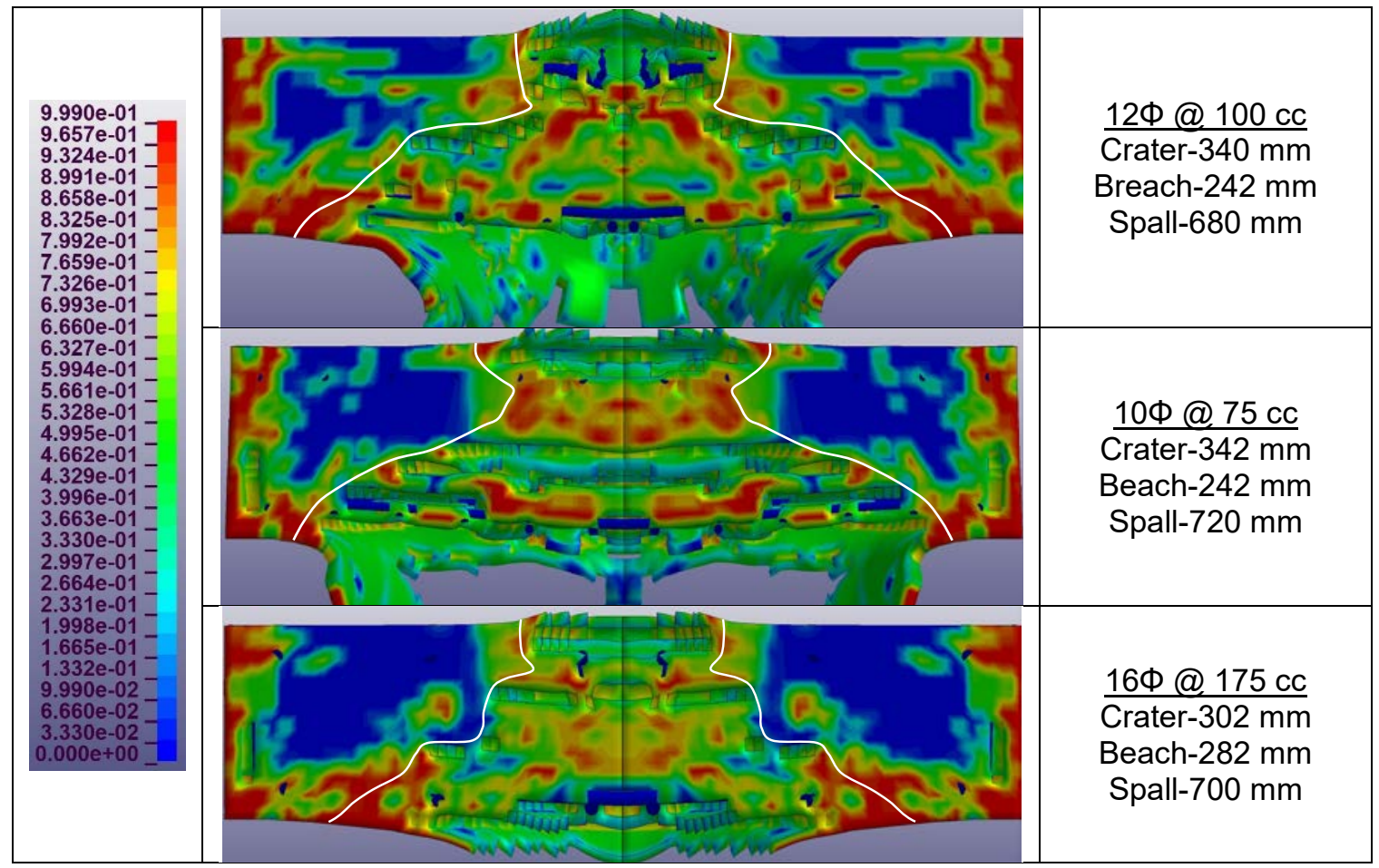

It can be concluded that higher reinforcement ratios have a significant effect on the breach threshold explosive mass. Whilst, the reinforcement spacing does not have a significant effect on the response. Hence a higher reinforcement ratio is recommended for improving the blast resistance of RC slabs subjected to contact explosion effects. This effect may be attributed to better concrete confinement provided by higher reinforcement ratios. The reinforcement spacing was not found to significantly influence the breach threshold explosive mass. However, it may be noted that only $200 \mathrm{~mm}$ thick slab was investigated, and the reinforcement was present under the explosive for all cases whereas it may be possible for larger spaced reinforcements to have no bar under the explosive. This may need further investigation. 


\subsubsection{Influence of Slab Thickness}

It is apparent that an increase in the slab thickness improves the contact explosion resistance. This section quantifies the increase in the breach threshold explosive mass with an increase in the slab thickness. RC slab thicknesses of $100 \mathrm{~mm}, 300$ $\mathrm{mm}$ and $400 \mathrm{~mm}$ with 0.012 reinforcement ratios were numerically modeled and subjected to contact explosion of varied explosive mass. The threshold explosive mass for each thickness was identified and presented in Table 3-18. As expected, the blast-resistance of the RC slabs to breach improves significantly with increase in the slab thickness.

Table 3-18: Influence of slab thickness on breach threshold explosive mass

\begin{tabular}{|c|c|c|}
\hline Thickness, $\mathrm{mm}$ & Reinforcement ratio, - & Threshold explosive mass, $\mathrm{kg}$ \\
\hline 100 & 0.011 & 0.5 \\
\hline 200 & 0.011 & 1.0 \\
\hline 300 & 0.011 & 2.5 \\
\hline 400 & 0.011 & 4.0 \\
\hline
\end{tabular}

\subsubsection{Influence of Contact Area between the Explosive and the Target}

It is expected that the area of contact between the explosive and the target will influence the target's response. An RC slab of $400 \mathrm{~mm}$ thickness and 0.012 reinforcement ratio was modeled with a varying contact area of the explosive mass. The $400 \mathrm{~mm}$ thickness slab with 0.012 reinforcement ratio was determined to have a breach threshold explosive mass of $4 \mathrm{~kg}$ when the explosive was a cuboid with a contact surface area dimension length $(\mathrm{l}) \times$ width $(\mathrm{w}) \times$ height $(\mathrm{h})$ of $180 \times 160 \times 70 \mathrm{~mm}$. On the other hand, for a $4.5 \mathrm{~kg}$ explosive mass with a contact surface area of $200 \times 200 \times 90 \mathrm{~mm}$, the $400-\mathrm{mm}$ thick slab with 0.012 reinforcement 
ratio was not breached. The cross-sections of the damage profiles for both simulations are presented in Figure 3-20.

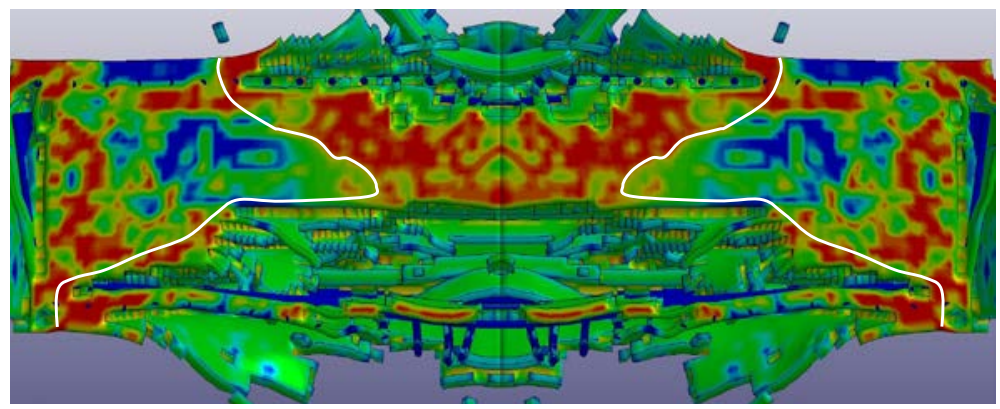

(a)

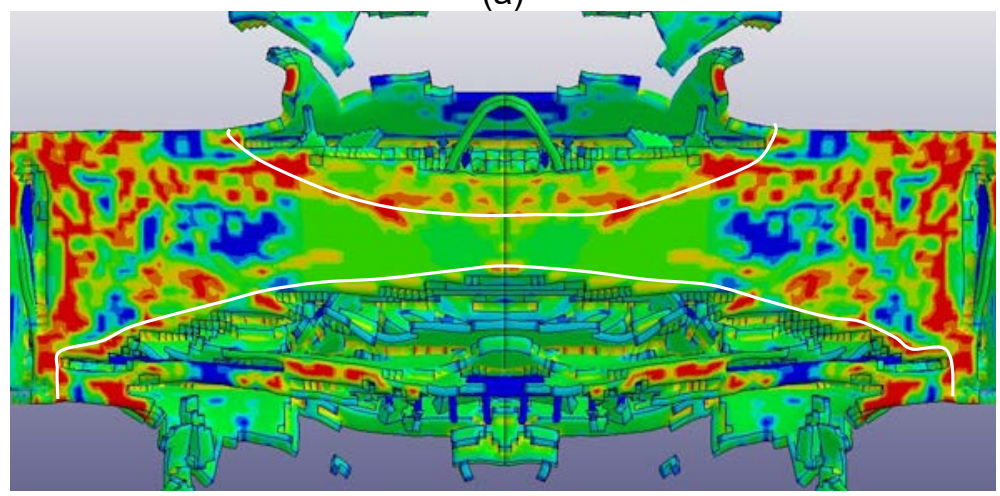

(b)

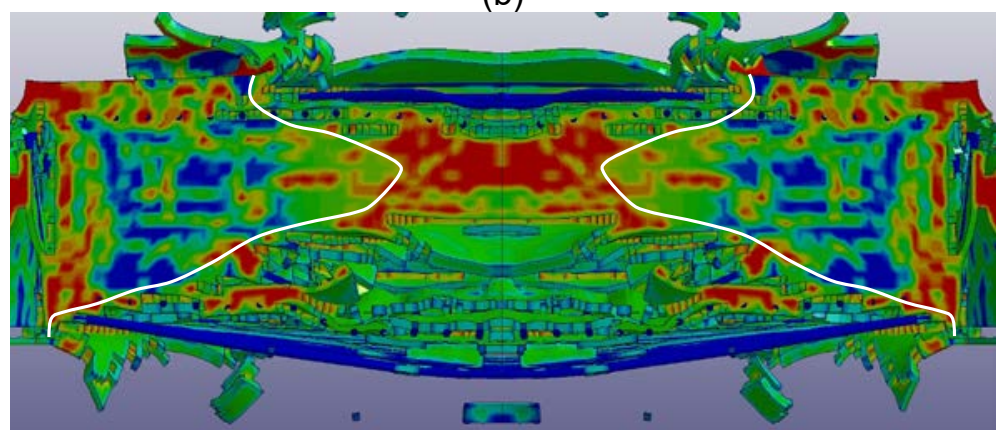

(c)

Figure 3-20: Influence of contact area between explosive and target (a) $4 \mathrm{~kg}$ as $180 \times 160 \times 90 \mathrm{~mm}$ (b) $4.5 \mathrm{~kg}$ as $200 \times 200 \times 70 \mathrm{~mm}$ (c) $4.5 \mathrm{~kg}$ as $180 \times 180 \times 90 \mathrm{~mm}$

The explosive was detonated at the center and hence the run-up distance is $h / 2$ which represents the distance between the point of detonation and the surface of the explosive. Assuming I to be the longer dimension, the $\mathrm{I} / \mathrm{h}$ ratio for $4 \mathrm{~kg}$ explosive was 2 whereas the $\mathrm{l} / \mathrm{h}$ ratio for $4.5 \mathrm{~kg}$ was close to 3 . Even though the contact area was higher in case of $4.5 \mathrm{~kg}$ explosive, the effects could not breach the slab. To 
ascertain this further a simulation with $4.5 \mathrm{~kg}$ explosive and $\mathrm{l} / \mathrm{h}$ ratio of 2 was performed and a breach was observed in the RC slab (Figure 3-20(c)). This is due to the run-up distance of the shock wave from the point of detonation. A higher run-up distance causes more damage in the target.

At the same time, the contact area is also important to transfer the impulse to the target. The breach threshold explosive mass of $200 \mathrm{~mm}$ thick slab was determined as $1 \mathrm{~kg}$ with contact surface area of $100 \times 80$ and a thickness of $80 \mathrm{~mm}(\mathrm{l} / \mathrm{h} \sim 1)$ (Table 3-14). The same slab was numerically subjected to $1.5 \mathrm{~kg}$ explosive mass with the same contact surface area of $100 \times 80$ but a thickness of $120 \mathrm{~mm} \mathrm{(1/h}$ 0.75). The contact explosion effects could not breach the slab (Figure 3-21) with higher explosive mass and the same contact surface area. Hence, as $1 / h$ ratio approaches 1, the damage caused to the RC slab subjected to contact explosion effects is maximized. The lateral dimension of I $\times w$ should not vary much for this to be true.

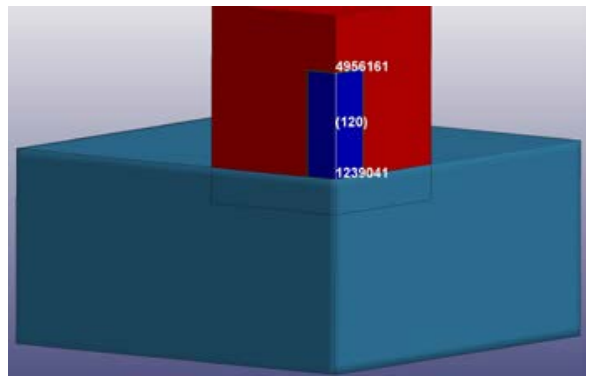

(a)

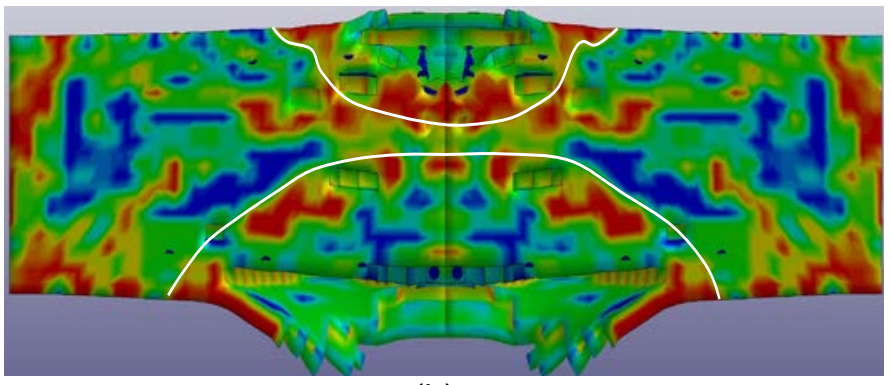

(b)

Figure 3-21: Response of $200 \mathrm{~mm}$ thick RC slab to $1500 \mathrm{~g}$ TNT explosion in contact (a) $120 \mathrm{~mm}$ thick TNT slab with $\mathrm{l} / \mathrm{h} \sim 0.75$ (b) Damage profile of the cross-section 


\subsection{Dimensional Analysis: Breach Diameter}

The parameters influencing the breach diameter in an $\mathrm{RC}$ slab subjected to contact explosion effects are presented in Table 3-19. Applications of the Buckingham's theorem in blast response of concrete slabs is established in the literature (Lönnqvist, 1993). The theorem states that if there is a physically meaningful equation involving a certain number of physical variables $(n)$, then the original equation can be rewritten in terms of a set of $p=n-k$ dimensionless parameters $\pi 1$, $\pi_{2}, \ldots, \Pi_{p}$ constructed from the original variables where $k$ is the number of physical dimensions involved. The theorem was applied to determine the breach diameter normalized to slab thickness.

Table 3-19: Parameters considered for dimensional analysis

\begin{tabular}{|c|c|c|}
\hline & Unit & Dimension \\
\hline \multicolumn{3}{|l|}{ Load Parameters } \\
\hline Explosive Weight, $\mathrm{W}_{\text {exp }}$ & $\mathrm{Kg}$ & $\mathrm{M}$ \\
\hline Explosive Energy, Eexp & $\mathrm{J} / \mathrm{Kg}$ & $\mathrm{L}^{2} \mathrm{~T}^{-2}$ \\
\hline Explosive Density, $\rho_{\text {exp }}$ & $\mathrm{Kg} / \mathrm{m}^{3}$ & $\mathrm{ML}^{-3}$ \\
\hline Contact Area, Acon & $\mathrm{m}^{2}$ & $\mathrm{~L}^{2}$ \\
\hline \multicolumn{3}{|l|}{ Resistance Parameters } \\
\hline Slab Thickness, $\mathrm{t}$ & $\mathrm{m}$ & $\mathrm{L}$ \\
\hline Breach Diameter, $d$ & $\mathrm{~m}$ & $\mathrm{~L}$ \\
\hline Concrete Strength, $f_{c}$ & $\mathrm{~Pa}$ & $M^{-1} T^{-2}$ \\
\hline Concrete Density, $\rho_{c}$ & $\mathrm{Kg} / \mathrm{m}^{3}$ & $\mathrm{ML}^{-3}$ \\
\hline Transformed Area, A eq $_{\text {eq }}$ & $\mathrm{m}^{2}$ & $\mathrm{~L}^{2}$ \\
\hline
\end{tabular}

There are three dimensions involved in the problem as seen from Table 3-19; mass $(M)$, length $(L)$ and time $(T)$, hence there are six non-dimensional terms that can satisfy the equation:

$$
F\left(\pi_{1}, \pi_{2}, \pi_{3}, \pi_{4}, \pi_{5}, \pi_{6}\right)=0
$$

There are more than one set of terms that can satisfy the non-dimensional function and one such set is: 


$$
\begin{gathered}
\pi_{1}=\frac{d}{t} \quad \pi_{2}=\frac{A_{\text {con }}}{A_{e q}} \quad \pi_{3}= \\
\frac{\rho_{\text {exp }}}{\rho_{c}} \quad \pi_{4}=\frac{W_{\text {exp }}}{\rho_{c} \cdot t^{3}} \quad \pi_{5}=\frac{W_{\text {exp }} \cdot \rho_{\text {exp }} \cdot E_{\text {exp }}}{\mathrm{f}_{c} \cdot \rho_{c} \cdot t^{3}} \pi_{6}= \\
\frac{W_{\text {exp }} \cdot \rho_{\text {exp }} \cdot E_{\text {exp }} \cdot A_{c o n}}{\mathrm{f}_{c} \cdot \rho_{c} \cdot t^{3} \cdot A_{\text {eq }}}
\end{gathered}
$$

The influence of reinforcement has been included in the equivalent area of concrete through the modular ratio $(\mathrm{n})$. The function can be rewritten as equation 3-11

$$
\frac{d}{t}=F\left(\frac{A_{b r}}{A_{e q}}, \frac{\rho_{\text {exp }}}{\rho_{c}}, \frac{W_{\text {exp }}}{\rho_{c} \cdot t^{3}}, \frac{W_{\text {exp }} \cdot \rho_{\text {exp }} \cdot E_{\text {exp }}}{\mathrm{f}_{c} \cdot \rho_{c} \cdot t^{3}}, \frac{W_{\text {exp }} \cdot \rho_{\text {exp }} \cdot E_{\text {exp }} \cdot A_{c o n}}{\mathrm{f}_{c} \cdot \rho_{c} \cdot t^{4} \cdot b \cdot\left(1+n \frac{A_{s t}}{A_{c}}\right)}\right)
$$

where $b$ is the width of the slab, $A_{c}$ is the cross-sectional area of the slab $(b \times t), A_{s t}$ is the area of reinforcement and $A_{e q}$ is $A_{c}+A_{s t}$. The left-hand side is termed as the normalized breach diameter and the right-hand side is termed as the damage function $\left(\mathrm{D}_{\mathrm{f}}\right)$. Equation 3-11 is an extension of the relationship between the normalized breach diameter and the Df proposed by Lönnqvist (1993) and given by Equation 3-12.

$$
\frac{d}{\mathrm{t}}=\mathrm{F}\left(\frac{W_{\text {exp }} \cdot \rho_{\text {exp }} \cdot E_{\text {exp }}}{\mathrm{f}_{c} \cdot \rho_{c} \cdot t^{3}}\right)
$$

where $d$ is the breach diameter in $\mathrm{m}$ and $t$ is the thickness of the slab. The linear curve fit for the log scaled plot of the experimental data reported by Lönnqvist (1993) implementing equation 3-12 is presented in Figure 3-22. 


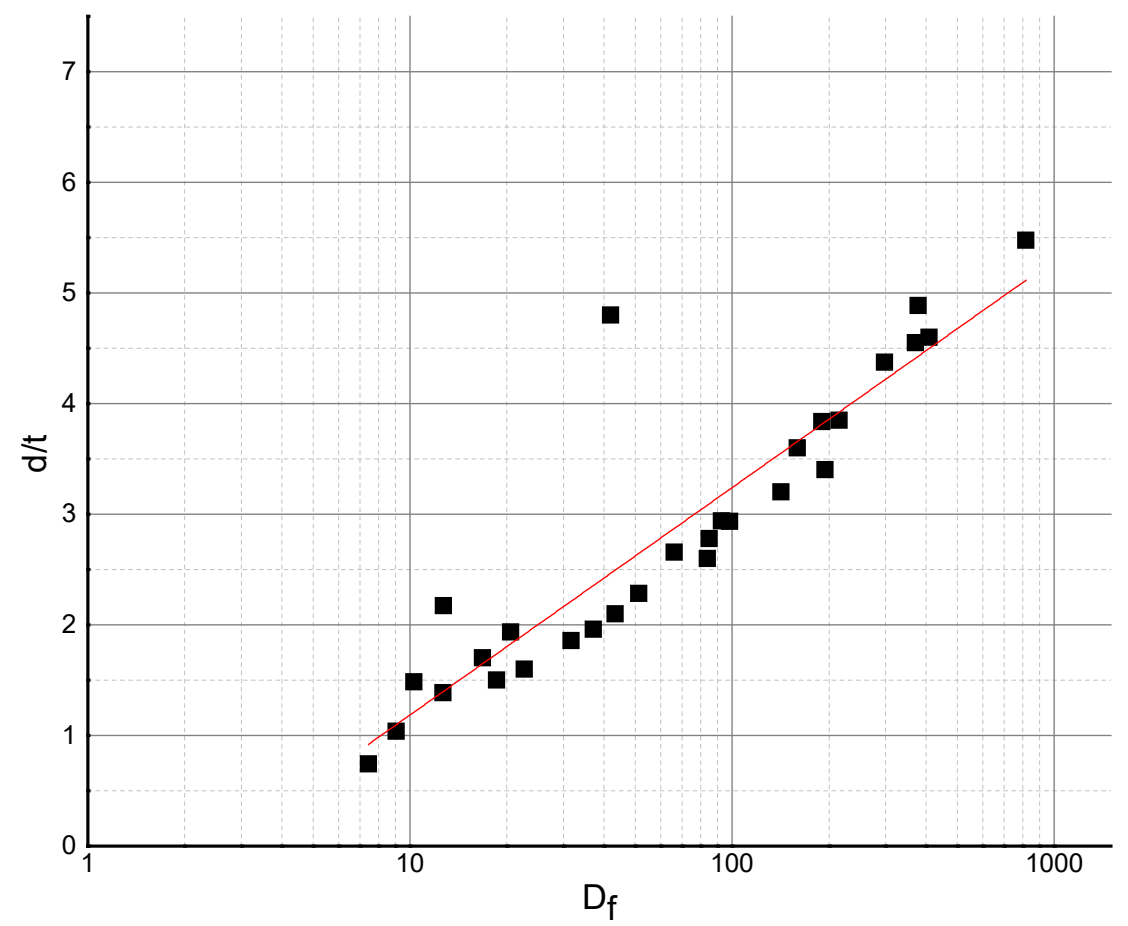

Figure 3-22: Breach damage parameter as a function of scaled explosive mass

In the case of minimum reinforcement, both the functions predict similar breach diameters. However, Equation 3-12 could give erroneous results when the reinforcement ratio is higher than the minimum as is common in many structures. The breach diameter predicted by Equation 3-11 was found to be lesser than Equation 3-12 in case of higher reinforcement ratios. As shown earlier, the breach diameter of RC slabs is influenced by the reinforcement percentage. A higher reinforcement ratio increases the confinement of the concrete core, thus improving the contact blast resistance. Accordingly, the breach diameter is lesser in cases where the reinforcement is considered.

To improve prediction of Equation 3-11, the experimental and numerical data collected in this study was augmented with the experimental results found in the 
literature in order to cover a wider range of reinforcement ratios. The effect of reinforcement ratio is presented in Table 3-20.

Table 3-20: Response data for dimensional analysis

\begin{tabular}{|c|c|c|c|c|c|c|c|c|c|}
\hline Source & $\begin{array}{l}W_{\text {exp }} \\
\mathrm{Kg}\end{array}$ & $\begin{array}{c}\rho_{\exp } \\
\mathrm{Kg} / \mathrm{m}^{3}\end{array}$ & $\begin{array}{l}E_{\text {exp, }} \\
\mathrm{kJ} / \mathrm{Kg}\end{array}$ & $\begin{array}{c}\sigma \\
\mathrm{MPa}\end{array}$ & $\mathrm{t}$, & $\begin{array}{c}\mathrm{b} \\
\mathrm{mm}\end{array}$ & $\begin{array}{l}\mathrm{d}, \\
\mathrm{mm}\end{array}$ & $\begin{array}{c}A_{s t} / A_{c}, \\
\%\end{array}$ & $A_{c o n}, m^{2}$ \\
\hline \multirow{10}{*}{ Dua \& Braimah } & 1 & 1550 & 4000 & 20 & 200 & 900 & 182 & 1.2 & 0.008 \\
\hline & 1.25 & 1550 & 4000 & 20 & 200 & 900 & 242 & 1.2 & 0.01 \\
\hline & 1.5 & 1550 & 4000 & 20 & 200 & 900 & 534 & 1.2 & 0.0196 \\
\hline & 1.5 & 1550 & 4000 & 35 & 200 & 900 & 406 & 1.2 & 0.0196 \\
\hline & 1.5 & 1550 & 4000 & 45 & 200 & 900 & 260 & 1.2 & 0.0196 \\
\hline & 1.5 & 1550 & 4000 & 55 & 200 & 900 & 224 & 1.2 & 0.0196 \\
\hline & 0.5 & 1550 & 4000 & 20 & 100 & 1500 & 302 & 1.2 & 0.0096 \\
\hline & 4 & 1550 & 4000 & 20 & 400 & 1500 & 346 & 1.2 & 0.0288 \\
\hline & 2.5 & 1550 & 4000 & 20 & 300 & 1800 & 275 & 1.2 & 0.0192 \\
\hline & 4.5 & 1550 & 4000 & 20 & 400 & 1500 & 388 & 1.2 & 0.0324 \\
\hline \multirow{29}{*}{$\begin{array}{l}\text { Lönnqvist } \\
\text { (1993) }\end{array}$} & 0.01 & 1770 & 5540 & 38 & 40 & 1000 & 68 & 0.17 & 0.0007 \\
\hline & 0.025 & 1770 & 5540 & 38 & 40 & 1000 & 84 & 0.17 & 0.0012 \\
\hline & 0.05 & 1770 & 5540 & 38 & 40 & 1000 & 104 & 0.17 & 0.0018 \\
\hline & 0.125 & 1770 & 5540 & 50 & 40 & 1000 & 144 & 0.17 & 0.0033 \\
\hline & 0.25 & 1770 & 5540 & 43 & 40 & 1000 & 182 & 0.17 & 0.0053 \\
\hline & 0.5 & 1770 & 5540 & 39 & 40 & 1000 & 219 & 0.17 & 0.0083 \\
\hline & 0.01 & 1770 & 5540 & 44 & 50 & 1000 & 37 & 0.14 & 0.0007 \\
\hline & 0.025 & 1770 & 5540 & 44 & 50 & 1000 & 75 & 0.14 & 0.0012 \\
\hline & 0.05 & 1770 & 5540 & 44 & 50 & 1000 & 98 & 0.14 & 0.0018 \\
\hline & 0.125 & 1770 & 5540 & 48 & 50 & 1000 & 139 & 0.14 & 0.0033 \\
\hline & 0.25 & 1770 & 5540 & 42 & 50 & 1000 & 170 & 0.14 & 0.0053 \\
\hline & 0.5 & 1770 & 5540 & 40 & 50 & 1000 & 230 & 0.14 & 0.0083 \\
\hline & 0.025 & 1770 & 5540 & 46 & 60 & 1000 & 89 & 0.11 & 0.0012 \\
\hline & 0.05 & 1770 & 5540 & 46 & 60 & 1000 & 116 & 0.11 & 0.0018 \\
\hline & 0.125 & 1770 & 5540 & 46 & 60 & 1000 & 137 & 0.11 & 0.0033 \\
\hline & 0.25 & 1770 & 5540 & 48 & 60 & 1000 & 176 & 0.11 & 0.0053 \\
\hline & 0.5 & 1770 & 5540 & 44 & 60 & 1000 & 231 & 0.11 & 0.0083 \\
\hline & 1 & 1770 & 5540 & 50 & 60 & 1000 & 293 & 0.11 & 0.0132 \\
\hline & 0.05 & 1770 & 5540 & 47 & 70 & 1000 & 97 & 0.1 & 0.0018 \\
\hline & 0.125 & 1770 & 5540 & 47 & 70 & 1000 & 130 & 0.1 & 0.0033 \\
\hline & 0.25 & 1770 & 5540 & 45 & 70 & 1000 & 186 & 0.1 & 0.0053 \\
\hline & 0.5 & 1770 & 5540 & 42 & 70 & 1000 & 224 & 0.1 & 0.0083 \\
\hline & 1 & 1770 & 5540 & 40 & 70 & 1000 & 306 & 0.1 & 0.0132 \\
\hline & 0.05 & 1770 & 5540 & 44 & 80 & 1000 & 83 & 0.09 & 0.0018 \\
\hline & 0.125 & 1770 & 5540 & 44 & 80 & 1000 & 128 & 0.09 & 0.0033 \\
\hline & 0.25 & 1770 & 5540 & 46 & 80 & 1000 & 168 & 0.09 & 0.0053 \\
\hline & 0.5 & 1770 & 5540 & 43 & 80 & 1000 & 235 & 0.09 & 0.0083 \\
\hline & 1 & 1770 & 5540 & 42 & 80 & 1000 & 307 & 0.09 & 0.0132 \\
\hline & 5 & 1770 & 5540 & 49 & 320 & 1000 & 695 & 0.09 & 0.0384 \\
\hline \multirow{2}{*}{$\begin{array}{l}\text { Akers et al. } \\
(2005)\end{array}$} & 8.31 & 1550 & 4000 & 25 & 200 & 2400 & 760 & 0.42 & 0.09 \\
\hline & 0.771 & 1550 & 4000 & 25 & 200 & 2400 & 200 & 0.42 & 0.009 \\
\hline $\begin{array}{c}\text { Gebbeken et al. } \\
(2004)\end{array}$ & 1.411 & 1550 & 4000 & 44 & 300 & 1000 & 247 & 0.54 & 0.0095 \\
\hline
\end{tabular}




\begin{tabular}{|c|c|c|c|c|c|c|c|c|c|}
\hline $\begin{array}{c}\text { J. Li et al. } \\
(2016)\end{array}$ & 1 & 1550 & 4000 & 40 & 120 & 800 & 320 & 1.2 & 0.0113 \\
\hline $\begin{array}{c}\text { Krivtsun and } \\
\text { Mentus (2009) }\end{array}$ & 0.1 & 1550 & 4000 & 56 & 100 & 1000 & 100 & 0.5 & 0.00363 \\
\hline $\begin{array}{c}\text { Wang et al. } \\
(2008)\end{array}$ & 2 & 1550 & 4000 & 32 & 300 & 3000 & 250 & 0.5 & 0.018 \\
\hline $\begin{array}{c}\text { Weerheijm et al. } \\
(1984)\end{array}$ & 0.5 & 1550 & 4000 & 35 & 180 & 1000 & 180 & 1 & 0.007 \\
\hline
\end{tabular}

An empirical formula relating the normalized breach diameter and $D_{f}$ as per the Equation 3-11 was developed by linear regression from the above data (Equation 3-13). The function is valid for a range explosive charge masses: $10 \mathrm{~g}-4500 \mathrm{~g}$ TNT, concrete strength: $20-55 \mathrm{MPa}$, reinforcement ratio: $0.002-0.025$ and slab thickness: $40-400 \mathrm{~mm}$.

$$
\frac{d}{t}=1.41 \times \log _{10}\left(\frac{W_{\text {exp }} \cdot \rho_{\text {exp }} E_{\text {exp }} \cdot A_{c o n}}{\sigma \cdot \rho_{c} \cdot t^{4} \cdot b \cdot\left(1+n \frac{A_{s t}}{A_{c}}\right)}\right)+1.85
$$

The linear curve fit of the scatter plot of the above data in log scale is presented as Figure 3-23. The scatter plot is based on equation 3-11 that incorporates all the parameters influencing the response of RC slab subjected to contact explosion effects. 


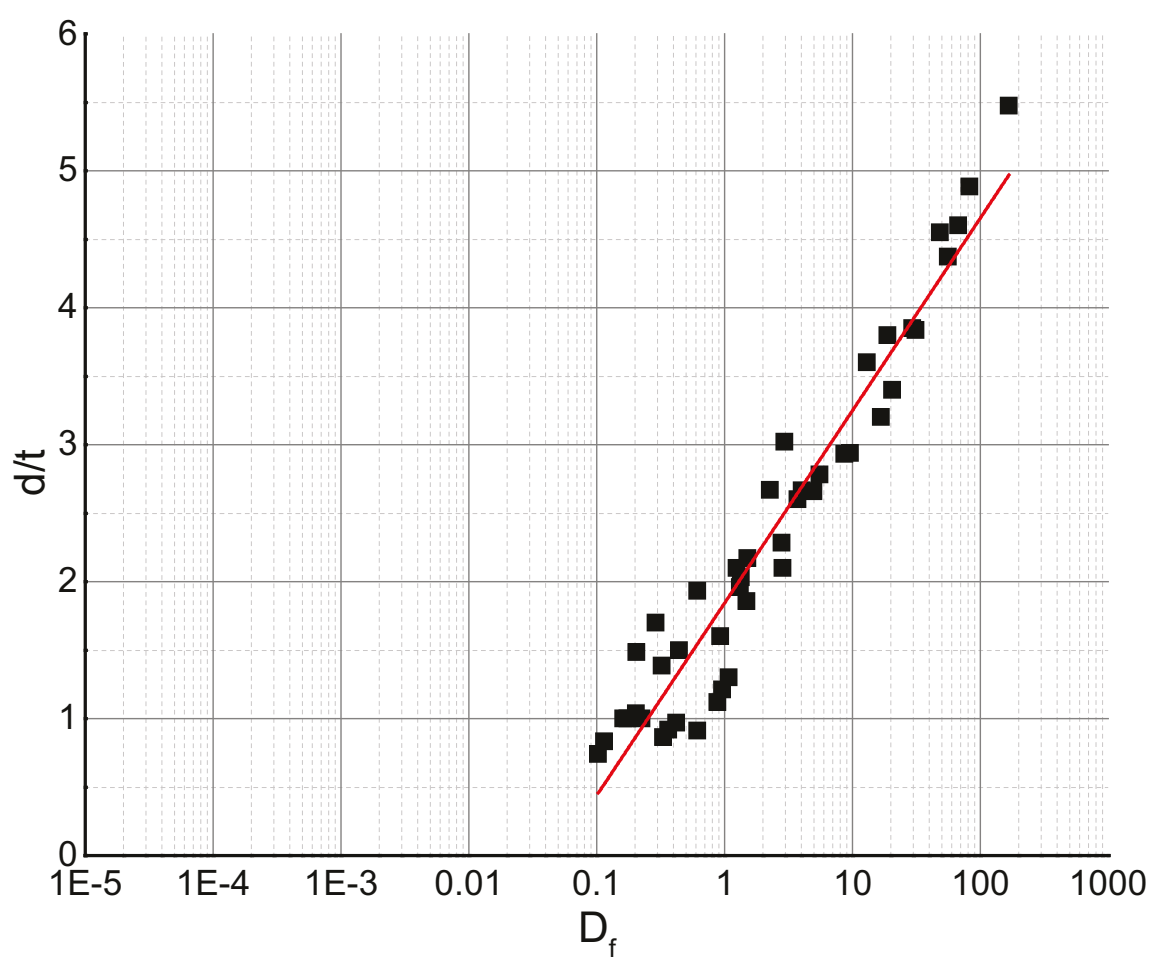

Figure 3-23: Fitted function for calculating breach diameter

\subsection{Conclusions}

This study investigates the response of concrete slabs subjected to contact explosion effects. Experimental results of full-scale tests on concrete slabs are scarce in the literature and most of the research work is restricted to numerical simulations. Full-scale tests on PC and RC slabs were conducted in this study and validated numerical models developed in LS-DYNA to investigate the response of PC and RC slabs under contact explosion effects. The numerical models were used for parametric analyses to study the effect of design parameters on the contact explosion resistance. The following conclusions can be drawn from the research program. 
- Concrete slab exhibits two failure modes when subjected to contact explosion effects: breach and crater-spall failure modes. The breach failure mode can further be classified into a punching failure or perforation breach failure.

- The reinforcement ratio of an RC slab influences the contact explosion resistance. A high reinforcement ratio can effectively prevent a breach in the concrete slab due to contact explosion effects.

- The concrete compressive strength in the range of 20-55 $\mathrm{MPa}$ was observed to have a minor influence on the contact explosion resistance of the slab in context of preventing a breach failure.

- The contact surface area between the explosive mass and the slab affects the failure mode significantly. The damage due to contact explosion effects is maximized when the $\mathrm{l} / \mathrm{h}$ ratio approaches 1 .

- Dimensional analysis based on experimental and numerical results was used to establish an empirical equation to predict the breach diameter of an $\mathrm{RC}$ slab subjected to contact explosion effects.

\subsection{References}

Akers, S., Weed, R., Rickman, D., \& Danielson, K. 2005. Numerical Simulations of Explosive Wall Breaching. Computer Society: IEEE

Arlery, M., Rouquand, A., \& Chhim, S. 2013. Numerical Dynamic Simulations for the Prediction of Damage and Loss of Capacity of RC Column Subjected to 
Contact Detonations. VIII International Conference on Fracture Mechanics of Concrete and Concrete Structures: University of Colorado Toledo, Spain. ASCE. 2011. Blast Protection of Buildings: Standard ASCE/SEI 59-11: American Society of Civil Engineers (ASCE). USA.

Beppu, M., Ohno, T., Ohkubo, T., Li, B., \& Satoh, K. 2010. Contact Explosion Resistance of Concrete Plates Externally Strengthened with FRP Laminates. International Journal of Protective Structures, 1(2): 257-270.

Bessette, G., Bell, R., Cole, R., Vaughan, C., Yarrington, L., \& Attaway, S. 2003. Zapotek: A Coupled Eulerian-Lagrangian Computer Code, Methodology and User Manual, Version 1.0. Scandia National Laboratories.

Børvik, T., Hanssen, A., Langseth, M., \& Olovsson, L. 2009. Response of Structures to Planar Blast Loads - A Finite Element Engineering Approach. Computers \& Structures, 87: 507-520.

Braimah, A., Siba, F., \& Rosen, B. V. 2015. Near-field explosion effects on reinforced concrete columns. Protect 2015, Fifth international workshop on performance, protection and strengthening of structures under extreme loading: DEStech Publications, Inc. MI, USA pp. 504-514.

Clarke, S. D., Fay, S. D., Warren, J. A., Tyas, A., Rigby, \& Elgy, I. 2015. A large scale experimental approach to the measurement of spatially and temporally localized loading from detonation of shallow buried explosives. Measurement science and technology, 26: 10pp.

Cormie, D., Shin, J., Willkinson, W., \& Whittaker, A. S. 2013. Scaled-distance relationships for close-in detonations. 15th International Symposium on the 
Interaction of the Effects of Munitions with Structures (ISIEMS): Potsdam, Germany.

Cormie, D., Shin, J., Whittaker, A. S., \& Wilkinson, W. 2014. Numerical modelling of close-in detonations of high explosives. Engineering Structures, 81: 8897.

Canadian Standards Association (CSA). 2017. Design and Assessment of Buildings Subjected to Blast Loads, S850-12 (R2017). Canada.

US Department of Army (DoA). 2007. Explosives and Demolitions, FM 3-34.214. Department of Army Washington USA.

Dobratz, B., \& Crawford, P. 1985. LLNL explosives handbook.

US Department of Defense (DoD). 2002. Design and Analysis of Hardened Structures to Conventional Weapons Effects, UFC-3-340-01. Department of Defense USA.

US Department of Defense (DoD). 2007a. Minimum Antiterrorism Standards for Buildings, UFC-4-010-01. Department of Defense (UFC-4-010-01), USA.

US Department of Defense (DoD). 2007b. DoD Minimum Antiterrorism Standoff Distances for Buildings, UFC-4-010-02. Department of Defense (UFC-4010-02), USA.

US Department of Defense (DoD). 2008. Design of structures to resist the effects of accidental explosions, UFC-3-340-02. Department of Defense Washington, D.C.

Dua, A., Braimah, A., \& Matsagar, V. 2017. Understanding the Response of Reinforced Concrete Slabs due to Contact explosion of TNT. 6th 
International Engineering Mechanics and Materials Conference: Canadian Society for Civil Engineering (CSCE) Vancouver, Canada. pp. 522 521-510. Ducibella, R., \& Cunningham, J. 2010. Design Considerations. In D. O. Dusenberry (Ed.), Handbook for Blast-Resistant Design of Structures. New Jersey, USA: John Wiley \& Sons.

Federal Emergency Management Agency (FEMA). 2005. Reference Manual to Mitigate Potential Terrorist Attacks Against Buildings, FEMA-426. Federal Emergency Management Agency (FEMA) USA.

Gebbeken, N., Greulich, S., Pietzsch, A., \& Landmann, M. 2004. The EngineeringTool XPLOSIM to Determine the Effects of Explosive Loadings on Reinforced and Fibre Reinforced Concrete Structures. 18th International Symposium for Military Aspects of Blast and Shock:

Giroux, E. D. 1973. HEMP User Manual. University of California, Livermore: Lawrence Livermore Laboratory.

Hanssen, A., Enstock, L. K., \& Langseth, M. 2004. Close-Range Blast Loading of Aluminum Foam Panels. International Journal of Impact Engineering, 27: 593-618.

Kakogiannis, D., Hemelrijck, D. V., Wastiels, J., Palanivelu, S., Paepegem, W. V., Vantomme, J., . . Kostopoulos, V. 2010. Assessment of Pressure Waves Generated by Explosive Loading. CMES-Computer Modelling in Engineering \& Sciences, 65(1): 75-93. 
Kalra, A., Zhu, F., Yang, K. H., \& King, A. I. 2014. Key Parameters in Blast Modeling Using 2D to 3D ALE Mapping Technique. 13th International LSDYNA Users Conference: LSTC Detroit, USA.

Kingery, C. N., \& Pannill, B. F. 1964. Peak overpressure vs scaled distance for TNT surface bursts (hemispherical charges).

Kingery, C. N., \& Bulmash, G. 1984. Air blast parameters from TNT spherical air burst and hemispherical surface burst. Ballistic Research Lab (BRL), Technical Report, ARBRL-TR-02555.

Krivtsun, V. I., \& Mentus, I. E. 2009. Determination of the Basic Characteristics of Contact Charges for Breaching Walls. Annual Publications of the Taras Shevchenko National University of Kiev, Ukraine: 8-10 (in Ukrainian).

L.S.T.C. 2015. LS-DYNA Keyword User's Manual, Volume I. Livermore, California, USA: LSTC.

Lapoujade, V., Dorsselaer, N. V., Kevorkian, S., \& Cheval, K. 2010. A Study of Mapping Technique for Air Blast Modelling. 11th International LS-DYNA Users Conference: LSTC Detroit, USA.

Li, B., Nair, A., \& Kai, Q. 2012. Residual Axial Capacity of Reinforced Concrete Columns with Simulated Blast Damage. Journal of Performance of Constructed Facilities, 26(3): 287-299.

Li, J., Wu, C., \& Hao, H. 2016. Spallation of Reinforced Concrete Slabs under Contact Explosion. Second Asian Conference on Defence Technology: Chiang Mai, Thailand. 
Lin, Y., Shunfeng, G., \& Weiliang, J. 2008. Spallation Mechanism of RC Slabs Under Contact Explosion. Transactions of Tianjin University, SpringerVerlag, 14:464.

Lönnqvist, L. 1993. The effects of High Explosives in Contact with Reinforced Concrete Slabs. Sixth International Symposium on Interaction of Nonnuclear Munitions with Structures: Department of Defense Florida, USA Morishita, M., Tanaka, H., Ito, M., \& Yamaguchi, H. 2000. Damage of Reinforced Concrete Slabs Subjected to Contact Detonations (in Japanese). Journal of Structural Engineering, 46A(1787-1797).

Murray, Y. D. 2007. User's Manual for LS-DYNA Concrete Material Model 159. FHWA-HRT-05-062, Federal Highway Administration.

Remennikov, A., Mentus, I., \& Uy, B. 2015. Explosive Breaching of Walls with Contact Charges: Theory and Applications. International Journal of Protective Structures, 6(4): 629-647.

Rigby, Tyas, A., Clarke, S., Fay, S., Warren, J., Elgy, I., \& Gant, M. 2014. Testing apparatus for the spatial and temporal pressure measurements from nearfield free air explosions. 6th International Conference on Protection of structures against hazards: Tianjin, China.

Rigby, Tyas, A., Clarke, S. D., Fay, S. D., Reay, J. J., Warren, J. A., . . Elgy, I. 2015. Observations From Preliminary Experiments on Spatial and Temporal Pressure Measurements from Near-Field Free Air Explosions. International Journal of Protective Structures, 6(2): 175-190. 
Salamakhin, T. M. 1974. Fundamental of Mechanical Effects of Explosion on Structures and Methods of Predicting. Military Engineering Academy Publications (in Russian).

Schwer, L. 2014. Modelling Rebar: The Forgotten Sister in Reinforced Concrete Modelling. 13th International LS-DYNA User Conference: LSTC Detroit, USA.

Souli, M., Aquelet, N., Al-Bahkali, E., \& Moatamedi, M. 2013. A Mapping Method for Shock Waves Using ALE Formulation. Computer Modelling in Engineering \& Sciences, 91(2): 119-133.

Sullivan, T., Straten, M., Beggs, K., Lander, D., Watrous, A., \& Yowell, J. 2006. History and Testing Shapes of Strength for Building Teach Engineering. USA: University of Colorado.

Tagel-Din, H., \& Rahman, N. A. 2006. Simulation of the Alfred P. Murrah Federal Building Collapse Due to Blasts Loads. Architectural Engineering Conference: ASCE Nebraska, USA. pp. 32-47.

Telford, T. 1993. CEB-FIB Model Code 1990. Comité Euro-International du Béton, Lausanne, Switzerland.

Trajkovski, J., Kunc, R., Perenda, J., \& Prebil, I. 2014. Minimum mesh design criteria for blast wave development and structural response - MMALE method. Latin American Journal of Solids and Structures, 11: 1999-2017.

Wang, F., Wan, Y. K. M., Chong, O. Y. K., Lim, C. H., \& Lim, E. T. M. 2008. Reinforced concrete slab subjected to close-in explosion. LS-DYNA Conference: Bamberg. 
Weerheijm, J., Karthaus, W., \& Opschoor, G. 1984. The Failure Mode of Layered Concrete Construction Due to Contact Charges. 21st Department of Defense Explosive Safety Seminar: Department of Defense Houston, Texas, USA

Williams, G. D., \& Williamson, E. B. 2011. Response of Reinforced Concrete Bridge Columns Subjected to Blast Loads. Journal of Structural Engineering, 137(9): 903-913.

Wu, K.-C., Li, B., \& Tsai, K.-C. 2011. Residual Axial Compression Capacity of Localized Blast-Damaged RC Columns. International Journal of Impact Engineering, 38: 29-40.

Yuan, S., Hao, H., Zong, Z., \& Li, J. 2017. A Study of RC Bridge Columns Under Contact Explosion. International Journal of Protective Structures, 109: 378390.

Zakrisson, B., Wikman, B., \& Häggblad, H.-Å. 2011. Numerical simulations of blast loads and structural deformation from near-field explosions in air. International Journal of Impact Engineering, 38(7): 597-612.

Zukas, J. A., \& Scheffler, D. R. 2000. Practical Aspects of Numerical Simulations of Dynamic Events: Effects of Meshing. International Journal of Impact Engineering, 24(9): 925-945. 


\title{
Chapter 4 Contact Explosion Response of Reinforced Concrete Columns: Experimental and Numerical Investigation
}

\begin{abstract}
Protective design of critical infrastructure and iconic buildings against terrorist attacks requires the incorporation of elements of blastresistant design. Consequently, the response of structures subjected to blast loading has gained importance in the past two decades or so. Past research efforts have mostly focussed on the response of structural members to blast loading from the far-field explosion with limited emphasis on the near-field and contact explosion response. Thus, there is a lack of knowledge on the response of structural members, especially reinforced concrete columns, to the effects of near-field and contact explosion. There is limited experimental test data available on the response of concrete columns subjected to contact explosions. Columns are the most vulnerable and critical member in any structure and are at risk of contact explosion attacks using small quantities of explosives. A benchmark study for the response of full scale reinforced concrete columns subjected to live contact explosions of varying charge mass is presented in this study. The quantitative and qualitative assessments of concrete spalling and/or scabbing and the residual axial load capacity of the column are presented. The experimental data was used to establish a set of validated numerical LS-DYNA models that were used for parametric studies to establish the influence of various design parameters on the response. Results of the parametric studies show that the breaching charge mass for an RC column is considerably lower than the breaching charge mass for an RC slab of the same depth and material properties. Concrete strength was found to have a limited influence on the residual axial capacity of blast-damaged columns while the longitudinal reinforcement ratio and transverse reinforcement spacing improved the residual axial capacity.
\end{abstract}

Keywords: Contact explosion, FSI, Blast response, RC columns, Detonation, LSDYNA

\subsection{Introduction}

Critical infrastructures such as major bridges, petrochemical refineries, thermal or

Submitted to the Structures and Building Journal of Institution of Civil Engineers (ICE), UK in a revised form.

Authors - Dua, Alok; Braimah, Abass; Kumar, Manish 
nuclear power plants, stock exchanges, military or political headquarters, and iconic monuments have been the targets for terrorist attacks in the past. The Bombay Stock Exchange (BSE) and the Air India building in India were the prime targets during the series of 12 bomb explosions in Mumbai in 1993. The series of bombings led to 257 deaths and 713 injuries. The damage to internal columns due to the blast effects led to the partial collapse of concrete floor slabs in the BSE and Air India Building. In an earlier attack on the World Trade Centre, New York, in 1993, an explosive-laden truck was detonated in the underground parking targeting the columns. However, the column's resistance to the induced blast loads prevented collapse (Bažant \& Zhou, 2002). The 1995 attack on Alfred P. Murrah building also targeted critical load-bearing columns and resulted in the partial collapse of the building. Detonation of $4000 \mathrm{lbs}$. (1818 kg) Trinitrotoluene (TNT)equivalent explosive in a cargo truck parked near the building led to shear failure of two load-bearing exterior columns. The lack of capacity of the remaining structural members, to resist the increased loading, led to the progressive collapse of a large part of the building. The incident resulted in 268 fatalities and severe damage to nearby buildings which were later demolished (Mlakar et al., 1998; Tagel-Din \& Rahman, 2006). In 2006 a series of seven bombings took place on Mumbai local trains. The explosives were placed in pressure cookers to enhance the effects by prolonging the blast wave duration and peak pressures by the confinement. The attack led to 209 deaths and 500 injuries. On October 14, 2017, more than 500 people were killed in Mogadishu due to a massive truck bomb with an explosive yield of $600-800 \mathrm{~kg}$ TNT. The blast loads from the explosion induced 
failure in critical columns leading to the complete collapse of several buildings. In addition to the terrorist attacks, there are also instances of security forces targeting critical columns with precision to induce the complete collapse of terrorist hideout buildings without collateral damage (Tait, 2014).

These past attacks show that terrorist threats to critical infrastructure are evolving and need an equally evolved and developed protective design capability. Additionally, there is an ever more stringent control over explosives and other energetic materials required for large-scale bombings. The threat perception of critical reinforced concrete $(\mathrm{RC})$ columns subjected to contact explosion of small charge weight explosives is a viable possibility. A strategically planned contact explosion on a critical RC column can render the column with zero residual load carrying capacity leading to partial or a complete collapse of the building.

Currently, studies on the response of RC members subjected to contact explosions are limited to numerical analyses and data from experimental work is scarce. Access to experimental facilities for live explosion testing is limited to a select few government organizations and research institutions. Additionally, the data acquisition systems for contact explosion events is not well established.

A contact explosion event yields high-temperature fireball and extreme pressure on the target and hence most instrumentation does not survive in this environment. This makes it is difficult to acquire experimental data such as pressure and shock wave properties. The lack of quantitative experimental data for validation of 
numerical models impedes research on the response of RC members subjected to contact explosion. The meager data available is limited to qualitative validation via comparison of damage profiles, accelerometer readings away from the center of the explosion, and blast pressure time histories in the far-field distances.

The experimental data from studies on RC slabs cannot be extended to RC columns due to its distinct failure mechanism. The response of RC slab subjected to contact explosion can be approximated as a one-dimensional (1-D) stress propagation phenomenon and is influenced by limited parameters like charge mass to slab thickness ratio, the compressive strength of concrete and yield strength and detailing (ratio and spacing) of the reinforcement. On the other hand, the response of RC columns subjected to contact explosion can be approximated as a two-dimensional (2-D) stress propagation phenomenon and is influenced by additional parameters like the aspect ratio of the column cross-section, axial load ratio, infill boundary condition, area and spacing of longitudinal and transverse reinforcement etc. The response of RC columns is hence complex to predict and remains a field of continuing research.

\subsection{Literature Review}

\subsubsection{Past Studies on Contact Explosion Events}

The blast loading response of structural elements subjected to contact and far-field explosion effects differ significantly (Dua \& Braimah, 2016). A contact explosion yields spatially and temporally non-uniform loading that predominantly results in a 
local shear response, while a far-field explosion yields a uniform loading on the structure causing a global flexural response. The material response to contact explosion is highly non-linear and often leads to plastic deformations (crushing and spalling). As a result, the empirical methods applicable to far-field blast response analysis cannot be extended to contact explosion events. Limited studies are available in the literature to predict the response of RC members subjected to contact explosions.

Prior to Williamson et al. (2009), no experimental data existed in the public domain documenting the response of RC concrete columns subjected to near-field and near-contact explosions. Williamson et al. (2009) documented the response of RC bridge columns of varied cross-sections due to explosions at far-field, near-field distances and in contact. Numerical modeling guidelines for LS-DYNA were presented and code-ready blast load prediction on RC concrete bridge columns was presented which correlated well with the experimental observations (Williams, 2009). The authors also reported that the side face spalling in RC columns subjected to contact explosion is attributed to the Poisson's effect. The compressive stress due to a contact explosion causes expansion of the column core perpendicular to the direction of loading and it occurs early in the loading duration, before the global response of the column.

DoA (2007) proposed an empirical relation (Equation 4-1) for calculating the breaching charge mass required for demolition of RC members like bridge pier, bridge abutments, and field fortifications. 


$$
W=R^{3} K C
$$

where $W$ is the TNT charge weight in pounds, $R$ is the required breach radius in feet, $K$ is the material factor and $C$ is the placement factor. Equation $4-1$ is based on field trials, details of which are not provided in the manual. Factors like concrete strength, transverse and longitudinal reinforcement ratio are not accounted for explicitly in Equation 4-1. In case of a $300 \times 300 \mathrm{~mm}$ cross-section RC column subjected to contact explosion of TNT charge, emplaced on the ground without tamping, the values for $K$ and $C$ are 1.76 and 3.6 respectively (Figure $4-1$ ). This yields a demolition charge mass of $2.9 \mathrm{~kg}$ TNT. This charge mass is close to the breaching charge mass for a $300 \mathrm{~mm}$ thick RC slab (Dua \& Braimah, 2018b), however, it will be shown later in the chapter that a mere $500 \mathrm{~g}$ TNT charge can crush the concrete core of $300 \times 300 \mathrm{~mm}$ cross-section.

\begin{tabular}{|c|c|c|}
\hline Material & $\mathbf{R}$ & $\mathrm{K}$ \\
\hline Earth & All values & 0.07 \\
\hline $\begin{array}{l}\text { Poor Masonry, } \\
\text { Shale, Hardpan, } \\
\text { Good timber, } \\
\text { Earth construction }\end{array}$ & $\begin{array}{l}\text { Less than } 1.5 \mathrm{~m}(5 \mathrm{ft}) \\
1.5 \mathrm{~m}(5 \mathrm{ft}) \text { or more }\end{array}$ & $\begin{array}{l}0.32 \\
0.29\end{array}$ \\
\hline $\begin{array}{c}\text { Good Masonry, } \\
\text { Concrete block, } \\
\text { Rock }\end{array}$ & $\begin{array}{c}0.3 \mathrm{~m}(1 \mathrm{ft}) \text { or less } \\
\text { Over } 0.3 \mathrm{~m}(1 \mathrm{ft}) \text { to less than } 0.9 \mathrm{~m}(3 \mathrm{ft}) \\
0.9 \mathrm{~m}(3 \mathrm{ft}) \text { to } 1.5 \mathrm{~m}(5 \mathrm{ft}) \\
1.5 \mathrm{~m}(5 \mathrm{ft}) \text { to less than } 2.1 \mathrm{~m}(7 \mathrm{ft}) \\
2.1 \mathrm{~m}(7 \mathrm{ft}) \text { or more }\end{array}$ & $\begin{array}{l}0.88 \\
0.48 \\
0.40 \\
0.32 \\
0.27\end{array}$ \\
\hline $\begin{array}{c}\text { Dense concrete, } \\
\text { First-class } \\
\text { masonry }\end{array}$ & $\begin{array}{c}0.3 \mathrm{~m}(1 \mathrm{ft}) \text { or less } \\
\text { Over } 0.3 \mathrm{~m}(1 \mathrm{ft}) \text { to less than } 0.9 \mathrm{~m}(3 \mathrm{ft}) \\
0.9 \mathrm{~m}(3 \mathrm{ft}) \text { to } 1.5 \mathrm{~m}(5 \mathrm{ft}) \\
1.5 \mathrm{~m}(5 \mathrm{ft}) \text { to less than } 2.1 \mathrm{~m}(7 \mathrm{ft}) \\
2.1 \mathrm{~m}(7 \mathrm{ft}) \text { or more }\end{array}$ & $\begin{array}{l}1.14 \\
0.62 \\
0.52 \\
0.41 \\
0.35\end{array}$ \\
\hline $\begin{array}{c}\text { Reinforced } \\
\text { Concrete (factor } \\
\text { does not consider } \\
\text { cutting steel) }\end{array}$ & $\begin{array}{c}0.3 \mathrm{~m}(1 \mathrm{ft}) \text { or less } \\
\text { Over } 0.3 \mathrm{~m}(1 \mathrm{ft}) \text { to less than } 0.9 \mathrm{~m}(3 \mathrm{ft}) \\
0.9 \mathrm{~m}(3 \mathrm{fto} 1.5 \mathrm{~m}(5 \mathrm{ft}) \\
1.5 \mathrm{~m}(5 \mathrm{ft}) \text { to less than } 2.1 \mathrm{~m}(7 \mathrm{ft}) \\
2.1 \mathrm{~m}(7 \mathrm{ft}) \text { or more }\end{array}$ & $\begin{array}{l}1.76 \\
0.96 \\
0.80 \\
0.63 \\
0.54\end{array}$ \\
\hline
\end{tabular}

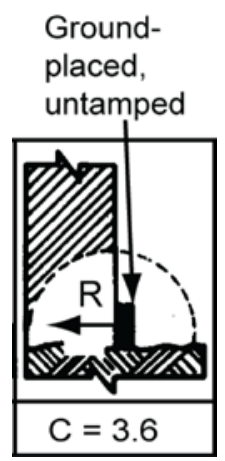

Figure 4-1: (a) Material factor for breaching charges (b) Placement factor for ground placed charge (DoA, 2007) 
In blast-resistant design practice, it is often assumed that the column failure is due to transverse loading rather than the axial load and hence the axial load effects are ignored in all the studies found in the literature pertaining to the response of RC columns subjected to contact explosion effects. Krauthammer et al. (2013) however, reported that axial load can have a significant effect on the overall response of RC columns subjected to blast loading. The authors conducted a single degree of freedom (SDOF) analysis and reported that the response of RC columns to blast loading both in the quasi-static and impulsive regime is affected by the axial load supported by the RC column. The flexural strength of the column improved with higher axial load up to the balanced eccentricity which signifies the maximum axial load and moment capacity of the column. Beyond the balanced eccentricity of the column, the flexural strength starts to reduce when subjected to blast loads as the failure mode shifts from ductile tension failure to brittle compression failure. On the other hand, an axial load of less than $50 \%$ of the balanced axial load significantly reduced the ability to withstand impulsive loading (Krauthammer et al., 2013).

Wu et al. (2011b) and Wu et al. (2011a) presented experimentally validated empirical relations for residual axial compression capacity of localized blastdamaged RC columns and steel composite RC columns. The authors defined a term 'explosive mass ratio' that represents the ratio of explosive charge mass to the mass of 1-m high column, to carry out the parametric analysis in their study. They reported that an explosive mass ratio of 0.04 yielded $60 \%$ residual capacity after a contact explosion located at the bottom of the column as compared to $90 \%$ 
residual capacity due to a contact explosion from the same mass of explosive at a height of $1.5 \mathrm{~m}$. Parametric analysis for effect of column height was presented and it was concluded that column height does not have any effect on the residual capacity of blast-damaged columns. An element size of 50-mm was used to model the column as well as the Arbitrary Lagrangian-Eulerian (ALE) domains.

Contact explosion events have been numerically simulated by numerous authors. The Multi-Material Arbitrary Lagrangian-Eulerian (MMALE) formulation has been reported to be an appropriate method for modeling explosive detonation and blast wave propagation. However, its main disadvantage of mesh dependency can prove computationally expensive (Hanssen et al., 2004; Børvik et al., 2009; Kakogiannis et al., 2010). The accuracy of the numerical results is highly sensitive to the mesh properties and can lead to large differences in the results. Zukas and Scheffler (2000) reported that numerical results of a problem provided by four experienced LS-DYNA users varied by as much as $80 \%$ due to different mesh properties. In particular, the mesh dependency is directly related to the computational requirement for simulating a near-field or contact explosion. Hence, mesh sensitivity analysis is important for such studies in order to produce accurate results from a computationally cost-effective model.

Trajkovski et al. (2014) presented a mesh sensitivity study in three-dimensions (3D) for determining the incident and reflected blast parameters from a TNT explosion. The incident and reflected blast parameters from the different mesh sizes and were compared to results reported by Hyde (1988) and DoD (2008). 
Trajkovski et al. (2014) reported that reasonably accurate blast parameters can be achieved by using 10 elements across the charge radius if the distance between the charge and the Lagrangian part is four times or more than the charge radius.

Cui et al. (2015) presented numerical results for the response of RC columns subjected to close-in explosions. Far-field explosion yields flexural response associated with cover spalling, as in most cases, the shear capacity exceeds the shear demand from the loading. A damage criterion defined as the ratio of the depth of column and relative residual deflection was used to perform a parametric analysis. It was reported that a larger cross-section, higher transverse reinforcement ratio and thinner cover improved the blast response of the columns by reducing the depth of concrete spalling.

Yuan et al. (2017) presented a study on the response of RC bridge columns subjected to contact explosion. Experimental tests were conducted on the square and circular cross-section columns subjected to the detonation of $1 \mathrm{~kg}$ of TNT in contact. The column axial compression from imposed loads was not considered for the experimental tests. LS-DYNA numerical models were presented and reported to predict the tests well except for the back-face damage. The damage profiles of experimental and numerical results were compared for qualitative validation while accelerometer data were compared for quantitative validation. 


\subsubsection{Numerical Modeling}

There are three prevalent techniques used for blast analysis of structures: (a) Simplified analytical methods such as Pressure-Impulse (PI) charts, single degree of freedom (SDOF) or multi-degree of freedom (MDOF) dynamic analysis using blast load parameters generated from empirical charts provided by Kingery and Bulmash (1984), DoD (1987), DoD (2008) or other such codes, (b) Non-linear finite element analysis implementing blast load parameters generated from underlying empirical equations and charts by Kingery and Bulmash (1984), DoD (1987), DoD (2008) and (c) high fidelity finite element analysis programs with explicit modeling of the detonation process, blast wave propagation and fluid-structure-interaction (FSI). While the first two methods can accurately predict far-field blast response (Cormie et al., 2014a; Braimah et al., 2015), contact explosion effects can only be accurately modeled with MMALE formulation as it provides a complete description

of the blast wave parameters (Børvik et al., 2009; Trajkovski et al., 2014). The technique involves modeling the chemical reaction during detonation and consequent blast wave propagation. However, the primary disadvantage of modeling detonation and blast wave propagation is the mesh dependence (Kakogiannis et al., 2010) and hence a higher computational cost due to a fine mesh requirement. Kalra et al. (2014) presented a 2D to 3D MMALE mapping technique in LS-DYNA for reducing the computational cost. The explosive detonation and blast wave propagation were simulated in the 2D domain and mapped to a 3D domain to implement the FSI between the generated blast wave and the Lagrangian entity. This technique, however, cannot be implemented for 
modeling contact explosions as the explosive detonation and FSI occur simultaneously. Simulating detonation and FSI in 2D will not represent the phenomenon as the blast wave is spatially and temporally non-linear around the explosive. Moreover, the spatially non-linear Lagrangian response in 3D will not be captured with the $2 \mathrm{D}$ model. Hence, a finely meshed $3 \mathrm{D}$ domain is required to accurately model the detonation process and the Lagrangian response during a contact explosion event.

The finely meshed 3D air domain must be modeled large enough to avoid reflection of the blast wave from the air domain boundary during the whole event. This results in a large memory prerequisite. Lately, massive parallel processing (MPP) abilities have been introduced by LS-DYNA that allow parallel processing and availability of large memory resources. However, these resources are difficult to access.

\subsection{Research Significance}

\subsubsection{Gaps in Research Data}

The literature review presented in the preceding section suggests a paucity of experimental data pertaining to contact explosion effects on RC columns specifically. Experimental tests reviewed above were conducted on columns without realistic boundary conditions. Williamson et al. (2009) presented experimental tests on full-scale columns, however the specific details of charge mass, cross-sectional details, and reinforcement ratio were not made available in the public domain. Furthermore, it has been reported based on numerical results, 
that contact explosion yields local response. Thus, in cases where the explosive is placed on the ground, many researchers do not provide support at the top of the column. Lastly, no experimental data could be found in the public domain benchmarking the effect of service axial loads on the response of RC columns subjected to contact explosions.

The numerical models reported in the literature model the detonation process and blast propagation with element sizes of $5 \mathrm{~mm}-50 \mathrm{~mm}$ whereas a mesh size of 1 $\mathrm{mm}$ is recommended to accurately simulate detonation process in LS-DYNA (Cormie et al., 2014b; Dua \& Braimah, 2018a). The numerical models were qualitatively validated via damage profiles and accelerometer readings, however, none of the studies have performed quantitative validation of the numerical models without which the validation remains inconclusive. Hence, the empirical relations based on these models for predicting the residual capacity of blast-damaged RC columns may be inaccurate due to the coarse element size and lack of quantitative experimental validation.

\subsubsection{Objectives of the Study}

The objectives of the study presented herein are to:

- Characterize the damage profile on RC columns subjected to the detonation of different TNT explosive charge masses in contact with the column face and placed on the ground. 
- Determine the residual axial load carrying capacities of the blast-damaged columns and to quantify the range of explosive charge mass that can render an $\mathrm{RC}$ column to zero residual axial capacity.

- Establish experimentally validated numerical models to perform parametric analyses to evaluate the effect of different design parameters on the response of RC columns under contact explosion effects.

- Numerically investigate the influence of explosive charge mass, standoff distance, concrete compressive strength and transverse bar spacing on the residual axial load carrying capacity of the blast-damaged RC columns.

\subsection{Experimental Investigation}

The entire experimental program consisted of four phases that investigated the response of RC slabs (Dua \& Braimah, 2018a), bare RC columns (this study), cladded RC columns (Dua et al., 2018b) and RC walls (Dua et al., 2018a). Phase I of the program, presented in Chapter 3 , helped understand the response phenomenon of RC members and gave insight for numerical modeling of contact explosion events. The research study presented in this chapter (benchmark experimental phase) extends the conclusions from Phase I to understand the response of RC columns in order to set up a benchmark which can be further implemented for mitigation strategies. 


\subsubsection{Contact Explosion Test}

Three RC columns were subjected to contact explosion of different charge masses in the benchmark experimental phase. The material properties, cross-sectional details, and reinforcement ratio were the same for all three columns (Figure 4-2). The longitudinal reinforcement ratio was 0.014 while the transverse reinforcement consisted of $10-\mathrm{mm}$ diameter ties at $100 \mathrm{~mm} \mathrm{c} / \mathrm{c}$ as per requirements of the Canadian code for Design of Concrete Structures (CSA, 2004). The test designations are presented in Figure 4-2 (b).

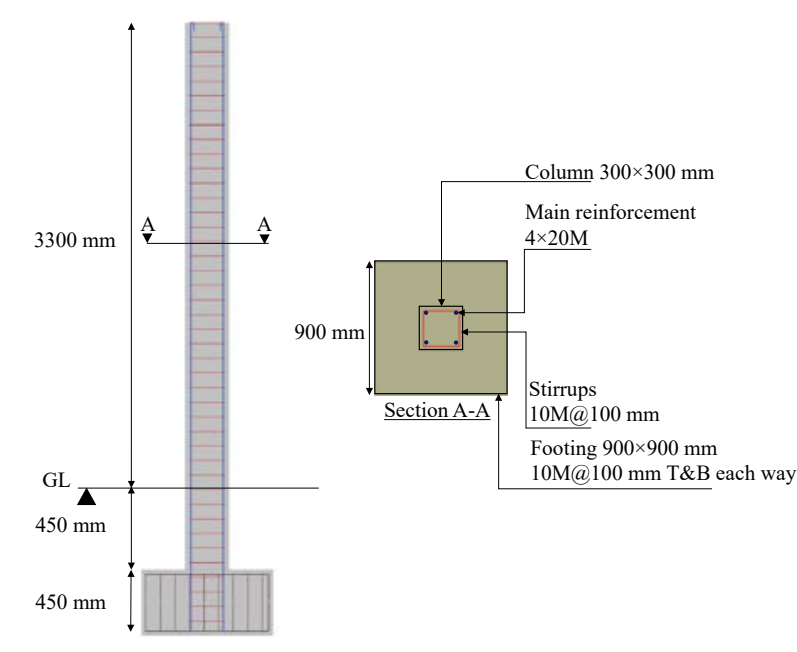

(a)

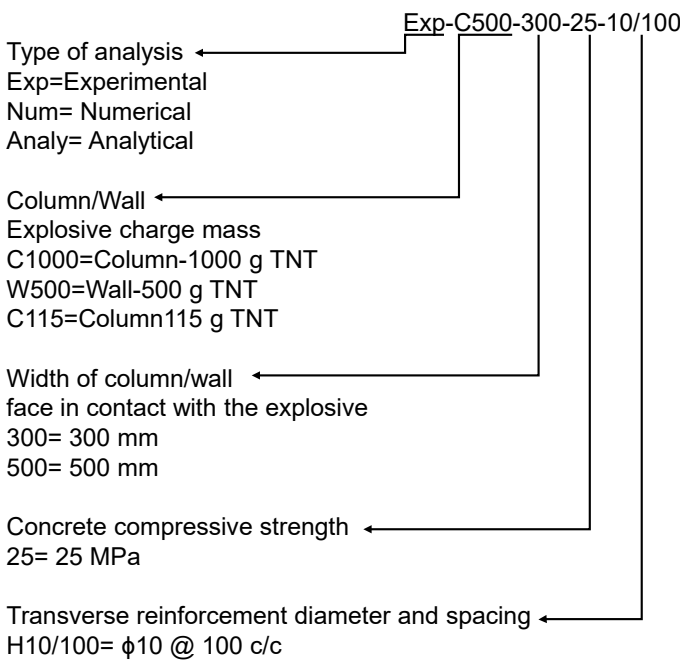

(b)

Figure 4-2: (a) Test column details (b) Test designations

Fixed support condition was provided at the bottom via a pad footing founded at $900 \mathrm{~mm}$ below the ground. The column top was not provided any support during the benchmark contact explosion to simplify the test setup and reduce the experimental cost.

Ready-mix concrete with a 28-day design strength of $30 \mathrm{MPa}, 25 \mathrm{~mm}$ maximum aggregate size and a slump of $125 \mathrm{~mm}$ was used to cast the columns. The 
concrete was poured in two lifts and a pencil vibrator was employed for compaction. The open foundation pit was backfilled with native soil and compacted after wet curing of the concrete.

The achieved concrete compressive strength was determined through compressive testing of three $75-\mathrm{mm}$ diameter cores extracted from the blastdamaged columns. The cores were extracted from the portion of the column outside the blast-damaged region and between the transverse reinforcement. The average compressive strength and density of the concrete were determined as 25 $\mathrm{MPa}$ and $2635 \mathrm{~kg} / \mathrm{m}^{3}$ respectively. The cavities of the cylindrical cores from the RC columns were filled with micro-concrete of $25 \mathrm{MPa}$ compressive strength prior to residual capacity testing on the columns.

Figure 4-3 presents the pre-contact explosion experimental setup for $1000-\mathrm{g}$ and 115-g TNT charge tests. The explosive was placed on the ground in contact with the column face emulating an explosive device placed in a possible terrorist threat scenario. Demolition explosives manufactured for the commercial purpose were used for the tests. The detonation velocity, density, and mass of one slab reported by the manufacturer were $6930 \mathrm{~m} / \mathrm{s}, 1550 \mathrm{~kg} / \mathrm{m}^{3}$ and $500 \mathrm{~g}$ respectively. 


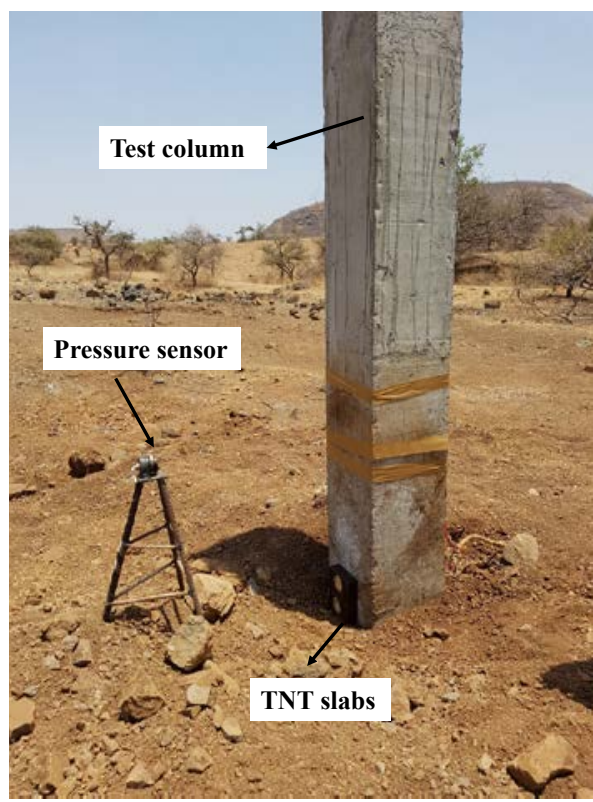

(a)

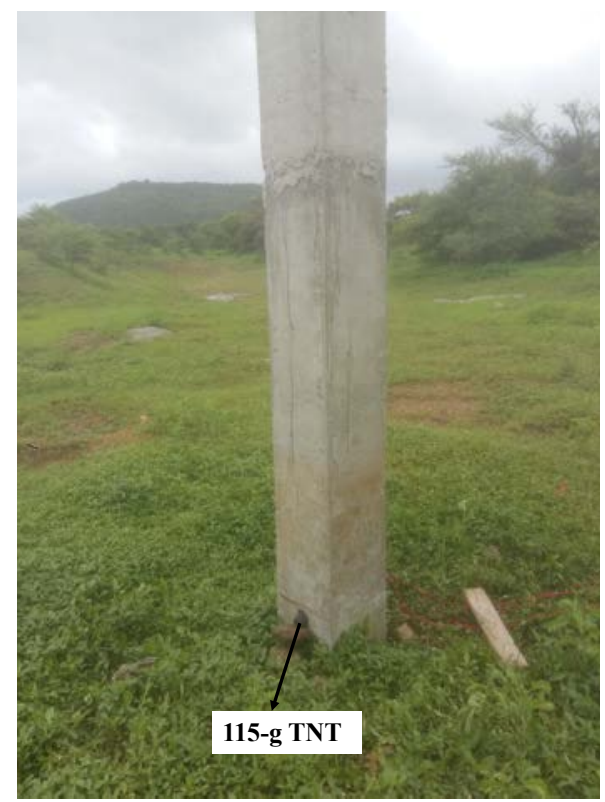

(b)

Figure 4-3: Experimental test setup for (a) 1000-g TNT (b) 115-g TNT equivalent

\subsubsection{Residual Capacity Test}

For comparison with the residual capacity of the blast-damaged column, the nominal axial load resistance $\left(P_{0}\right)$ of the $R C$ column was calculated to be $2431 \mathrm{kN}$ while the factored axial load resistance was $1365 \mathrm{kN}$ (CSA, 2004). The balanced nominal moment capacity and eccentricity of the test column cross-section are 130 $\mathrm{kNm}$ and $163 \mathrm{~mm}$ respectively (Figure 4-4). 


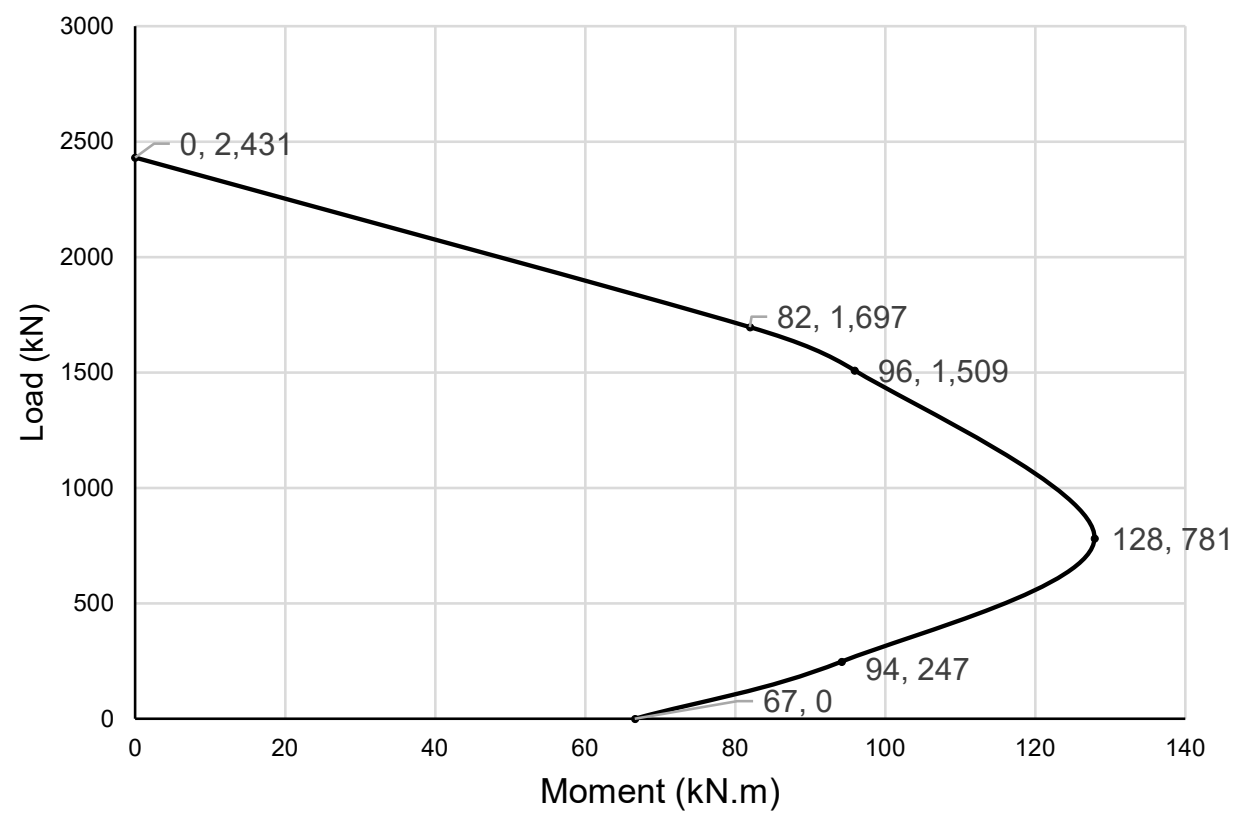

Figure 4-4: Column interaction diagram

The blast-damaged column was extracted and prepared for residual capacity testing to determine the residual axial load capacity $\left(P_{r}\right)$. The extent of damage caused due to contact explosion effects were quantified with the damage index (D), given by Equation 4-2.

$$
D=1-\frac{P_{r}}{P_{o}}
$$

The experimental setup for the residual axial capacity test is presented in Figure 4-5. The blast-damaged columns were axially loaded on a $3000-k N$ capacity reaction frame. An oil-controlled hydraulic jack was fixed on the bottom girder while a load cell was placed between the test column and the top girder. 


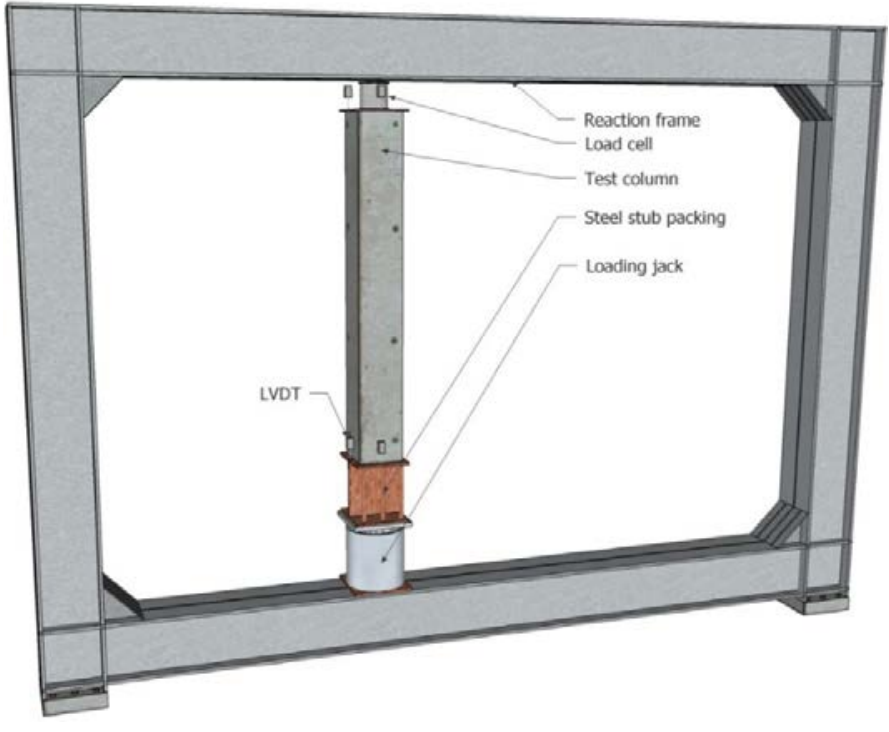

(a)

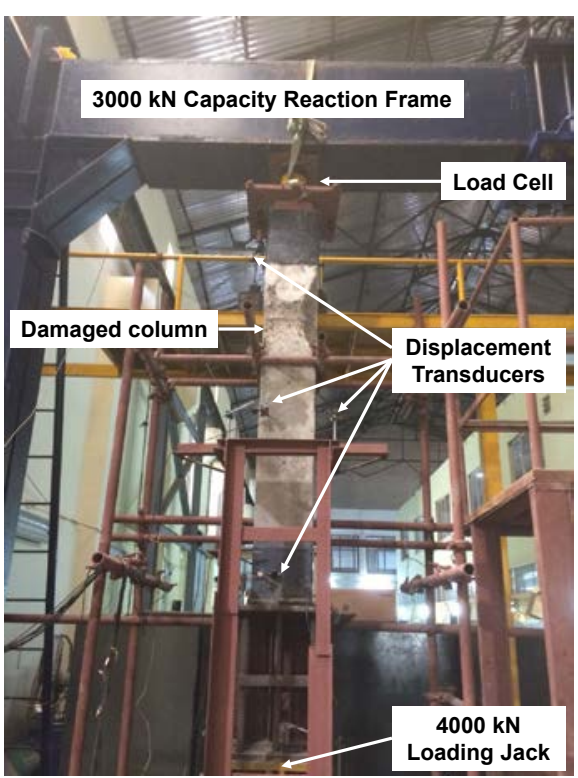

(b)

Figure 4-5: Reaction frame for axial loading of damaged columns

The maximum height of the specimen that could be tested in the test frame was $2500 \mathrm{~mm}$. Hence, concrete wire cutters were used to cut the columns to size. As the blast-damaged columns were tested for residual axial capacity without any eccentricity, the height of the column was not of much significance (Wu et al., 2011b, 2011a). Bearing plates were installed at the top and bottom of the column to transfer the load to the concrete column. The column was wrapped with 300$\mathrm{mm}$ wide carbon fibre-reinforced polymer (CFRP) at both ends to confine the section and allow effective transfer of axial load without premature failure in concrete at the ends, Figure 4-5 (b).

Eight linear variable displacement transducers (LVDT) were installed on an independent support frame to measure column displacements in axial and lateral directions. The column shortening was recorded via two LVDTs placed on the 
loading jack and the load cell. The axial load on the column was measured through the load cell on top of the test column (Figure 4-5).

\subsection{Experimental Results}

\subsubsection{Contact Explosion}

The damage profile of RC columns subjected to contact explosion of varied explosive mass are presented in Figure 4-6. In the case of the column subjected to 1000-g of TNT explosive, the concrete core was crushed, rendering the column with zero residual axial strength (Figure 4-6(a)). The effects of 500-g TNT explosive also crushed the concrete cover and the major portion of the concrete core (Figure 4-6(b)). The column buckled during removal from the soil indicating severe damage to the confined concrete core due to the contact explosion event.

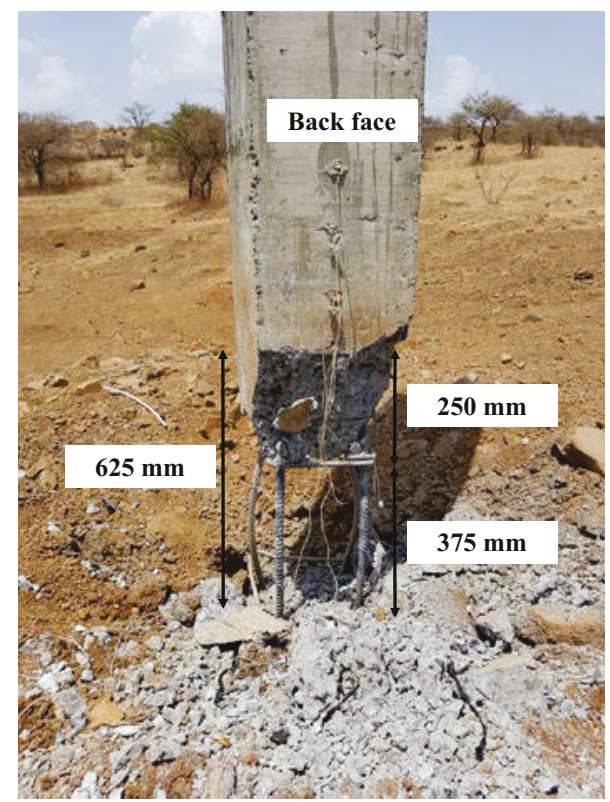

(a)

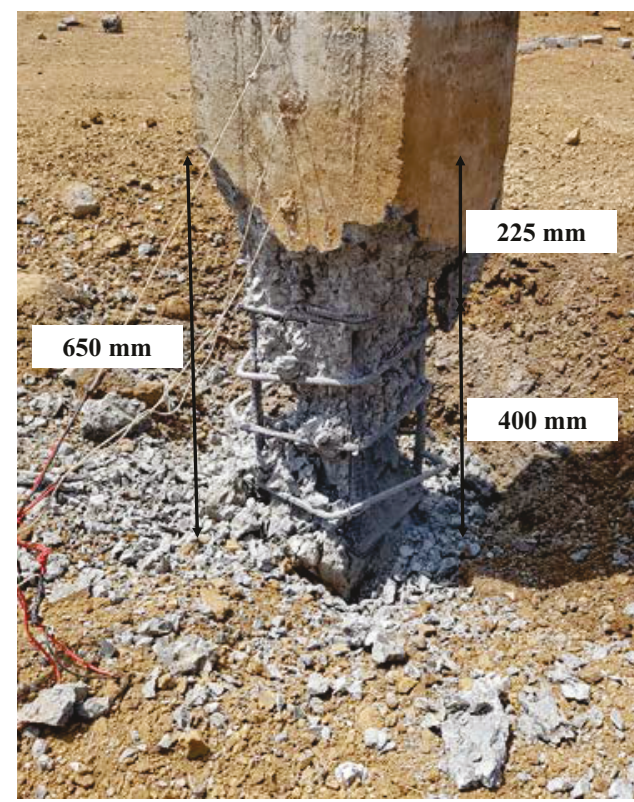

(b) 


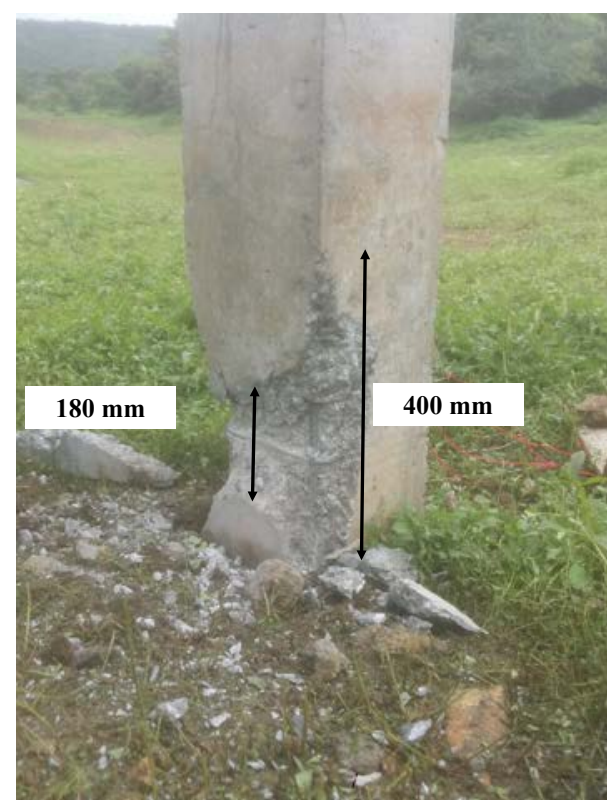

(c)

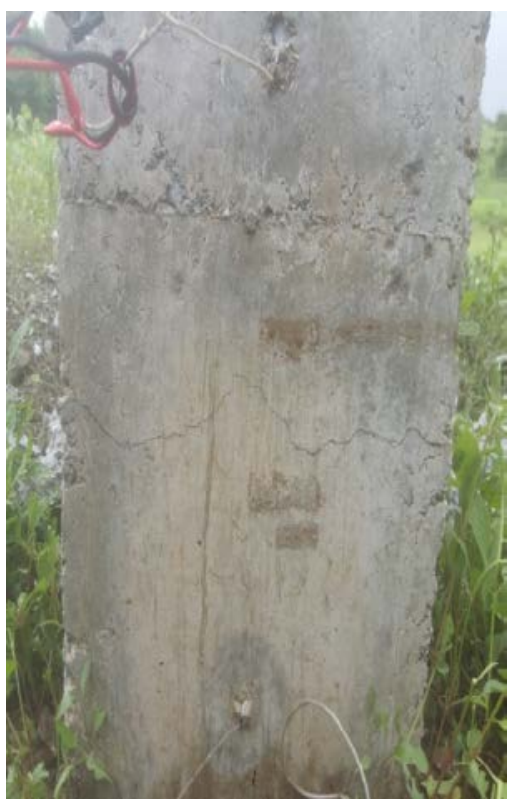

(d)

Figure 4-6: Post blast damage profiles for (a) 1000-g TNT (b) 500-g TNT and 115-g TNT (c) Incident face (d) Distal face

On the other hand, the 115-g TNT equivalent charge caused a cratering with a minimum height of $180 \mathrm{~mm}$ diameter at the point of detonation on the column. The cratering occurred due to the direct impact of the detonation that crushed the concrete around the area of contact. The shock wave imparted to the column reflected from the side faces and resulted in spalling of concrete cover where the tensile strength is least. The concrete spalled up to a height of $400 \mathrm{~mm}$ at the corners of the front face and side faces. Furthermore, the spall region extended into the crater forming a damage profile as seen in Figure 4-6(c). There was no concrete spalling observed on the distal face. However minor cracks were observed (Figure 4-6(d)). This column was extracted and tested under static conditions for residual axial load carrying capacity. 


\subsubsection{Residual Axial Capacity}

The load-displacement curve for blast-damaged column subjected to 115-g TNT explosion in contact is presented in Figure 4-7.

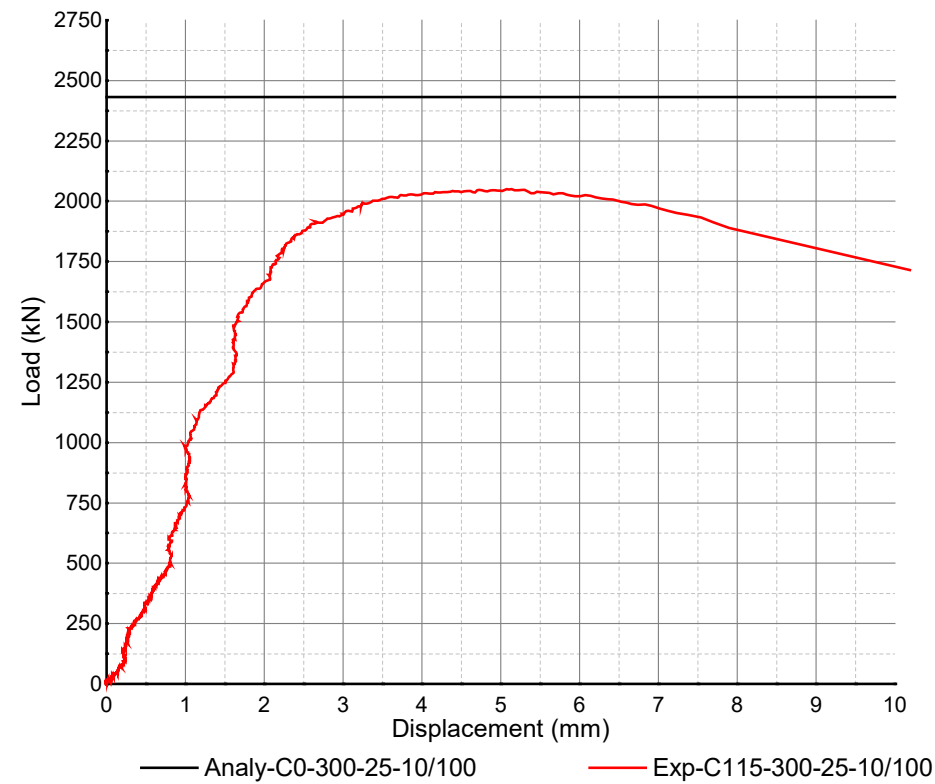

Figure 4-7: Load-Displacement curve for residual axial load carrying capacity test

The nominal axial load carrying capacity of an undamaged column is plotted along with the residual axial load versus displacement response of the blast-damaged column subjected to effects of $115 \mathrm{~g}$ TNT explosion. The blast-damaged column exhibited a peak axial failure load of $2050 \mathrm{kN}$ which is $84 \%$ of the nominal axial load capacity of the undamaged column. The summary of experimental tests is presented as Table 4-1

Table 4-1: Summary of Experimental Tests

\begin{tabular}{|c|c|c|c|}
\hline $\begin{array}{c}\text { Explosive } \\
\text { mass, } \mathrm{g}\end{array}$ & $\begin{array}{c}\text { Analytical axial strength of RC } \\
\text { column, } \mathrm{P}_{\mathrm{o}}(\mathrm{kN})\end{array}$ & $\begin{array}{c}\text { Residual axial strength, } \\
\operatorname{Pr}(\mathrm{kN})\end{array}$ & $\begin{array}{c}\text { Damage } \\
\text { index, } \mathrm{D}\end{array}$ \\
\hline 115 & 2431 & 2050 & 0.16 \\
\hline $500^{*}$ & 2431 & 0 & 1.0 \\
\hline $1000^{*}$ & 2431 & 0 & 1.0 \\
\hline
\end{tabular}

* - column lost core concrete and was not tested. 
The damage profile of the blast-damaged column due to residual axial capacity test is presented in Figure 4-8. A shear failure mode was observed in the column due to concentric axial loading as against the calculated nominal capacity of compression failure of the undamaged column.

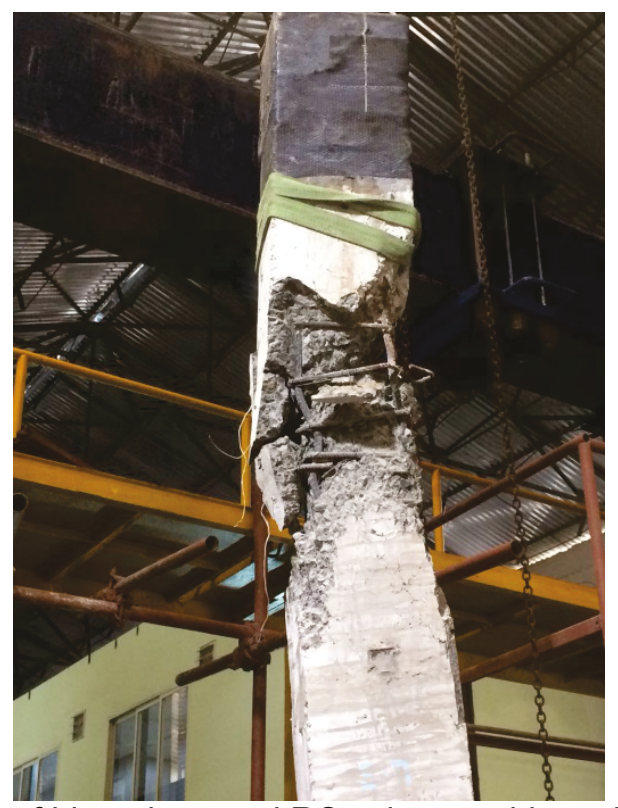

Figure 4-8: Damage profile of blast-damaged RC column subjected to 115-g TNT explosion in contact due to non-eccentric axial loading

\subsection{Numerical Modeling}

\subsubsection{Material Models}

\subsubsection{Concrete}

There are several concrete constitutive material models in LS-DYNA. These constitutive models require an understanding of the heterogeneous material behavior and its response when subjected to high strain rate loading like contact explosions. Mat_72R3 (Karagozian and Case Model), Mat_159 (Continuous Surface Cap Model or CSCM) and Mat_84 (Winfrith model) are a few models that 
allow automatic generation of material parameters from the unconfined compressive strength of concrete. The underlying material parameters in the model are based on experimental tests performed for a wide range of unconfined compressive strengths. Mat_159 was chosen and implemented for modeling concrete, based on the results from a study by Dua and Braimah (2017); Dua et al. (2017). The system of units implemented for numerical modeling was MPa, mm, sec and metric ton $(T)$. The material input parameters in the adopted unit system are presented in Table 4-2.

Table 4-2: Input Parameters for Mat_159

\begin{tabular}{|c|c|c|c|c|}
\hline $\begin{array}{c}\text { Density, } \\
\mathrm{T} / \mathrm{mm}^{3}\end{array}$ & $\begin{array}{c}\text { Unconfined Compressive } \\
\text { Strength (Cylinder), MPa }\end{array}$ & $\begin{array}{c}\text { Aggregate } \\
\text { Size, } \mathrm{mm}\end{array}$ & $\begin{array}{c}\text { Erosion } \\
\text { Criteria }\end{array}$ & $\begin{array}{c}\text { Rate } \\
\text { Effects }\end{array}$ \\
\hline $2.635 \times 10^{-9}$ & 25 & 25 & 2.0 & on \\
\hline
\end{tabular}

\subsubsection{Reinforcement}

The response of $\mathrm{RC}$ members is sensitive to the confinement effects of the transverse reinforcement which is captured by the shear dilation phenomenon. The mat_159 concrete constitutive model can simulate the shear dilation phenomenon if the reinforcement is coupled with the concrete elements. A comprehensive review of various techniques available for modeling reinforcement in $\mathrm{RC}$ members has been presented by Schwer (2014) where the CONSTRAINED_LAGRANGE_IN_SOLID (CLIS) algorithm with constraint type (CTYPE) 2 is recommended for modeling the reinforcement. Recently, an improved version of the CLIS algorithm, CONSTRAINED_BEAM_IN_SOLID (CBIS), was added to LS-DYNA to address the limitations of the CLIS algorithm (L.S.T.C, 2015a). CBIS algorithm was chosen for coupling the reinforcement to 
concrete elements, while the MAT_PIECEWISE_LINEAR_PLASTICITY (Mat_24) constitutive model was adopted for modeling the reinforcement. The input parameters for the constitutive model and CBIS keyword in the adopted unit system are presented in Table 4-3 and Table 4-4 respectively.

Table 4-3: Input Parameters for Mat_24

\begin{tabular}{|c|c|c|c|c|}
\hline $\begin{array}{c}\text { Density, } \\
\mathrm{T} / \mathrm{mm}^{3}\end{array}$ & $\begin{array}{c}\text { Modulus of Elasticity, } \\
\mathrm{MPa}\end{array}$ & $\begin{array}{c}\text { Poisson's } \\
\text { Ratio, }-\end{array}$ & $\begin{array}{c}\text { Yield Strength, } \\
\mathrm{MPa}\end{array}$ & $\begin{array}{c}\text { Tangent Modulus, } \\
\mathrm{MPa}\end{array}$ \\
\hline $7.85 \times 10^{-9}$ & $2 \times 10^{5}$ & 0.3 & 500 & 1600 \\
\hline
\end{tabular}

Table 4-4: Input parameters for CBIS keyword

\begin{tabular}{|c|c|}
\hline No. of coupling points, NCOUP & Coupling Direction, CDIR \\
\hline 10 & 0 (All directions) \\
\hline
\end{tabular}

\subsubsection{Air and TNT}

The MMALE formulation was adopted for modeling the air and explosive domains. MMALE is an extension of the arbitrary Lagrangian-Eulerian (ALE) algorithm used for describing gas flow from explosive detonation. An MMALE element can have several different materials, with tracked material interfaces in one single element. This is considered to be more efficient for modeling gas flows with large gradients as there can be Eulerian elements in the model with both air and detonation products (Zakrisson et al., 2011). MMALE currently remains the most widely used algorithm for blast simulations in both far-field and near-field explosion events (Trajkovski et al., 2014).

In MMALE formulation the air domain is defined as MAT_NULL which allows the equation of state (EOS) to be considered without computing deviatoric stresses (L.S.T.C, 2015b). The linear polynomial EOS (EOS_LINEAR_POLYNOMIAL) 
defines the air domain and permits it to behave like a fluid. The pressure, $\underline{P}$ in an air element is given by Equation 4-3 where $\underline{C_{0}}$ to $\underline{C_{6}}$ are polynomial equation coefficients and $\mu$ is given by $\frac{\rho}{\rho_{0}}-1$ ( $\rho$ is the reference density and $\rho_{0}$ is the current density).

$$
P=C_{0}+C_{1} \mu+C_{2} \mu^{2}+C_{3} \mu^{3}+\left(C_{4}+C_{5} \mu+C_{6} \mu^{2}\right) E
$$

Input parameters for MAT_NULL and EOS_LINEAR_POLYNOMIAL in the adopted unit system are presented in Table 4-5.

Table 4-5: Input Parameters for Air Domain

\begin{tabular}{|c|c|c|c|c|c|c|}
\hline Density, $\mathrm{T} / \mathrm{mm}^{3}$ & $\mathrm{C}_{0}$ & $\mathrm{C}_{1}, \mathrm{C}_{2}, \mathrm{C}_{3}$ and $\mathrm{C}_{6}$ & $\mathrm{C}_{4}$ & $\mathrm{C}_{5}$ & $\mathrm{E}_{0}, \mathrm{MPa}$ & $\mathrm{V}_{0}$ \\
\hline $1.29 \times 10^{-12}$ & $-1 \times 10^{-6}$ & 0 & 0.4 & 0.4 & 0.2531 & 1 \\
\hline
\end{tabular}

The explosive domain can be defined by two techniques: creating a separate part for the explosive or using the INITIAL_VOLUME_FRACTION keyword. The first option requires that all the boundary nodes of the explosive domain be merged with the air domain nodes. On the other hand, with the second option, a defined geometrical shape within the air domain is filled with the explosive material. The second option was adopted for the simulations presented herein.

The explosive material was defined with MAT_HIGH_EXPLOSIVE_BURN which allows the modeling of detonation of a high explosive when defined with an EOS. EOS_JWL was adopted for the detonation modeling which defines the pressure, $p$ as Equation 4-4 where $A, B$ are constants with units of pressure, $E_{0}$ is the 
detonation energy per unit volume, $V_{0}$ is the initial relative volume and $R_{1}, R_{2} \& \omega$ are unitless constants.

$$
p=A\left(1-\frac{\omega}{R_{1} V}\right) e^{-R_{1} V}+A\left(1-\frac{\omega}{R_{2} V}\right) e^{-R_{2} V}+\frac{\omega E}{V}
$$

The input parameters for the above two keywords required to define the explosive domain are presented in Table 4-6.

Table 4-6: Input Parameters for MAT_HIGH_EXPLOSIVE_BURN and EOS_JWL

\begin{tabular}{|c|c|c|c|c|c|c|c|c|c|}
\hline $\begin{array}{c}\text { Density, } \\
\mathrm{T}^{\prime} \mathrm{mm}^{3}\end{array}$ & $\begin{array}{c}\text { Detonation } \\
\text { Velocity, } \\
\mathrm{mm} / \mathrm{s}\end{array}$ & $\begin{array}{c}\text { Chapman- } \\
\text { Jouguet } \\
\text { Pressure, } \mathrm{MPa}\end{array}$ & $\mathrm{A}, \mathrm{MPa}$ & $\begin{array}{c}\mathrm{B}, \\
\mathrm{MPa}\end{array}$ & $\mathrm{R}_{1,-}$ & $\mathrm{R}_{2,-}$ & $\omega_{,-}$ & $\begin{array}{c}\mathrm{E}_{0,} \\
\mathrm{MPa}\end{array}$ & $\mathrm{V}_{0,-}$ \\
\hline $1.55 \times 10^{-9}$ & $6930 \times 10^{3}$ & 21000 & 371200 & 3231 & 4.15 & 0.95 & 0.3 & 7000 & 1 \\
\hline
\end{tabular}

\subsubsection{Soil}

The response of RC column differs in case the explosive is detonated on the ground in contact with the column as opposed to it being detonated at the middle of the column (Wu et al., 2011b, 2011a). The soil domain was created to capture the reflection of the blast wave from the ground as was the case in the experimental program. MAT_MOHR_COULOMB material model was adopted for defining the soil around the column. This constitutive model is for solid elements only, intended to represent sandy and granular soils. The input parameters for the model are presented in Table 4-7.

Table 4-7: Input Parameters for MAT_MOHR_COULOMB

\begin{tabular}{|c|c|c|c|c|}
\hline Density, $\mathrm{T} / \mathrm{mm}^{3}$ & $\mathrm{G}_{\text {mod, }}-$ & $\mathrm{V},-$ & $\Phi,-$ & Cohesion, - \\
\hline $1.55 \times 10^{-9}$ & 0.222 & 0.35 & 0.0873 & 0.139 \\
\hline
\end{tabular}

\subsubsection{Strain-Rate Effects}

It is an established fact that concrete exhibits strain-rate dependency. It fails at a higher compressive/tensile load when subjected to a high strain-rate loading 
compared to its established 28-day strength. In analytical methods, the strength increase is incorporated with a dynamic increase factor (DIF) (Telford, 1993); defined as the ratio of dynamic to static failure load. The DIF can be adopted in simple input constitutive models like Mat_72R3 and Mat_159. Murray (2007) presented the DIF specifications for Mat_159 and they are reported to provide a good fit to strain-rate effects both in tension and compression. The strain-rate effects can be activated through the IRATE parameter on the Mat_159 keyword.

Two simulations emulating the experimental test of $R C$ column subjected to $115-\mathrm{g}$ TNT were run to investigate the influence of strain-rate effects. An error of $42 \%$ with respect to the experimental results was observed when predicting the residual axial capacity of the blast-damaged column without strain-rate effects. The numerical results with strain-rate effects compared well with the experimental results Consequentially, the strain-rate effects were activated for the numerical modeling.

\subsubsection{Mesh size, FSI and Reinforcement contact}

The numerical models presented are half symmetric with appropriate boundary conditions applied to the axis of symmetry. The first chained simulation was initialized with 1-mm element size air domain while the Lagrangian entities of RC column and soil were modeled with $10-\mathrm{mm}$ and $5-\mathrm{mm}$ sized solid elements respectively. The FSI between the detonation products and Lagrangian entities

was implemented by the CLIS keyword with CTYPE 5. L.S.T.C (2015a) recommends a smaller element size for the Lagrangian entities being coupled in 
an FSI problem as compared to the element size of the ALE domain. Alternatively, a larger NQUAD value is recommended. CLIS is a penalty-based algorithm and hence the mesh densities of the interacting domains play an important role in preventing leakage of detonation products into the Lagrangian entities. In case tighter controls are implemented to prevent leakage, the computational demand is higher, and the detonation products may reflect due to higher penalty forces. Additionally, the correct NQUAD settings vary with material and relative mesh density. Essentially, selecting the NQUAD is based on experience and experimental validation. The CLIS parameters implemented for 1-mm and 5-mm element size mesh in this study are presented in Table 4-8. The geometric numerical model for the second simulation is presented in Figure 4-9.

Table 4-8: CLIS parameters for Concrete and Soil

\begin{tabular}{|c|c|c|c|c|c|c|c|c|c|c|}
\hline \multirow{2}{*}{ Entity } & \multicolumn{2}{|c|}{ NQUAD } & CTYPE & \multirow{2}{*}{ DIREC } & \multicolumn{2}{|c|}{ PFAC } & ILEAK & \multicolumn{2}{|c|}{ PLEAK } & PFACMM \\
\cline { 2 - 6 } & $\begin{array}{c}1- \\
\mathrm{mm}\end{array}$ & $\begin{array}{c}5- \\
\mathrm{mm}\end{array}$ & & & $\begin{array}{c}1- \\
\mathrm{mm}\end{array}$ & $\begin{array}{c}5- \\
\mathrm{mm}\end{array}$ & & $\begin{array}{c}1- \\
\mathrm{mm}\end{array}$ & $\begin{array}{c}5- \\
\mathrm{mm}\end{array}$ & \\
\hline $\begin{array}{c}\text { RC } \\
\text { column }\end{array}$ & 10 & 10 & 5 & 3 & 5 & 5 & 2 & 5 & 5 & 3 \\
\hline Soil & 26 & 10 & 5 & 3 & 1500 & 150 & 2 & 1500 & 150 & 3 \\
\hline
\end{tabular}

CONTACT_AUTOMATIC_GENERAL (CAG) was adopted for modeling the contact between the longitudinal reinforcement and transverse reinforcement and CONTACT_ERODING_SURFACE_TO_SURFACE (CESS) was implemented for contact between the soil and the RC column. 


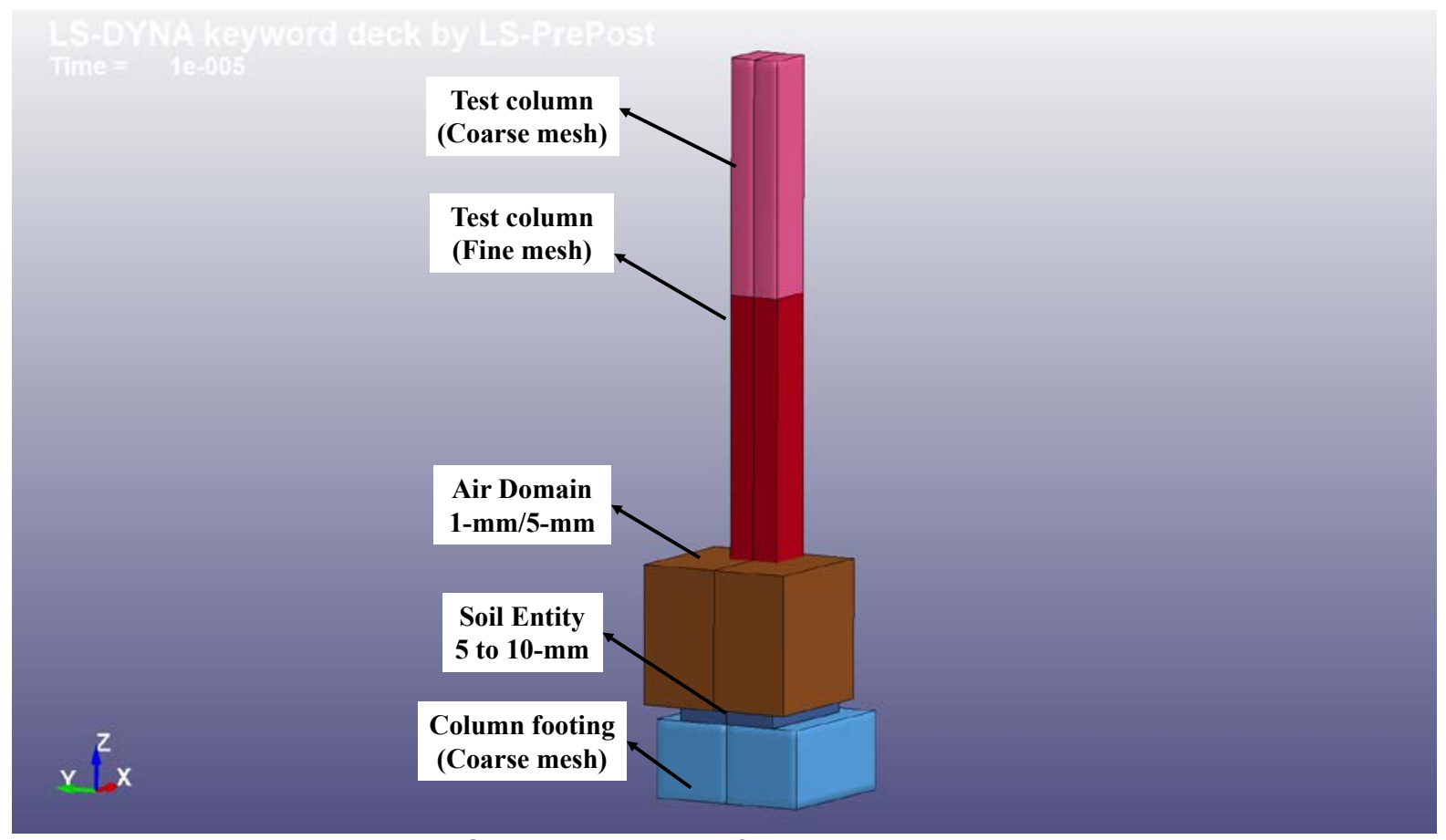

Figure 4-9: Geometrical model for multistage simulations

A penalty-based contact was used in CAG and a segment-based contact was implemented for the CESS keyword.

\subsubsection{Mesh Sensitivity Analysis}

\subsubsection{ALE Domain}

A mesh sensitivity analysis was performed prior to the numerical simulation of the experimental tests. The mesh sensitivity simulations were validated with experimental results presented by Rigby et al. (2015). The normal and radial reflected blast parameters acquired via split Hopkinson's pressure bars (SHPB) were reported at a close-in scaled distance of $0.15 \mathrm{~m} / \mathrm{kg}^{1 / 3}$. Quarter symmetric models of the experimental setup were implemented with varying element size (2 $\mathrm{mm}-0.75 \mathrm{~mm}$ ) for the air domain, Figure $4-10(\mathrm{a}) \&(\mathrm{~b})$. The generated time histories for reflected blast parameters at $0.15 \mathrm{~m} / \mathrm{kg}^{1 / 3}$ scaled distance were plotted 
together with the upper and lower bound results from the six tests reported by

Rigby et al. (2015) and are presented as Figure 4-10 (c) \& (d).

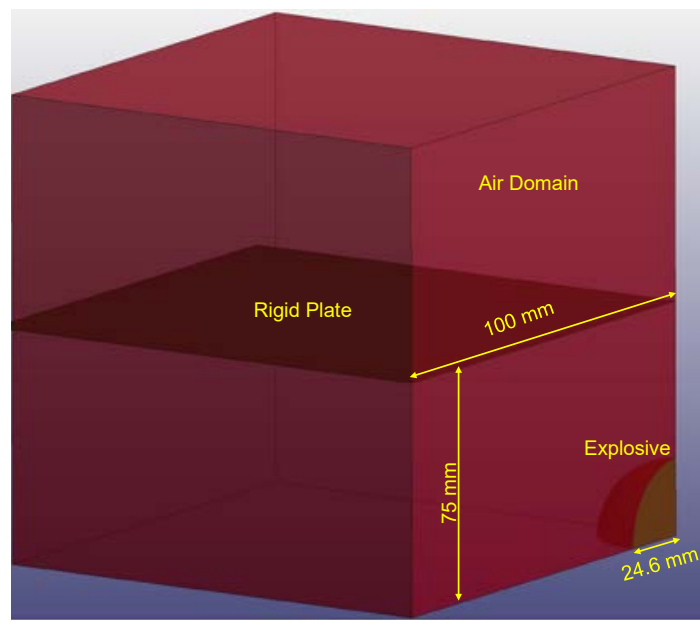

(a)

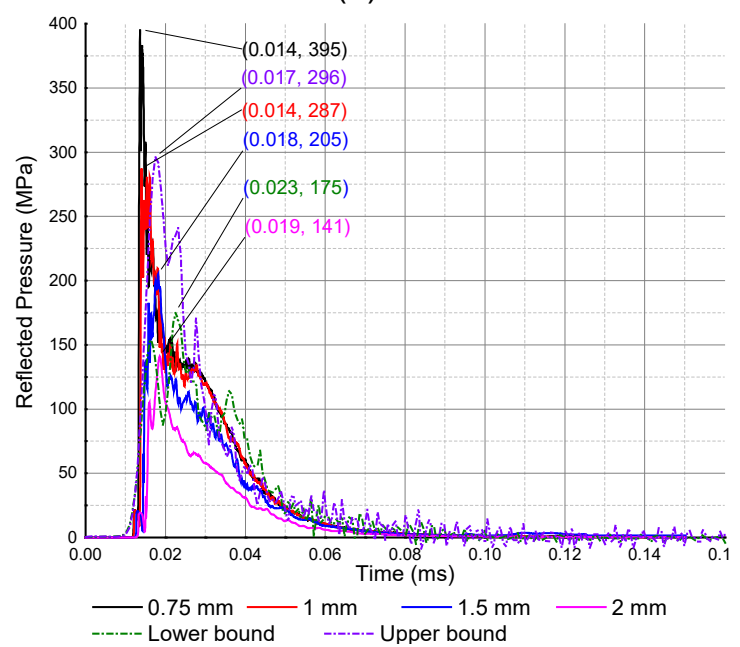

(c)

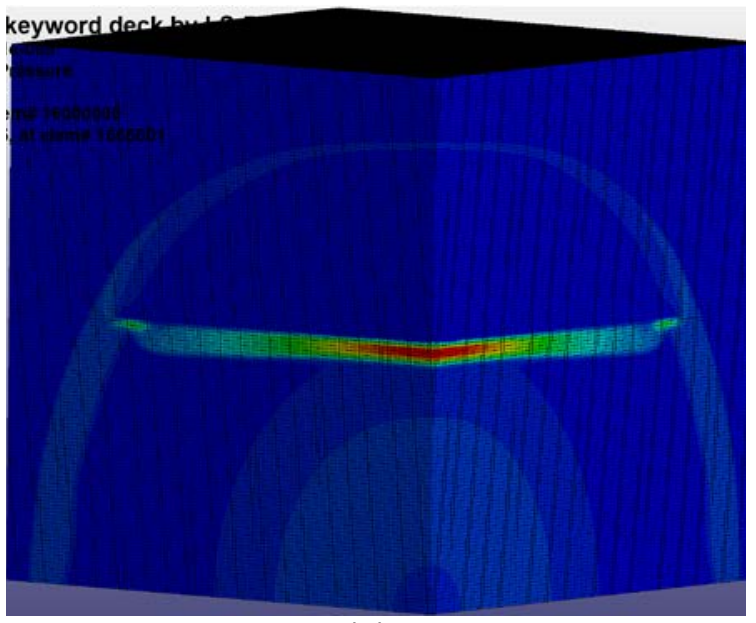

(b)

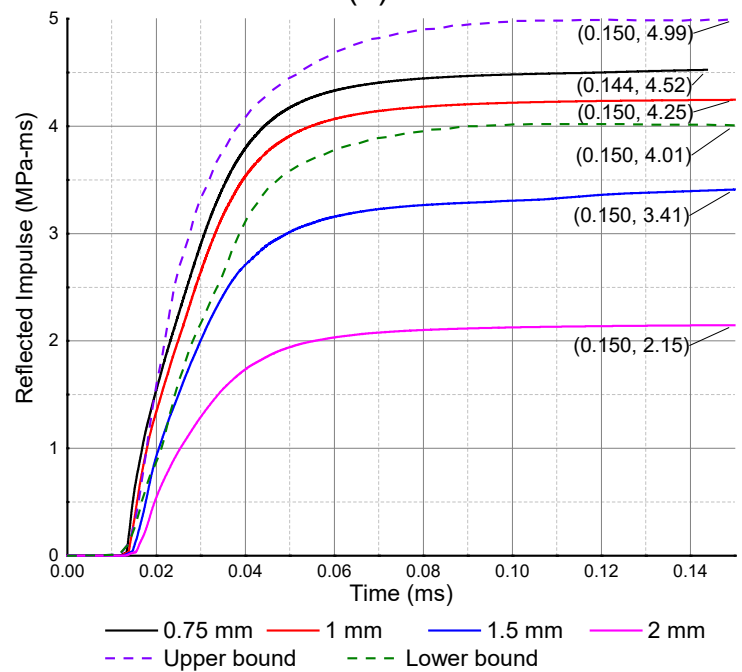

(d) 


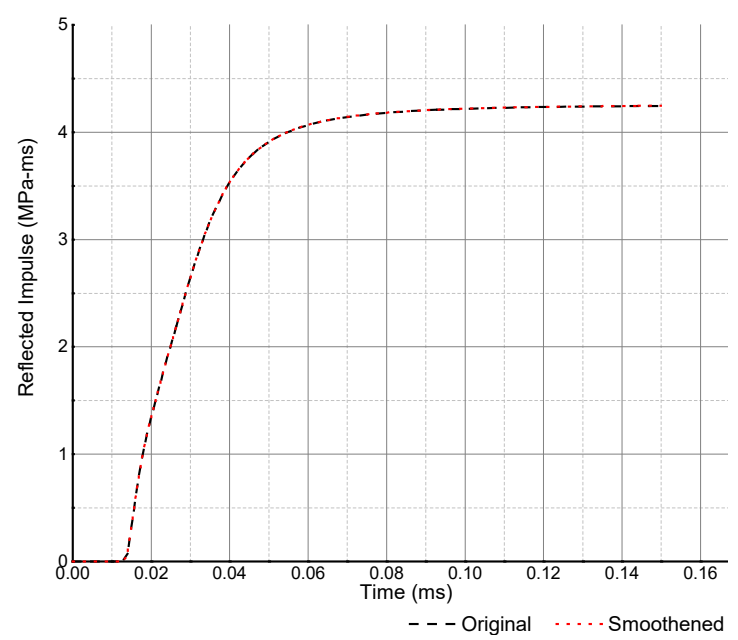

(e)

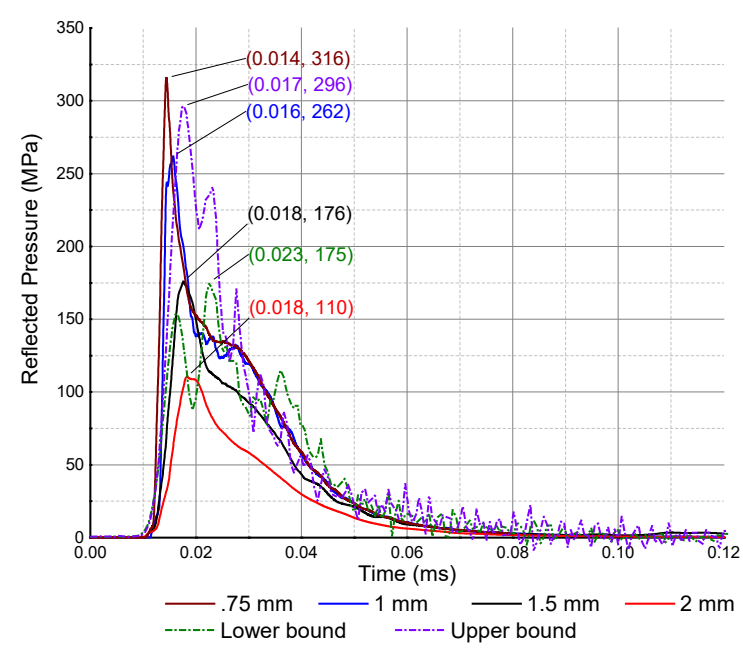

$(\mathrm{f})$

Figure 4-10: (a) Quarter symmetric model (b) Pressure fringe plot (1-mm); Time-histories for reflected (c) pressure (d) impulse (e) impulse after smoothening (f) pressure after smoothening

The numerically predicted impulse values converged at $1 \mathrm{~mm}$ size element mesh as there was negligible change in the impulse with a $0.75 \mathrm{~mm}$ element size mesh. The reflected impulse for $0.75 \mathrm{~mm}$ and $1 \mathrm{~mm}$ size element mesh predicted numerically were within the experimental upper and lower bounds, while $1.5 \mathrm{~mm}$ and $2 \mathrm{~mm}$ size mesh predicted the impulse outside this range. This is in agreement with the results reported by Rigby et al. (2014); Clarke et al. (2015); Rigby et al. (2015). The oscillating peaks in the pressure time-history predicted numerically are due to the shocked air trapped between the expanding detonation products and the target. These oscillatory peaks do not represent the true peak overpressure due to the explosion (Rigby et al. (2014); Clarke et al. (2015); Rigby et al. (2015)). To ascertain the mesh convergence, these oscillations were smoothened by the adjacent-average method. There was no change in the impulse time-history due to this smoothening (Figure 4-10(e)). The peak-overpressure converged for a 1$\mathrm{mm}$ element size mesh and was within the experimental bounds (Figure 4-10(f)). 
As presented in Table 4-9, the peak impulse is highly sensitive to the air domain element size. The peak reflected impulse converged with 1-mm element size air domain and was also validated from the experimental results. This is in agreement with the results reported by Trajkovski et al. (2014) and Cormie et al. (2014b).

In view of the foregoing results, 1-mm element size was implemented for the air domain and explosive material in order to generate accurate peak impulse value which is critical for modeling near-field or contact explosion events. The system's RAM requirement for simulating the response of a Lagrangian entity with a fine mesh like the ALE domain can be significant (more than 256 GB). Additionally, the time required for running the simulations is also expected to be very long.

Table 4-9: Mesh Sensitivity Analysis for Reflected Pressure and Impulse

\begin{tabular}{|c|c|c|c|c|c|}
\hline Air Mesh & Experimental Range & $0.75 \mathrm{~mm}$ & $1 \mathrm{~mm}$ & $1.5 \mathrm{~mm}$ & $2 \mathrm{~mm}$ \\
\hline Reflected peak pressure (MPa) & $296-175$ & 316 & 262 & 176 & 110 \\
\hline Reflected peak impulse (MPa.ms) & $4.01-4.99$ & 4.52 & 4.25 & 3.41 & 2.15 \\
\hline
\end{tabular}

\subsubsection{Lagrangian Domain}

The $300 \times 300 \mathrm{~mm}$ cross-section RC column subjected to $115 \mathrm{~g}$ TNT was modeled with 2-mm and 10-mm element mesh size. The damage profiles at the last timestep of both simulations are compared to the experimental results in Figure 4-11 to investigate the mesh sensitivity of the Lagrangian domain. The damage profile predicted with 2-mm element mesh correlated well with the experimental results when compared to $10-\mathrm{mm}$ mesh. However, it was computationally expensive. On the other hand, the mesh-size had a negligible effect on the residual axial load carrying capacity of the blast-damaged columns. An exhaustive 
parametric study with 2-mm element size was not found to be computationally cost-effective. The numerical results for the predicted residual axial capacity obtained with $10-\mathrm{mm}$ mesh size presented subsequently show good correlation with the experimental results.

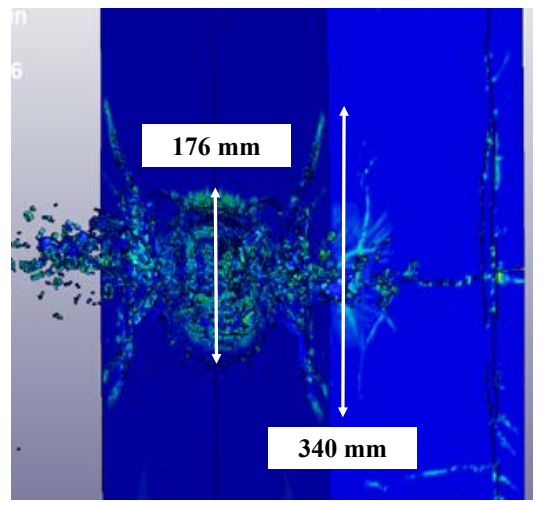

(a)

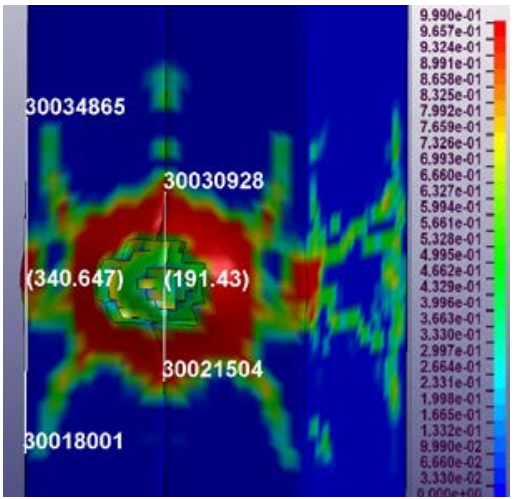

(b)

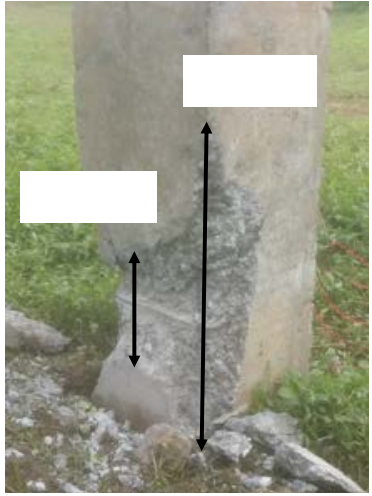

(c)

Figure 4-11: Mesh sensitivity analysis for blast response with (a) 2-mm mesh and (b) 10-mm mesh; (c) Experimental response

The mesh sensitivity analysis was also performed with mesh sizes between 5-20 $\mathrm{mm}$ for the static regime loading of the $\mathrm{RC}$ column. Axial load was applied until failure and the predicted axial failure load was compared to analytically determined capacity. The load-displacement time-histories predicted numerically for an undamaged column with varying element mesh sizes when subjected to axial loading are presented as Figure 4-12. 


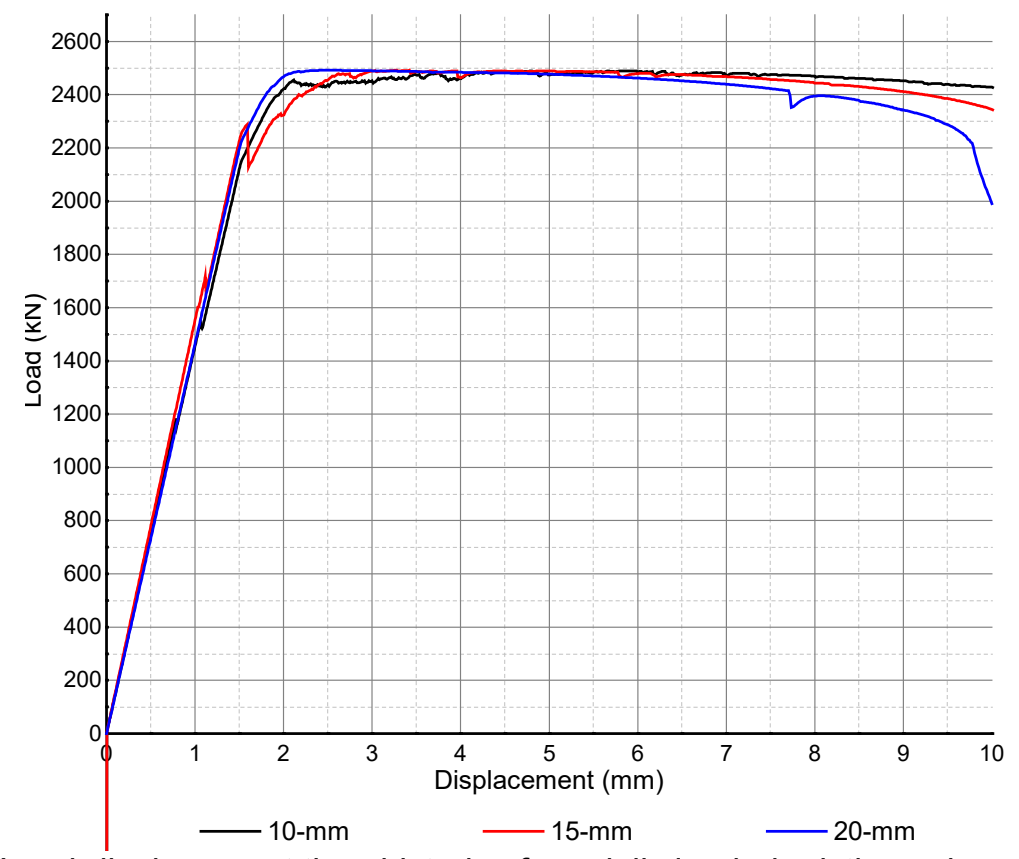

Figure 4-12: Load-displacement time-histories for axially loaded pristine columns with varying mesh sizes.

Based on the above results and as reported in Murray (2007), Mat_159 is not sensitive to the element mesh size for static analysis. The computational effort however increased exponentially for a finer mesh with negligible change in the predicted results (Table 4-10).

Table 4-10: Influence of element mesh size on the axial capacity of the pristine column

\begin{tabular}{|c|c|c|c|c|c|c|c|}
\hline $\begin{array}{c}\text { Column } \\
\text { Cross- } \\
\begin{array}{c}\text { Section, } \\
\mathrm{mm}\end{array}\end{array}$ & $\begin{array}{c}\text { Concret } \\
\mathrm{e} \\
\text { Strength } \\
\mathrm{MPa}\end{array}$ & $\begin{array}{c}\text { Steel } \\
\text { Rebar, } \\
\text { Ultimate } \\
\text { Tensile } \\
\text { Strength } \\
\mathrm{MPa}\end{array}$ & $\begin{array}{c}\text { Analytically } \\
\text { Determine } \\
\mathrm{d} \text { Axial } \\
\text { Capacity, } \\
\mathrm{kN}\end{array}$ & $\begin{array}{c}\text { Elemen } \\
\text { t Mesh } \\
\text { Size, } \\
\mathrm{mm}\end{array}$ & $\begin{array}{c}\text { Numericall } \\
\mathrm{y} \\
\text { Determine } \\
\mathrm{d} \text { Axial } \\
\text { Capacity, } \\
\mathrm{kN}\end{array}$ & $\begin{array}{c}\text { Error } \\
, \%\end{array}$ & $\begin{array}{c}\text { Computationa } \\
\text { I Time, Hours }\end{array}$ \\
\hline $\begin{array}{c}300 \times 30 \\
0\end{array}$ & 25 & $\begin{array}{c}4 \times 20 \mathrm{M}, \\
500\end{array}$ & 2431 & 15 & 2488 & 2.4 & 17 \\
\cline { 5 - 9 } & & & 10 & 2476 & 1.9 & 27 \\
\hline
\end{tabular}

Based on the above two studies, an element size of $10 \mathrm{~mm}$ was adopted for modeling the RC member. 


\subsubsection{Modeling Technique}

It was highlighted in the literature review that the finely meshed 3D air domain must be large enough to avoid reflection of the blast wave from the air domain boundary during the whole event. This results in a large memory prerequisite. To overcome these problems, a novel chained mapping technique for ALE domains was implemented on a shared memory parallel (SMP) solver to accurately predict the impulse generated due to the contact explosion and the response of Lagrangian entity to the contact explosion event. The chained-simulation details are presented in the following paragraphs.

In the first simulation, the detonation of the explosive was modeled in a 1-mm element sized 3D mesh for the air domain and the FSI with Lagrangian domain was activated simultaneously. The first simulation was terminated prior to the arrival of the generated blast wave at the boundaries of the air domain to avoid reflection. Although LS-DYNA provides a keyword BOUNDARY_NON_REFLECTING, this keyword is applicable to Lagrangian entities and acoustic waves and not to the ALE domains with Euler entities. Hence each simulation must be terminated prior to the reflection from the boundaries of the air domain. The second simulation involves a larger ALE domain of 5-mm element size while the other entities are kept the same. A 3D to 3D ALE mapping was implemented between these two simulations wherein the underlying algorithm initializes the 5-mm element size ALE domain with the pressures at the last timestep of the first simulation. The Lagrangian entities were also initialized with the stress condition at the last timestep of the previous run. These steps were 
performed with a full deck restart that enables the addition or deletion of Lagrangian and/or ALE entities. The second simulation was run until the blast wave interacted and diffracted around the Lagrangian entity. The same procedure can be continued until the impulse has been imparted to the Lagrangian entities. In the case of the simulations presented in this study, only two chained-simulations (with $1 \mathrm{~mm}$ and $5 \mathrm{~mm}$ element sizes) were implemented for FSI.

The generated shock wave from the detonation of explosive material is transmitted to the Lagrangian domain through $\mathrm{FSI}$, imparting acceleration to the elements. The simulation is required to be run for a longer time after the detonation event for an accurate assessment of the response of the Lagrangian entity to the contact explosion event. This is due to the inertial effects of concrete that takes a longer time for the stresses to develop and stabilize as compared to the impulsive loading due to the contact explosion that occurs over a very short duration (Gebbeken et al., 2004). Hence, a third simulation was run without the ALE domain to completely capture the damage in the Lagrangian entities. The ALE domain was removed for the last simulation as the duration of impulsive loading due to contact explosion effects will be of the order of $10^{-4} \mathrm{~s}$ and the impulse is completely imparted to the Lagrangian entities within this period (Weerheijm et al., 1984).

The chained-simulation technique presented above predicts the blast-response of Lagrangian entities to contact explosion effects and can be implemented for any type of Lagrangian entity like RC slab, RC column, RC wall etc. For this study, investigating the response of RC columns to contact explosion effects, the blast- 
damaged column was further modeled for residual axial capacity to quantify the damage due to contact explosion effects. A full deck restart was performed to initialize the damage state of the RC column from the blast-analysis simulation. Displacement controlled axial load was applied to the column similar to loading in the experimental tests and the load-displacement curves were acquired from the simulations. The sequence of the chained simulations is presented as Figure 4-13.

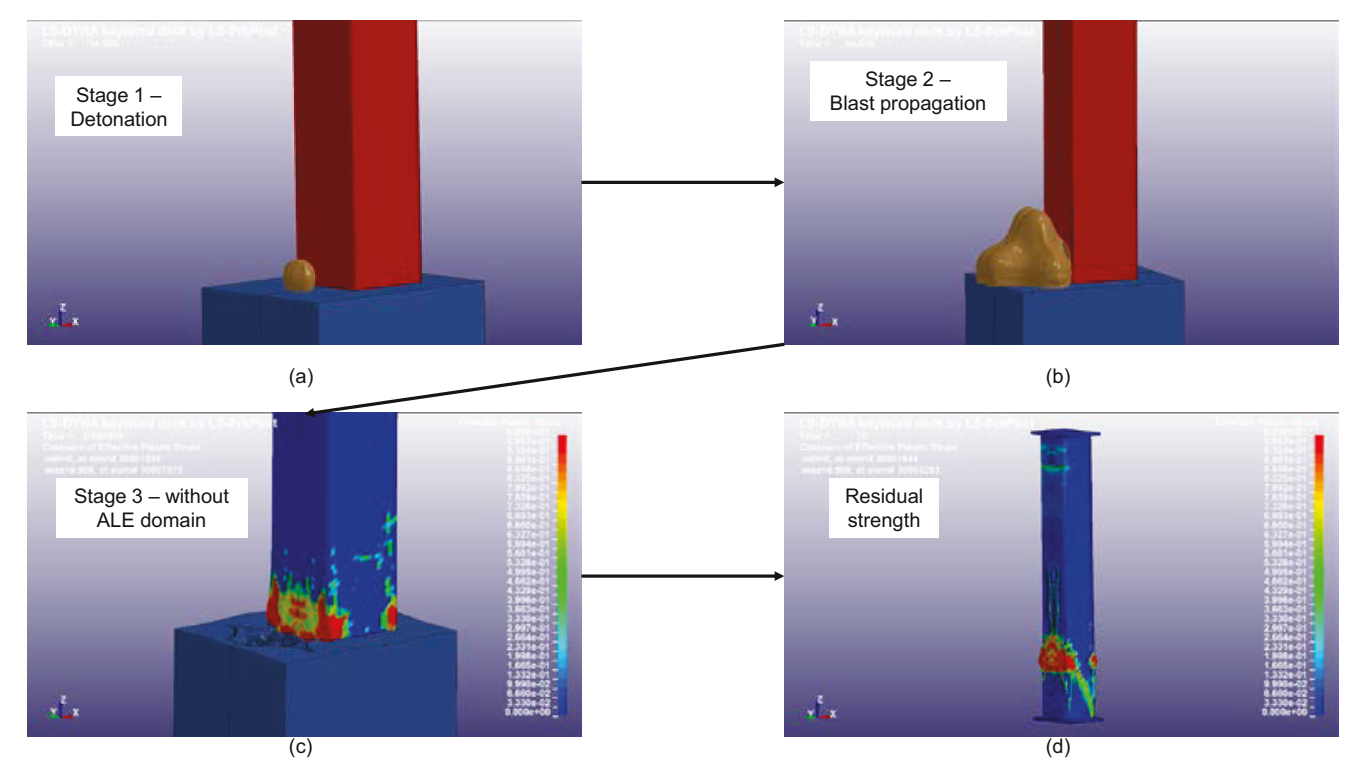

Figure 4-13: Sequence of chained simulations

\subsection{Numerical Results}

\subsubsection{Axial Capacity of Undamaged RC Column}

Prior to the comparison of the experimental and numerical results of blastdamaged columns the axial capacity of an undamaged RC column was first determined numerically. The RC column was modeled in LS-DYNA and a displacement-controlled concentric axial load was applied until failure. The details of numerical modeling are the same as used for the blast-damaged columns. The 
ultimate axial load carrying capacity of $2465 \mathrm{kN}$ was determined numerically which compared well with the analytical strength of $2431 \mathrm{kN}$ as presented in Figure 4-14.

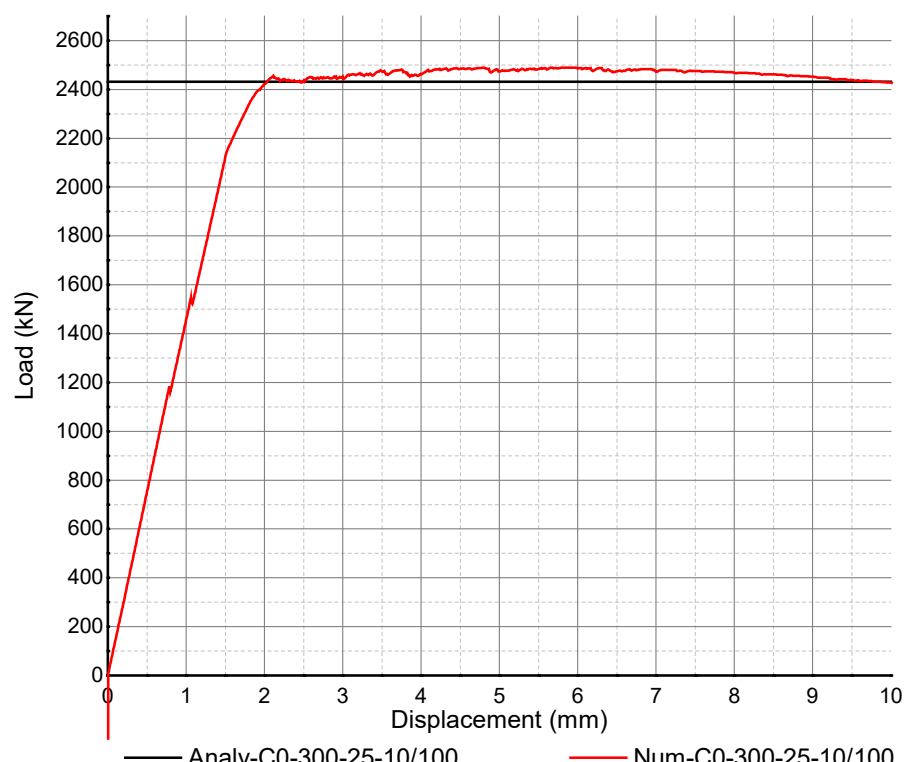

Figure 4-14: Numerical vs analytical strength of the pristine column

\subsubsection{Blast-damaged RC column Subjected to $115 \mathrm{~g}$ TNT Explosion}

In the first simulation, the detonation of the explosive in a 1-mm element size air domain was modeled. This simulation was terminated at $0.01 \mathrm{~ms}$ after the lighting (detonation) time and before the shock front reached the air domain boundary. This is to prevent blast wave reflection off the air-domain boundaries. The air domain size is restricted due to the computational memory available on the computer system. The pressure fringe plots at the initial and last cycle of the first simulation are presented in Figure 4-15 (a) \& (b). The range of pressure fringe plot is $0-50 \mathrm{MPa}$ to highlight the extent of the blast wave. 


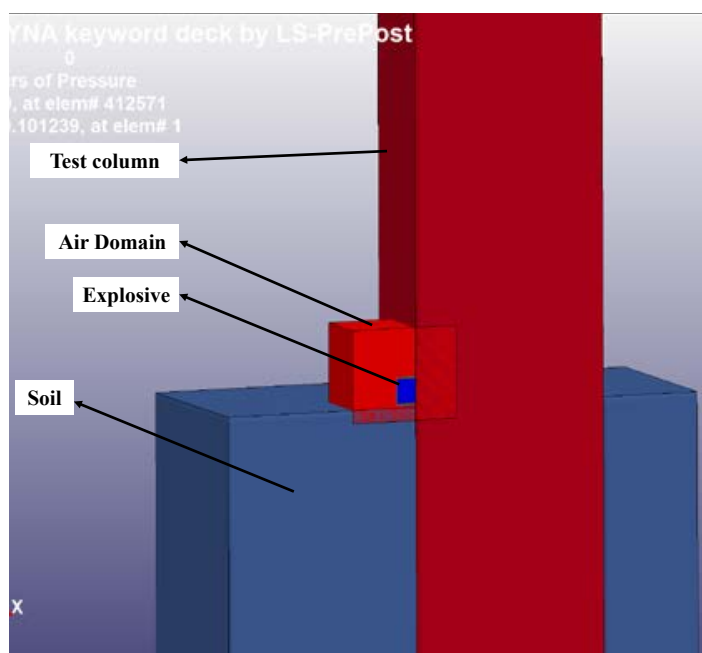

(a)

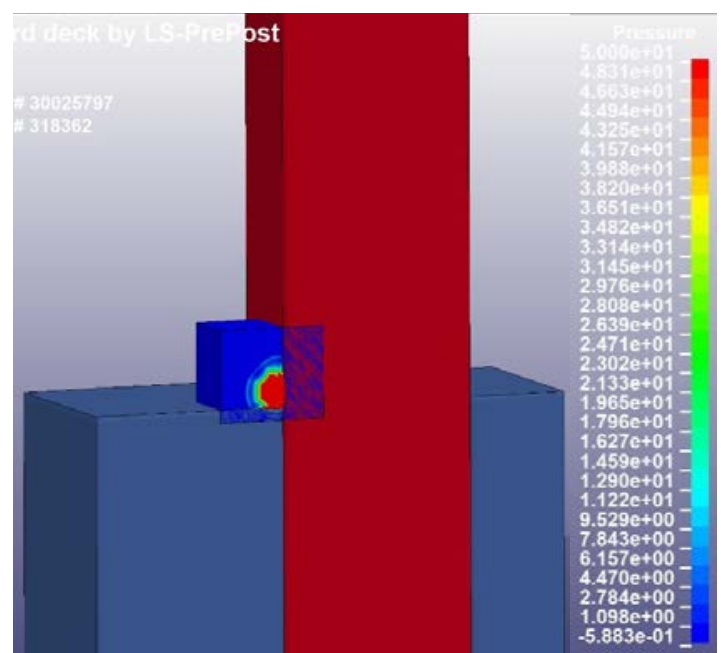

(b)

Figure 4-15: Multistage pressure fringe plots (a) initial pressure for 1-mm element size (b) last cycle for 1-mm element size

The pressure from the last cycle of the first simulation was mapped to a larger ALE domain with 5-mm element size (second simulation). The stress time histories of the Lagrangian entities were also initialized from the first simulation and the simulation was run to $0.06 \mathrm{~ms}$ to avoid reflection of the propagating blast wave from the air domain boundary, Figure 4-16 (a) \& (b). The preliminary simulations revealed that coupling the blast effects for up to $0.06 \mathrm{~ms}$ imparted majority of the impulse to the RC column. Coupling the blast effects more than $0.06 \mathrm{~ms}$ did not reduce the residual axial capacity of the RC column any further. 


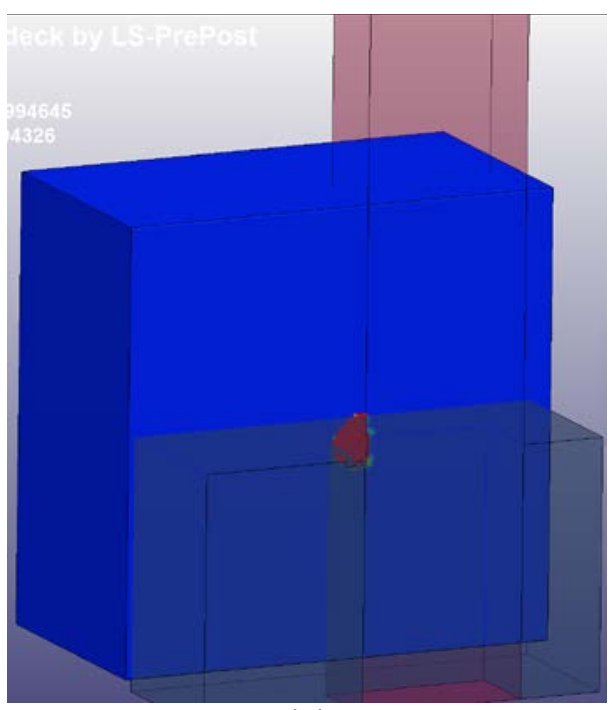

(a)

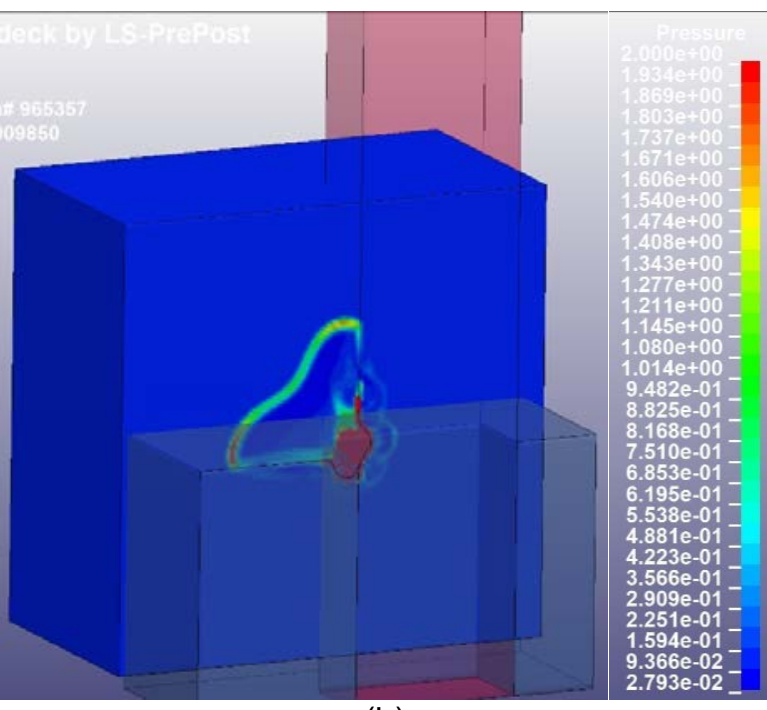

(b)

Figure 4-16: Blast wave propagation of 115-g TNT detonation (a) Initial pressure for 5-mm element size (b) last cycle for 5-mm element size

The concrete response time is more than the impulse uptake from the contact explosion and hence the last simulation was implemented to $0.4 \mathrm{~s}$ without the ALE domain to capture the full response of $\mathrm{RC}$ column to contact explosion effects.

The numerically predicted damage profile of the RC column subjected to $115 \mathrm{~g}$ TNT explosion effects are compared to the experimental results in Figure 4-11 (b) and (c). The presented fringe plot represents accumulated damage in concrete elements ranging between 0-0.99 (L.S.T.C, 2015a). The circular damage on the contact face due to the crushing of concrete was accurately predicted as $191 \mathrm{~mm}$. The numerical damage profile qualitatively correlated well with the experimental results.

Another simulation on the same methodology as presented above was performed with $500 \mathrm{~g}$ TNT explosion in contact with the RC column. Figure 4-17 (a) represents the cross-section across the point of contact with the 115-g explosive. No damage 
was observed in the core of the RC column subjected to 115-g TNT explosion whereas the concrete core was completely damaged in case of RC column subjected to 500-g TNT explosion (Figure 4-17(b)). The hollow portion of the column represents the mirror image of the half-symmetric model and cannot be filled in a cross-sectional view.

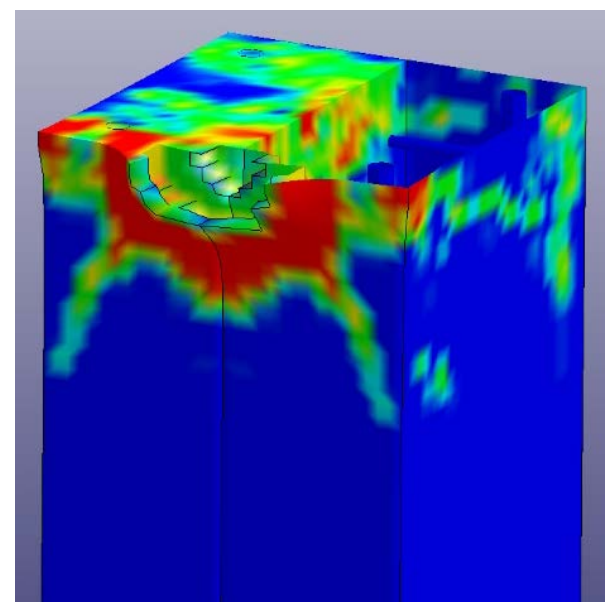

(a)

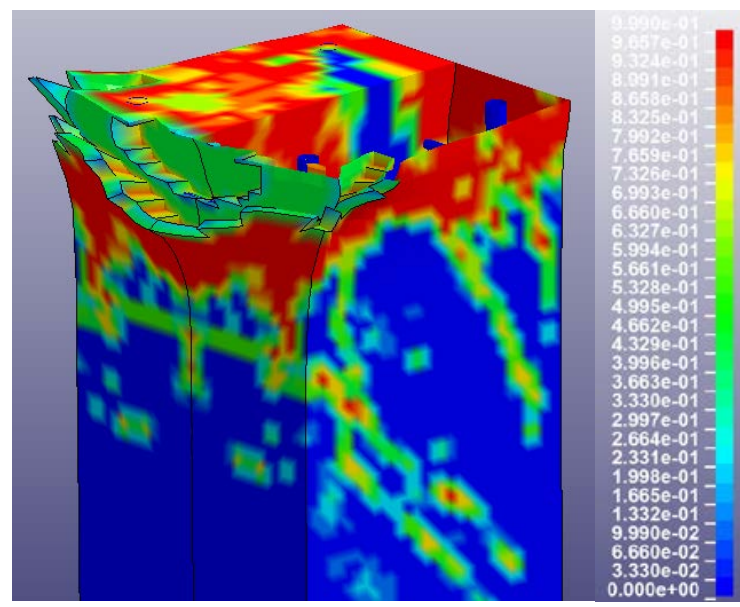

(b)

Figure 4-17: Cross-section across the point of contact with the explosive representing the damage profile of RC column subjected to (a) 115-g TNT (b) 500-g TNT

The residual axial load carrying capacity of the blast-damaged column was predicted in the last simulation. The column in its blast-damaged state was axially loaded in a static regime. Displacement controlled load was applied via steel plates to emulate the experimental results. The numerical model for predicting the residual capacity of the blast-damaged column is presented in Figure 4-18(a). The column yielded a peak axial load capacity of $2031 \mathrm{kN}$ which correlates well with the experimentally determined residual axial load carrying capacity. Both the experimental and numerical failure modes were by crushing of the concrete core indicating that there was no damage to the concrete core due to the contact explosion effects of $115 \mathrm{~g}$ TNT. The damage was restricted to the concrete cover. 
The numerically predicted the load-displacement response of the 115-g TNT and 500-g TNT plotted against the experimentally acquired load-displacement response and failure loads for the pristine undamaged column are presented in Figure 4-18(b).

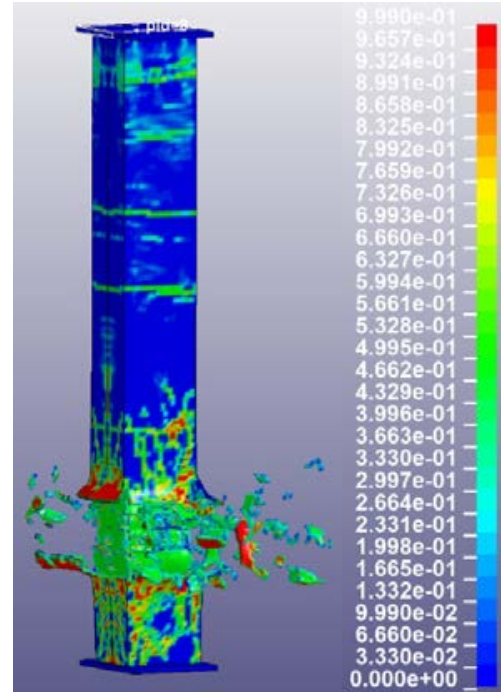

(a)

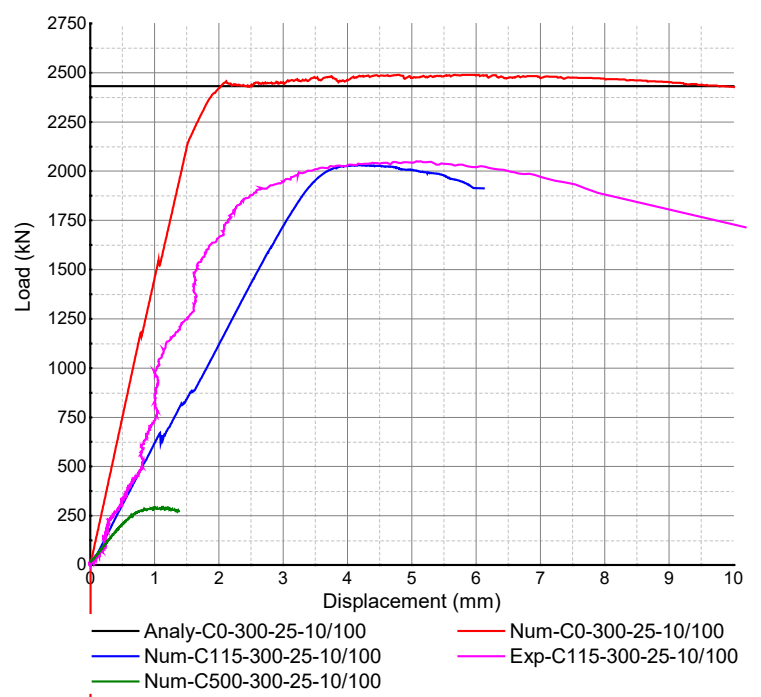

(b)

Figure 4-18: (a) Numerical model for residual axial load carrying capacity of the blast-damaged column (b) Load-displacement curve for the residual axial load capacity of the blast-damaged RC column

Residual axial load carrying capacity of the RC column subjected to 500-g TNT explosion could not be predicted experimentally due to the damage caused by selfweight of the footing and backfill during the extraction of the blast-damaged column from the soil. The residual strength of $280 \mathrm{kN}$ predicted numerically is due to the axial strength provided by the longitudinal reinforcement and crushed concrete core. The axial failure loads acquired experimentally and predicted numerically for all three tests are presented in Table 4-11. 
Table 4-11: Quantitative error between Numerical and Experimental results

\begin{tabular}{|c|c|c|}
\hline Explosive mass, $\mathrm{g}$ & Experimental failure load, $\mathrm{kN}$ & Numerical failure load, $\mathrm{kN}$ \\
\hline 115 & 2050 & 2031 \\
\hline 500 & 0 (Crushed core) & 280 \\
\hline 1000 & 0 (Crushed core) & - \\
\hline
\end{tabular}

\subsection{Presentation of Results and Discussion}

\subsubsection{Experimental Results}

The response of RC column to contact explosion effects of varying explosive mass was studied. The damage due to contact explosion effects were found to be more severe than damage in RC slabs of lesser thickness and same concrete compressive strength (Dua \& Braimah, 2018a). A 500-g TNT explosion in contact with RC slab of 200-mm thickness did not breach the slab, however, the same explosive mass breached the RC column of $300 \times 300 \mathrm{~mm}$ cross-section. This is because of the concrete spall from the side faces of the column due to the reflected blast wave exceeding the tensile strength of concrete. The tensile strength of concrete is significantly lower than its compressive strength, hence the spalling of concrete in the tensile stress wave zone after reflection from sides and back faces. This phenomenon of 2D stress wave propagation is absent in the case of RC slabs.

The demolition charge mass for a $300 \times 300 \mathrm{~mm}$ cross-section RC member calculated as per the empirical equation recommended by DoA (2007), is $2.9 \mathrm{~kg}$ TNT. From the experimental observations, the demolition charge mass for the reinforced concrete column is between the range of $115 \mathrm{~g}-500 \mathrm{~g}$. Thus, the charge calculated with the empirical equation underestimated the more realistic value. 
The experimental tests exhibited a local material failure mode that would further lead to a shear failure under concentric axial loading. This phenomenon was evident from the residual axial capacity tests on the blast-damaged columns. The material failure was predominantly in the concrete cover in case of $115 \mathrm{~g}$ TNT charge mass while the concrete core was completely crushed during the contact explosion due to a 1000-g TNT and 500-g TNT explosive charge masses.

The impulse generated due to a contact explosion is transferred to the RC column and generates a compressive shock wave that propagates outwards from the contact point (Puryear et al., 2012). The shock wave attenuates as it propagates through the concrete core towards the side and back faces compressing the material along its path. In case the compressive stress generated by the shock wave exceeds the compressive strength of the concrete, the crushing of material is observed. On arriving at the side and back faces the compressive wave is reflected and transmitted depending on impedance values of the concrete and surrounding air. The reflected wave is a tensile wave that propagates back into the core of the concrete element. The reflected tensile shock wave may develop scabbing of side and back faces when the tensile stress exceeds the tensile strength of concrete. The reinforcement ties confine the concrete core of the column providing enhanced compressive and tensile strengths. This damage mechanism resulted in spalling of the side face corners whereas due to the attenuation and confinement effects, there was no back-face scabbing observed in the RC column subjected to $115 \mathrm{~g}$ TNT equivalent explosive. The amount of 
concrete spalling and scabbing has a direct bearing on the residual axial load carrying capacity of the RC columns.

There was no global response of the RC columns to contact explosion effects as the amount of explosive used was too small for producing global effects. It is obvious that a higher explosive charge mass that can produce global effects would first crush the concrete core due to local damage and the global effects are of no significance afterward. Two distinct local response phenomena were observed in the RC columns; (a) compressive crushing on the front face and (b) scabbing on the side and back faces. The spalling of concrete due to scabbing in the tensile zone occurred at the weakest interface i.e the concrete cover-to-concrete core. In case of the lower explosive mass (115-g TNT), the concrete cover spalled forming a scab from the side faces however there was no scab formation on the distal face. The scabbing was more severe at the corners of the face in contact with the explosive when compared to the back face as the shock wave reflection occurs earlier on the side faces than the back face. The reflected tensile wave from the back face and sides encounters the inbound compressive stress resulting in total stress that is subtractive. When the total stress is tensile (tensile stress greater than inbound compressive) and exceeds the tensile strength of concrete a scab is formed. As the back face is farther from the detonation point on the front face, the stresses diminish. This explains the lack of back face scabbing. With an increase in the explosive mass, the two failure phenomena are accompanied by damage to the concrete core which is due to combined effect of direct compression caused by the explosion and the reflected tensile waves from the side and back faces. The 
threshold limit of transition between cracked-core and crushed-core is hypothesized to control the axial failure of a blast damaged column. The threshold limit can be improved by increasing the concrete compressive strength and closely spaced transverse reinforcement. It will be shown later in the parametric studies that all these factors significantly improve the residual strength of $\mathrm{RC}$ column.

The above damage phenomenon also highlights another factor that can improve the residual capacity of blast-damaged columns; the aspect ratio of the column. The width to depth ratio of $\mathrm{RC}$ column cross-section may significantly improve the residual capacity due to attenuation of the shock wave in the concrete before it is reflected from the sides. A higher aspect ratio will exhibit damage evolution similar to an RC slab and is likely to have a superior residual capacity.

\subsubsection{Numerical Results}

Mat_159 was not sensitive to mesh element size for quantitative analysis of residual axial load carrying capacity of $\mathrm{RC}$ columns subjected to contact explosion effects. The numerically predicted axial load carrying capacity of undamaged and blast-damaged columns correlated well with the analytical values and experimental results respectively with a $10-\mathrm{mm}$ Lagrangian element size mesh for the Lagrangian domain. However, the damage profile is sensitive to the mesh size. It is not recommended to rely upon the qualitative damage profile alone for analysis of the response to contact explosion effects. 
Numerical modeling of explosive detonation and blast wave propagation is sensitive to the ALE mesh element. The overpressure and impulse values converged at 1-mm element size air mesh and correlated well with the experimental results. It is recommended to model the detonation process and blast wave propagation problems in 3D with a 1-mm element size mesh.

The disparity in mesh size of ALE and Lagrangian domain leads to leakage of ALE material into the Lagrangian domain (L.S.T.C, 2015a, 2015b). An excessive leakage reduces the coupling force between the ALE material and the Lagrangian domain. Hence, the NQUAD parameter in CLIS keyword that represents the number of coupling points is critical for accurate prediction of the damage caused to the RC column due to the contact explosion. NQUAD is selected on trial and error basis for each condition to ensure there is no leakage of ALE material into the Lagrangian domain and also retain the computational time efficiency.

\subsection{Parametric Studies}

\subsubsection{Influence of Explosive Charge Mass}

The experimentally validated numerical models were implemented to predict the response of RC column to detonation effects of varying explosive charge mass in order to study the damage thresholds in the concrete core. The damage index, $D$, for test cases for columns subjected to $115-\mathrm{g}$ and $500-\mathrm{g}$ TNT contact explosions (C115-300-25-10/100 and C500-300-25-10/100) were experimentally evaluated 
as 0.16 and 1 respectively. The damage profile and residual capacities for these two tests were predicted numerically with fair accuracy (Table 4-11).

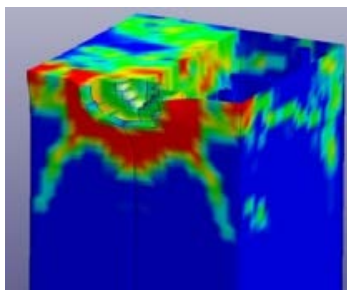

(a)

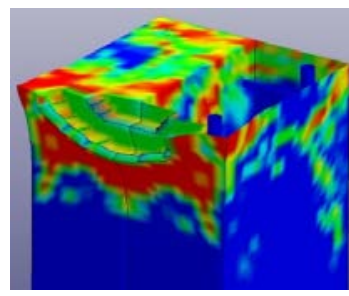

(b)

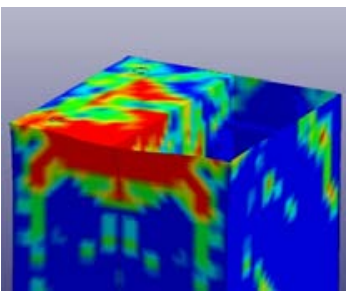

(c)

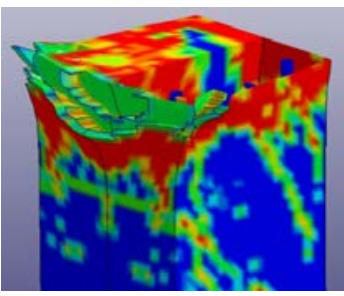

(d)

Figure 4-19: Cross-section at the point of contact presenting the damage in concrete core of the blast-damaged RC column subjected to the detonation of explosive mass (a) 115-g TNT (b) 200 g TNT (c) 300-g TNT (d) 500-g TNT

Two additional simulations were implemented for $200-\mathrm{g}$ TNT and 300-g TNT explosive mass to augment the results from the experimental and numerical investigation. The cross-section of RC columns at the point of contact depicting the damage to the concrete core, when subjected to contact explosion effects of different explosive masses, are presented in Figure 4-19.

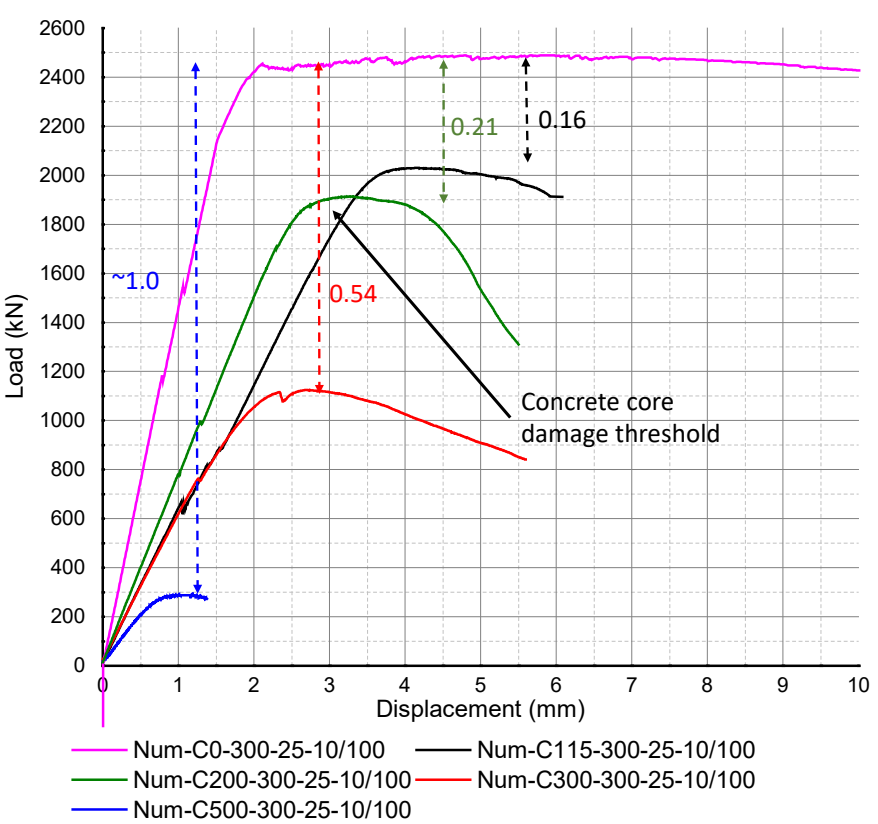

Figure 4-20: Influence of explosive mass on the damage index of the blast-damaged column (dashed arrows show damage indices) 
Figure 4-20, on the other hand, presents the load-displacement response predicted numerically for columns subjected to contact explosion from explosive charge masses in the range of $115-500 \mathrm{~g}$ TNT.

Up to 200-g TNT explosive, the damage was only within the concrete cover and negligible damage was observed in the concrete core (Figure 4-19). An increase in the explosive charge mass to $300-\mathrm{g}$ initiated damage in the concrete core and resulted in reduction in the residual axial capacity of the blast-damaged column. This shows that the threshold explosive mass for $300 \times 300 \mathrm{~mm}$ column crosssection is within the range of $200-300 \mathrm{~g}$ TNT. Inevitably, the damage index increased at a higher rate in case of explosive mass more than 300-g TNT (Table $4-12)$.

Table 4-12: Influence of explosive mass on the damage index of RC column

\begin{tabular}{|c|c|c|c|}
\hline $\begin{array}{c}\text { Explosive } \\
\text { Mass, } g\end{array}$ & $\begin{array}{c}\text { Residual axial load } \\
\text { capacity }\left(\mathrm{P}_{\mathrm{r}}\right), \mathrm{kN}\end{array}$ & $\begin{array}{c}\text { Analytical load capacity of the } \\
\text { pristine column }\left(\mathrm{P}_{\mathrm{o}}\right), \mathrm{kN}\end{array}$ & $\begin{array}{c}\mathrm{D}, 1- \\
\left(\mathrm{P}_{\mathrm{r}} / \mathrm{P}_{\mathrm{o}}\right)\end{array}$ \\
\hline 115 & 2031 & 2431 & 0.16 \\
\hline 200 & 1920 & 2431 & 0.21 \\
\hline 300 & 1125 & 2431 & 0.54 \\
\hline 500 & 280 (practically zero) & 2431 & $\sim 1$ \\
\hline
\end{tabular}

\subsubsection{Influence of Concrete Strength}

The damage mechanism described earlier illustrates that an increase in concrete strength may improve the residual capacity of the blast-damaged RC columns by reducing the local material damage in the concrete core. The experimentally validated numerical model was used to investigate the influence of concrete strength on the residual axial capacity and response of RC column under contact explosion effects. The multistage simulation technique described earlier was 
implemented to the contact explosion and residual axial load capacity testing of $\mathrm{RC}$ columns with concrete compressive strengths of $20 \mathrm{MPa}, 25 \mathrm{MPa}, 35 \mathrm{MPa}, 45$ $\mathrm{MPa}$, and $55 \mathrm{MPa}$. The load-displacement response from the residual capacity simulations for different concrete compressive strengths are compared against the analytically determined strengths of companion undamaged columns in Figure 4-21.

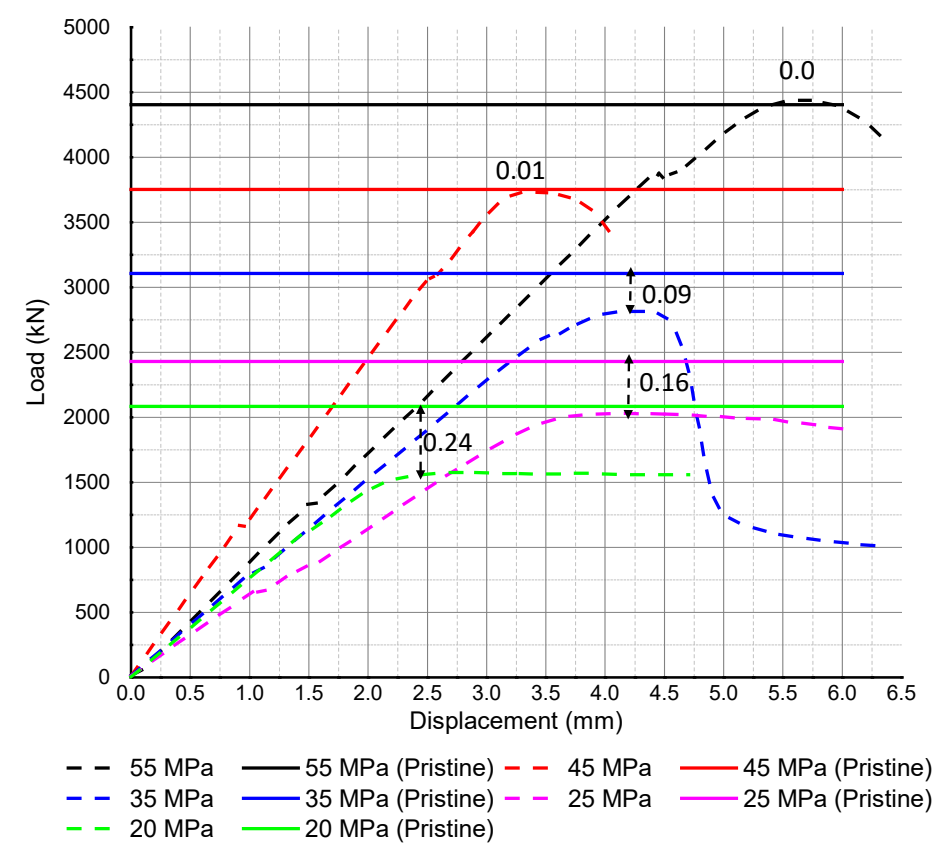

Figure 4-21: Influence of concrete compressive strength on the damage index of the blastdamaged column (dashed arrows show damage indices)

Table 4-13 presents the damage indices $(D)$ of RC columns of varying concrete compressive strengths when subjected to 115-g TNT explosion in contact. An increase in concrete compressive strength reduced the damage index of the RC column from 0.24 in case of $20 \mathrm{MPa}$ concrete to 0.01 in the case of $45 \mathrm{MPa}$ concrete. The column with a concrete compressive strength of $55 \mathrm{MPa}$ indicated a damage index of 0 and retained $100 \%$ of axial capacity. 
Table 4-13: Influence of concrete compressive strength on the damage index of RC column subjected to 115-G TNT explosion in contact

\begin{tabular}{|c|c|c|c|}
\hline $\begin{array}{c}\text { Concrete } \\
\text { Compressive } \\
\text { Strength, } \\
\text { MPa }\end{array}$ & $\begin{array}{c}\text { Residual axial load } \\
\text { capacity }\left(\mathrm{Pr}_{\mathrm{r}}\right), \mathrm{kN}\end{array}$ & $\begin{array}{c}\text { Analytical load capacity of the } \\
\text { pristine column (Po), kN }\end{array}$ & $D$ \\
\hline 20 & 1580 & 2084 & 0.24 \\
\hline 25 & 2031 & 2431 & 0.16 \\
\hline 35 & 2814 & 3106 & 0.09 \\
\hline 45 & 3730 & 3753 & 0.01 \\
\hline 55 & 4438 & 4405 & 0.00 \\
\hline
\end{tabular}

\subsubsection{Influence of Transverse Reinforcement Spacing}

Damage to the concrete core has a direct bearing on the damage index of the RC column subjected to contact explosion effects. The blast resistance of RC column can be improved by increasing the core confinement. The transverse reinforcement provides confinement to the concrete core which is influenced by the tie spacing. To capture the influence of tie spacing, $\mathrm{RC}$ column with a varying spacing of $50 \mathrm{~mm}, 100 \mathrm{~mm}, 150 \mathrm{~mm}$ and $200 \mathrm{~mm}$ were numerically modeled and subjected to 300-g TNT contact explosion. The explosive mass implemented for this study was taken as $300 \mathrm{~g}$ to capture the full range of influence as the higher explosive mass reduced the damage index from 0.16 to 0.54 when compared to 115-g TNT explosive mass (Figure 4-20). The concrete compressive strength was $25 \mathrm{MPa}$ as in the case of experimental tests. Figure 4-22 presents the loaddisplacement curve predicted by the numerical simulations with varying transverse reinforcement spacing. 


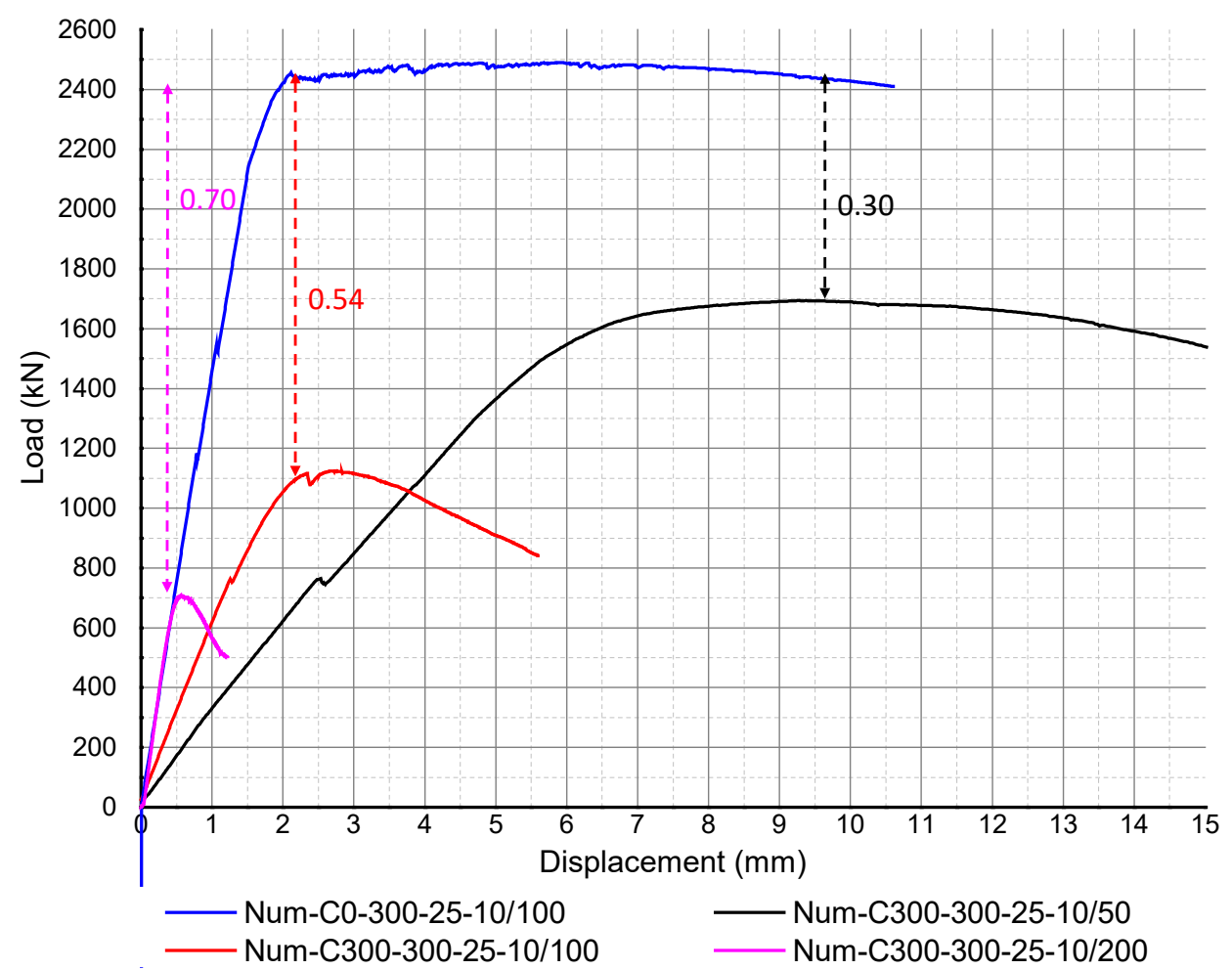

Figure 4-22: Influence of reinforcement tie bar on the damage index of the blast-damaged column (dashed arrows show damage indices)

The damage indices corresponding to the range of bar spacing is presented in Table 4-14. There was a significant improvement in the blast resistance of the RC columns subjected to contact explosion effects could be obtained by reducing the transverse reinforcement spacing. A decrease in spacing from $100 \mathrm{~mm}$ to $50 \mathrm{~mm}$, reduced the damage index by 0.24 .

The reduction in transverse reinforcement spacing improves the confinement of the concrete core. Concrete in confined condition has better resistance to impact as compared to unconfined concrete. Confined concrete also exhibits improved crack control. Hence reduction in the transverse reinforcement spacing improved the blast resistance to contact explosion effects. 
Table 4-14: Influence of transverse Reinforcement spacing on the damage index of RC column subjected to $300-\mathrm{g}$ TNT explosion in contact

\begin{tabular}{|c|c|c|c|}
\hline $\begin{array}{c}\text { Transverse } \\
\text { Reinforcement } \\
\text { spacing, } \mathrm{mm}\end{array}$ & $\begin{array}{c}\text { Residual axial } \\
\text { load capacity }\left(\mathrm{P}_{\mathrm{r}}\right), \\
\mathrm{kN}\end{array}$ & $\begin{array}{c}\text { Analytical load capacity of the } \\
\text { undamaged column }\left(\mathrm{P}_{\mathrm{o}}\right), \mathrm{kN}\end{array}$ & $\mathrm{D}$ \\
\hline 200 & 706 & 2431 & 0.70 \\
\hline 100 & 1125 & 2431 & 0.54 \\
\hline 50 & 1693 & 2431 & 0.30 \\
\hline
\end{tabular}

\subsection{Conclusions}

The study analyzed the response of RC columns subjected to live contact explosion effects of varying charge mass. A quantified benchmark was presented by identifying the range of explosive mass that could demolish a square $\mathrm{RC}$ column of $300 \times 300 \mathrm{~mm}$ cross-section with $25 \mathrm{MPa}$ concrete compressive strength, 0.014 longitudinal reinforcement ratio and 10M@100 mm c/c transverse reinforcement. The residual axial load carrying capacity of the blast-damaged column was also determined experimentally. An experimentally validated LS-DYNA numerical model was presented and used in parametric analyses to investigate the effect of various design parameters on the response of RC columns to contact explosions. The following are the most important conclusions from the study:

- A relatively small amount of explosive can demolish an RC column when deployed in contact as compared to RC slab. The increased damage in columns is due to reflection of the shock wave from three faces that results in significant concrete scabbing.

- The failure mode of RC columns subjected to contact explosion effects is in the local damage regime and global effects are negligible. 
- An explosive charge mass of 500-g TNT demolished a $300 \times 300 \mathrm{~mm}$ crosssection RC column with $25 \mathrm{MPa}$ concrete compressive strength, 0.014 longitudinal reinforcement ratio and 10M@100 mm c/c transverse reinforcement.

- The response mechanism under contact explosion effects is a local phenomenon involving concrete crushing on the attack face and spalling on the side and back faces. The amount of concrete spalling and scabbing has a direct bearing on the damage index. An increase in the concrete compressive strength reduces the level of concrete crushing and spalling, and hence, reduces the damage index.

- The confinement of concrete core influences the damage index of blastdamaged columns. A reduction in transverse reinforcement spacing provides better confinement to the concrete core and reduces the damage to the concrete core produced by contact explosion effects thereby reducing the damage index.

\subsection{References}

Bažant, Z. P., \& Zhou, Y. 2002. Why Did the World Trade Center Collapse? Simple Analysis. Journal of Engineering Mechanics, 128(1): 12-18.

Børvik, T., Hanssen, A., Langseth, M., \& Olovsson, L. 2009. Response of Structures to Planar Blast Loads - A Finite Element Engineering Approach. Computers \& Structures, 87: 507-520. 
Braimah, A., Siba, F., \& Rosen, B. V. 2015. Near-field explosion effects on reinforced concrete columns. Protect 2015, Fifth international workshop on performance, protection and strengthening of structures under extreme loading: DEStech Publications, Inc. MI, USA pp. 504-514.

Clarke, S. D., Fay, S. D., Warren, J. A., Tyas, A., Rigby, \& Elgy, I. 2015. A large scale experimental approach to the measurement of spatially and temporally localized loading from detonation of shallow buried explosives. Measurement science and technology, 26: 10pp.

Cormie, D., Shin, J., Whittaker, A. S., \& Aref, A. J. 2014a. Air Blast effects on civil structures, MCEER-14-0006. State University of New York.

Cormie, D., Shin, J., Whittaker, A. S., \& Wilkinson, W. 2014b. Numerical modelling of close-in detonations of high explosives. Engineering Structures, 81: 8897.

Canadian Standards Association (CSA). 2004. Design of Concrete Structures, A23.3-04. Mississuaga, Canada.

Cui, J., Shi, Y., Li, Z.-X., \& Chen, L. 2015. Failure analysis and damage assessment of RC-columns under close-in explosions. Journal of Performance of Constructed Facilities, 29(5): B40150034015001:4015011.

US Department of Army (DoA). 2007. Explosives and Demolitions, FM 3-34.214. Department of Army Washington USA.

US Department of Defense (DoD). 1987. Fundamentals of Protective Design for Conventional Weapons, TM5-855-1. Washington DC, USA. 
US Department of Defense (DoD). 2008. Design of structures to resist the effects of accidental explosions, UFC-3-340-02. Department of Defense Washington, D.C.

Dua, A., \& Braimah, A. 2016. State-of-the-Art in Near-Field and Contact Explosion Effects on Reinforced Concrete Columns. 5th International Structural Specialty Conference: Canadian Society for Civil Engineering London, Canada. pp. 1:12 (STR-836).

Dua, A., \& Braimah, A. 2017. Efficacy of Concrete Constitutive Models for Bullet Impact Tests. 6th International Engineering Mechanics and Materials Conference: Canadian Society of Civil Engineers Vancouver, Canada. pp. $521521-510$.

Dua, A., Braimah, A., \& Matsagar, V. 2017. Understanding the Response of Reinforced Concrete Slabs due to Contact explosion of TNT. 6th International Engineering Mechanics and Materials Conference: Canadian Society for Civil Engineering (CSCE) Vancouver, Canada. pp. 522 521-510.

Dua, A., \& Braimah, A. 2018a. Assessment of Reinforced Concrete Slab Response Due to Contact Explosion Events. Journal of Performance of Constructed Facilities (ASCE), Under Review.

Dua, A., \& Braimah, A. 2018b. Quick Assessment of Reinforced Concrete Slab Reinforced Concrete Slab Response Due to Contact Explosion Events. In Progress. 
Dua, A., Braimah, A., \& Kumar, M. 2018a. Experimental and Numerical Investigation of Reinforced Concrete Walls Under Contact Explosion Effects. Journal of Engineering Structures, Being Communicated.

Dua, A., Braimah, A., \& Kumar, M. 2018b. Mitigation Effects of Cladding on Reinforced Concrete Columns Subjected to Contact Explosions. Journal of Structural Engineering (ASCE), Under Review.

Gebbeken, N., Greulich, S., Pietzsch, A., \& Landmann, M. 2004. The EngineeringTool XPLOSIM to Determine the Effects of Explosive Loadings on Reinforced and Fibre Reinforced Concrete Structures. 18th International Symposium for Military Aspects of Blast and Shock:

Hanssen, A., Enstock, L. K., \& Langseth, M. 2004. Close-Range Blast Loading of Aluminum Foam Panels. International Journal of Impact Engineering, 27: 593-618.

Hyde, D. 1988. User's guide for microcomputer programs CONWEP and FUNPRO - Applications of TM 5-855-1.

Kakogiannis, D., Hemelrijck, D. V., Wastiels, J., Palanivelu, S., Paepegem, W. V., Vantomme, J., . . Kostopoulos, V. 2010. Assessment of Pressure Waves Generated by Explosive Loading. CMES-Computer Modelling in Engineering \& Sciences, 65(1): 75-93.

Kalra, A., Zhu, F., Yang, K. H., \& King, A. I. 2014. Key Parameters in Blast Modeling Using 2D to 3D ALE Mapping Technique. 13th International LSDYNA Users Conference: LSTC Detroit, USA. 
Kingery, C. N., \& Bulmash, G. 1984. Air blast parameters from TNT spherical air burst and hemispherical surface burst. Ballistic Research Lab (BRL), Technical Report, ARBRL-TR-02555.

Krauthammer, T., Astarlioglu, S., Morency, D., \& Tran, T. P. 2013. Behavior of Reinforced Concrete Columns Under Combined Effects of Axial and Blastinduced Transverse Loads. Engineering Structures, 55: 26-34.

L.S.T.C. 2015a. LS-DYNA Keyword User's Manual, Volume I. Livermore, California, USA: LSTC.

L.S.T.C. 2015b. LS-DYNA Keyword User's Manual, Volume II-Material Models. Livermore, California, USA: LSTC.

Li, J., Wu, C., \& Hao, H. 2015. Investigation of Ultra-high Performance Concrete Slab and Normal Strength Concrete Slab under Contact Explosion. Engineering Structures, 102: 395-408.

Malvar, L., \& Crawford, J. E. 1998. Dynamic Increase Factors for Concrete. Naval Facilities Engineering Service Center.

Mlakar, P. F., Corley, W. G., Sozen, M. A., \& Thornton, C. H. 1998. The Oklahoma City Bombing: Analysis of Blast Damage to the Murrah Building. Journal of Performance of Constructed Facilities, 12(3): 113-119.

Murray, Y. D. 2007. User's Manual for LS-DYNA Concrete Material Model 159. FHWA-HRT-05-062, Federal Highway Administration.

Puryear, J. M. H., Stevens, D. J., Marchand, K. A., Williamson, E. B., Sammarco, E. L., \& Crane, C. K. 2012. Predicting Spall and Breach for Blast-Loaded 
Reinforced-Concrete Columns. Texas ASCE Centennial Conference: ASCE Dallas, USA

Rigby, Tyas, A., Clarke, S., Fay, S., Warren, J., Elgy, I., \& Gant, M. 2014. Testing apparatus for the spatial and temporal pressure measurements from nearfield free air explosions. 6th International Conference on Protection of structures against hazards: Tianjin, China.

Rigby, Tyas, A., Clarke, S. D., Fay, S. D., Reay, J. J., Warren, J. A., . . Elgy, I. 2015. Observations From Preliminary Experiments on Spatial and Temporal Pressure Measurements from Near-Field Free Air Explosions. International Journal of Protective Structures, 6(2): 175-190.

Schwer, L. 2014. Modelling Rebar: The Forgotten Sister in Reinforced Concrete Modelling. 13th International LS-DYNA User Conference: LSTC Detroit, USA.

Tagel-Din, H., \& Rahman, N. A. 2006. Simulation of the Alfred P. Murrah Federal Building Collapse Due to Blasts Loads. Architectural Engineering Conference: ASCE Nebraska, USA. pp. 32-47.

Tait, R. (2014). Israel's destruction of Gaza tower blocks a 'war crime', says Amnesty, The Telegraph.

Telford, T. 1993. CEB-FIB Model Code 1990. Comité Euro-International du Béton, Lausanne, Switzerland.

Trajkovski, J., Kunc, R., Perenda, J., \& Prebil, I. 2014. Minimum mesh design criteria for blast wave development and structural response - MMALE method. Latin American Journal of Solids and Structures, 11: 1999-2017. 
Weerheijm, J., Karthaus, W., \& Opschoor, G. 1984. The Failure Mode of Layered Concrete Construction Due to Contact Charges. 21st Department of Defense Explosive Safety Seminar: Department of Defense Houston, Texas, USA

Williams, G. D. 2009. Analysis and Response Mechanisms of Blast-Loaded Reinforced Concrete Columns. (Doctor of Philosophy), University of Texas, Austin, USA.

(Williamson, E. B., Bayrak, O., Williams, G. D., Davis, C. E., Marchand, K. A., McKay, A. E., . . . Wassef, W.). 2009. Blast-Resistant Hignway Bridges: Design and Detailing Guidlines. National Cooperative Highway Research Program (NCHRP) (Report No. 645), USA.

Wu, K.-C., Li, B., \& Tsai, K.-C. 2011a. The Effects of Explosive Mass Ratio on Residual Compressive Capacity of Contact Blast Damaged Composite Columns. Journal of Constructional Steel Research, 67: 602-612.

Wu, K.-C., Li, B., \& Tsai, K.-C. 2011b. Residual Axial Compression Capacity of Localized Blast-Damaged RC Columns. International Journal of Impact Engineering, 38: 29-40.

Yuan, S., Hao, H., Zong, Z., \& Li, J. 2017. A Study of RC Bridge Columns Under Contact Explosion. International Journal of Protective Structures, 109: 378390.

Zakrisson, B., Wikman, B., \& Häggblad, H.-Å. 2011. Numerical simulations of blast loads and structural deformation from near-field explosions in air. International Journal of Impact Engineering, 38(7): 597-612. 
Zukas, J. A., \& Scheffler, D. R. 2000. Practical Aspects of Numerical Simulations of Dynamic Events: Effects of Meshing. International Journal of Impact Engineering, 24(9): 925-945. 


\section{Chapter 5 Mitigation of Contact Explosion Effects by Claddings on RC Columns}

Abstract: Global terrorism has been on the rise in the past few decades. Critical structures and buildings with high occupancy are often the prime targets to inflict maximum casualties and structural damage. The modus operandi of terrorist attacks is to cause progressive collapse of such buildings through detonation of explosives close to structures. Most of the attacks in the past have been carried out at far-field distances and only a few have resulted in the complete collapse of the structure. Terrorists attacks using large amounts of explosives has gradually become less likely due to difficulty in acquiring large quantities of explosives and enhancement of security measures in many jurisdictions. A plausible threat scenario is the detonation of small quantities of concealed explosive in contact with critical load-bearing structural members to compromise the stability of the structure leading to its partial or complete collapse. Thus, there is a need to study and develop mitigation techniques for contact explosion threat to concrete columns. This study investigates the effect of cladding around reinforced concrete (RC) columns in mitigating the contact explosion effects. Three columns were enclosed with plywood cladding at different spacing and were subjected to contact explosion. The post-blast residual capacities of the columns were obtained through residual capacity testing in the laboratory. The results are compared to that of a benchmark column without cladding subjected to a contact explosion of the same yield. The results of the experimental studies indicate that the column cladding can significantly mitigate the effects of contact explosion on RC columns. A numerical analysis through validated models was carried out to investigate the effect of cladding on reinforced concrete columns. The simulation results predicted the residual axial capacity of the blastdamaged columns with good accuracy. Furthermore, the influence of energy absorbing material in the cladding gap was numerically modeled. The use of 100-mm thick energy absorbing material in the gap improved the contact explosion resistance of the RC columns.

Keywords: Contact explosion, FSI, Blast response, RC columns, Detonation, LS-DYNA, Mitigation

Submitted to the Journal of Structural Engineering, ASCE in a revised form Authors - Dua, Alok; Braimah, Abass; Kumar, Manish 


\subsection{Introduction}

Military structures and high occupancy buildings are often the prime targets of terrorist attacks to inflict maximum casualties by inducing complete or partial collapse of the structure. It is common knowledge that progressive collapse of a building is typically initiated by the sudden failure of load-bearing structural members such as columns. The survivability of buildings under blast loads is contingent on performance of the columns, as highlighted by the following review of past structural failures caused by the blast loads.

The terrorist attack on Alfred P. Murrah building in 1995 resulted in the partial collapse of the building due to the failure of critical load-bearing columns. Detonation of about $4000 \mathrm{lbs}(1814 \mathrm{~kg})$ of Trinitrotoluene (TNT) equivalent in a cargo truck parked near the building led to the failure of two load-bearing exterior columns. The lack of redundancy in the structure resulted in the progressive collapse of a large part of the building (Figure 5-1 (a)). The incident resulted in 268 fatalities and severe damage to nearby buildings which later needed to be demolished (Mlakar et al., 1998; Tagel-Din \& Rahman, 2006). In an earlier attack on the World Trade Centre in 1993, an explosive-laden vehicle was detonated in the underground parking of the building close to the columns, however, the adequate resistance of the columns to the induced blast loads prevented a collapse (Bažant \& Zhou, 2002) (Figure 5-1 (b)). 


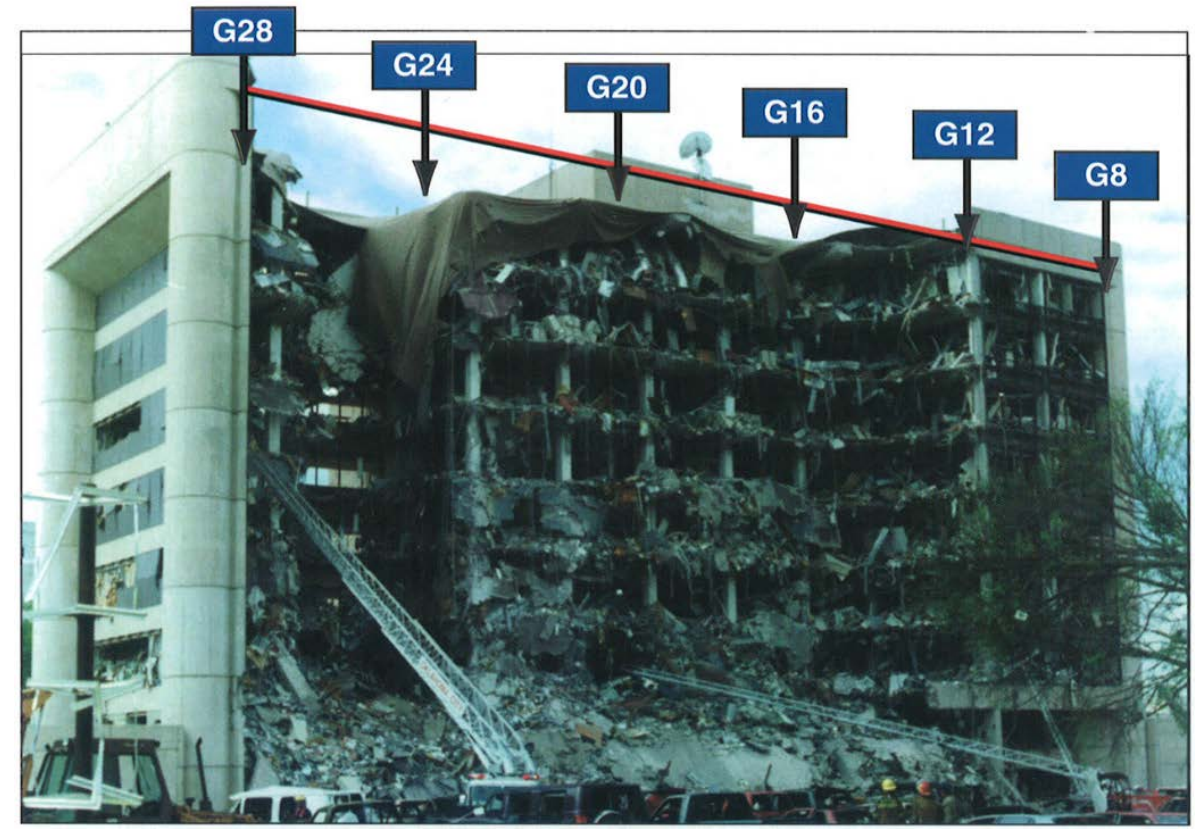

(a)

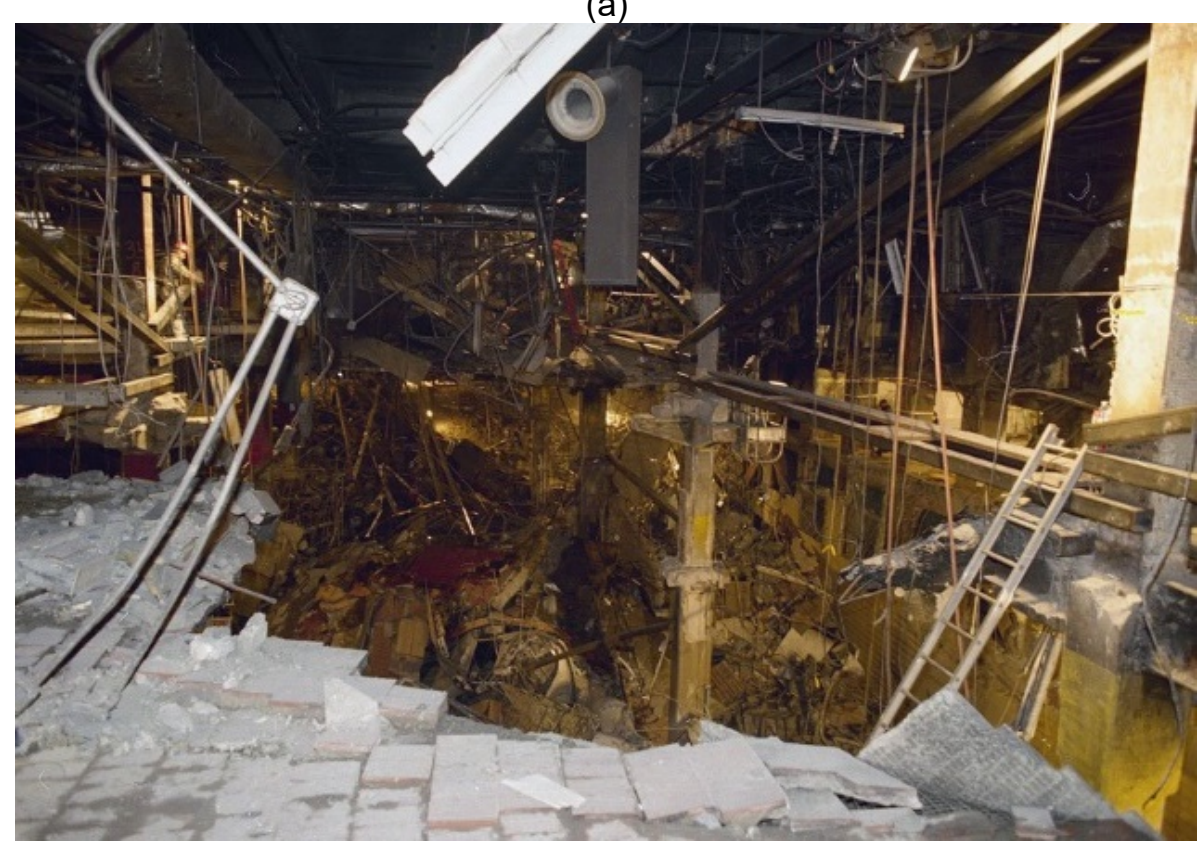

(b)

Figure 5-1 (a) 1995 Alfred P. Murray building bombing (FEMA, 1996) (b) 1993 World Trade Centre (WTC) bombing (DoHS, 1993)

Five buildings collapsed after the detonation of RDX placed in direct contact with critical columns of the buildings in the Russian apartment bombings in 1999 causing 293 deaths and 1000 injuries (Satter, 2003). In a recent attack in Mogadishu on October 14, 2017, more than 500 people were reported killed after 
a truck loaded with about $600-800 \mathrm{~kg}$ of TNT equivalent was detonated. The transverse loads due to blast pressure on building columns induced failure leading to complete collapse of several buildings. Apart from terrorist attacks against columns, there are instances where security forces are interested in targeting critical columns with precision to induce complete collapse of terrorists' hideout buildings without collateral damage (Tait, 2014).

A systematic approach towards an efficient protective design methodology has been developed for more resilient structures. However, the methodology is focussed on the global response of structures subjected to far-field explosion effects (DoD, 1987; FEMA, 2005; DoD, 2008). Although a few researchers have studied the response of reinforced concrete $(R C)$ members subjected to near-field effects, there is still a lack of knowledge on contact explosion effects. Contact explosion induces local shear damage or brisance failure in RC columns. Unlike a far-field explosion, the blast load parameters for contact explosion are difficult to characterize and challenging to acquire experimentally. There are no empirical or analytical methods available in the literature to assess the residual axial load capacity of RC columns damaged by contact explosions. Furthermore, mitigation techniques for contact explosion effects on RC members have not been adequately studied. This study presents the mitigation potential of cladding installed on building columns against contact explosion effects. The commonly used cladding materials are aluminum paneling, ceramics, wood, cementitious sheets (gypsum boards) and stone. The potential of widely available and costeffective plywood cladding in improving the resistance of RC columns to contact 
explosion effects is presented in the study. Claddings are considered sacrificial in nature and only the benefits of the increased standoff distance between the explosive and the RC columns are investigated. The performance of columns with cladding installed at different spacing are benchmarked against bare columns. Effect of cladding on the post-blast residual axial load capacity of columns is investigated qualitatively and quantitatively.

\subsection{Literature Review}

The analysis and design of reinforced concrete (RC) structural members to resist far-field explosions has been extensively studied. The analysis and design methodologies presented in design manuals and guidelines (DoD (1987), DoD (2002), FEMA (2005) and DoD (2008)) are appropriate for far-field explosion effects, where far-field explosions are defined as those with a scaled distance greater than $1.18 \mathrm{~m} / \mathrm{kg}^{1 / 3}$ (DoD (2008) and ASCE (2011)). Cormie et al. (2014a); Cormie et al. (2014b) have reported the inaccuracy of blast parameters predicted by Kingery and Bulmash (1984) charts and the ConWep computer program (Hyde, $1988)$ in the near-field range $\left(<0.4 \mathrm{~m} / \mathrm{kg}^{1 / 3}\right)$. A number of researchers have conducted numerical and experimental investigations into the response of RC members subject to near-field explosion effects; Hanssen et al. (2004); Enstock and Smith (2007); F. Wang et al. (2008); W. Wang et al. (2013); D. Zhang et al. (2013); Cormie et al. (2014b); Crawford et al. (2014); Naito et al. (2014); Cui et al. (2015). However, few researchers have extended their research to include the behavior of RC structural members subject to contact explosion effects. 
Furthermore, there are limited mitigation strategies presented in the literature to resist the effects of contact explosions on columns (Dua \& Braimah, 2016).

\subsubsection{Response of RC Components Subjected to Contact Explosion Effects}

The reference manual produced by the US Army Corps of Engineers (DoA, 2007), which presents explosive and demolition procedures for combat operations, provides an empirical relationship to calculate the breaching charge mass required for demolition of RC members like bridge pier, bridge abutments, and field fortifications. The weight of TNT required to breach RC piers is given as:

$$
P=R^{3} K C
$$

where $P$ is the TNT charge mass in pounds, $R$ is the required breach radius in feet, $K$ is the material factor (Table 5-1) and $C$ is the placement factor (Figure 5-2). Equation 5-2 is based on field trials, details of which are not disclosed in the manual. Effects of concrete strength, transverse reinforcement spacing and, longitudinal reinforcement ratio are not included in the empirical relation.

Table 5-1: Recommended values for material factors (DoA, 2007)

\begin{tabular}{|c|c|c|}
\hline Material & $\mathrm{R}$ & $\mathrm{K}$ \\
\hline Earth & All values & 0.07 \\
\hline Poor Masonry, Shale, Hardpan, Good & Less than $1.5 \mathrm{~m}(5 \mathrm{ft})$ & 0.32 \\
timber, Earth construction & $1.5 \mathrm{~m}(5 \mathrm{ft})$ or more & 0.29 \\
\hline Good Masonry, Concrete block, Rock & $0.3 \mathrm{~m}(1 \mathrm{ft})$ or less & 0.88 \\
& Over $0.3 \mathrm{~m}(1 \mathrm{ft})$ to less than $0.9 \mathrm{~m}(3 \mathrm{ft})$ & 0.48 \\
& $0.9 \mathrm{~m}(3 \mathrm{ft})$ to $1.5 \mathrm{~m}(5 \mathrm{ft})$ & 0.40 \\
& $1.5 \mathrm{~m}(5 \mathrm{ft})$ to less than $2.1 \mathrm{~m}(7 \mathrm{ft})$ & 0.32 \\
& $2.1 \mathrm{~m}(7 \mathrm{ft})$ or more & 0.27 \\
\hline Dense concrete, First-class masonry & $0.3 \mathrm{~m}(1 \mathrm{ft})$ or less & 1.14 \\
& Over $0.3 \mathrm{~m}(1 \mathrm{ft})$ to less than $0.9 \mathrm{~m}(3 \mathrm{ft})$ & 0.62 \\
& $0.9 \mathrm{~m}(3 \mathrm{ft})$ to $1.5 \mathrm{~m}(5 \mathrm{ft})$ & 0.52 \\
& $1.5 \mathrm{~m}(5 \mathrm{ft})$ to less than $2.1 \mathrm{~m}(7 \mathrm{ft})$ & 0.41 \\
\cline { 2 - 3 } & &
\end{tabular}




\begin{tabular}{|c|c|c|}
\hline & $2.1 \mathrm{~m}(7 \mathrm{ft})$ or more & 0.35 \\
\hline \multirow{5}{*}{$\begin{array}{l}\text { Reinforced Concrete (factor does not } \\
\text { consider cutting steel) }\end{array}$} & $0.3 \mathrm{~m}(1 \mathrm{ft})$ or less & 1.76 \\
\hline & Over $0.3 \mathrm{~m}(1 \mathrm{ft})$ to less than $0.9 \mathrm{~m}(3 \mathrm{ft})$ & 0.96 \\
\hline & 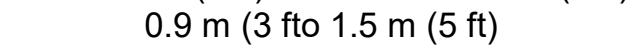 & 0.80 \\
\hline & $1.5 \mathrm{~m}(5 \mathrm{ft})$ to less than $2.1 \mathrm{~m}(7 \mathrm{ft})$ & 0.63 \\
\hline & $2.1 \mathrm{~m}(7 \mathrm{ft})$ or more & 0.5 \\
\hline
\end{tabular}

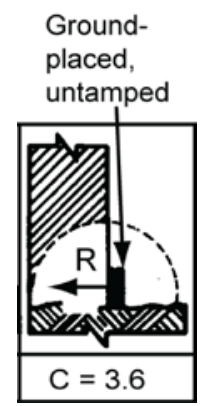

(b)

Figure 5-2: Placement factor for a charge mass placed on the ground (DoA, 2007)

DoT (2009) reported experimental tests to investigate the response of RC bridge columns subjected to far-field, near-field and contact explosions (Williams, 2009). Both square and circular cross-section columns were tested at various scaled distances. Numerical models were qualitatively validated from the experimental results by comparing the damage profile. The authors reported that while the backface spalling due to blast loading was documented in the literature, the side-cover spalling in RC columns was not well documented (Williams \& Williamson, 2011). The side face spalling in RC columns subjected to contact explosion was attributed to the Poisson's effect. The compressive force due to a contact explosion caused expansion of the column core perpendicular to the direction of loading and that this expansion occured early during the loading phase prior to global response of the column. Strain rate effects were not considered for the numerical simulations presented in the study. It was concluded that the perceived increase in concrete strength at high strain rate loading is due to the inertial confinement provided by the outer concrete layer. Since this phenomenon is inherently captured by finite 
element formulation, dynamic increase factors (DIF) were not incorporated in the material model of the concrete.

Riedel et al. (2010) reviewed a range of predictive methods for damage assessment of RC components subjected to explosion effects at various scaled distances (Z). A review of experimental and numerical studies reported in the literature was also presented. The parameters used for damage quantification were crater depth, crater diameter, spall depth, and spall diameter. Riedel et al. (2010) reported that for $Z>0.5 \mathrm{~m} / \mathrm{kg}^{1 / 3}$, an $R C$ wall responds in global bending whereas for $Z<0.5 \mathrm{~m} / \mathrm{kg}^{1 / 3}$, shear or punching failures are observed.

Wu et al. (2011) proposed empirical relationships, based on experimental and numerical data, to calculate residual axial compression capacity of localized blastdamaged RC columns and steel composite RC columns. The authors subjected two RC columns to the detonation of $25 \mathrm{~kg}$ TNT mass at $200 \mathrm{~mm}$ and $500 \mathrm{~mm}$ distance. The columns were provided with foundation blocks at top and bottom. The columns were laid on the ground and hence only the ground reaction supported the columns. The high explosive mass crushed the concrete core and the damage profile was used to validate the numerical models. For the numerical simulations, an element size of $50 \mathrm{~mm}$ was used to create the column as well as the Arbitrary Lagrangian-Eulerian (ALE) domains. The effects of the initial axial load were not considered in this study. Actual boundary conditions as in the case of real-life structures were not created in this study for the experimental tests. An explosive mass ratio, defined as the ratio of explosive charge mass to the mass of 
1-m high column, was proposed and utilized to quantify explosion damage to columns. Contact explosion due to the explosive mass ratio of 0.04 resulted in a $60 \%$ residual axial capacity when an explosive was detonated at the bottom of the column. On the other hand, $90 \%$ residual axial capacity was obtained when the explosive was detonated at a height of $1.5 \mathrm{~m}$ from the ground. The column height did not have any effect on the residual capacity of blast-damaged columns.

Arlery et al. (2013) performed numerical simulations to predict the damage and residual axial capacity of RC columns subjected to contact explosions. Numerical models were developed in ABAQUS and validated using the experimental data of the study presented by Wu et al. (2011). The RC columns, air domain, and explosive domain were meshed with $15-\mathrm{mm}$ size brick elements to numerically model the response of RC columns subjected to contact explosion effects. An empirical equation was reported based on the parametric analysis to predict the residual axial capacity of the blast-damaged columns. The authors reported that thickness of the column, charge mass and the standoff distance are the most significant parameters for the response due to contact or near-contact events. The column width, column height, and concrete compressive strength do not play important role in the response.

J. Li et al. (2015) conducted experimental and numerical studies to assess the performance of Ultra-High-Performance Concrete (UHPC) slabs subjected to contact explosion. The performance of UHPC slabs was compared to normal strength concrete slabs. The LS-DYNA models for the study used DIF to include 
strain rate effects in the material model of concrete as per the recommendation of Malvar and Crawford (1998). Damage profiles were compared qualitatively through observation of the crater diameter on top and scab diameter on the bottom of the slabs. The numerical results were reported to be consistent with the experimental observation. The study concluded that UHPC slabs exhibited enhanced blast resistance compared to normal strength concrete slabs.

Recently, Yuan et al. (2017) presented a study on the experimental and numerical response of square and circular RC bridge piers subjected to contact explosion of $1 \mathrm{~kg}$ TNT equivalent explosive. Axial load on the column was not considered for the experimental tests. The experimental and numerical damage profiles were compared for qualitative validation while accelerometer data were compared for quantitative validation. The Lagrangian entities in the LS-DYNA model were meshed with element sizes varying between $8 \mathrm{~mm}$ and $20 \mathrm{~mm}$ and the MMALE domain was meshed with an element size of $20 \mathrm{~mm}$. The LS-DYNA numerical models reasonably captured the experimental results, except for the damage to the column face opposite to detonation.

As is evident from the above discussion, only a few studies are available in open literature on the response of $\mathrm{RC}$ members subject to contact explosion. Moreover, many of the studies have investigated the response of RC slabs to contact explosions. However, the response of RC slabs cannot be extended to RC columns. This is because the predominantly one-dimensional (1D) shock wave propagation mechanism in RC slabs differs significantly from shock wave 
propagation in columns which is predominantly two-dimensional (2D). The slab failure modes of crater-spall and punching (breach) result in a definite crushed, scabbed or punched diameters and hence are easy to validate (Dua et al., 2017). Few studies are available on response $\mathrm{RC}$ columns due to contact explosion when compared to RC slabs. The results reported by DoT (2009) are the most exhaustive, however complete experimental data has not been made open sourced and hence validation from these results is not possible. In addition to the experimental studies, the numerical results reported in the literature were obtained using meshed element sizes in the range of $8 \mathrm{~mm}$ to $50 \mathrm{~mm}$ for the Lagrangian entities and $10 \mathrm{~mm}$ to $20 \mathrm{~mm}$ for the MMALE domains. However, recent studies (Trajkovski et al., 2014; Dua \& Braimah, 2018) recommends an element size of 1 $\mathrm{mm}$ to accurately model MMALE domain and the detonation phenomenon.

\subsubsection{Numerical Simulations}

Numerical simulations of near-field and contact explosion events have been presented by many researchers (Akers et al., 2005; Zhao et al., 2008; Zakrisson et al., 2011; Arlery et al., 2013; Cheng et al., 2013; W. Wang et al., 2013; Cormie et al., 2014b; J. Li \& Hao, 2014; P. Zhang et al., 2014). Wu et al. (2011) presented residual axial compression capacity of RC columns subjected to contact explosion effects. The numerical model was qualitatively validated by comparing the numerically predicted damage profile of concrete elements to the experimental results. The numerical model was further implemented for predicting the residual axial load carrying capacity of the blast-damaged columns. B. Li et al. (2012) experimentally evaluated the residual axial capacity of $\mathrm{RC}$ columns subjected to 
simulated blast loads for $0.72 \mathrm{~m} / \mathrm{kg}^{1 / 3}$ scaled distance. $\mathrm{RC}$ column specimens were deflected laterally to emulate numerically predicted lateral response to far-field blast loading. These specimens were then loaded axially to acquire the axial capacity of simulated blast-damaged columns. The authors concluded that axially loaded columns display better resistance to blast effects due to increased stiffness and shear resistance. This effect is applicable up to a certain impulse range beyond which the lateral displacement would increase tremendously. It was reported that higher transverse reinforcement ratios provided additional shear strength. An empirical equation to predict the residual axial capacity of blastdamaged column was proposed by the authors. Wu et al. (2011); Yuan et al. (2017) recently conducted live explosion tests on RC columns and developed validated numerical models to predict the spall damage.

There are three prevalent techniques used for blast analysis of structures: (a) Simplified analytical methods such as Pressure-Impulse (PI) charts, single degree of freedom (SDOF) or multi-degree of freedom (MDOF) dynamic analysis using blast load parameters generated from empirical charts provided by DoD (2008), Kingery and Bulmash (1984), DoD (1987) or other such codes, (b) Non-linear finite element analysis implementing blast load parameters generated from empirical equations and charts by Kingery and Bulmash (1984), DoD (2008), DoD (1987) and (c) high fidelity finite element analysis programs with explicit modelling of the detonation process, blast wave propagation and fluid-structure-interaction (FSI). While the first two methods can accurately predict far-field blast response, contact explosion can be accurately modeled with MMALE formulation as it provides a 
complete description of the blast wave parameters (Børvik et al., 2009). The technique involves modeling the chemical reaction during detonation and consequent blast wave propagation. However, the primary disadvantage of modeling detonation and propagation is mesh sensitivity (Kakogiannis et al., 2010) and hence a higher computational cost due to a fine mesh requirement. Kalra et al. (2014) presented a 2D to 3D MMALE mapping technique in LS-DYNA for reducing the computational cost. The explosive detonation and blast wave propagation was simulated in the $2 \mathrm{D}$ domain and mapped to a $3 \mathrm{D}$ domain to implement the FSI between the generated blast wave and the Lagrangian entity. This technique, however, cannot be implemented for modeling contact explosions as the explosive detonation and FSI occurs simultaneously. Simulating detonation and FSI in 2D will not represent the phenomenon as the blast wave is spatially and temporally non-linear around the explosive. Moreover, the spatially non-linear Lagrangian response in 3D will not be captured. Hence, a finely meshed 3D domain is required to accurately model the detonation process and the Lagrangian response during a contact explosion event.

The finely meshed 3D air domain must be modeled large enough to avoid reflection of the blast wave from the air domain boundary during the whole event. This results in a large memory prerequisite. Lately, massive parallel processing (MPP) abilities have been introduced by LS-DYNA that allows parallel processing and availability of large memory resources. Albeit these, resources are difficult to access and demands additional skills for setup. 
A review of the numerical studies in the literature suggests a scarcity of research on contact explosion events. The limited studies found in the literature are either not validated experimentally or are qualitatively validated by comparing the damage profiles of the blast-damaged members. Moreover, the element mesh size considered for the detonation process is coarse as per the mesh sensitivity analysis presented in this study.

\subsubsection{Mitigation Strategies}

Mitigation strategies such as high strength materials and energy absorption materials are recommended in the literature for far-field events. J. Li et al. (2015) presented the benefits of ultra-high-performance concrete (UHPC) over normal strength concrete to resist blast effects. Soft condensed materials were used successfully by Nesterenko (2003) for mitigation of shock/blast waves due to contact explosion effects. However, it was reported that the ensuing amplitude of the blast load on the structure may be enhanced by the soft condensed material resulting in higher damage compared to unprotected target/structure. This may come into effect if the energy absorbing material is too porous or too thin for the shock wave generated by the explosion. The author presented a critical thickness of the energy absorbing medium to preclude the shock amplitude enhancement in this study. The mitigation potential of cladded columns was not found in the literature. 


\subsection{Research Significance}

The literature review above identifies certain gaps in the state-of-the-art in the response of RC columns subjected to contact explosion effects and mitigation strategies. This study investigates the mitigation of contact explosion effect by providing a plywood cladding over the RC columns. The main objectives of the study are as follows:

- Experimentally obtain the response of cladded RC columns subjected to effects of the detonation of varying explosive mass in contact with the cladding and compare the results those for bare RC columns.

- Experimentally investigate the influence of standoff between the cladding and incident column face.

- Experimentally test the residual axial load carrying capacity of the blastdamaged columns to quantify the damage.

- Develop experimentally validated numerical models on LS-DYNA and study the failure modes in RC columns subjected to contact explosion effects.

\subsection{Experimental Investigation}

Six experimental tests were performed on bare $\mathrm{RC}$ columns and clad RC columns. The columns were founded $900 \mathrm{~mm}$ below ground level with an isolated footing of $900 \times 900 \times 450 \mathrm{~mm}$. A square cross-section of $300 \times 300 \mathrm{~mm}$ was provided to all the columns. No support provided at the top and the columns were thus free-standing. Three bare columns were subjected to contact explosion of different explosive 
masses and the residual axial capacity of the blast-damaged columns was obtained experimentally. Clad columns of the same geometric specifications as the bare columns were subjected to detonation effects of the same range of explosive mass to quantify the improvement in the residual capacity of the blastdamaged cladded columns.

\subsubsection{Contact Explosion}

Three bare RC columns of $300 \times 300 \mathrm{~mm}$ cross-section with $25 \mathrm{MPa}$ design compressive strength and 0.014 longitudinal reinforcement ratio were subjected to contact explosion effects of 1000-g, 500-g and 115-g TNT charges. The details of the RC columns are presented in Figure 5-3(a). Three plywood clad RC columns with details as shown in Figure 5-3(c) were subjected to the contact explosion effects of 115-g and 500-g TNT charges. The clad columns had a design concrete strength of $25 \mathrm{MPa}$ and were reinforced with steel bars having a reinforcement ratio of 0.01 . The three columns were enclosed with $3 \mathrm{~mm}$ thick plywood cladding up to a height of $1 \mathrm{~m}$ from the ground. The enclosures were offset $50-\mathrm{mm}$ and $100-$ $\mathrm{mm}$ from the incident face. The test layouts before subjecting the columns to contact explosion effects are presented as Figure 5-3(c) \& (d) for bare and cladded $\mathrm{RC}$ columns respectively. 


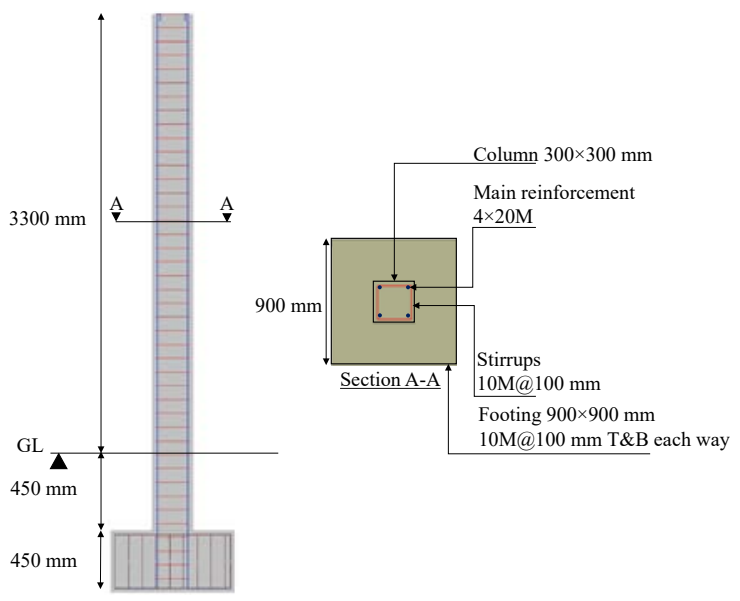

(a)

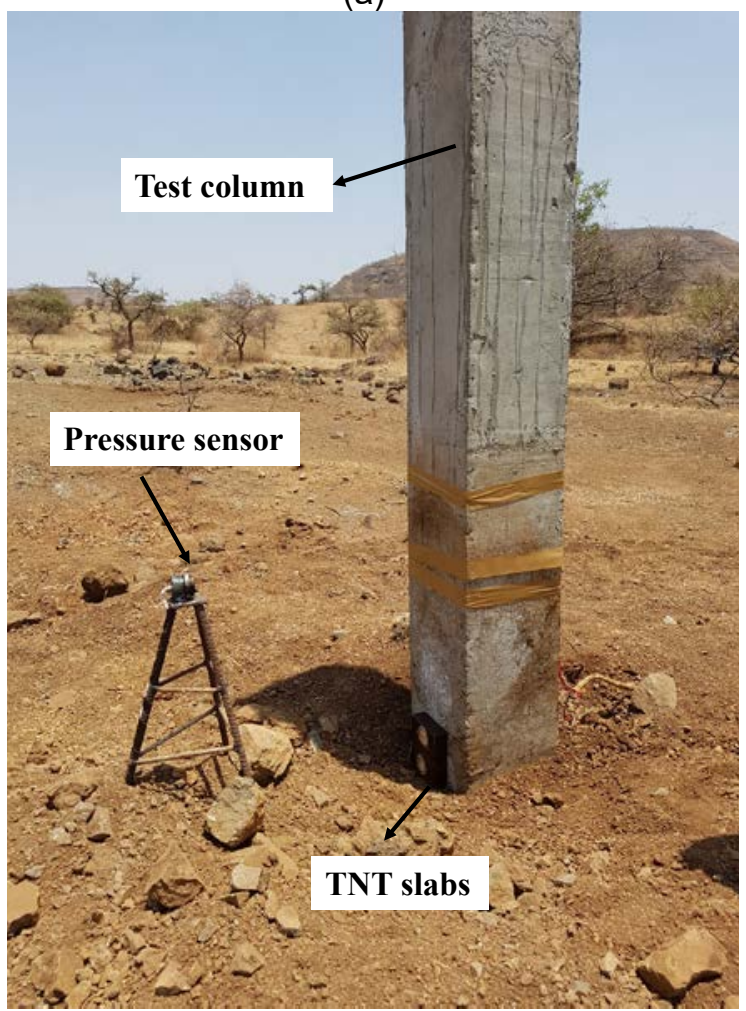

(c)

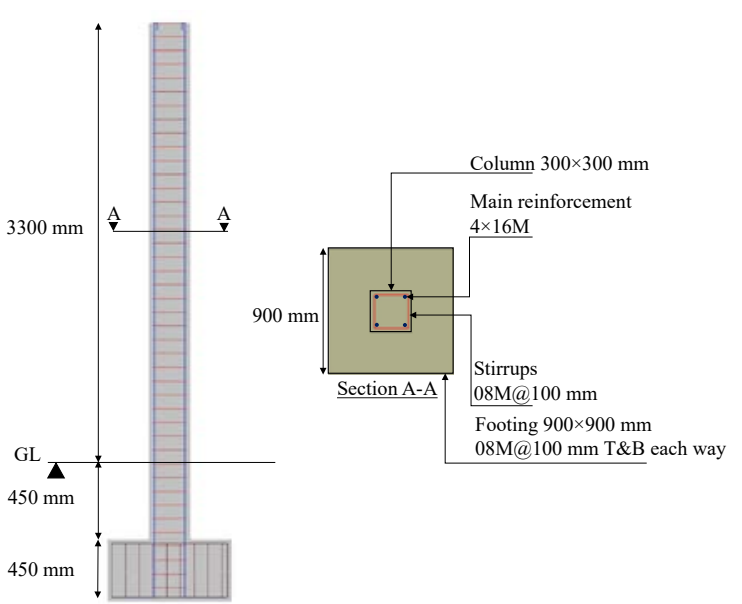

(b)

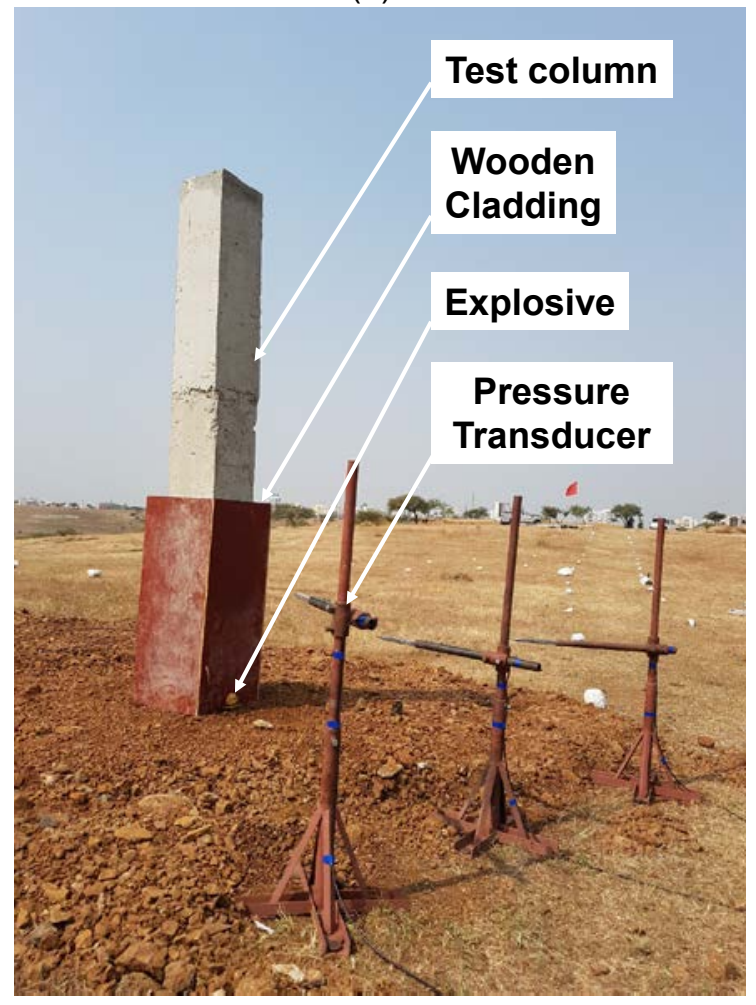

(d)

Figure 5-3: RC column details for (a) Bare columns (b) Clad columns; Test layout for (c) Bare columns (d) Clad columns

The test (or sample) designations are presented in Figure 5-4. 


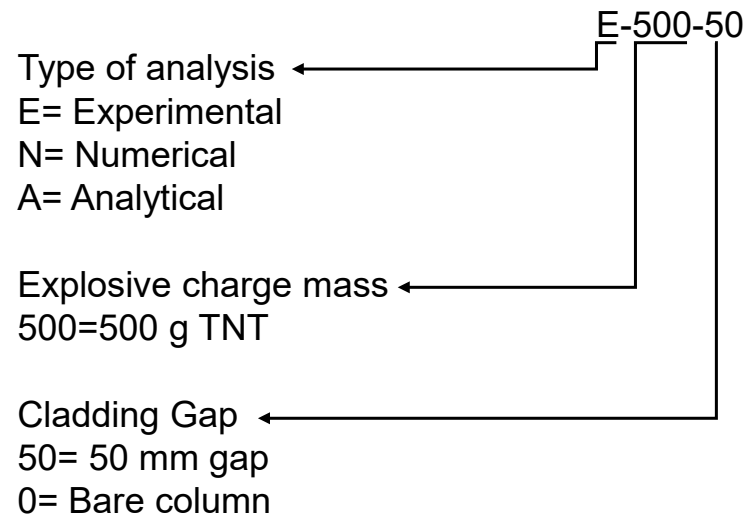

Figure 5-4: Test case designation.

The tests were conducted in two phases; bare columns and clad columns and hence the concrete was cast in two lots. The concrete compressive strength achieved was obtained by sampling and testing $75 \mathrm{~mm}$ cores from the six columns. The average concrete compressive strength for the bare columns was $25 \mathrm{MPa}$ and that for the cladded columns was $20 \mathrm{MPa}$. Accordingly, the nominal axial load carrying capacity of bare columns was $2431 \mathrm{kN}$ and for cladded columns was 1865 $\mathrm{kN}$. The column interaction diagrams for both the columns are presented in Figure $5-5(a) \&(b)$. The axial capacity of the columns was also simulated in LS-DYNA and the load-displacement curves until failure are presented in Figure 5-5(c)\&(d). The numerically determined failure loads compared well with the analytical nominal failure loads under pure axial loading. 


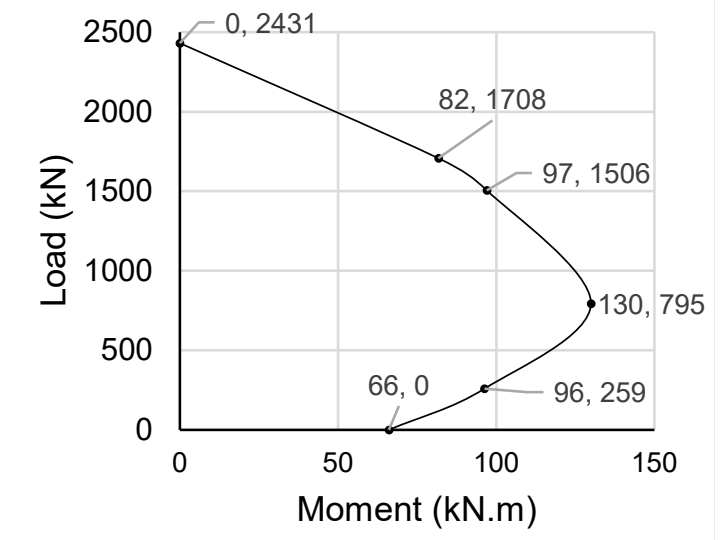

(a)

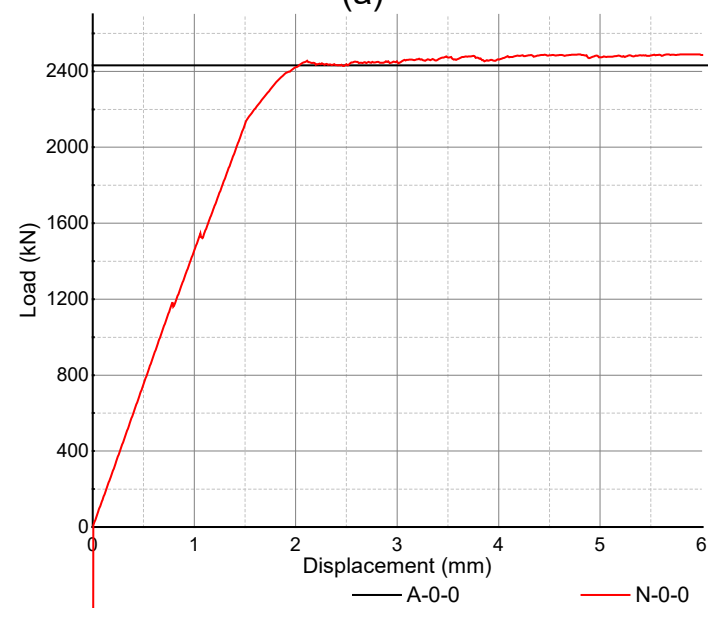

(c)

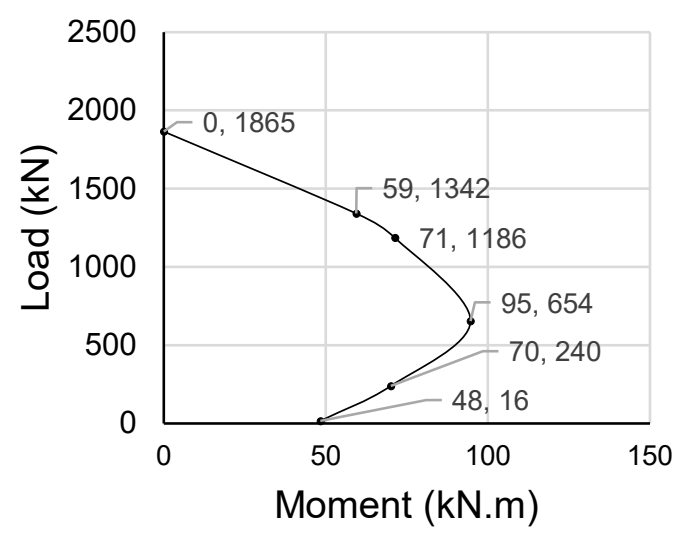

(b)

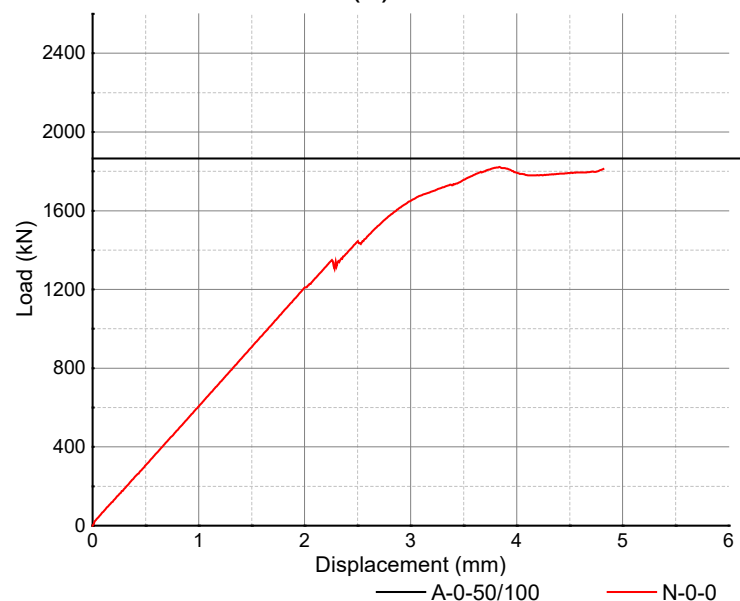

(d)

Figure 5-5: Column interaction diagram for (a) Bare columns (b) Clad columns; Loaddisplacement curve for (c) Bare columns (d) Clad columns

The explosives were placed at the ground level in direct contact with the column or the cladding. The test matrix is presented in Table 5-2.

Table 5-2: Test Matrix

\begin{tabular}{|c|c|c|c|}
\hline $\begin{array}{l}\text { Test } \\
\text { No. }\end{array}$ & $\begin{array}{c}\text { Column } \\
\text { type }\end{array}$ & Air gap & TNT Explosive-mass (g) \\
\hline 1 & \multirow{3}{*}{ Bare } & 0 & 1000 \\
\hline 2 & & 0 & 500 \\
\hline 3 & & 0 & 115 \\
\hline 4 & \multirow[t]{3}{*}{ Cladded } & 50 & 115 \\
\hline 5 & & 50 & 500 \\
\hline 6 & & 100 & 500 \\
\hline
\end{tabular}


The detonation velocity and density of the TNT explosive used for the tests were $6930 \mathrm{~m} / \mathrm{s}$ and $1550 \mathrm{~kg} / \mathrm{m}^{3}$ respectively.

\subsubsection{Residual Axial Load Capacity}

The blast-damaged columns were extracted from the ground and prepared for residual axial load tests. The experimental setup is illustrated in Figure 5-6(a) and the test layout is presented in Figure 5-6(b).

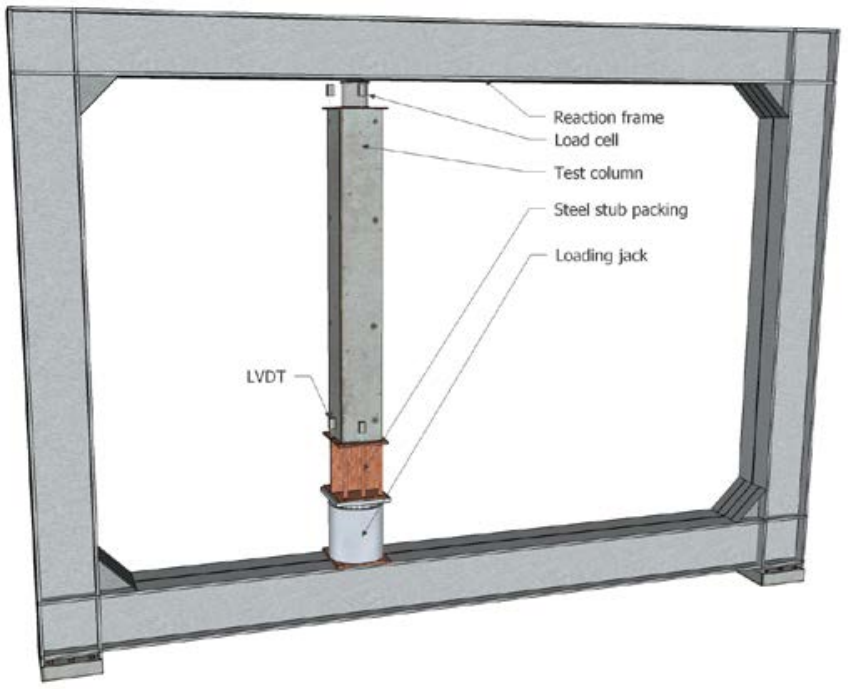

(a)

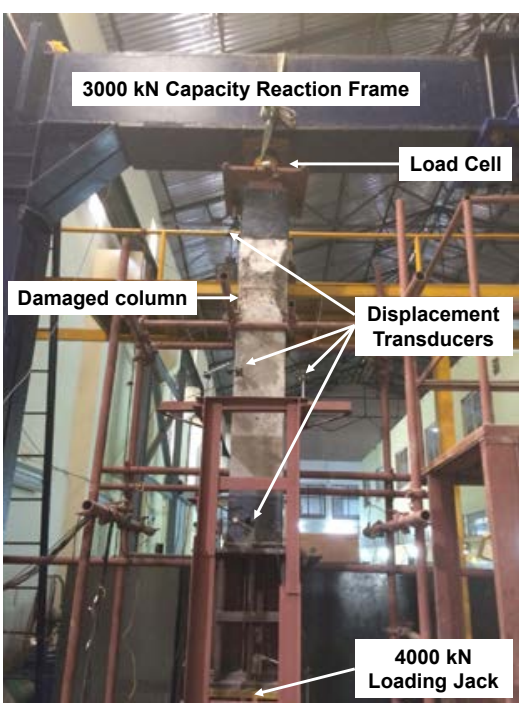

(b)

Figure 5-6: Experimental layout for residual axial capacity tests (a) Illustration (b) Actual layout

A 3000-kN capacity self-reacting frame was used to load the columns axially. A hydraulic jack was placed on the bottom girder while a load cell was placed between the test column and the top girder to monitor the concentric axial loading. Due to the height restriction of the testing frame, the columns were cut to size using diamond wire cutters (Figure 5-7(a)). The damage induced on the RC columns due to contact explosion was concentrated at the point of detonation without visible damage to the concrete $1-\mathrm{m}$ or more above the point of contact detonation. 
Accordingly, it was assumed that cutting the RC columns to size outside of the blast damaged section will not have a significant effect on the residual axial capacity of the columns.

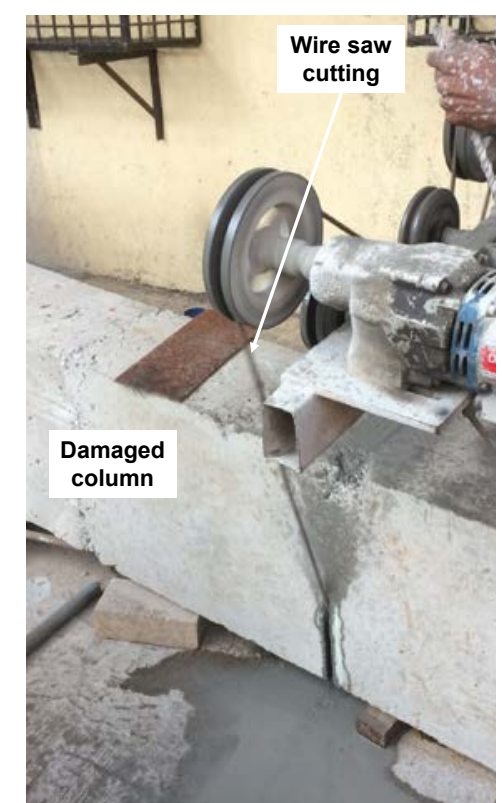

(a)

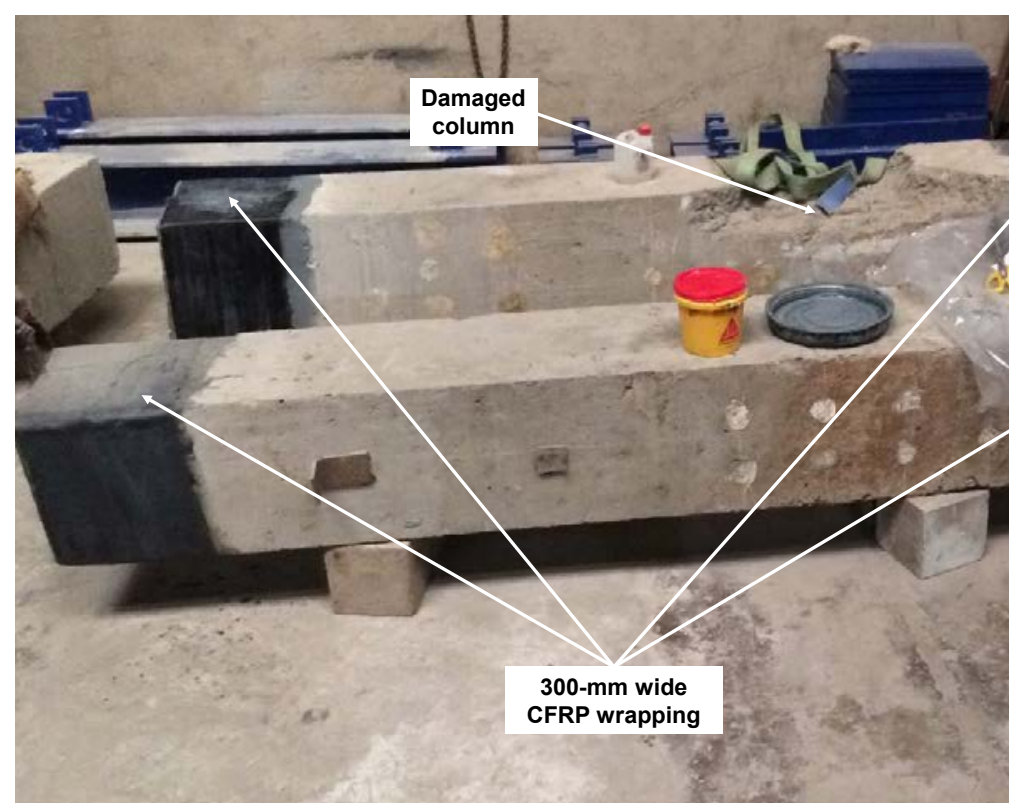

(b)

Figure 5-7: Preparation of columns for residual axial load carrying capacity tests (a) Wire saw concrete cutting (b) CFRP wrapping at top and bottom for strain compatibility

Bearing plates were installed on top and underneath the column to transfer the load to the RC column. The 300-mm ends of the column were wrapped with carbon fibre reinforced polymer (CFRP) sheets to confine the concrete and allow for effective transfer of axial load without premature failure of concrete at the ends (Figure 5-7(b))

Eight linear variable displacement transducers (LVDT) were installed on an independent support frame to measure axial and lateral deformations of the RC columns. 


\subsection{Experimental Results}

\subsubsection{Contact Explosion}

The bare RC columns were subjected to contact explosion effects of $1 \mathrm{~kg}, 500 \mathrm{~g}$ and $115 \mathrm{~g}$ TNT. The concrete core up to a length of $375 \mathrm{~mm}$ from the ground level was completely removed by the effects of the $1 \mathrm{~kg}$ TNT explosion (Figure 5-8 (a)). The $500 \mathrm{~g}$ TNT explosion effects resulted in the crushing of the concrete cover up to $675 \mathrm{~mm}$ and led to severe damage to the core (Figure 5-8 (b)). The column subjected to 1-kg TNT explosion effects clearly possessed zero residual axial load capacity. The column subjected to $500 \mathrm{~g}$ TNT explosion effects buckled under selfweight during removal from the ground and was not tested under static loading conditions. The 115-g TNT explosion caused a crater-spall failure mode. On the other hand, the 115-g TNT equivalent charge caused a cratering with a minimum height of $180 \mathrm{~mm}$ diameter at the point of detonation on the column. The cratering occurred due to the direct impact of the detonation that crushed the concrete around the area of contact. The shock wave imparted to the column reflected from the side faces and resulted in spalling of concrete cover where the tensile strength is least. The concrete spalled up to a height of $400 \mathrm{~mm}$ at the corners of the front face and side faces. Furthermore, the spall region extended into the crater forming a damage profile as seen in Figure 5-8 (c). The back face displayed no spall damage but a horizontal hair-line crack was formed (Figure 5-8 (c)). 


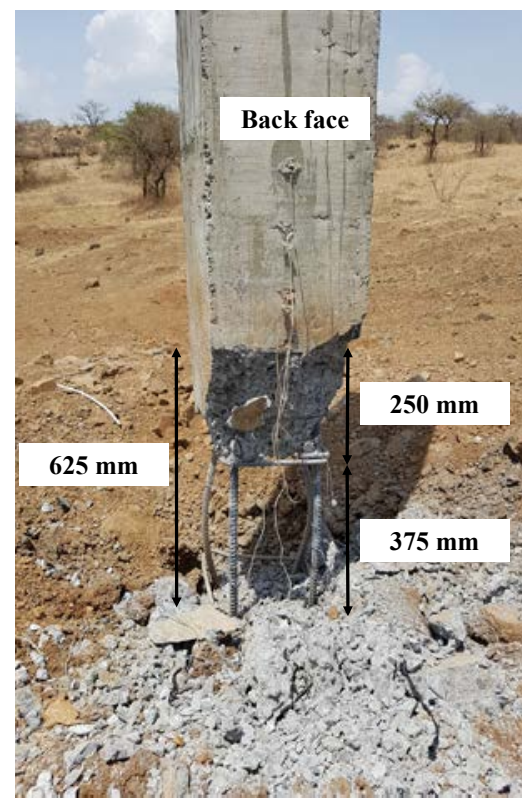

(a)

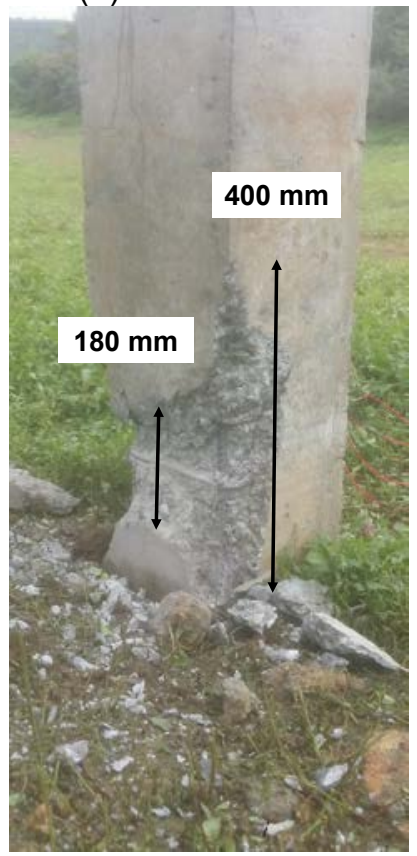

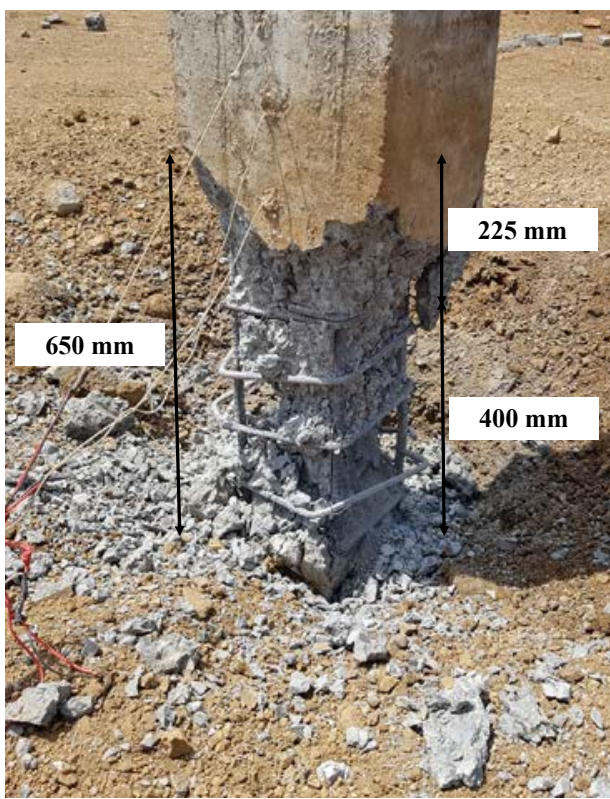

(b)

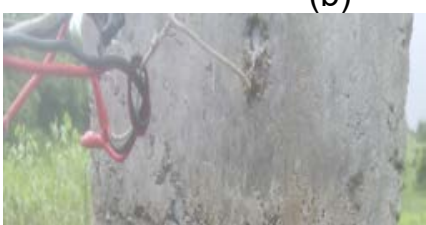

Single crack

in distal face

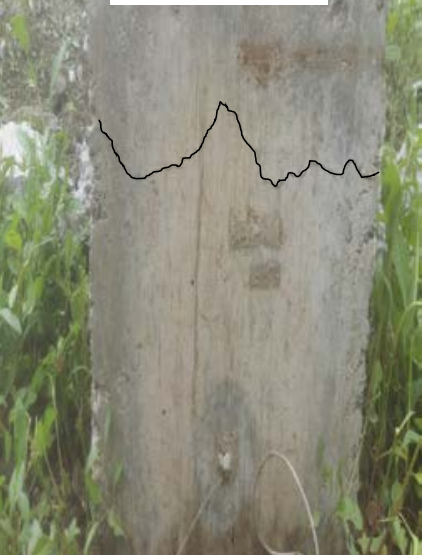

(c)

Figure 5-8: Response of RC columns to the detonation of (a) $1000 \mathrm{~g}$ TNT (b) $500 \mathrm{~g}$ TNT (c) $115 \mathrm{~g}$ TNT

The clad RC column with 50-mm gap suffered negligible damage under the effect of 115-g TNT explosion in contact with the cladding Figure 5-9(b). The plywood cladding was damaged completely and got stripped. A 90-mm diameter crater was formed on the front face due to the crushing of concrete and minor concrete 
spalling was observed at the corners of the front face. There was no visual damage to the concrete core. The damage profiles of bare and clad columns subjected to explosion effects of $115 \mathrm{~g}$ TNT are compared in Figure 5-9(a) and (b). The damage profiles suggest that the $50-\mathrm{mm}$ gap induced via plywood cladding preserved the crushing and spalling effects on the column. The response of the clad RC columns was better than that of the bare columns despite the lower concrete compressive strength in the former.

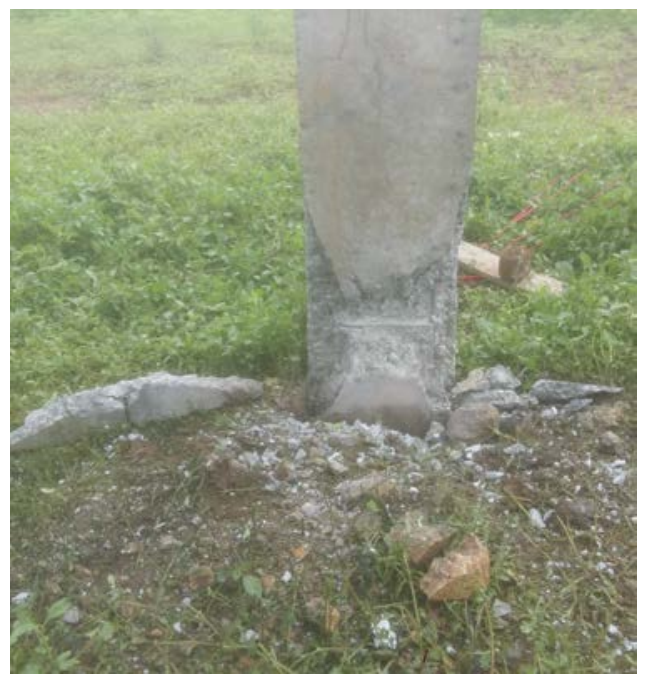

(a)

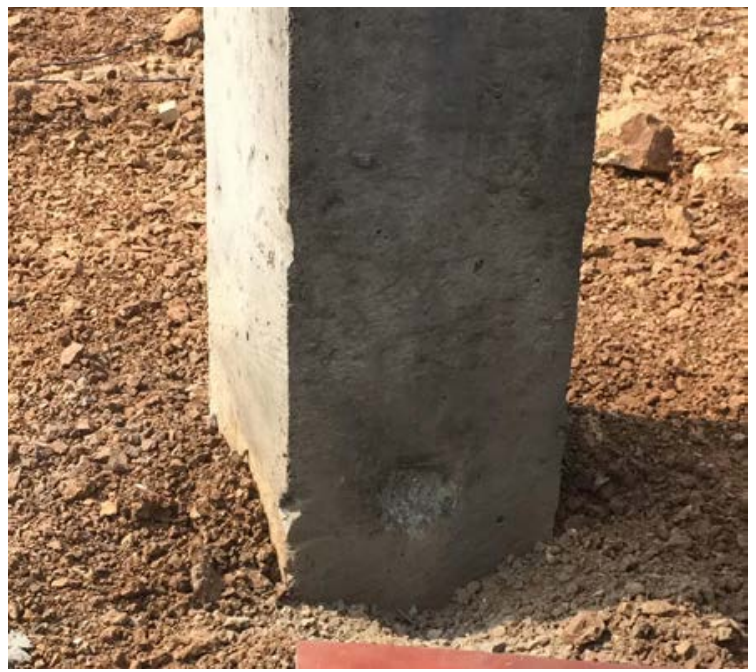

(b)

Figure 5-9: Comparison of bare and clad columns (a) E-115-0 (b) E-115-50

Figure 5-10 (a) presents the damage profile for the clad RC column with a $50 \mathrm{~mm}$ gap when subjected to contact explosion effects of $500 \mathrm{~g}$ TNT. The concrete cover on the sides spalled from front corner to back corner up to a height of $480 \mathrm{~mm}$ from the ground level. The detonation resulted in concrete spall up to a height of $100-$ $\mathrm{mm}$ on the incident face that merged with the side face concrete cover spall. Concrete cracking was observed between the corners of the distal face, Figure 5-31 (d). The exposed portions of the core had visual cracks that suggest damage 
extension into the core. The damage profile is compared to the response of bare column subjected to the contact explosion effects of $500 \mathrm{~g}$ TNT (Figure 5-10 (b)). The damage profiles suggest that the $50 \mathrm{~mm}$ gap induced by the plywood cladding improved the column performance in resisting contact explosion effects.

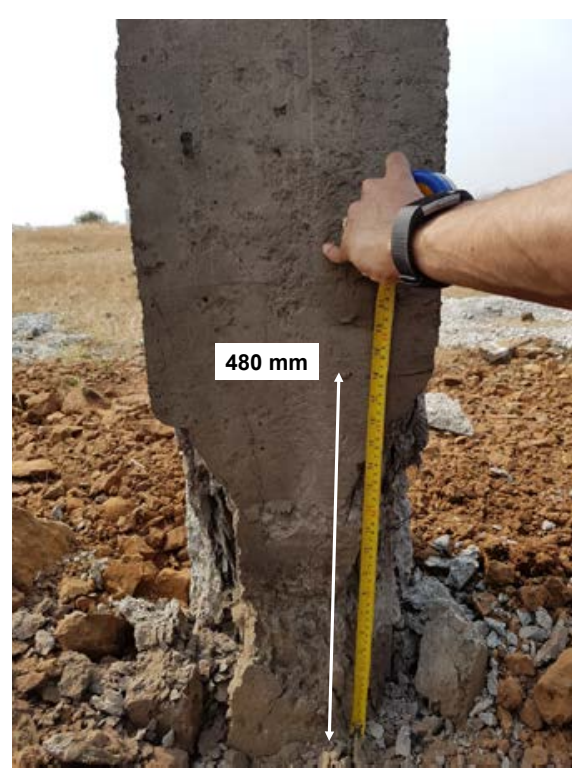

(a)

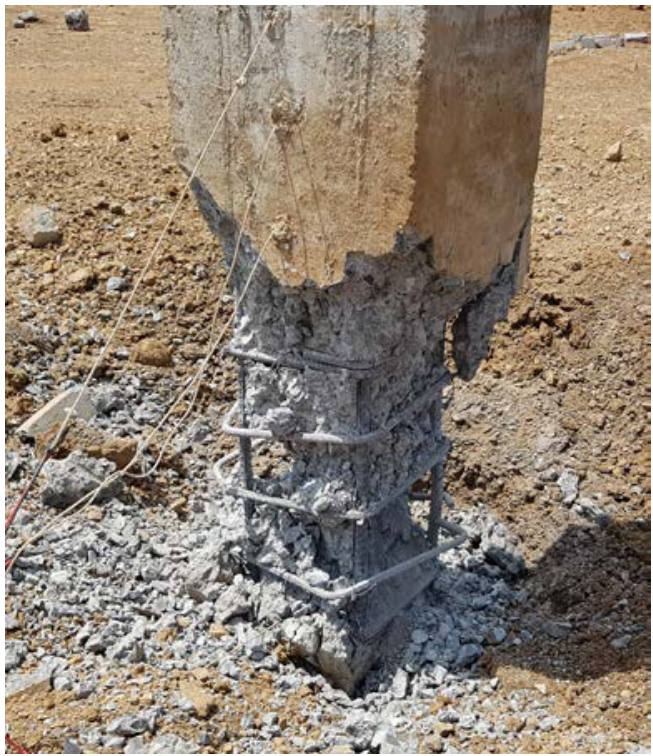

(b)

Figure 5-10: Damage profile of blast-damaged (a) E-500-50 (b) E-500-0

The third test investigated the effect of the gap between the cladding and the column face. A cladded RC column with 100-mm gap was subjected to the contact explosion effects of $500 \mathrm{~g}$ TNT. Concrete cover up to a height of $500 \mathrm{~mm}$, from the ground level, spalled from the side face corners. No visual damage to the concrete core was observed. A 100-mm crater was formed on the front face while the back face suffered superficial cracking extending between the sides. Figure 5-11(a) \& (b) present the test setup and damage profile for test E-500-100. A comparison of damage profiles presented in Figure 5-9 (b), Figure 5-10 (a) \& Figure 5-11 (b) clearly brings out the evolution in the damage mechanism of an RC column subjected to the effects of same explosive mass at various cladding gaps. The 
effects of contact explosion on a bare column crushed the concrete core completely, however a gap as small as $50 \mathrm{~mm}$ prevented the total crumbling of the core. Furthermore, a gap of $100 \mathrm{~mm}$ induced via the plywood cladding reduced the concrete spall significantly.

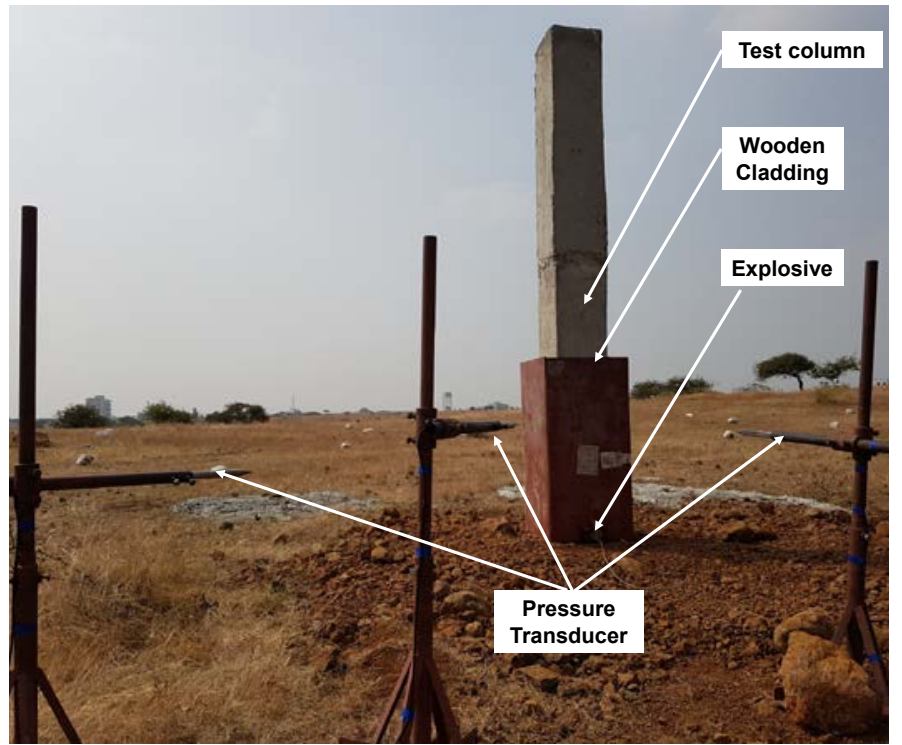

(a)

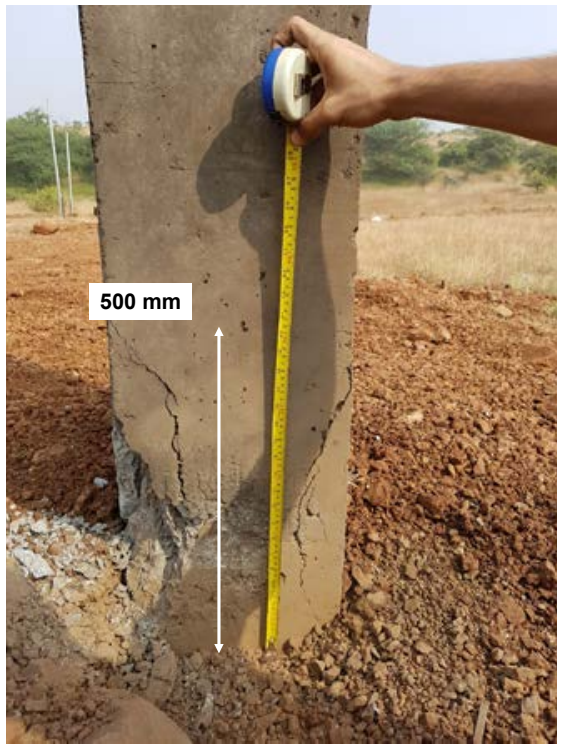

(b)

Figure 5-11: (a) Test setup (b) Post-explosion damage profile

\subsubsection{Residual Axial Load Capacity}

The residual axial capacity of the bare RC column subjected to the effects of 115 g TNT contact explosion was experimentally determined to be $2050 \mathrm{kN}$. The axial load was applied until failure of the column and as expected, the column failed due to crushing of concrete at the blast-damaged zone (Figure 5-12(b)). The residual axial capacity of the column subjected to $115-\mathrm{g}$ TNT contact explosion was $84 \%$ of the nominal analytical capacity of the undamaged column.

The bare columns subjected to $500 \mathrm{~g}$ and $1 \mathrm{~kg}$ TNT explosion effects were not tested for residual capacity. The $1 \mathrm{~kg}$ TNT explosion removed the bare column's 
core completed and obviously it did not have any residual capacity (Figure 5-8(a)) while the bare column subjected to the effects of $500 \mathrm{~g}$ TNT explosion (Figure $5-8(b))$ buckled under self-weight during removal from the ground. This indicates that the column had failed and did not have any significant axial strength left.

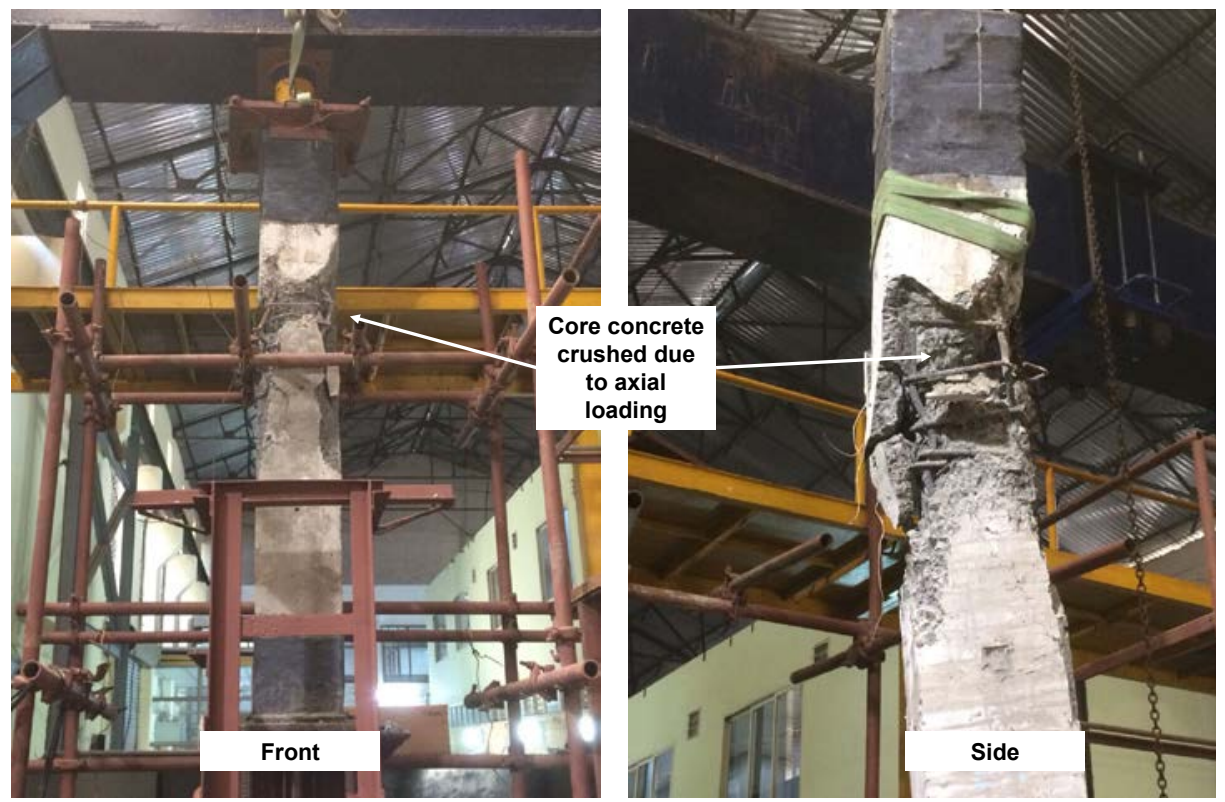

Figure 5-12: Residual axial load carrying capacity for test E-115-0

The clad RC column with $50 \mathrm{~mm}$ gap subjected to the effects of 115-g TNT contact explosion failed at an axial load of $1778 \mathrm{kN}$ which is almost equal to the axial capacity of $1865 \mathrm{kN}$ for the undamaged column. The failure occurred in the top zone of the concrete column just below the CFRP wrap, suggesting that there was no significant damage to the column due to the explosion (Figure 5-13). The residual axial capacity of the clad column was $95 \%$ of the analytical nominal axial capacity of the undamaged column. 


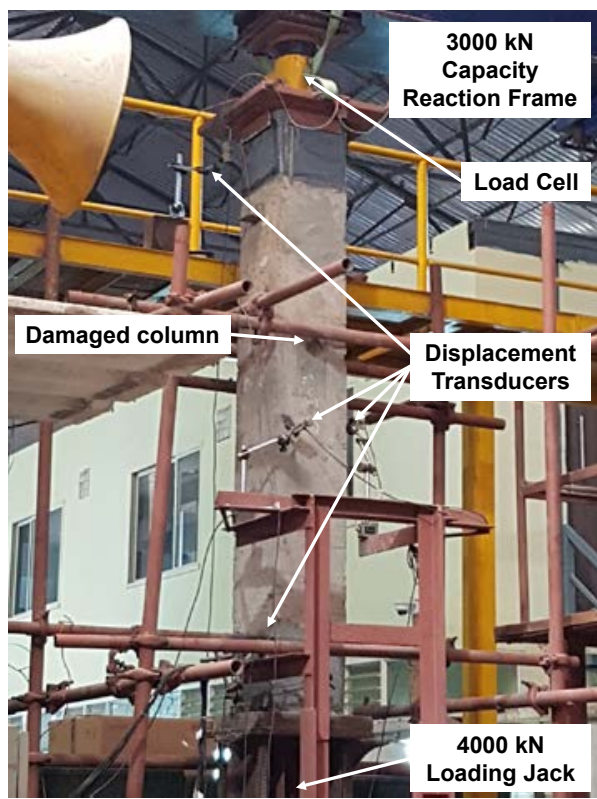

(a)

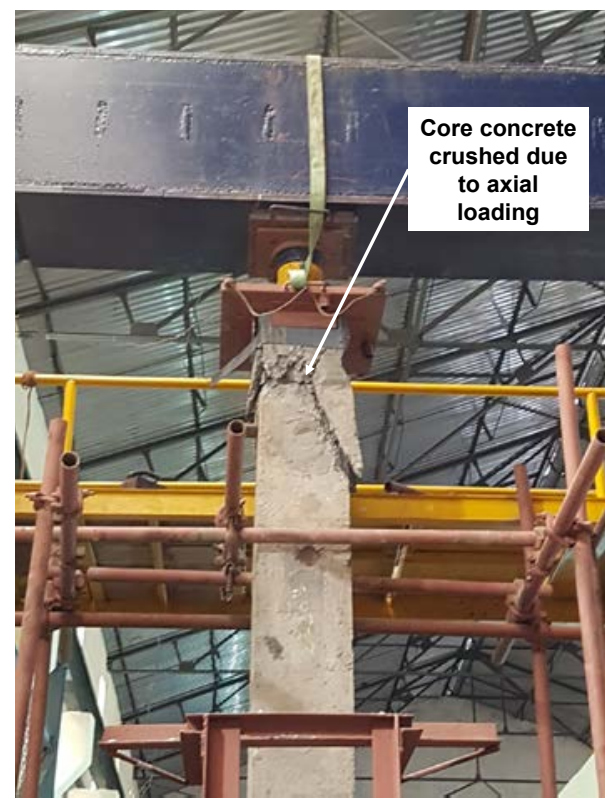

(b)

Figure 5-13: Residual axial load carrying capacity for E-115-50 (a) Blast-damaged column prior to axial loading (b) Post residual axial load capacity test damage profile

The clad RC column with $50 \mathrm{~mm}$ gap subjected to effects of $500-\mathrm{g}$ TNT contact explosion exhibited an axial capacity of $945 \mathrm{kN}$. The column failed due to the crushing of concrete in the blast-damaged zone (Figure 5-14). The post-explosion residual axial load carrying capacity was identified as $50 \%$ of the analytically determined nominal axial capacity of the undamaged column when $50-\mathrm{mm}$ spaced cladding was provided as opposed to zero residual axial load carrying capacity when cladding was not provided. 


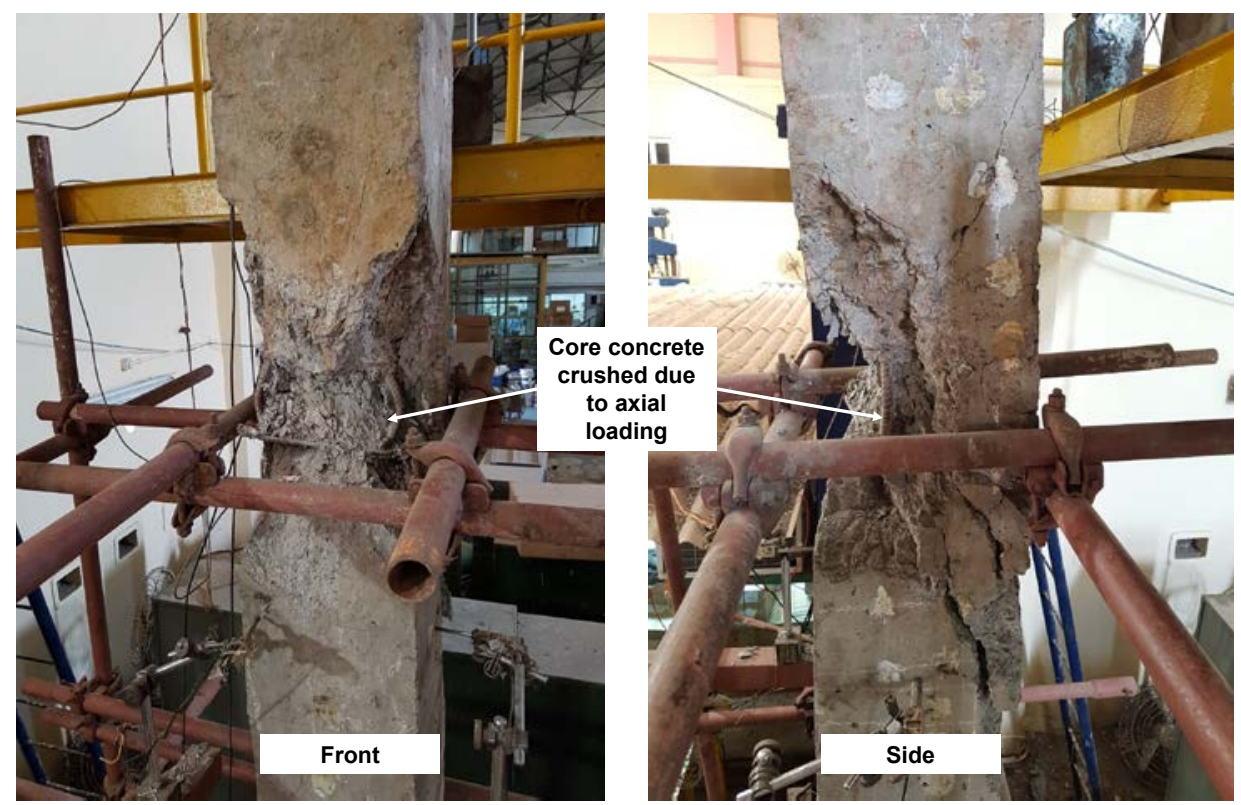

Figure 5-14: Residual axial load carrying capacity of test E-500-50

Lastly, the clad RC column with $100 \mathrm{~mm}$ gap subjected to the effects of $500 \mathrm{~g}$ TNT explosion in contact was tested for residual axial capacity. The column failed at an axial load of $1345 \mathrm{kN}$ which is higher than that of the clad column with a $50 \mathrm{~mm}$ gap. Residual axial load carrying capacity of the RC column with an increased air gap was determined as $72 \%$ of the analytically determined nominal axial capacity of the undamaged column. Figure 5-15 presents the post-detonation damage profile and post residual axial load carrying capacity test damage profile for the column. 


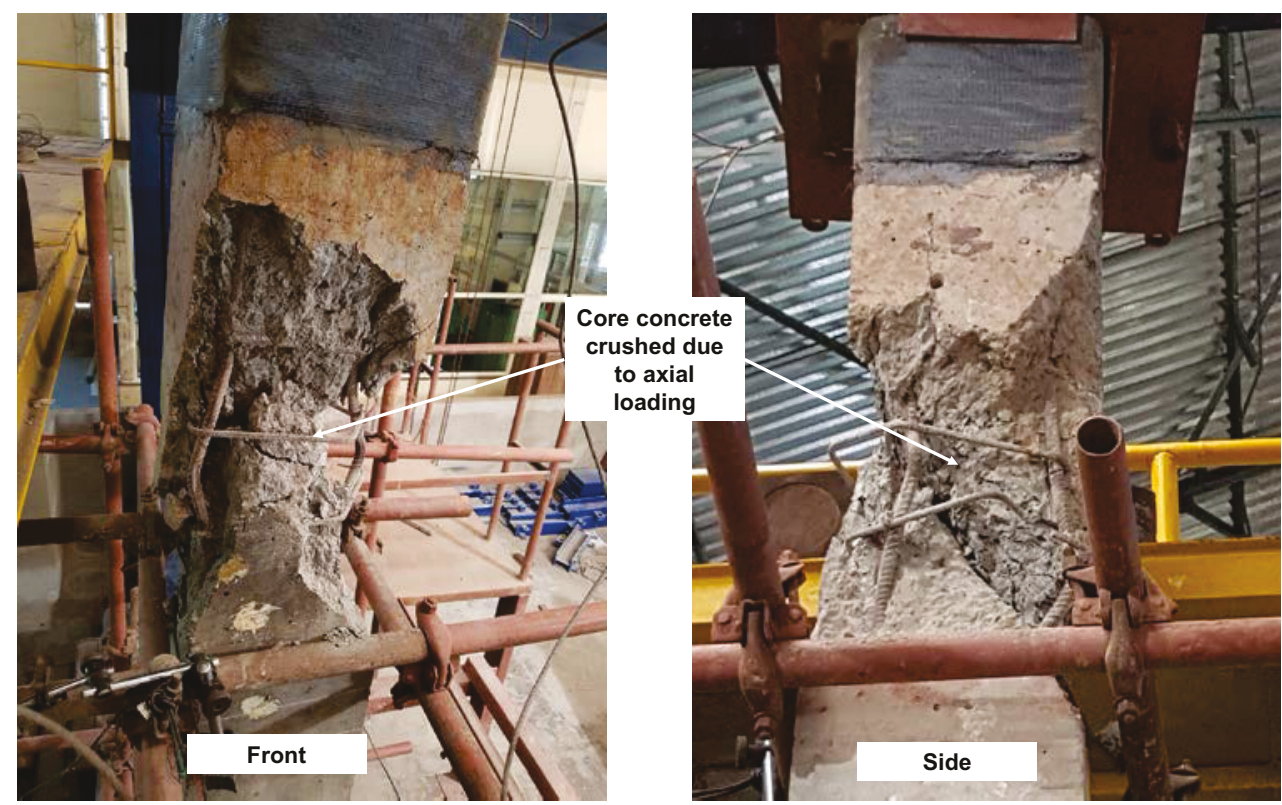

Figure 5-15: Residual axial load carrying capacity for test E-500-100

\subsection{Numerical Modeling}

\subsubsection{Material Models}

\subsubsection{Concrete}

There are many concrete constitutive material models in LS-DYNA. These constitutive models require a complete understanding of the heterogeneous material behavior and its response when subjected to high strain rate loading like contact explosions. Mat_72R3 (Karagozian and Case Model), Mat_159 (Continuous Surface Cap Model or CSCM) and Mat_84 (Winfrith model) are a few models that allow automatic generation of material parameters from the unconfined compressive strength of concrete. The underlying material parameters in the model are based on experimental tests performed for a wide range of unconfined compressive strength. In this study, Mat_159 was implemented for modeling concrete based on the results presented by Dua and Braimah (2017); 
Dua et al. (2017). The material input parameters in the adopted unit system are presented in Table 5-3.

Table 5-3: Input Parameters for Mat_159 Concrete Constitutive Model

\begin{tabular}{|c|c|c|c|c|}
\hline $\begin{array}{c}\text { Density, } \\
\text { T/mm }\end{array}$ & $\begin{array}{c}\text { Unconfined Compressive } \\
\text { Strength, MPa }\end{array}$ & $\begin{array}{c}\text { Aggregate Size, } \\
\mathrm{mm}\end{array}$ & $\begin{array}{c}\text { Erosion } \\
\text { Criteria }\end{array}$ & $\begin{array}{c}\text { Rate } \\
\text { Effects }\end{array}$ \\
\hline $2.635 \times 10^{-9}$ & 25 & 25 & 2.0 & on \\
\hline
\end{tabular}

\subsubsection{Reinforcements}

The response of RC members is sensitive to the confinement effects of reinforcements that are captured by the shear dilation phenomenon. Mat_159 concrete constitutive model can simulate the shear dilation phenomenon if the reinforcement is coupled with the concrete elements. A comprehensive review of various techniques available for modeling Reinforcements in RC members has been presented by Schwer (2014) where the CONSTRAINED_LAGRANGE_IN_SOLID (CLIS) algorithm with constraint type (CTYPE) 2 has been recommended for modeling reinforcements bars. Recently an improved version of the CLIS technique, CONSTRAINED_BEAM_IN_SOLID (CBIS), was implemented to address some limitations of the CLIS technique (L.S.T.C, 2015b). The MAT_PIECEWISE_LINEAR_PLASTICITY (Mat_24) constitutive model was adopted for modeling the reinforcement in this study. The input parameters for the constitutive model and CBIS keyword in the adopted unit system are presented in Table 5-4 and Table 5-5 respectively.

Table 5-4: Input Parameters for Mat_24

\begin{tabular}{|c|c|c|c|c|}
\hline $\begin{array}{c}\text { Density, } \\
\text { T/mm }\end{array}$ & $\begin{array}{c}\text { Modulus of Elasticity, } \\
\mathrm{MPa}\end{array}$ & $\begin{array}{c}\text { Poisson's } \\
\text { Ratio,- }\end{array}$ & $\begin{array}{c}\text { Yield Strength, } \\
\mathrm{MPa}\end{array}$ & $\begin{array}{c}\text { Tangent Modulus, } \\
\mathrm{MPa}\end{array}$ \\
\hline $7.85 \times 10^{-9}$ & $2 \times 10^{5}$ & 0.3 & 500 & 1600 \\
\hline
\end{tabular}


Table 5-5: Input parameters for CBIS keyword

\begin{tabular}{|c|c|}
\hline No. of coupling points, NCOUP & Coupling Direction, CDIR \\
\hline 10 & 0 (All directions) \\
\hline
\end{tabular}

\subsubsection{Air and TNT}

The multi-material ALE (MMALE) formulation was adopted for modeling the air and explosive domains. MMALE is an extension of the Eulerian algorithm used for describing gas flow from explosive detonation. An MMALE element can have several different materials, with tracked material interfaces in one single element. This is considered to be more efficient for modeling gas flow with large gradients as there can be Eulerian elements in the model with both air and detonation products (Zakrisson et al., 2011). MMALE currently remains the most widely used FSI algorithm for blast analysis in both far-field and near-field explosion events, (Trajkovski et al., 2014).

In MMALE formulation, the air domain is defined as MAT_NULL which allows the equation of state (EOS) to be considered without computing deviatoric stresses (L.S.T.C, 2015a). The linear polynomial EOS (EOS_LINEAR_POLYNOMIAL) defines the air domain and permits it to behave like a fluid. The pressure, $\mathrm{P}$ in an air element is given by Equation $5-4$ where $C_{0}$ to $C_{6}$ are polynomial equation

coefficients and $\mu$ is given by $\frac{\rho}{\rho_{0}}-1$ ( $\rho$ is the reference density and $\rho_{0}$ is the current density).

$$
P=C_{0}+C_{1} \mu+C_{2} \mu^{2}+C_{3} \mu^{3}+\left(C_{4}+C_{5} \mu+C_{6} \mu^{2}\right) E
$$


Input parameters for MAT_NULL and EOS_LINEAR_POLYNOMIAL in the adopted unit system are presented in Table 5-6.

Table 5-6: Input Parameters for Air Domain

\begin{tabular}{|c|c|c|c|c|c|c|}
\hline Density, $\mathrm{T} / \mathrm{mm}^{3}$ & $\mathrm{C}_{0}$ & $\mathrm{C}_{1}, \mathrm{C}_{2}, \mathrm{C}_{3}$ and $\mathrm{C}_{6}$ & $\mathrm{C}_{4}$ & $\mathrm{C}_{5}$ & $\mathrm{E}_{0}, \mathrm{MPa}$ & $\mathrm{V}_{0}$ \\
\hline $1.29 \times 10^{-12}$ & $-1 \times 10^{-6}$ & 0 & 0.4 & 0.4 & 0.2531 & 1 \\
\hline
\end{tabular}

The explosive domain can be defined by two techniques: creating a separate part for the explosive or with the INITIAL_VOLUME_FRACTION keyword. The first option requires that all the boundary nodes of the explosive domain be merged with the air domain nodes. On the other hand, with the second option, a defined geometrical shape within the air domain is filled with the explosive. The second option was adopted for the simulations presented in this study.

The explosive material was defined with MAT_HIGH_EXPLOSIVE_BURN which allows the modeling of detonation of a high explosive when defined with an EOS. EOS_JWL was adopted for the detonation modeling which defines the pressure, $p$ as Equation 5-5 where $A, B$ are constants with units of pressure, $E_{0}$ is the detonation energy per unit volume, $V_{0}$ is the initial relative volume and $R_{1}, R_{2} \& \omega$ are unitless constants.

$$
p=A\left(1-\frac{\omega}{R_{1} V}\right) e^{-R_{1} V}+A\left(1-\frac{\omega}{R_{2} V}\right) e^{-R_{2} V}+\frac{\omega E}{V}
$$

The input parameters for the above two keywords required to define the explosive domain are presented in Table 5-7. 
Table 5-7: Input Parameters for MAT_HIGH_EXPLOSIVE_BURN and EOS_JWL

\begin{tabular}{|c|c|c|c|c|c|c|c|c|c|}
\hline $\begin{array}{c}\text { Density, } \\
\mathrm{T} / \mathrm{mm}^{3}\end{array}$ & $\begin{array}{c}\text { Detonation } \\
\text { Velocity, } \\
\mathrm{mm} / \mathrm{s}\end{array}$ & $\begin{array}{c}\text { Chapman- } \\
\text { Jouguet } \\
\text { Pressure, } \\
\mathrm{MPa}\end{array}$ & $\mathrm{A}, \mathrm{MPa}$ & $\begin{array}{c}\mathrm{B}, \\
\mathrm{MPa}\end{array}$ & $\mathrm{R}_{1,-}$ & $\mathrm{R}_{2,-}$ & $\omega_{,-}$ & $\begin{array}{c}\mathrm{E}_{0,} \\
\mathrm{MPa}\end{array}$ & $\mathrm{V}_{0,-}$ \\
\hline $\begin{array}{c}1.55 \times 10^{-} \\
9\end{array}$ & $6930 \times 10^{3}$ & 21000 & 371200 & 3231 & 4.15 & 0.95 & 0.3 & 7000 & 1 \\
\hline
\end{tabular}

\subsubsection{Soil}

MAT_MOHR_COULOMB was adopted for defining the soil around the column.

This constitutive model is for solid elements only intended to represent sandy and granular soils. The input parameters for the model are presented in Table 5-8. The soil domain was implemented to capture the reflection of the blast wave from the ground. The response of soil and edge effects due to a smaller size is not of any significance to the response of RC columns.

Table 5-8: Input Parameters for MAT_MOHR_COULOMB

\begin{tabular}{|c|c|c|c|c|}
\hline Density, $\mathrm{T} / \mathrm{mm}^{3}$ & $\mathrm{G}_{\mathrm{mod},-}$ & $\mathrm{V},-$ & $\Phi_{,-}$ & Cohesion,-- \\
\hline $1.55 \times 10^{-9}$ & 0.222 & 0.35 & 0.0873 & 0.139 \\
\hline
\end{tabular}

\subsubsection{Strain-Rate Effects}

It is an established fact that concrete exhibits strain-rate dependency. It fails at a higher compressive/tensile load when subjected to a high strain-rate loading compared to its established 28-day strength. In analytical methods, the strength increase is incorporated with a dynamic increase factor (DIF) (Telford, 1993); defined as the ratio of dynamic to static failure load. The DIF can be adopted in simple input constitutive models like Mat_72R3 and Mat_159. Murray (2007) presented the DIF specifications for Mat_159 and reported a good fit to strain rate effects both in tension and compression. The strain-rate effects can be activated through the IRATE parameter on the Mat_159 keyword. 
Two simulations emulating the test of RC column subjected to 115-g TNT were implemented to investigate the influence of strain-rate effects. An error of $42 \%$ was observed in predicting the residual axial capacity of the blast-damaged column when compared to experimental results when strain-rate effects were not activated. Consequently, the strain-rate effects were activated for the numerical results presented in this study.

\subsubsection{Mesh Sensitivity Analysis}

\subsubsection{ALE Domain}

A mesh sensitivity analysis was performed prior to the numerical simulation of the experimental tests. The mesh sensitivity simulations were validated with experimental results presented by Rigby et al. (2015). The normal and radial reflected blast parameters acquired via split Hopkinson's pressure bars (SHPB) were reported at a close-in scaled distance of $0.15 \mathrm{~m} / \mathrm{kg}^{1 / 3}$. Quarter symmetric models of the experimental setup were implemented with varying element size for the air domain (Figure 5-16(a) \& (b)). The generated time histories for reflected blast parameters at $0.15 \mathrm{~m} / \mathrm{kg}^{1 / 3}$ scaled distance were plotted together with the upper and lower bound results from the six tests reported by Rigby et al. (2015) and are presented as Figure 5-16 (c) \& (d). 


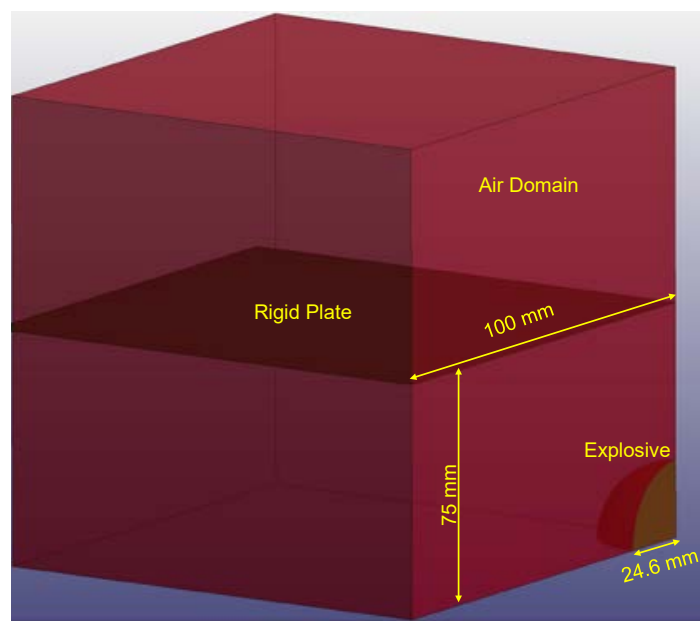

(a)

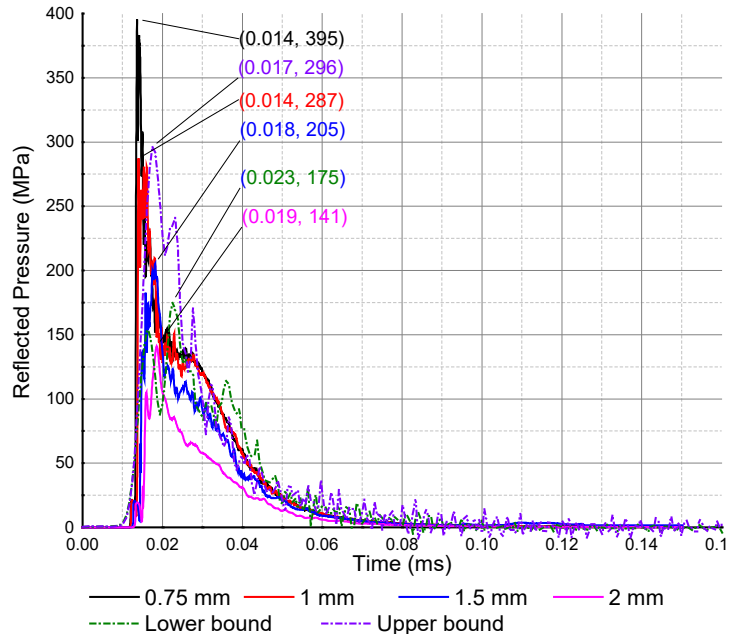

(c)

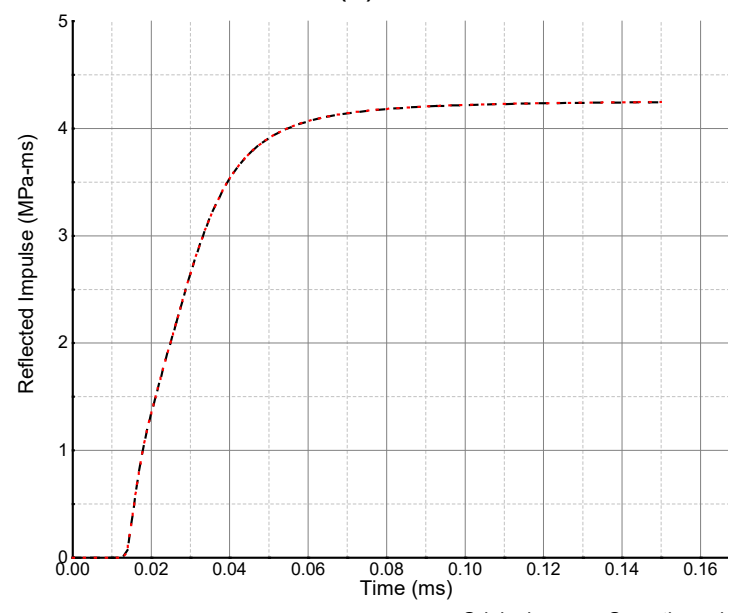

(e)

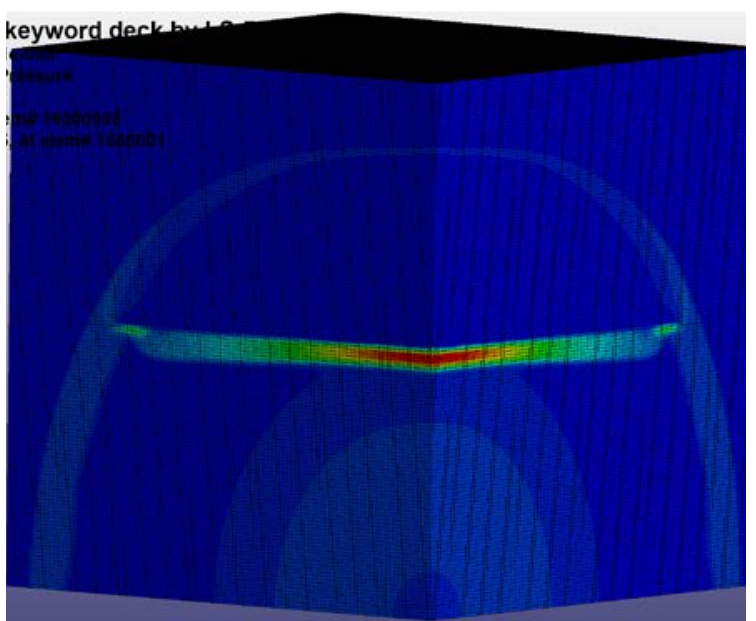

(b)

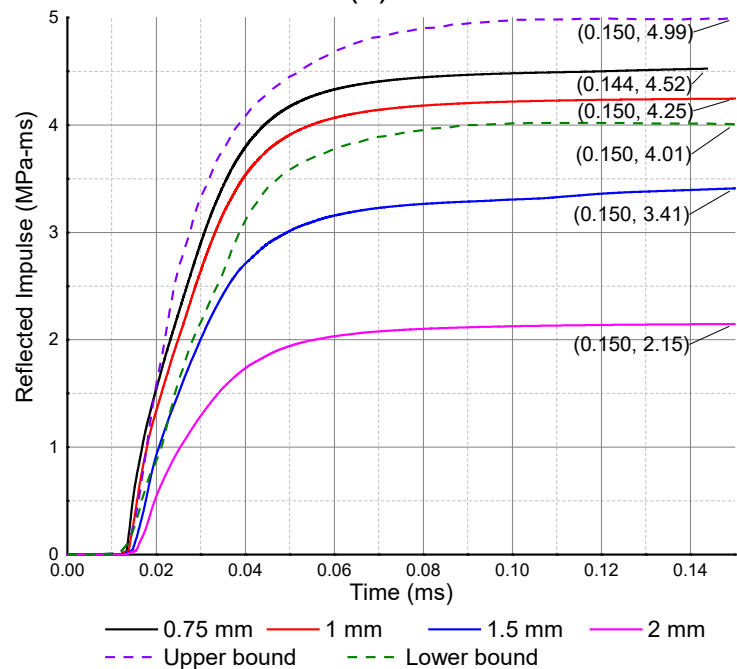

(d)

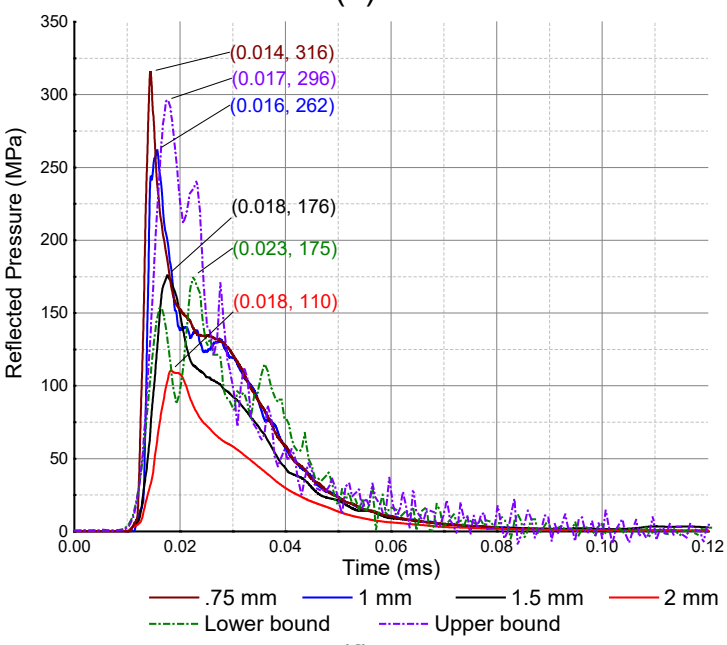

(f)

Figure 5-16: (a) Quarter symmetric model (b) Pressure fringe plot (1-mm); Time-histories for reflected (c) pressure (d) impulse (e) impulse after smoothening (f) pressure after smoothening 
The numerically predicted impulse values converged at $1-\mathrm{mm}$ sized element mesh as there was negligible change in the impulse with a $0.75-\mathrm{mm}$ element size mesh. The reflected impulse for $0.75 \mathrm{~mm}$ and $1 \mathrm{~mm}$ size element mesh predicted numerically were within the experimental upper and lower bounds, while $1.5 \mathrm{~mm}$ and $2 \mathrm{~mm}$ size mesh predicted the impulse outside this range. This is in agreement with the results reported by Rigby et al. (2014); Clarke et al. (2015); Rigby et al. (2015). The oscillating peaks in the pressure time-history predicted numerically are due to the shocked air trapped between the expanding detonation products and the target. These oscillatory peaks do not represent the true peak overpressure due to the explosion (Rigby et al., 2014; Clarke et al., 2015; Rigby et al., 2015). To ascertain the mesh convergence, these oscillations were smoothened by the adjacent-average method. There was no change in the impulse time-history due to this smoothening (Figure 5-16 (e)). The peak-overpressure also converged for the 1-mm element size mesh and was within the experimental bounds (Figure 5-16 (f)).

As presented in Table 5-9, the reflected impulse is highly sensitive to the air domain element size. The reflected impulse converged to the 1-mm element size air domain. The converged reflected impulse agreed with the experimental results.

In view of the foregoing results, 1-mm element size was implemented for the air domain and explosive material in order to generate accurate peak impulse value which is critical for modeling near-field or contact explosion events. The system's RAM requirement for simulating the response of a Lagrangian entity with a fine 
mesh like the ALE domain can be significant (more than $256 \mathrm{~GB}$ ). Additionally, the time required for running the simulations is also expected to be very long.

Table 5-9: Mesh Sensitivity Analysis for Reflected Pressure and Impulse

\begin{tabular}{|c|c|c|c|c|c|}
\hline Air Mesh & Experimental Range & $0.75 \mathrm{~mm}$ & $1 \mathrm{~mm}$ & $1.5 \mathrm{~mm}$ & $2 \mathrm{~mm}$ \\
\hline Reflected peak pressure (MPa) & $296-175$ & 316 & 262 & 176 & 110 \\
\hline Reflected peak impulse (MPa.ms) & $4.01-4.99$ & 4.52 & 4.25 & 3.41 & 2.15 \\
\hline
\end{tabular}

\subsubsection{Lagrangian Domain}

The $300 \times 300 \mathrm{~mm}$ cross-section RC columns were modeled with 2-mm and 10-mm Lagrangian element mesh size and were subjected to contact explosion effects. The damage profiles at the last timestep of both simulations are compared to the experimental results in Figure 5-17. The damage profile of the RC column predicted with 2-mm Lagrangian element mesh correlated well with the experimental results when compared to $10-\mathrm{mm}$ mesh, however, it was computationally expensive. On the other hand, there was a negligible effect of the mesh-size on the residual axial load carrying capacity of the blast-damaged columns. An exhaustive parametric study with 2-mm element size was not found to be computationally cost-effective. The numerical results presented subsequently show a good correlation of the predicted residual axial capacity with 10-mm Lagrangian element size when compared to experimental results. 


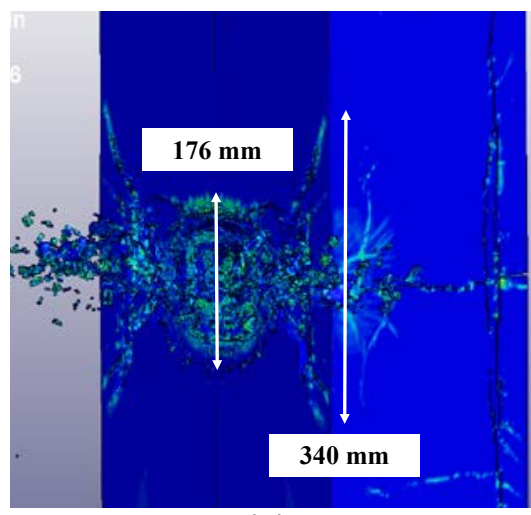

(a)

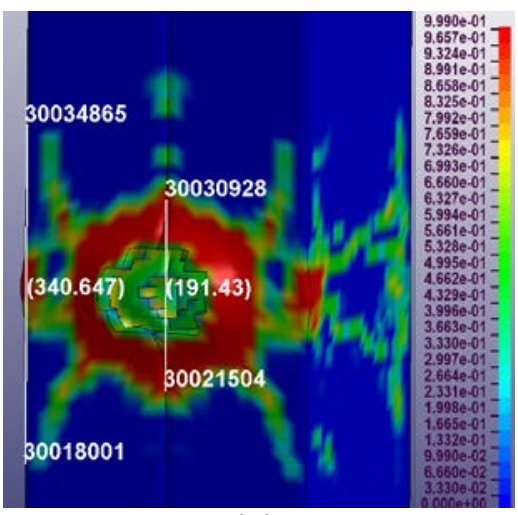

(b)

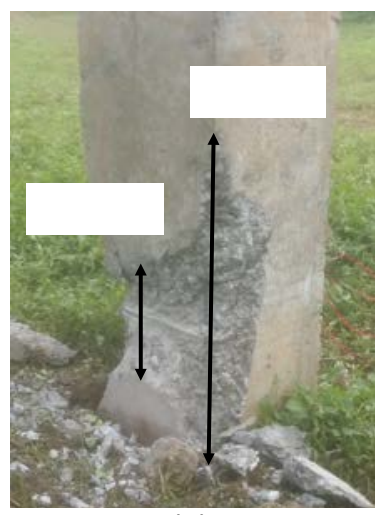

(c)

Figure 5-17: Mesh sensitivity analysis for blast response with (a) 2-mm mesh and (b) 10-mm mesh; (c) Experimental response

Mesh sensitivity analysis was also performed in the static regime with mesh sizes between 5-20 $\mathrm{mm}$ for the RC column. Axial load was applied until failure and the predicted axial failure load was compared to analytically determined nominal capacity. The load-displacement behavior predicted numerically for an undamaged column with varying element mesh sizes when subjected to axial loading are presented as Figure 5-18.

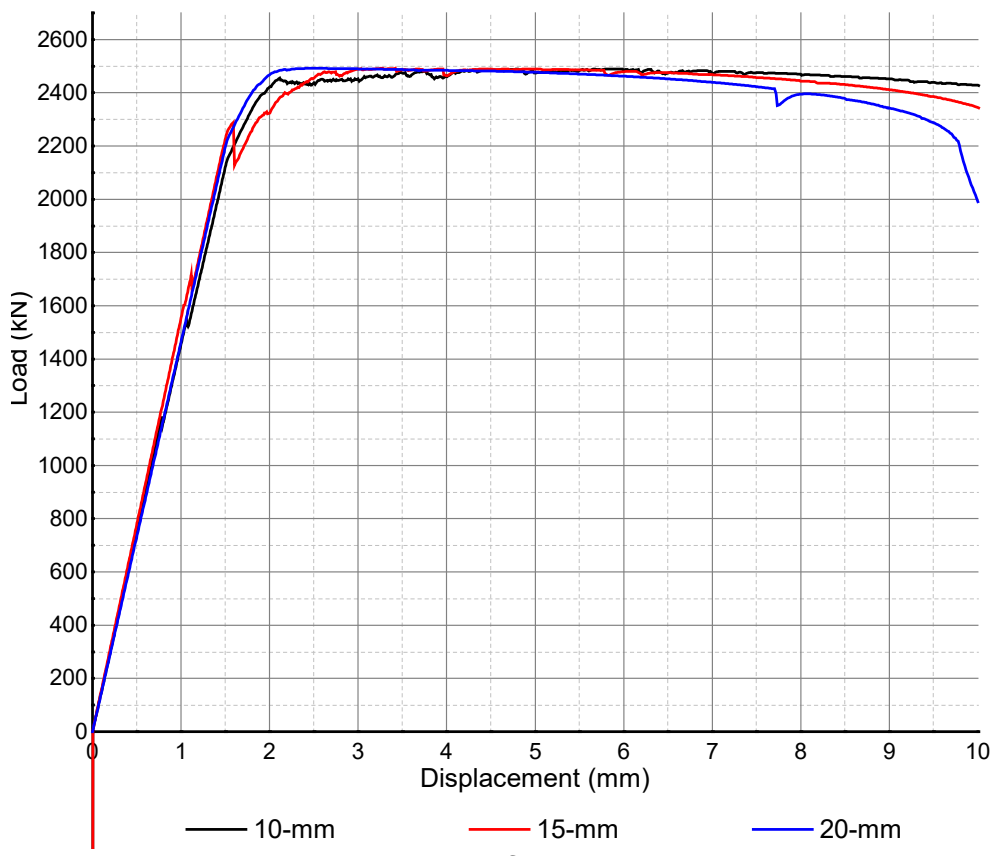

Figure 5-18: Load-displacement time-histories for axially loaded pristine columns with varying mesh sizes. 
The static analysis above with variable mesh size for the concrete domain revealed that Mat_159 is not sensitive to the element mesh size. The computational effort however increased exponentially for a finer mesh with negligible change in the predicted capacity (Table 5-10).

Table 5-10: Influence of element mesh size on the axial capacity of the pristine column

\begin{tabular}{|c|c|c|c|c|c|c|}
\hline $\begin{array}{c}\text { Column } \\
\text { Cross- } \\
\text { Section, } \\
\text { mm }\end{array}$ & $\begin{array}{c}\text { Concrete } \\
\text { Strength, } \\
\mathrm{MPa}\end{array}$ & $\begin{array}{c}\text { Steel } \\
\text { Rebar, } \\
\text { Ultimate } \\
\text { Tensile } \\
\text { Strength, } \\
\text { MPa }\end{array}$ & $\begin{array}{c}\text { Analytically } \\
\text { Determined } \\
\quad \text { Axial } \\
\text { Capacity, kN }\end{array}$ & $\begin{array}{l}\text { Element } \\
\text { Mesh } \\
\text { Size, } \\
\text { mm }\end{array}$ & $\begin{array}{c}\text { Numerically } \\
\text { Determined } \\
\text { Axial } \\
\text { Capacity, kN }\end{array}$ & $\begin{array}{c}\text { Computational } \\
\text { Time, Hours }\end{array}$ \\
\hline \multirow{3}{*}{$300 \times 300$} & \multirow{3}{*}{25} & \multirow{3}{*}{$\begin{array}{c}4 \times 20 \mathrm{M} \\
500\end{array}$} & \multirow{3}{*}{2431} & 20 & 2488 & 14 \\
\hline & & & & 15 & 2488 & 17 \\
\hline & & & & 10 & 2476 & 27 \\
\hline
\end{tabular}

\subsubsection{Mesh size, FSI and reinforcement contact}

The numerical models presented in this study are half symmetric with appropriate boundary conditions applied to the mid-section. The first chained simulation was initialized with 1-mm element size air domain while the Lagrangian entities of RC column and soil were modeled with $10-\mathrm{mm}$ and $5-\mathrm{mm}$ sized solid elements respectively. The FSI between the detonation products and Lagrangian entities was implemented by the CLIS keyword with CTYPE 5. L.S.T.C (2015b) recommends a smaller element size for the Lagrangian entities being coupled in an FSI problem as compared to the element size of the ALE domain. Alternatively, a high NQUAD value is recommended. CLIS is a penalty-based algorithm and hence the mesh densities of the interacting domains play an important role in preventing leakage of detonation products into the Lagrangian entities. In case tighter controls are implemented to prevent leakage, the computational demand is higher, and the detonation products may reflect due to higher penalty forces. 
Additionally, the correct NQUAD settings vary with material and relative mesh density. Essentially, selecting the NQUAD is based on experience and experimental validation. The CLIS parameters implemented for 1-mm and 5-mm element size mesh for the ALE domains in this study is presented as Table 5-11. The geometric numerical model for $5-\mathrm{mm}$ size air domain is presented as Figure 5-19.

Table 5-11: Validated CLIS parameters for Concrete and Soil

\begin{tabular}{|c|c|c|c|c|c|c|c|c|c|c|}
\hline Entity & \multicolumn{2}{|c|}{ NQUAD } & CTYPE & DIREC & \multicolumn{2}{|c|}{ PFAC } & ILEAK & \multicolumn{2}{|c|}{ PLEAK } & PFACMM \\
\cline { 2 - 6 } & $\begin{array}{c}1- \\
\mathrm{mm}\end{array}$ & $\begin{array}{c}5- \\
\mathrm{mm}\end{array}$ & & & $\begin{array}{c}1- \\
\mathrm{mm}\end{array}$ & $\begin{array}{c}5- \\
\mathrm{mm}\end{array}$ & & $\begin{array}{c}1- \\
\mathrm{mm}\end{array}$ & $\begin{array}{c}5- \\
\mathrm{mm}\end{array}$ & \\
\hline $\begin{array}{c}\text { RC } \\
\text { column }\end{array}$ & 10 & 10 & 5 & 3 & 5 & 5 & 2 & 5 & 5 & 3 \\
\hline Soil & 26 & 10 & 5 & 3 & 1500 & 150 & 2 & 1500 & 150 & 3 \\
\hline
\end{tabular}

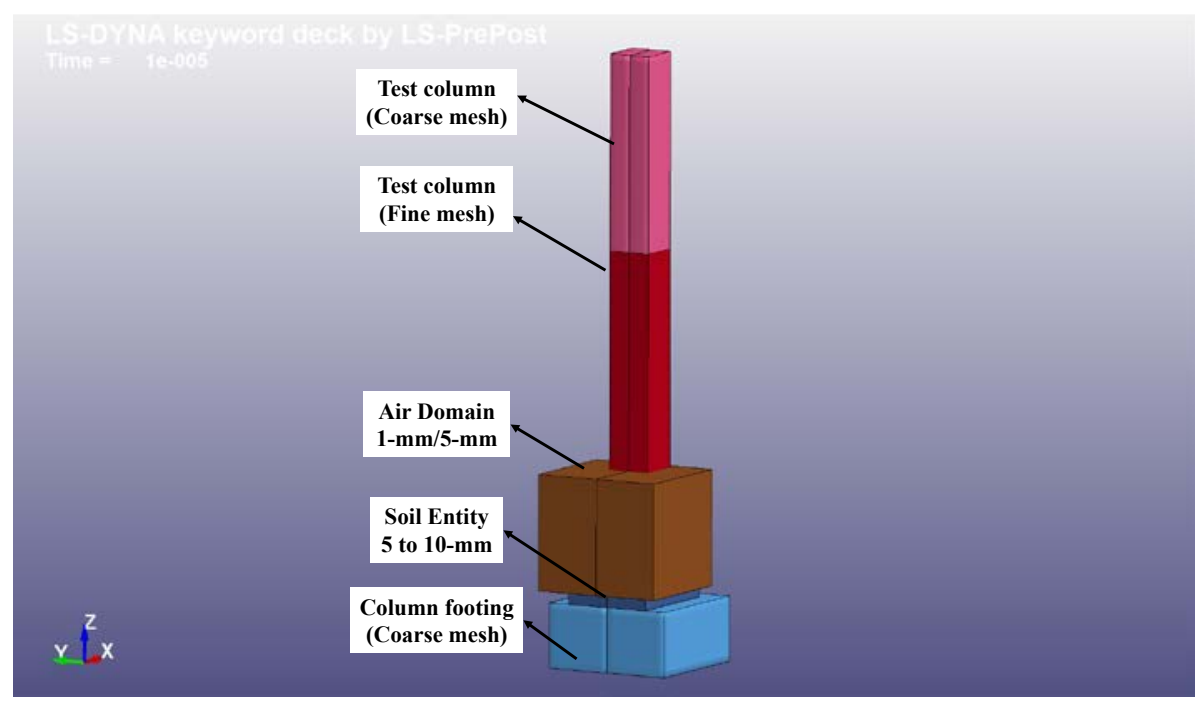

Figure 5-19: Geometrical model for multistage simulations

CONTACT_AUTOMATIC_GENERAL was implemented for modeling the contact between the longitudinal reinforcement and transverse reinforcement and CONTACT_ERODING_SURFACE_TO_SURFACE was implemented for contact 
between the soil and RC column entities. Table 5-12 presents the parameters for the contacts implemented in the numerical simulations.

Table 5-12: Keyword parameters for implementing contacts

\begin{tabular}{|c|c|c|c|}
\hline & $\begin{array}{c}\text { Coefficient of friction, } \\
\text { FS }\end{array}$ & $\begin{array}{c}\text { Penetration check, } \\
\text { PENCHK }\end{array}$ & $\begin{array}{c}\text { Soft constraint option, } \\
\text { SOFT }\end{array}$ \\
\hline Reinforcements & 0.5 & 1 (on) & 0 (penalty formulation) \\
\hline Soil-Column & 0.0 & 1 (on) & 2 (segment based) \\
\hline
\end{tabular}

\subsubsection{Modeling Technique}

In this study, a chained mapping technique for ALE domains was implemented on a shared memory parallel (SMP) solver to accurately predict the impulse generated due to the contact explosion and the response of Lagrangian entity to this event.

Initially, the detonation of the explosive was modeled in a 1-mm element size 3D air domain with simultaneous FSI with the Lagrangian entity to ensure accurate prediction of the pressure and impulse values. The first simulation was terminated prior to the arrival of the generated blast wave at the boundaries of the air domain to avoid reflection. Although LS-DYNA provides a keyword BOUNDARY_NON_REFLECTING, this keyword is applicable to Lagrangian entities and acoustic waves and not to the ALE domains with Euler entities. Hence each simulation has to be terminated prior to blast wave reflection. The succeeding simulation started with a larger ALE domain of 5-mm element size until the blast wave cleared away from the Lagrangian entity. A 3D-3D ALE mapping was implemented between these two simulations wherein the underlying algorithm initializes the current ALE domain with the ALE mesh element data of the last cycle in the previous run. The Lagrangian entities of the column and the soil were 
initialized with the stress histories from the previous run. These steps were performed with a full deck restart that enables the addition or deletion of Lagrangian entities.

The generated shock wave from the detonation of explosive material is transmitted to the Lagrangian domain through FSI imparting acceleration to the elements. The simulation is required to be run for a longer time after the detonation event for an accurate assessment of the RC column's response to the event. This is due to the inertial effects of concrete that takes a longer time for the stresses to develop and stabilize as compared to the impulsive loading due to the contact explosion that occurs over a very short duration. Hence the third simulation without the ALE domain was implemented up to $0.4 \mathrm{~ms}$, after termination of the second simulation with 5-mm element size air domain.

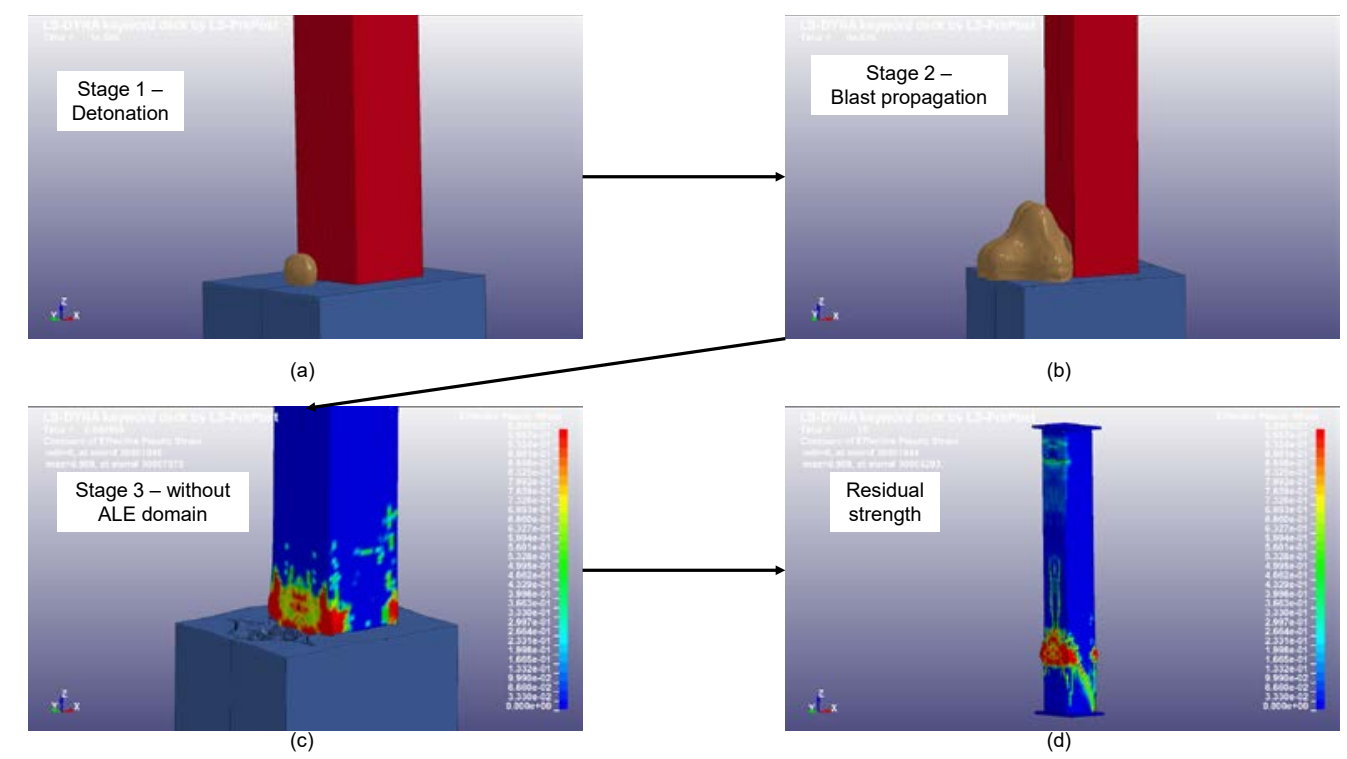

Figure 5-20: Sequence of multi-stage simulations for response prediction of RC columns with cladding 
The last simulation was run for selective cases in which residual axial load carrying capacities of the blast damaged columns were required. A full deck restart was performed to initialize the stress state in concrete and reinforcement from the previous simulation without the ALE domain. Displacement controlled axial load was applied to the column like the experimental tests and the load-displacement curves were acquired from the simulations. A complete representation of the chained simulations is presented in Figure 5-20. The system of units implemented for numerical modeling was $\mathrm{MPa}, \mathrm{mm}, \mathrm{sec}, \mathrm{T} / \mathrm{mm}^{3}$, and $\mathrm{N}$. The cladding material was not modeled explicitly and only the gap was introduced between the explosive and the RC column face.

\subsection{Numerical Results}

The numerical results of clad columns are presented in this section. The readers are encouraged to read Dua et al. (2018) for numerical results and parametric studies on bare column response to contact explosion effects.

\subsubsection{Clad Column (50 mm) Subjected to $115 \mathrm{~g}$ TNT Contact Explosion}

The pressure fringe plot representing the second simulation of the multi-stage chain with 5-mm air domain for the response of clad RC columns subjected to contact explosion effects is presented in Figure 5-21. The pressure plot range is 0-10 MPa. For the numerical parameters presented above, no leakage of ALE material ensues into the Lagrangian domain and the blast wave is reflected from the soil and the RC column. 


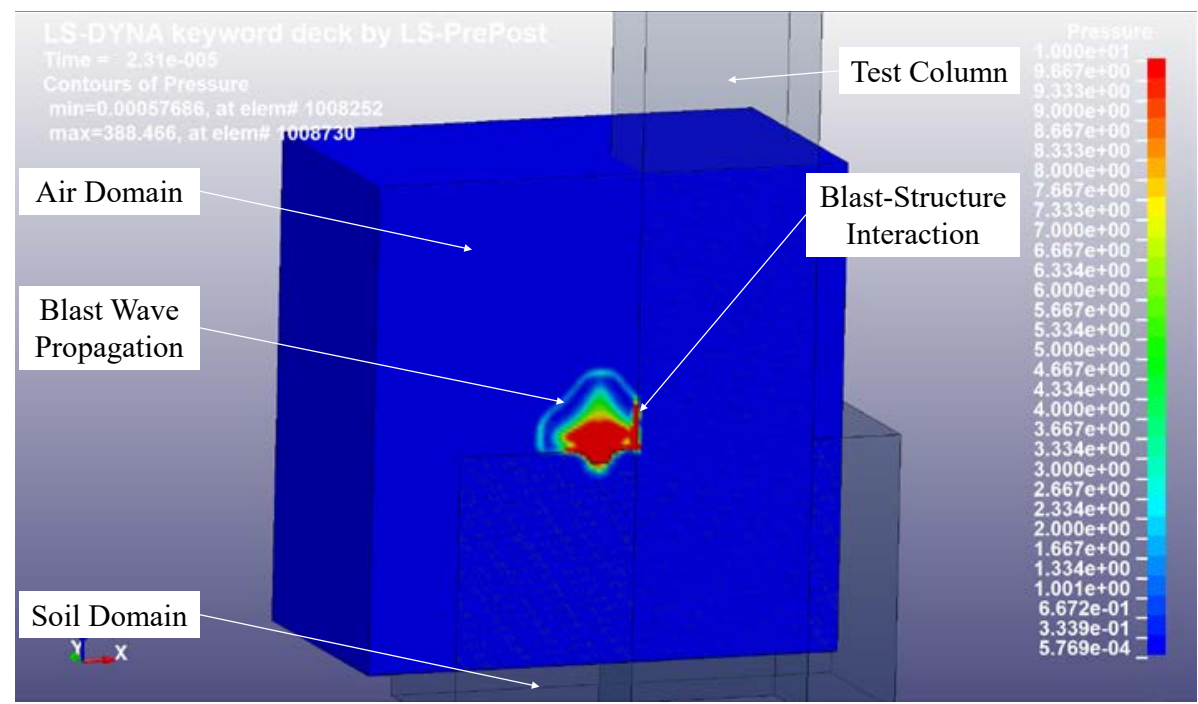

(a)

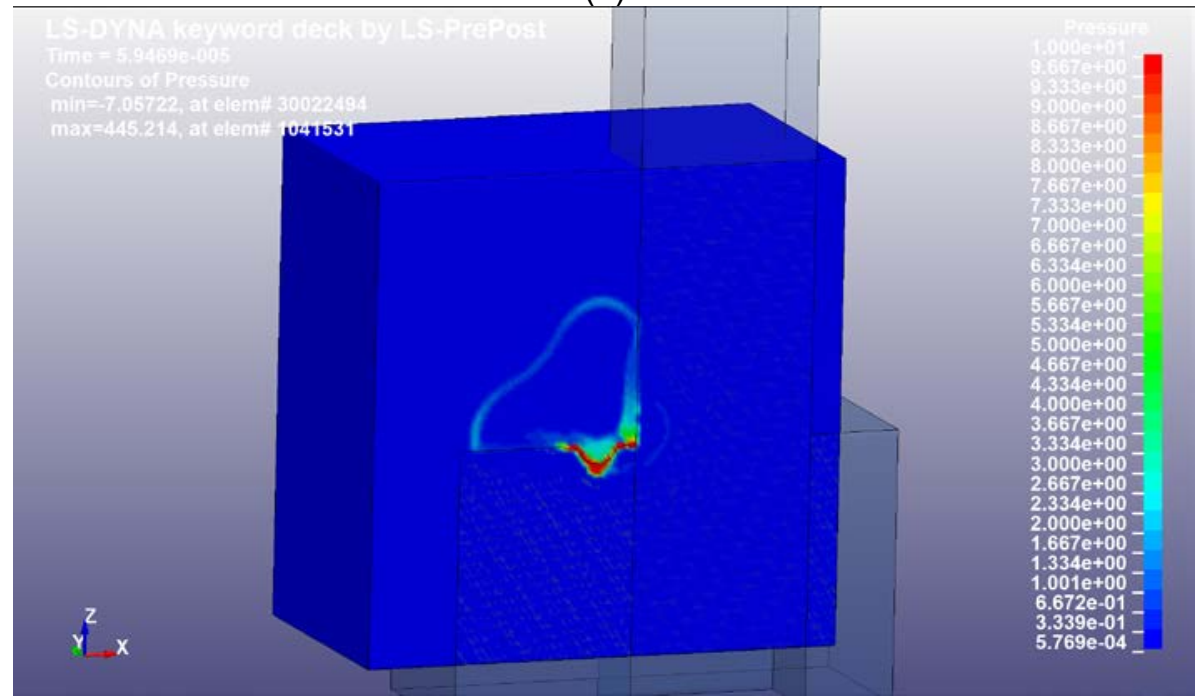

(b)

Figure 5-21: Blast wave propagation in 5-mm element size mesh (a) first time step (b) last time step

The third simulation was implemented without the ALE domain. The cross-section of the RC column at the last time step opposite to the point of contact between the explosive and the cladding is presented as Figure 5-22. 


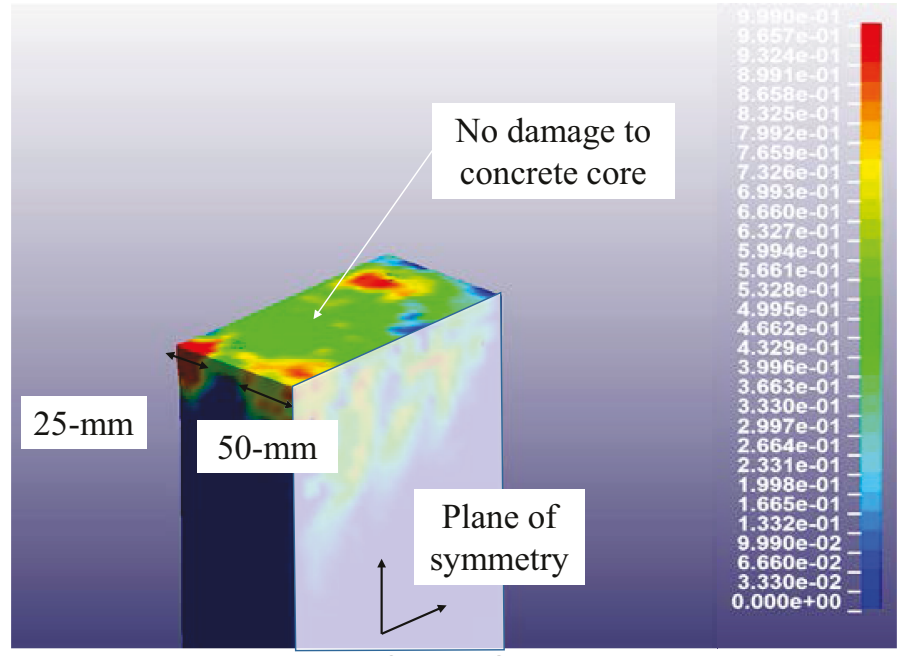

Figure 5-22: Half-symmetric cross-section of the RC column across the point of detonation at the last step of the third simulation

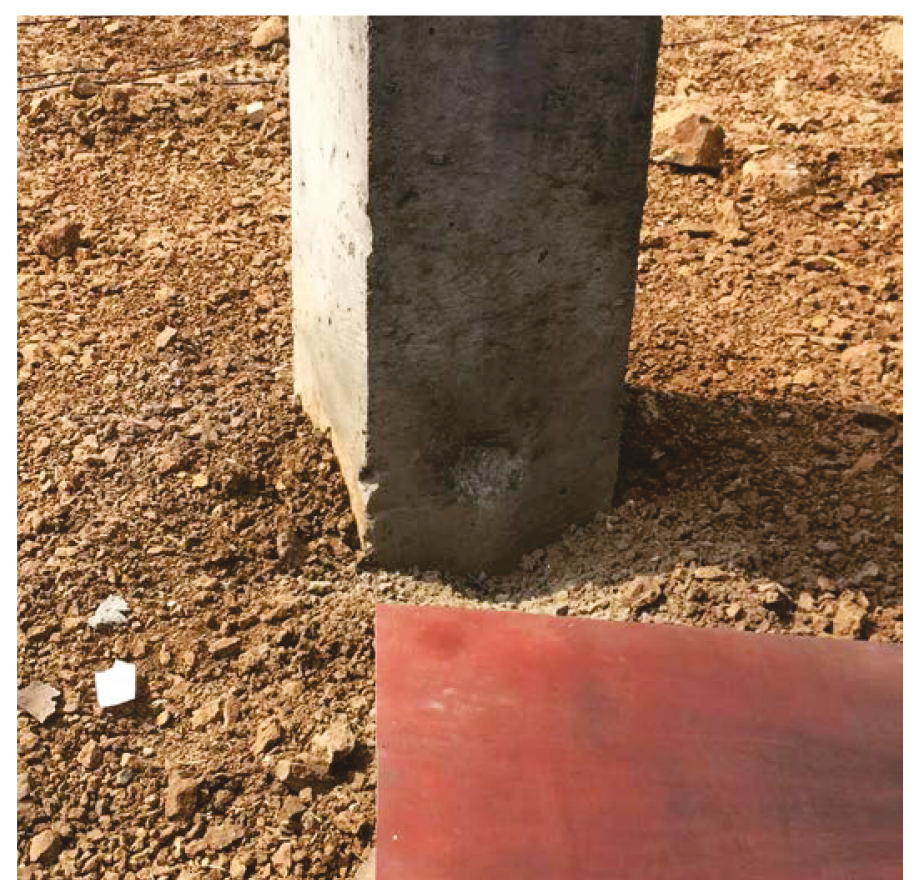

Figure 5-23: Damage profile of RC column subjected to 115-g TNT

Detonation of 115-g TNT charge at 50-mm spacing did not induce any damage to the concrete core and caused minor crushing to the concrete cover in the compressive zone and minor concrete spalling on the corners. Mat_159 by default labels the accumulated damage (D) as 'effective plastic strain' which is in the range of $0-0.99$. An element loses all the strength and stiffness as D approaches 1.0. 
The damage profile predicted numerically is a close approximation of the experimental results presented in Figure 5-23.

The numerical model setup for the last simulation (residual capacity testing) of the multi-stage chain is presented in Figure 5-24(a). The blast-damaged column was subjected to axial loads via steel plates emulating the experimental tests. A quasistatic displacement-controlled load was applied until failure of the RC column and the load-displacement time-history was acquired (Figure 5-24).

Residual capacity of the blast-damaged cladded column subjected to contact explosion effects of $115 \mathrm{~g}$ TNT was numerically predicted as $92 \%$ of the analytically determined nominal axial capacity of the analytically determined nominal axial capacity of the undamaged column. The numerical prediction of 1716 $\mathrm{kN}$ compared well with the experimentally determined residual capacity of 1778 $k N$.

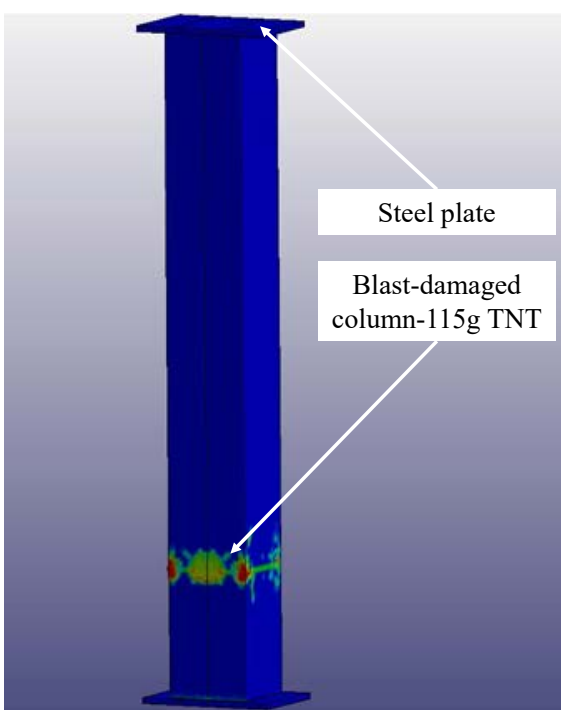

(a) 


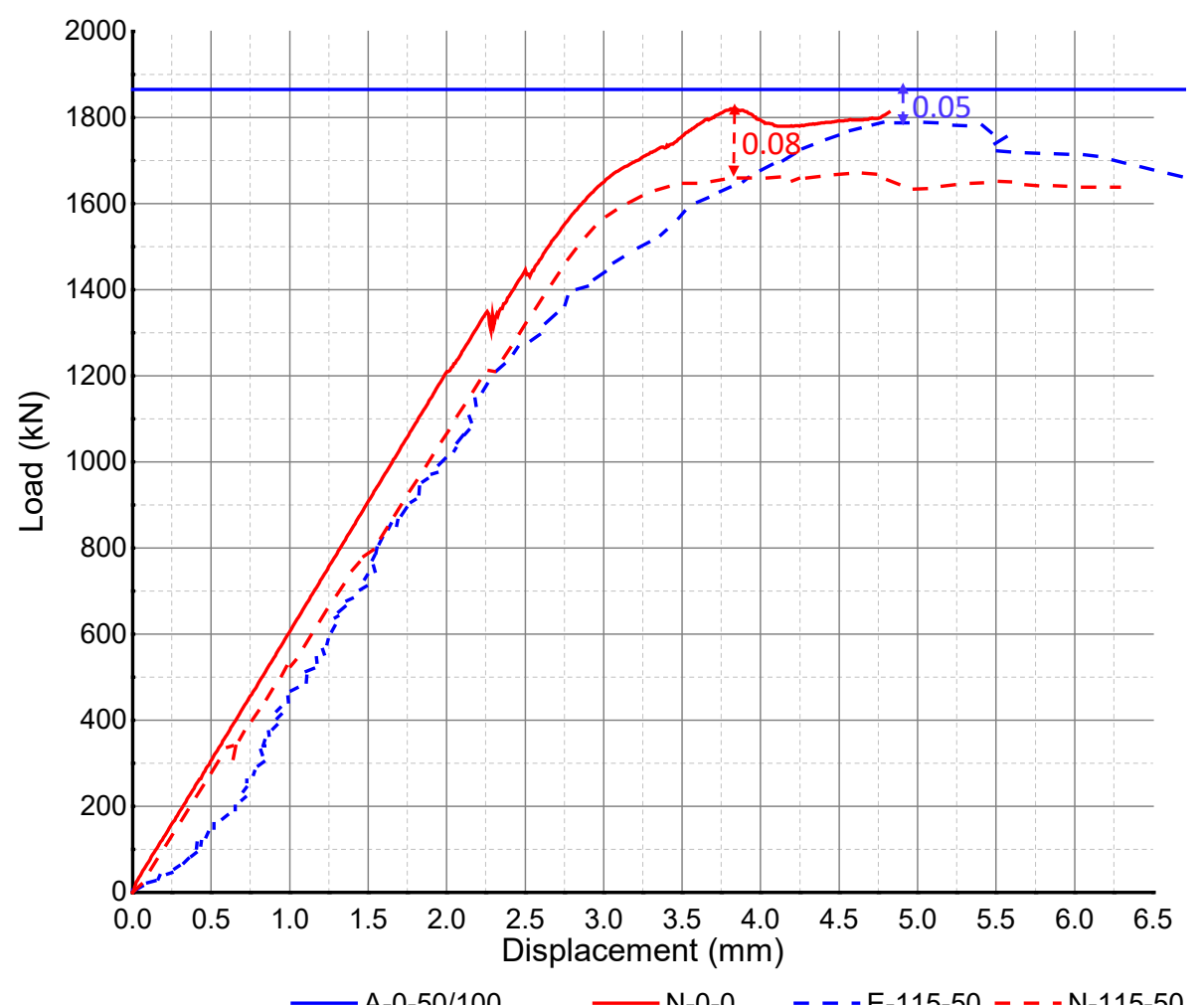

Figure 5-24: (a) Numerical model setup (b) Numerical vs experimental results (dashed arrows show damage indices)

\subsubsection{Clad Column $(100 \mathrm{~mm})$ Subjected to $500 \mathrm{~g}$ TNT Contact Explosion}

Figure 5-25(a) shows the $500 \mathrm{~g}$ TNT explosive at $100 \mathrm{~mm}$ gap from the column. Figure 5-25(b) presents the extent of detonation products in the $1 \mathrm{~mm}$ element size air domain. The detonated products coupled only with the soil and the interaction with the column occurred in the next simulation. The mapped pressure fringe plot in $5 \mathrm{~mm}$ element size air domain is presented as Figure 5-25 (c). The simulation was run to $0.6 \mathrm{~ms}$ and terminated before the blast wave got reflected from the boundaries of the air domain as seen in Figure 5-25 (d) 


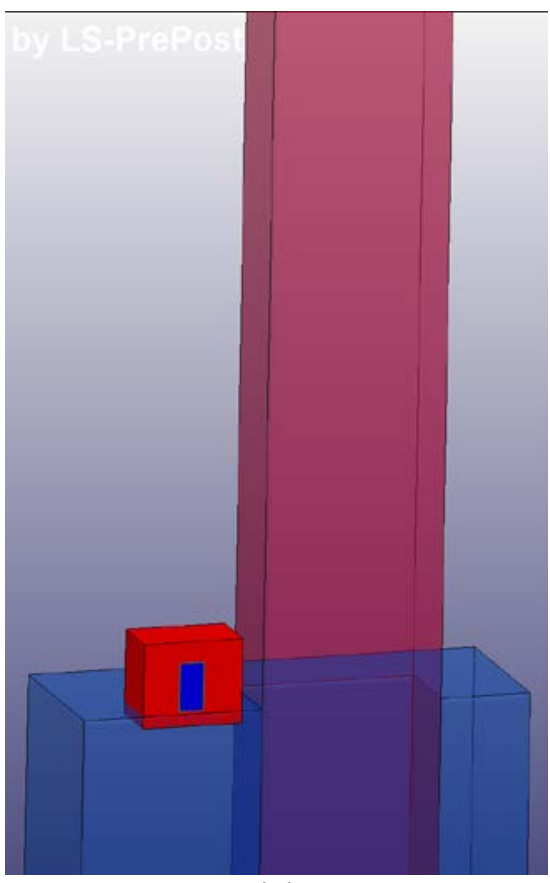

(a)

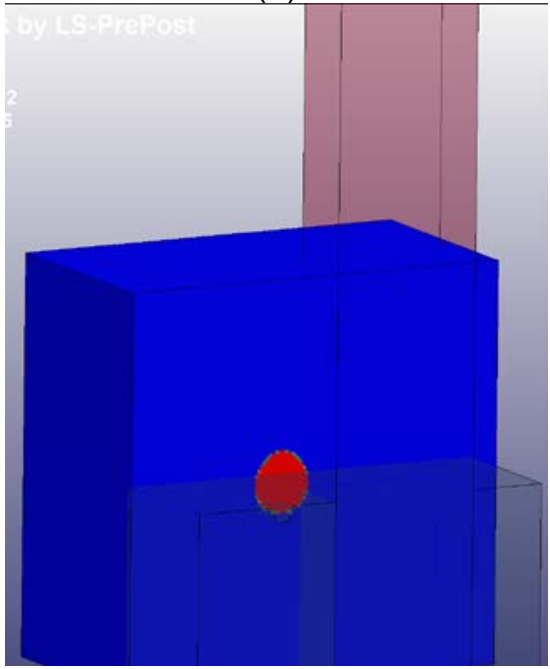

(c)

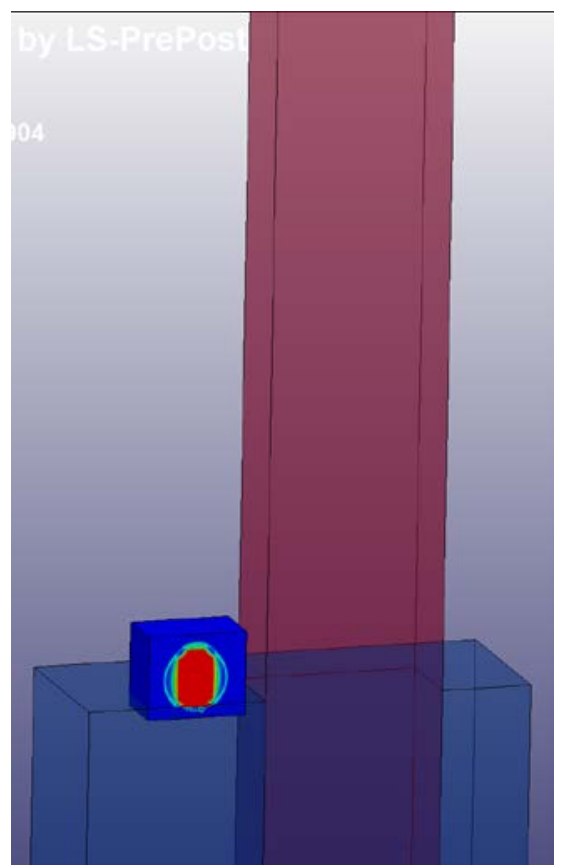

(b)

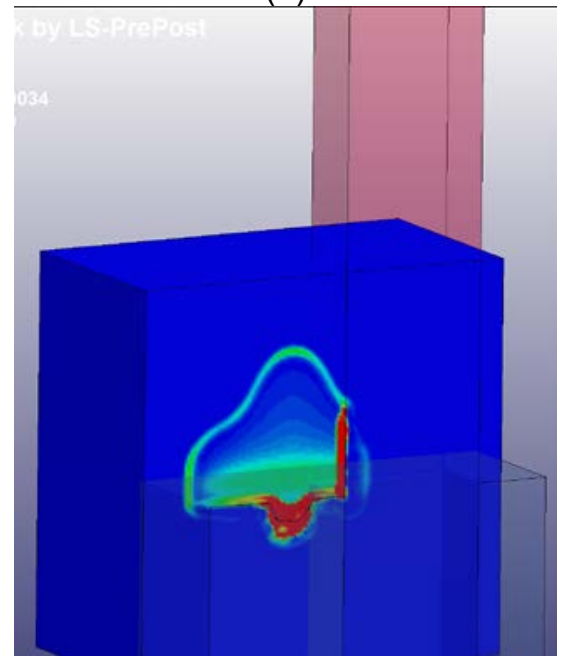

(d)

Figure 5-25: Pressure fringe plots at (a) first time-step \& (b) last time-step in 1-mm air domain; (c) first time-step \& (d) last time-step in 5-mm air domain for E-500-100 test.

Figure 5-26 presents the numerically predicted damage profile of the blastdamaged column compared with the experimentally observed results. The column cross-section shows negligible damage to the concrete core. 


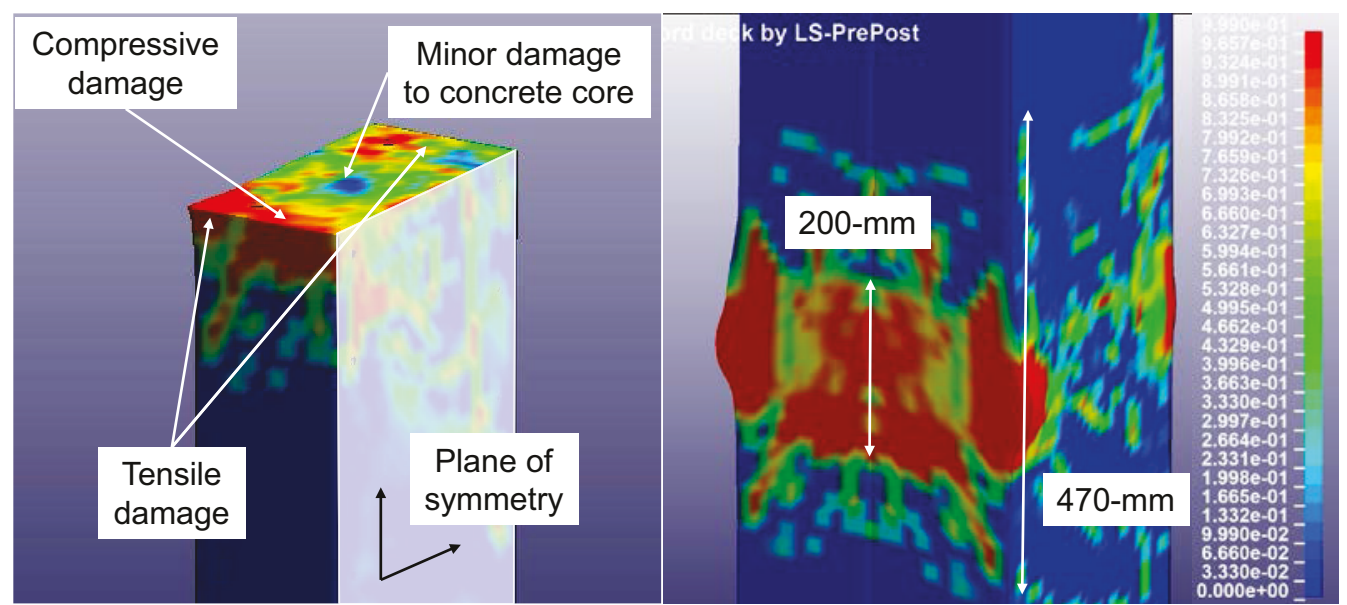

(a)

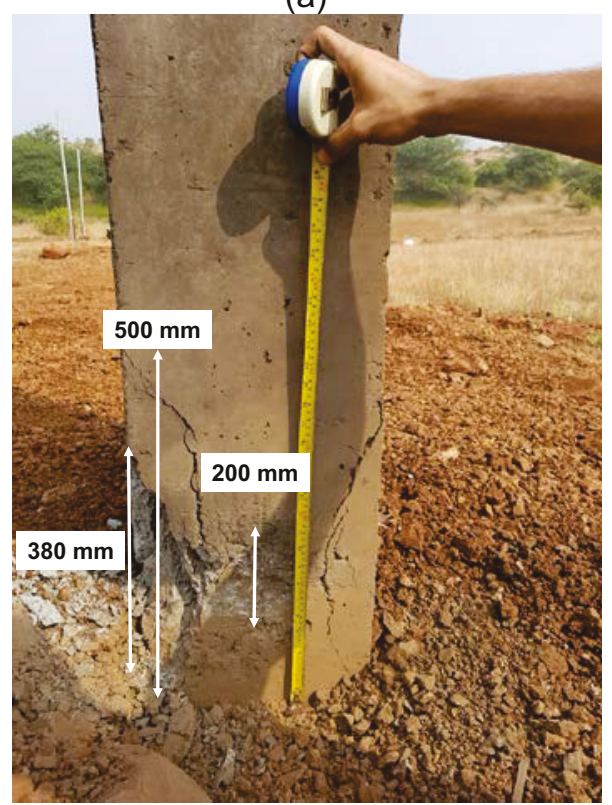

(b)

Figure 5-26: (a) Numerically predicted damage profile vs (b) experimentally observed damage profile

Residual capacity of the blast-damaged column was predicted as $1301 \mathrm{kN}$ which is close to the experimentally acquired value of $1345 \mathrm{kN}$. The load-displacement time-history for the residual axial capacity test is presented as Figure 5-27 along with the numerically predicted time-history. The numerically determined residual axial capacity of the blast damaged RC column with cladding is $30 \%$ lower than the analytically determined nominal axial capacity of the undamaged column. 


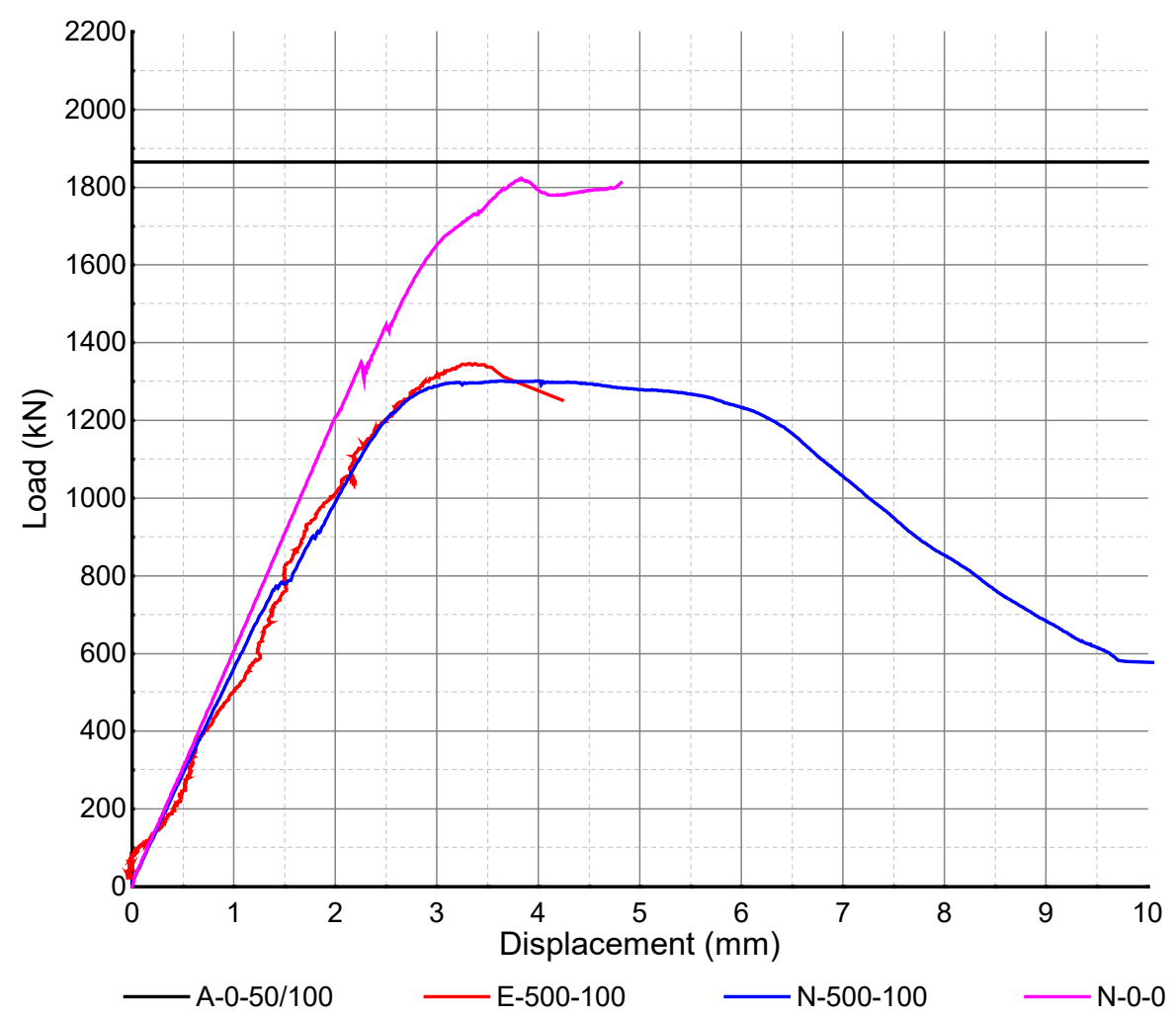

Figure 5-27: Numerical vs experimental load-displacement time-histories for 500-g TNT on 100mm gap cladding

\subsubsection{Clad Column (50 mm) Subjected to $500 \mathrm{~g}$ TNT Contact Explosion}

Numerically predicted damage profile of the RC column subjected to 500-g TNT in contact with cladding at $50-\mathrm{mm}$ from the column face is presented as Figure 5-28. The residual capacity of the blast-damaged column was numerically predicted as $714 \mathrm{kN}$ as compared to $944 \mathrm{kN}$ residual capacity acquired experimentally (Figure $5-29)$. 

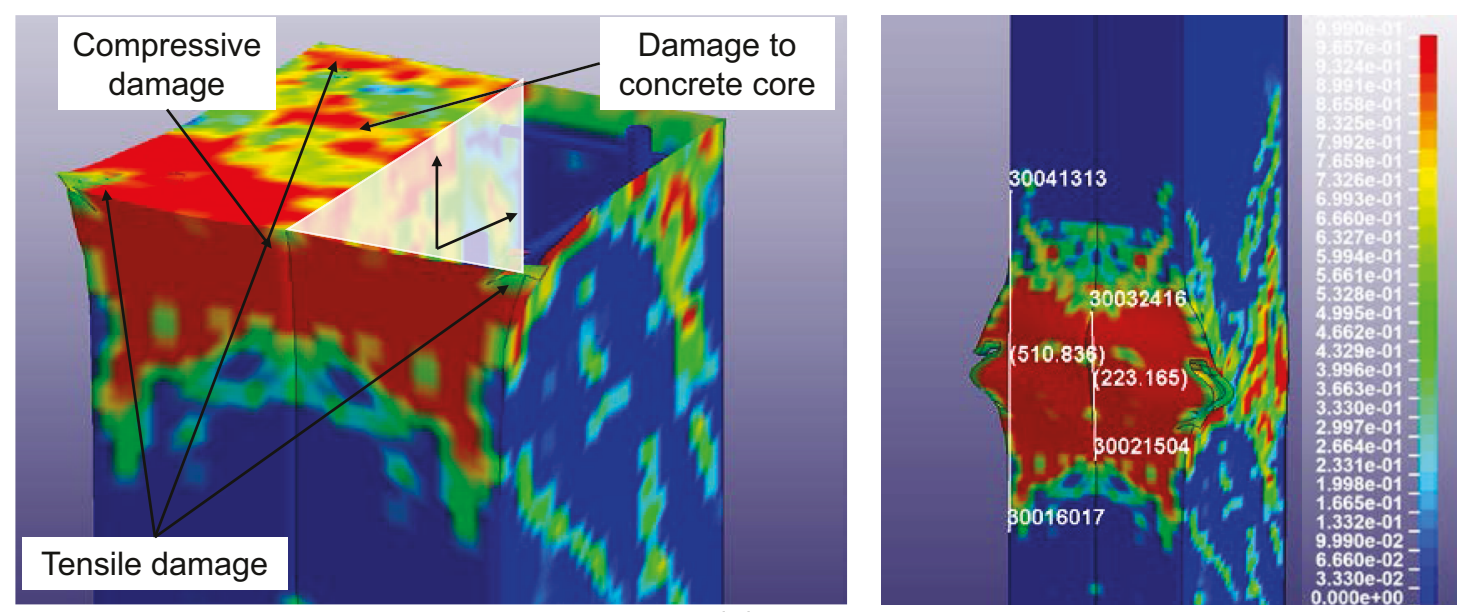

(a)

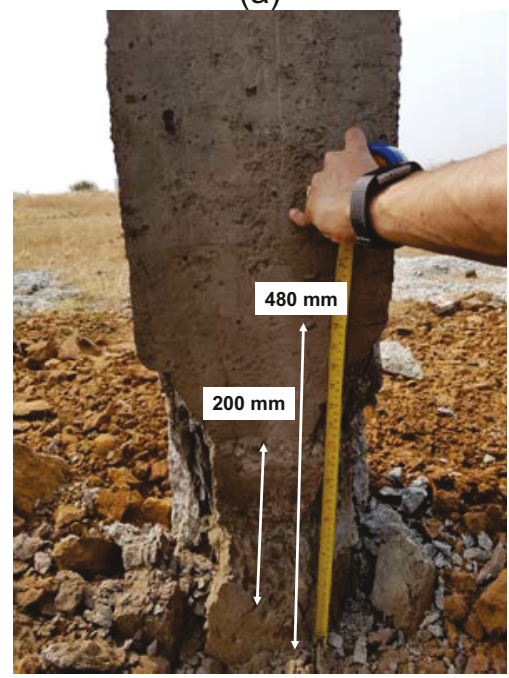

(b)

Figure 5-28: (a) Numerically predicted damage profile vs (b) experimentally observed damage profile

The numerical model parameters presented above quantitatively predicted the three experimental tests within $25 \%$ error. The qualitative damage profile of the blast-damaged column represented the experimental results with good accuracy. The numerically determined residual axial capacity of the RC column with cladding at $50 \mathrm{~mm}$ gap subjected to the effects of $500 \mathrm{~g}$ TNT detonation in contact is $38 \%$ of the nominal axial capacity of the undamaged column determined analytically. 


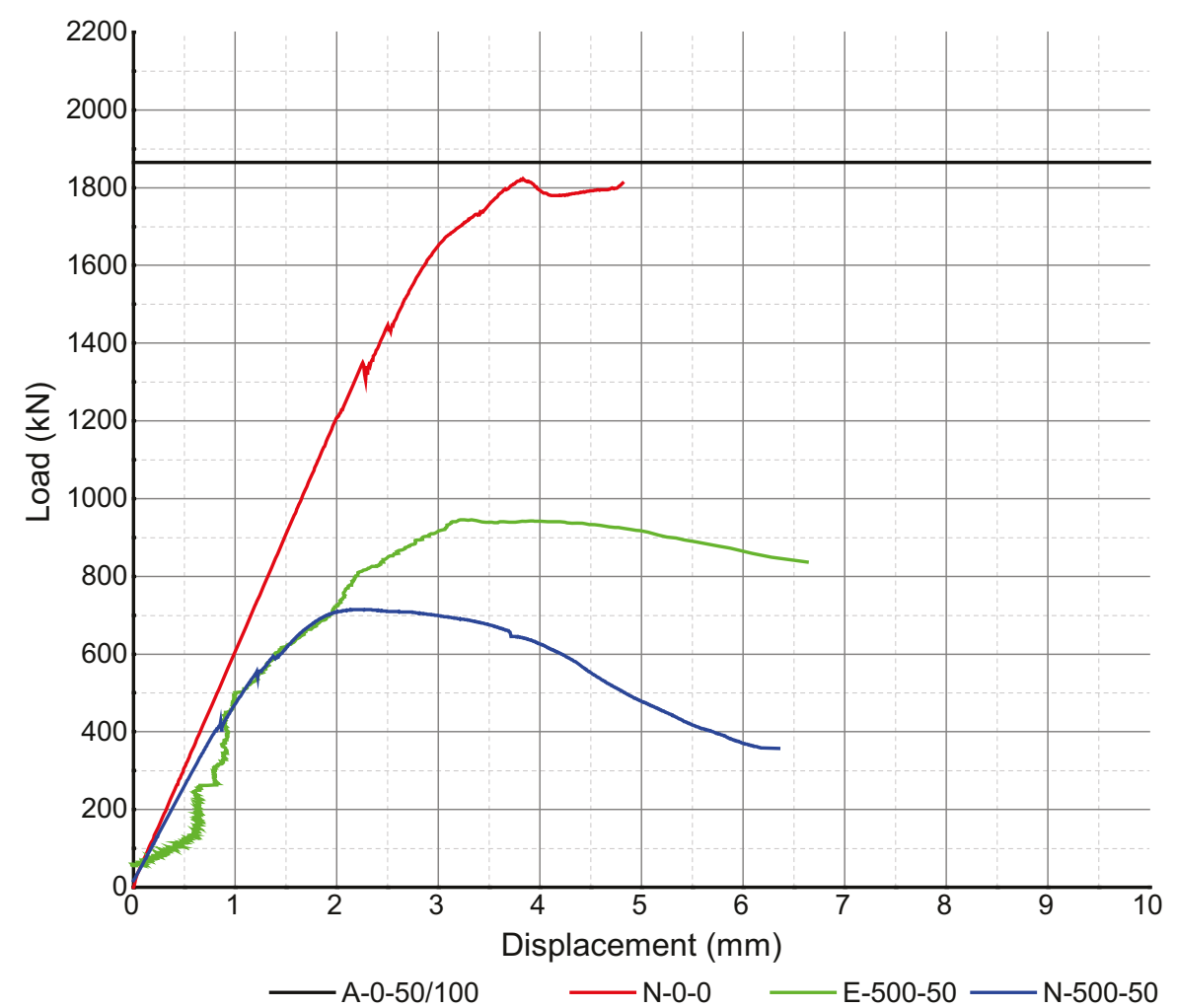

Figure 5-29: Load-displacement curve for residual axial capacity tests

\subsection{Summary and Discussion}

\subsubsection{Summary}

Table 5-13 summarizes the results observed from the residual capacity tests of the blast damaged $\mathrm{RC}$ columns. A damage index, $D$, defined by Equation $5-5$ has been used to discuss the results. The mitigation effect of plywood cladding on the columns is expressed as a reduction in $D$ with increased gap due to the cladding.

$$
D=1-\frac{P_{r}}{P_{o}}
$$


Table 5-13: Summary of Results

\begin{tabular}{|c|c|c|c|c|c|}
\hline Test Designation & $\begin{array}{c}\text { Concrete } \\
\text { compressive } \\
\text { strength, MPa }\end{array}$ & $\begin{array}{l}\text { Theoretical } \\
\text { axial } \\
\text { strength of } \\
\text { the } \\
\text { column, } P_{\circ} \\
\text { (kN) }\end{array}$ & $\begin{array}{c}\text { Residual } \\
\text { axial } \\
\text { strength } \\
\text { after blast, } P_{r} \\
(\mathrm{kN})\end{array}$ & $\mathrm{D}$ & $\begin{array}{l}\text { Mitigation } \\
\text { effect } \\
\text { D benchmark- }_{\text {cladded }}\end{array}$ \\
\hline E-1000-0 & \multirow{3}{*}{25} & \multirow{3}{*}{2431} & 0 & 1 & - \\
\hline E-500-0 & & & 0 & 1 & - \\
\hline$E-115-0$ & & & 2050 & 0.16 & - \\
\hline E-500-100 & \multirow{3}{*}{20} & \multirow{3}{*}{1865} & 1345 & 0.28 & 0.72 \\
\hline E-500-50 & & & 945 & 0.49 & 0.51 \\
\hline$E-115-50$ & & & 1778 & 0.05 & 0.11 \\
\hline
\end{tabular}

\subsubsection{Shock Wave Propagation in RC columns}

The shock wave propagation through RC columns is a 2-D phenomenon, which significantly differs from the 1-D wave propagation phenomenon observed in slabs (Puryear et al., 2012; Dua \& Braimah, 2016). It is observed based on the contact explosions tests performed as part of this study that the shock wave reflection from side boundaries caused greater spalling and loss of concrete from the crosssection (Figure 5-30).

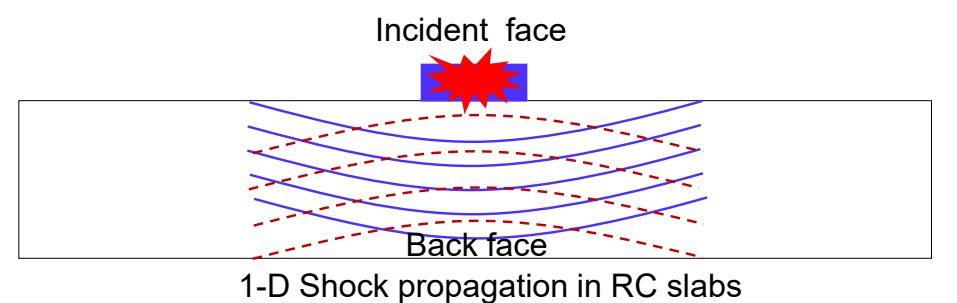

Primary Shock wave

- - - - Reflected Shock wave

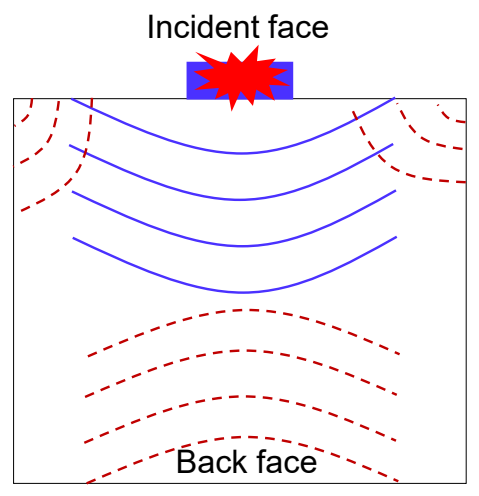

2-D Shock propagation in RC columns

Figure 5-30: Shock wave propagation in RC slabs and RC columns

The damage profiles at all faces of the cladded column with a $50 \mathrm{~mm}$ gap are presented as Figure 5-31. Concrete cracks could only be observed at the back face, however, the side face indicated scabbing. The damage was limited to only 
the concrete cover. Damage to the core concrete was only observed in the direct compression zone of the detonation.

The shock wave reflection initiates at the corners of the detonated face and propagates towards the back face before getting reflected again. The double reflection from sides and the back face is termed as 2-D propagation. Accordingly, damage initiates at the point of detonation due to concrete crushing followed by concrete scabbing at the corners and lastly cracking/scabbing at the back face. In the case of RC columns, the loss of concrete is more severe on the side faces compared to the back face. This is because the shock wave arrives at the side faces before the distal face as the distance of the side face from the point of detonation is half as compared to the distal face. Dua and Braimah (2018) reported that an RC slab of $200 \mathrm{~mm}$ thickness subjected to contact explosion effects of 500 $\mathrm{g}$ of TNT was not breached. However, the same amount of explosive demolished an RC column of the higher depth of $300 \mathrm{~mm}$ across the explosive mass (Figure 5-8(b)). This highlights the difference between wave propagation mechanisms and their damaging effects on RC slabs and columns. 


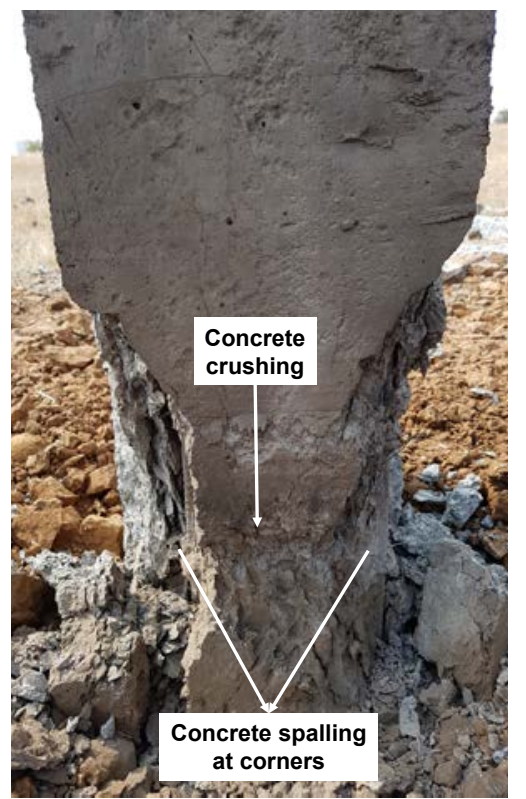

(a)

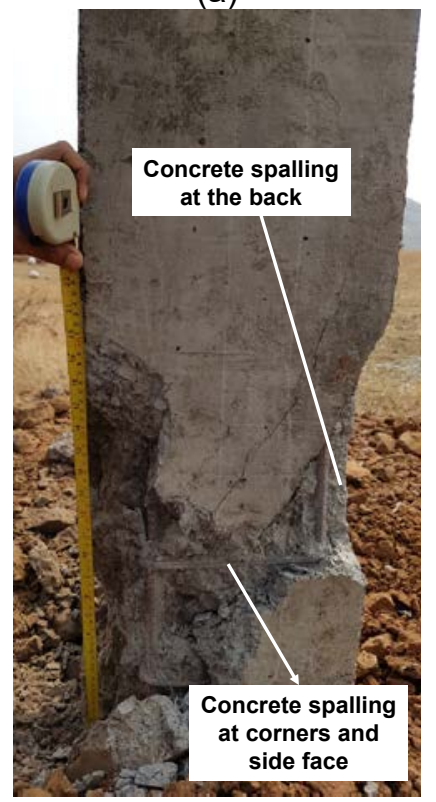

(c)

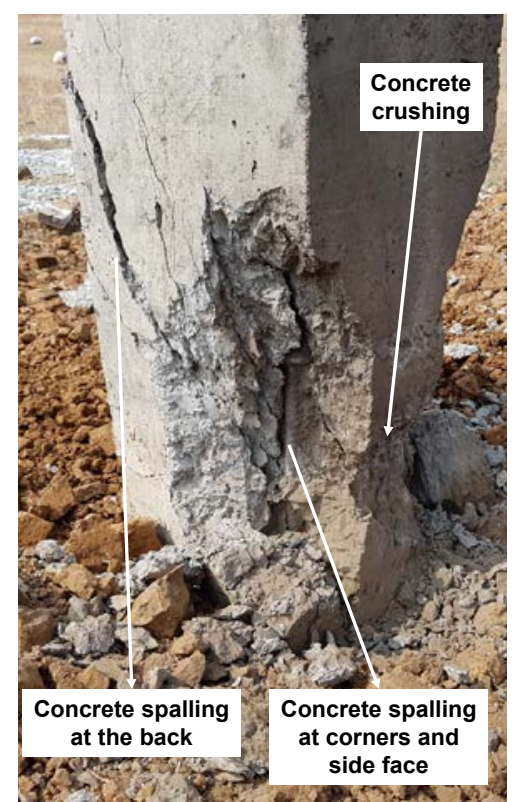

(b)

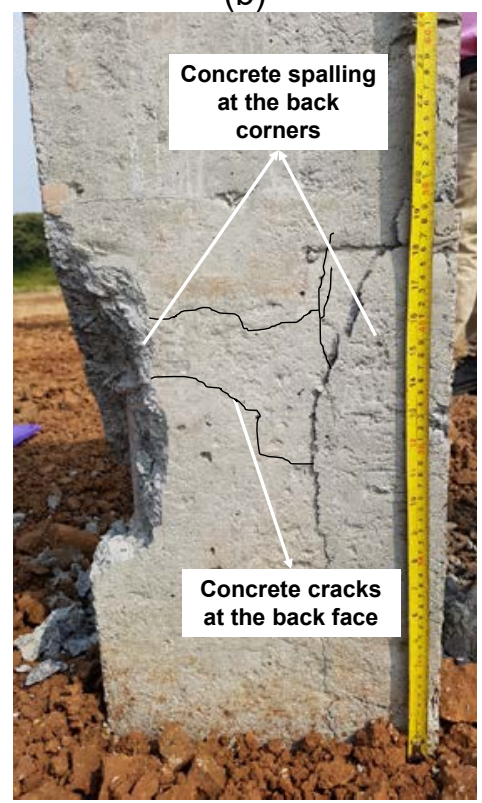

(d)

Figure 5-31: Damage profile of RC column with 50-mm spaced cladding on the (a) Front face (b) Left face (c) Right face (d) Back face

\subsubsection{Failure Mechanism of Blast Damaged RC Columns}

The experimental results indicate local material failure as the predominant damage mechanism. This is in agreement with previous studies by Weerheijm et al. (1984). Reduction in the cross-sectional area of the RC columns due to spalling of cover concrete marginally reduced the axial load carrying capacity. On the other hand, 
any damage to the core concrete confined within the ties significantly reduced the residual axial capacity. This local damage to the core concrete causes disruption in the axial load transfer mechanism of the column. In the case of complete loss of concrete core as presented in Figure 5-8(a) \& (b), the residual axial load capacity is reduced to zero. The damage is limited to scabbing and spalling of concrete cover for columns presented in Figure 5-8(c), Figure 5-9 (b), Figure 5-10 (a) and Figure 5-11 (b) with the core concrete still intact with possible cracks. These columns exhibited residual axial load carrying capacities.

These blast-damaged columns failed in shear when the axial load was applied during the residual axial load capacity tests.

\subsubsection{Mitigation Potential of the Cladding Induced Gap}

The results established the potential of clad $\mathrm{RC}$ columns to mitigate contact explosion effects. The RC column subjected to an explosive yield of $500 \mathrm{~g}$ of TNT was rendered without any axial load carrying capacity whereas clad columns with $50 \mathrm{~mm}$ and $100 \mathrm{~mm}$ air gaps retained $51 \%$ and $72 \%$ axial load carrying capacities respectively when subjected to contact explosion effects of the same yield. Figure 5-32(a) and (b) present the comparison of residual capacity and damage indices of the bare and cladded columns. The damage index of the cladded column subjected to the contact explosion effects of $115 \mathrm{~g}$ of TNT is improved by $11 \%$ ( 0.16 to 0.05 ) when compared with the bare column subjected to contact explosion effects of the same yield. 


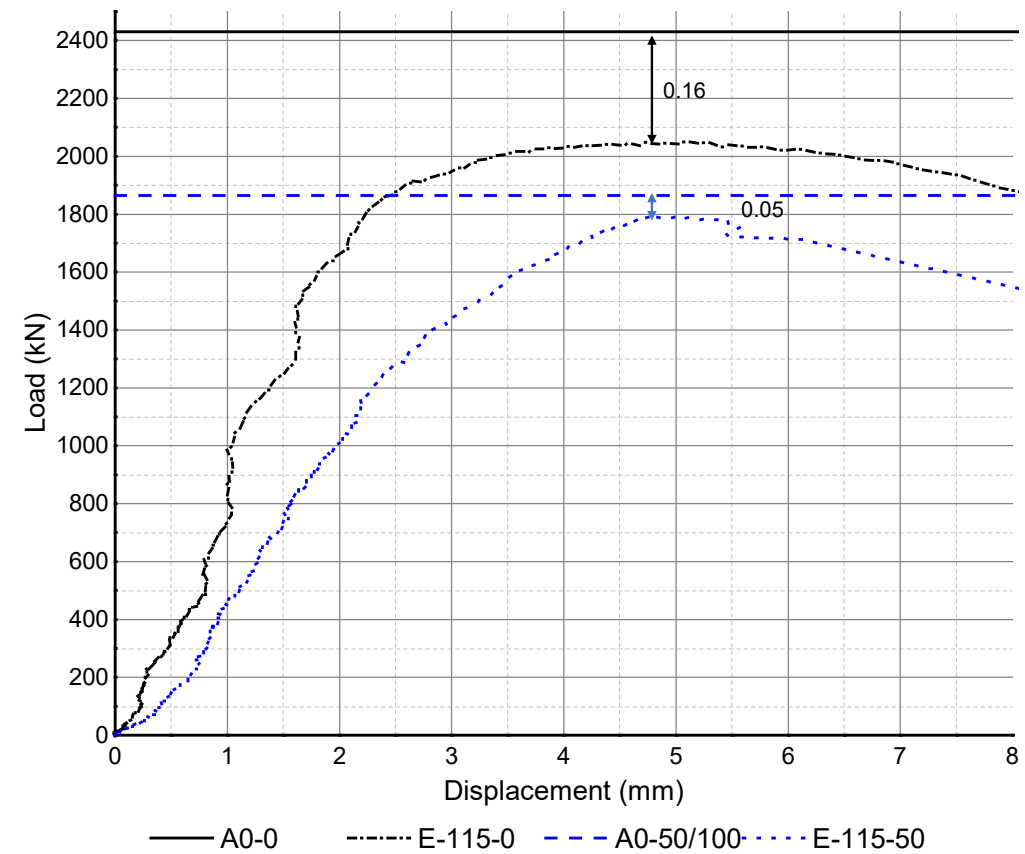

(a)

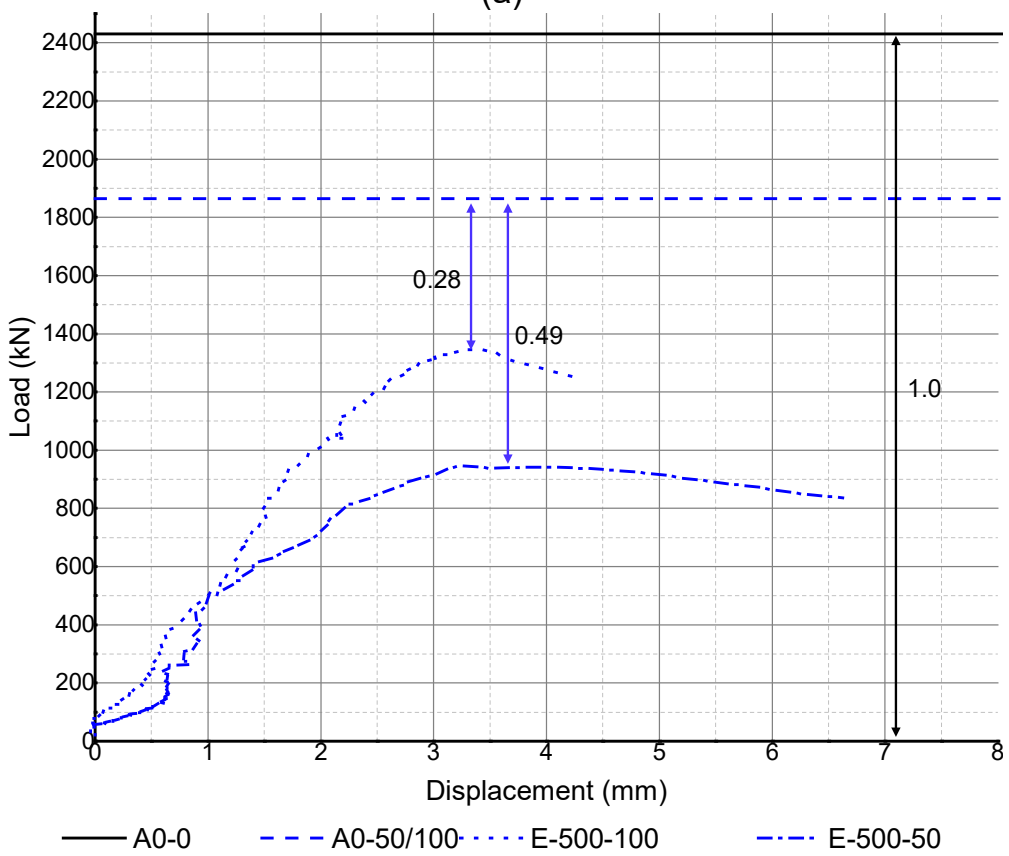

(b)

Figure 5-32: Load-Displacement curves bare and cladded blast-damaged columns subjected to (a) $115 \mathrm{~g}$ TNT (b) $500 \mathrm{~g}$ TNT explosion effects (arrows show damage indices)

In the case of contact explosion effects of $500 \mathrm{~g}$ TNT, the bare column was demolished and hence the damage index is 1 as compared to damage indices of 0.28 and 0.49 for clad columns with $100 \mathrm{~mm}$ and $50 \mathrm{~mm}$ gaps respectively. 
Apropos, the gap induced by means of cladding on RC columns was found to be an effective method to mitigate contact explosion effects.

\subsection{Influence of Energy Absorbing Material in Cladding Gap}

The performance of cladding can be further improved by filling the air-gap with energy absorbing materials like Styrofoam or aluminum foam (Nesterenko, 2003; Braimah et al., 2012). Two models with 50-mm and 100-mm thick Aluminum foam panels in the cladding gap were developed (Figure 5-33). The mitigation effects of Aluminum foam in the cladding gap was numerically assessed by subjecting $300 \times 300 \mathrm{~mm}$ cross-section columns to contact explosion effects of $500 \mathrm{~g}$ TNT. The Aluminum foam was modeled with Mat_26 and the constitutive properties are presented at Table 5-14 Elnasri and Zhao (2015).

Table 5-14: Constitutive properties of the Aluminum Foam

\begin{tabular}{|c|c|c|c|c|c|}
\hline $\begin{array}{c}\text { Density, } \\
\mathrm{kg} / \mathrm{m}^{3}\end{array}$ & $\begin{array}{c}\text { Young's } \\
\text { Modulus, GPa }\end{array}$ & $\begin{array}{c}\text { Poisson's } \\
\text { Ratio }\end{array}$ & $\begin{array}{c}\text { Yield Stress, } \\
\mathrm{MPa}\end{array}$ & $\begin{array}{c}\text { Relative } \\
\text { volume }\end{array}$ & $\begin{array}{c}\text { Tensile failure } \\
\text { strain, } \%\end{array}$ \\
\hline 235 & 70 & 0.285 & 240 & 0.23 & 5 \\
\hline
\end{tabular}

The response of $\mathrm{RC}$ column is likely to change with the change in the constitutive properties of the Aluminum foam, however, the effects of this change has not been studied in this thesis. 


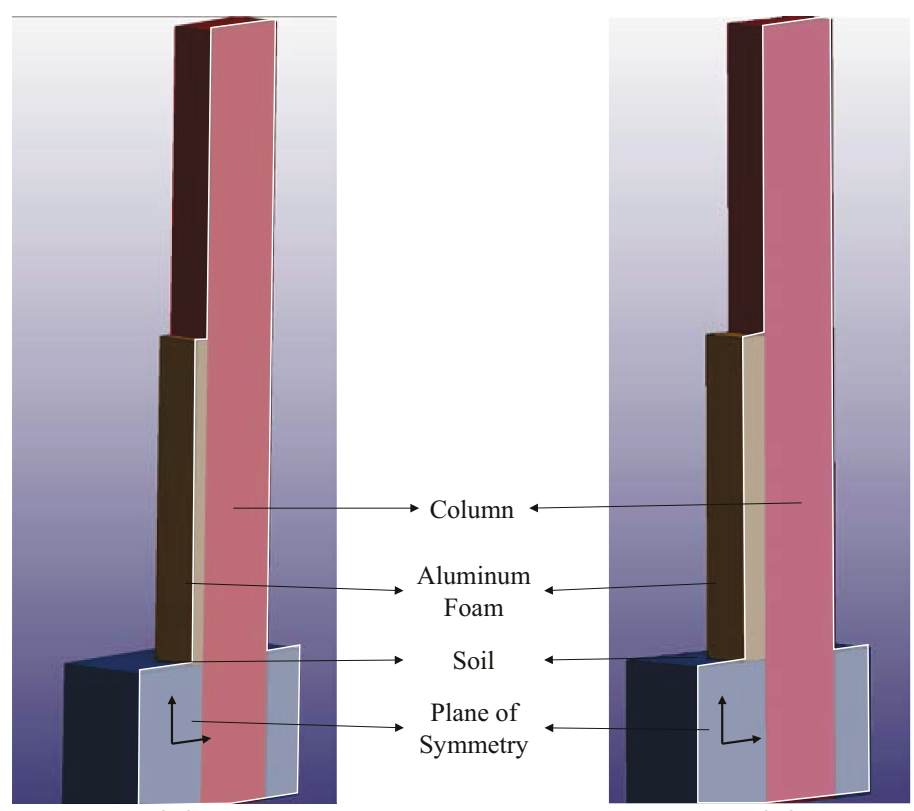

(a)

(b)

Figure 5-33: Numerical models with (a) $50 \mathrm{~mm}$ and (b) $100 \mathrm{~mm}$ thick Aluminum foam panels

The chained simulations were implemented for the two models and the damage profiles at the last timestep of the third simulation are presented in Figure 5-34.

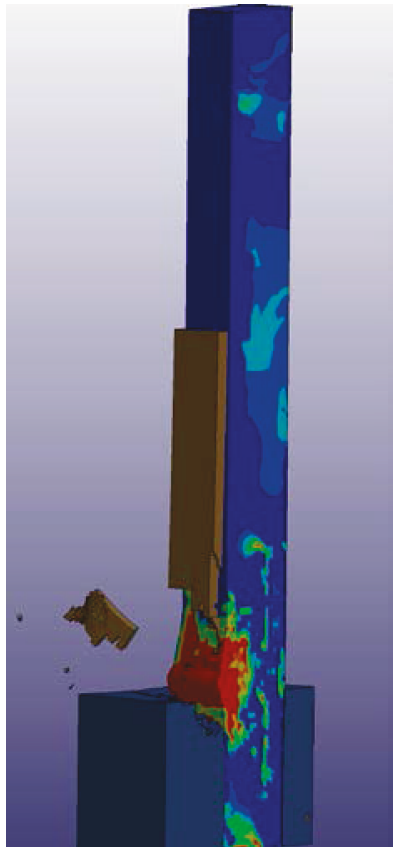

(a)

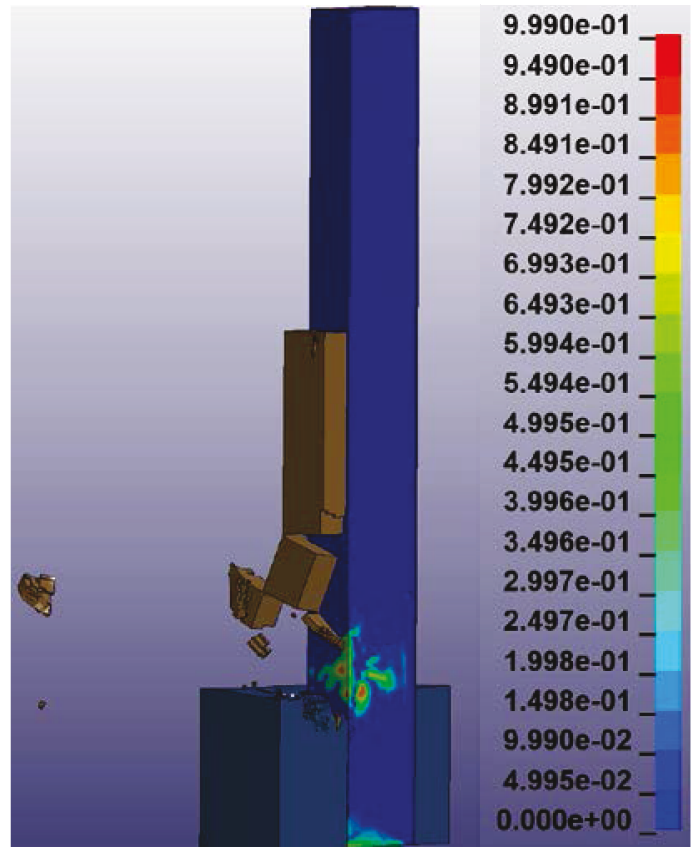

(b)

Figure 5-34: Damage profiles of RC columns with (a) $50 \mathrm{~mm}$ and (b) $100 \mathrm{~mm}$ thick Aluminum foam panels due to contact explosion effects of $500 \mathrm{~g}$ TNT 
The Aluminum foam was crushed in both cases, however, the damage to the RC column was significantly reduced in the case of $100-\mathrm{mm}$ thick foam panel. The residual axial capacities of the blast damaged columns were numerically determined. Figure 5-35 presents the load-displacement curves of the blast damaged columns with and without the Aluminum foam along with the analytically determined nominal capacity of the undamaged column.

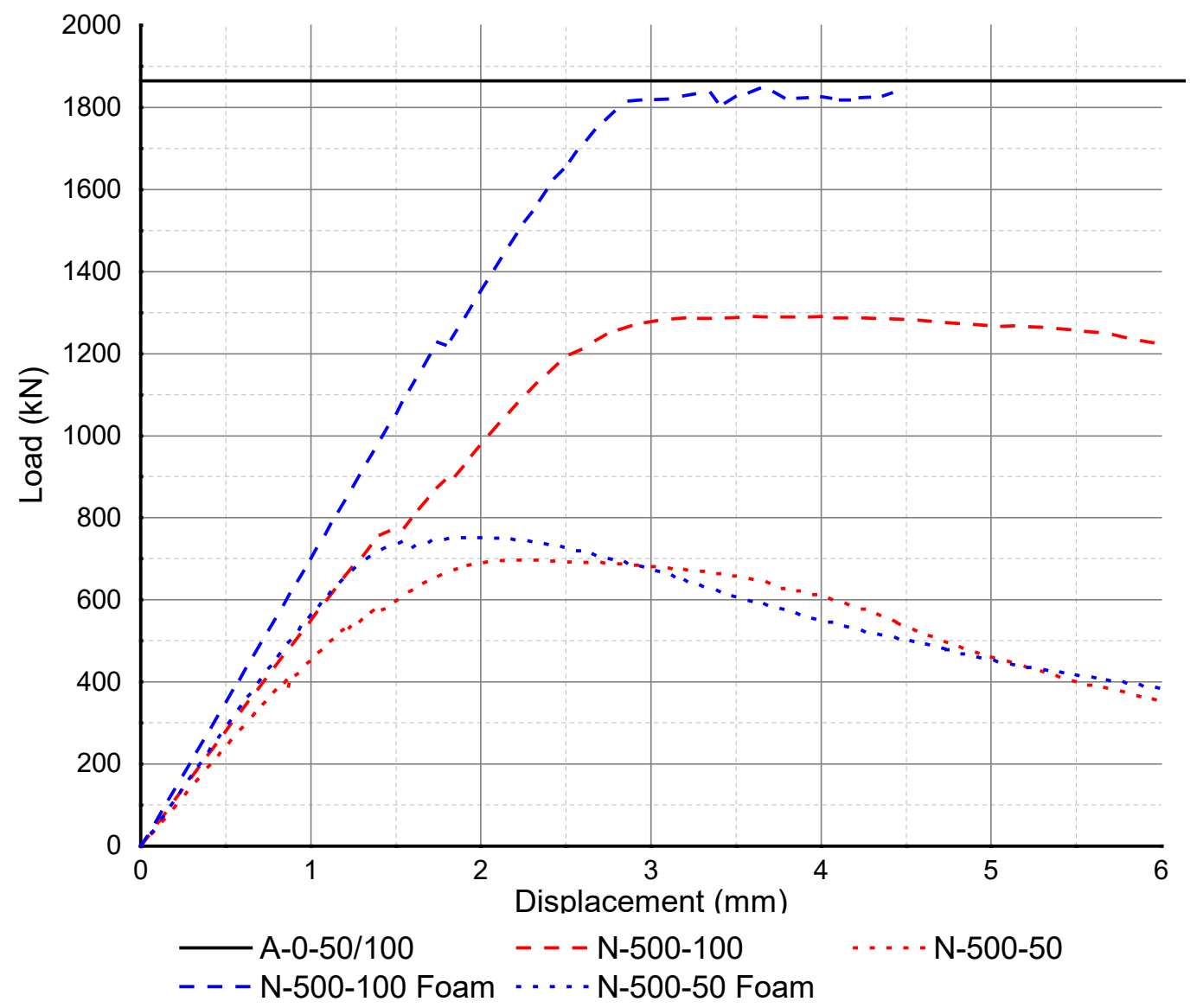

Figure 5-35: Influence of Aluminum foam in mitigating contact explosion effects

The 100-mm thick Aluminum foam panel in the cladding gap improved the residual capacity of the RC column from $1345 \mathrm{kN}$ (without foam) to $1860 \mathrm{kN}$ which is approximately same as the axial capacity of the undamaged column. Hence a 100- 
$\mathrm{mm}$ thick Aluminum panel in the cladding prevented any damage to the concrete core of the RC column. The performance of $50-\mathrm{mm}$ thick Aluminum foal panel in the cladding gap was not substantial and residual axial capacity improved from $600 \mathrm{kN}$ (no foam) to $700 \mathrm{kN}$. However, it is highlighted that contact explosion effects of $500 \mathrm{~g}$ TNT removed the concrete core of a bare column resulting in zero residual axial capacity.

\subsection{Conclusions}

This study investigates the efficacy of plywood cladding in mitigating the damage to RC columns subjected to contact explosion effects. Plywood cladded RC columns with varying air gaps were subjected to contact explosions of 115-g and 500-g TNT. The residual axial load capacity of the blast damaged columns was experimentally determined. The columns with plywood cladding sustained lower damage due to contact explosion effects and exhibited greater residual capacities than columns without cladding. The residual axial load carrying capacities of cladded columns were between $51 \%$ to $95 \%$ of the undamaged strength.

The 2-D shock wave propagation phenomenon in $R C$ columns due to contact explosion effects was studied. The 2-D wave propagation exacerbated the damage in $\mathrm{RC}$ columns when compared to 1-D wave propagation in $\mathrm{RC}$ slabs. The concrete spall patterns were similar in all the columns. The extent of damage to columns can be classified into two categories; (a) concrete cover spall with the intact core (b) complete cover loss and damage to the core. While the columns with the first 
category of damage are likely to have residual capacity, the columns with the second damage category are not expected to have significant residual capacities. Greater concrete spall was observed at the side face compared to the back face due to closer proximity to the point of detonation. Hence, increasing the aspect ratio of an RC column perpendicular to the face of detonation may significantly improve its resistance when subjected to contact explosion effects. Although, this hypothesis requires experimental verification. The blast-damaged columns failed in diagonal shear under concentric axial loads. The failure was brittle and limited ductility was offered by the blast-damaged column when compared to the undamaged column.

The conclusions of this study are summarized below:

- Clad RC columns offer better resistance to contact explosion effects by means of the standoff distance between the explosive in contact with the cladding and the incident column face when compared to bare columns.

- The performance of clad RC columns is enhanced by increasing the air gap between the cladding and the incident column face.

- The use of energy absorbing materials like Aluminum foam in the cladding gap significantly improves the resistance of the RC column to contact explosion effects. 


\subsection{References}

Akers, S., Weed, R., Rickman, D., \& Danielson, K. 2005. Numerical Simulations of Explosive Wall Breaching. Computer Society: IEEE

Arlery, M., Rouquand, A., \& Chhim, S. 2013. Numerical Dynamic Simulations for the Prediction of Damage and Loss of Capacity of RC Column Subjected to Contact Detonations. VIII International Conference on Fracture Mechanics of Concrete and Concrete Structures: University of Colorado Toledo, Spain.

ASCE. 2011. Blast Protection of Buildings: Standard ASCE/SEI 59-11: American Society of Civil Engineers (ASCE). USA.

Bažant, Z. P., \& Zhou, Y. 2002. Why Did the World Trade Center Collapse? Simple Analysis. Journal of Engineering Mechanics, 128(1): 12-18.

Børvik, T., Hanssen, A., Langseth, M., \& Olovsson, L. 2009. Response of Structures to Planar Blast Loads - A Finite Element Engineering Approach. Computers \& Structures, 87: 507-520.

Braimah, A., Elshafey, M., Halim, A. E. H. O. A. E., \& Contestabile, E. 2012. Experimental Investigation of Aluminum Foam Lined Suppressive Shield Containment Vessels. International Journal of Protective Structures, 3(2): 193-220.

Cheng, D.-S., Hung, C.-W., \& Pi, S.-J. 2013. Numerical Simulation of Near-Field Explosion. Journal of Applied Science and Engineering, 16(1): 61-67.

Clarke, S. D., Fay, S. D., Warren, J. A., Tyas, A., Rigby, \& Elgy, I. 2015. A large scale experimental approach to the measurement of spatially and 
temporally localized loading from detonation of shallow buried explosives. Measurement science and technology, 26: 10pp.

Cormie, D., Shin, J., Whittaker, A. S., \& Aref, A. J. 2014a. Air Blast effects on civil structures, MCEER-14-0006. State University of New York.

Cormie, D., Shin, J., Whittaker, A. S., \& Wilkinson, W. 2014b. Numerical modelling of close-in detonations of high explosives. Engineering Structures, 81: 8897.

Crawford, J. E., Morrill, K. B., \& Magallenes, J. M. 2014. Protective design for columns against close-in blast effects. Structures Congress: ASCE USA

Cui, J., Shi, Y., Li, Z.-X., \& Chen, L. 2015. Failure analysis and damage assessment of RC-columns under close-in explosions. Journal of Performance of Constructed Facilities, 29(5): B40150034015001:4015011.

US Department of Army (DoA). 2007. Explosives and Demolitions, FM 3-34.214. Department of Army Washington USA.

US Department of Defense (DoD). 1987. Fundamentals of Protective Design for Conventional Weapons, TM5-855-1. Washington DC, USA.

US Department of Defense (DoD). 2002. Design and Analysis of Hardened Structures to Conventional Weapons Effects, UFC-3-340-01. Department of Defense USA.

US Department of Defense (DoD). 2008. Design of structures to resist the effects of accidental explosions, UFC-3-340-02. Department of Defense Washington, D.C. 
Department of Homeland Security (DoHS). 1993. The World Trade Center Bombing: Report and Analysis. Department of Homeland Security The New York City, New York.

US Department of Transportation (DoT). 2009. Blast-Resistant Highway Bridges: Design and Detailing Guidelines. Transportation Research Board, National Cooperative Highway Research Program (NCHRP) (Report No. 645), Washington, USA.

Dua, A., \& Braimah, A. 2016. State-of-the-Art in Near-Field and Contact Explosion Effects on Reinforced Concrete Columns. 5th International Structural Specialty Conference: Canadian Society for Civil Engineering London, Canada. pp. 1:12 (STR-836).

Dua, A., \& Braimah, A. 2017. Efficacy of Concrete Constitutive Models for Bullet Impact Tests. 6th International Engineering Mechanics and Materials Conference: Canadian Society of Civil Engineers Vancouver, Canada. pp. $521521-510$

Dua, A., Braimah, A., \& Matsagar, V. 2017. Understanding the Response of Reinforced Concrete Slabs due to Contact explosion of TNT. 6th International Engineering Mechanics and Materials Conference: Canadian Society for Civil Engineering (CSCE) Vancouver, Canada. pp. 522 521-510.

Dua, A., \& Braimah, A. 2018. Assessment of Reinforced Concrete Slab Response Due to Contact Explosion Events. Journal of Performance of Constructed Facilities (ASCE), Under Review. 
Dua, A., Braimah, A., \& Kumar, M. 2018. Contact Explosion Response of Reinforced Concrete Columns: Experimental and Numerical Investigation. Structures and Buildings (ICE), Under Review.

Elnasri, I., \& Zhao, H. 2015. Perforation of aluminium foam core sandwich panels under impact loading: A numerical and analytical study. $11^{\text {th }}$ International Conference on the Mechanical and Physical Behaviour of Materials under Dynamic Loading: EPJ Web Conference Lugano, Switzerland.

Enstock, L. K., \& Smith, P. D. 2007. Measurement of impulse from the close-in explosion of doped charges using a pendulum. International Journal of Impact Engineering, 34(3): 487-494.

Federal Emergency Management Agency (FEMA). 1996. The Oklahoma City Bombing: Improving Building Performance through Multi-hazard Mitigation, FEMA-277. Federal Emergency Management Agency Washington, DC, USA.

Federal Emergency Management Agency (FEMA). 2005. Reference Manual to Mitigate Potential Terrorist Attacks Against Buildings, FEMA-426. Federal Emergency Management Agency (FEMA) USA.

Gebbeken, N., Greulich, S., Pietzsch, A., \& Landmann, M. 2004. The EngineeringTool XPLOSIM to Determine the Effects of Explosive Loadings on Reinforced and Fibre Reinforced Concrete Structures. 18th International Symposium for Military Aspects of Blast and Shock: 
Hanssen, A., Enstock, L. K., \& Langseth, M. 2004. Close-Range Blast Loading of Aluminum Foam Panels. International Journal of Impact Engineering, 27: 593-618.

Hyde, D. 1988. User's guide for microcomputer programs CONWEP and FUNPRO - Applications of TM 5-855-1.

Kakogiannis, D., Hemelrijck, D. V., Wastiels, J., Palanivelu, S., Paepegem, W. V., Vantomme, J., . . Kostopoulos, V. 2010. Assessment of Pressure Waves Generated by Explosive Loading. CMES-Computer Modelling in Engineering \& Sciences, 65(1): 75-93.

Kalra, A., Zhu, F., Yang, K. H., \& King, A. I. 2014. Key Parameters in Blast Modeling Using 2D to 3D ALE Mapping Technique. 13th International LSDYNA Users Conference: LSTC Detroit, USA.

Kingery, C. N., \& Bulmash, G. 1984. Air blast parameters from TNT spherical air burst and hemispherical surface burst. Ballistic Research Lab (BRL), Technical Report, ARBRL-TR-02555.

Krauthammer, T., Astarlioglu, S., Morency, D., \& Tran, T. P. 2013. Behavior of Reinforced Concrete Columns Under Combined Effects of Axial and Blastinduced Transverse Loads. Engineering Structures, 55: 26-34.

L.S.T.C. 2015a. LS-DYNA Keyword User's Manual, Volume II-Material Models. Livermore, California, USA: LSTC.

L.S.T.C. 2015b. LS-DYNA Keyword User's Manual, Volume I. Livermore, California, USA: LSTC. 
Li, B., Nair, A., \& Kai, Q. 2012. Residual Axial Capacity of Reinforced Concrete Columns with Simulated Blast Damage. Journal of Performance of Constructed Facilities, 26(3): 287-299.

Li, J., \& Hao, H. 2014. Numerical study of concrete spall damage to blast loads. International Journal of Impact Engineering, 68: 41-55

Li, J., Wu, C., \& Hao, H. 2015. Investigation of Ultra-high Performance Concrete Slab and Normal Strength Concrete Slab under Contact Explosion. Engineering Structures, 102: 395-408.

Lin, Y., Shunfeng, G., \& Weiliang, J. 2008. Spallation Mechanism of RC Slabs Under Contact Explosion. Transactions of Tianjin University, SpringerVerlag, 14:464.

Malvar, L., \& Crawford, J. E. 1998. Dynamic Increase Factors for Concrete. Naval Facilities Engineering Service Center.

Mlakar, P. F., Corley, W. G., Sozen, M. A., \& Thornton, C. H. 1998. The Oklahoma City Bombing: Analysis of Blast Damage to the Murrah Building. Journal of Performance of Constructed Facilities, 12(3): 113-119.

Murray, Y. D. 2007. User's Manual for LS-DYNA Concrete Material Model 159. FHWA-HRT-05-062, Federal Highway Administration.

Naito, C., Olmati, P., Trasborg, P., Davidson, J., \& Newberry, C. 2014. Assessment of insulated concrete walls to close-in blast demands. American society of civil engineers, 10.

Nesterenko, V. F. 2003. Shock (Blast) Mitigation by "Soft" Condensed Matter. MRS Proceedings: Pittsburg, USA 
Puryear, J. M. H., Stevens, D. J., Marchand, K. A., Williamson, E. B., Sammarco, E. L., \& Crane, C. K. 2012. Predicting Spall and Breach for Blast-Loaded Reinforced-Concrete Columns. Texas ASCE Centennial Conference: ASCE Dallas, USA

Riedel, W., Mayrhofer, C., Thoma, K., \& Stoltz, A. 2010. Engineering and Numerical Tools for Explosion Protection of Reinforced Concrete. International Journal of Protective Structures, 1(1): 85-101.

Rigby, Tyas, A., Clarke, S., Fay, S., Warren, J., Elgy, I., \& Gant, M. 2014. Testing apparatus for the spatial and temporal pressure measurements from nearfield free air explosions. 6th International Conference on Protection of structures against hazards: Tianjin, China.

Rigby, Tyas, A., Clarke, S. D., Fay, S. D., Reay, J. J., Warren, J. A., . . Elgy, I. 2015. Observations From Preliminary Experiments on Spatial and Temporal Pressure Measurements from Near-Field Free Air Explosions. International Journal of Protective Structures, 6(2): 175-190.

Satter, D. 2003. Darkness at Dawn: Yale University Press.

Schwer, L. 2014. Modelling Rebar: The Forgotten Sister in Reinforced Concrete Modelling. 13th International LS-DYNA User Conference: LSTC Detroit, USA.

Tagel-Din, H., \& Rahman, N. A. 2006. Simulation of the Alfred P. Murrah Federal Building Collapse Due to Blasts Loads. Architectural Engineering Conference: ASCE Nebraska, USA. pp. 32-47. 
Tait, R. (2014). Israel's destruction of Gaza tower blocks a 'war crime', says Amnesty, The Telegraph.

Telford, T. 1993. CEB-FIB Model Code 1990. Comité Euro-International du Béton, Lausanne, Switzerland.

Trajkovski, J., Kunc, R., Perenda, J., \& Prebil, I. 2014. Minimum mesh design criteria for blast wave development and structural response - MMALE method. Latin American Journal of Solids and Structures, 11: 1999-2017.

Wang, F., Wan, Y. K. M., Chong, O. Y. K., Lim, C. H., \& Lim, E. T. M. 2008. Reinforced concrete slab subjected to close-in explosion. LS-DYNA Conference: Bamberg.

Wang, W., Zhang, D., Lu, F., Wang, S.-C., \& Tang, F. 2013. Experimental study and numerical simulation of the damage mode of a square reinforced concrete slab under close-in explosion. Engineering Failure Analysis, 27: $41-51$.

Weerheijm, J., Karthaus, W., \& Opschoor, G. 1984. The Failure Mode of Layered Concrete Construction Due to Contact Charges. 21st Department of Defense Explosive Safety Seminar. Department of Defense Houston, Texas, USA

Williams, G. D. 2009. Analysis and Response Mechanisms of Blast-Loaded Reinforced Concrete Columns. (Doctor of Philosophy), University of Texas, Austin, USA. 
Williams, G. D., \& Williamson, E. B. 2011. Response of Reinforced Concrete Bridge Columns Subjected to Blast Loads. Journal of Structural Engineering, 137(9): 903-913.

Wu, K.-C., Li, B., \& Tsai, K.-C. 2011. Residual Axial Compression Capacity of Localized Blast-Damaged RC Columns. International Journal of Impact Engineering, 38: 29-40.

Yuan, S., Hao, H., Zong, Z., \& Li, J. 2017. A Study of RC Bridge Columns Under Contact Explosion. International Journal of Protective Structures, 109: 378390.

Zakrisson, B., Wikman, B., \& Häggblad, H.-Å. 2011. Numerical simulations of blast loads and structural deformation from near-field explosions in air. International Journal of Impact Engineering, 38(7): 597-612.

Zhang, D., Yao, S., Lu, F., Chen, X., Lin, G., Wang, W., \& Lin, Y. 2013. Experimental study on scaling of RC beams under close-in blast loading. Engineering Failure Analysis, 33: 497-504.

Zhang, P., Cheng, Y., \& Liu, J. 2014. Numerical Analysis of Dynamic Response of Corrugated Core Sandwich Panels subjected to Near-Field air blast loading. Shock and Vibration, 2014: 16.

Zhao, X. Q., Kuznetsov, V. A., Hao, H., \& Waschl, J. 2008. Numerical Prediction of Concrete Slab Response to Blast Loading. International Journal of Impact Engineering, 35: 1186-2000. 


\title{
Chapter 6 Experimental and Numerical Investigation of Reinforced Concrete Walls Under Contact Explosion Effects
}

\begin{abstract}
Response of reinforced concrete (RC) columns subjected to contact explosion effects is more severe than the response to non-contact explosions due to local material failure. The local material damage is due to reflection from three column faces, when compared to $\mathrm{RC}$ slabs wherein the shock-wave reflection from the back-face only is significant. The loss of concrete cross section reduces the axial load and bending capacity of the RC columns. It is hypothesized that the concrete loss from the sides can be prevented by varying the aspect ratio of the RC column cross section. This study experimentally investigates the response of RC columns with varying aspect ratios of the cross section, subjected to contact explosion effects. A range of aspect ratios was investigated to preclude the side face damage for a given depth of RC column. High fidelity numerical models were developed to predict the blast-response and the residual axial capacity of the blast-damaged columns. The numerical models were validated, and the results show a good correlation with the experimental results. Using an RC column cross-section aspect ratio that precludes the side face spall significantly improves the residual axial capacity of the blast-damaged columns. Furthermore, parametric analyses were performed to numerically investigate the influence of the width on the residual axial load carrying capacity of RC columns subjected to contact explosion effects of breach charge mass required for the provided depth. An increase in the width of the column improved the damage resistance of the column while the column was breached around the point of detonation. Hence, the aspect ratio of the column cross-section can be effectively used to mitigate contact explosion effects.
\end{abstract}

Keywords: Contact explosion, LS-DYNA, RC column, FSI, Blast, RC wall

\subsection{Introduction}

$\mathrm{RC}$ columns are critical load bearing members in a framed structure and abrupt failure of non-redundant columns due to material loss can initiate a cascading failure (Krauthammer et al., 2013). In the past few decades, many terrorist attacks

Submitted to the Journal of Engineering Structures, Elsevier in a revised form

Authors - Dua, Alok; Braimah, Abass; Kumar, Manish 
and accidental explosions have resulted in the complete or partial collapse of buildings causing high fatalities and loss of property. For example, the world trade centre attack in 1993 caused failure of floor slabs however adequate redundancy of the columns prevented building collapse (Bažant \& Zhou, 2002); the Oklahoma City Bombing in 1995 led to partial collapse of the Alfred P. Murrah building and caused 268 deaths (Mlakar et al., 1998); attack on five residential apartments in Russian in 1999 led to the building collapse and 293 deaths (Satter, 2003). These are just a few examples that show the severity of damage and casualty levels that the inadequacy in blast-resistance of RC columns can cause. Moreover, the damage in RC columns is higher due to contact explosion effects which is a credible terrorist threat. Concealed explosives in the range of 5-25 kg can possibly render an $\mathrm{RC}$ column with zero residual axial load carrying capacity that can be detrimental to the structural integrity of the structure. Therefore, it is imperative to design strategically important structures envisaged as a potential target for terrorist attacks by incorporating mitigation strategies that limit the damage caused by contact explosions.

Structural resiliency against far-field events is well established in the literature however experimental work on contact explosion effects is scarce. The response of RC components to contact explosion effects is highly non-linear and is an ongoing field of study. Besides, mitigation of contact explosion effects is yet to be studied. This study examines the possibility of reducing the local material damage in an RC column subjected to contact explosion effects. The aspect ratio of RC 
columns was varied to preclude the side face damage restricting the material loss in the concrete core.

\subsection{Literature Review}

\subsubsection{Contact Explosion}

The blast response analysis and protective design methodologies are presented in manuals like DoD (1987), DoD (2002), DoD (2008) and FEMA (2005) that are appropriate for far-field detonations. DoD (2008) and ASCE (2011) defines the near-field range as scaled distance smaller than $1.18 \mathrm{~m} / \mathrm{kg}^{1 / 3}$. Several other researchers (e.g., Cormie et al. (2014a); Cormie et al. (2014b) and Braimah et al. (2015)) have reported that the blast parameters presented by Kingery and Bulmash (1984) and ConWep (Hyde, 1988) are not accurate in the near-field range and specifically for a scaled distance smaller than $0.4 \mathrm{~m} / \mathrm{kg}^{1 / 3}$. The numerical and experimental response of $\mathrm{RC}$ members subject to near-field explosion effects have been reported recently (e.g., Hanssen et al. (2004); Enstock and Smith (2007); F. Wang et al. (2008); W. Wang et al. (2013); Zhang et al. (2013); Cormie et al. (2014b); Crawford et al. (2014); Naito et al. (2014); Cui et al. (2015)). However, these are limited to RC slabs and façade members. There is limited information available on the behavior of RC columns subject to contact explosion effects and its mitigation strategies (Dua \& Braimah, 2016).

DoT (2009) reported experimental data on the response of RC bridge columns subjected to near-field and contact explosions. The document also presented the 
numerical response of RC bridge columns subjected to far-field explosion effects that correlated well with the experimental observations (Williams, 2009). The side face spalling in RC columns subjected to contact explosion is attributed to the Poisson's effect. The compressive force due to a contact explosion causes expansion of the column core perpendicular to the direction of loading and it occurs early during the loading prior to global response of the column. Strain rate effects were not considered for the numerical simulations presented in the study by Williams (2009). It was concluded that the perceived increase in concrete strength at high strain rate loading is due to the inertial confinement provided by the outer concrete layer. This phenomenon is inherently captured by finite element formulation. Hence, dynamic increase factors (DIF) were not incorporated in the material model of the concrete (Williams, 2009).

Wu et al. (2011a) and Wu et al. (2011b) proposed empirical relationships using experimental and numerical data to calculate residual axial compression capacity of localized blast-damaged RC columns and steel composite RC columns. A parameter, explosive mass ratio, defined as the ratio of explosive charge mass to the mass of $1-\mathrm{m}$ high column was utilized in the study to express the contact explosion effect on RC columns. Contact explosion due to the explosive mass ratio of 0.04 resulted in a $60 \%$ residual compression capacity when an explosive was detonated at the bottom of the column. On the other hand, $90 \%$ residual compression capacity was obtained when the explosive was detonated at a height of $1.5 \mathrm{~m}$ from the ground. The overall column height did not have any effect on the residual capacity of blast-damaged columns. The location of contact explosion had 
a significant effect on the residual axial capacity. An explosion on the bottom of the column resulted in lower residual axial capacity when compared to an explosion at $1.5 \mathrm{~m}$ height. For the numerical simulations, an element size of $50-\mathrm{mm}$ was used to model the column as well as the Arbitrary Lagrangian-Eulerian (ALE) domains. The effects of the service axial load on the columns were not considered in this study. Actual boundary conditions as in the case of real-life structures were not created for the experimental tests.

Braimah et al. (2015) reported experimental results from tests on RC columns subjected to near-field explosion effects. RC columns with varied transverse reinforcement detailing were subjected to an explosion at scaled distances of less than $1 \mathrm{~m} / \mathrm{kg}^{1 / 3}$. RC columns detailed for seismic load resistance were found to have better blast resistance compared to conventional detailing.

Recently, Yuan et al. (2017) presented a study on the experimental and numerical response of square and circular RC bridge piers subjected to contact explosion of $1 \mathrm{~kg}$ of equivalent Trinitrotoluene (TNT) explosive. Axial load on the column was not considered for the experimental tests. The experimental and numerical damage profiles were compared for qualitative validation and accelerometer readings were compared for quantitative validation. The Lagrangian entities in the LS-DYNA model were meshed with an element size of $8 \mathrm{~mm}$ to $20 \mathrm{~mm}$ and the multi-material ALE (MMALE) domain was meshed with an element size of $20 \mathrm{~mm}$. LS-DYNA numerical models reasonably captured the experimental results, except for the damage to the column face opposite to detonation. 


\subsubsection{Numerical Modeling}

There are three prevalent techniques used for blast analysis of structures: (a) Simplified analytical methods such as Pressure-Impulse (PI) diagrams, single degree of freedom (SDOF) or multi-degree of freedom (MDOF) dynamic analysis using blast load parameters generated from empirical charts provided by DoD (2008), Kingery and Bulmash (1984), DoD (1987) or other such codes, (b) Nonlinear finite element analysis implementing blast load parameters generated from underlying empirical equations and charts by Kingery and Bulmash (1984), DoD (2008), DoD (1987) and (c) high fidelity finite element analysis programs with explicit modelling of the detonation process, blast wave propagation and fluidstructure interaction (FSI). While the first two methods have been reported to accurately predict far-field blast response (Cormie et al., 2014a; Braimah et al., 2015), contact explosion effects can only be accurately modeled with MMALE formulation as it provides a complete description of the blast wave parameters (Børvik et al., 2009). The technique involves modeling the chemical reaction during detonation and consequent blast wave propagation. However, the primary disadvantage of modeling detonation and blast wave propagation is its mesh dependence (Kakogiannis et al., 2010) and hence a higher computational cost due to a fine mesh requirement. Kalra et al. (2014) presented a 2D to 3D MMALE mapping technique in LS-DYNA for reducing the computational cost. The explosive detonation and blast wave propagation was simulated in the $2 \mathrm{D}$ domain and mapped to a 3D domain to implement the FSI between the generated blast wave and the Lagrangian entity. This technique, however, cannot be implemented for 
modeling contact explosions as the explosive detonation and FSI occur simultaneously. Simulating detonation and FSI in 2D will not represent the true phenomenon as the blast wave is spatially and temporally non-linear around the explosive. Moreover, the spatially non-linear Lagrangian response in 3D will not be captured with the $2 \mathrm{D}$ model. Hence, a finely meshed $3 \mathrm{D}$ domain is required to accurately model the detonation process and the Lagrangian response during a contact explosion event.

The finely meshed 3D air domain must be modeled large enough to avoid reflection of the blast wave from the air domain boundary during the whole event. This results in a large memory prerequisite. Lately, massive parallel processing (MPP) abilities have been introduced by LS-DYNA that allows parallel processing and availability of large memory resources. However, these resources are difficult to access.

\subsubsection{Mitigation Techniques}

For far-field explosions, mitigation strategies such as the use of high strength materials and energy absorption materials have been recommended. Li et al. (2015) have presented the benefits of ultra-high-performance concrete (UHPC) over normal strength concrete against a contact explosion. Soft condensed materials were used successfully by Nesterenko (2003) for mitigation of shock/blast waves due to contact explosion effects. However, it was reported that the ensuing amplitude of the blast load on the structure may be enhanced by the soft condensed material resulting in higher damage compared to unprotected target/structure. Critical thickness of the energy absorbing medium was 
recommended to preclude the shock amplitude enhancement. Limited mitigation strategies could be found in the literature to improve the response of normal strength RC members, particularly columns, against contact explosions. Experimental verification of mitigation potential of the column width remains uninvestigated in the literature.

\subsection{Research Significance}

The response of RC columns subjected to non-contact explosion effects is well established in the literature. In recent past, the research focus has shifted to contact explosion events and experimental results on the response of $\mathrm{RC}$ columns have been presented in the literature. The results are mostly restricted to the qualitative analysis of the damage profile in terms of spall diameter or area. Only a handful of studies have been found in the literature that have reported a quantitative analysis of the blast response in terms of residual axial capacity. These quantitative results are restricted to the square and circular columns. The response of RC columns with rectangular cross-section subjected to contact explosion effects remain uninvestigated. This study addresses this gap and has the following objectives:

- Experimentally determine the range of aspect ratio of the RC column crosssection that precludes side face spalling due to contact explosion effects. 
- Develop an experimentally validated high fidelity numerical model to predict the contact blast response of $\mathrm{RC}$ walls and the residual axial load carrying capacity of blast-damaged RC wall.

- Experimentally test the residual axial load carrying capacity of the blastdamaged $\mathrm{RC}$ walls to validate the numerical model.

- Numerically investigate the influence of wall width on the residual axial load carrying capacity of the RC wall subjected to contact explosion effects of explosive mass that can breach an RC slab of the same depth.

\subsection{Experimental Investigation}

\subsubsection{Contact Explosion}

Three RC square columns and three RC walls of varying aspect-ratios were tested in the experimental program. The three RC square columns were cast and tested in phase 1 while the RC walls were cast and tested in phase 2 of the overall research program.

The RC columns were of $300 \mathrm{~mm} \times 300 \mathrm{~mm}$ cross-section and were cast with ready-mix-concrete of $25 \mathrm{MPa}$ compressive strength and 0.014 longitudinal reinforcement ratio. The nominal axial capacity of the RC column was calculated to be $2431 \mathrm{kN}$. An isolated footing of $900 \mathrm{~mm} \times 900 \mathrm{~mm} \times 450 \mathrm{~mm}$ was provided at a depth of $900 \mathrm{~mm}$ from the ground level. Details of the square RC column and the test setup are presented in Figure 6-1(a) \& (b) respectively. 


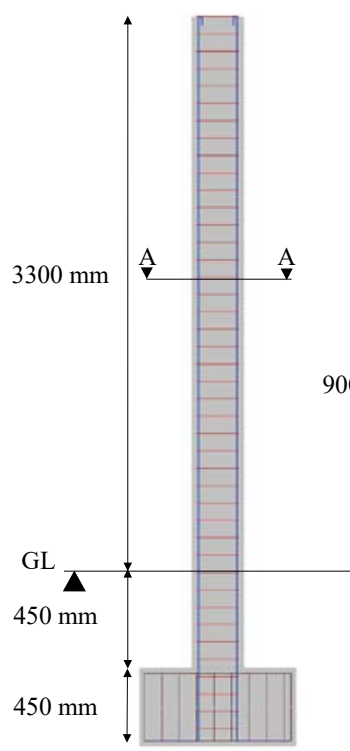

(a)

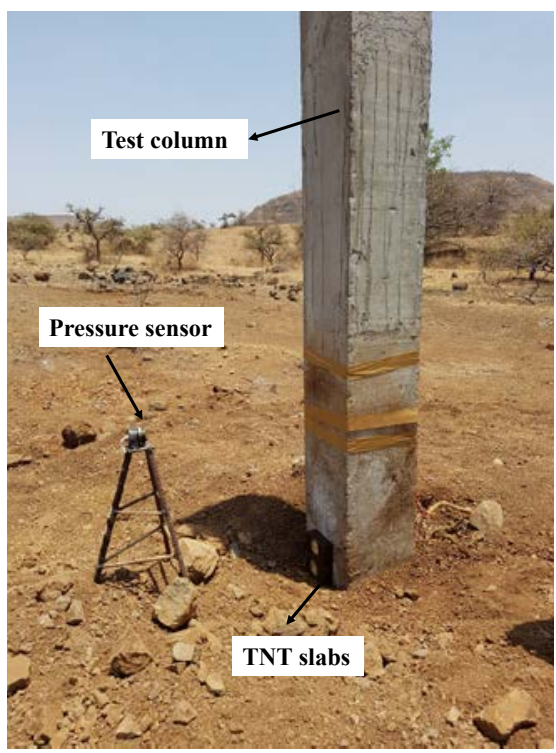

(b)

Figure 6-1: (a) RC column details for benchmark tests (b) Test setup for $1 \mathrm{~kg}$ explosive (c) Test designations

The geometric details of the three RC walls are as presented in Figure 6-2. The depth of the wall across the explosive mass was kept same $(300 \mathrm{~mm})$ as the square $\mathrm{RC}$ column. The walls were cast with ready-mix-concrete of $25 \mathrm{MPa}$ mix design. The reinforcement ratios provided were $0.0081,0.0060$ and 0.0060 respectively for $300 \times 500 \mathrm{~mm}, 300 \times 700 \mathrm{~mm}$ and $300 \times 900 \mathrm{~mm}$ cross-sections (aspect-ratios). The nominal axial load carrying capacities of the walls were 3044 $\mathrm{kN}, 4028 \mathrm{kN}$, and $5206 \mathrm{kN}$ respectively for the $300 \times 500 \mathrm{~mm}, 300 \times 700 \mathrm{~mm}$ and $300 \times 900 \mathrm{~mm}$ aspect-ratios. An isolated footing of $450 \mathrm{~mm}$ thickness as per Figure 6-2 was provided for each wall.

All six members were free-standing members and no support was provided at the top. The members were cast in two lifts: footing and the main cross-section. Wet burlap curing was carried out on all members for 14 days and the contact explosion tests were conducted 28 days after the concrete pour for the second lift. 
Core samples of $75 \mathrm{~mm}$ diameter were extracted from the undamaged portion of the members after the contact explosion tests. The average concrete compressive strength for the square columns and the RC walls was determined to be $25 \mathrm{MPa}$ and $20 \mathrm{MPa}$ respectively. The cavities of the cylindrical cores from the $\mathrm{RC}$ columns were filled with premix-concrete of $25 \mathrm{MPa}$ compressive strength prior to residual capacity testing on the columns.

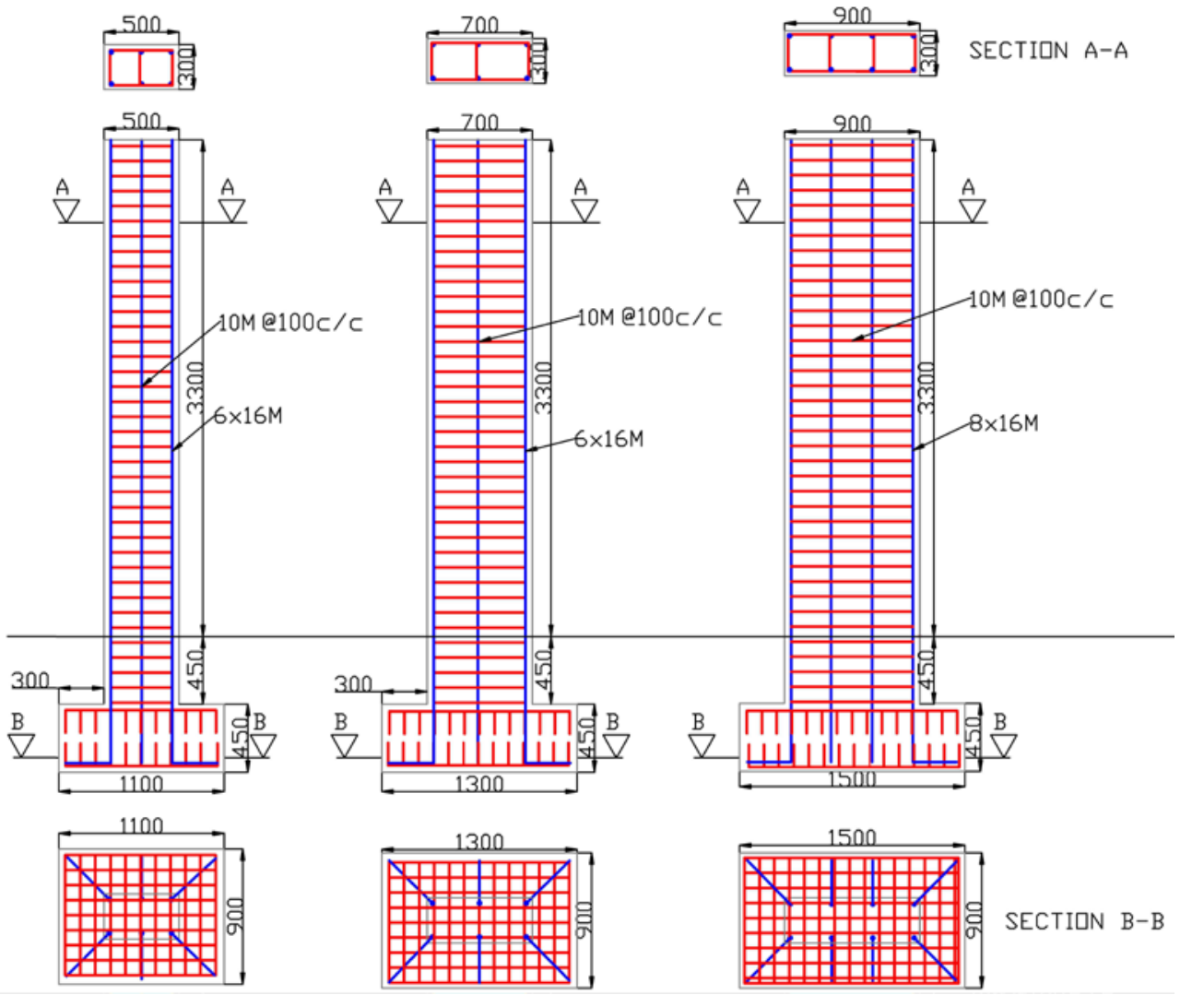

Figure 6-2: RC wall details for $500 \times 300 \mathrm{~mm}, 700 \times 300 \mathrm{~mm}$ and $900 \times 300 \mathrm{~mm}$ aspect-ratios

The test sample designation used in this study is presented in Figure 6-3. 


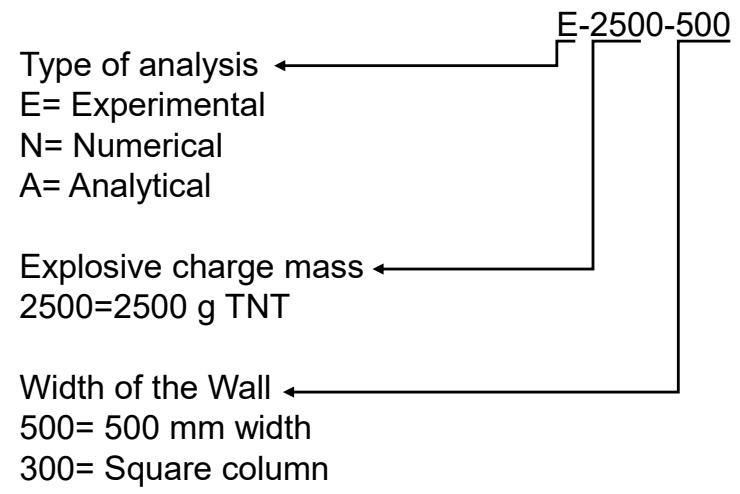

Figure 6-3: Test case designation

The three RC columns were subjected to contact detonation effects of $1000 \mathrm{~g}, 500$ $\mathrm{g}$ and $115 \mathrm{~g}$ TNT explosive masses. This was done to identify the range of explosive mass that can cause crushing of the concrete core and render the square RC columns with zero residual axial capacity. On the other hand, an explosive mass of $500 \mathrm{~g}$ was detonated in contact with the three walls to identify the width of the RC wall that can preclude 2D blast-propagation. The test setup for the RC wall with $300 \times 900 \mathrm{~mm}$ cross-section is presented in Figure $6-4$. The explosive was placed on the ground in contact with the wall face emulating an explosive device placed in a possible terrorist threat scenario. Demolition explosives manufactured for the commercial purpose were used for the tests. The detonation velocity, density, and mass of one slab reported by the manufacturer were $6.93 \times 10^{6} \mathrm{~mm} / \mathrm{s}, 1.55 \times 10^{6} \mathrm{~T} / \mathrm{mm}^{3}$ and $500 \mathrm{~g}$ respectively. 


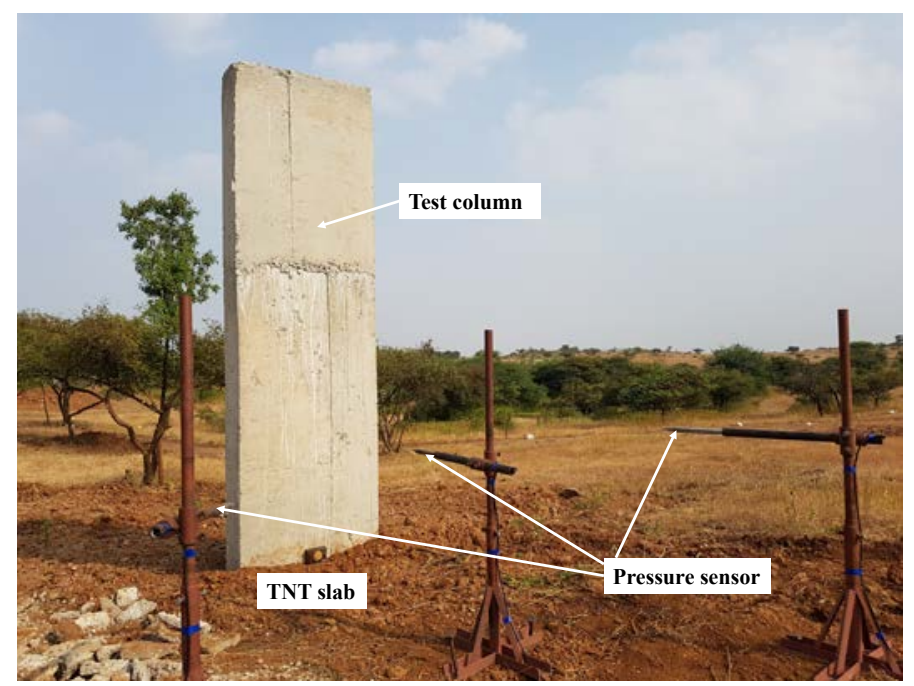

Figure 6-4: Experimental test setup for E-500-900 test

\subsubsection{Residual Axial Capacity}

The residual axial capacities of the blast-damaged columns E-115-300 and E-500500 were experimentally determined to quantitatively validate the numerical models. The blast-damaged members were extracted from the ground and transported to the structures laboratory for testing. The members were prepared for the residual axial load tests by cutting off the footing and wrapping the top and bottom ends with carbon fibre reinforced polymer (CFRP) sheets to preclude premature failure at the ends. A $400 \mathrm{~T}$ hydraulic jack was placed on top of the loading frame and underneath the wall to load it while a load cell was placed between the top of the wall and bearing against the reaction-frame to monitor the applied load (Figure 6-5). Linear variable displacement transducers (LVDT) were fixed to the concrete walls to acquire the displacement time histories in axial and lateral directions. 


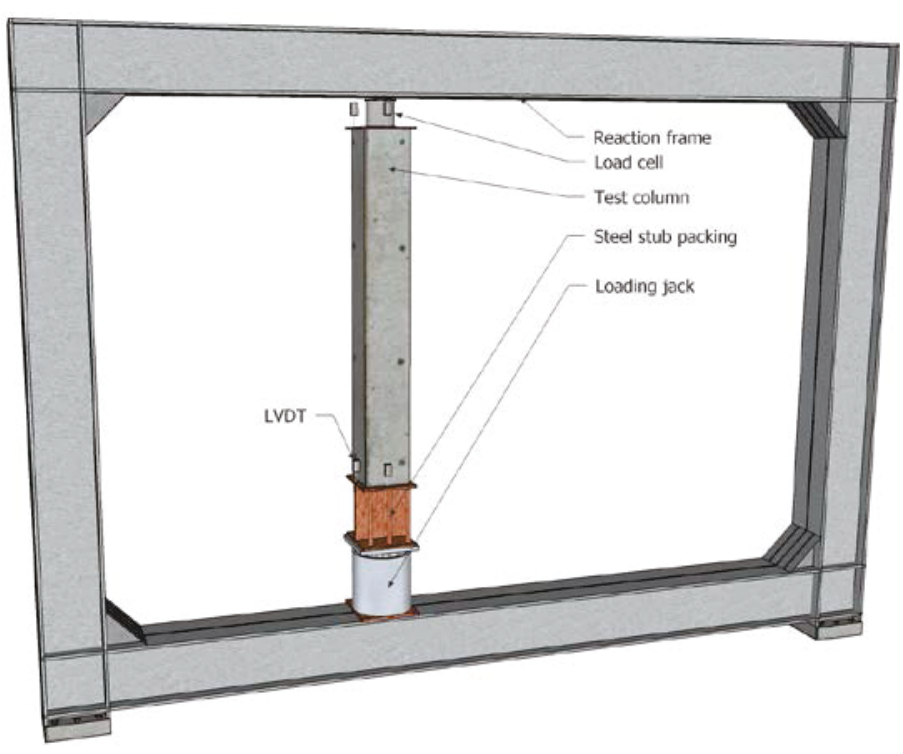

(a)

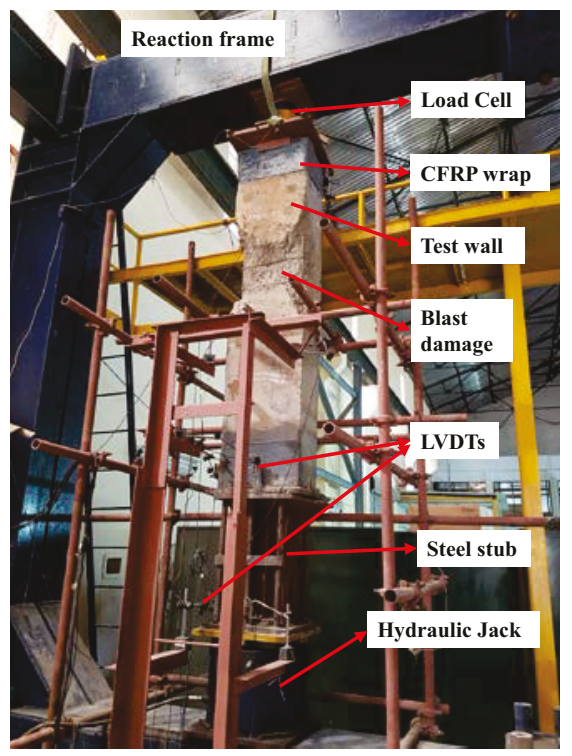

(b)

Figure 6-5: Test setup for residual axial load capacity (a) Schematic layout (b) Actual layout

\subsection{Experimental Results}

\subsubsection{Contact Explosion Response}

Three square RC columns were subjected to contact explosion effects of $1000 \mathrm{~g}$, $500 \mathrm{~g}$ and $115 \mathrm{~g}$ TNT in the experimental program. The concrete core up to a length of $375 \mathrm{~mm}$ from the ground level, of the $300 \times 300 \mathrm{~mm}$ column, was crushed and an additional $250 \mathrm{~mm}$ spalled from all sides (total damage $625 \mathrm{~mm}$ ) due to the 1000-g TNT explosion (Figure 6-6 (a)). The 500-g TNT explosion crushed the concrete cover up to $675 \mathrm{~mm}$ and caused severe damage to the core (Figure 6-6 (b)). The two columns clearly had zero residual axial load capacity and were thus not included in the residual capacity tests. The 115-g TNT explosion caused a crater-spall failure mode. A $180-\mathrm{mm}$ diameter crater was formed on the incident face. The crater merged with the side face spall of $400 \mathrm{~mm}$ length. There was no concrete spalling on the distal face of the column however, a horizontal crack was created due to the contact explosion event (Figure 6-6 (c)). 


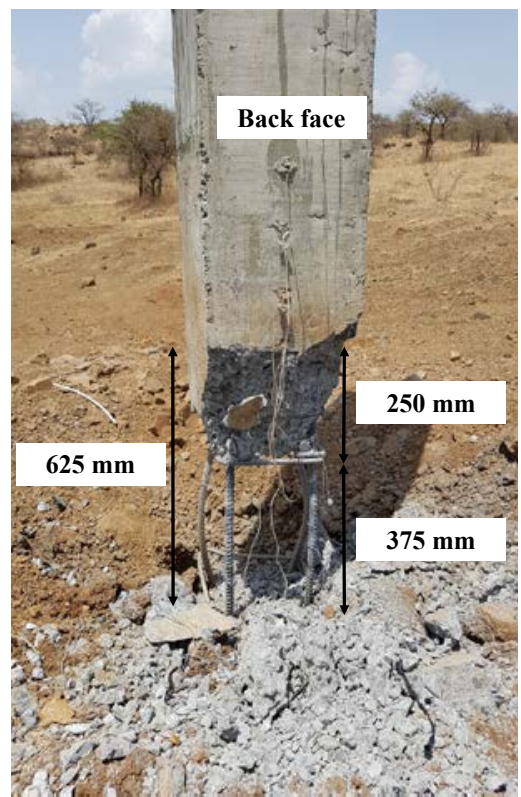

(a)

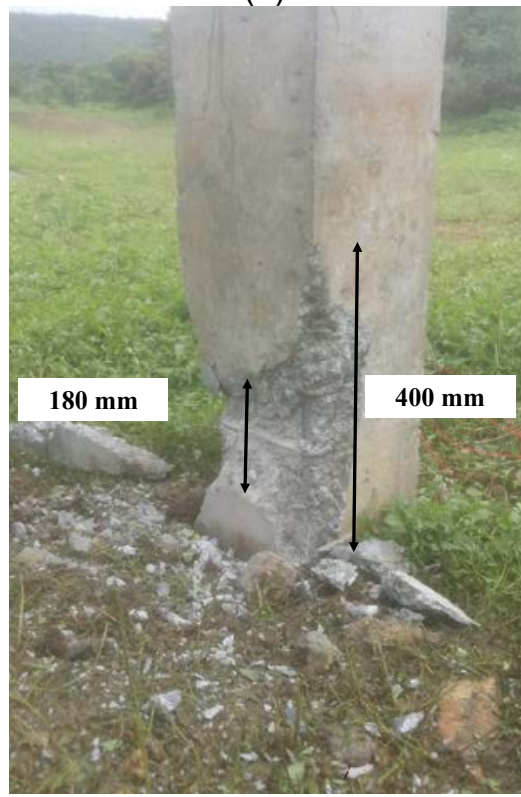

Front face

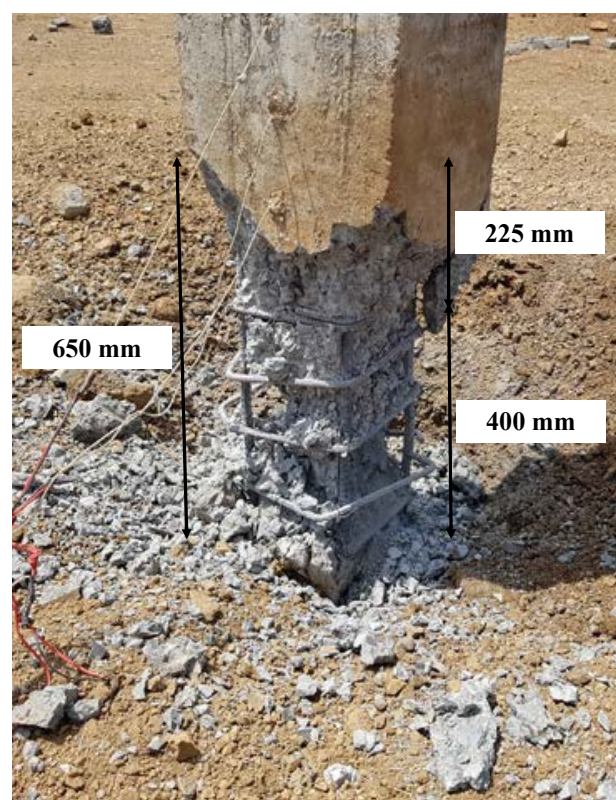

(b)

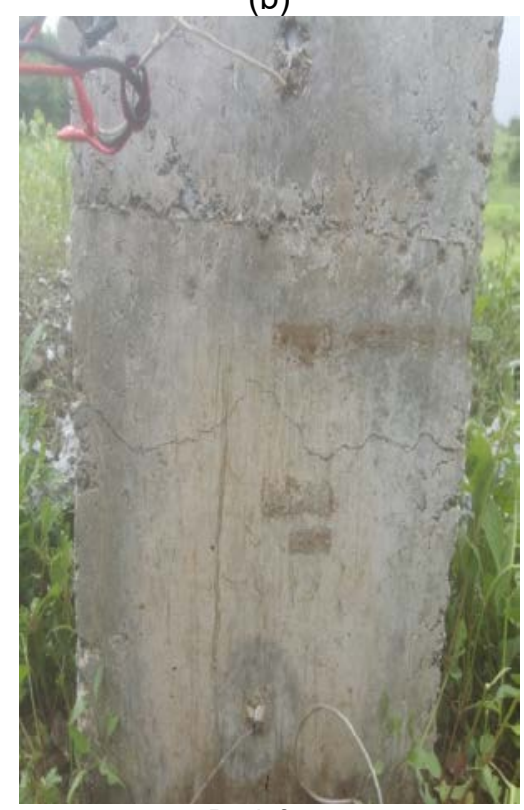

Back face

(c)

Figure 6-6: Damage profile for (a) E-1000-300 (b) E-500-300 (c) E-115-300

The $300 \times 900 \mathrm{~mm}$ and $300 \times 700 \mathrm{~mm}$ walls exhibited the crater-spall failure mode however the spall damage to the side faces and distal face was limited to cracking (Figure 6-7 (a) \& (b)). The back face of these columns displayed minor cracks however the concrete cover was intact. A circular crater of approximately $300 \mathrm{~mm}$ in diameter was created on the contact face. The failure mode in RC walls with no 
side face spalling is similar to the failure mode in RC slabs reported in Dua and Braimah (2018).

On the other hand, the concrete cover spalled from side faces and the distal face of the $300 \times 500 \mathrm{~mm}$ wall. A crater of $350 \mathrm{~mm}$ diameter was formed on the incident face that merged with the side face spall resulting in a damage profile as shown in Figure 6-7 (c). The exposed concrete core appeared cracked at certain locations on visual inspection.

It can be concluded from the experimental tests that the threshold aspect ratio that precludes side face spall in a $300 \mathrm{~mm}$ thick wall subjected to contact detonation of $500 \mathrm{~g}$ TNT is in the range of $500-700 \mathrm{~mm}$.

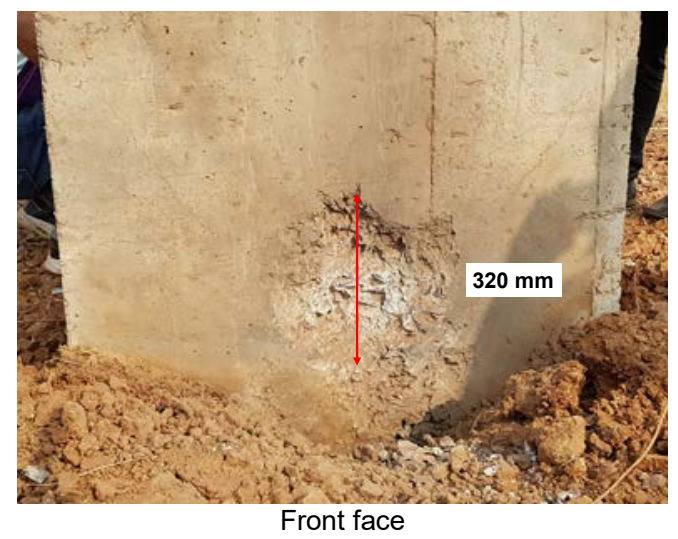

(a)

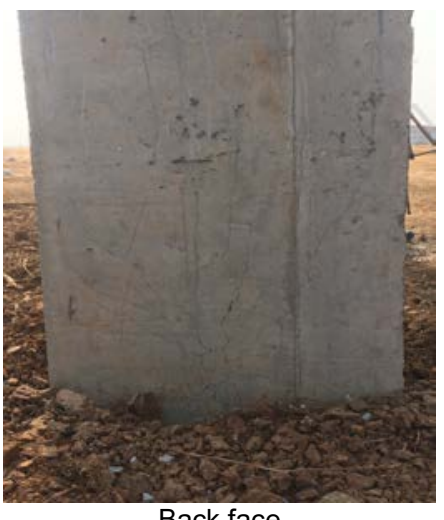

Back face 


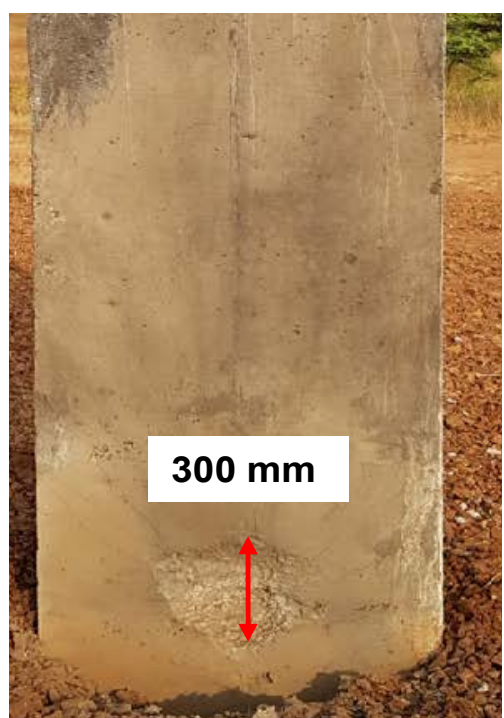

Front face

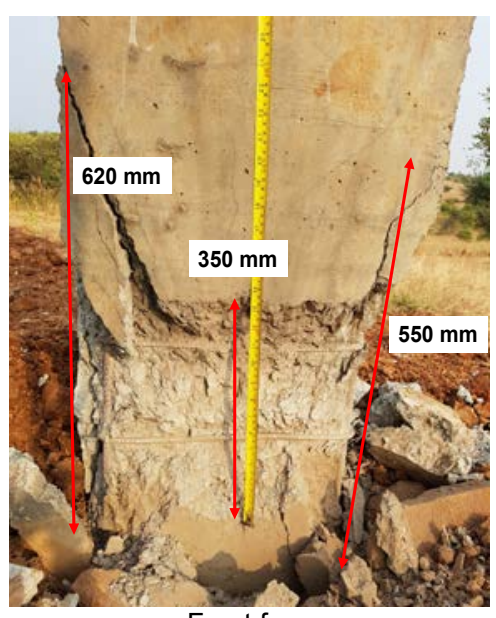

Front face

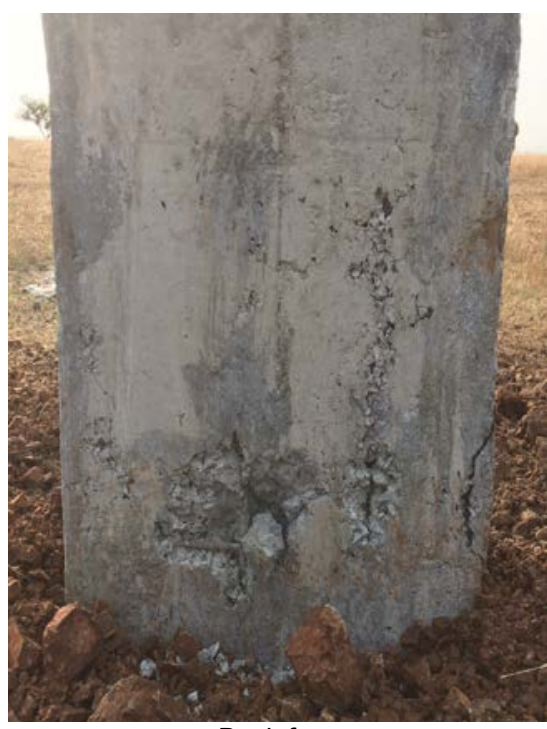

Back face

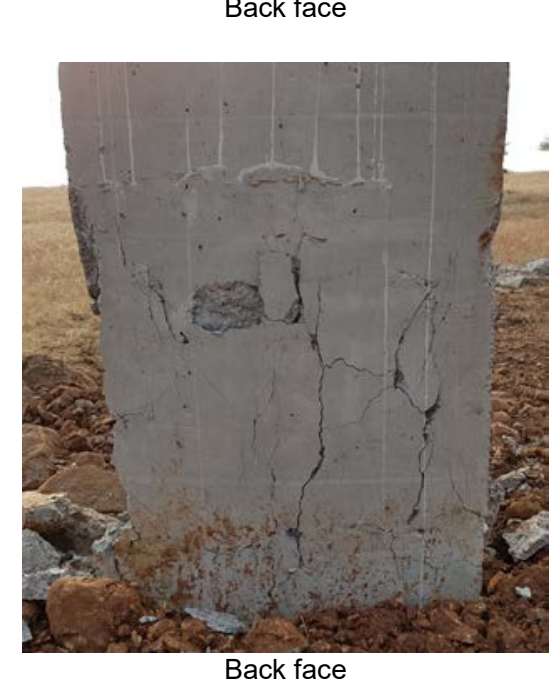

Back face

(c)

(b)

(a) E-500-900 (b) E-500-700 (c) E-500-500

\subsubsection{Residual Axial Capacity Results}

A damage-index $(D)$ represented by Equation 6-1 was used to compare the blast damage on the RC walls.

$$
D=1-\frac{P_{r}}{P_{o}}
$$

where $P_{r}$ is the residual axial capacity of the blast-damaged wall and $P_{o}$ is the nominal axial capacity of the wall. The nominal axial load carrying capacity of the 
undamaged wall with $300 \times 500-\mathrm{mm}$ cross-section is $3044 \mathrm{kN}$. On the other hand, the residual capacity of the blast-damaged wall was experimentally determined to be $901 \mathrm{kN}$ i.e. $D=0.70$. The damage profile of the wall after the residual capacity test shows a compression failure at the blast-damaged zone under axial loading (Figure 6-8).

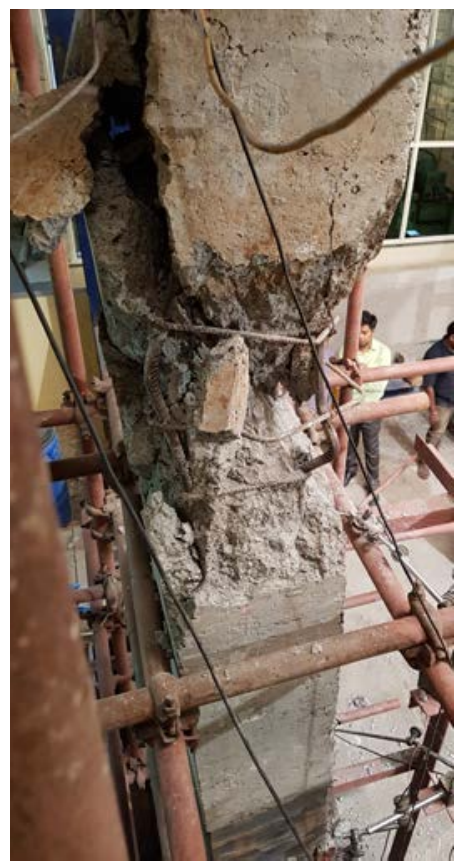

(a)

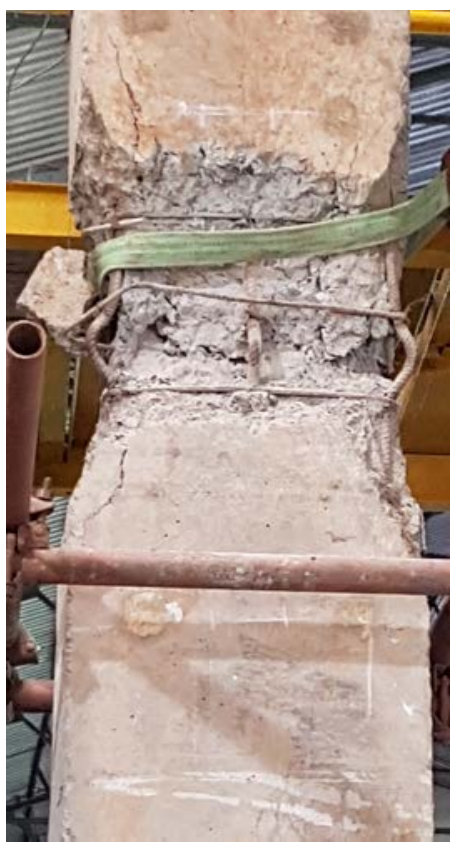

(b)

Figure 6-8: Damage profile of blast-damaged RC wall with $300 \times 500-\mathrm{mm}$ cross-section after the residual axial capacity test (a) Side (b) Front

The walls E-500-700 and E-500-900 suffered negligible damage to the concrete cover on the incident face and there was no damage observed on the side or distal faces. A similar trend was observed in the $300 \times 300 \mathrm{~mm} \mathrm{RC}$ column subjected to $115 \mathrm{~g}$ TNT explosion at $50 \mathrm{~mm}$ distance (cladding was used to give the standoff distance). The damage index of this column was tested as zero (Dua et al., 2018a). Hence, the damage index for $300 \times 700 \mathrm{~mm}$ and $300 \times 900 \mathrm{~mm}$ aspect ratios is 
assumed as zero for this study based on the test results that show negligible damage.

\subsection{Numerical Modeling}

\subsubsection{Material Models}

\subsubsection{Concrete}

There are many concrete constitutive material models in LS-DYNA. These constitutive models require an understanding of the heterogeneous material behavior and its response when subjected to high strain rate loading such as under contact explosion effects. Mat_72R3 (Karagozian and Case Model), Mat_159 (Continuous Surface Cap Model or CSCM) and Mat_84 (Winfrith model) are a few models that allow automatic generation of material parameters from the unconfined compressive strength of concrete. The underlying material parameters in the model are based on experimental tests performed for a wide range of unconfined compressive strengths. Mat_159 was chosen and implemented for modeling concrete based on the results from a study by Dua and Braimah (2017); Dua et al. (2017). The material input parameters in the adopted unit system are presented in Table 6-1.

Table 6-1: Input Parameters for Mat_159

\begin{tabular}{|c|c|c|c|c|}
\hline $\begin{array}{c}\text { Density, } \\
\text { T/mm }\end{array}$ & $\begin{array}{c}\text { Unconfined Compressive } \\
\text { Strength, MPa }\end{array}$ & $\begin{array}{c}\text { Aggregate Size, } \\
\mathrm{mm}\end{array}$ & $\begin{array}{c}\text { Erosion } \\
\text { Criteria }\end{array}$ & $\begin{array}{c}\text { Rate } \\
\text { Effects }\end{array}$ \\
\hline $2.635 \times 10^{-9}$ & 25 & 25 & 2.0 & on \\
\hline
\end{tabular}




\subsubsection{Reinforcement}

The response of RC members is sensitive to the confinement effects of the transverse reinforcement which is captured by the shear dilation phenomenon. The Mat_159 concrete constitutive model can simulate the shear dilation phenomenon if the reinforcement is coupled with the concrete elements. A comprehensive review of various techniques available for modeling reinforcement in RC members has been presented by Schwer (2014) where the CONSTRAINED_LAGRANGE_IN_SOLID (CLIS) algorithm with constraint type (CTYPE) 2 is recommended for modeling reinforcement. Recently an improved version of the CLIS algorithm, CONSTRAINED_BEAM_IN_SOLID (CBIS), was implemented to address some limitations of the original CLIS algorithm (L.S.T.C, 2015a). The MAT_PIECEWISE_LINEAR_PLASTICITY (Mat_24) constitutive model was adopted for modeling the reinforcement. The input parameters for the constitutive model and CBIS keyword in the adopted unit system are presented in Table 6-2 and Table 6-3 respectively.

Table 6-2: Input Parameters for Mat_24

\begin{tabular}{|c|c|c|c|c|}
\hline $\begin{array}{c}\text { Density, } \\
\text { T/mm }\end{array}$ & $\begin{array}{c}\text { Modulus of Elasticity, } \\
\mathrm{MPa}\end{array}$ & $\begin{array}{c}\text { Poisson's } \\
\text { Ratio, }-\end{array}$ & $\begin{array}{c}\text { Yield Strength, } \\
\mathrm{MPa}\end{array}$ & $\begin{array}{c}\text { Tangent Modulus, } \\
\mathrm{MPa}\end{array}$ \\
\hline $7.85 \times 10^{-9}$ & $2 \times 10^{5}$ & 0.3 & 500 & 1600 \\
\hline
\end{tabular}

Table 6-3: Input parameters for CBIS keyword

\begin{tabular}{|c|c|}
\hline No. of coupling points, NCOUP & Coupling Direction, CDIR \\
\hline 10 & 0 (All directions) \\
\hline
\end{tabular}

\subsubsection{Air and TNT}

The MMALE formulation was adopted for modeling the air and explosive domains. MMALE is an extension of the ALE algorithm used for describing gas flow from explosive detonation. An MMALE element can have several different materials, 
with tracked material interfaces in the one single element. This is considered to be more efficient for modeling gas flows with large gradients as there can be Eulerian elements in the model with both air and detonation products (Zakrisson et al., 2011). MMALE currently remains the most widely used FSI algorithm for blast analysis in both far-field and near-field explosion events, (Trajkovski et al., 2014).

In MMALE formulation the air domain is defined as MAT_NULL which allows the equation of state (EOS) to be considered without computing deviatoric stresses (L.S.T.C, 2015b). The linear polynomial EOS (EOS_LINEAR_POLYNOMIAL) defines the air domain and permits it to behave like a fluid. The pressure, $P$ in an air element is given by Equation 6-2 where $C_{0}$ to $C_{6}$ are polynomial equation coefficients and $\mu=\frac{\rho}{\rho_{0}}-1$ ( $\rho$ is the reference density and $\rho_{0}$ is the current density).

$$
P=C_{0}+C_{1} \mu+C_{2} \mu^{2}+C_{3} \mu^{3}+\left(C_{4}+C_{5} \mu+C_{6} \mu^{2}\right) E
$$

Input parameters for MAT_NULL and EOS_LINEAR_POLYNOMIAL in the adopted unit system are presented in Table 6-4.

Table 6-4: Input Parameters for Air Domain

\begin{tabular}{|c|c|c|c|c|c|c|}
\hline Density, $\mathrm{T} / \mathrm{mm}^{3}$ & $\mathrm{C}_{0}$ & $\mathrm{C}_{1}, \mathrm{C}_{2}, \mathrm{C}_{3}$ and $\mathrm{C}_{6}$ & $\mathrm{C}_{4}$ & $\mathrm{C}_{5}$ & $\mathrm{E}_{0}, \mathrm{MPa}$ & $\mathrm{V}_{0}$ \\
\hline $1.29 \times 10^{-12}$ & $-1 \times 10^{-6}$ & 0 & 0.4 & 0.4 & 0.2531 & 1 \\
\hline
\end{tabular}

The explosive domain can be defined by two techniques: creating a separate part for the explosive or using the INITIAL_VOLUME_FRACTION keyword. The first option requires that all the boundary nodes of the explosive domain be merged with the air domain nodes. On the other hand, with the second option, a defined geometrical shape within the air domain is filled with the explosive material. The second option was adopted for the simulations presented herein. 
The explosive material was defined with MAT_HIGH_EXPLOSIVE_BURN which allows the modeling of detonation of a high explosive when defined with an EOS. EOS_JWL was adopted for the detonation modeling which defines the pressure, $p$ as Equation 6-3 where $A, B$ are constants with units of pressure, $E_{0}$ is the detonation energy per unit volume, $V_{0}$ is the initial relative volume and $R_{1}, R_{2} \& \omega$ are unitless constants.

$$
p=A\left(1-\frac{\omega}{R_{1} V}\right) e^{-R_{1} V}+A\left(1-\frac{\omega}{R_{2} V}\right) e^{-R_{2} V}+\frac{\omega E}{V}
$$

The input parameters for the above two keywords required to define the explosive domain are presented in Table 6-5.

Table 6-5: Input Parameters for MAT_HIGH_EXPLOSIVE_BURN and EOS_JWL

\begin{tabular}{|c|c|c|c|c|c|c|c|c|c|}
\hline $\begin{array}{c}\text { Density, } \\
\mathrm{T}^{\prime} \mathrm{mm}^{3}\end{array}$ & $\begin{array}{c}\text { Detonation } \\
\text { Velocity, } \\
\mathrm{mm} / \mathrm{s}\end{array}$ & $\begin{array}{c}\text { Chapman- } \\
\text { Jouguet } \\
\text { Pressure, MPa }\end{array}$ & $\mathrm{A}, \mathrm{MPa}$ & $\begin{array}{c}\mathrm{B}, \\
\mathrm{MPa}\end{array}$ & $\mathrm{R}_{1,-}$ & $\mathrm{R}_{2,-}$ & $\omega_{,-}$ & $\begin{array}{c}\mathrm{E}_{0,} \\
\mathrm{MPa}\end{array}$ & $\mathrm{V}_{0,-}$ \\
\hline $1.55 \times 10^{-9}$ & $6930 \times 10^{3}$ & 21000 & 371200 & 3231 & 4.15 & 0.95 & 0.3 & 7000 & 1 \\
\hline
\end{tabular}

\subsubsection{Soil}

MAT_MOHR_COULOMB material model was adopted for defining the soil around the column. This constitutive model is for solid elements only intended to represent sandy and granular soils. The input parameters for the model are presented in Table 6-6. The soil domain was implemented to capture the reflection of the blast wave from the ground. The response of soil and edge effects is not significant to the response of the $\mathrm{RC}$ column. 
Table 6-6: Input Parameters for MAT_MOHR_COULOMB

\begin{tabular}{|c|c|c|c|c|}
\hline Density, $\mathrm{T} / \mathrm{mm}^{3}$ & $\mathrm{G}_{\text {mod, }}-$ & $\mathrm{V},-$ & $\Phi,-$ & Cohesion,- \\
\hline $1.55 \times 10^{-9}$ & 0.222 & 0.35 & 0.0873 & 0.139 \\
\hline
\end{tabular}

\subsubsection{Strain-Rate Effects}

It is an established fact that concrete exhibits strain-rate dependency. It fails at a higher compressive/tensile stress when subjected to a high strain-rate loading compared to its established 28-day strength. In analytical methods, the strength increase is incorporated with a dynamic increase factor (DIF) (Telford, 1993); defined as the ratio of dynamic to static failure load. The DIF can be adopted in simple input constitutive models like Mat_72R3 and Mat_159. Murray (2007) presented the DIF specifications for Mat_159 and are reported to be a good fit to strain rate effects both in tension and compression. The strain-rate effects can be activated through the IRATE parameter on the Mat_159 keyword.

Two simulations emulating the test of RC column subjected to 115-g TNT explosion were implemented to investigate the influence of strain-rate effects. An error of $42 \%$ was observed in predicting the residual axial capacity of the blastdamaged column when compared to experimental results when strain-rate effects were not activated. Consequentially, the strain-rate effects were activated for numerical modeling.

\subsubsection{Mesh Sensitivity Analysis}

\subsubsection{ALE Domain: Detonation and Blast Wave Propagation}

A mesh sensitivity analysis was performed prior to the numerical simulation of the experimental tests. The mesh sensitivity simulations were validated with 
experimental results presented by Rigby et al. (2015). The normal and radial reflected blast parameters acquired via split Hopkinson's pressure bars (SHPB) were reported at a close-in scaled distance of $0.15 \mathrm{~m} / \mathrm{kg}^{1 / 3}$. Quarter symmetric models of the experimental setup were implemented with varying element size for the air domain (Figure 6-9(a) \& (b)). The generated time histories for reflected blast parameters at $0.15 \mathrm{~m} / \mathrm{kg}^{1 / 3}$ scaled distance were plotted together with the upper and lower bound results from the six tests reported by Rigby et al. (2015) and are presented as Figure 6-9 (c) \& (d).

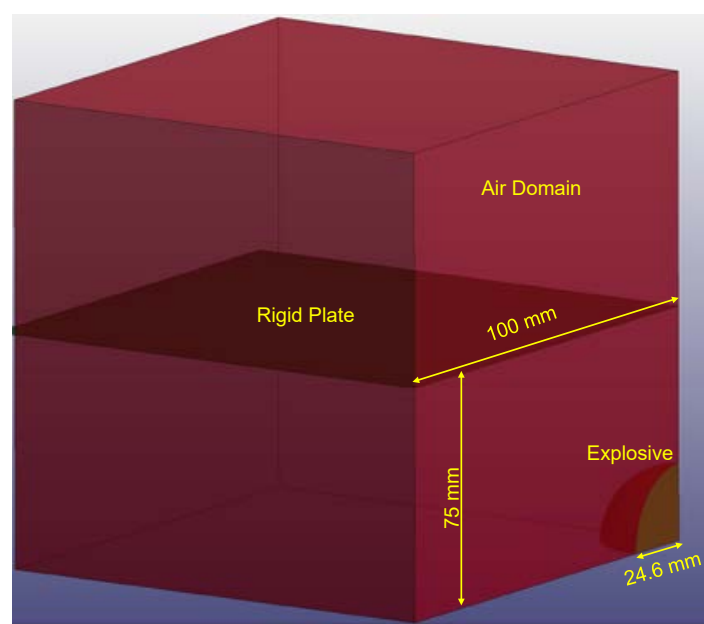

(a)

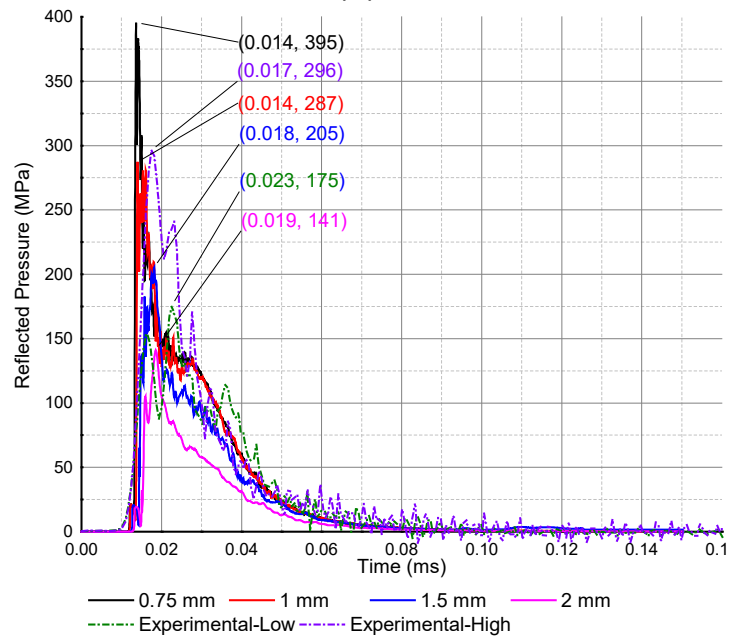

(c)

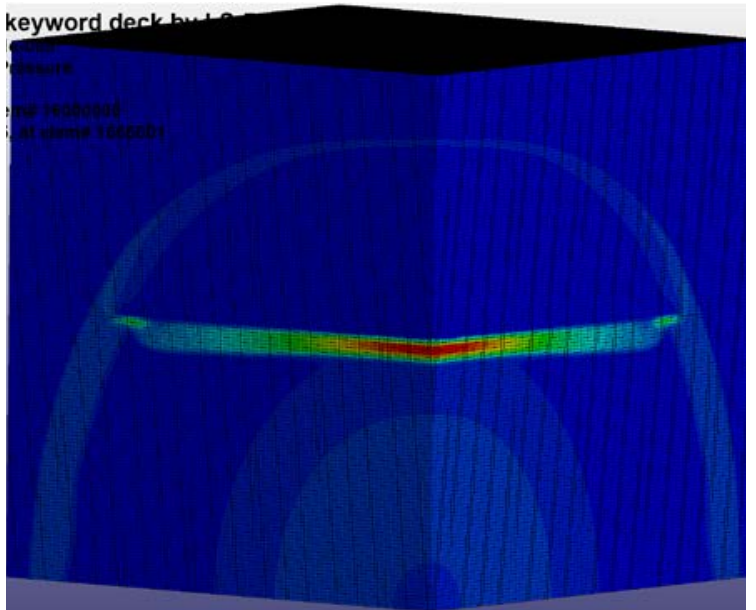

(b)

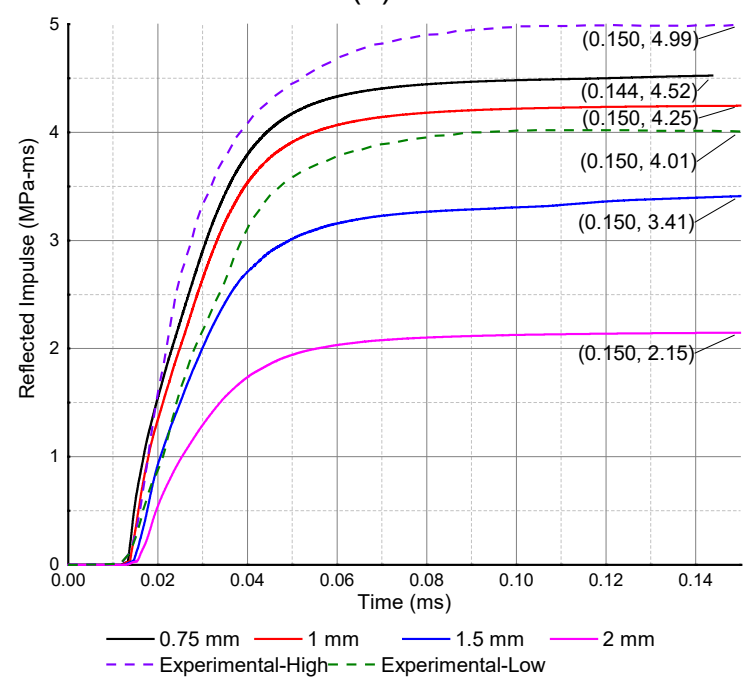

(d) 


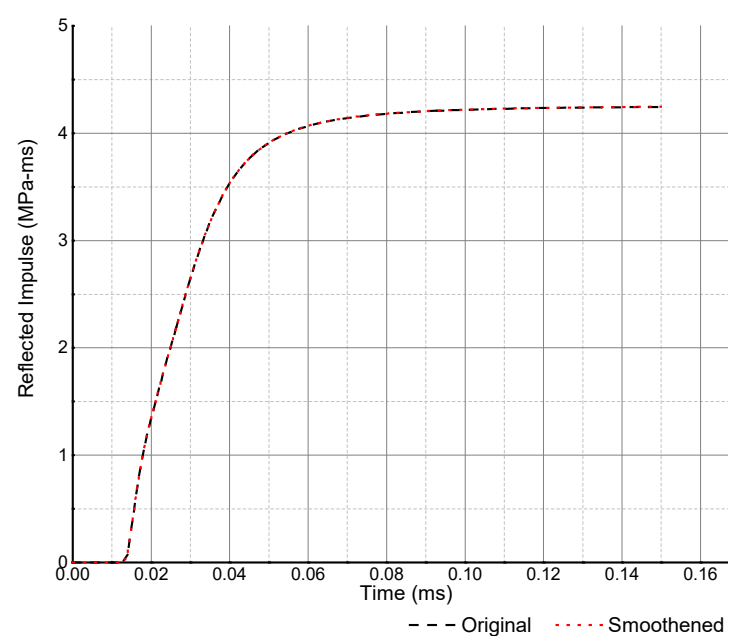

(e)

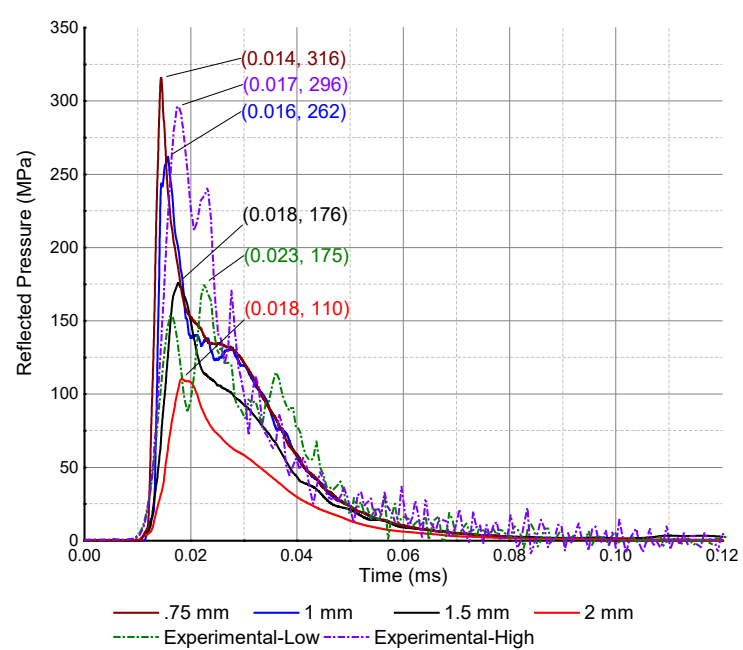

(f)

Figure 6-9: (a) Quarter symmetric model (b) Pressure fringe plot (1-mm); Time-histories for reflected (c) pressure (d) impulse (e) impulse after smoothening (f) pressure after smoothening

The numerically predicted impulse values converged at $1 \mathrm{~mm}$ size element mesh as there was negligible change in the impulse with a $0.75 \mathrm{~mm}$ element size mesh. The reflected impulse for $0.75 \mathrm{~mm}$ and $1 \mathrm{~mm}$ size element mesh predicted numerically were within the experimental upper and lower bounds, while $1.5 \mathrm{~mm}$ and $2 \mathrm{~mm}$ size mesh predicted the impulse outside this range. This is in agreement with the results reported by Rigby et al. (2014); Clarke et al. (2015); Rigby et al. (2015). The oscillating peaks in the pressure time-history predicted numerically are due to the shocked air trapped between the expanding detonation products and the target. These oscillatory peaks do not represent the true peak overpressure due to the explosion (Rigby et al., 2014; Clarke et al., 2015; Rigby et al., 2015). To ascertain the mesh convergence, these oscillations were smoothened by the adjacent-average method. There was no change in the impulse time-history due to this smoothening (Figure 6-9 (e)). The peak-overpressure converged for a 1$\mathrm{mm}$ element size mesh and was within the experimental bounds (Figure 6-9 (f)). 
In near-field or contact explosions, the duration of blast loading is shorter than the time to maximum response of the member. In such cases, the structural members are analyzed for impulse loading and not the blast pressure loading, (Dua \& Braimah, 2016). Hence, the prediction of peak impulse is more important than that of the peak pressure. As presented in Table 6-7, the peak impulse is highly sensitive to the air domain element size. The peak reflected pressure converged with 1-mm element size air domain and was also validated from the experimental results. This is in agreement with the results reported by Trajkovski et al. (2014).

In view of the foregoing results, 1-mm element size was implemented for the air domain and explosive material in order to generate accurate peak impulse value which is critical for modeling near-field or contact explosion events. The system's RAM requirement for simulating the response of a Lagrangian entity with a fine mesh like the ALE domain can be significant (more than $256 \mathrm{~GB}$ ). Additionally, the time required for running the simulations is also expected to be very long.

Table 6-7: Mesh Sensitivity Analysis for Reflected Pressure and Impulse

\begin{tabular}{|c|c|c|c|c|c|}
\hline Air Mesh & Experimental Range & $0.75 \mathrm{~mm}$ & $1 \mathrm{~mm}$ & $1.5 \mathrm{~mm}$ & $2 \mathrm{~mm}$ \\
\hline Reflected peak pressure (MPa) & $296-175$ & 316 & 262 & 176 & 110 \\
\hline Reflected peak impulse (MPa.ms) & $4.01-4.99$ & 4.52 & 4.25 & 3.41 & 2.15 \\
\hline
\end{tabular}

\subsubsection{Lagrangian Domain}

A blast simulation was implemented with 2-mm and 10-mm element mesh size for $300 \times 300 \mathrm{~mm}$ cross-section RC column. The damage profiles at the last timestep of both simulations are compared to the experimental results in Figure 6-10. The damage profile predicted with 2-mm element mesh correlats well with the experimental results when compared to $10-\mathrm{mm}$ mesh. However, the analysis was 
computationally expensive. On the other hand, there was a negligible effect of the mesh-size on the residual axial load carrying capacity of the blast-damaged columns. An exhaustive parametric study with 2-mm element size was not found to be computationally cost-effective. The numerical results presented subsequently show a good correlation of the predicted residual axial capacity with 10-mm element size when compared to experimental results.

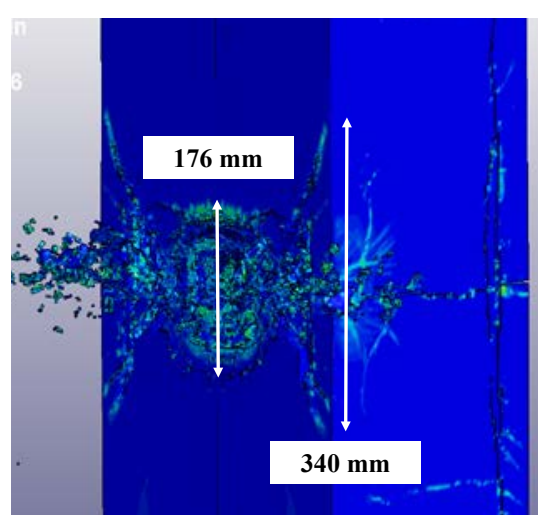

(a)

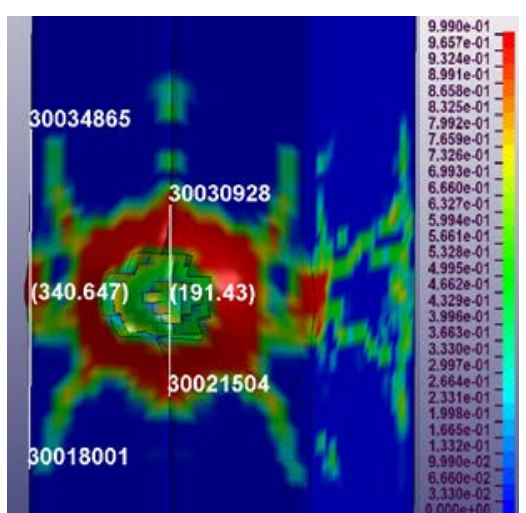

(b)

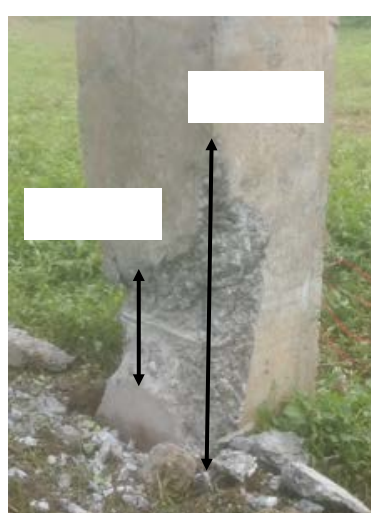

(c)

Figure 6-10: Mesh sensitivity analysis for blast response with (a) 2-mm mesh and (b) 10-mm mesh; (c) Experimental response

Mesh sensitivity analysis was also performed in the static regime with mesh sizes between $5-20 \mathrm{~mm}$ for the RC column. Axial load was applied until failure and the predicted axial failure load was compared to analytically determined capacity. The load-displacement response predicted numerically for a pristine undamaged column with varying element mesh sizes when subjected to axial loading are presented as Figure 6-11. 


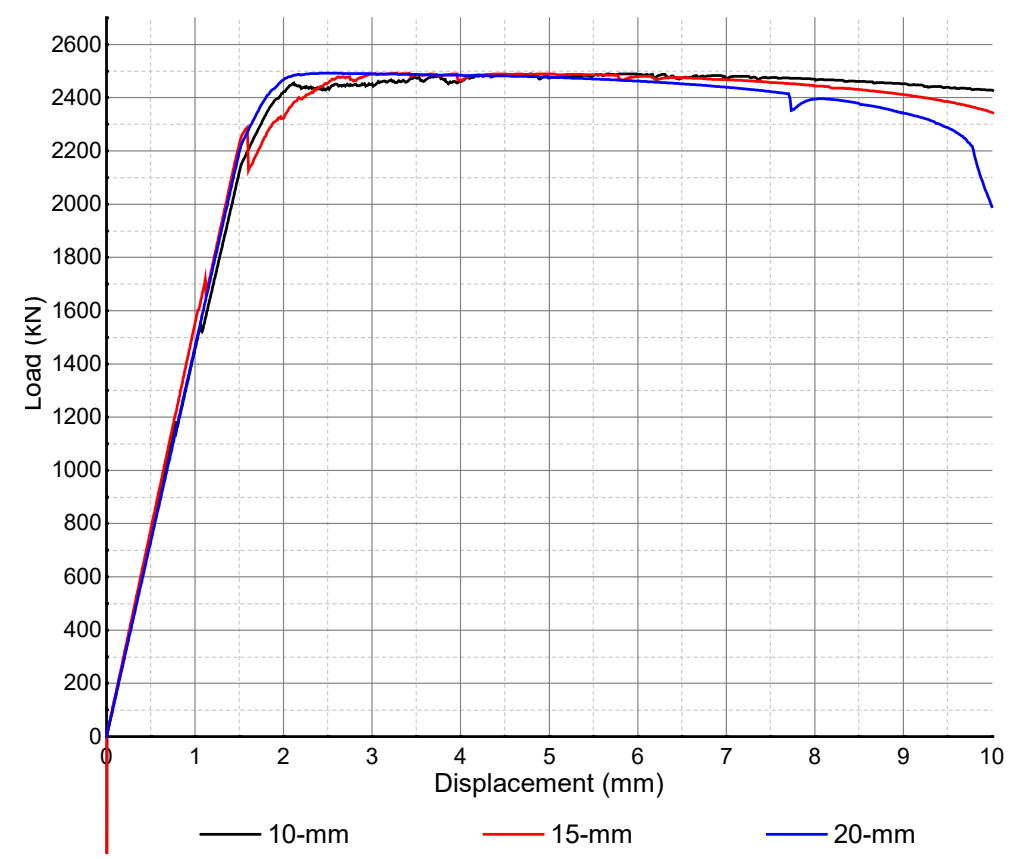

Figure 6-11: Load-displacement time-histories for axially loaded pristine columns with varying mesh sizes.

The static analysis above with variable mesh size for the concrete domain revealed that Mat_159 is not sensitive to the element mesh size. The computational effort however increased exponentially for a finer mesh with negligible change in the predicted results (Table 6-8).

Table 6-8: Influence of element mesh size on the axial capacity of the undamaged column

\begin{tabular}{|c|c|c|c|c|c|c|}
\hline $\begin{array}{l}\text { Column } \\
\text { Cross- } \\
\text { Section, } \\
\mathrm{mm}\end{array}$ & $\begin{array}{c}\text { Concrete } \\
\text { Strength, } \\
\text { MPa }\end{array}$ & $\begin{array}{c}\text { Steel } \\
\text { Rebar, } \\
\text { Ultimate } \\
\text { Tensile } \\
\text { Strength, } \\
\text { MPa }\end{array}$ & $\begin{array}{l}\text { Analytically } \\
\text { Determined } \\
\text { Nominal } \\
\text { Axial } \\
\text { Capacity, kN }\end{array}$ & $\begin{array}{l}\text { Element } \\
\text { Mesh } \\
\text { Size } \\
\text { mm }\end{array}$ & $\begin{array}{c}\text { Numerically } \\
\text { Determined } \\
\text { Axial } \\
\text { Capacity, kN }\end{array}$ & $\begin{array}{l}\text { Computational } \\
\text { Time, Hours }\end{array}$ \\
\hline \multirow{3}{*}{$300 \times 300$} & \multirow{3}{*}{25} & \multirow{3}{*}{$\begin{array}{c}4 \times 20 \mathrm{M} \\
500\end{array}$} & \multirow{3}{*}{2431} & 20 & 2488 & 14 \\
\hline & & & & 15 & 2488 & 17 \\
\hline & & & & 10 & 2476 & 27 \\
\hline
\end{tabular}

\subsubsection{Mesh size, FSI and Reinforcement contact}

The numerical models presented are half symmetric with appropriate boundary conditions applied to the XZ plane of symmetry when the column height and depth are in the $\mathrm{Z}$ and $\mathrm{X}$ directions respectively. The $\mathrm{Y}$ degree of freedom (DOF) was 
constrained for displacement and the X \& Z DOFs were constrained for rotation. The first chained simulation was initialized with 1-mm element size air domain while the Lagrangian entities of RC column and soil were modeled with 10-mm and 5-mm sized solid elements respectively. The FSI between the detonation products and Lagrangian entities was implemented by the CLIS keyword with CTYPE 5. L.S.T.C (2015a) recommends a smaller element size for the Lagrangian entities being coupled in an FSI problem as compared to the element size of the ALE domain. Alternatively, a larger NQUAD value is recommended. CLIS is a penalty-based algorithm and hence the mesh densities of the interacting domains play an important role in preventing leakage of detonation products into the Lagrangian entities. In case tighter controls are implemented to prevent leakage, the computational demand is higher, and the detonation products may reflect due to higher penalty forces. Additionally, the correct NQUAD settings vary with material and relative mesh density. Essentially, selecting the NQUAD is based on experience and experimental validation. The CLIS parameters implemented for 1$\mathrm{mm}$ and 5-mm element size mesh in this study is presented in Table 6-9.

Table 6-9: Validated CLIS parameters for Concrete and Soil

\begin{tabular}{|c|c|c|c|c|c|c|c|c|c|c|}
\hline \multirow{2}{*}{ Entity } & \multicolumn{2}{|c|}{ NQUAD } & CTYPE & DIREC & \multicolumn{2}{|c|}{ PFAC } & ILEAK & \multicolumn{2}{|c|}{ PLEAK } & PFACMM \\
\cline { 2 - 6 } & $\begin{array}{c}1- \\
\mathrm{mm}\end{array}$ & $\begin{array}{c}5- \\
\mathrm{mm}\end{array}$ & & & $\begin{array}{c}1- \\
\mathrm{mm}\end{array}$ & $\begin{array}{c}5- \\
\mathrm{mm}\end{array}$ & & $\begin{array}{c}1- \\
\mathrm{mm}\end{array}$ & $\begin{array}{c}5- \\
\mathrm{mm}\end{array}$ & \\
\hline $\begin{array}{c}\text { RC } \\
\text { column }\end{array}$ & 10 & 10 & 5 & 3 & 5 & 5 & 2 & 5 & 5 & 3 \\
\hline Soil & 26 & 10 & 5 & 3 & 1500 & 150 & 2 & 1500 & 150 & 3 \\
\hline
\end{tabular}

CONTACT_AUTOMATIC_GENERAL was implemented for modeling the contact between the longitudinal reinforcement and transverse reinforcement and 
CONTACT_ERODING_SURFACE_TO_SURFACE was implemented for contact between the soil and RC column entities.

A penalty-based contact was implemented between the longitudinal and transverse reinforcement and a segment-based contact was implemented for the contact interaction between the soil and the concrete column.

\subsubsection{Modeling Technique}

A novel chained mapping technique for ALE domains was implemented on a shared memory parallel (SMP) solver to accurately predict the impulse generated due to the contact explosion and the response of the Lagrangian entity to the contact explosion event.

Initially, the detonation was modeled in a 1-mm element sized air mesh to ensure accurate prediction of the pressure and impulse values. The first simulation was terminated prior to the arrival of the generated blast wave at the boundaries of the selected air domain to avoid reflection. Although LS-DYNA provides a keyword BOUNDARY_NON_REFLECTING, this keyword is applicable to Lagrangian entities and acoustic waves and not to the ALE domains with Euler entities. Hence each simulation has to be terminated prior to reflection at the domain boundaries. The subsequent simulation started with a larger ALE domain of 5-mm element size until the blast wave interacted with and diffracted around the Lagrangian entity. A 3D to 3D ALE mapping was implemented between these two simulations wherein the underlying algorithm initializes the current ALE domain with the ALE mesh element data of the last cycle in the previous run. The Lagrangian entities of the 
column and the soil were initialized with the stress condition at the last timestep of the previous run. These steps were performed with a full deck restart that enables the addition or deletion of Lagrangian entities.

The generated shock wave from the detonation of explosive material is transmitted to the Lagrangian domain through FSI imparting acceleration to the elements. The simulation is required to be run for a longer time after the detonation event for an accurate assessment of the RC column's response to the contact explosion event. This is due to the inertial effects of concrete that lead to a longer time for the stresses to develop and stabilize as compared to the impulsive loading due to the contact explosion that occurs over a very short duration (Gebbeken et al., 2004). A third simulation was run up to 0.4 ms to completely capture the damage in $\mathrm{RC}$ column due to contact explosion event. The ALE domain was removed for the last simulation as contact explosion effects on the column last for less than $0.06 \mathrm{~ms}$ and the impulse has been completely imparted to the column.

The last simulation was run to predict the residual axial load carrying capacities of the blast damaged columns. A full deck restart was performed to initialize the damage state in concrete and reinforcement from the previous simulation without the ALE domain. Displacement controlled axial load was applied to the column similar to loading in the experimental tests and the load-displacement curves were acquired from the simulations. 
A complete representation of the chained simulations is presented in Figure 6-12. The system of units implemented for numerical modeling was $\mathrm{MPa}, \mathrm{mm}, \mathrm{sec}$ and metric ton $(\mathrm{T})$.

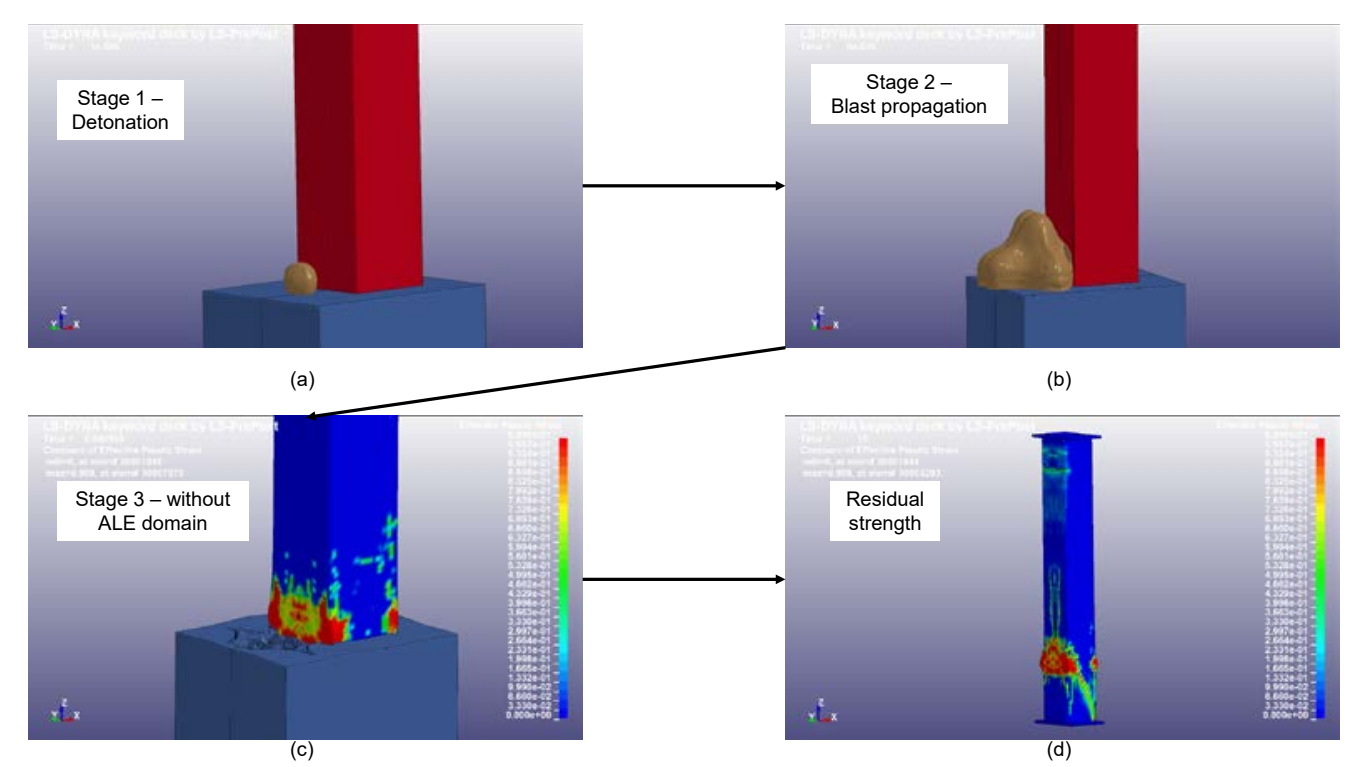

Figure 6-12: Sequence of chained simulations

\subsubsection{Numerical Model Details}

The geometric setup and parameters for the numerical model to predict the axial capacity of the undamaged column, chained simulations for contact explosion loading and the residual capacity of the blast-damaged RC wall with $300 \times 500 \mathrm{~mm}$ cross-section are presented in this section. A half-symmetric model was created with the plane of symmetry in the $X Z$ plane. The cross-sectional area of the reinforcement in the plane of symmetry was taken as half of the area provided in the experimental tests.

Complete details for modelling the square RC column is presented elsewhere (Dua et al. (2018b)). 


\subsubsection{Axial Capacity of Undamaged RC Wall}

The nominal axial load carrying capacity of the undamaged RC wall was numerically determined to establish the efficacy of the numerical model results. A displacement controlled axial load was numerically applied on the half symmetric RC wall of $300 \times 500 \mathrm{~mm}$ cross-section. The axial load was applied via displacement of a steel plate which emulates the experimental test for the residual axial capacity of the blast-damaged walls as well (Figure 6-13). The steel plate at the bottom was fixed while the plate at the top was displaced at $0.2 \mathrm{~mm} / \mathrm{s}$; correlating to a strain-rate of $10^{-4} / \mathrm{s}$ for the RC wall. The simulation was run for 20 $\mathrm{s}$ and the sectional load at the bottom of the RC wall was acquired during this time.

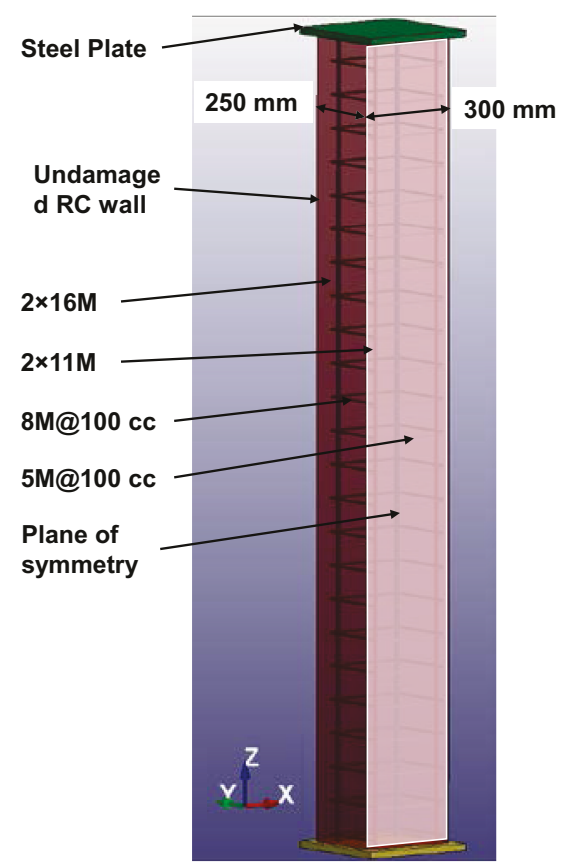

Figure 6-13: Geometric model for the nominal axial capacity of undamaged RC wall

\subsubsection{Contact Explosion Loading}

To predict the damage profile of the $\mathrm{RC}$ wall due to contact explosion effects of $500 \mathrm{~g}$ TNT, the explosive mass was detonated in contact with the RC wall (Figure 
6-14). An element size of $1 \mathrm{~mm}$ was used for the air domain and the explosive mass was filled in the air mesh during the first simulation of the chained procedure. The first simulation was terminated at $0.01 \mathrm{~ms}$ to prevent reflection of the blast wave from the air domain boundaries. The mapping command was specified during model initialization to record the nodal pressures of ALE domains (air and explosive) at the last timestep of the first simulation. The stresses in the Lagrangian domains were saved in the d3plot file written at the end of each simulation. These two files were provided as input for the second simulation.

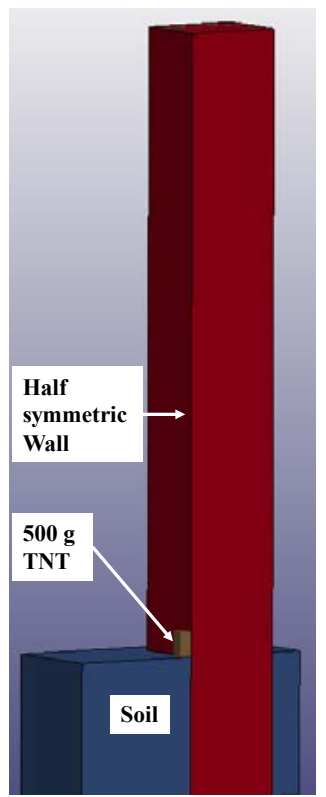

(a)

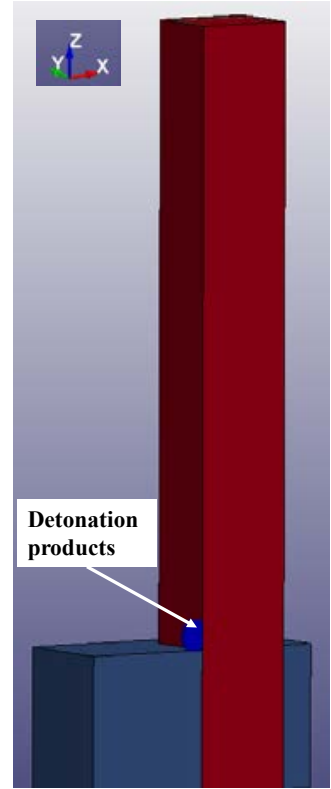

(b)

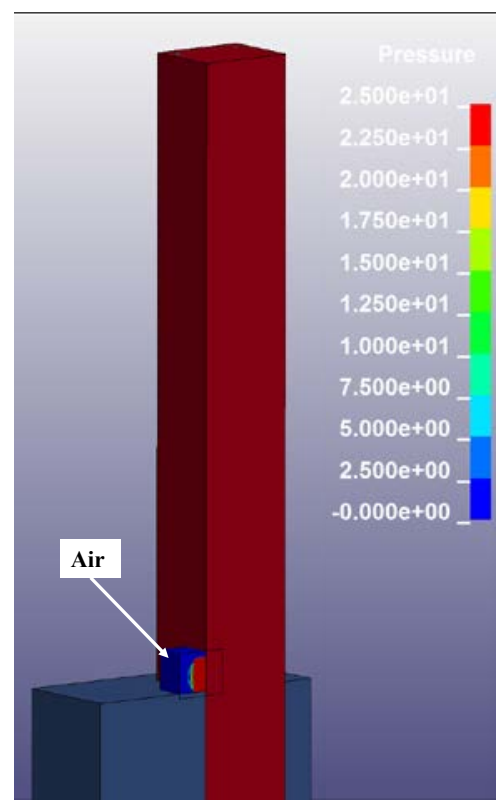

(c)

Figure 6-14: Geometric model for E-500-500 illustrating the (a) Explosive mass (b) Extent of the detonation products \& (c) the pressure fringe plot at the last time-step

The 1-mm element size air domain was replaced by a 5-mm element size domain for the second simulation. The air domain was initialized with the pressures at the last time-step of the first run. A full-deck restart of the first simulation initialized the Lagrangian entities to the stress condition at the last-timestep of the previous run. The FSI was continued as implemented for the first run. The simulation was 
terminated at $0.06 \mathrm{~ms}$ that is before the blast wave arrived at the air mesh boundaries. Majority of the impulse was transferred to the RC wall within this period (Weerheijm et al., 1984). This was verified by executing the second simulation for a longer duration of $1.2 \mathrm{~ms}$, and there was no significant effect on the residual axial capacity of the blast-damaged wall.

No leakage of detonation products into the Lagrangian domains was observed for the parameters presented (Figure 6-15). Leakage of detonation products into the Lagrangian domain is non-physical and indicates the blast loads are not being completely coupled with the Lagrangian domains.

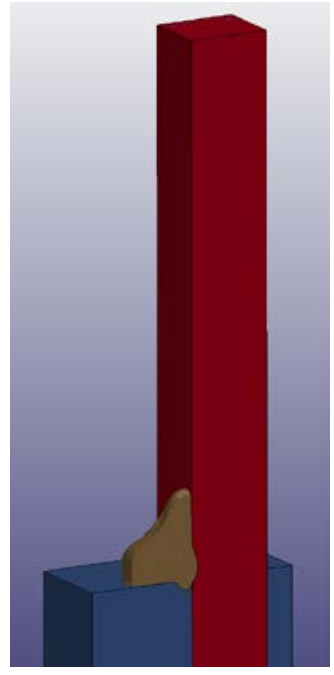

(a)

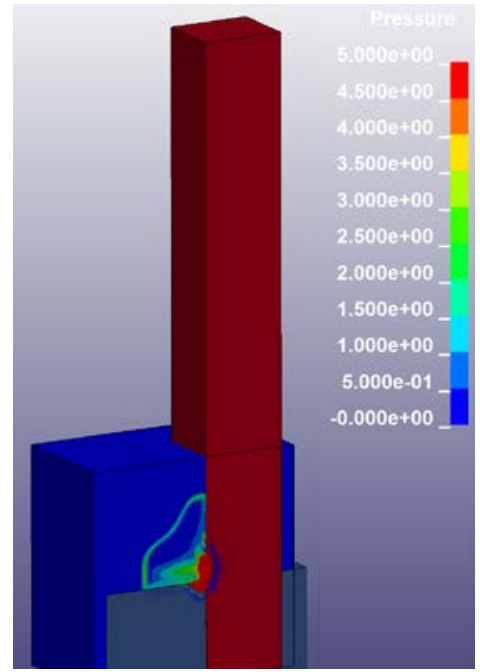

(b)

Figure 6-15: (a) Extent of detonation products \& (b) Pressure fringe at $0.06 \mathrm{~ms}$.

The third simulation was run without the ALE domain to capture the complete response of the $\mathrm{RC}$ wall to the effects of contact explosion. The explosive loading occurs over $0.1 \mathrm{~ms}$ (Weerheijm et al., 1984) whereas the response time of concrete is higher than this period due to the inertial effects. For this reason, the third simulation was run to $0.4 \mathrm{~s}$ within which the velocity of $\mathrm{RC}$ wall elements 
reduced to approximately zero which signifies that the complete response had been captured. The RC wall and soil domains were initialized with the stresses from the last timestep of the second simulation by executing a full-deck restart (Figure 6-16).

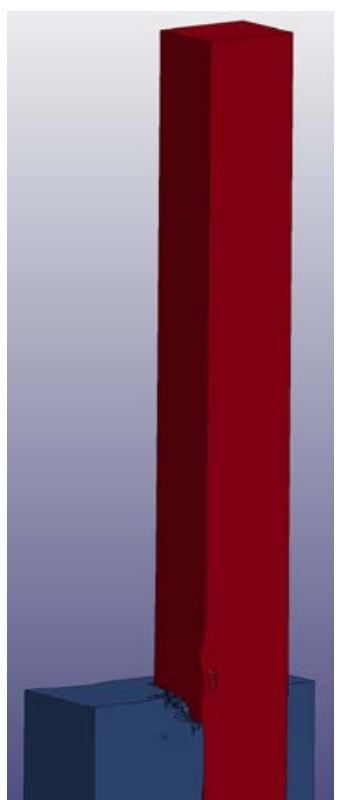

Figure 6-16: Geometrical setup for the last simulation without ALE domain

\subsubsection{Residual Axial Capacity of Blast-damaged RC Wall}

The last simulation was run to predict the residual axial load carrying capacity of the blast-damaged RC wall. The model setup was the same as presented in Figure 6-13 for the undamaged column except that the column was initialized with the stresses from the last timestep of the third simulation. The top steel plate was displaced at $0.2 \mathrm{~mm} / \mathrm{s}$ that correlates to a strain-rate of $10^{-4} / \mathrm{s}$ for the RC wall. The simulation was run for $20 \mathrm{~s}$ and the sectional load at the bottom of the RC wall was acquired during this time. 


\subsection{Numerical Results}

\subsubsection{Axial Capacity of Undamaged RC Wall}

The nominal axial capacity of RC A-0-500 was determined to be $3044 \mathrm{kN}$. The numerically predicted axial capacity for N-0-500 was 3019 kN. Figure 6-17 presents the numerical load-displacement response of the wall until failure. The numerically predicted capacity correlates well with the analytically determined capacity establishing the efficacy of the numerical model in the static regime.

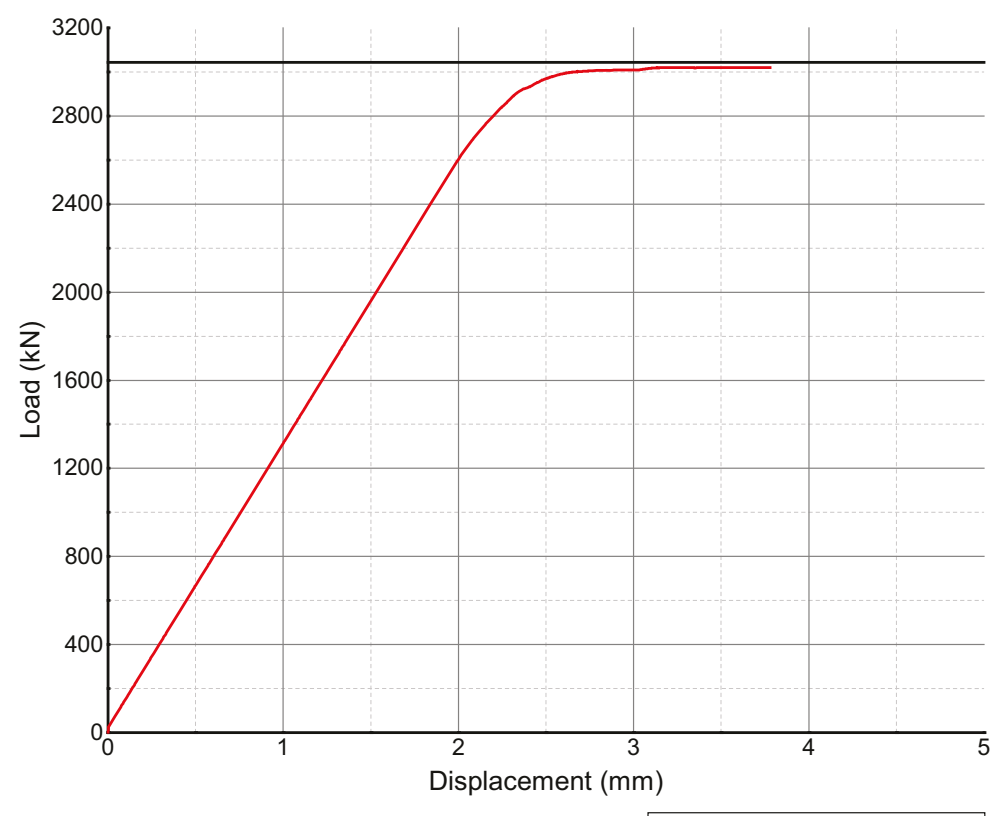

Figure 6-17: Numerically predicted and analytical axial capacity of $500 \times 300 \mathrm{~mm}$ wall

\subsubsection{Contact Explosion Response}

The third simulation of the chained procedure predicted the damage profile for the $300 \times 500 \mathrm{~mm}$ wall. The numerical damage profile is compared to the experimental result in Figure 6-18. The damage profile predicted numerically compares well with the experimental results. The diameter of the incident face crater was predicted 
with a $3 \%$ error while the length of concrete spall on the corners of incident and side face had an error of $23 \%$. The concrete cover spall on the side face is not distinctively identified in Figure 6-18 (b). The cross-section of the column shows the concrete cover spall from the side face coalescing with the crater formed around the contact surface area of the explosive (Figure 6-18 (c)). Concrete spalling was not observed on the distal face in the numerical model as well as in the experimental results.

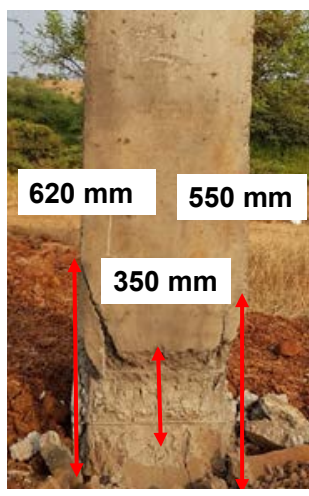

(a)

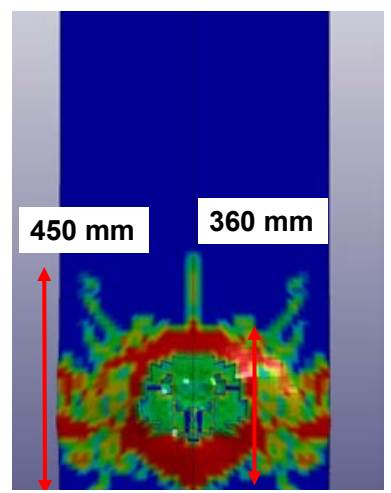

(b)

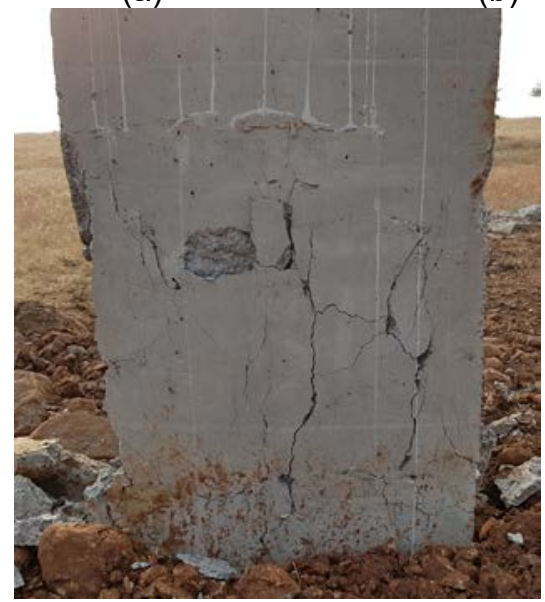

(d)

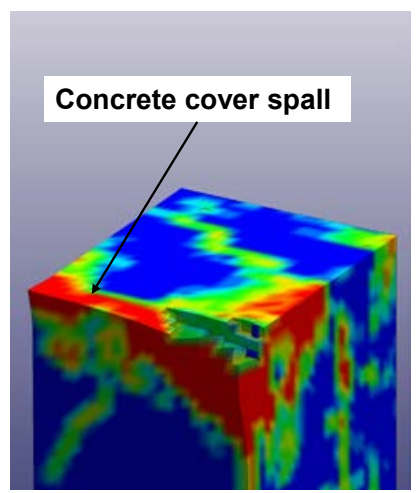

(c)

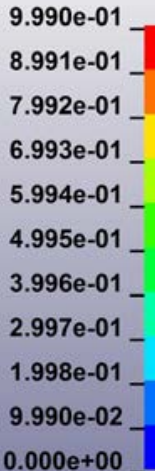

$0.000 e+00$

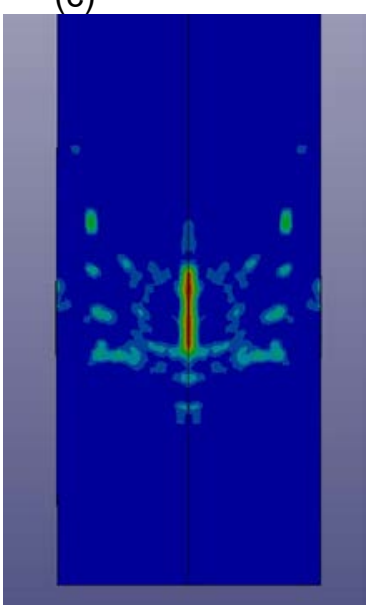

(e)

Figure 6-18: Comparison of damage profiles for N-500-500 and E-500-500 (a) Experimental profile (front face) (b) Numerical profile (front face) (c) Cross-section across incident face (d) Experimental profile (back face) (e) Numerical profile (back face) 


\subsubsection{Residual Axial Capacity}

The numerical model was further validated quantitatively by comparing the residual axial load carrying capacities predicted numerically and determined experimentally. Figure 6-19 shows the analytical, numerical and experimental load-displacement response up to failure under axial load for the $300 \times 500 \mathrm{~mm}$ wall. The axial failure load of $895 \mathrm{kN}$, predicted by the numerical model, correlates well with the experimentally determined failure load of $901 \mathrm{kN}$.

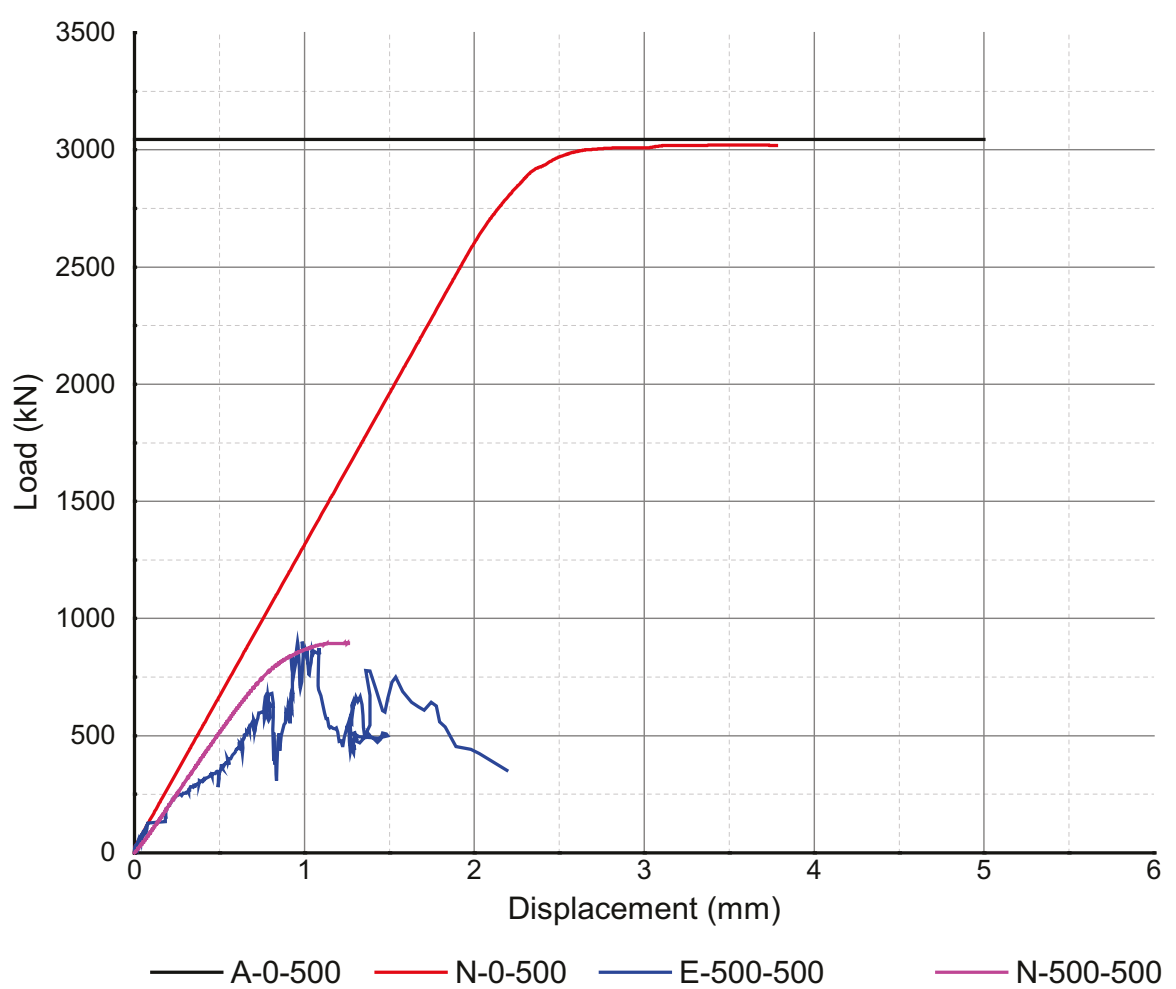

Figure 6-19: Load-time curve under axial loading of E-500-500 and N-500-500 test cases

\subsection{Summary and Discussion of Experimental and Numerical Results}

The numerical results presented in the study predicted the experimental response with acceptable accuracy. The salient dimensions of damage profiles were 
predicted within an error of $23 \%$ whereas the residual axial capacity of the wall was predicted with an error of $1 \%$. The residual capacity quantified the response prediction and established the efficacy of the numerical model in blast load regime. The numerical results were accurate for the square column as well (Dua et al., 2018b).

The damage indices of the square RC column and RC walls of the same depth across the TNT explosive mass of $500 \mathrm{~g}$ detonated in contact with the members are presented at Table 6-10.

Table 6-10: Damage indices for members subjected to contact explosion effects of $500 \mathrm{~g}$ TNT

\begin{tabular}{|c|c|c|c|}
\hline $\begin{array}{c}\text { Cross-section, } \\
\mathrm{mm} \times \mathrm{mm}\end{array}$ & $\begin{array}{c}\text { Nominal capacity } \\
\left(\mathrm{P}_{\mathrm{o}}\right), \mathrm{kN}\end{array}$ & $\begin{array}{c}\text { Numerical Residual } \\
\text { Capacity; }\left(\mathrm{Pr}_{\mathrm{r}}\right), \mathrm{kN}\end{array}$ & Damage index, D \\
\hline $300 \times 300$ & 2431 & 0 & 1.00 \\
\hline $300 \times 500$ & 3044 & $895(901)$ & 0.71 \\
\hline $300 \times 700$ & 4028 & 4028 (not tested) & 0.00 \\
\hline $300 \times 900$ & 5206 & 5206 (not tested) & 0.00 \\
\hline
\end{tabular}

The results present in Table 6-10 show the mitigation potential of wall width to mitigate contact explosion effects of $500 \mathrm{~g}$ TNT.

In the case of RC slabs subjected to contact explosion effects, an incident compressive wave is generated around the point of detonation. This compressive wave propagates radially outwards and gets reflected into a tensile wave at the distal face due to impedance mismatch between the concrete and air. The reflected tensile wave from the distal face encounters the inbound compressive stress resulting in total stress that is subtractive. When the total stress is tensile (tensile stress greater than inbound compressive stress) and exceeds the tensile strength of concrete a scab is formed. As concrete is comparatively weaker in 
tensile strength, the damage at the distal face is higher than on the incident face. This phenomenon is termed as one-dimensional (1D) wave propagation. On the other hand, in case of square RC columns subjected to contact explosion effects, the phenomenon is significantly different. The compressive wave is reflected from the side faces in addition to the distal face. This intensifies the tensile stress damage and results in a higher damage index in case of square RC column of same depth across the explosive mass when compared to the RC slab. The failure mechanism in an RC wall emulates that of an RC slab and as the width of the wall is increased the slab effect becomes more predominant improving the resistance to contact explosion effects. The results presented in Table 6-10 correlates well with the results for RC slabs reported in Dua and Braimah (2018). The authors reported a crater-spall failure mode in an RC slab of $200 \mathrm{~mm}$ thickness and 900 $\mathrm{mm}$ in width. There was no breach in the slab and no damage was visually detected in the confined concrete core.

\subsection{Parametric Study}

A parametric study was performed with the validated numerical model to further investigate the influence of explosive mass on the potential of increased aspect ratio to mitigate contact explosion effects on RC columns. Dua and Braimah (2018) reported a breach threshold explosive mass of $2.5 \mathrm{~kg}$ for breaching an RC slab of $300 \mathrm{~mm}$ thickness, $20 \mathrm{MPa}$ concrete compressive strength, and 0.011 reinforcement ratio. It is obvious that $2.5 \mathrm{~kg}$ explosive mass detonated in contact with a $300 \times 300 \mathrm{~mm}$ cross-section RC column will crush the concrete core, as was 
the case with $1 \mathrm{~kg}$ explosive mass presented earlier. Three numerical simulations were performed to predict the damage indices of RC walls with $300 \times 500 \mathrm{~mm}$, $300 \times 900 \mathrm{~mm}$ and $300 \times 1200 \mathrm{~mm}$ cross-sections subjected to contact explosion effects of the breach threshold explosive mass of $2.5 \mathrm{~kg}$. The damage profiles of the three cross-sections are presented in Figure 6-20.

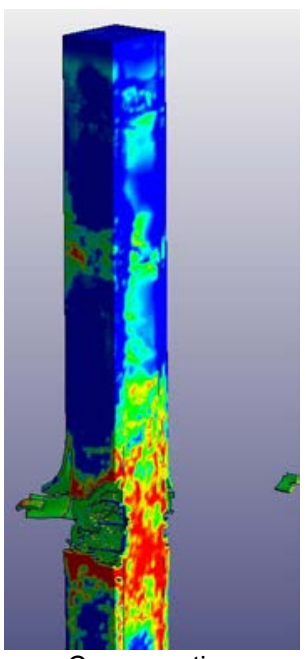

Cross-section

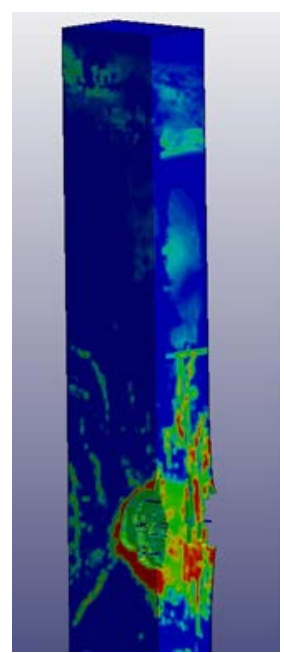

Cross-section

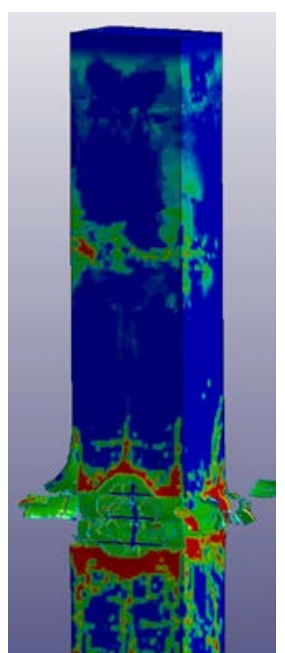

Front face

(a)

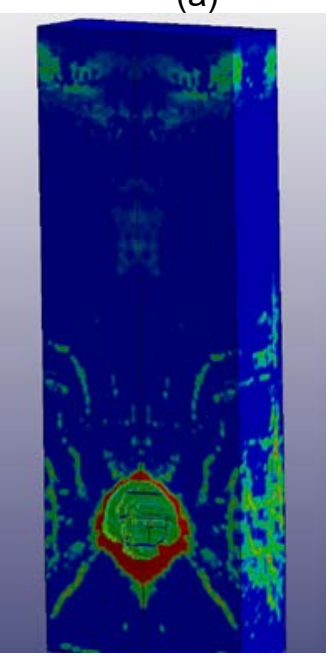

Front face

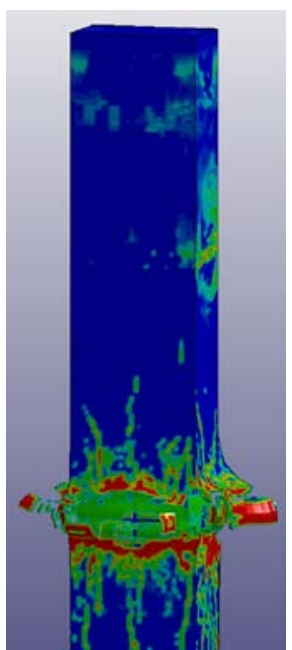

Back face

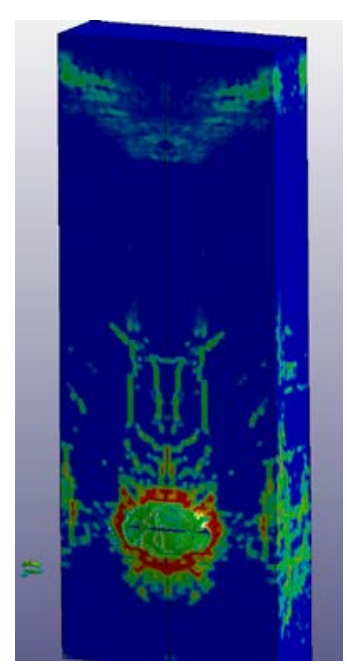

Back face 


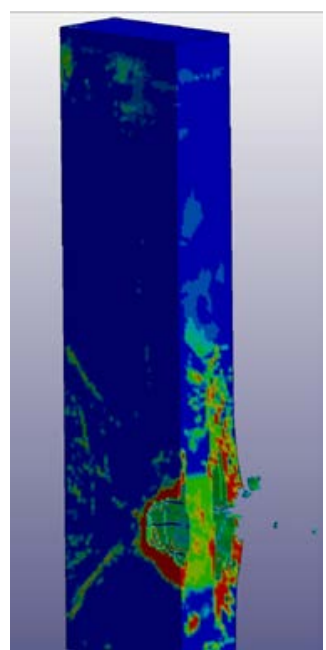

Cross-section

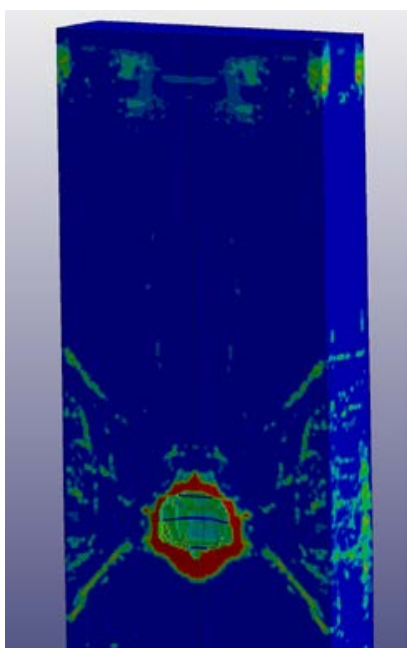

Front face

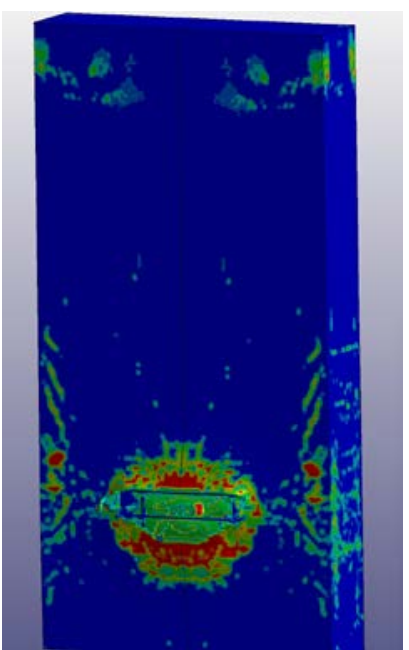

Back face

(c)

Figure 6-20: Damage profiles on the front and back faces) for (a) N-2500-500 (b) N-2500-900 (c) N-2500-1200

The contact explosion effects of $2.5 \mathrm{~kg}$ TNT resulted in a 2D phenomenon in the $300 \times 500 \mathrm{~mm}$ wall and the damage was accordingly enhanced. The fringe plot in red color (damage accumulation $>0.99$ ) depicts the portion that has failed and has completely lost the ability to support any load. The concrete spall from the side and distal face in the $300 \times 500 \mathrm{~mm}$ wall is evident from Figure $6-20$ (a). For a wall width greater than $500 \mathrm{~mm}$ the failure mechanism starts to transition from 2D to $1 \mathrm{D}$. Hence, crater-spall failure mode with no side spalling is observed in both N-2500900 and N-2500-1200 models (Figure 6-20 (b) \& (c)). The contact explosion effects cause breach of $300 \times 900 \mathrm{~mm}$ and $300 \times 1200 \mathrm{~mm}$ walls, however, the portion with accumulated damage of zero outside the breach zone remained undamaged.

Figure 6-21 compares the damage indices of the three numerical simulations. 


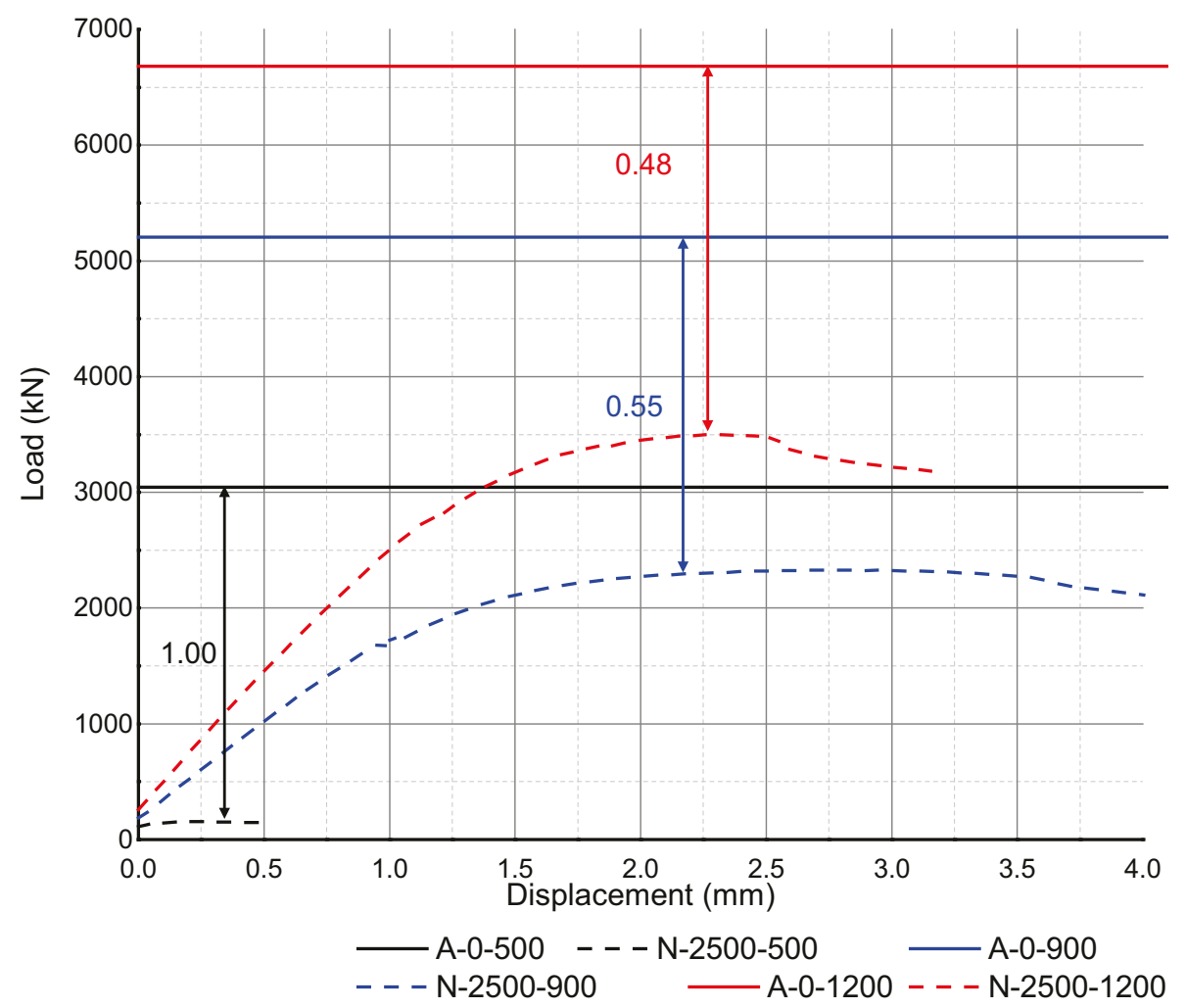

Figure 6-21: Comparison of damage indices of walls subjected to contact explosion effects of 2.5 $\mathrm{kg}$ TNT (arrows show damage indices)

The damage index of the RC walls with the same depth across the explosive mass reduced from 1.0 to 0.48 with an increase in the width. It can be concluded that the width of the RC wall is effective in improving the performance of $R C$ walls subjected to contact explosion effects.

\subsection{Conclusions}

The research program presented in this paper investigated the potential of using column aspect ratio to mitigate the contact explosion effects. Three RC columns and three RC walls were subjected to contact explosion effects of varying explosive charge masses. The residual axial load carrying capacities of the blastdamaged members were tested to quantify the damage index. Numerical models 
were validated with experimental results and used to predict the damage profiles and the residual axial capacities of the blast-damaged walls, accurately. A parametric study was performed with the validated numerical model to investigate the effect of column width resisting the contact explosion effects of an explosive charge mass equal to the breach explosive mass for RC slab of the same depth.

The major conclusions of the study are as followed:

- RC walls provide better resistance to contact explosion effects when compared to square $\mathrm{RC}$ columns. The $2 \mathrm{D}$ shock wave propagation observed in a square RC column transitions into a 1D shock wave propagation with an increase in the width of the wall thereby improving the contact blast resistance.

- Under the contact explosion effects of $500 \mathrm{~g}$ TNT that caused a damage index of 1 in a square column, an increase in the width of the RC column by $67 \%$, reduced the damage index to 0.71 providing approximately $30 \%$ of the design capacity of the undamaged column. An increase in the width of $130 \%$ or more resulted in zero damage index.

- Under the contact explosion effects of breach charge mass of $2.5 \mathrm{~kg}$ TNT for $300 \times 500 \mathrm{~mm}$ column that caused a damage index of 1 , the increase in the column width by $80 \%$ and $140 \%$ resulted in reduction in damage indices to 0.55 and 0.48 respectively. 


\subsection{References}

Krauthammer et al., 2013ASCE. 2011. Blast Protection of Buildings: Standard ASCE/SEI 59-11: American Society of Civil Engineers (ASCE). USA.

Bažant, Z. P., \& Zhou, Y. 2002. Why Did the World Trade Center Collapse? Simple Analysis. Journal of Engineering Mechanics, 128(1): 12-18.

Børvik, T., Hanssen, A., Langseth, M., \& Olovsson, L. 2009. Response of Structures to Planar Blast Loads - A Finite Element Engineering Approach. Computers \& Structures, 87: 507-520.

Braimah, A., Siba, F., \& Rosen, B. V. 2015. Near-field explosion effects on reinforced concrete columns. Protect 2015, Fifth international workshop on performance, protection and strengthening of structures under extreme loading: DEStech Publications, Inc. MI, USA pp. 504-514.

Clarke, S. D., Fay, S. D., Warren, J. A., Tyas, A., Rigby, \& Elgy, I. 2015. A large scale experimental approach to the measurement of spatially and temporally localized loading from detonation of shallow buried explosives. Measurement science and technology, 26: 10pp.

Cormie, D., Shin, J., Whittaker, A. S., \& Aref, A. J. 2014a. Air Blast effects on civil structures, MCEER-14-0006. State University of New York.

Cormie, D., Shin, J., Whittaker, A. S., \& Wilkinson, W. 2014b. Numerical modelling of close-in detonations of high explosives. Engineering Structures, 81: 8897.

Crawford, J. E., Morrill, K. B., \& Magallenes, J. M. 2014. Protective design for columns against close-in blast effects. Structures Congress: ASCE USA 
Cui, J., Shi, Y., Li, Z.-X., \& Chen, L. 2015. Failure analysis and damage assessment of RC-columns under close-in explosions. Journal of Performance of Constructed Facilities, 29(5): B40150034015001:4015011.

US Department of Defense (DoD). 1987. Fundamentals of Protective Design for Conventional Weapons, TM5-855-1. Washington DC, USA.

US Department of Defense (DoD). 2002. Design and Analysis of Hardened Structures to Conventional Weapons Effects, UFC-3-340-01. Department of Defense USA.

US Department of Defense (DoD). 2008. Design of structures to resist the effects of accidental explosions, UFC-3-340-02. Department of Defense Washington, D.C.

US Department of Transportation (DoT). 2009. Blast-Resistant Highway Bridges: Design and Detailing Guidelines. Transportation Research Board, National Cooperative Highway Research Program (NCHRP) (Report No. 645), Washington, USA.

Dua, A., \& Braimah, A. 2016. State-of-the-Art in Near-Field and Contact Explosion Effects on Reinforced Concrete Columns. 5th International Structural Specialty Conference: Canadian Society for Civil Engineering London, Canada. pp. 1:12 (STR-836).

Dua, A., \& Braimah, A. 2017. Efficacy of Concrete Constitutive Models for Bullet Impact Tests. 6th International Engineering Mechanics and Materials 
Conference: Canadian Society of Civil Engineers Vancouver, Canada. pp. $521521-510$.

Dua, A., Braimah, A., \& Matsagar, V. 2017. Understanding the Response of Reinforced Concrete Slabs due to Contact explosion of TNT. 6th International Engineering Mechanics and Materials Conference: Canadian Society for Civil Engineering (CSCE) Vancouver, Canada. pp. 522 521-510.

Dua, A., \& Braimah, A. 2018. Assessment of Reinforced Concrete Slab Response Due to Contact Explosion Events. Journal of Performance of Constructed Facilities (ASCE), Under Review.

Dua, A., Braimah, A., \& Kumar, M. 2018a. Mitigation Effects of Cladding on Reinforced Concrete Columns Subjected to Contact Explosions. Journal of Structural Engineering (ASCE), Under Review.

Dua, A., Braimah, A., \& Kumar, M. 2018b. Contact Explosion Response of Reinforced Concrete Columns: Experimental and Numerical Investigation. Structures and Buildings (ICE), Under Review.

Enstock, L. K., \& Smith, P. D. 2007. Measurement of impulse from the close-in explosion of doped charges using a pendulum. International Journal of Impact Engineering, 34(3): 487-494.

Federal Emergency Management Agency (FEMA). 2005. Reference Manual to Mitigate Potential Terrorist Attacks Against Buildings, FEMA-426. Federal Emergency Management Agency (FEMA) USA.

Gebbeken, N., Greulich, S., Pietzsch, A., \& Landmann, M. 2004. The EngineeringTool XPLOSIM to Determine the Effects of Explosive Loadings on 
Reinforced and Fibre Reinforced Concrete Structures. 18th International Symposium for Military Aspects of Blast and Shock:

Hanssen, A., Enstock, L. K., \& Langseth, M. 2004. Close-Range Blast Loading of Aluminum Foam Panels. International Journal of Impact Engineering, 27: 593-618.

Hyde, D. 1988. User's guide for microcomputer programs CONWEP and FUNPRO - Applications of TM 5-855-1.

Kakogiannis, D., Hemelrijck, D. V., Wastiels, J., Palanivelu, S., Paepegem, W. V., Vantomme, J., . . Kostopoulos, V. 2010. Assessment of Pressure Waves Generated by Explosive Loading. CMES-Computer Modelling in Engineering \& Sciences, 65(1): 75-93.

Kalra, A., Zhu, F., Yang, K. H., \& King, A. I. 2014. Key Parameters in Blast Modeling Using 2D to 3D ALE Mapping Technique. 13th International LSDYNA Users Conference: LSTC Detroit, USA.

Kingery, C. N., \& Bulmash, G. 1984. Air blast parameters from TNT spherical air burst and hemispherical surface burst. Ballistic Research Lab (BRL), Technical Report, ARBRL-TR-02555.

Krauthammer, T., Astarlioglu, S., Morency, D., \& Tran, T. P. 2013. Behavior of Reinforced Concrete Columns Under Combined Effects of Axial and Blastinduced Transverse Loads. Engineering Structures, 55: 26-34.

L.S.T.C. 2015a. LS-DYNA Keyword User's Manual, Volume I. Livermore, California, USA: LSTC. 
L.S.T.C. 2015b. LS-DYNA Keyword User's Manual, Volume II-Material Models. Livermore, California, USA: LSTC.

Li, J., Wu, C., \& Hao, H. 2015. Investigation of Ultra-high Performance Concrete Slab and Normal Strength Concrete Slab under Contact Explosion. Engineering Structures, 102: 395-408.

Mlakar, P. F., Corley, W. G., Sozen, M. A., \& Thornton, C. H. 1998. The Oklahoma City Bombing: Analysis of Blast Damage to the Murrah Building. Journal of Performance of Constructed Facilities, 12(3): 113-119.

Murray, Y. D. 2007. User's Manual for LS-DYNA Concrete Material Model 159. FHWA-HRT-05-062, Federal Highway Administration.

Naito, C., Olmati, P., Trasborg, P., Davidson, J., \& Newberry, C. 2014. Assessment of insulated concrete walls to close-in blast demands. American society of civil engineers, 10.

Nesterenko, V. F. 2003. Shock (Blast) Mitigation by "Soft" Condensed Matter. MRS Proceedings: Pittsburg, USA

Rigby, Tyas, A., Clarke, S., Fay, S., Warren, J., Elgy, I., \& Gant, M. 2014. Testing apparatus for the spatial and temporal pressure measurements from nearfield free air explosions. 6th International Conference on Protection of structures against hazards: Tianjin, China.

Rigby, Tyas, A., Clarke, S. D., Fay, S. D., Reay, J. J., Warren, J. A., . . Elgy, I. 2015. Observations From Preliminary Experiments on Spatial and Temporal Pressure Measurements from Near-Field Free Air Explosions. International Journal of Protective Structures, 6(2): 175-190. 
Satter, D. 2003. Darkness at Dawn: Yale University Press.

Schwer, L. 2014. Modelling Rebar: The Forgotten Sister in Reinforced Concrete Modelling. 13th International LS-DYNA User Conference: LSTC Detroit, USA.

Telford, T. 1993. CEB-FIB Model Code 1990. Comité Euro-International du Béton, Lausanne, Switzerland.

Trajkovski, J., Kunc, R., Perenda, J., \& Prebil, I. 2014. Minimum mesh design criteria for blast wave development and structural response - MMALE method. Latin American Journal of Solids and Structures, 11: 1999-2017.

Wang, F., Wan, Y. K. M., Chong, O. Y. K., Lim, C. H., \& Lim, E. T. M. 2008. Reinforced concrete slab subjected to close-in explosion. LS-DYNA Conference: Bamberg.

Wang, W., Zhang, D., Lu, F., Wang, S.-C., \& Tang, F. 2013. Experimental study and numerical simulation of the damage mode of a square reinforced concrete slab under close-in explosion. Engineering Failure Analysis, 27: $41-51$.

Weerheijm, J., Karthaus, W., \& Opschoor, G. 1984. The Failure Mode of Layered Concrete Construction Due to Contact Charges. 21st Department of Defense Explosive Safety Seminar. Department of Defense Houston, Texas, USA

Williams, G. D. 2009. Analysis and Response Mechanisms of Blast-Loaded Reinforced Concrete Columns. (Doctor of Philosophy), University of Texas, Austin, USA. 
Wu, K.-C., Li, B., \& Tsai, K.-C. 2011a. Residual Axial Compression Capacity of Localized Blast-Damaged RC Columns. International Journal of Impact Engineering, 38: 29-40.

Wu, K.-C., Li, B., \& Tsai, K.-C. 2011b. The Effects of Explosive Mass Ratio on Residual Compressive Capacity of Contact Blast Damaged Composite Columns. Journal of Constructional Steel Research, 67: 602-612.

Yuan, S., Hao, H., Zong, Z., \& Li, J. 2017. A Study of RC Bridge Columns Under Contact Explosion. International Journal of Protective Structures, 109: 378390.

Zakrisson, B., Wikman, B., \& Häggblad, H.-Å. 2011. Numerical simulations of blast loads and structural deformation from near-field explosions in air. International Journal of Impact Engineering, 38(7): 597-612.

Zhang, D., Yao, S., Lu, F., Chen, X., Lin, G., Wang, W., \& Lin, Y. 2013. Experimental study on scaling of RC beams under close-in blast loading. Engineering Failure Analysis, 33: 497-504. 


\section{Chapter 7 Summary and Contributions}

\subsection{Summary}

In today's heightened security environment, attacks involving contact explosion on critical structural members of the target building pose a credible threat. There is a lack of reported experimental research on contact explosion effects in the literature. This thesis presents the experimental and numerical investigations on concrete members with an aim to improve the current understanding of the response of such members to contact explosion effects. Live explosive tests were performed on full-scale concrete slabs and columns and the response was recorded to set a benchmark for future studies. Numerical models developed on LS-DYNA were validated from the experimental results and parametric studies were performed. The following summary can be drawn from the studies presented in this thesis:

- Contact explosion events induce local damage on the target due to the highintensity impulse imparted during detonation. This causes concrete crushing on the incident face and spalling on the distal faces. The damage caused to concrete targets due to contact explosion effects is higher than the damage induced by far-field events which remain in the global response range.

- A compressive wave is initiated in the target due to the impulse generated by the contact explosion. The compressive wave propagates radially 
outwards and gets attenuated in the target medium. If the compressive wave arrives at a distal face of the target before getting completely attenuated, a reflected wave is initiated due to the impedance mismatch. The reflected tensile wave from the distal face encounters the inbound compressive stress resulting in total stress that is subtractive. When the total stress is tensile (tensile stress greater than inbound compressive) and exceeds the tensile strength of concrete, a scab is formed.

- The damage mechanism in RC slabs differs significantly from RC columns. In the case of RC slabs, the reflection of the compressive wave happens only opposite to the incident face. There is no or insignificant effect on the sides as the shock wave gets attenuated before arrival. On the other hand, in the case of RC columns, the reflection occurs on all three distal faces thereby enhancing the concrete spall. Hence, the damage to an RC column due to contact explosion effects is higher than in a RC slab for the same explosive mass and depth of the target.

- RC slabs exhibit two types of failure mechanisms under contact explosion effects. A crater-spall failure mode occurs when the effects are not adequate to breach the slab. Whereas, a breach failure mode occurs when the crater merges with the distal face spall thereby perforating the slab. The breach failure mode may also occur in case the impulse imparted to the slab is high enough to punch a crater throughout the slab. 
- The reinforcement ratio of an $\mathrm{RC}$ slab has a significant influence on the response to contact explosion effects. The reinforcement provides confinement to the concrete thereby enhancing its resistance towards the contact explosion effects. The reinforcement also distributes the impulse over a wider area at the incident face.

- The contact surface area of the explosive mass with the target has an influence on the response of the target. The damage is maximized in case the ratio of length and runup distance from the point of detonation approaches one.

- The concrete compressive strength of an RC slab has less influence on the response to contact explosion effects within the range of 20-55 $\mathrm{MPa}$ in the context of this study.

- RC columns can be demolished with a lesser amount of explosive mass as compared to the explosive mass required to breach an $\mathrm{RC}$ slab of the same depth perpendicular to the explosive.

- There are two failure modes in RC columns subjected to contact explosion effects; (a) Concrete cover spall (b) Concrete core damage. The transformation between the failure modes occurs at the critical explosive mass whose magnitude depends on the material and geometrical properties of the RC column. The contact explosion effects of an explosive 
mass less than the critical explosive mass will result in concrete crushing on the incident face and spalling from the distal faces however there will be no damage to the concrete core. Hence the residual axial capacity of such a column will be high enough to carry the service loads. On the other hand, an RC column subjected to the contact explosion effects due to an explosive mass greater than the critical explosive mass will cause damage to the concrete core and the column will not be able to sustain the service loads reliably.

- The transverse reinforcement ratio of an RC column has a significant effect on the column resistance to contact explosion effects. Seismic detailing with low transverse reinforcement spacing provides higher confinement to the concrete core thereby improving the resistance to contact explosion effects.

- Numerical analysis of RC columns subjected to contact explosion effects must be quantitatively validated. Validation via comparison of damage profiles of the blast-damaged columns is not reliable. The residual axial or bending capacity tests are reliable means of validating the numerical models.

- A small gap of 50-150 mm between the contact explosive mass and the incident face can significantly improve the residual axial capacity of the blast-damaged columns. The gap can be induced by providing a cladding around the RC column. 
- Energy absorbing materials like Aluminum foam in the cladding gap further improves the contact explosion resistance of RC columns by reducing the impact induced to the incident face.

- RC walls can effectively mitigate contact explosion effects as the failure mechanism transforms into the mechanism observed in RC slabs wherein the concrete spall from the side faces is reduced or precluded completely.

\subsection{Recommendation for Further Research}

The following are recommended as a scope for further study:

- Influence of axial gravity loads: RC columns carry axial loads which were not considered during the tests performed for this thesis. It is known that axial loads improve the blast-resistance of $\mathrm{RC}$ columns by providing better shear resistance, however in impulsive regime, the effects can be detrimental. An experimental study augmented with numerical study may be carried out to investigate the influence of axial loads on the residual axial capacity of damaged RC columns subjected to contact explosion effects.

- The influence of Aluminum foam in the cladding gap of RC columns to improve the blast resistance of RC columns was presented in this thesis. It is recommended that futher studies be carried out to examine the effects of varying density of Aluminum foam on the response. 
- The threshold width of an RC wall at which there is no further reduction in the damage index due to contact explosion effects of breach charge mass needs to be examined further.

- The effect of boundary condition at the top of the RC columns was not considered in this thesis and may be examined.

\subsection{Contributions}

\subsubsection{Journal Papers}

Four journal papers have been or are being submitted from the studies presented in this thesis:

- Structures and Buildings, Institution of Civil Engineers, UK (Submitted)

- Journal of Structural Engineering, ASCE (Submitted)

- Journal of Performance of Constructed Facilities, ASCE (Being Submitted)

- Journal of Engineering Structures, Elsevier (Submitted)

\subsubsection{Conference Papers}

Four conference papers were presented from the preliminary studies and results of the experimental work reported in this thesis: The conferecnce papers on literature review and bullet impact studies are attached as Appendix $A$ and Appendix B. 
- Dua, A., \& Braimah, A. 2016. State-of-the-Art in Near-Field and Contact Explosion Effects on Reinforced Concrete Columns. 5th International Structural Specialty Conference: Canadian Society for Civil Engineering London, Canada. pp. 1:12 (STR-836).

- Dua, A., \& Braimah, A. 2017. Efficacy of Concrete Constitutive Models for Bullet Impact Tests. 6th International Engineering Mechanics and Materials Conference: Canadian Society of Civil Engineers Vancouver, Canada. pp. $521521-510$

- Dua, A., \& Braimah, A. 2017. Understanding the Response of Reinforced Concrete Slabs due to Contact explosion of TNT. 6th International Engineering Mechanics and Materials Conference: Canadian Society for Civil Engineering (CSCE) Vancouver, Canada. pp. 522 521-510.

- Dua, A., Braimah, A., \& Kumar, M. 2018. Contact Explosion Response of Reinforced Concrete Columns: Experimental and Validation of Numerical Model. 6th International Disaster Mitigation Specialty Conference: Canadian Society for Civil Engineering (CSCE) Fredericton, New Brunswick. 


\title{
Appendix A: Keyword Files for RC Slabs
}

\author{
$\underline{\text { First Simulation }}$
}

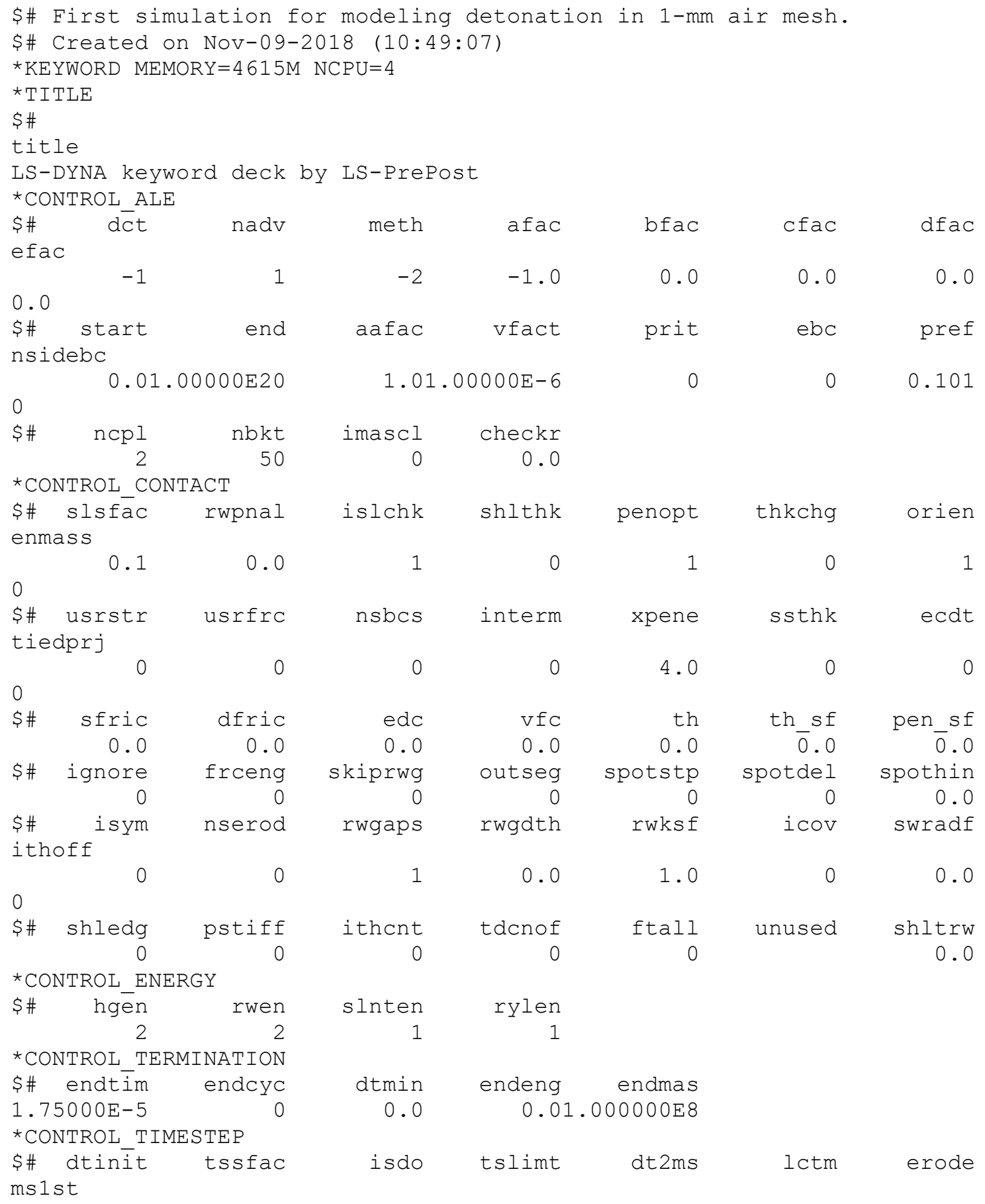

1

vfC

th

0.0

0.0

erode 


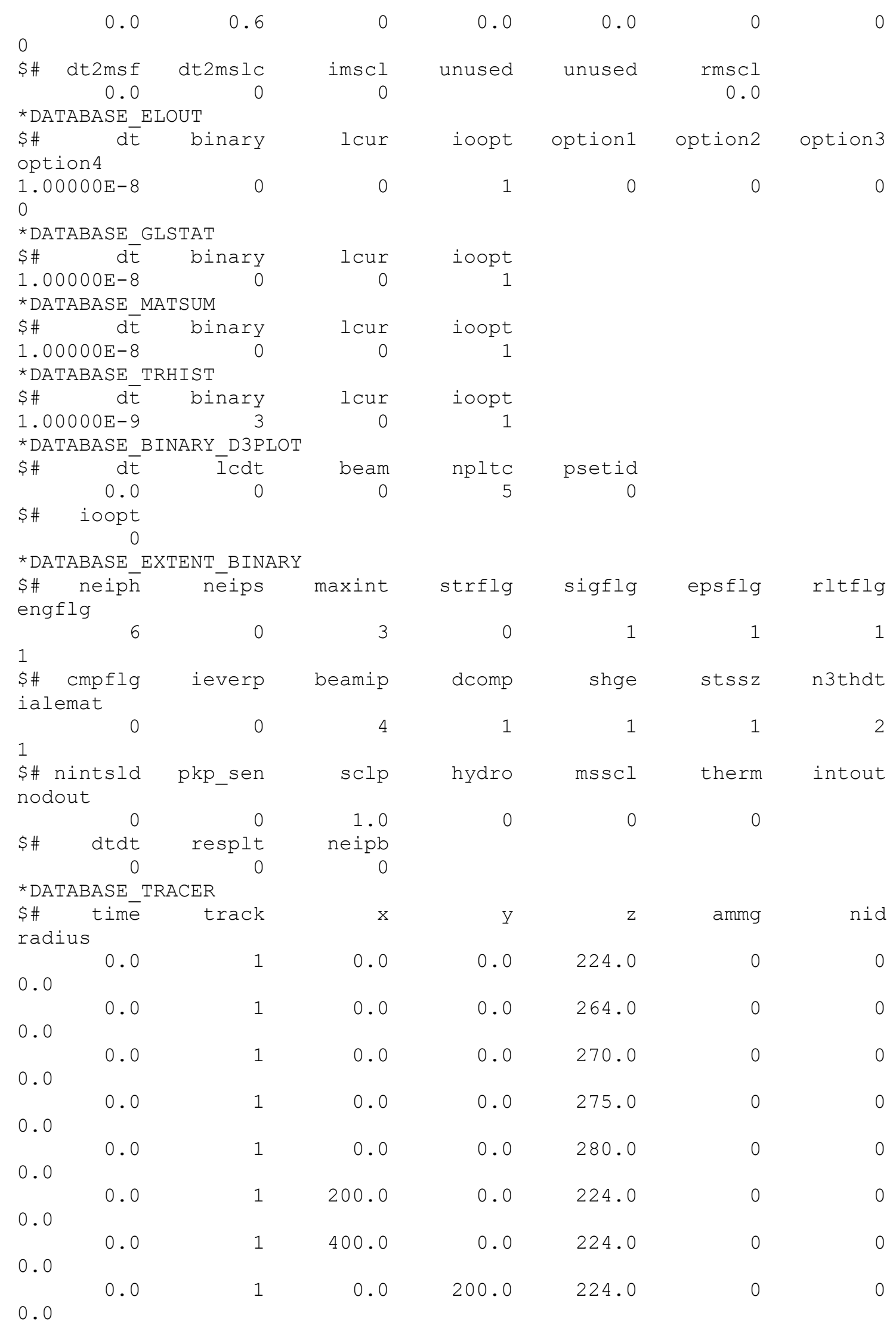




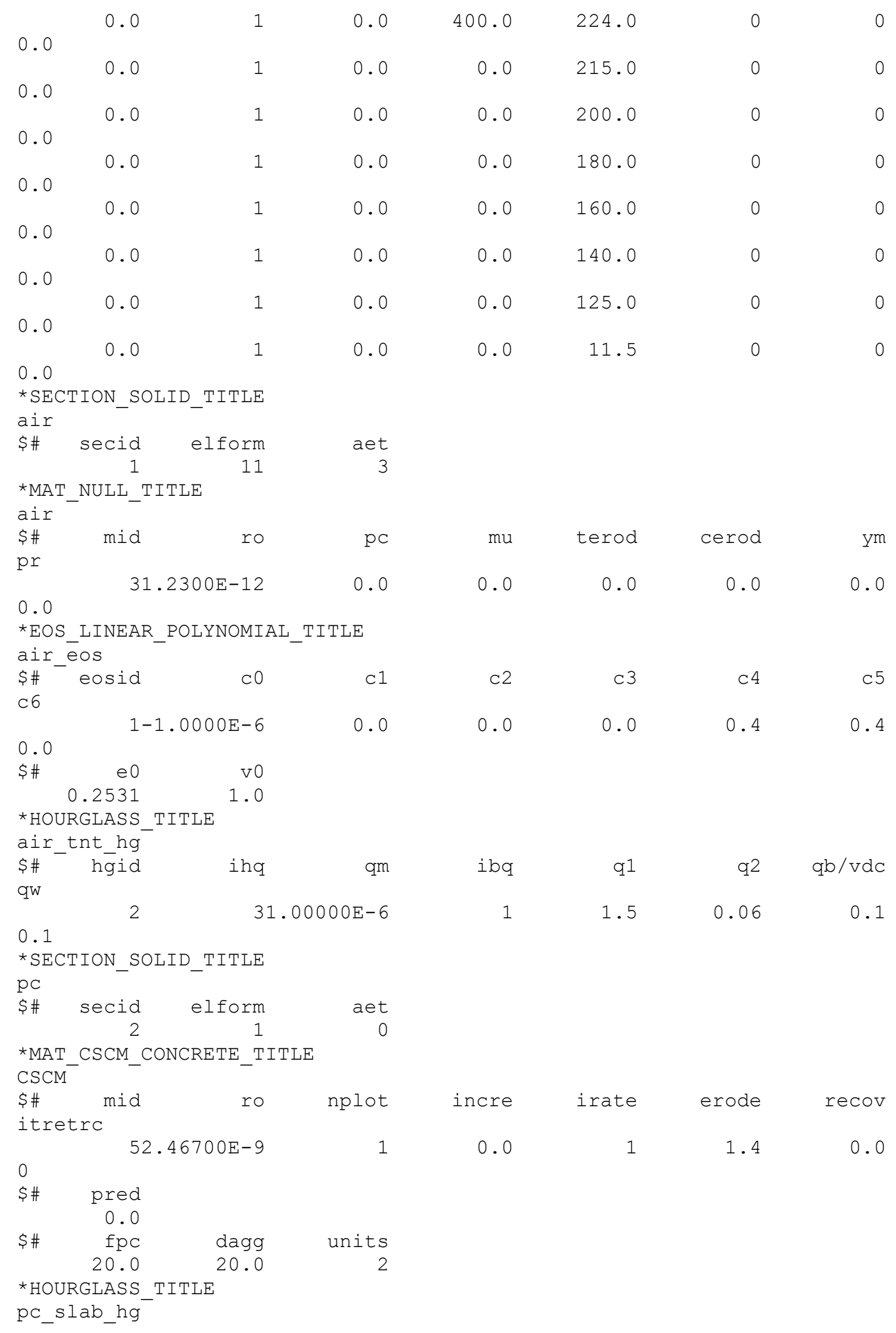




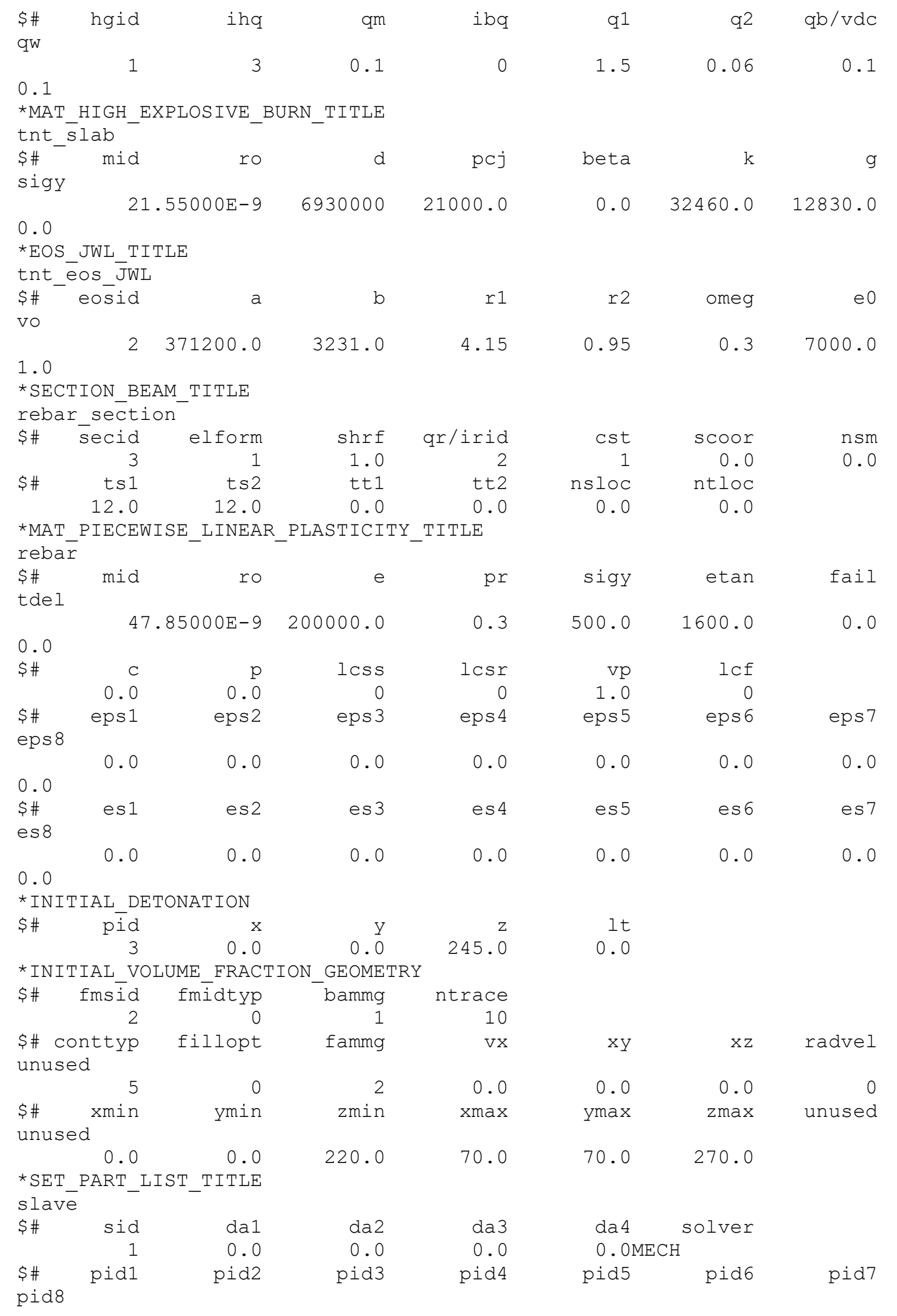




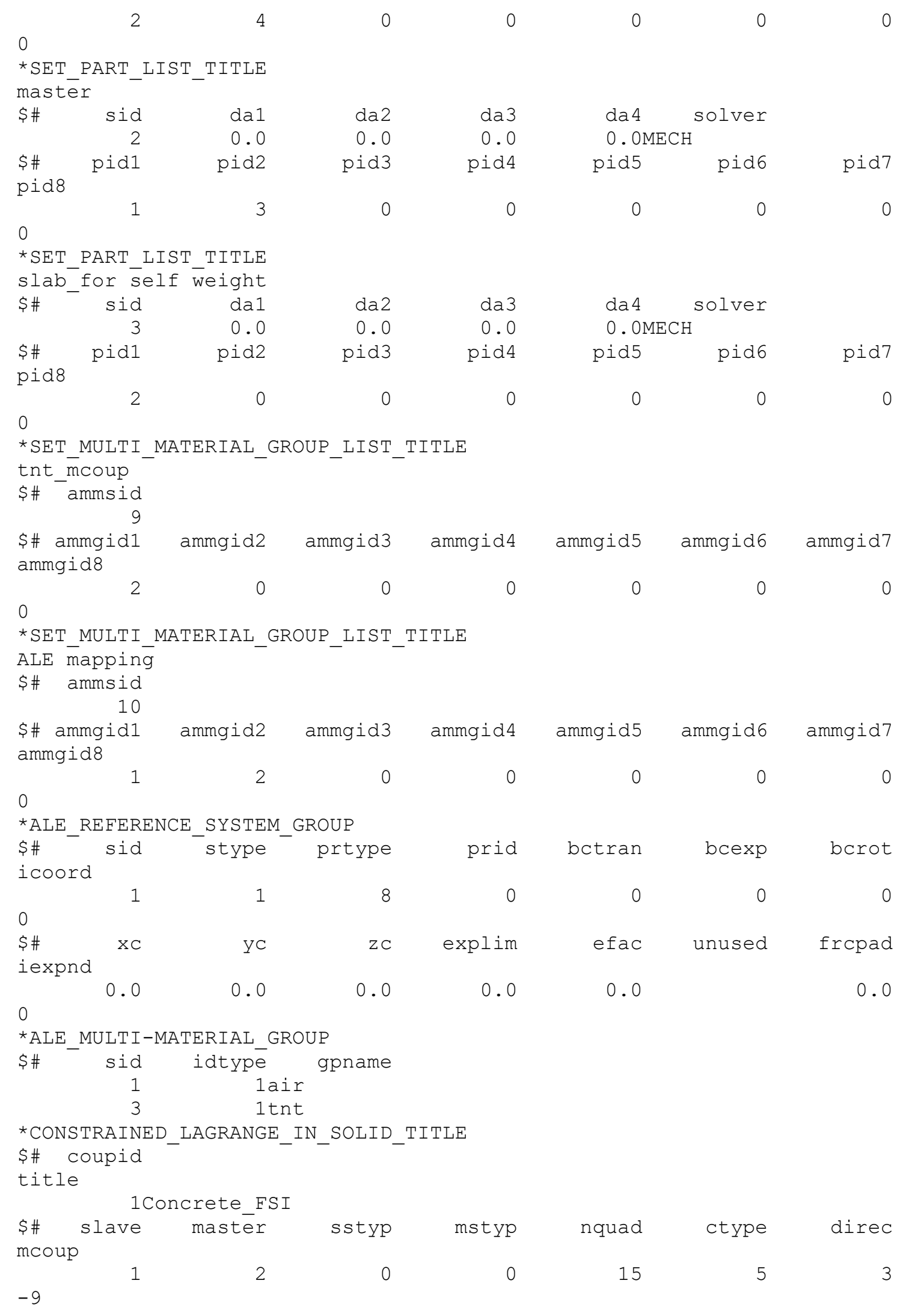




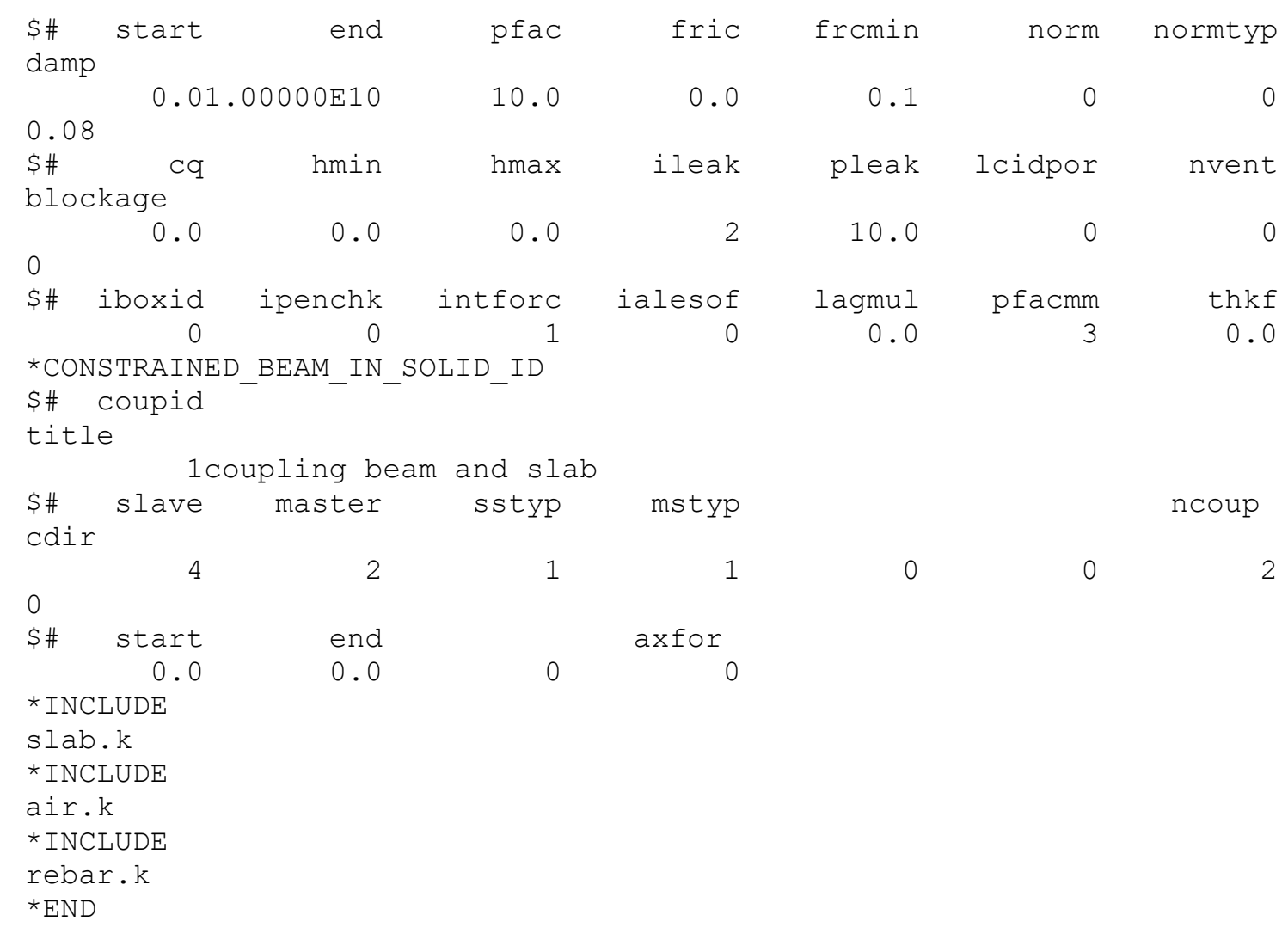

\section{$\underline{\text { Second Simulation }}$}

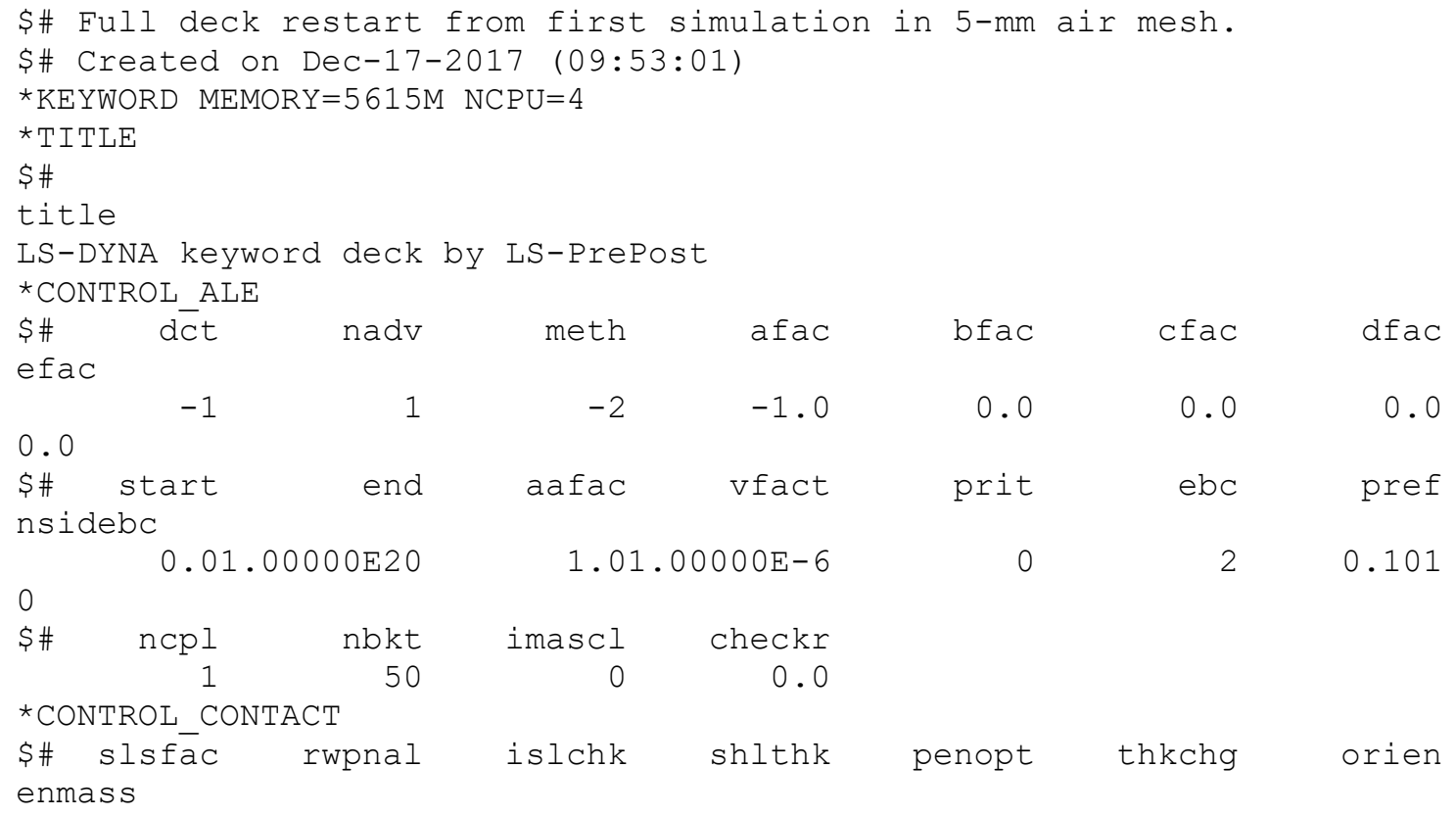




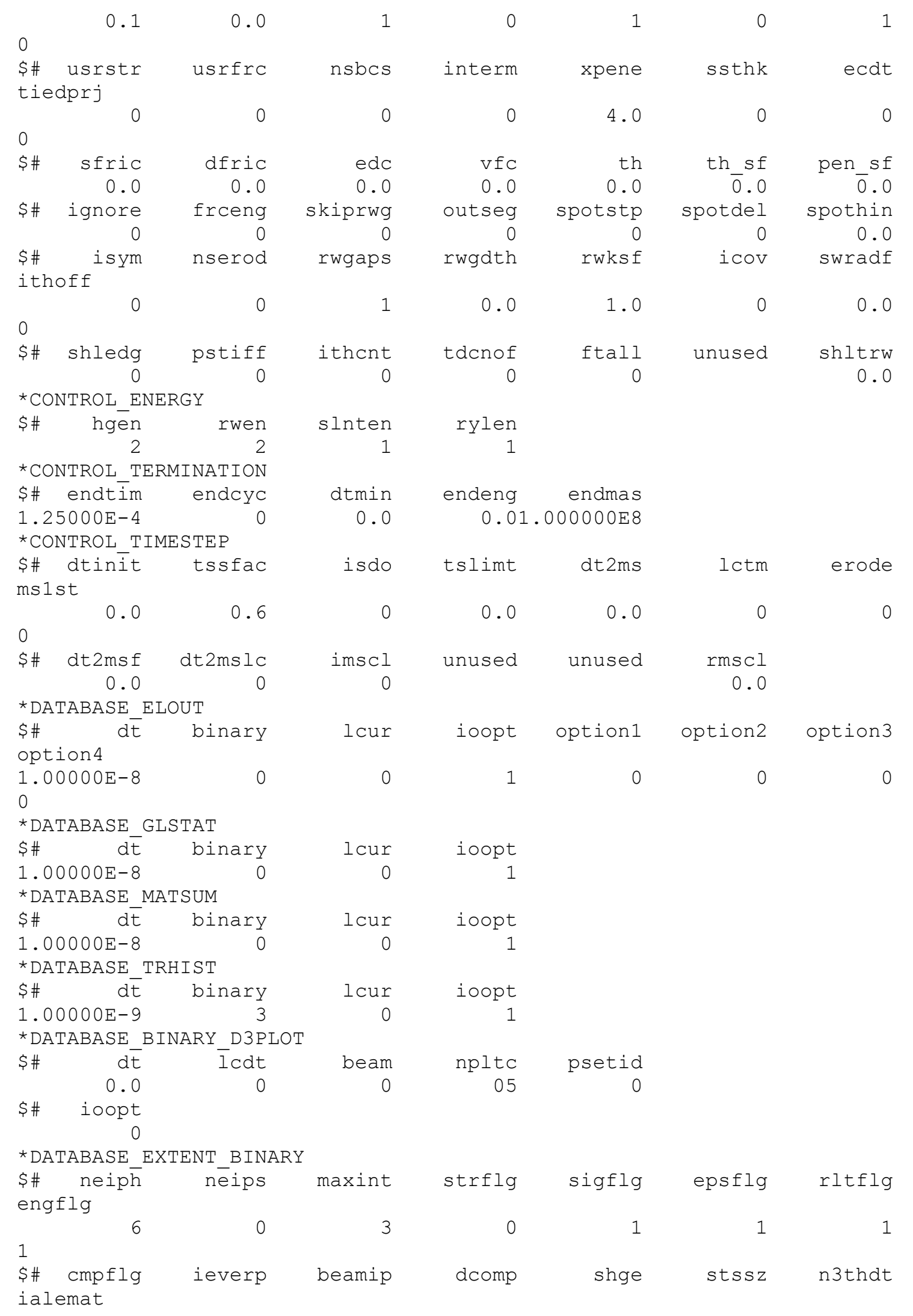




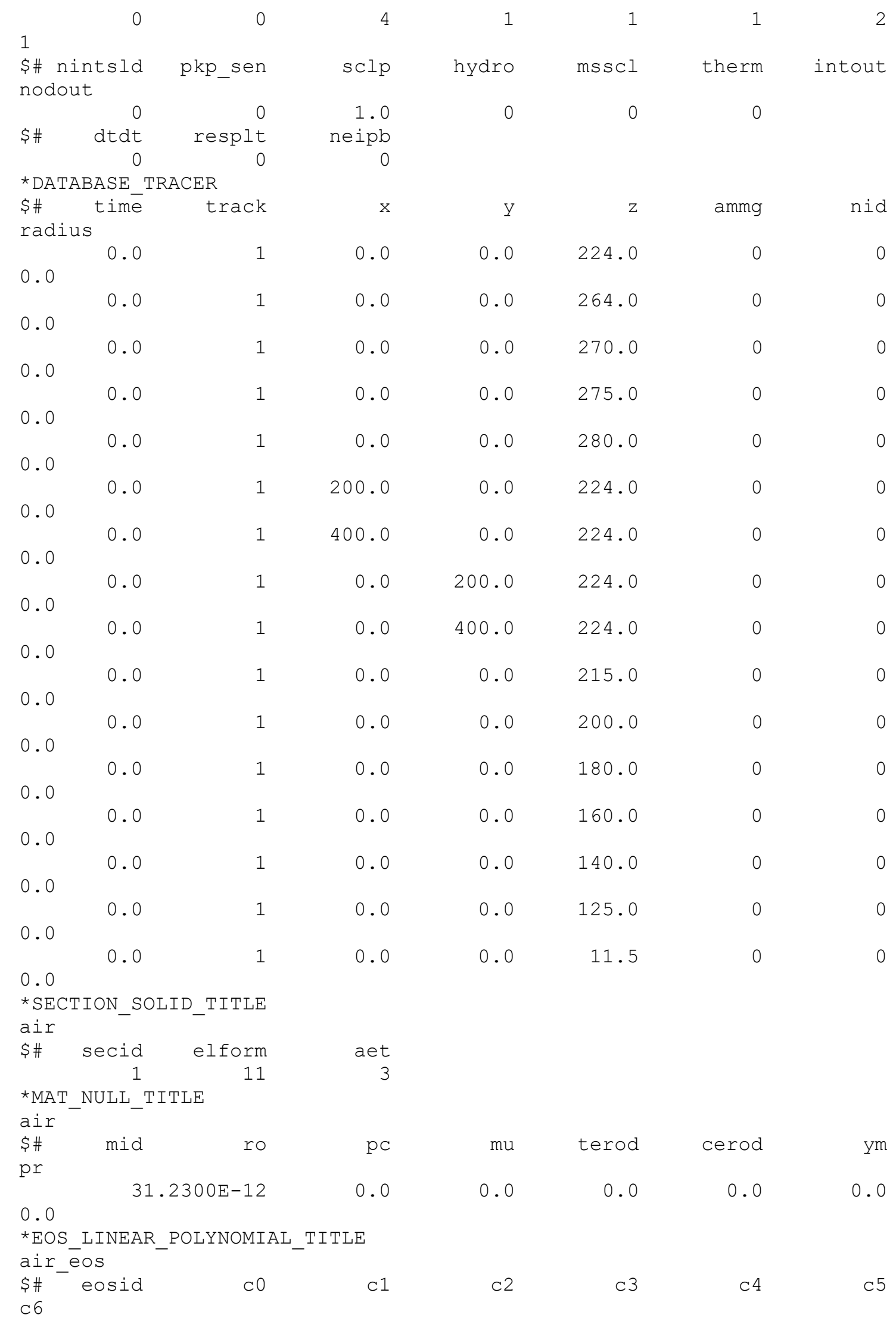




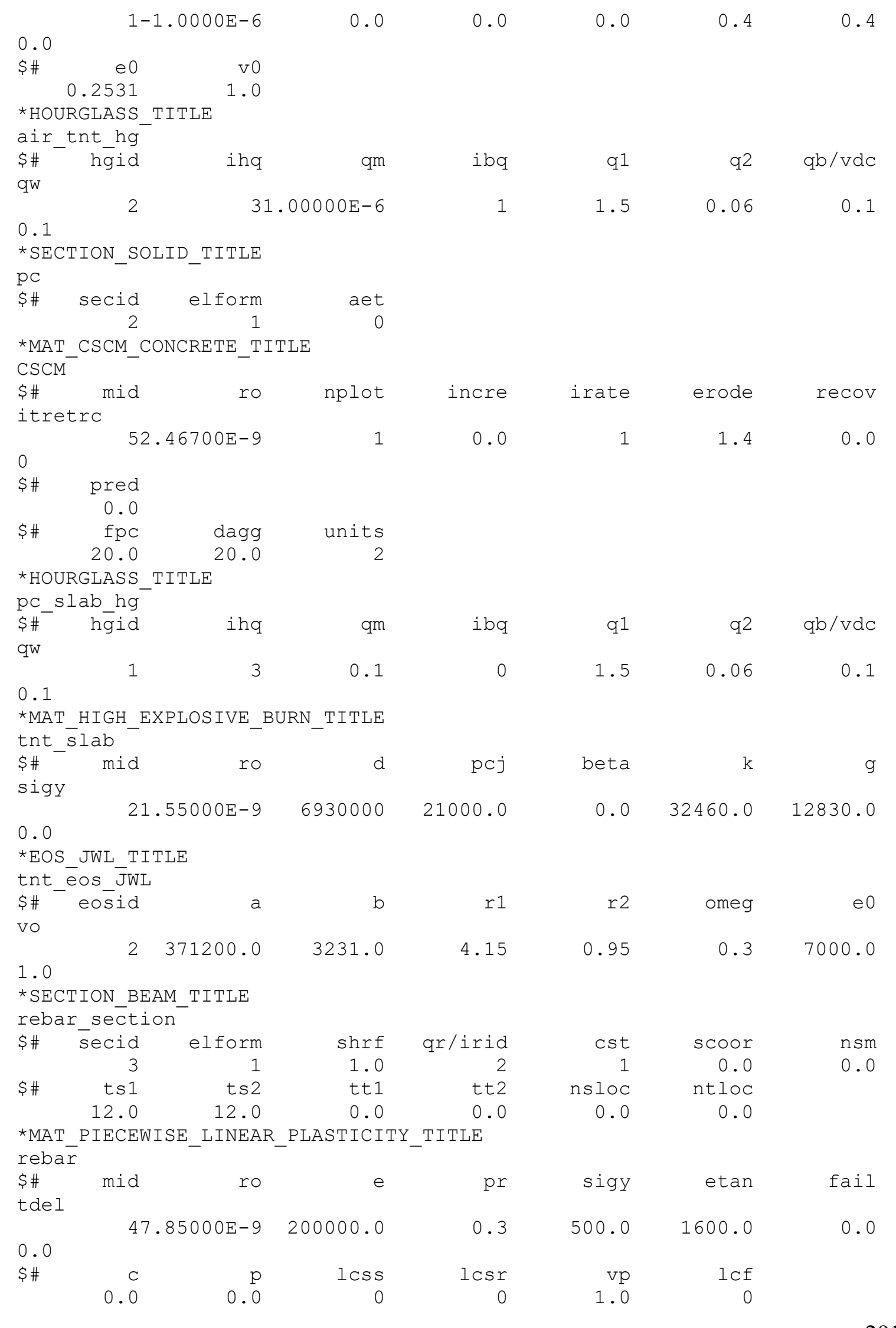




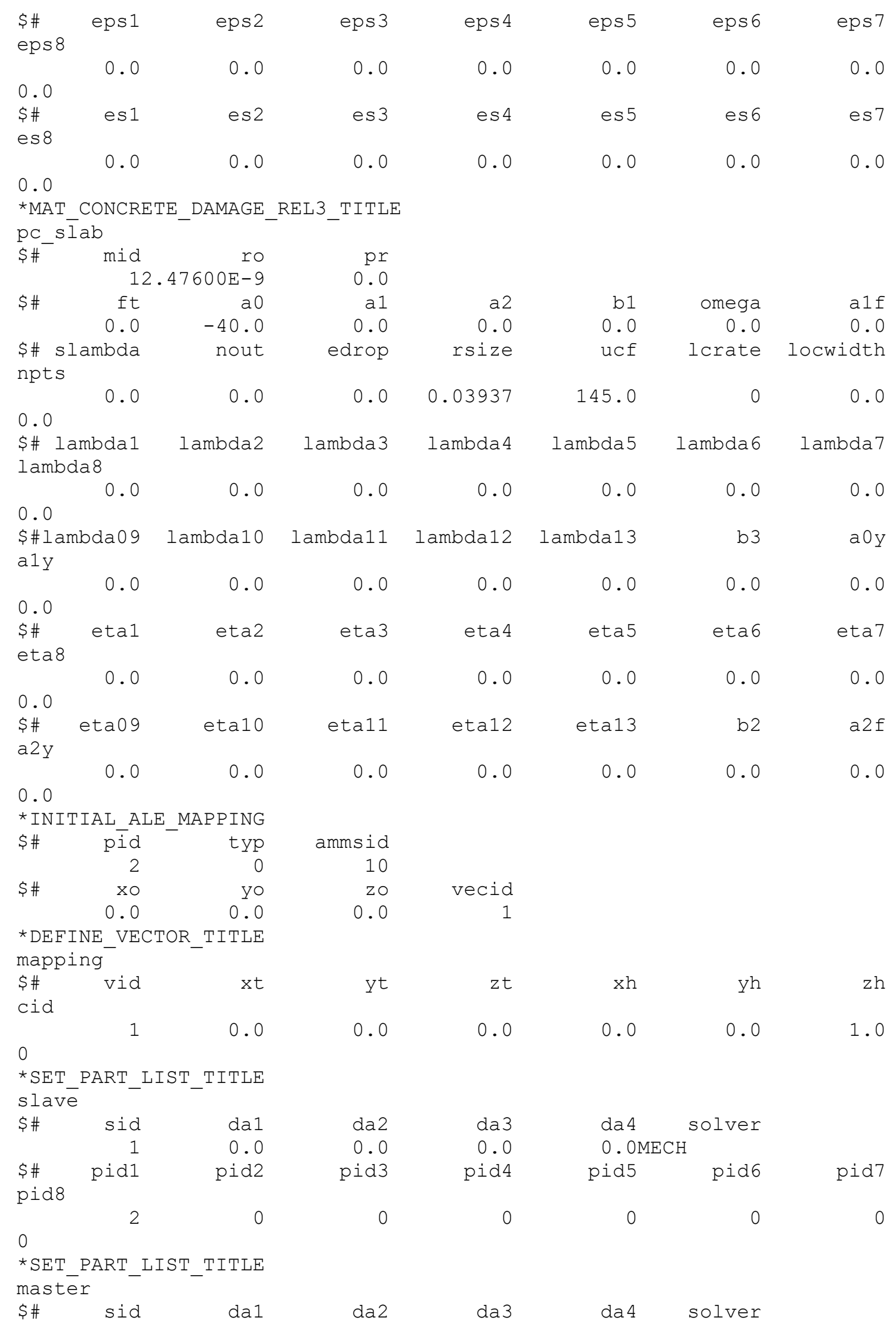




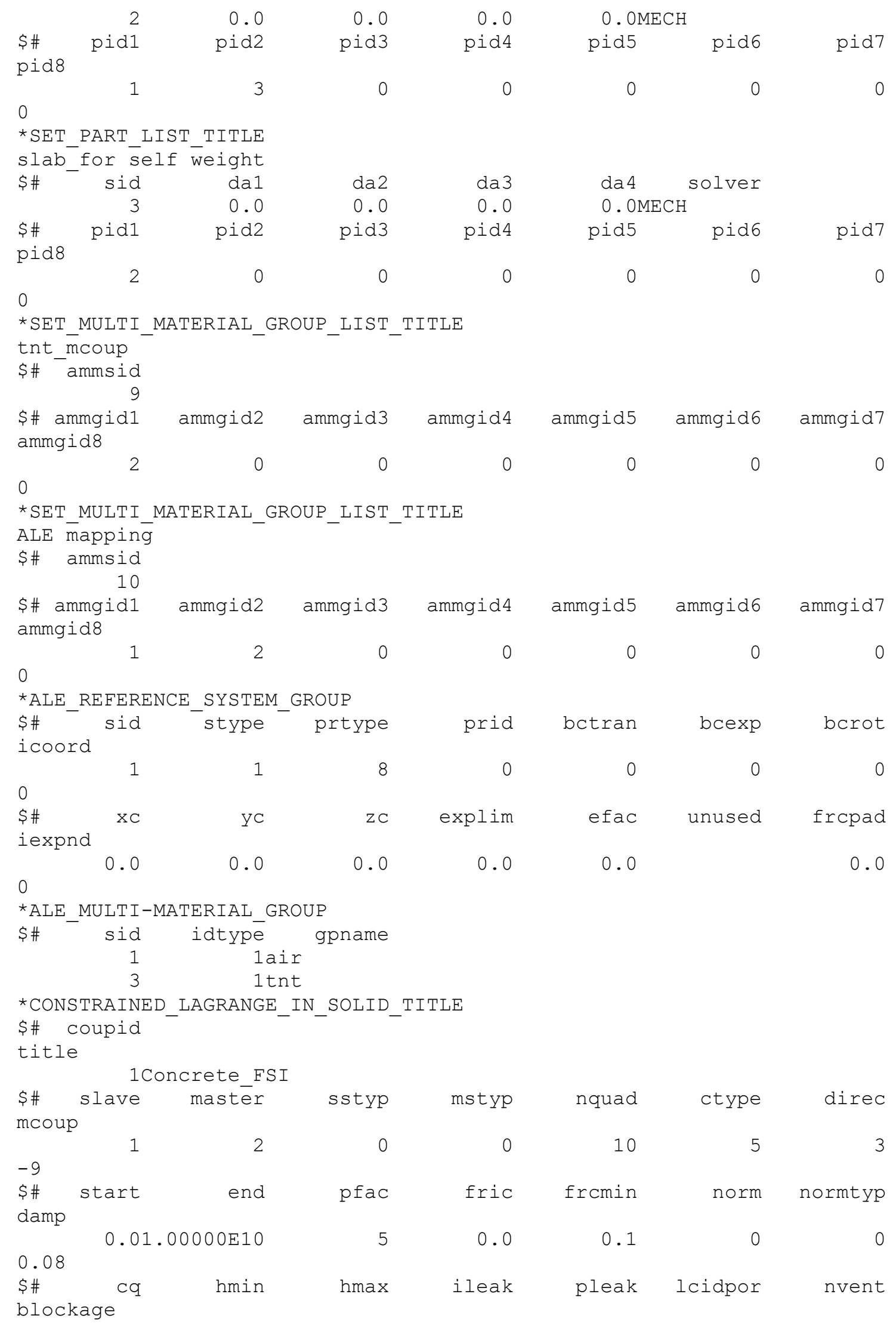




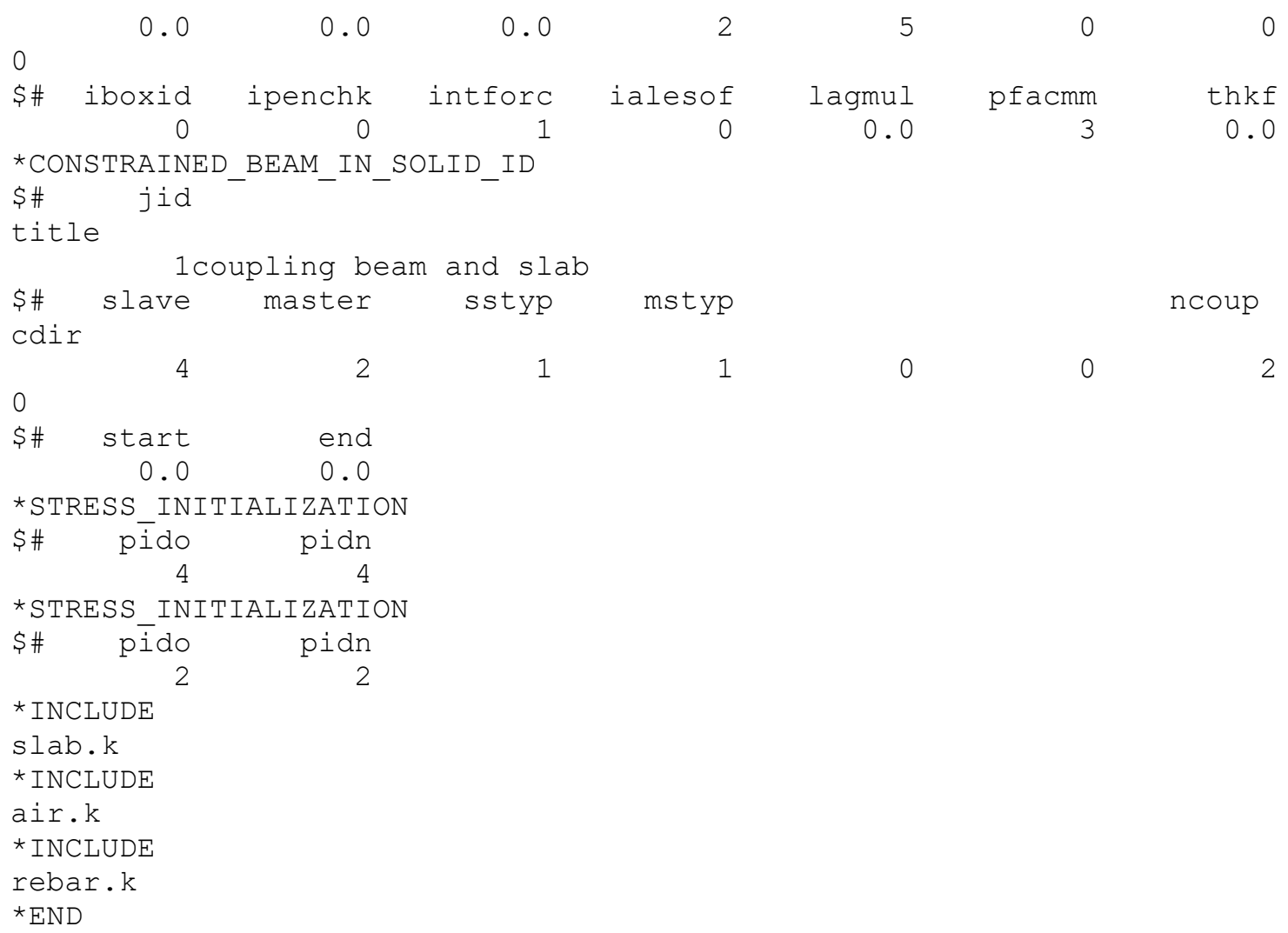

\section{Third Simulation without ALE domains}

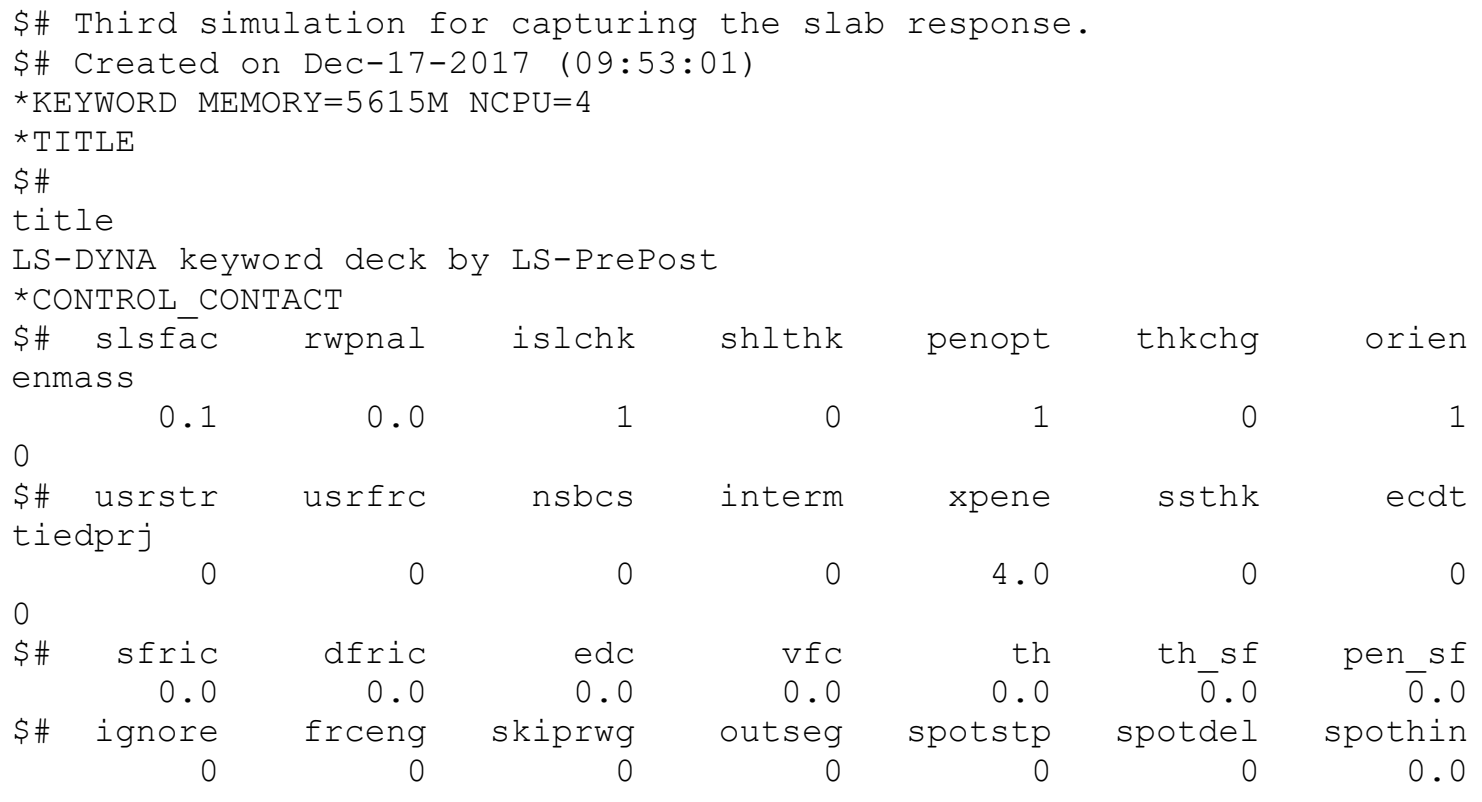

$$
0
$$

th_sf
0.0
spotdel

spotdel

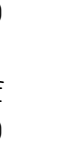




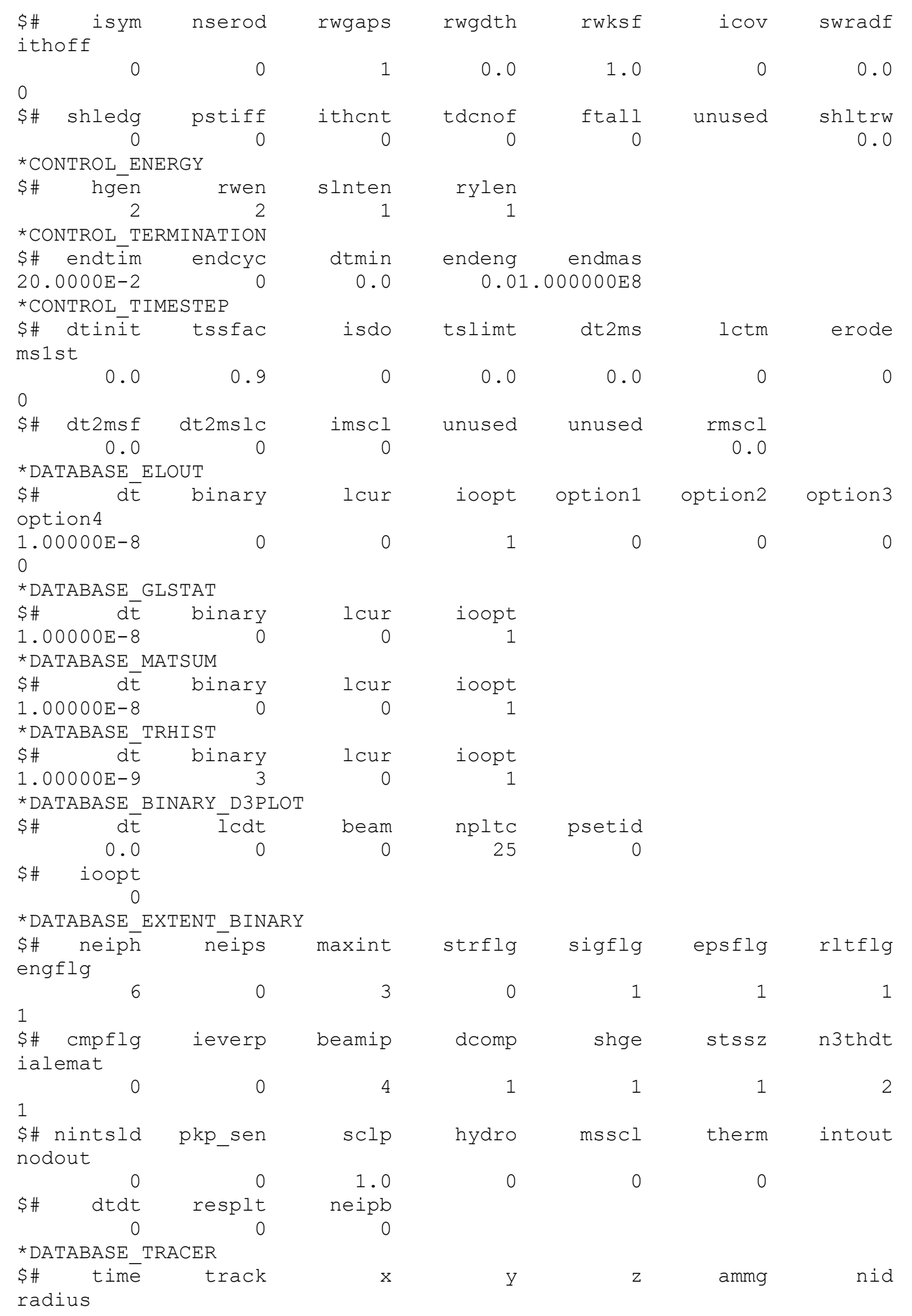




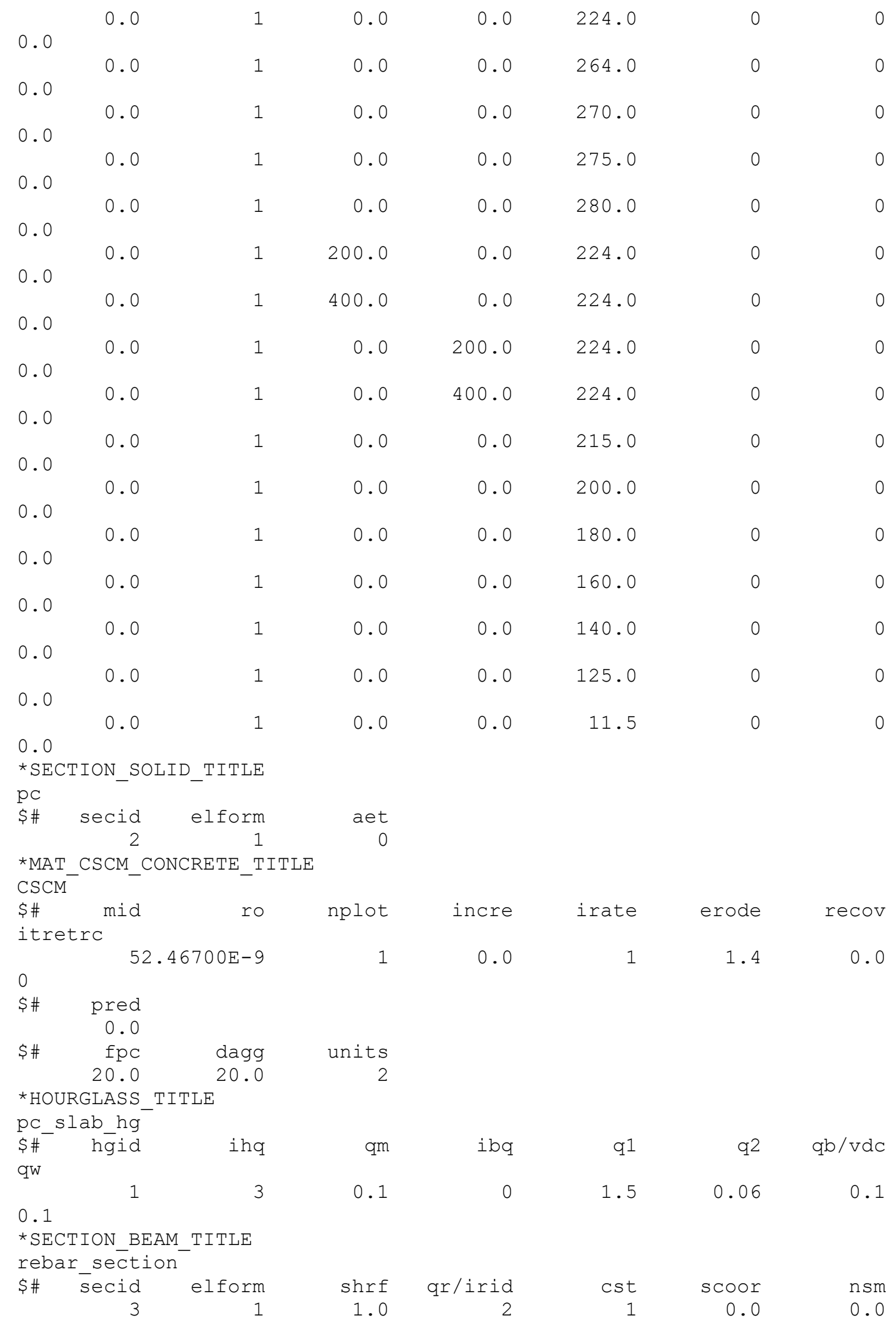




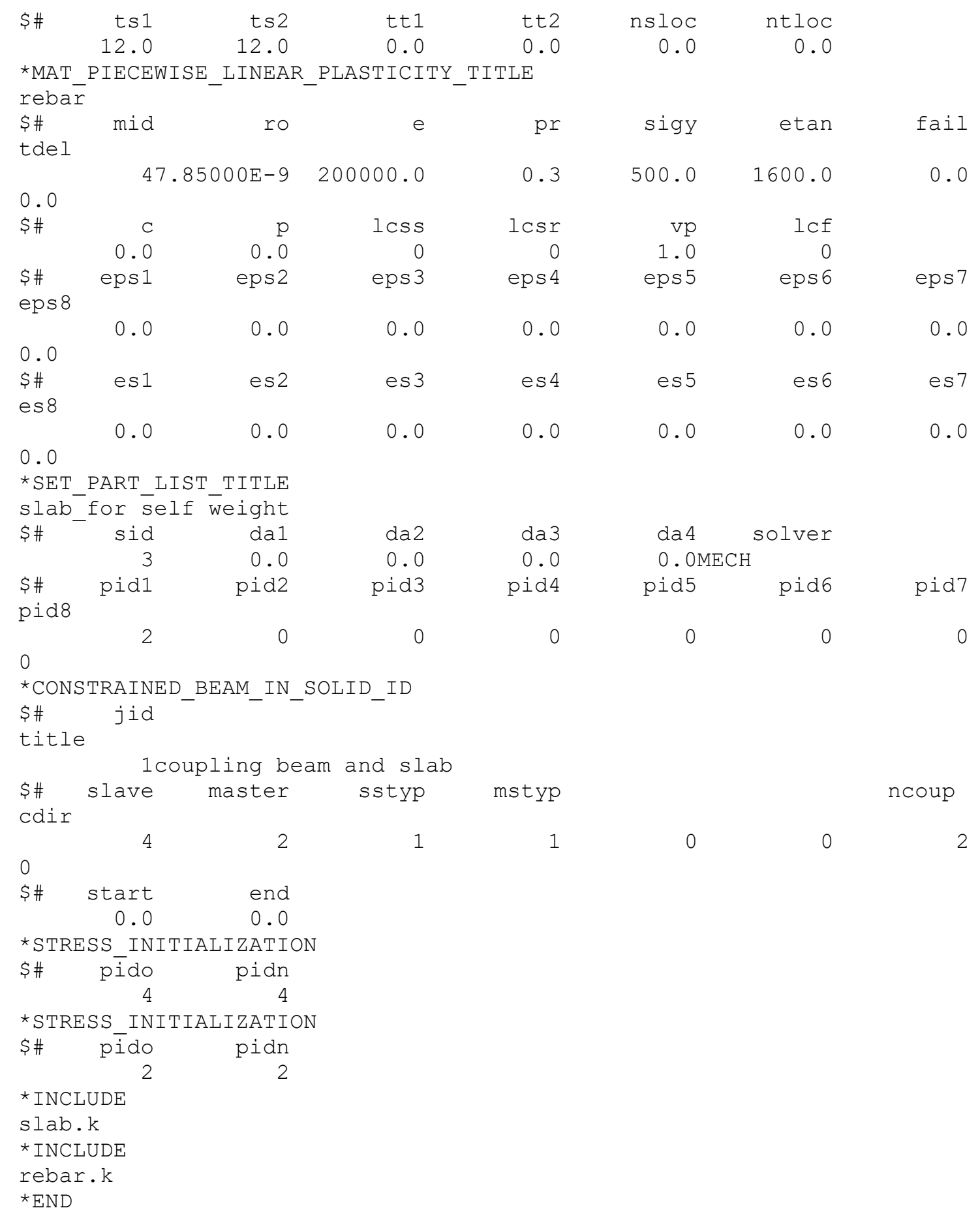




\title{
Appendix D: Keyword Files for RC Bare
}

\section{Columns/Cladded Columns/Walls}

\author{
First Simulation
}

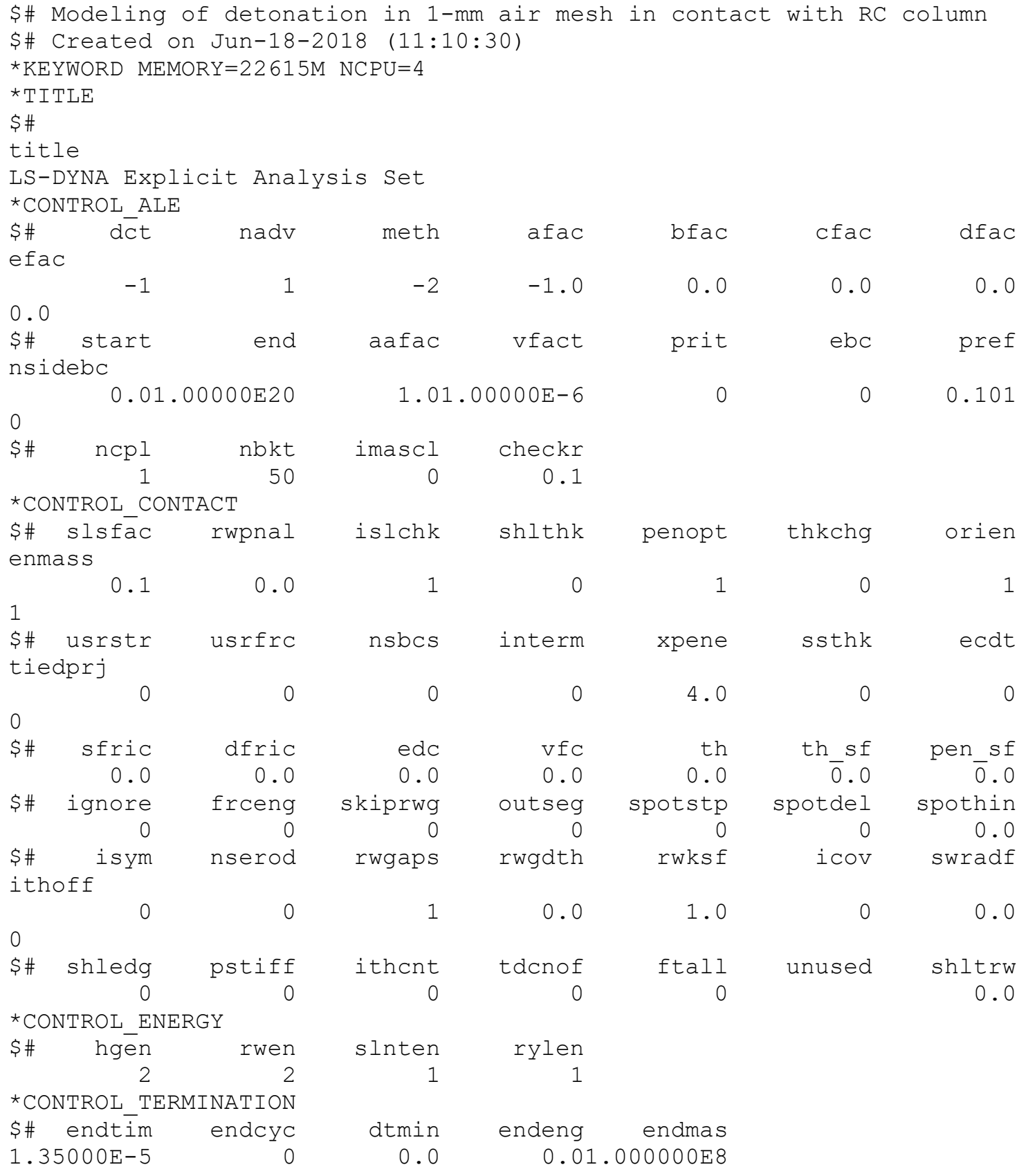




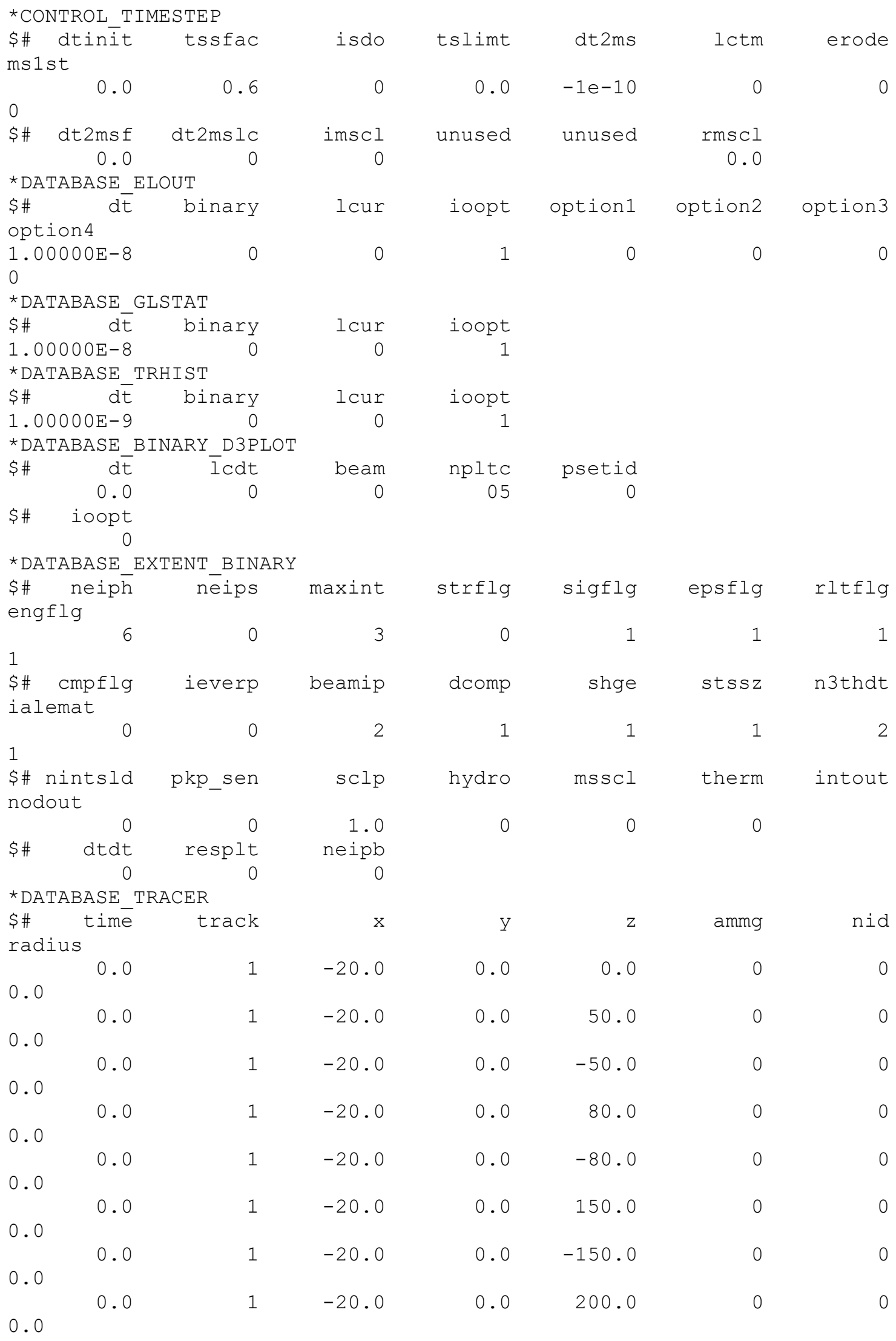




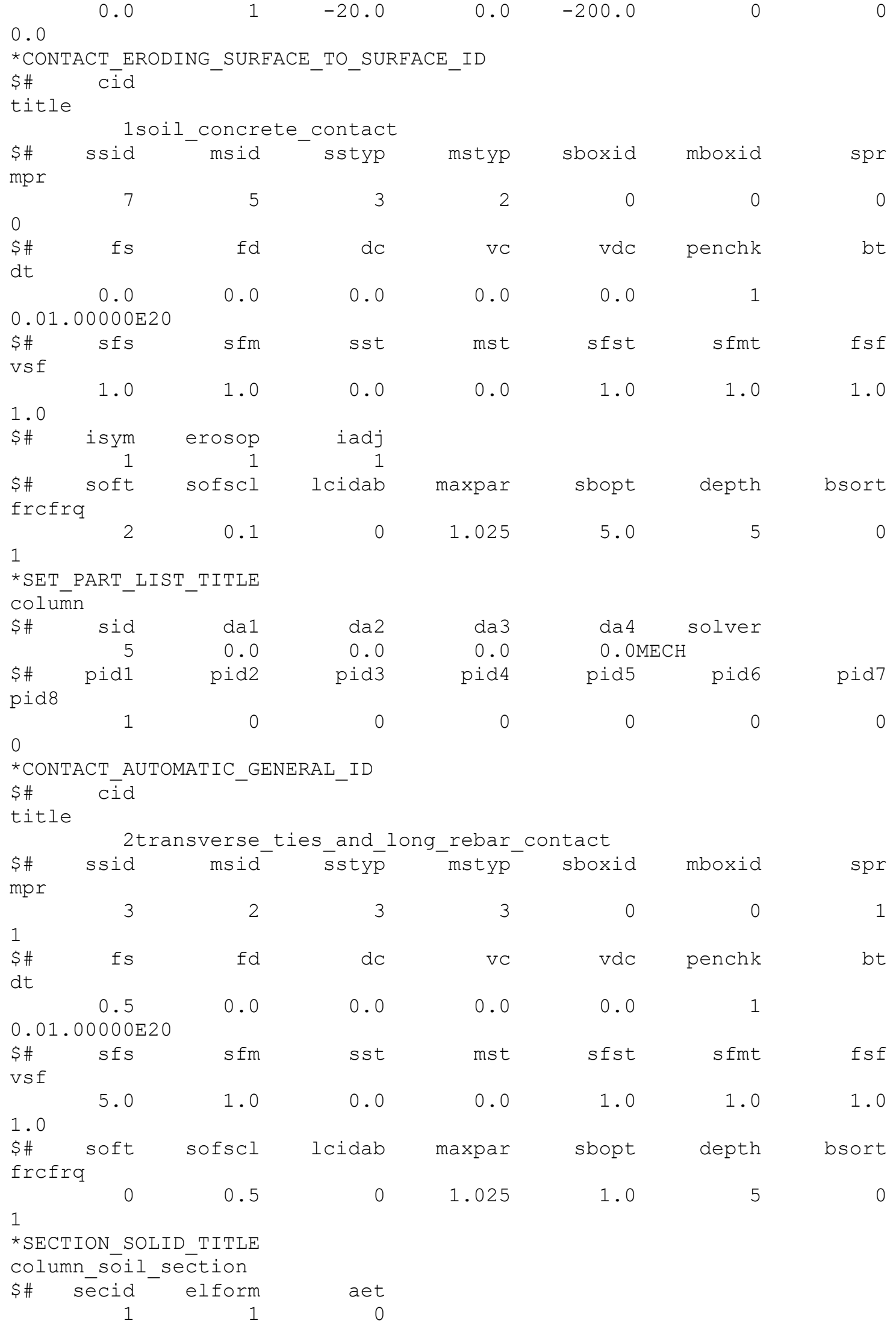




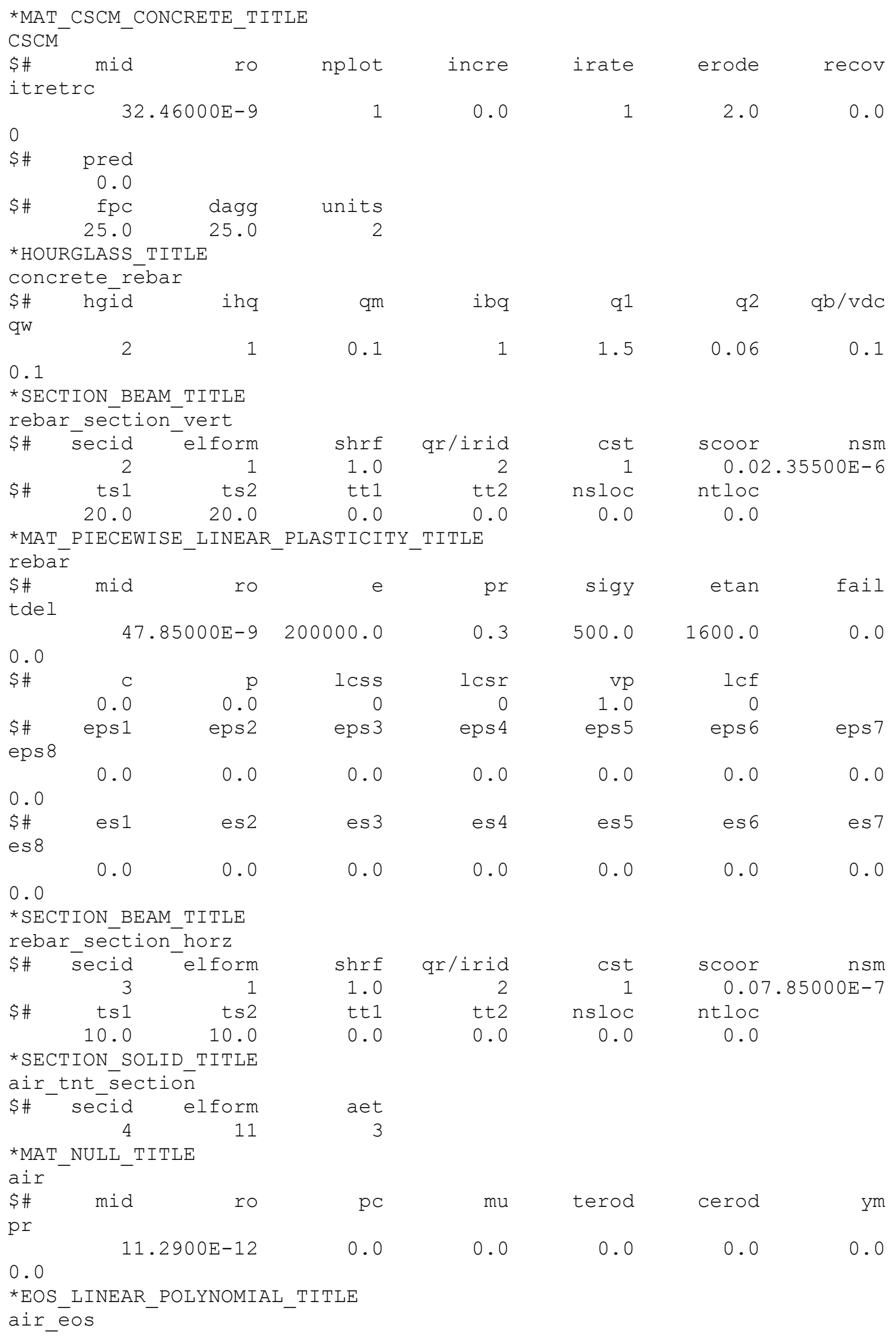




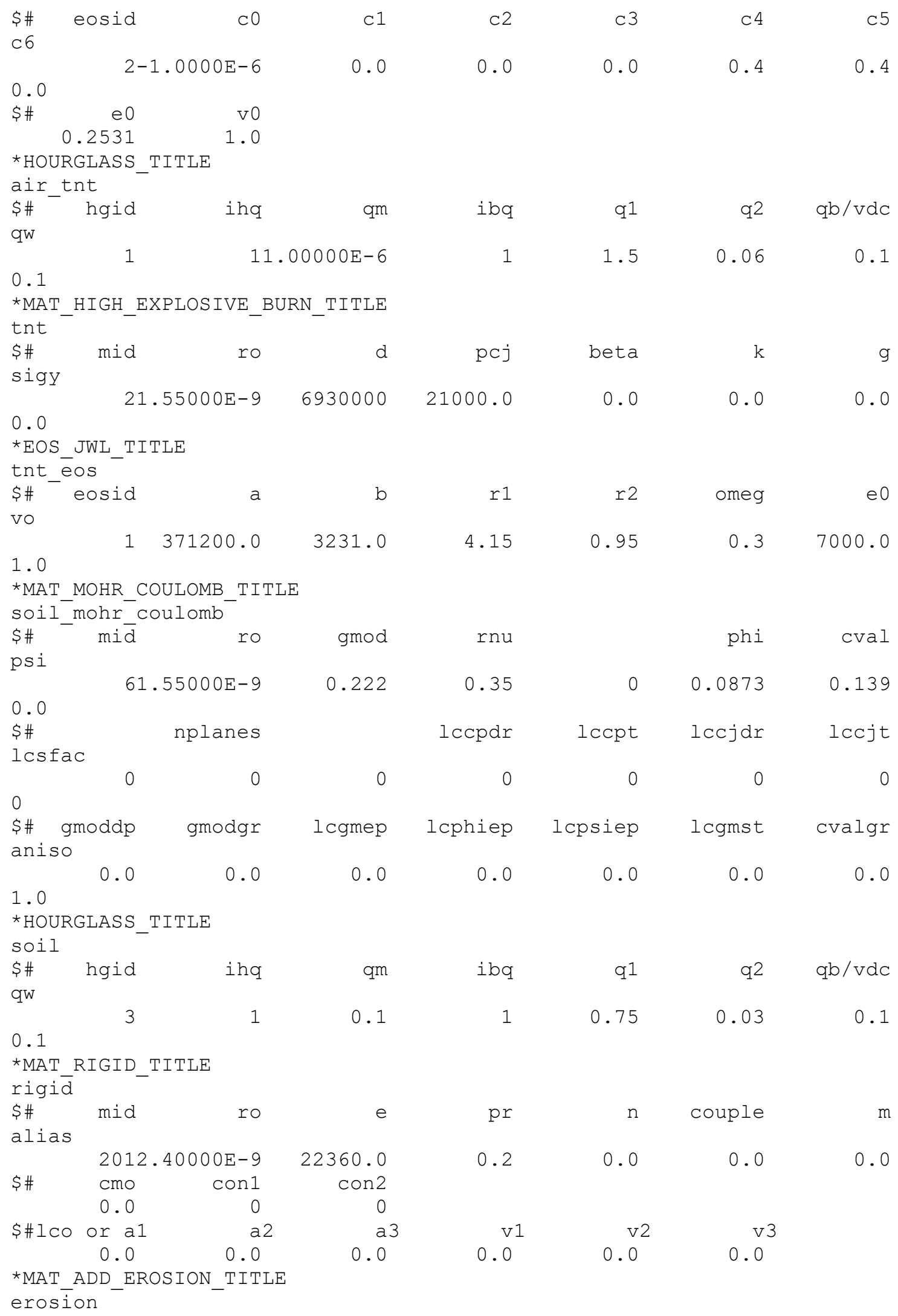

0.0

lcgmst

cvalgr

1.0

*HOURGLASS_TITLE

soil

\$\# hgid

qW

$\begin{array}{lll}3 & 1 & 0.1\end{array}$

ibq

q1

q2

$q \mathrm{qb} / \mathrm{vdc}$

0.1

0.1

0.75

0.03

0.1

*MAT RIGID TITLE

rigi d

\$\# mid ro

e

pr

n

couple

m alias

$2012.40000 \mathrm{E}-9 \quad 22360.0$

$\$ \#$

cmo con1 con2

0.2

0.0

0.0

0.0

\$ I co or al

a 2

0
0.0
0.0
0.0

$\mathrm{V} 1$

v2

v3

*MAT_ADD_EROSION_TITLE erosion

0.0

0.0 


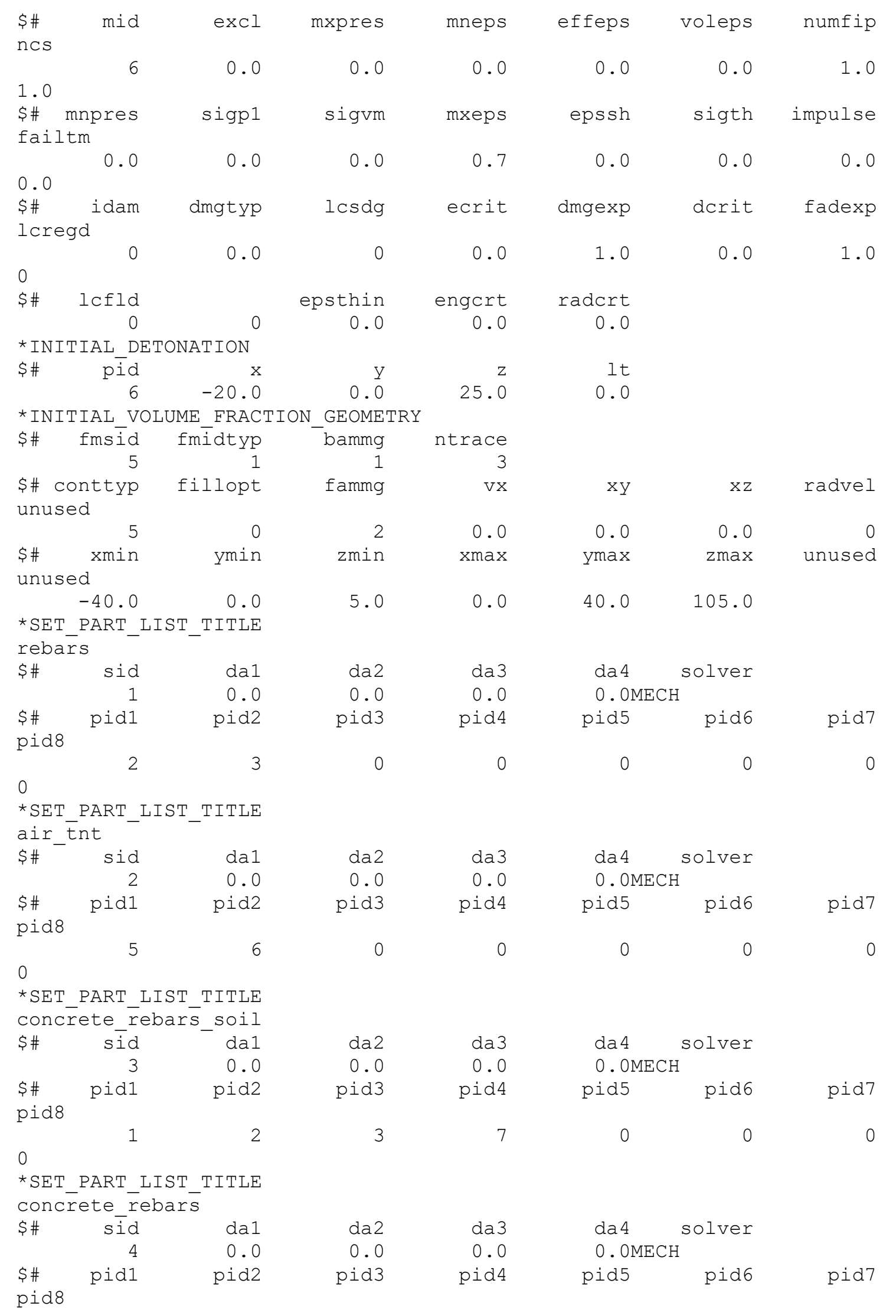




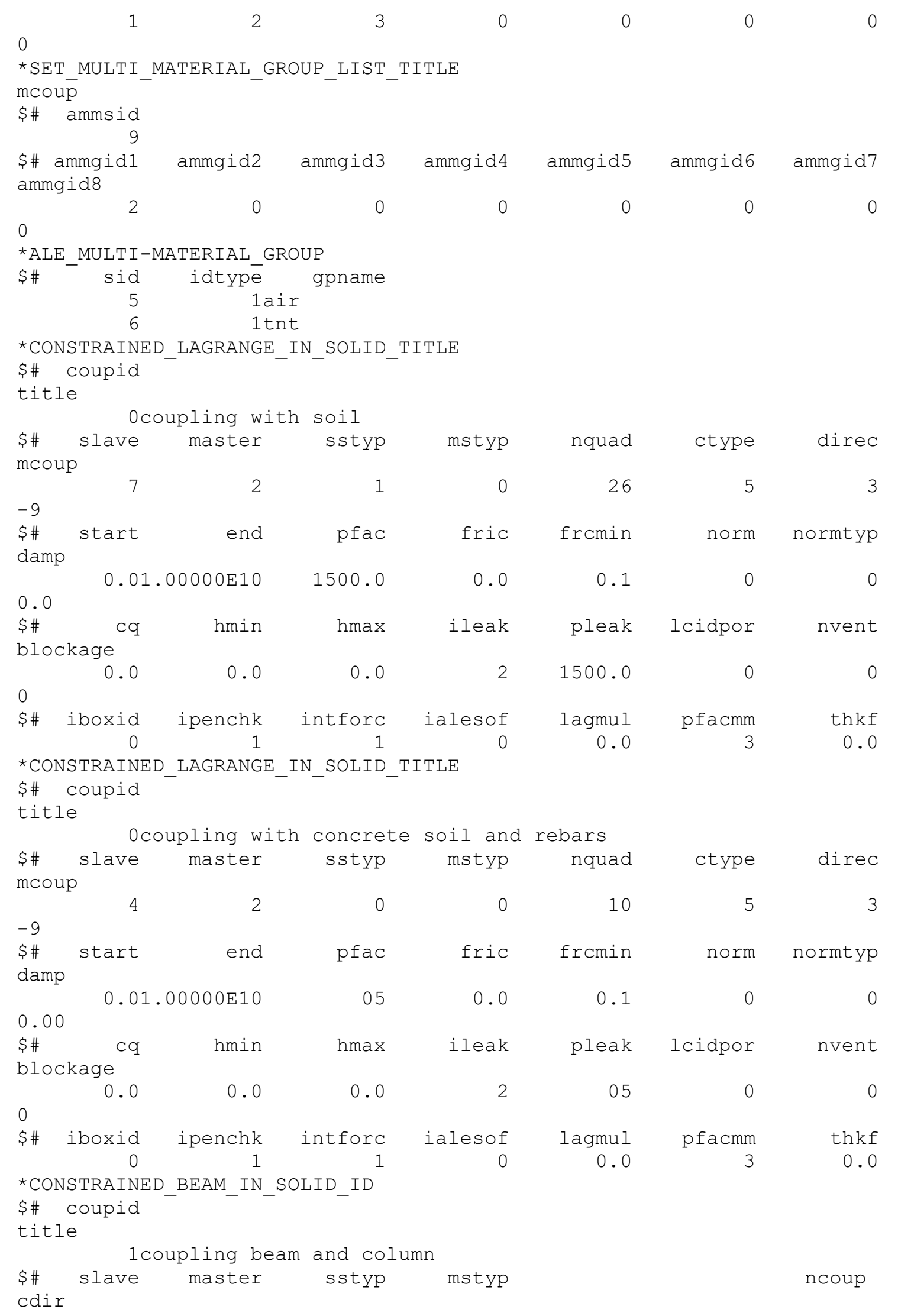




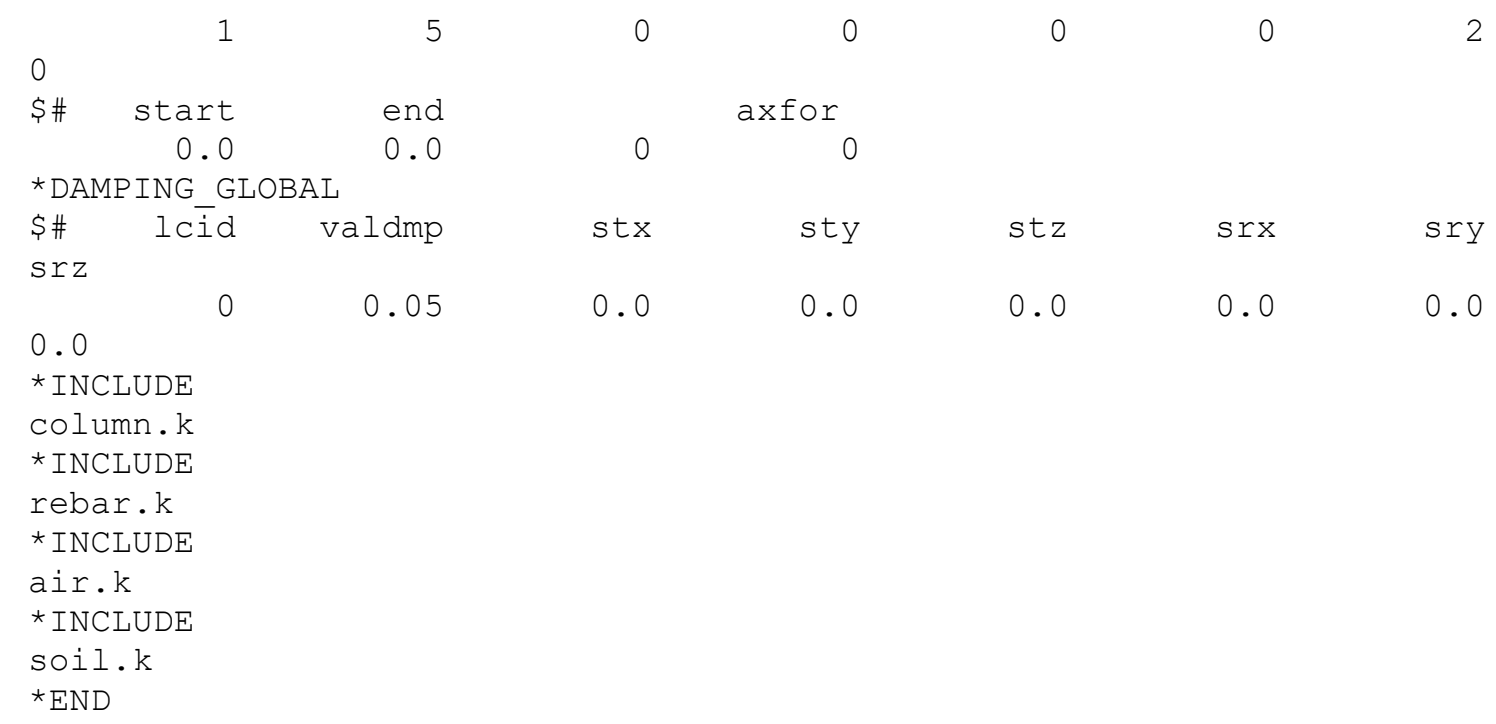

\section{Second Simulation}

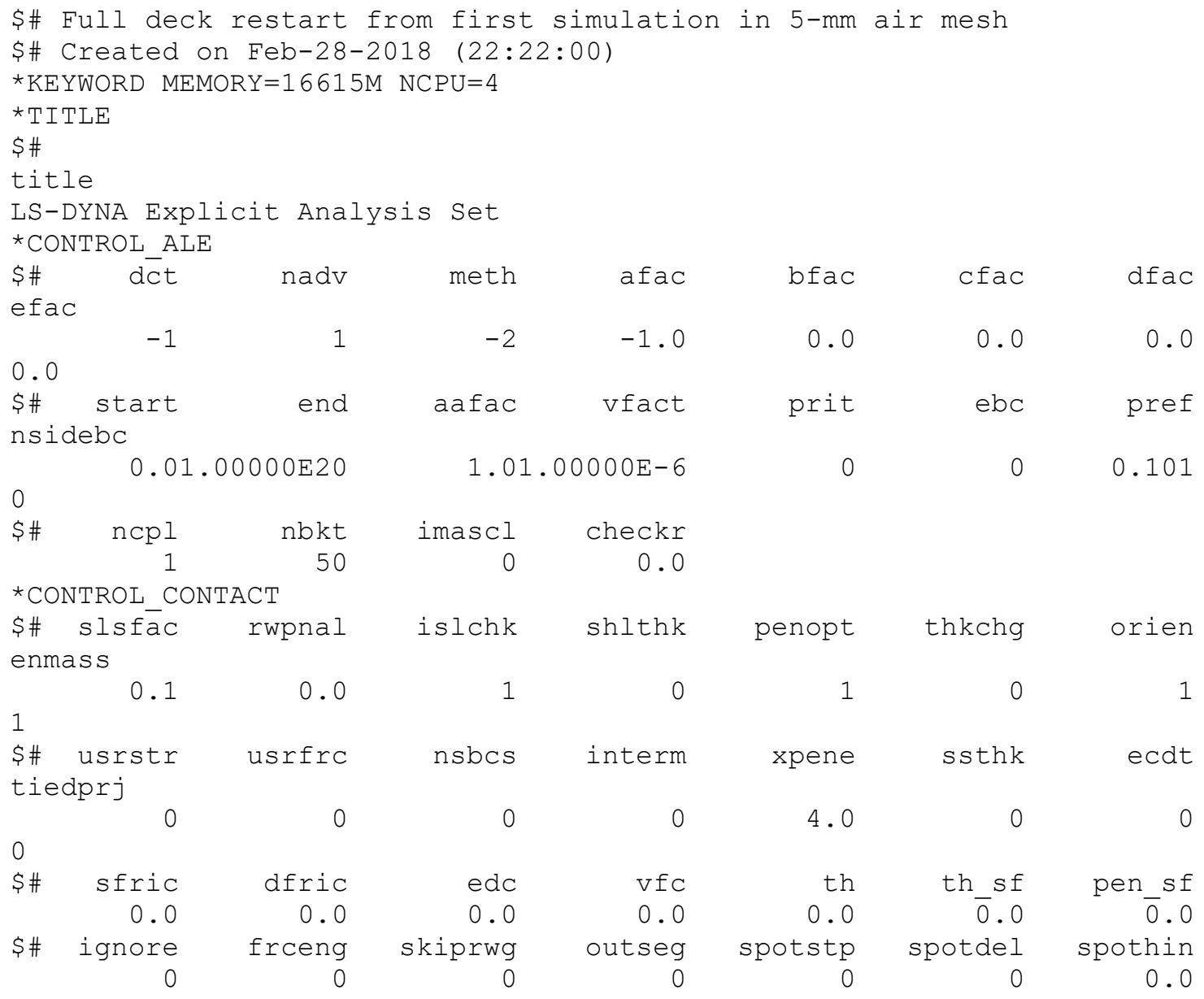




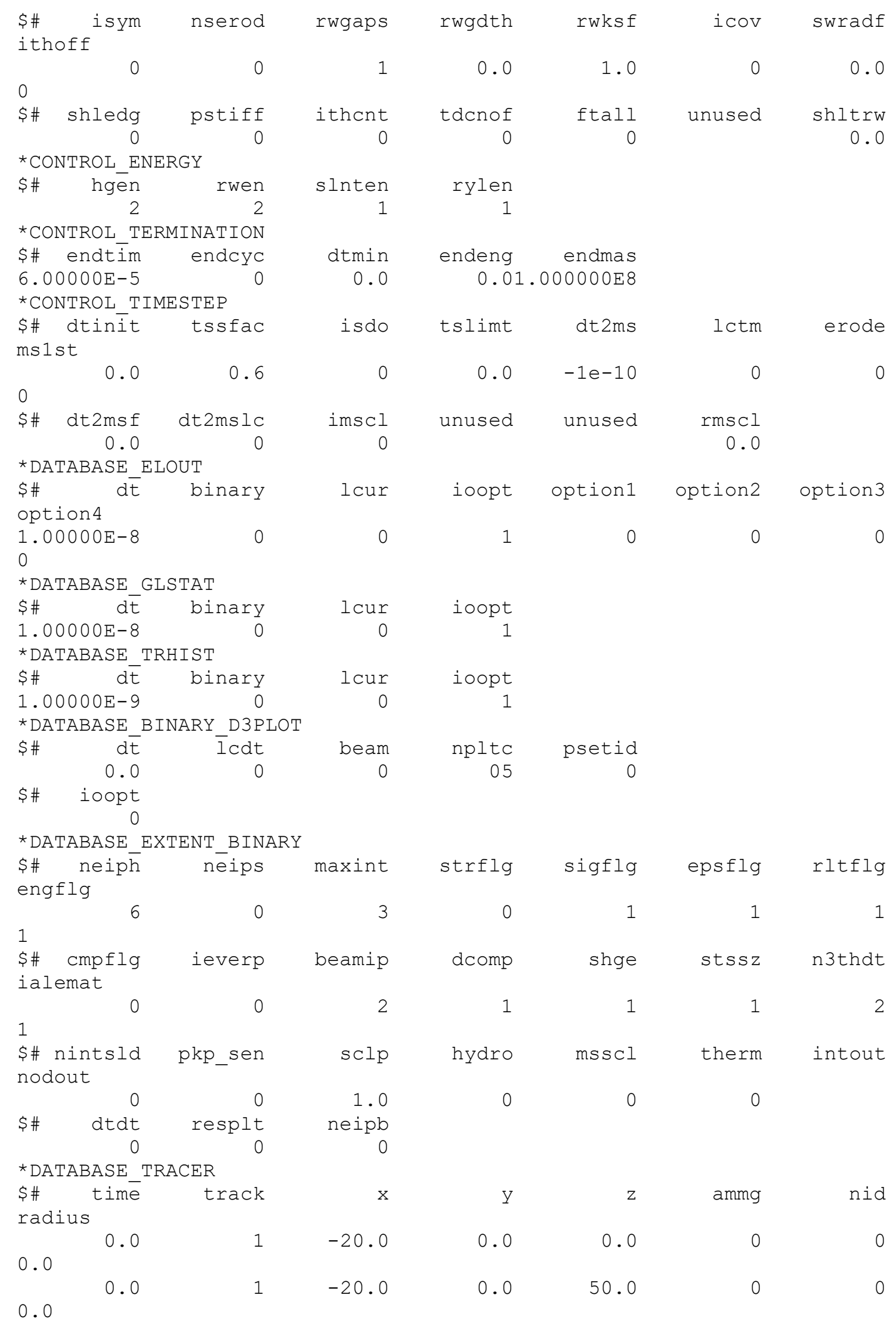




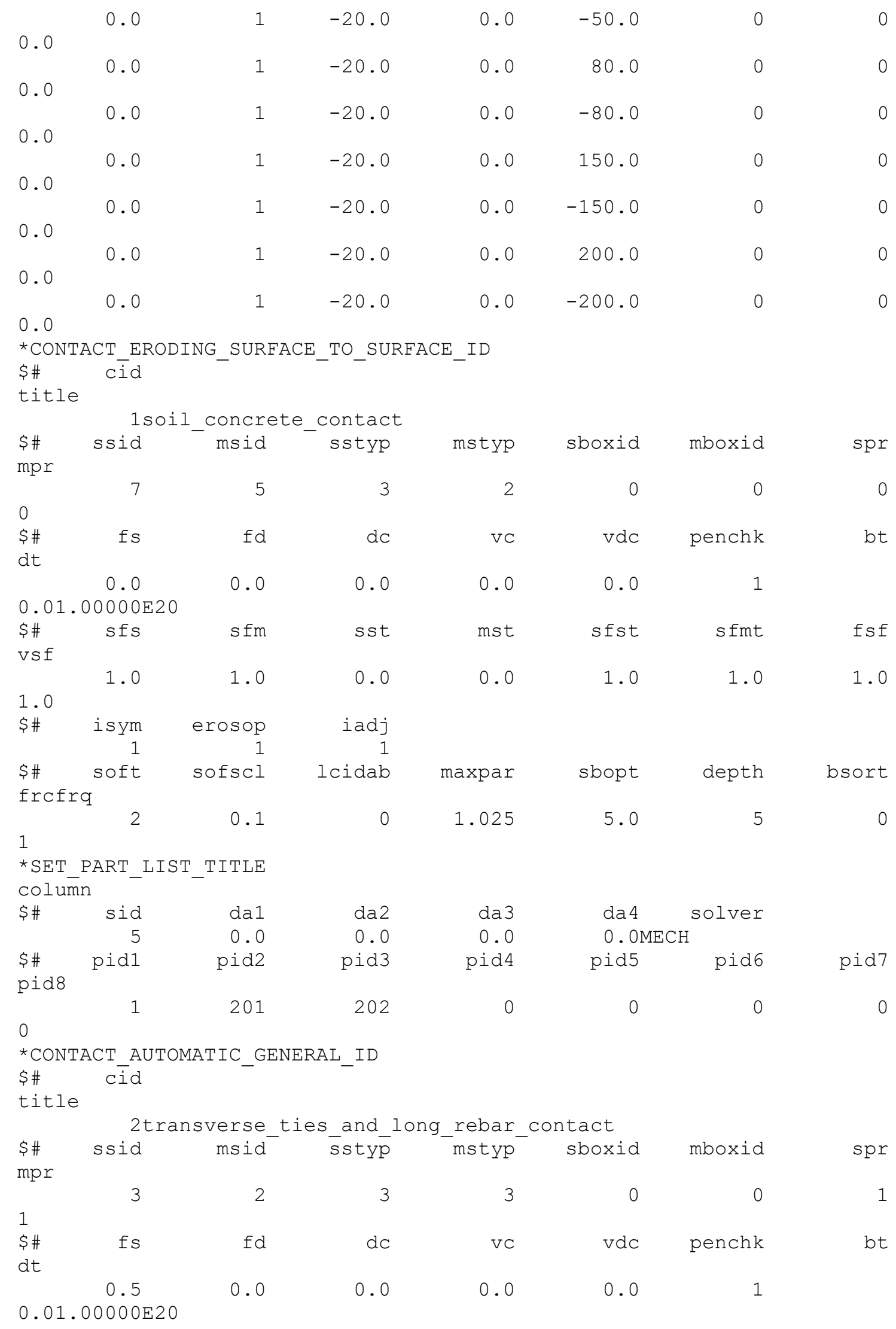




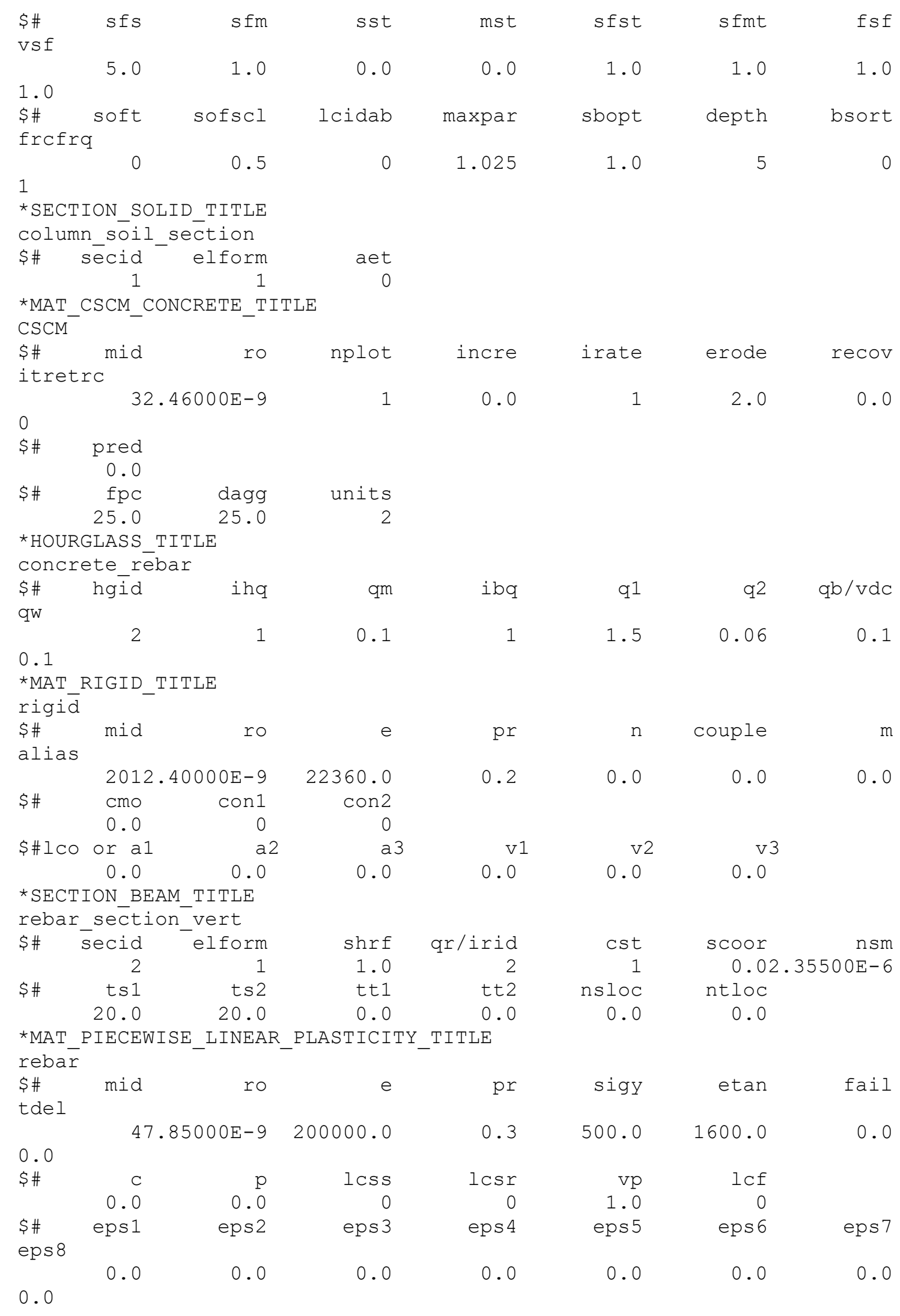




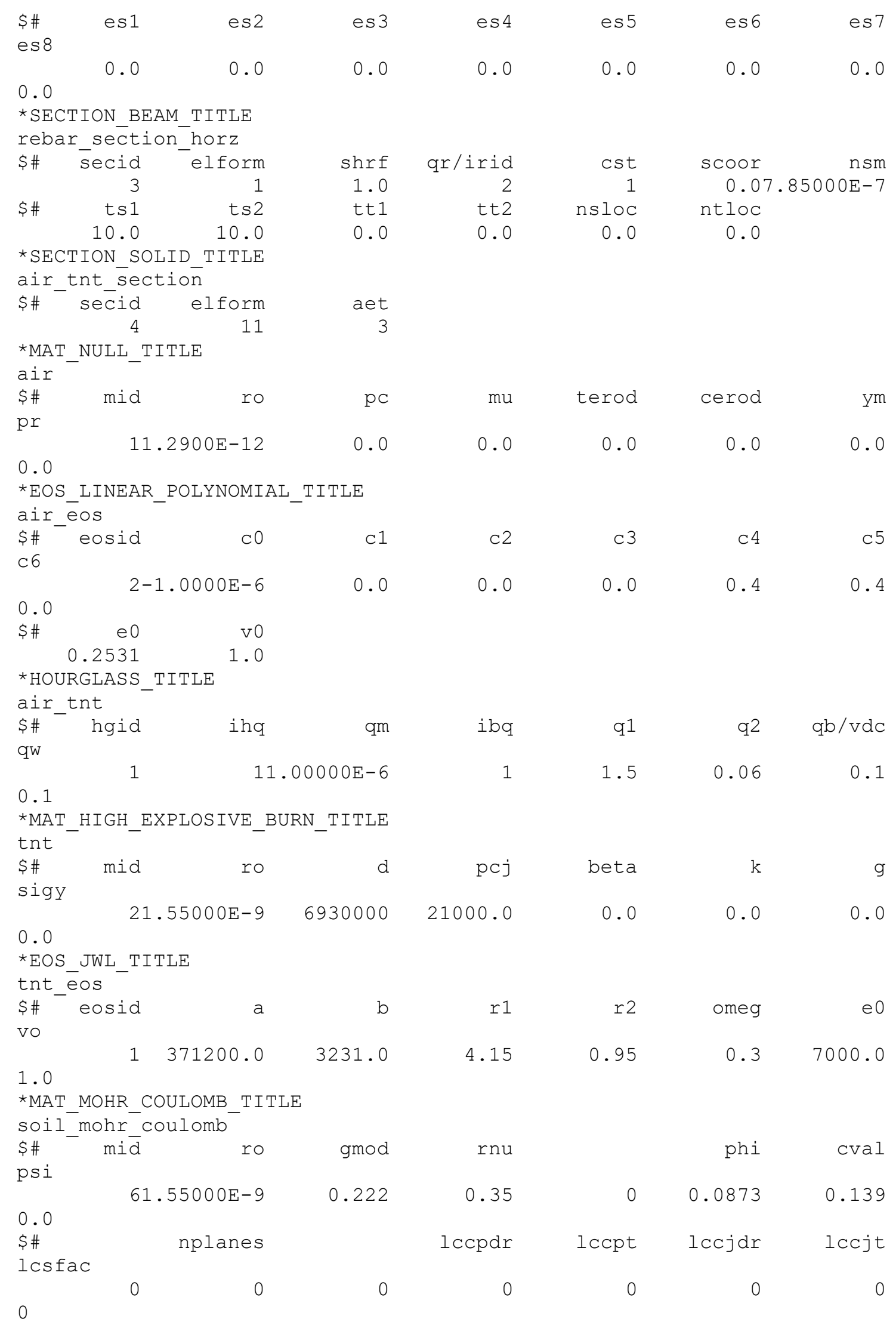




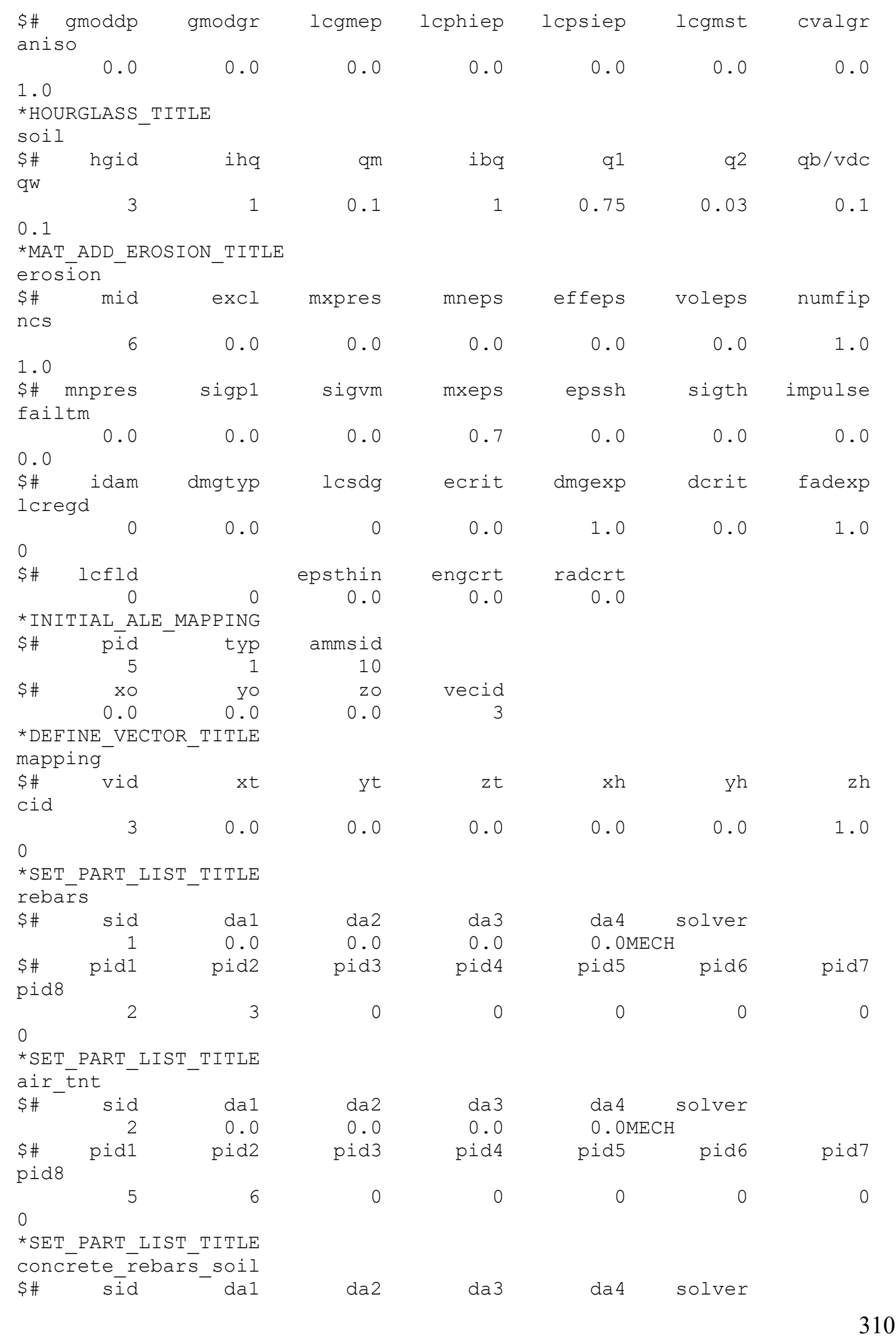




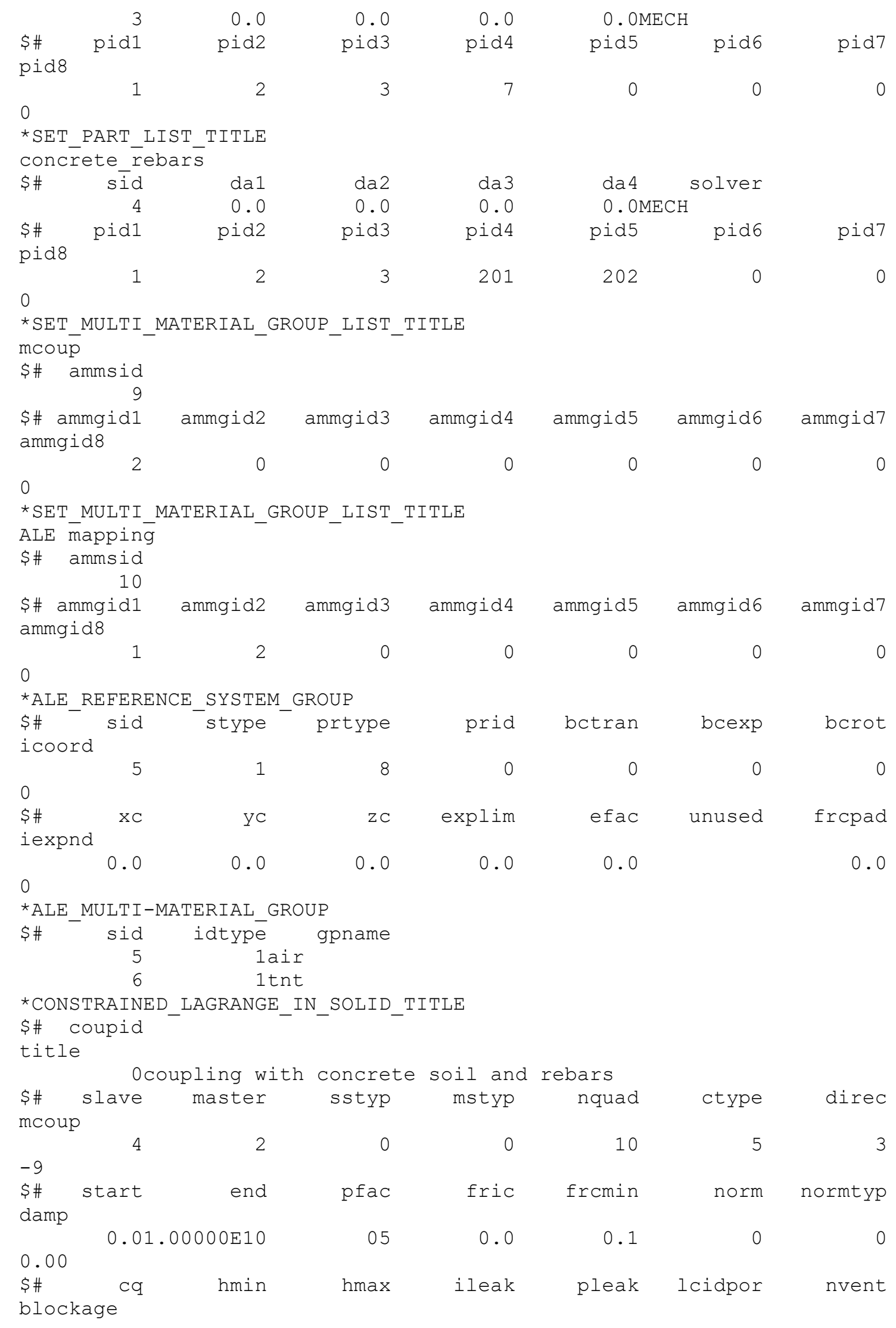



0.0
0.0
0.0
05
0

0

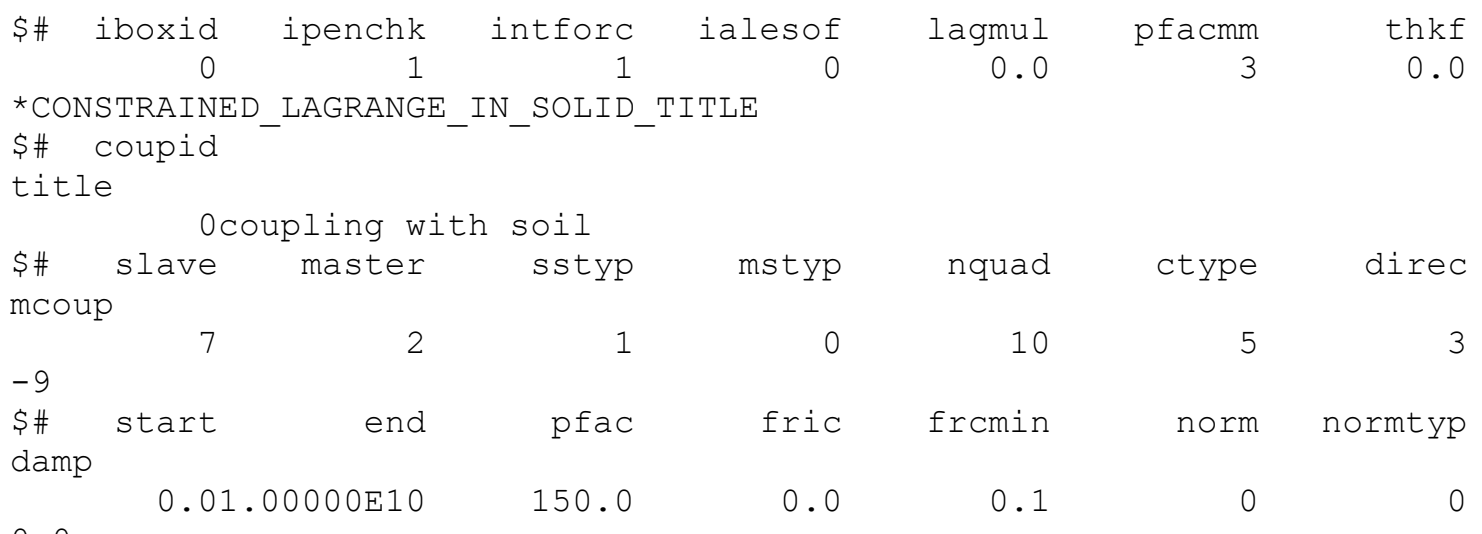

0.0

$0.01 .00000 \mathrm{E} 10 \quad 150.0$

1.

\$\# cq hmin hmax

max ileak pleak lcidpor nvent

0 .

$0.0 \quad 0.0 \quad 0.0$

$2 \quad 150.0$

0

0

0

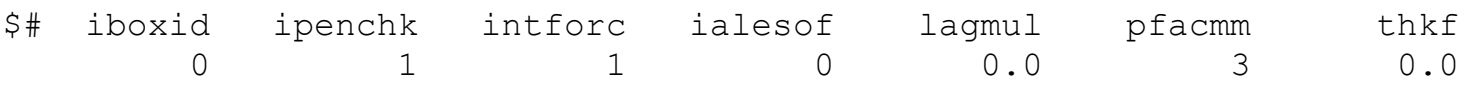

*CONSTRAINED_BEAM_IN_SOLID_ID

\$\# jid

title

1 coun

1coupling beam and column

$\begin{array}{lrr}\text { \$\# } & \text { slave } & \text { master } \\ \text { cdir } & & \\ & 1 & \\ 0 & & \text { end } \\ \text { \$\# } & \text { start } & 0.0\end{array}$

*DAMPING_GLOBAL

\$\# lcīd valdmp

srz

$0 \quad 0.05$

0.0 sstyp mstyp

*STRESS_INITIALIZATION

\$\# pído pidn

*STRESS_INITIALIZATION

\$\# pído pidn

*STRESS_INITIALIZATION

\$\# pído pidn

*STRESS_INITIALIZATION

\$\# pído pidn

* INCLUDE

column. $\mathrm{k}$

* INCLUDE

rebar. $\mathrm{k}$

* INCLUDE

air.k

* INCLUDE 
soil.k

$\star$ END

\section{$\underline{\text { Third Simulation }}$}

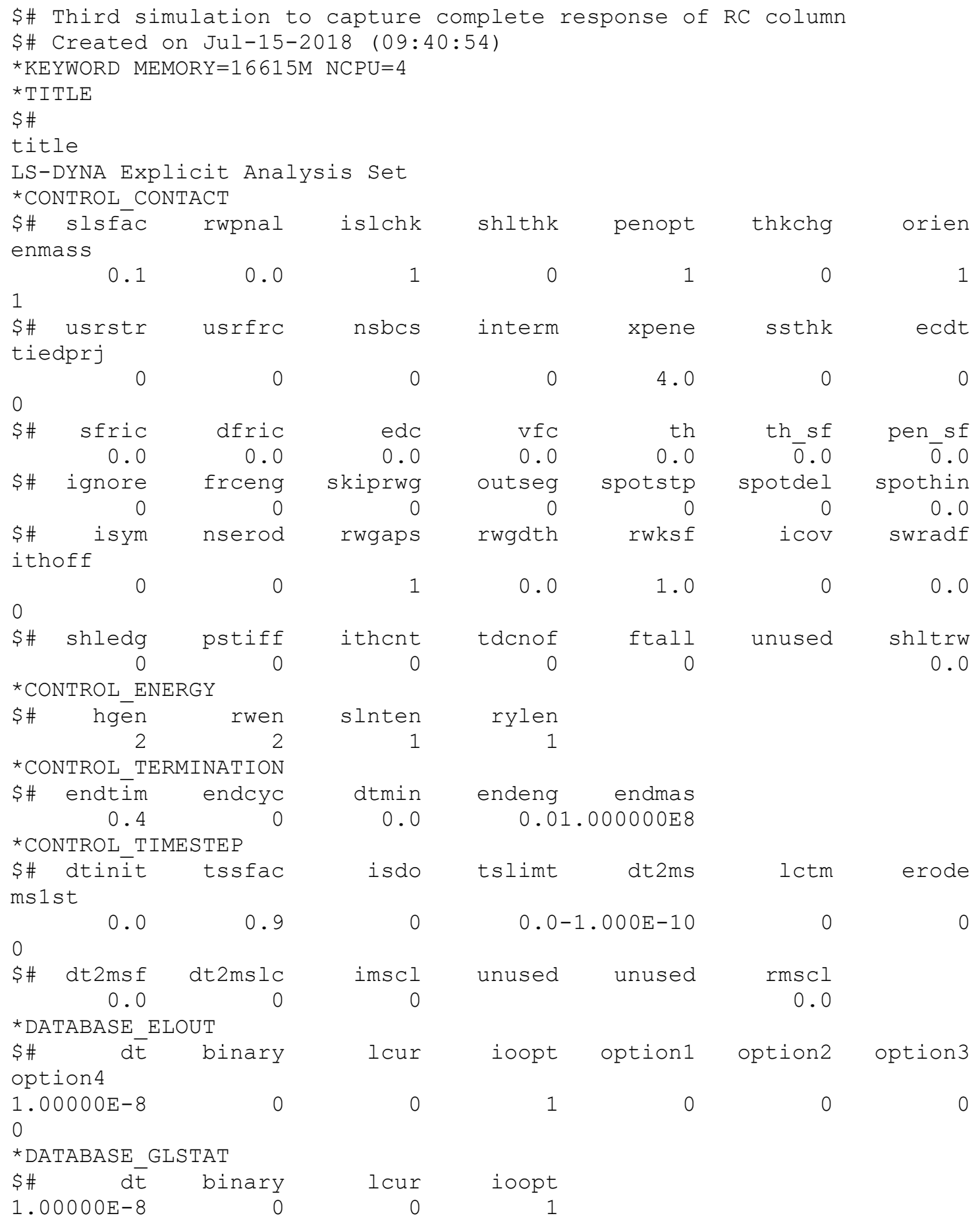




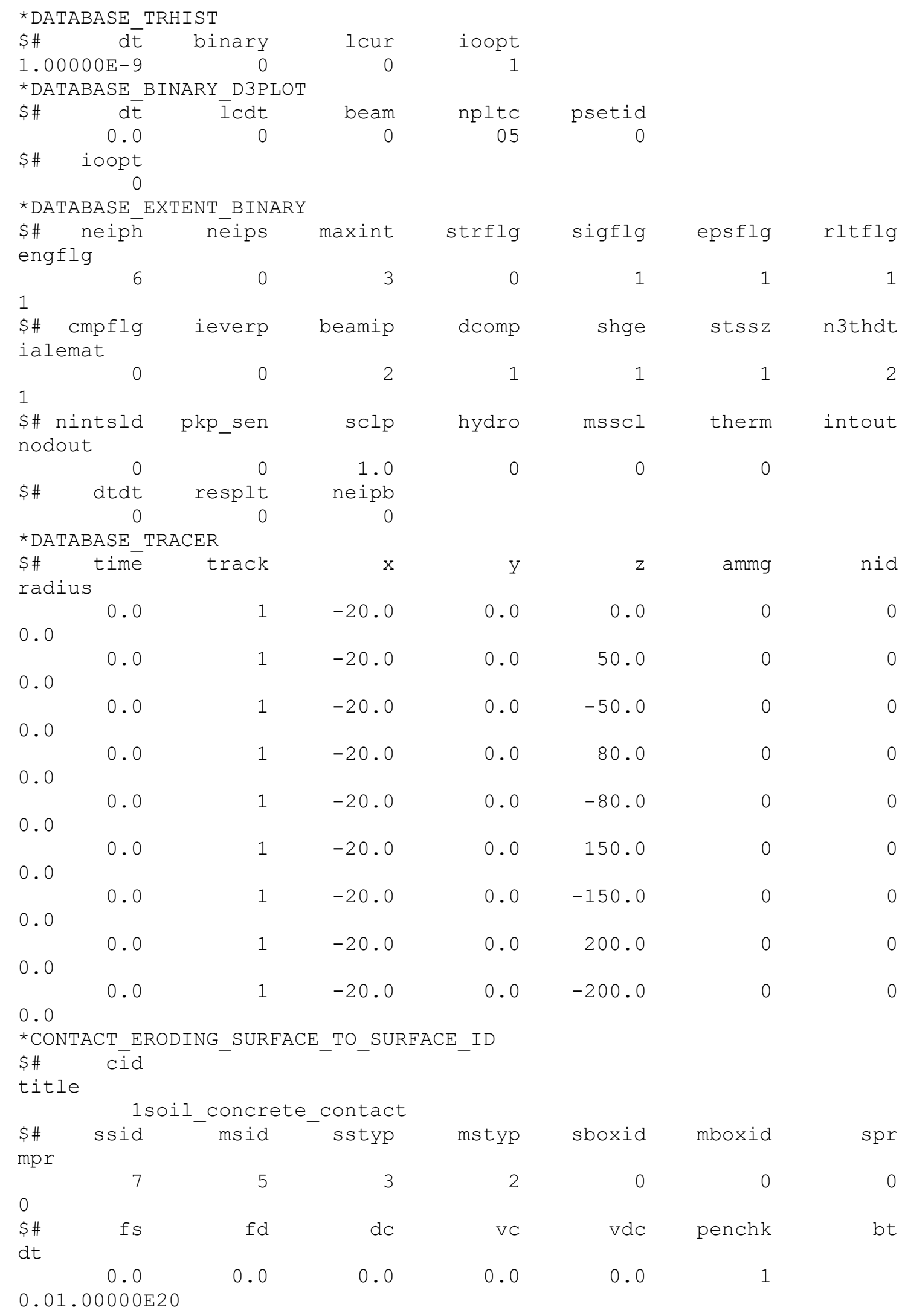




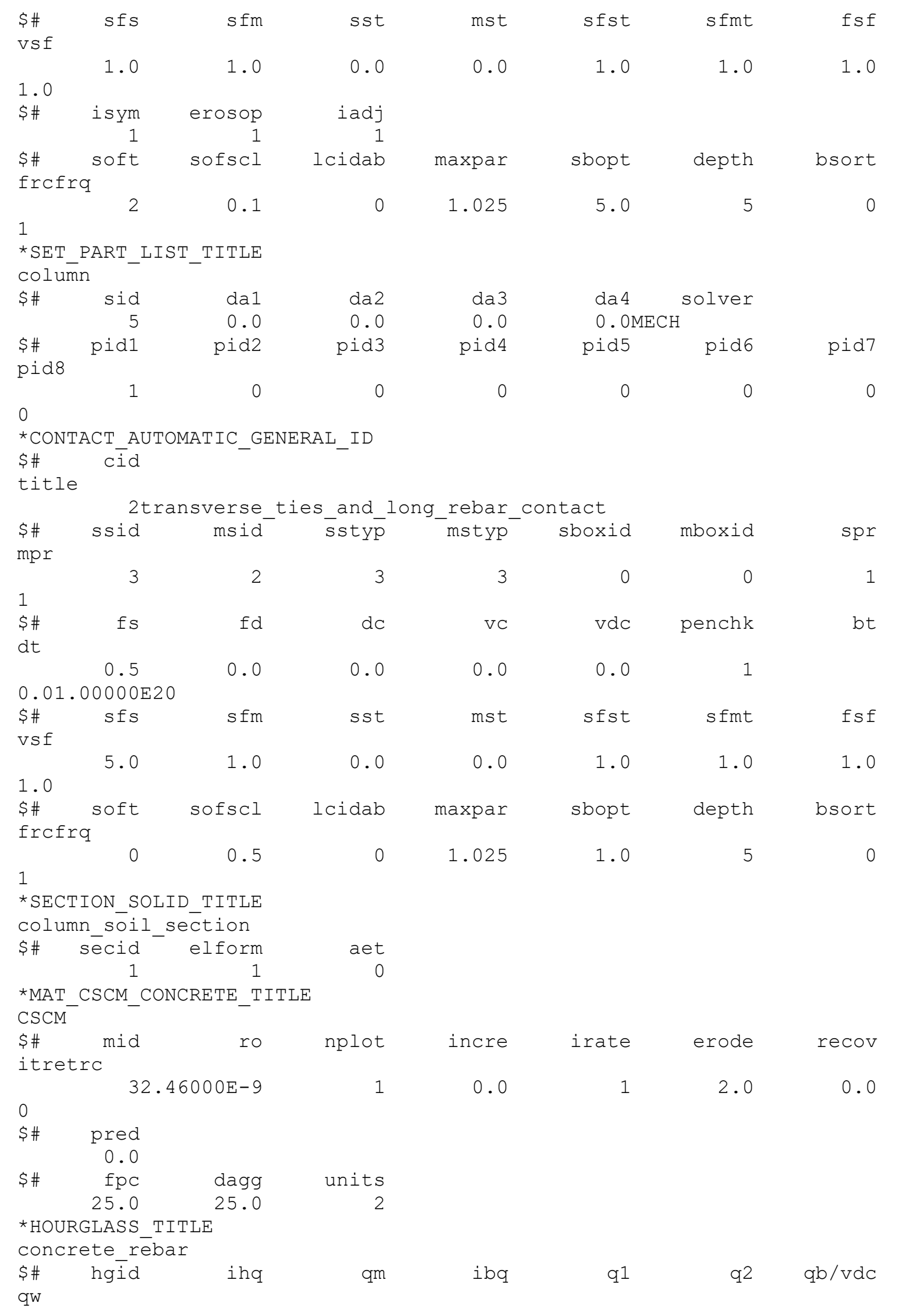




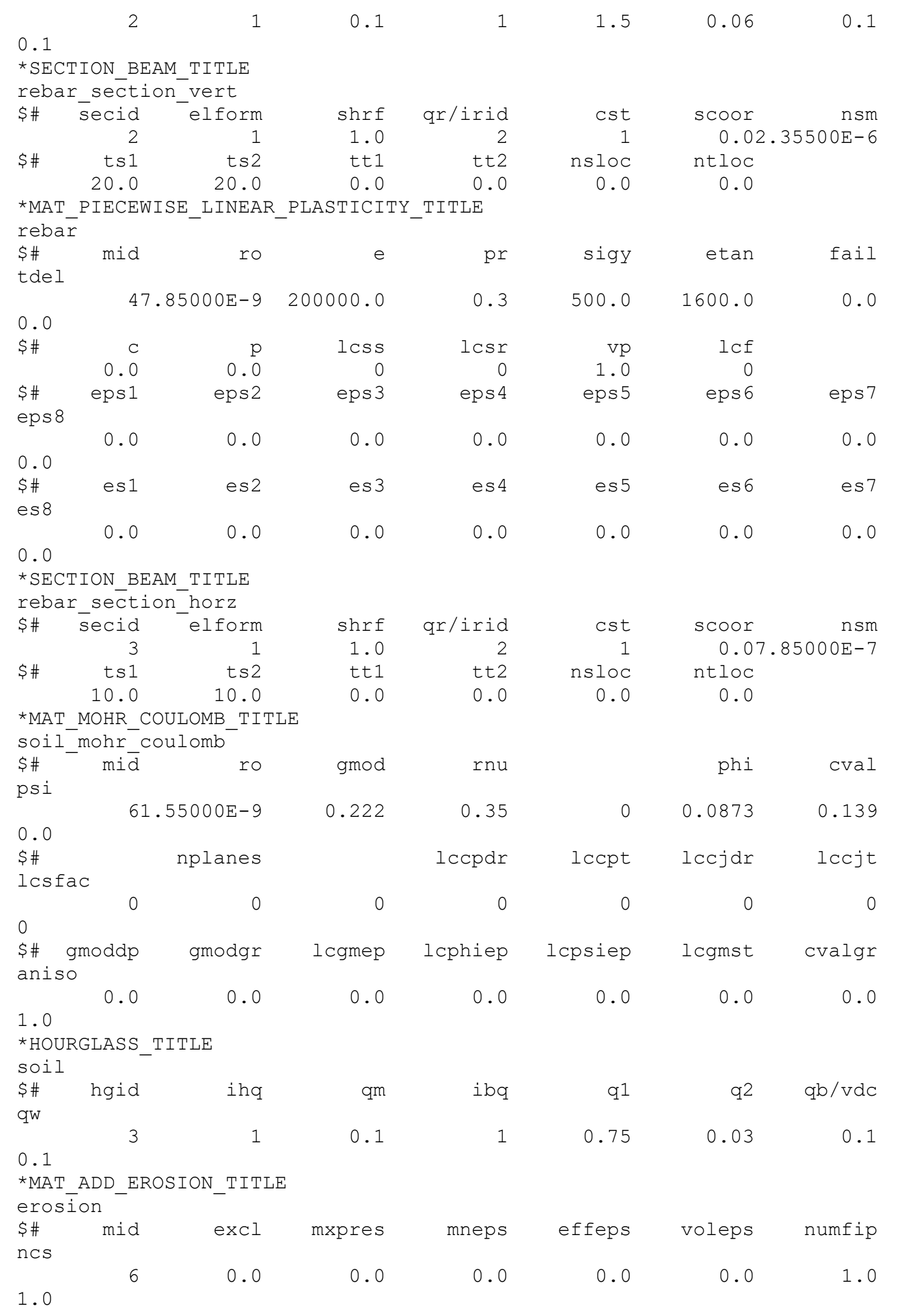




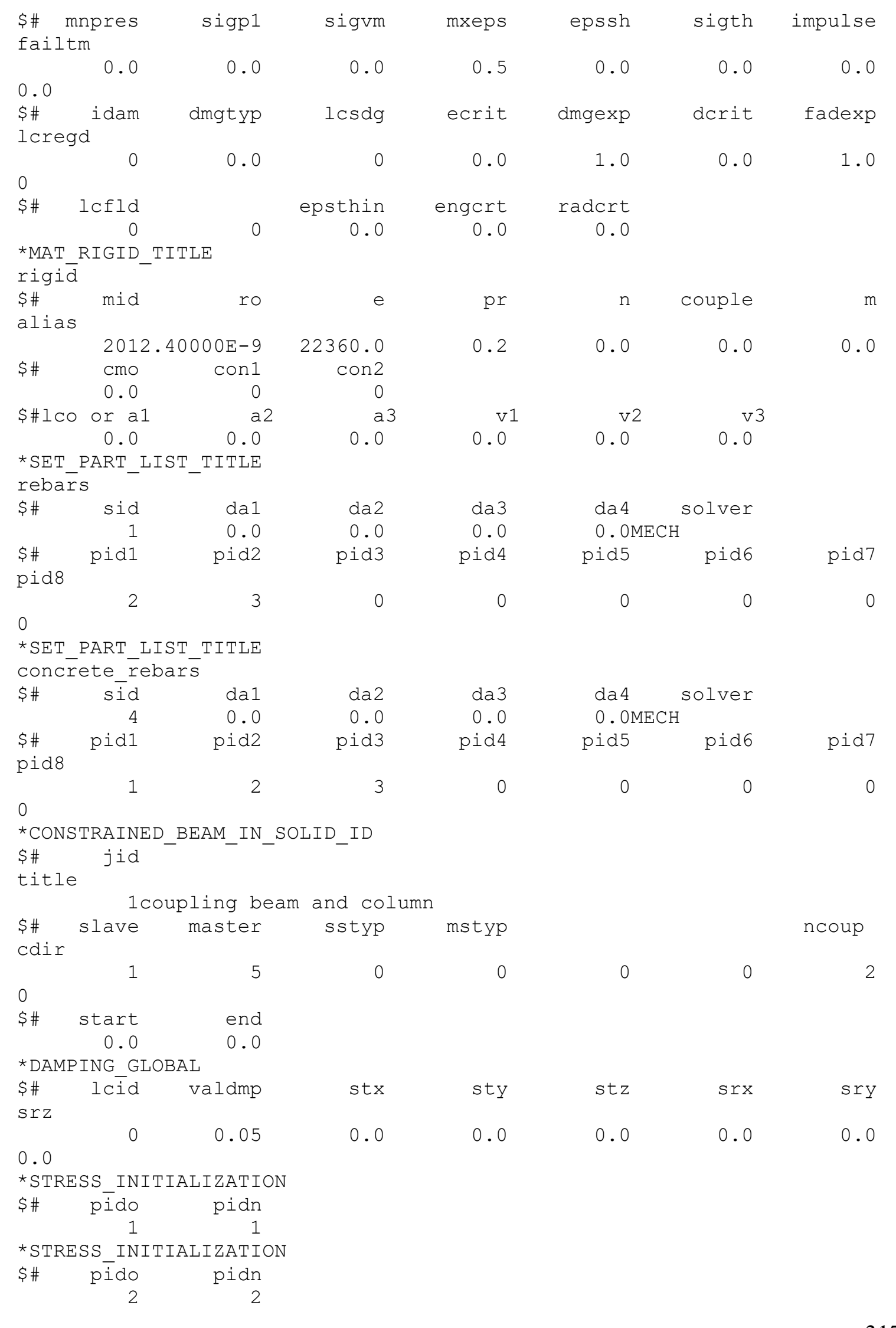




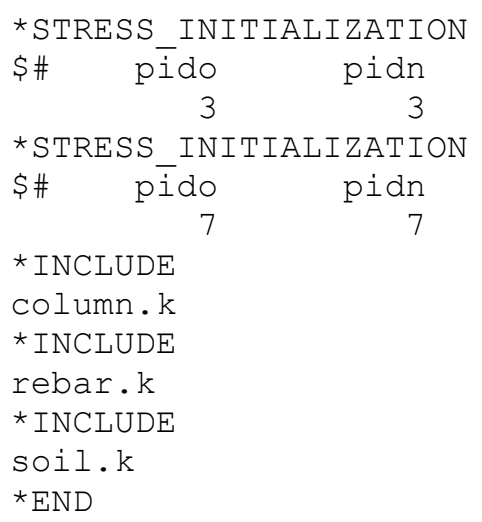

\section{Modeling of Residual Axial Capacity}

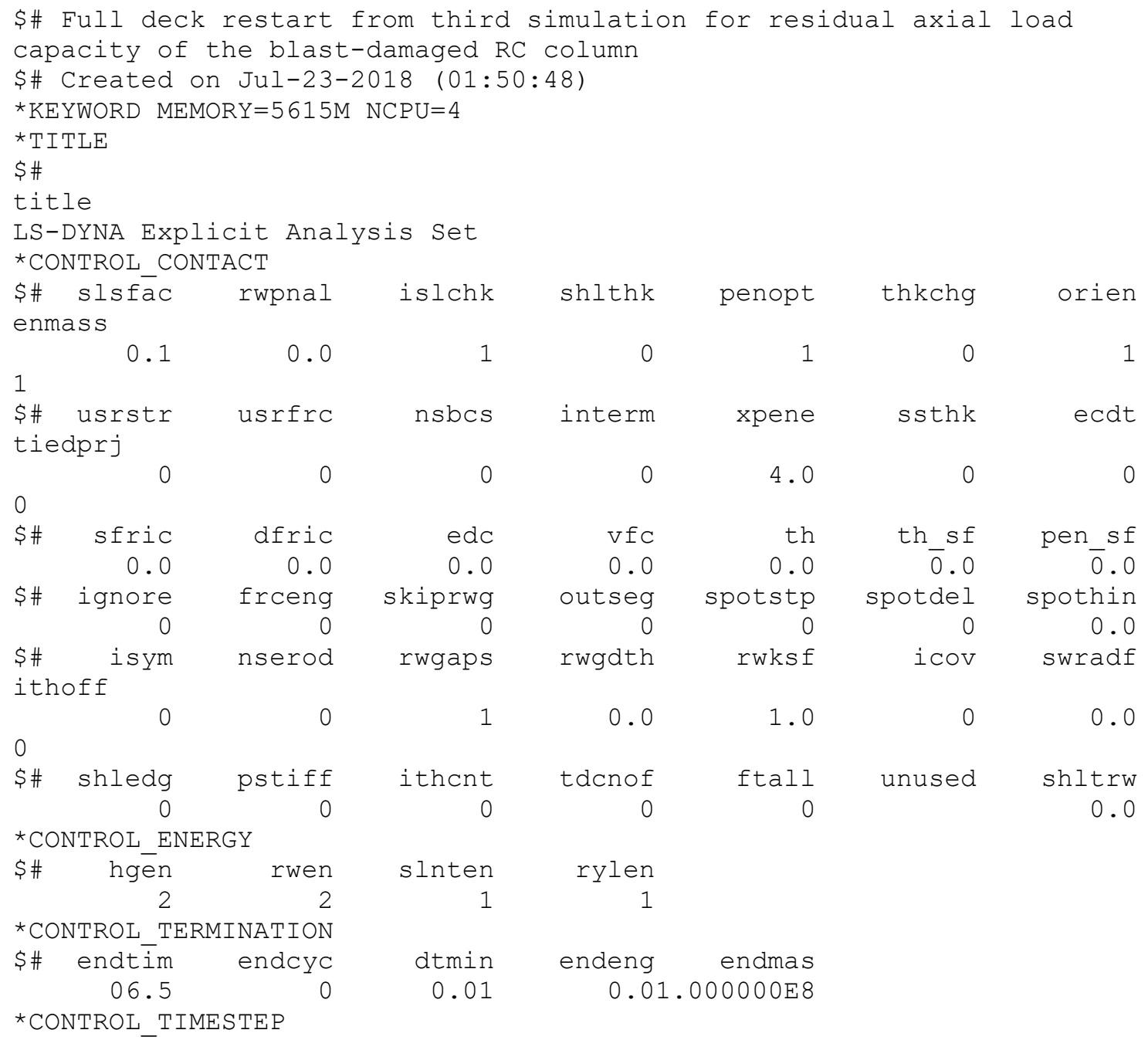




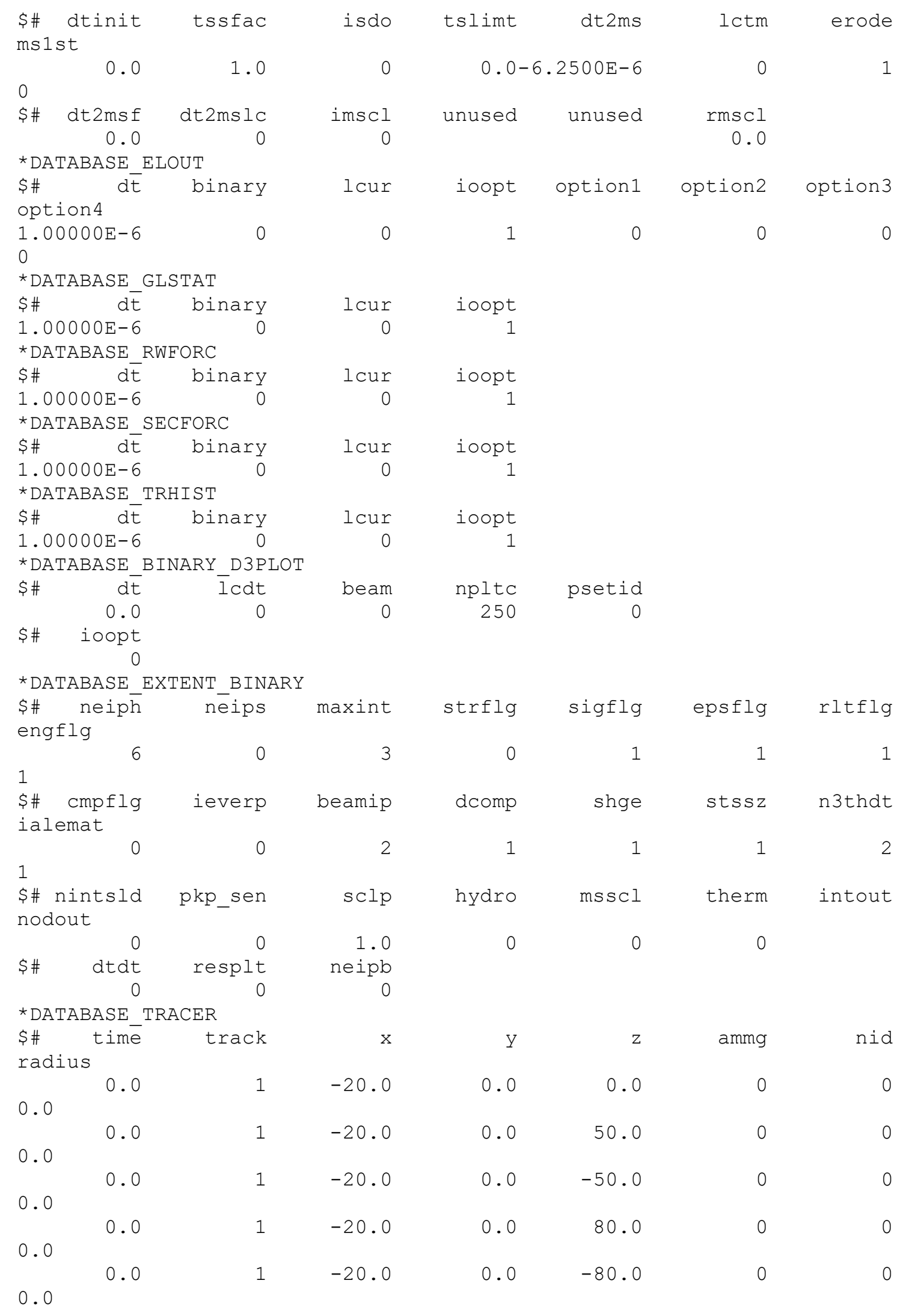




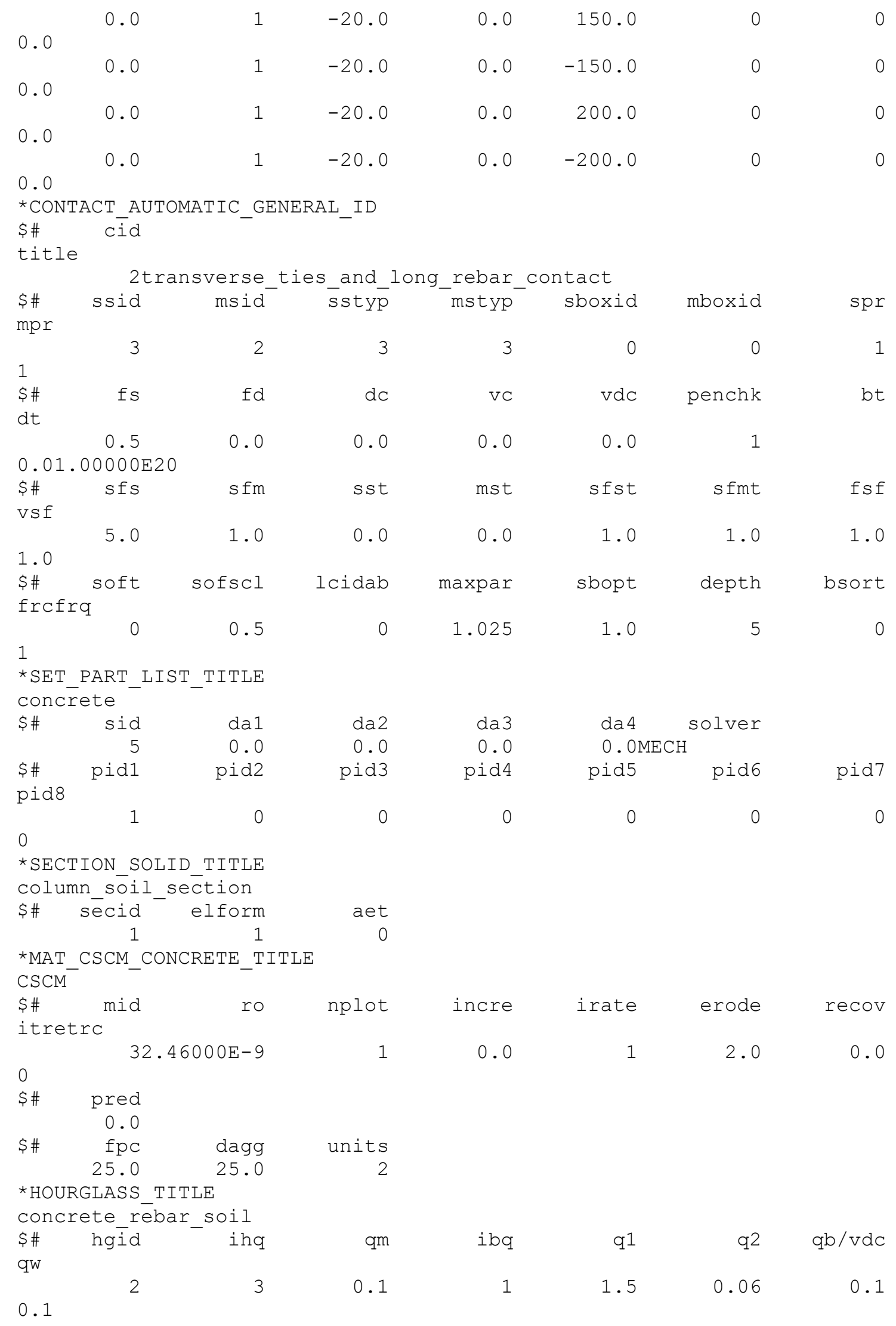




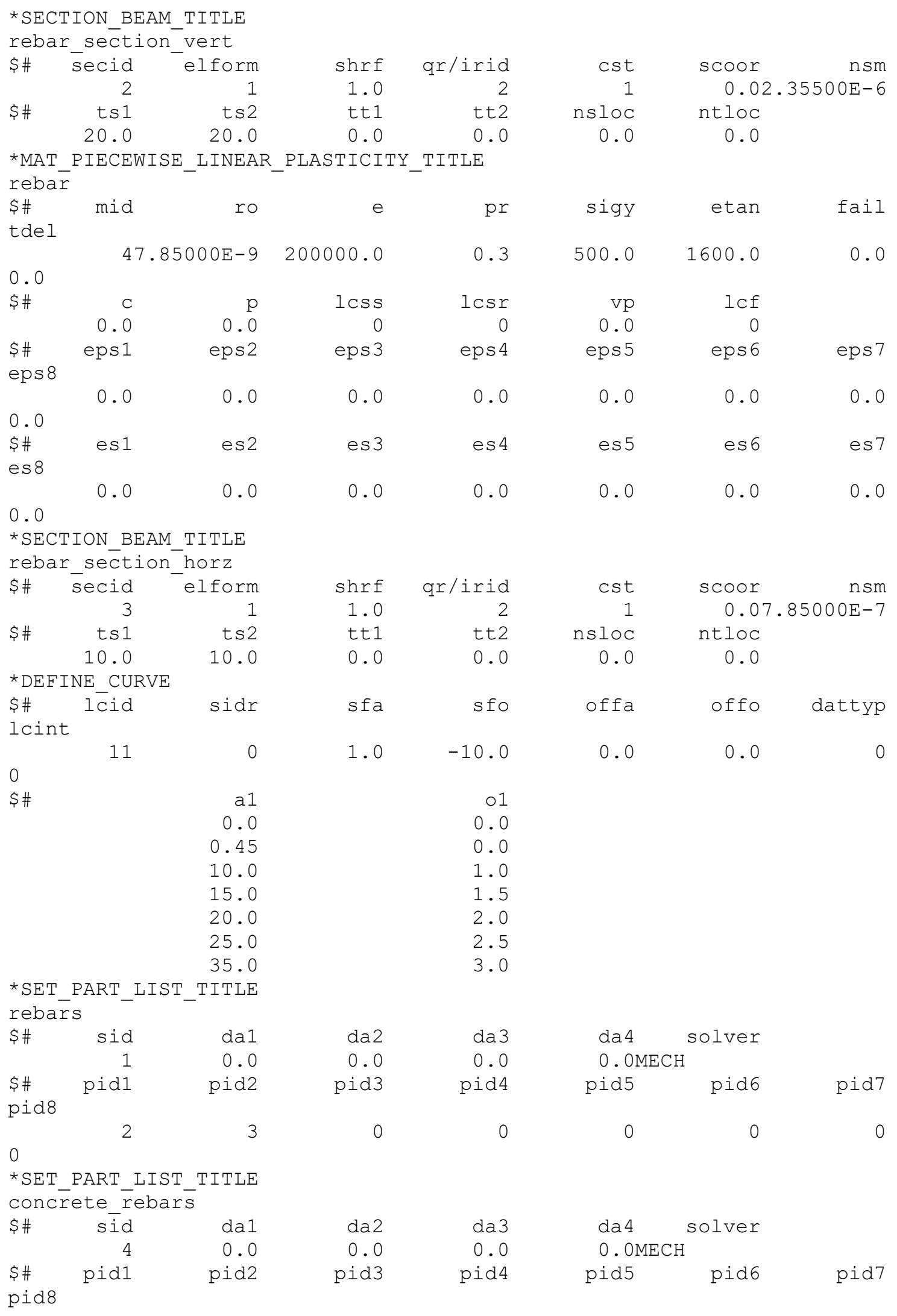




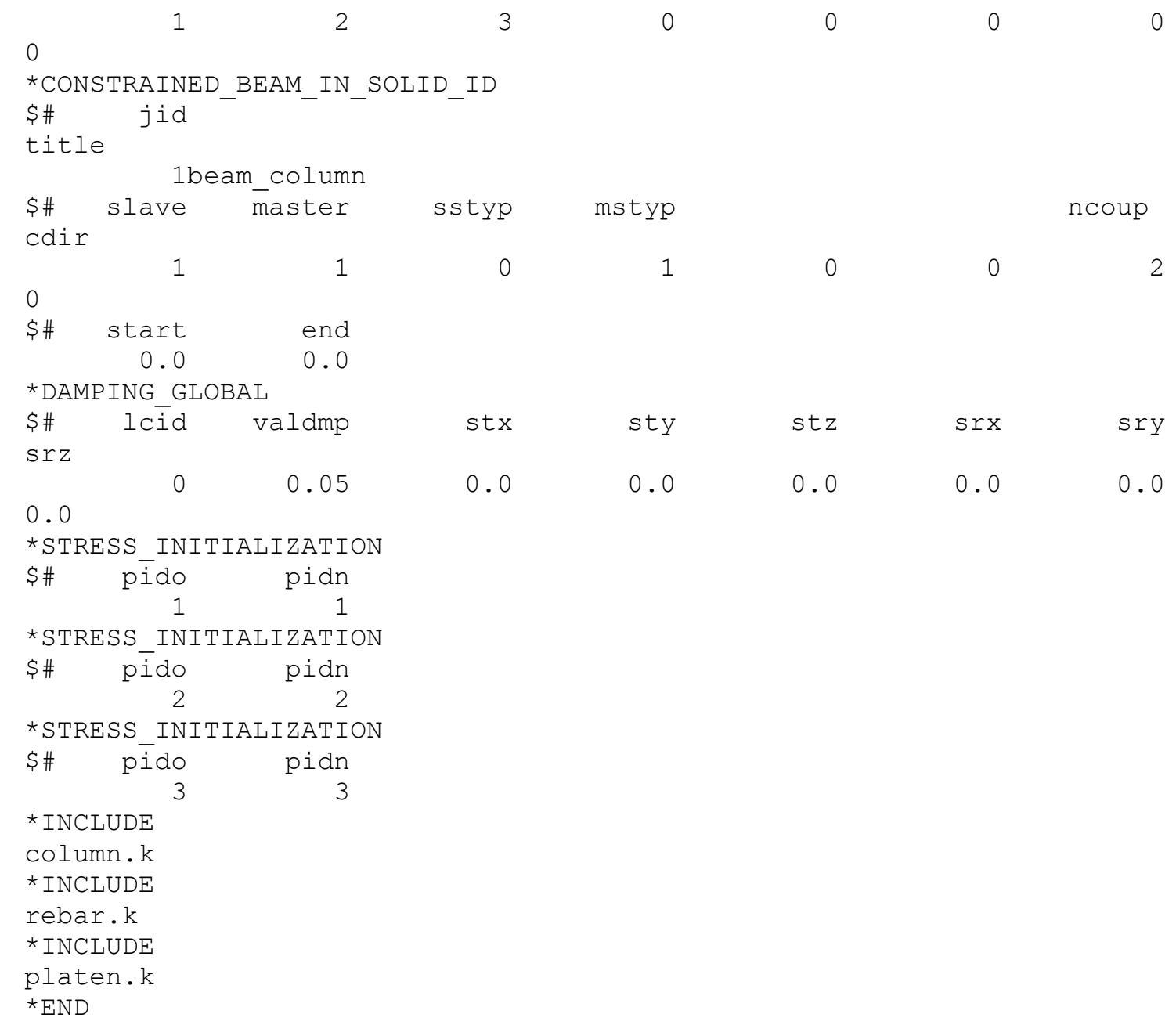

